\title{
A Study of Potential Applications of Automation and Robotics Technology in Construction, Maintenance and Operation of Highway Systems: A Final Report
}

Ernest Kent

Intelligent Systems Division

U.S. DEPARTMENT OF COMMERCE Technology Administration

National Institute of Standards and Technology

Bldg. 220 Rm. B124

Gaithersburg, MD 20899

QC 



\section{A Study of Potential Applications of Automation and Robotics Technology in Construction, Maintenance and Operation of Highway Systems: A Final Report}

Ernest Kent

Intelligent Systems Division

U.S. DEPARTMENT OF COMMERCE

Technology Administration

National Institute of Standards and Technology

Bldg. 220 Rm. B124

Gaithersburg, MD 20899

June 1995

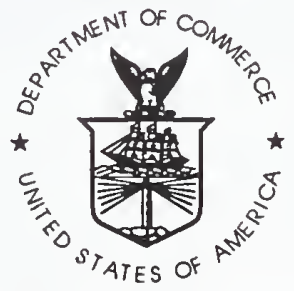

U.S. DEPARTMENT OF COMMERCE Ronald H. Brown, Secretary

TECHNOLOGY ADMINISTRATION

Mary L. Good, Under Secretary for Technology

NATIONAL INSTITUTE OF STANDARDS

AND TECHNOLOGY

Arati Prabhakar, Director 


\title{
FINAL REPORT
}

\author{
VOLUME: 2
}

To:

FEDERAL HIGHWAY ADMINISTRATION

\author{
Prepared by:
}

NATIONAL INSTITUTE OF STANDARDS AND TECHNOLOGY Dr. Ernest Kent 


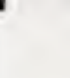




\section{TABLE OF CONTENTS}

Volume: 1

Acknowledgments

Section

Executive Summary

2

Overview of the Study

Summary of Results and Recommendations

4

White Papers on Selected Topics

5

Bibliographic Study

6

Volume: $2 \quad * * *$ This Volume ${ }^{* * *}$

Technology Proposals Submitted for Evaluation

CERF Cost/Benefits Analysis of Technology

Proposals

Measures of Merit

8

Volume: 3

1st Workshop Report:

Industry Views and Requirements

2nd Workshop Report:

Technical State of the Art

Volume: 4

Final Proposals for Potential Research Efforts 
SECTION: 7

\section{TECHNOLOGY PROPOSALS SUBMITTED FOR EVALUATION}





\title{
Proposed Research Topics For Evaluation
}

\author{
FHWA/NIST Study Group
}

May 27, 1993

\begin{abstract}
The FHWA/NIST study group has spent the last six months reviewing potential applications of automation and robotics to problems of highway construction, maintenance and operations. This process has included workshops for representatives of the highway construction industry, literature surveys, and site-visits to highway construction and operations sites. This document presents the first step in the panel's attempt to reduce this body of information to a few specific proposals for areas of research which appear feasible from the panel's technical expertise, and which appear to fill needs it has identified from its review of current practice.

The study group has evolved a working list of short-term, mediumterm, and long-term research programs which seem to combine feasibility with need and opportunity. This list will be refined into a recommendation to the FHWA regarding opportunities for cost-effective programs of research support. This document presents a technical overview of these proposals and the objectives which the panel members believe could be achieved if the indicated research programs were succesfully carried out.
\end{abstract}

\section{Overview of Potential Areas for Research.}

The matrix in Figure 1a presents in graphic form the intersection that the panel has found between areas of potential application for robotics and au- 
tomation in highway construction, maintenance, and operations on the one hand, and the state of current technology on the other. The potential areas for research are broken down in figure $1 \mathrm{~b}$ into Near-Term, Medium-Term, and Long-Term opportunities. Near-Term implies that the basic technologies exist today, and that the effort required would be to integrate and apply these technologies to specific highway problems of interest to FHWA. Near-Term work is thought to be feasible in an 18-month time frame. Medium-Term work indicates that the panel believes that most technologies required for the application are available, but that some research is required for further technological development. This indicates that the general principles are thought to be understood and applicable to the task, but that some gaps in our understanding will have to be filled, and problems in application remain to be identified and solved. Experimentation will be required. Medium-Term work is estimated to require a time-frame up to three years. Long-Term work is that which the panel believes represents feasible targets for in-depth research studies aimed at discovering new and improved methods which will extend our technology in the directions required to apply it to the indicated problems. Time estimates for this sort of work must be open-ended, but the areas selected indicate those where the panel's professional opinion is that the research ought to be successful within five years.

\section{Specific Proposals for Benefit Evaluation.}

There are six specific proposals which the study group would like to put forward for evaluation of actual benefits. These problems have both long and short-term aspects, and in several cases the proposed work spans more than one time frame, with various benefits appearing at each stage. Some represent potential individual research programs, others represent possible large demonstration projects by consortia of investigators. They represent a selection from the areas of study indicated in the matrix which the panel members feel are the most timely from the standpoint of a "quick hit" where the current state of the art in automation appears to mesh with significant issues in highway construction and maintenance. These proposals are summarized together here. The subsequent sections contain more detailed discussion of 
each, prepared by various members of the panel.

1) Site Integration.

The primary objective of this work would be to very substantially reduce the construction time on highway projects, perhaps by as much as $50 \mathrm{in}$ manufacturing. Computerized design databases exist today which can be used as the basis of automated planning, scheduling and logistical control of materials and resources. Advanced control techniques can be used to dynamically reschedule the equipment on a site, as well as to coordinate the arrival of materials and relocation of men and equipment based on the current state of the site. In the short term, using design databases, survey databases, and on-site data entry, it is possible to do real-time global optimization of projects with man-in-the-loop interfaces, including equipment deployment and scheduling, and delivery of materials. Other advantages would include reduced materials waste and automated collection of data for as-built databases. The fundamental requirement is gathering and distributing information in a timely manner to optimize work for the entire site rather than just a small part of it. Longer-term efforts could extend to semi-automated control of grading and materials-placement directly from plans and survey data through advanced operator interfaces, or to automated sensing and control of interactions between pieces of equipment, such as between trucks and concrete-spreaders/asphalt pavers, or between front-end loaders and bulldozers or graders.

\section{2) Automated Bridge Decking.}

The goal of this work would be to substantially reduce time and manpower required to deck or re-deck bridges, while improving quality and reducing the need for rework. The aim of this proposed national demonstration project would be to show that it is possible to incrementally add automated capabilities to today's technology in order to achieve this goal. Existing screeds used in bridge work already provide a basic, globally-referenced, physical platform. With this device as the common integrating target, researchers at many institutions could work towards implementing automated functions such as: 
a) Subgrade inspection using photometric, range, and strain-gauge sensors.

b) Computer-aided design, organization, and tracking of rebar.

c) Laying down rebar, either individually or in sheets, including laying down the supports needed for the rebar.

d) Automated tying of rebar.

e) Monitoring concrete supply flow with respect to the subgrade profile and the design specification by use of optical, ranging, and strain-gauge sensors.

f) Inspection of the concrete slab immediately behind the screed to automatically correct pits or voids, and control overall deck profile to conform to specifications.

g) Other floating and tining operations automatically carried out and inspected.

3) Automated trenching and pipelaying.

This proposal would attempt to automate most phases of the trenching and pipelaying process through the use of sensors, automation controllers, and smart end-effectors for equipment. The advantages which would result from accomplishing these objectives include the automation of all in-trench operations to remove humans from trench which would greatly increase safety, and permit the cutting of minimum-width trenches to reduce time and decrease interference with adjoining structures, utilities, or landscape; the reduction of damage to buried utilities; increased efficiency of machines and operators; reduction of survey and site-layout time, and automatic creation of as-built databases for future utility maps. The proposed research would bring together in one specific application area many of the automation concepts from manufacturing which can be applied to construction work in the field. In addition, it proposes specific retro-fittable devices which can be used to increase the versatility of traditional equipment such as backhoe excavators. The inherent safety problems of trenching operations suggest this as a high-profile area for potential demonstrations of automated technology. 
4) Bridge inspection and maintenance.

Develop improved alternatives to "Snoopers" for poistioning and manipuilating automated bridge inspection and maintenance operations. Elimination of workers from paint-stripping environments, and improved containment of lead-based paint and shot are examples of potential advantages of automation. In the short term, advanced control techniques can provide coordinated motion for devices adapted from existing machines. In the longer term, wholly-new forms of robotic devices could be designed for delivery of many inspection and maintenance services. Such machines would be programmed from databases describing each bridge. The bridge databases would be developed originally from "as-built" databases, which in turn would be developed during construction by noting deviations from "as-designed" databases generated during design. Each time a bridge is repaired or otherwise modified, an new "as-is" database would be generated. These "as-is" databases would constitute the input from planning and scheduling bridge repair, and for programming the robots to perform various functions such as inspection, paint stripping, and repainting.

Advanced robotic devices might be able to crawl along over and under bridges, automatically performing routine inspection, paint stripping, and repainting chores. Large bridges might have specially designed robots. Robots might be specially designed for classes of smaller bridges. Such robots might crawl along a bridge and its associated support structures and monitor a number of parameters that are a measure of the health of the bridge, such as macro-scale deformations, acoustic emissions, ultrasonic echo examination, paint condition, and chemical detection of corrosion.

5) Automated Pavement Inspection and Repair.

Currently human experts are required to visually inspect road surfaces. Many attempts have been made to apply machine vision to this process due to the very large amount of inspection that must be performed, but none has yet been sufficiently successful. The objective of this proposal is to develop an inspection system for roadway defects such as cracks with performance better than that of human inspectors. The minimum detectable crack size would be less, so that preventive maintenance could be carried out earlier, leading to 
increased savings in repairs. Quantitative measures of performance,detection rate, and false-alarm rate, could be accurately characterized. The goal would be to carry out the inspection (and, for defects of limited severity, the repair) at highway speeds. Much more roadway than the currently limited sample could be inspected, and, if repair could be carried out simultaneously, inspection and repair would become a one-pass operation with no need for road closing.

6) Temporary bridging.

Deployment of modular temporary bridging systems by automated means could provide several classes of benefits associated with different time-frames of technological development.

NEAR TERM - Temporary bridging for traffic diversion around bridge repairs can be placed with increased speed and efficiency by integrating existing new technologies for modular bridging with recently-developed robot crane technology which provides stable control of heavy lifting in six degrees of freedom.

MID TERM - Rapid and ecologically non-invasive bridging of wetlands during construction of new bridging could be accomplished with further extension of these technologies. The suspended Stewart platform crane technology can emplace lightweight modular bridging over ecologically-sensitive sites with little or no footprint. The net benefit would include elimination of costly reconstruction of damaged habitats, as well as minimal ecological intrusion.

LONG TERM - Relocateable temporary bridging to carry traffic over highway repair sites is an idea with a long history. Until recently the technology to make such proposals realistic has not existed. It now appears that combinations of recent developments in deployable bridging structures and robotic lifting and positioning technology make it reasonable to attack this problem in a serious manner. If this can be achieved, very substantial benefits to the economy would result from minimizing lost commuter time and delay of goods and services due to traffic congestion at repair sites. 


\begin{tabular}{|c|c|c|c|c|c|c|c|c|c|c|c|c|c|c|c|c|c|c|}
\hline \multirow{4}{*}{ 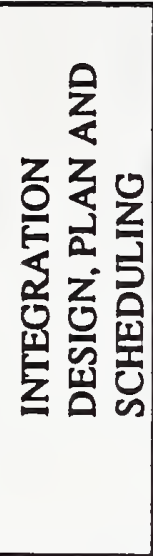 } & 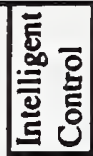 & $x$ & $x$ & $x$ & $x$ & $x$ & $x$ & $x$ & $x$ & $x$ & $x$ & $x$ & $x$ & $x$ & $x$ & $x$ & $x$ & $x$ \\
\hline & 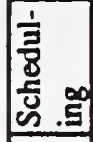 & $x$ & $x$ & $x$ & & & $x$ & & & $x$ & $x$ & $x$ & & & & & & \\
\hline & 岢 & $x$ & $x$ & $x$ & & & $x$ & & & $x$ & $x$ & $x$ & & & & $x$ & & \\
\hline & $\begin{array}{l}5 \\
\frac{5}{8} \\
\delta\end{array}$ & $x$ & $x$ & $x$ & & & $x$ & $x$ & $x$ & $x$ & $x$ & $x$ & $x$ & & & & $x$ & $x$ \\
\hline \multirow{3}{*}{ 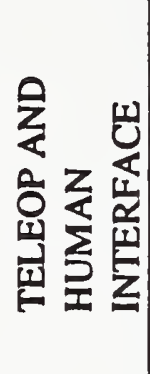 } & $\begin{array}{l}\dot{8} \\
\frac{2}{2} \\
\end{array}$ & & & & & & & & & & & & $x$ & $x$ & $x$ & $x$ & $x$ & $x$ \\
\hline & 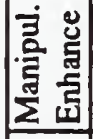 & & & & & & $x$ & & & $x$ & $x$ & $x$ & $x$ & & & $x$ & & $x$ \\
\hline & 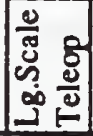 & & & & $x$ & $x$ & $x$ & $x$ & $x$ & $x$ & $x$ & $x$ & & & & $x$ & & $x$ \\
\hline \multirow{4}{*}{ 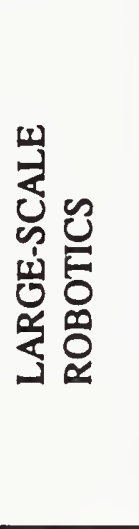 } & 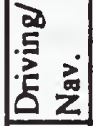 & & & & $x$ & $x$ & & & & & & & & $x$ & $x$ & & $x$ & \\
\hline & 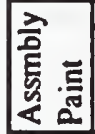 & & & & & & & & & $x$ & $x$ & & & & $x$ & & $x$ & $x$ \\
\hline & 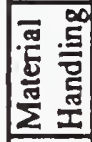 & & & & & & $x$ & $x$ & $x$ & & & $x$ & & & & & & \\
\hline & 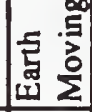 & & & & $x$ & $x$ & $x$ & & & & & & $x$ & & & & & \\
\hline \multirow{4}{*}{ 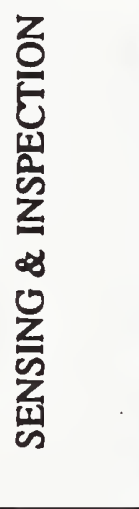 } & 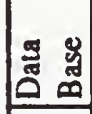 & $x$ & $x$ & $x$ & $x$ & $x$ & $x$ & $x$ & $x$ & $x$ & $x$ & $x$ & $x$ & & & $x$ & & $x$ \\
\hline & 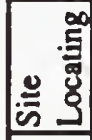 & & & $x$ & $x$ & $x$ & & & & $x$ & $x$ & $x$ & & & & $x$ & $x$ & $x$ \\
\hline & 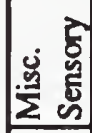 & & & & $x$ & $x$ & $x$ & & & & & & $x$ & $x$ & & $x$ & $x$ & $x$ \\
\hline & $\frac{5}{5}$ & & & & $x$ & $x$ & $x$ & & & $x$ & $x$ & & $x$ & $x$ & $x$ & $x$ & $x$ & $x$ \\
\hline 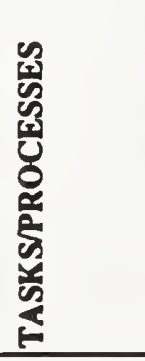 & & $\begin{array}{l}5 \\
\frac{50}{8} \\
\frac{8}{8} \\
\frac{8}{2}\end{array}$ & 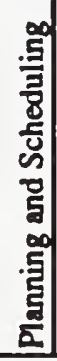 & 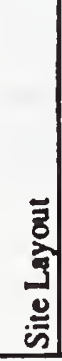 & . & 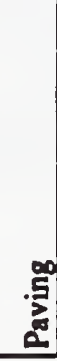 & है: & 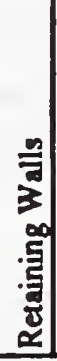 & 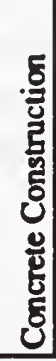 & 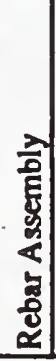 & 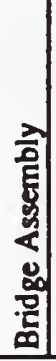 & 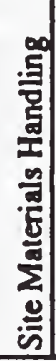 & 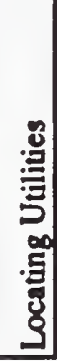 & $\begin{array}{l}5 \\
. \overline{3} \\
8 \\
5 \\
5 \\
8 \\
5 \\
5 \\
5 \\
z \\
8 \\
8\end{array}$ & $\begin{array}{c}.0 \\
.5 \\
8 \\
5 \\
\frac{5}{8} \\
5\end{array}$ & 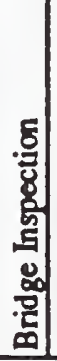 & 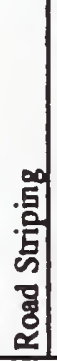 & 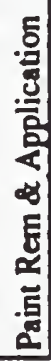 \\
\hline
\end{tabular}




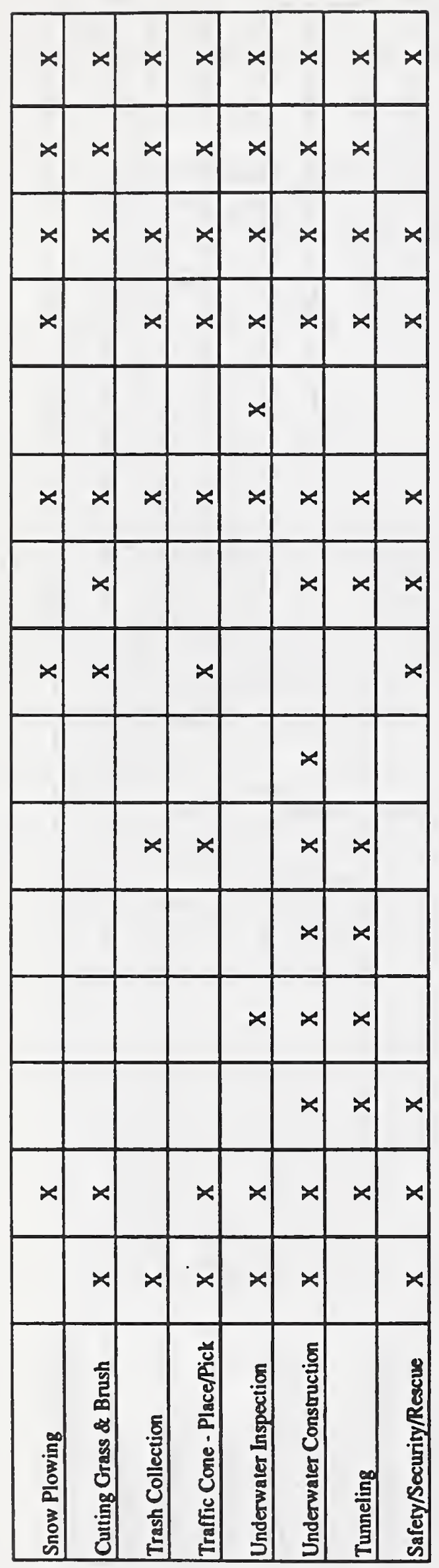




\section{SHORT TERM}

- Tying rebar -- especially on concrete beds.

- Weighing concrete to monitor flow during concrete paving.

- Improve pipe manipulation in trench .- reduce human hazard.

- Safety sensors around machines.

- Exploit current database standards.

- Add force feedback to machines.

- Expert systems for project costing.

- Automated planning and scheduling of rebar assembly operations.

\section{MEDIUM TERM}

- Site location system -- enhance human operator.

- Automated pipe laying and filling in trench.

- Real-time monitor of compaction -- soil and asphalt.

- Site layout and materials flow scheduling system.

- "Soft" links between machines for control and integration.

- Graphical display of project information system - human interface and monitoring.

- Prototype project information system -- linked to design database.

- Road surface visual inspection.

- Apply design-for-assembly to rebar structures.

- Computer aids to traffic rerouting during job planning.

- Demonstration of two-machine cooperative manipulation.

- Tomographic inspection of bridge columns.

- Machines with exchangeable tools.

- Demonstration of concurrent engineering bridge designed for inspection and maintenance.

- Study of safety issues related to humans in the workspace of automated systems.

\section{LONG TERM}

- Automatically guided vehicles using site location system.

- Common database exchange format for site, materials, and operations.

- Real-time control of compaction.

- Integration of design database to planning and scheduling -- Project Information Systems.

- Multimachine coordination by networking and distributed control.

- Automated on-site assembly of rebar structures.

- Bridge inspection and repair.

- Life-cycle concurrent engineering for construction, maintenance, and repair of selected projects, e.g. bridges, trenches and piping.

- Design with improved, smart and environmentally sound, materials to enhance automation and maintenance. 


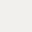


SITE INTEGRATION 


\title{
Site Integration Through Hierarchical Control
}

\author{
R. Lumia, Robot Systems Division, NIST \\ A. Sanderson, RPI
}

$05 / 21 / 93$

\section{Goal}

The goal of this work is to reduce construction time by half through the use of hierarchical control for the integration of all activities at the worksite. It will accomplish this through:

1) Automating planning and scheduling directly from databases of project planners, design engineers, contractors, and materials suppliers.

2) Generating detailed plans directly from automated survey data.

3) Increasing the efficiency with which men and machines are used by ensuring that all necessary tools, materials, and personnel are available at the proper places and times.

4) Optimally rescheduling use of men and machines in real-time in response to short-term disruptions caused by weather, equipment malfunction and similar unpredictable events.

5) Eliminating time spent searching for materials by automatically tracking and controlling materials delivery and storage.

6) Increasing the efficiency of machinery operators by providing them with exact visual guidance for earth removal, materials placement, and site-positioning.

7) Reducing re-work by enhancing the accuracy of siting, placing, cutting, and forming operations, controlling materials flows, and by directly guiding work from master plans and designs in real-time.

8) Acquiring as-built information as the work occurs to reduce turn-around time for checking and correcting operations.

In addition to reducing construction time, the proposed work will reduce materials costs by reducing waste, and enhance safety by monitoring equipment in motion.

\section{Background}

\subsection{Root of the problem}

It is well known that unforeseen events can idle equipment at the worksite, which wastes time and costs money. A traffic jam can result in the rejection of a cement delivery. Overnight rain can fill a hole and work cannot proceed until a pump arrives. An event can occur which requires equipment not at the worksite. Normally, it is the job of the site foreman to deal with these events. Our argument, however, is that the foreman can only oversee his "island" of activity and therefore is implementing a local rather than global optimization of a construction plan. The foreman's fundamental limitation is that he lacks information about what is happening at the other worksites of the project. Consequently, the key problems are the lack of global information and a method for using 
it effectively.

A site foreman does an excellent job in allocating resources at his worksite, i.e., he does the best job he can with the information he has. However, this local optimization results in sub-optimal use of equipment, sub-optimal planning for materials delivery, sub-optimal use of personnel. Theoretically, if the foreman knew about the state of all of the project worksites, resources could be allocated more effectively. However, in practice, the foreman would drown in the details. He needs tools to help him sort out the complexity in order to enhance his performance. Hierarchically organized control systems address this issue of complexity and provide a tool to make construction sites more efficient.

\subsection{Advantages and applications of hierarchical control}

Hierarchical control is not a new idea. It was practiced in China around 3000 B.C. It is commonly found in the military, and most business and government organizations. Recently, these concepts have been applied to controlling machines. Hierarchical control has been used for many systems including

- Factory control in an automated manufacturing research facility at NIST

- Factory workstation control

- Machine tool loading and unloading

- Robotic deburring

- Advanced controller for machine tools, robots, and coordinate measuring machines

- Advanced inspection system

- Vision-guided robot manipulation

- Vision-based automated highway driving

- Unmanned land and undersea vehicles

- Submarine operation automation

- Coal mine automation

- Space Station telerobotic servicer

- Robot crane

While this set of applications may appear disparate, the common thread is that complex systems require coordinated activities in order to achieve optimal performance. We argue that construction sites are also complex systems, and therefore are amenable to hierarchical control techniques.

\section{Hierarchical Control for Site Integration}

\subsection{Hierarchical control overview}

A hierarchical control architecture can integrate many people and machines into a coordinated system. It forms the "glue" which connects measurement technologies and equipment in order to 
enhance performance while reducing time and waste. A good hierarchical control system should provide an engineering methodology for the design and implementation of the system. It should define how global plans can be decomposed into local actions that can be executed by production equipment. Also, it should allow any amount of automation, i.e., it should support the entire range from teleoperation to autonomy, in its attempt to balance cost and performance. This is possible because hierarchical control systems deal with planning horizons ranging from years and months, down to jobs lasting weeks, days, and hours, as well as for tasks lasting minutes, seconds, and even milliseconds.

Some of the elements of a hierarchical control system architecture and how they pertain to site integration are shown in Figure 1. There are three parallel hierarchies: task decomposition, world modeling, and sensory processing. Task decomposition, as its name suggests, decomposes a task into smaller and smaller subtasks, eventually culminating in commands sent to the equipment. The world model stores a representation of the worksite. Sensory processing collects and analyzes data to keep the models in the world model in registration with reality.

Figure 1 also introduces the concept of multiple levels of control, only two of which are shown in the figure. Each level's planning horizon is roughly 10 times longer than the level below it. For example, the task decomposition box performing the strategic long-term plan could be planning a day's worth of activities while the level below is concerned with a sequence of tasks which require 15 minutes each. At the lowest level, the world model maintains an up to date model of the site, e.g., the site model could be concerned.with the functionality of the equipment, precisely where each piece of equipment is and what it is doing, and the current state of the task executing. At a higher level, where the time frames are more broad, the world model could store the CAD model of the road, the desired end product, as well as the as-built model, the reality of the constructed road. Similarly, sensor processing tasks could be divided between short time frames, e.g., gathering specific road measurements for a small part of the road, and longer time frames, e.g., integrating those short term measurements into a global measurement for longer road segments.

In applying hierarchical control to various applications, there is significant flexibility in choosing appropriate sensors, planners, etc., and configuring these components into a real-time control system to achieve any desired level of automation. The same approach applies to site integration by implementing the system in phases and demonstrating the value added for each phase.

Figure 2 shows how the real-time planner at the lowest level of the architecture would be used to coordinate construction equipment. Any desired level of automation is possible. For example, the system could simply provide instructions to the human operators of the equipment. Alternatively, it could use the human operator to control the location of the vehicle but automatically control the remainder of the equipment processes. The most sophisticated alternative would be to control the entire operation autonomously, which may be technologically possible but is probably too costly at the present time. In a similar fashion, Figure 3 shows how sensors could be connected and configured into a real-time system. Figures 4,5 , and 6 show more detail of a potential implementation of the hierarchy with different proportions of autonomy.

\subsection{Stages of integration}

Hierarchical control allows technology to be integrated in phases. For example, the output of the real-time planner in Figure 1, which connects to equipment, can take different forms depending on the state of technology. In the short term, the output could be a screen with instructions to the 
foreman and equipment operators. More advanced technology provides the operator with the CAD design superimposed and registered with the worksite. Using this graphics display, the operator could place structural materials, forms, etc. As graphics technology advances, virtual reality techniques can be incorporated. Ultimately, the commands could control the equipment directly with no human interaction.

To illustrate the sensory side of Figure 1, consider the following scenario. Truck 65 has arrived with shipment 16 and is supposed to dump its contents at the worksite. In the short term, the fact that truck 65 has arrived with shipment 16 is keyed manually into the system. The system responds with the instruction to dump contents at grid 87. Then, the truck driver views a display which informs him where he is, so that he can determine how to reach grid 87 exactly. As technology advances, the system could take control of the vehicle once it enters the worksite, automatically access the database to determine the desired location, drive the truck to that place, and control the dumping. In all cases, the system would automatically update the site model of the material database.

Consider another technology. If materials are bar-coded, the materials database can be updated every time material is moved from one location to another. Inventories can be adjusted, and orders generated automatically. Keeping track of the location of objects at the worksite goes beyond monitoring materials.

Position sensors can determine the precise location of equipment during operations at the worksite. For example, it is possible to measure the location of the backhoe bucket in real-time. This information can be used to update the site database in real-time, which ultimate instructs the operator precisely where and how to dig.

Laser surveying instruments are commercially available to build CAD models of the terrain. This information needs to be incorporated into the hierarchical control system to guide the crews and equipment operators. Ultimately, when updated by input from the field, these data can be used to create the as-built model of the site.

\section{Scheduling activities at the worksite}

A road construction project may be thought of as a set of large-scale tasks, such as excavation, grading, paving, bridge construction, etc., which must be carried out in a special order to accomplish the final construction goal. The execution of these tasks requires the careful coordination of resources delivered to and removed from the site, the availability of machines and people at particular places and times, and the arrangement and transport of parts and materials within the worksite. While many different factors affect the success of such a project, the design itself and the mapping of that design into a project plan are critical to the efficient management and resulting quality. Computer-based aids for the development and tracking of complex projects offer fundamental advantages to the road construction industry where coordination of multiple activities on a preset schedule is vital to efficient and safe operation.

Computer-based design tools are now required by many states for large highway construction projects. In this approach, the designer develops a representation of his highway project design as a computer-based (CAD) file, and can use that file as a basis for structural analysis, materials selection, project costing, environmental impact, and graphics rendering for presentation. The design itself provides the common core, and the computer representation enforces a consistency among 
the various types of analysis. Such techniques are commercially available and increasingly used for major projects. A CAD-based design and database representation will be an essential component of the proposed demonstration project.

While the current CAD tools provide useful means to capture the basic design of the construction project, there are many additional ways in which this representation may used for project coordination and management. Current CAD design methods are used in the preliminary costing and assessment of projects, but are not commonly used in the planning and operations themselves. We propose to bring the $\mathrm{CAD}$ design into the project planning and day-to-day management of the project in order to increase the efficiency and accuracy of these operations. One example of this use is the site layout problem. The CAD tools should be developed to represent a sequence of construction phases depicting the spatial configuration of partially completed work. Then, the layout of materials stores, equipment, and personnel may be configured to maximize the efficiency of the workplace. Minimizing the transport and relocation of materials achieves a significant gain in operations efficiency.

A second example of the integration of CAD tools into road construction operations, is the automated site positioning system. The CAD representation specifies the position, location, and shape of objects and surfaces in three-dimensions from the design. For example, the location, grade, and shaping of the final road surface is exactly specified. However, in practice, it is extremely difficult to map this specification onto a work site. Surveying, marking, and remarking of positions, elevations, and grades is a routine practice during road construction. Maintaining accuracy throughout the many steps which are required is a major task. An automated site location system provides a means to locate exact positions and orientations of objects in the three-dimensional workspace. A given machine, such as a bulldozer, would be tracked by beacons on the site, and its position and velocity would be monitored and displayed. Such systems are now under experimental development and demonstration of the integration of such a site location system with CAD specifications would be a major focus of the proposed demonstration project.

Given a project design which can be linked into the operations of the project, there are enormous opportunities to improve the task planning and scheduling for the project. There are already some existing tools which are used in road construction project planning. PERT (Program Evaluation and Review Technique) charts and CPM (Critical Path Methods) are the most common. These methods provide a means to evaluate alternative sequences of tasks within a complex project, assign costs or penalties to different tasks, and choose which sequences are best suited to the given project. In these approaches, planning is the process of choosing the order of work among the tasks and is usually shown as a linked series of nodes in the CPM diagram. Scheduling is the assignment of times, or time bounds, on these tasks and is used to estimate the overall completion time and the critical times for availability of resources. While these methods have provided important advances in the systematic approach to project planning, they have two principal deficiencies: (1). lack of embedded knowledge, and (2). lack of adaptive or dynamic behavior. These two deficiencies may be addressed by additional new developments in planning methods.

PERT and CPM do not embed design information or knowledge of the domain into the planning process. The formulation of the plan usually relies entirely on the skill and experience of the human planner to assess and assimilate the many variable which affect the planned sequence and its variability. The development of knowledge-based planning systems addresses this issue and has resulted in prototype programs which provide improved planning environments for specific do- 
mains. In our work on this demonstration project, we would emphasize the development and demonstration of two specific systems: First, a knowledge-based site layout system which would assist in the placement of materials and machines and the optimal configuration of the site for improved efficiency and safety. Second, a knowledge-based scheduling system which would optimize the utilization of machines and personnel based on internal representation of domain knowledge about the needs and constraints of the road construction domain. Incorporation of these tools will have a direct benefit to the efficiency of the project, the utilization of equipment and facilities, and the ability to monitor and assess progress.

A PERT or CPM analysis is usually done prior to the project and is difficult to change or update as unexpected events occur during the course of the project. This lack of adaptive or dynamic behavior often renders the original plan useless within a short period after the project commences. Instead, new tools are required which can respond to perturbations in the constraints of the plan, or dynamically replan successive tasks as necessary during the project. Such tools in effect become a top level of coordination for the principal tasks and provide a basis for the hierarchical decomposition of subtasks. These discrete-event modeling and control methods have been used extensively in the manufacturing domain where dynamic changes in requirements and resources require frequent revision of manufacturing plans. In the case of road construction, a "discrete-event" may be thought of as a specific task with well-defined start time and end time. Each such task has certain resources which are required. For example, a trenching and pipe-laying operation may require the availability of an excavator, a crane, a compactor, and the next section of pipe. The availability of these 'preconditions' to an event define a state of the system model and enable the execution of the event itself. The outcome of the event is a new set of state conditions.

A powerful set of models which represent these conditions and actions very effectively are called Petri nets. The Petri net uses a circle, or 'node', to represent the state of a resource, and a line with arrows, or 'transition', to represent the execution of an action ('firing of a transition'). Figure 7 illustrates this notation for Petri net models, and a sample Petri net model for the trenching and pipelaying problem is shown in Figure 8. In this example the crane is a resource which is shared by two subtasks, setting the new pipe section and placing the compactor in the trench. Mediating a shared resource in this fashion and coordinating parallel operations are particular strengths of the Petri net representation. It is important to recognize that this type of model represents a set of possible plans, rather than just one plan. All of the possible plans are consistent with the constraints of the problem, but may be initiated by different events. Thus the Petri net is inherently a dynamic model capable of responding to different conditions as the arise. In addition, we can attribute estimated execution times to different transitions and assess the alternative execution time of the whole task depending on different possible conditions which may arise. We thus assess the range of possible outcomes and incorporate that into our planning process. Responding efficiently to these 'what if?' questions in the planning domain is a key attribute of the Petri net modeling approach, and will provide a basis for coordination and control of discrete event sequences during execution of the project. Existing software tools are available which can be adopted to the demonstration project and would provide a framework for modeling and planning at the discreteevent level. As described below, further decomposition of tasks results in a hierarchy of continuous control modes which can be systematically organized as a hierarchical control system.

Implementation of the coordination and control functions in a complex work environment such as a construction site will require attention to communications and information transmission capabilities. A construction worksite may be thought of as a network of users and machines, each with 
different elements of the overall task. However, the coordination of these various functions will require that common elements, like the project design, by available and consistent for all of these users. In addition, as different aspects of the job proceed, it is necessary for the status of jobs to updated and communicated to other parts of the worksite. Such a distributed user community constitutes a network, and the definition and implementation of networking principles for a highway construction worksite will be a major component of the proposed demonstration project. This network will require agreed upon modes of transmission on information as well as establishment of protocols, or standards, for relay of information. For example, representation of the grade of the road in the design database might be transmitted to the grader control system in one form, but accessed by the pavement compaction inspection system in another form. These interactions must be specified and enforced in order to assure consistency among the different agents in the network system.

For the road construction site, many of the elements of the network will be machines which are concurrently carrying out real-time tasks. This real-time distributed interaction imposes still another requirement on the design of the system. A standard for communications among the real-time elements of the system must be adopted, and must take into account the timing of the individual processes and their interactions. This requirement for a real-time distributed operating system to coordinate processes is common to many other systems which integrate computers in an interactive domain. One approach to this problem utilizes a message-passing protocol which permits computers to communicate through messages which update the timing requirements and constraints from each of the other systems. The integration of a discrete-event control model, such as the Petri net, with a real-time distributed operating system provides the framework for implementation of communications and coordination of multiple tasks in the road construction demonstration project. Individual or hierarchies of continuous controllers, sensors, and modeling systems which control the motions of individual machines act as nodes on this communications network and report their status and functions through the distributed operating system mechanisms.

\section{Benefits of using hierarchical control}

Hierarchical control can help address the root cause of non-optimality at worksites: lack of global information and an effective way to use it. The following table lists a particular capability which can be achieved with a hierarchical control system, whether the time frame for its implementation is considered short term (1-3 years), medium term (3-5 years), or long term (5-10 years), and a specific example of that capability applied to site integration. The benefits of using hierarchical control transcend the list, and therefore this list should be considered to be representative of the types of benefits one should expect.

Table 1: Productivity improvement through hierarchical control

\begin{tabular}{|l|c|l|}
\hline \multicolumn{1}{|c|}{ CAPABILTTY } & TIME FRAME & \multicolumn{1}{c|}{ EXAMPLE } \\
\hline \hline $\begin{array}{l}\text { Efficient scheduling } \\
\text { based on variable work- } \\
\text { site conditions }\end{array}$ & Short & $\begin{array}{l}\text { When equipment breaks, a plan can be gener- } \\
\text { ated to optimize work for the entire site by } \\
\text { transferring equipment from one work site to } \\
\text { another. }\end{array}$ \\
\hline
\end{tabular}


Table 1: Productivity improvement through hierarchical control

\begin{tabular}{|c|c|c|}
\hline CAPABILITY & TIME FRAME & EXAMPLE \\
\hline & Short & $\begin{array}{l}\text { By having an up to date schedule based on the } \\
\text { actual state of the sites, people are sent to sites } \\
\text { when needed to perform specific tasks, thereby } \\
\text { minimizing idle time. }\end{array}$ \\
\hline & Short & $\begin{array}{l}\text { A weather report of overnight rain will automat- } \\
\text { ically generate scheduling of pumps to arrive at } \\
\text { sites where holes were previously dug. }\end{array}$ \\
\hline & Short & $\begin{array}{l}\text { Material delivery schedules and equipment use } \\
\text { plans can be re-generated in real-time and } \\
\text { reflect the most up to date information available } \\
\text { about the worksite. }\end{array}$ \\
\hline \multirow[t]{2}{*}{$\begin{array}{l}\text { Reduce time to locate } \\
\text { equipment or materials }\end{array}$} & Short & $\begin{array}{l}\text { When equipment breaks, or the state of the site } \\
\text { changes, new equipment may be necessary. The } \\
\text { system can request the "best" equipment auto- } \\
\text { matically by balancing the work done at one } \\
\text { particular site with the work in progress at all } \\
\text { other sites. }\end{array}$ \\
\hline & Short & $\begin{array}{l}\text { When new equipment is needed for a site, all of } \\
\text { the parts can located quickly, e.g., a pump must } \\
\text { arrive with hoses and the proper couplings in } \\
\text { order for it to be useful. }\end{array}$ \\
\hline $\begin{array}{l}\text { Real-time location of all } \\
\text { equipment registered } \\
\text { with } C A D \text { design of site }\end{array}$ & Medium & $\begin{array}{l}\text { By knowing the precise location of equipment } \\
\text { with respect to the design, time can be saved in } \\
\text { many tasks, e.g., compact the area around lane } \\
\text { joints to a greater extent than the remainder of } \\
\text { the road surface. }\end{array}$ \\
\hline \multirow[t]{2}{*}{$\begin{array}{l}\text { Survey integrated with } \\
\text { plan from highway } \\
\text { department }\end{array}$} & Short & $\begin{array}{l}\text { Moment by moment guidance can be sent to } \\
\text { operators of equipment to enhance performance, } \\
\text { e.g., graders minimize the removal of earth to } \\
\text { achieve the goal in real-time. }\end{array}$ \\
\hline & Short & $\begin{array}{l}\text { Minimize rework resulting from errors in read- } \\
\text { ing the blueprints for the site design. Measure- } \\
\text { ments can be made (semi)automatically. }\end{array}$ \\
\hline $\begin{array}{l}\text { Timely distribution of } \\
\text { design changes accessi- } \\
\text { bly from design database }\end{array}$ & Short & Minimize rework due to changes in design. \\
\hline
\end{tabular}


Table 1: Productivity improvement through hierarchical control

\begin{tabular}{|c|c|c|}
\hline CAPABILITY & TIME FRAME & EXAMPLE \\
\hline \multirow[t]{3}{*}{$\begin{array}{l}\text { Improve efficiency of } \\
\text { interaction between man } \\
\text { and equipment }\end{array}$} & Short & $\begin{array}{l}\text { Moment by moment guidance and instructions } \\
\text { to machine operators to prevent errors, and } \\
\text { maximize quality of work. Operators can have } \\
\text { complete information -- where, when, how } \\
\text { much -- using inexpensive visual displays. }\end{array}$ \\
\hline & Short & $\begin{array}{l}\text { Operator of backhoe can use CAD model of } \\
\text { location of various utilities by using real-time } \\
\text { display of digging operations to avoid cutting } \\
\text { through lines. }\end{array}$ \\
\hline & Medium & $\begin{array}{l}\text { Control system on backhoe prevents operator } \\
\text { from digging into volumes occupied by utility } \\
\text { lines. }\end{array}$ \\
\hline $\begin{array}{l}\text { Reduce time need for } \\
\text { "cut and try" situations }\end{array}$ & Medium & $\begin{array}{l}\text { Automatic calculation of the required dimen- } \\
\text { sions for materials can be recomputed in real- } \\
\text { time for "as-is" condition. }\end{array}$ \\
\hline \multirow{3}{*}{$\begin{array}{l}\text { Improve efficiency of } \\
\text { interaction between } \\
\text { machine and machine }\end{array}$} & Short & $\begin{array}{l}\text { Operator follows instructions on screen to per- } \\
\text { form mating of machine and its feeder. }\end{array}$ \\
\hline & Medium & $\begin{array}{l}\text { Operator drives feeder based on instructions but } \\
\text { all other mating and feeding operations are } \\
\text { automatic. }\end{array}$ \\
\hline & Long & $\begin{array}{l}\text { Machine controls all aspects of itself and its } \\
\text { feeder, from requesting the time of feeding, to } \\
\text { the actual coupling. }\end{array}$ \\
\hline $\begin{array}{l}\text { Automatic recovery of } \\
\text { as-built databases }\end{array}$ & Medium & $\begin{array}{l}\text { Minimizes cost and time if renovation is per- } \\
\text { formed at site at some future time. }\end{array}$ \\
\hline Increase safety & Medium & $\begin{array}{l}\text { Sensors on machines monitor the state of the } \\
\text { machine, detect errors, and shut down equip- } \\
\text { ment in an orderly fashion when a dangerous } \\
\text { situation occurs or a dangerous action is } \\
\text { requested by the operator. }\end{array}$ \\
\hline
\end{tabular}

\section{Summary}

Hierarchical control lends itself to the organization of complex systems by providing the glue to connect myriad technologies into a coherent and understandable system. The concepts of hierarchical control were presented along with examples of specific benefits resulting from the technology. 
The project described here will represent a demonstration of several major innovations in the integration of technologies for the planning, coordination, and control of activities on a highway construction site. The resulting improvements should fundamentally affect the way in which a construction project can be managed, and will result in more efficient use of manpower, equipment and materials, as well as increases in safety and quality of the project. The demonstration project will integrate a wide variety of technologies in a manner which demonstrates their utility. Many of these technologies will have substantial impact in themselves, and the incremental improvements which result from adaptation of specific individual innovations will be of substantial value. For example, improved knowledge-based planning tools will be valuable even with conventional worksite organization. Similarly, improved standards for $C A D$ interfaces, and well-defined networking protocols for worksites will have substantial benefits in the gradual improvement of worksite technology. 


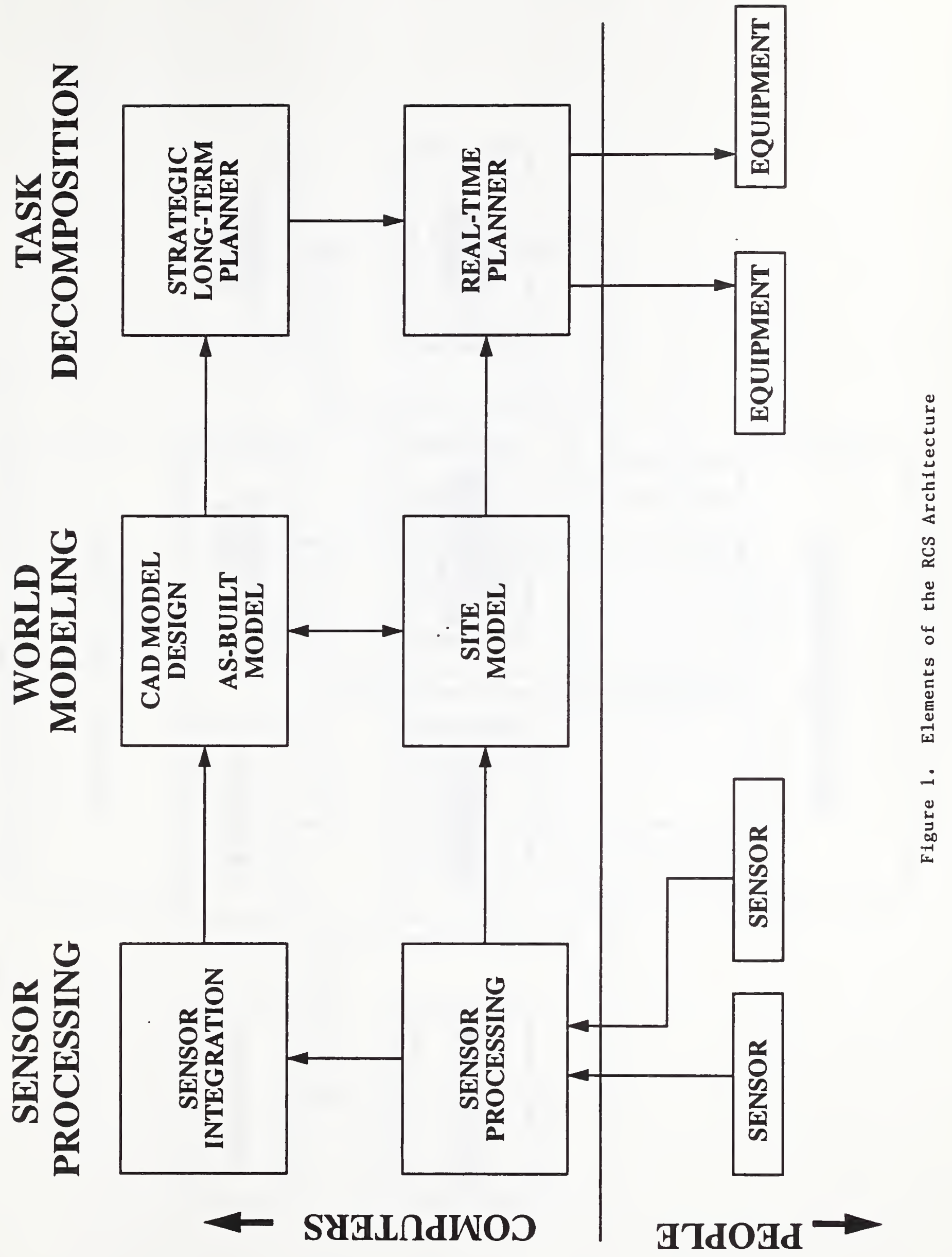




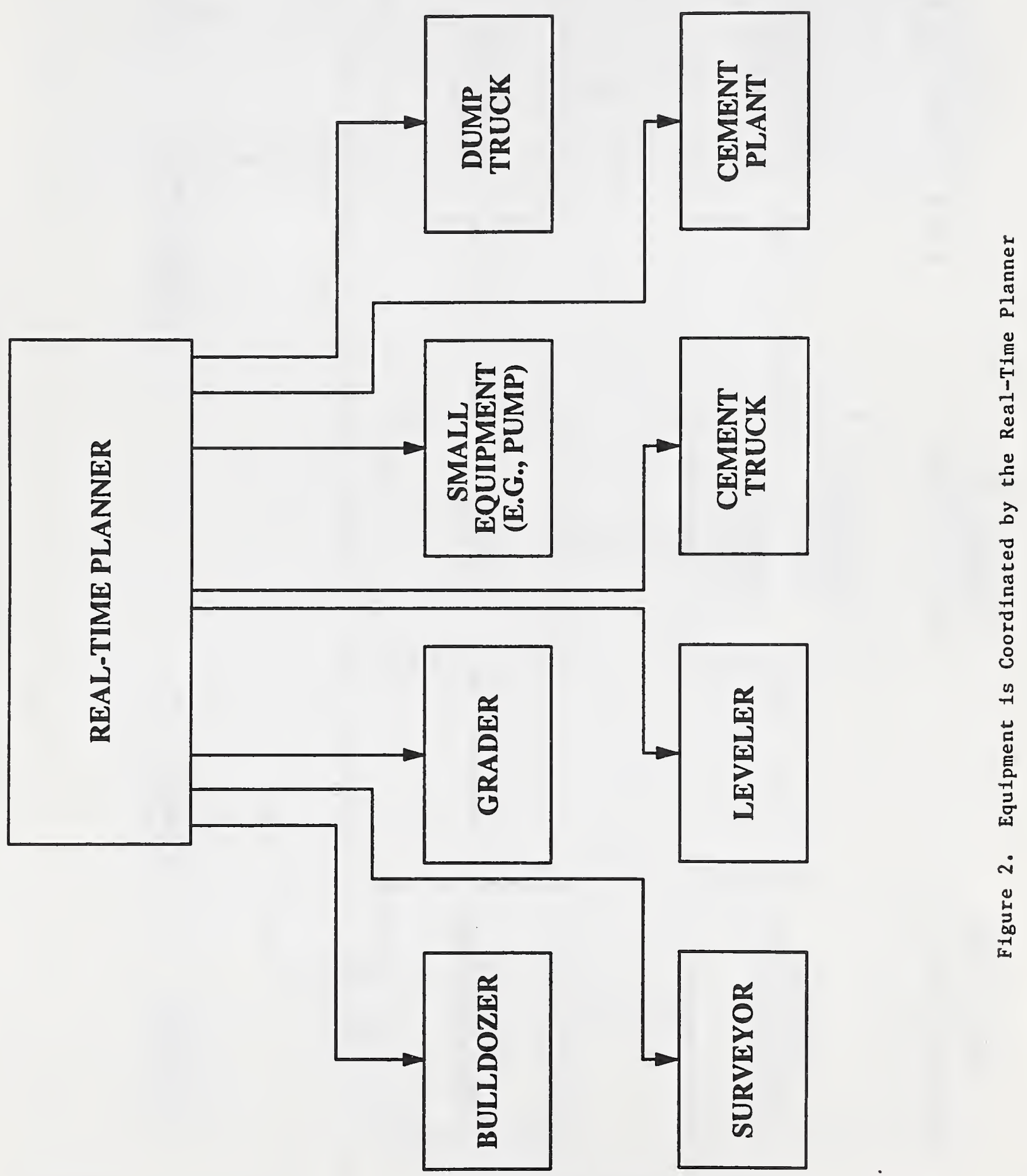




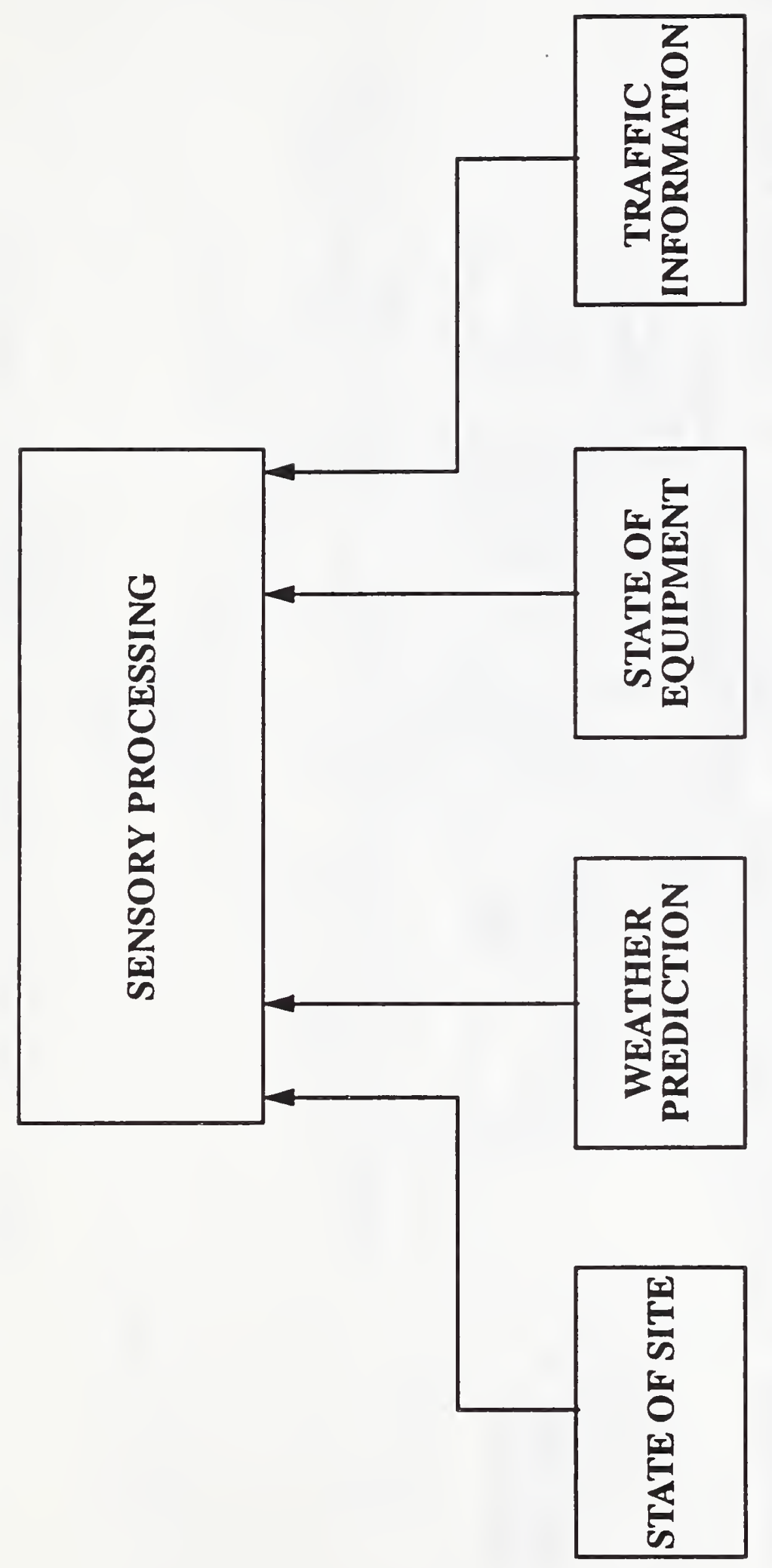

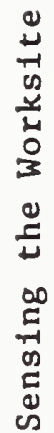

i 


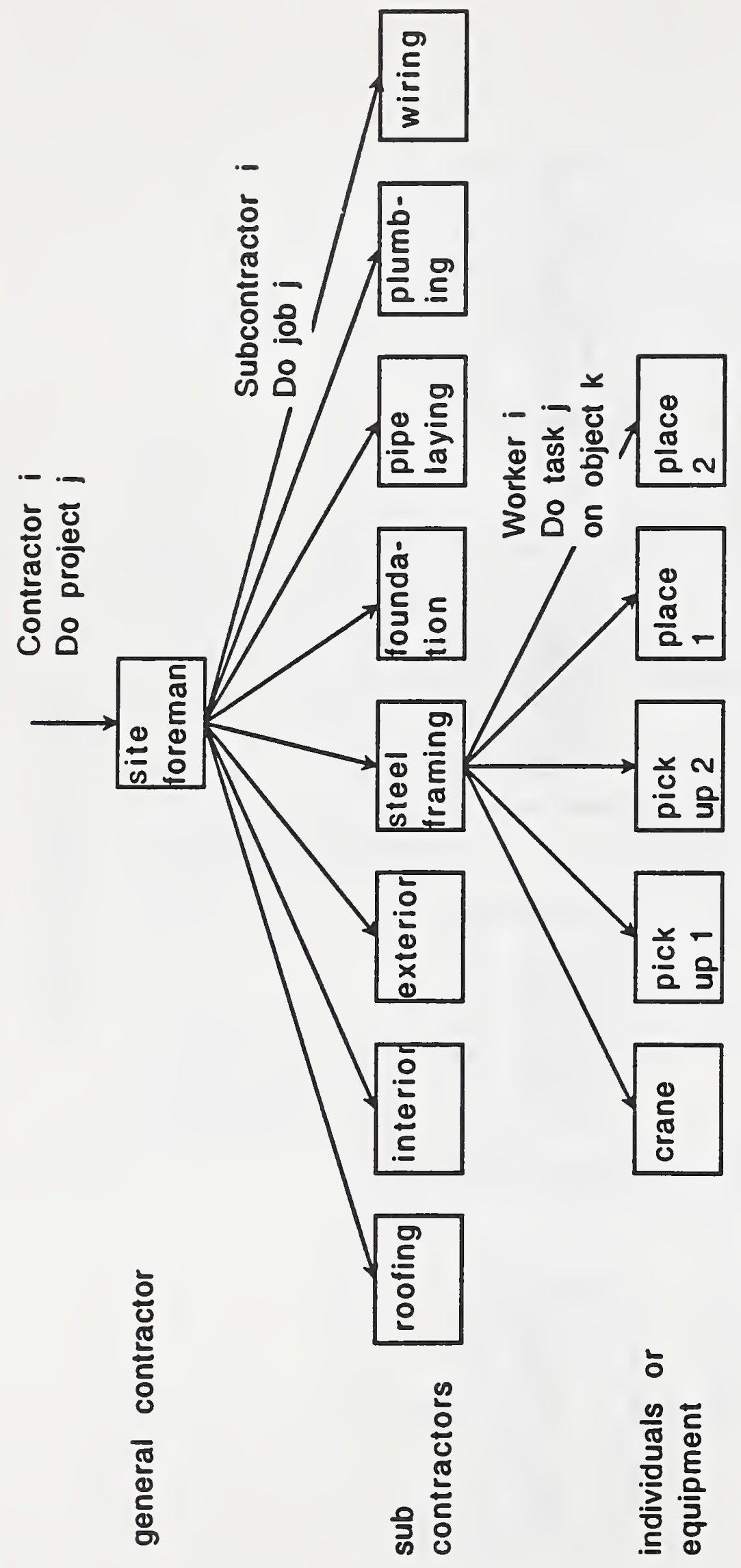

吾 


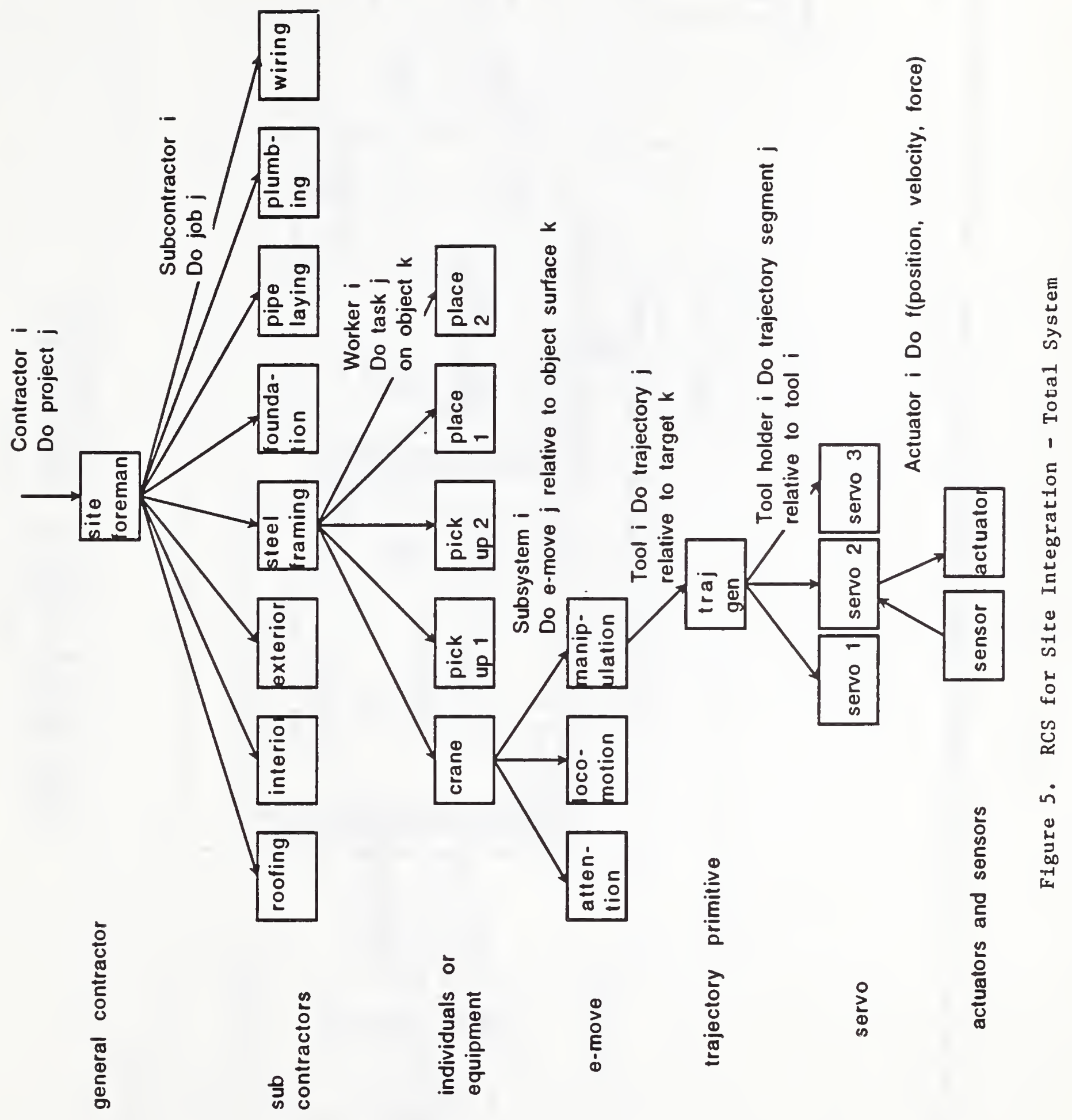



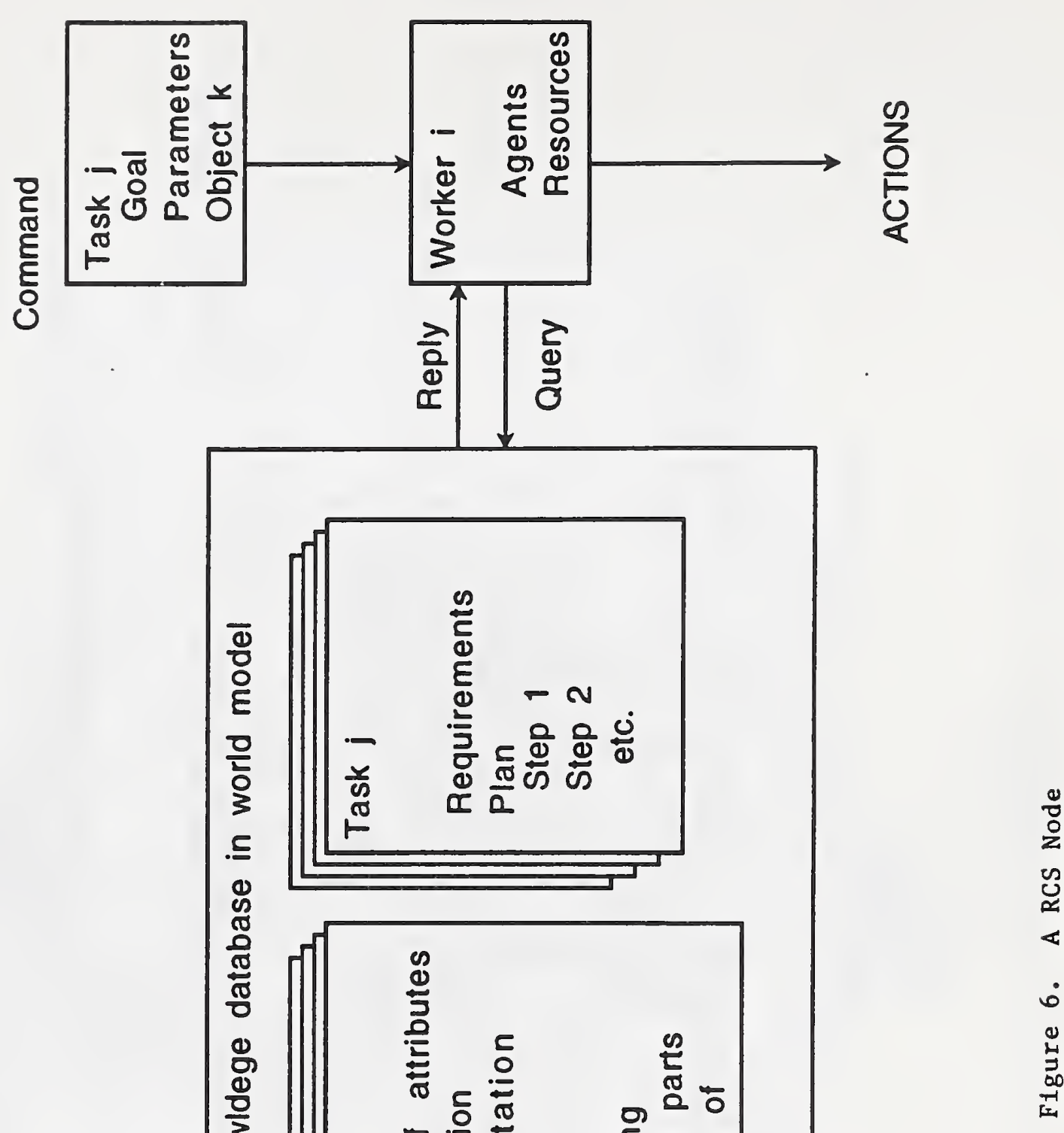


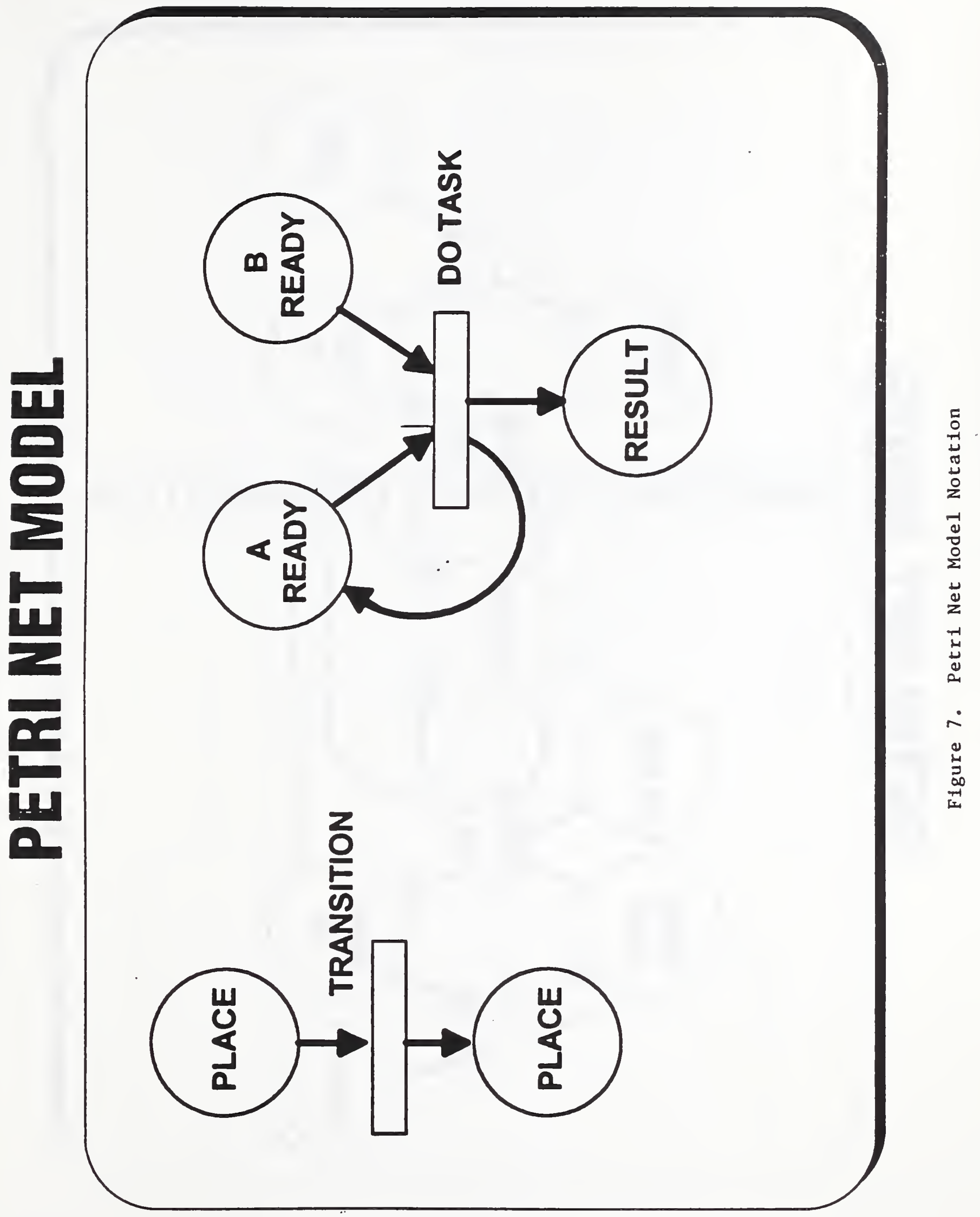




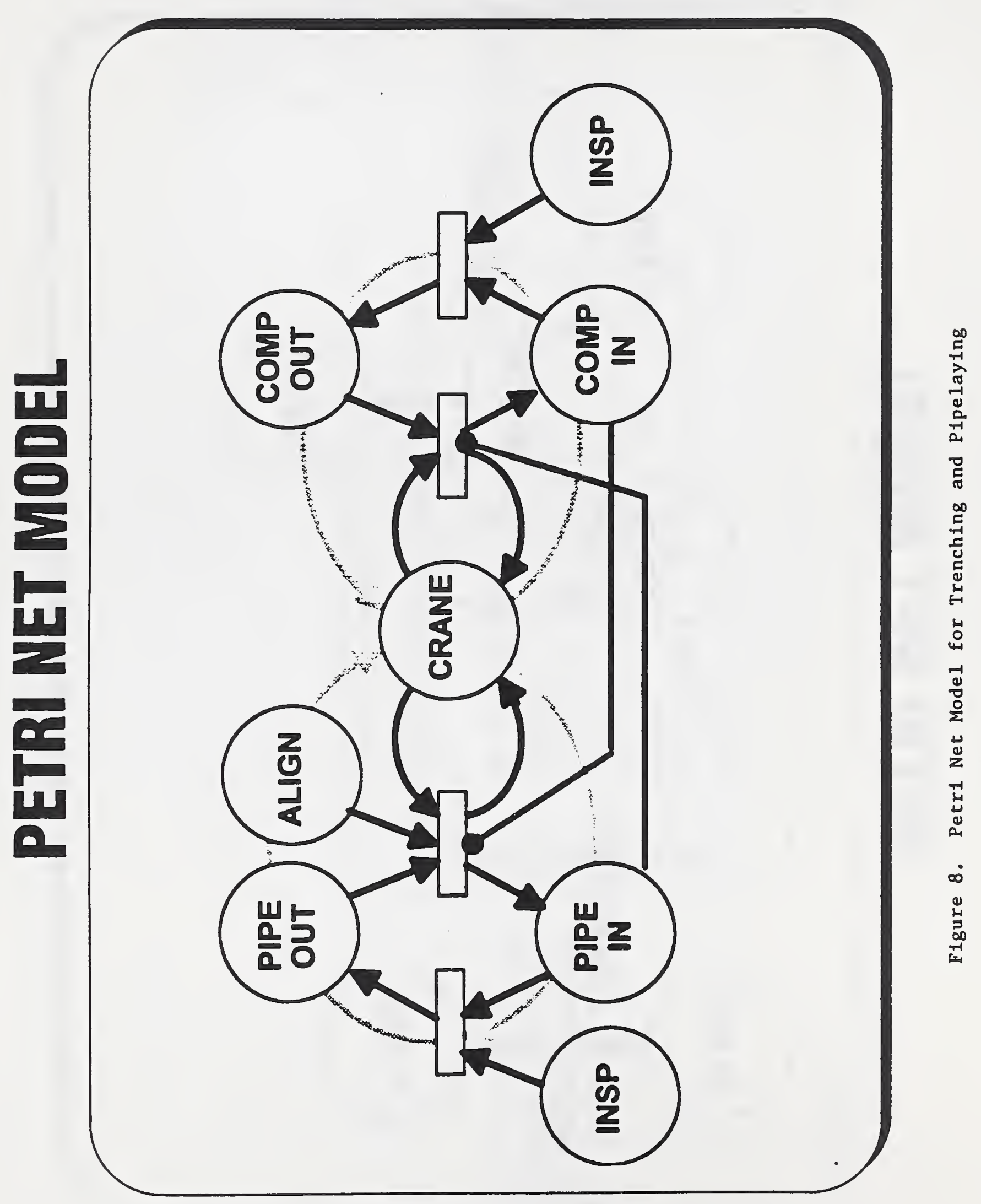




\section{AUTOMATED BRIDGE DECKING}




\title{
Proposal on Automated Bridge Deck Construction Section One: Overview
}

\author{
Avi Kak \\ Robert Cromwell \\ Robot Vision Lab \\ Purdue University
}

Recent studies carried out by a group convened by FHWA and NIST suggest that the automation of bridge deck construction would be highly beneficial. We believe that such automation could enhance productivity and efficiency by at least $30 \%$. The problem addressed here is how this might be carried out. In this section we give an overview of operations which might be candidates for such automation. We approach this from the standpoint of a "consortium" of investigators who could develop the required technologies for integration on a single automated system similar to existing screeds,and perhaps using an existing screed as a base platform. In the following section, Dr. Arthur Sanderson presents a more detailed discussion of one of these component technologies, rebar handling and assembly.

We feel that there are several steps which could be automated. They include:

[1] Inspection of the sub-grade to ensure all codes are met, including:

(a) Adequate pads and spacers between beams and sub-deck panels.

(b) Proper alignment of sub-deck panels.

(c) Absence of cracks or voids in sub-deck panels.

[2] Laying of rebar, including placing the chairs and tying the rebar. (see next section.)

[3] Application of water and/or other agents as needed.

[4] Monitoring the flow of supplied concrete to ensure proper volume and eliminate manual filling of low spots and subsequent extra smoothing passes.

[5] Applying mechanical vibration to ensure proper material flow.

[6] Monitoring the supplied concrete to ensure that standards regarding 
density and plasticity are continuously met.

[7] Monitoring the constructed deck extruded behind the machinery, to ensure internal and surface characteristics meet all standards.

[8] Floating and tining of the final surface.

Addressing these points in the order of operation, we see that inspection is the first step. This would most likely be visual inspection, and can be implemented as a combination of 2-D and 3-D visual sensing.

While ultrasonics is used for detection of internal stresses and micro-cracking, it is perhaps ill-suited for this application.

Cameras, possibly used in conjunction with structured-light sources, could be mounted on a gantry over the front of the machine. These sensors could ensure that the sub-deck panels are correctly aligned with the beams, that they are not cracked, etc. In the highly schematic Figure 1, the right-most gantry is shown as carrying out this task.

Mechanical devices (shown in figure 1 as arms on the front of the machine) will be used to acquire rebar from a supply bin and place it on chairs, properly aligned. After the rebar is tied, further visual inspection will ensure its proper placement. Rebar assembly and tying would be done by the second of the linked gantries in Figure 1. An alternative arrangement is shown in the next section.

Water must be sprayed before concrete is poured, to avoid drawing too much water out of the mix. Automated visual inspection could ensure that all surfaces had been adequately wetted, driving the spray mechanism to correct any areas slighted.

We propose to use simple range sensors to determine the cross-section of the sub-decking as the screed progresses, and also to measure the cross-section of the supplied concrete. In Figure 1, structured-light projectors on the screed, coupled with cameras mounted on the second gantry, make these measurements. In this way the screed could ensure adequate supply, but no more, by communicating with the concrete supply devices. We believe that these material sources, probably concrete pumps in this case, can be linked into a site-wide packet radio network. A packet cluster architecture would allow random inter-machine communication between any two pieces of equipment on a site, as well as central control by a machine supplying a primary service. We have not attempted to show the actual concrete supply in 
Figure 1, since we feel that a flexible approach is required. The automated system we propose would communicate with whatever material supply systems were available, be that a conveyor system, a concrete pump, or whatever, to request concrete (and rebar) as needed.

Finally, as the integrated system progresses along the bridge, 2-D and 3-D sensors could inspect the finished product. The cross-sectional profile could be measured to a high degree of accuracy in order to ensure that all standards were being met. These measurements could form a record that would be available for later analysis. Also, the surface moisture characteristics could be monitored, and corrected as necessary.

\section{Performance Issues}

What will be the productivity enhancement if such a system is deployed? A precise answer to that will depend on how many robotic devices and sensors are mounted on such a system. [On a wide span, separate robot and sensor suites could be assigned to each 12 foot section of the deck.] Although admittedly a very rough guess at this time, even without any parallelism in robot devices and sensors, we believe that the proposed system would increase the productivity by at least $30 \%$. Moreover, the quality of the decking would be superior, more consistent, and less prone to human error. This $30 \%$ figure is based on the manual observation of the current practice of deck construction in California. We observed the different cycles of interlocking steps that go into the process of laying down a deck and how, more often than not, the personnel assigned to one step have to stand around and wait while the other related steps are brought to completion. 


\title{
AUTOMATED BRIDGE DECK CONSTRUCTION PROPOSAL
}

\section{SECTION: AUTOMATED REBAR HANDLING AND ASSEMBLY}

\author{
Arthur C. Sanderson \\ Center for Advanced Technology in Automation and Robotics \\ Rensselaer Polytechnic Institute
}

\begin{abstract}
A major component of bridge deck construction consists of the handling, laying, and tying of rebar to provide the reinforcement for the concrete deck. In current practice, rebar bundles are delivered to a job site and stacked for future use. Bundles are manually sorted and arranged at a staging site, transported to the bridge deck at the time of construction, and individual pieces are again handled manually for positioning and tying. Automation of these procedures would result in more efficient handling of materials, higher quality in the positioning and tying of the reinforcement, increased safety due to the reduced manual handling of heavy parts, and reduction in the incidence of back injuries resulting from bending and tying of the rebar.
\end{abstract}

Two major steps in this process may be addressed by automation techniques in order to achieve these goals:

\section{(1). Computer-aided design, organization and tracking of rebar materials.}

Rebar pieces should be bundled, delivered, and handled in lots which map directly onto the deck assembly process itself. Computer-aided design tools should be used to specify the rebar design and layout. The designer or construction process planner then specifies the order or layout and assembly of the rebar structure. Based on this order of assembly, the rebar pieces are specified as groups or kits, and this grouping is specified to the rebar manufacturer for delivery in the prescribed form with labels attached to the groups. This planning and labeling avoids rehandling and sorting at the construction site. Ideally, the delivery of the materials themselves would be coordinated with the construction schedule so that the rebar materials are delivered directly for layout and assembly of the deck and do not require separate staging. This delivery and assembly schedule is worked into the overall project plan to very the coordination of rebar assembly with deck pouring in the integrated deck construction system. Efficiency in transport, handling, and assembly is gained by careful planning and scheduling of the tasks.

\section{(2). Automated assembly and tying of the rebar parts.}

The assembly process itself will be integrated into the automated decking system which travels along the bridge and performs the tasks of rebar tying, concrete pouring, smoothing and sensing in a single pass. The automated handling and tying of the rebar structure is a particularly challenging phase of this process. It is unlikely that general robot arms would effectively accomplish this task due to the length, flexibility, and weight of the rebar parts themselves. A more realistic scenario for rebar assembly is shown schematically in Figure (2), where manually assisted laying of the longitudinal rebar prepares the way for automated laying and tying of the 
transverse bars. The longitudinal bars are fed directly from a delivery vehicle or positioning in kits using a conventional crane. The manual operation sets the longitudinal bars on supports in their approximate final position. The first set of supports have built in physical spacers which align the ends of the bars with the prior set. The bar spacing for the remaining length will be set by the assembly and tying apparatus which tracks the longitudinal bars and adjusts their positions as it ties.

The transverse rebar placement and tying machine travels with the integrated decking system and is aligned to physical or optical guides along both sides of the bridge. The machine contains a feeder bin of transverse bars which have been loaded directly be crane according to the labelled groupings. Each transverse bar is fed and tied as the machine proceeds along the longitudinal bars. The longitudinal bars are tracked and positioning prior to tying. The proposed tying mechanism itself is a plastic "tie-wrap" loop analogous to ties which are used to secure cables and wires. Such a tie-wrap loop tightens securely and requires much less complexity in the automated tying mechanism. The intersections of each transverse bar with all the longitudinal bars are tied simultaneously by a set of tie-wrap mechanisms. The details of the feeding, tracking, and tying mechanisms are not provided in this description, but have been developed to a stage of conceptual design. Specific attention is given to the need to hold and tie the transverse bars while the machine is in motion. An added feature of the integrated machine could include an inspection device to scan the resulting rebar mesh and confirm both correct geometry and placement of ties and supports.

The automated rebar installation system described here represents several innovations in the procedures and the mechanisms available for automated bridge deck construction. The impact of these innovations would occur as a result of both of these processes. Improvement in design and planning tools provide a direct link into the organization and handling of the rebar materials. This change would reduce the time required to handle the rebar and increase the safety of the workers. Eliminating the staging and sorting of the rebar materials could improve the efficiency of this phase of the project by as much as $50 \%$.

The automated rebar laying and tying system would perform the rebar installation as a parallel operation with the concrete pouring. While the longitudinal layout would still be done largely with manual methods, the feeding and organization of the materials would be improved. The automated transverse bar assembly and tying would be entirely automated. Only the rebar feeder would need to be refilled as the task proceeded. This reduction in workforce and time required would increase the efficiency of this phase of the project by at least $50 \%$ and have additional benefits on health and safety issues.

The approach to rebar handling and assembly described here for bridge decking will impact other rebar assembly processes in road construction. Both the improved design and tracking approached, and the automated laying and tying devices can be adopted to other problems including center and sidewall construction and pilings. While the uniformity of the bridge deck problem suggests that it is particularly well-suited to automated technologies, these extensions to related areas will have similar benefits. 


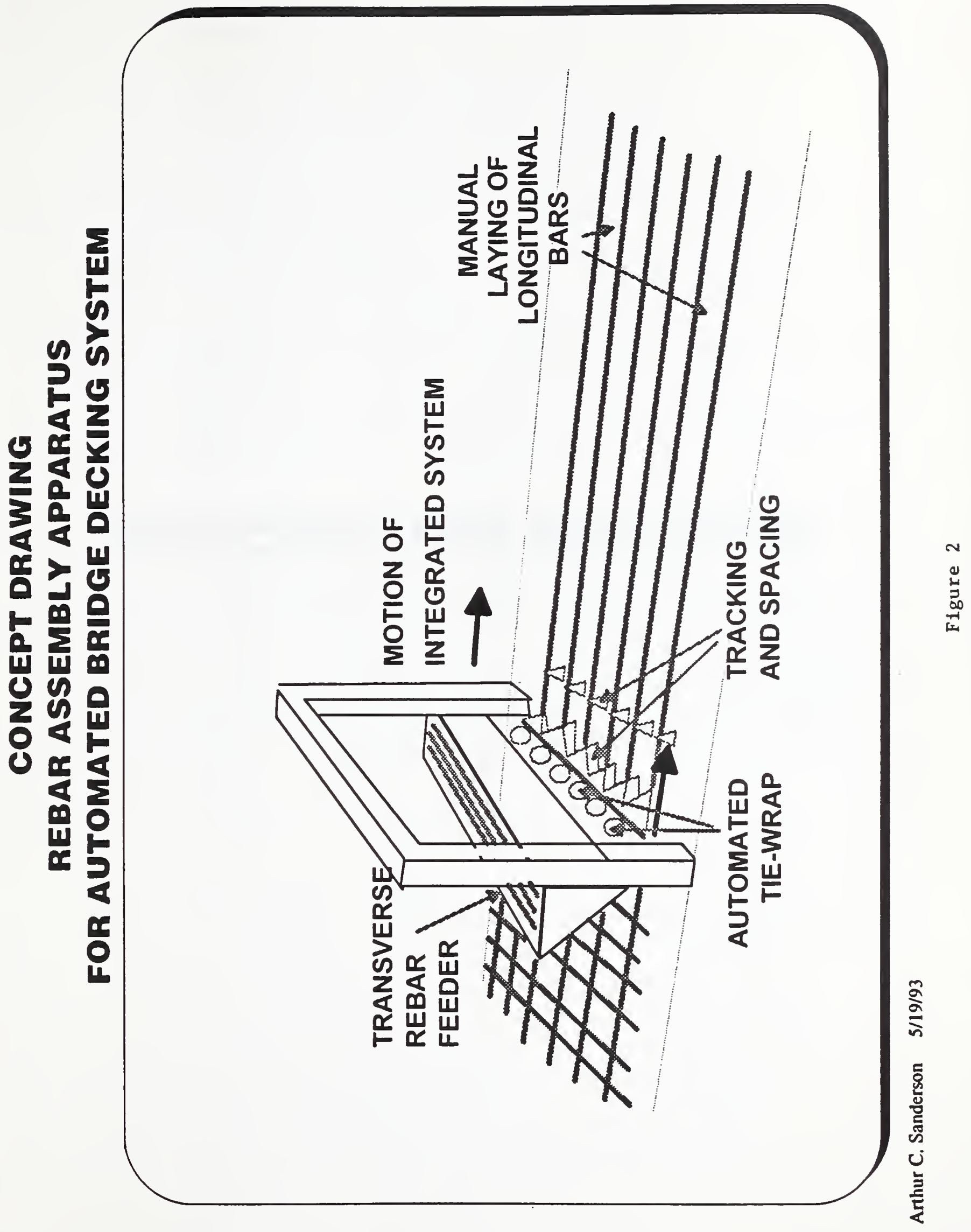


- 


\section{TRENCHING AND PIPELAYING}




$$
\text { ' }
$$




\title{
Automated Trenching and Pipelaying
}

\author{
Dr. Leonhard Bernold \\ Civil Engineering Department \\ North Carolina State University
}

The main benefits from using automation and robotics in trenching a pipe-laying can be summarized as follows:

1. Drastic reduction of fatal accidents and lost workday injuries.

2. Elimination of accidental damage of buried utilities such as water mains and power lines.

3. Augmentation of operator efficiency through sensory-based control methods.

4. Reduction of wasted production time due to surveying or other related measuring errors.

5. Elimination of the need for surveying stakes which are easily damaged and lost.

6. Increase of the versatility of key machinery (e.g., backhoe excavator) by allowing the control of "smart" attachment. This hardware versatility combined with the new sensory controls should greatly increase the productivity of the work crew as a whole.

7. Automatic creation of up-dated as-built underground utility maps.

8. The technologies can be applied in a retrofit mode. Thus, existing equipment could be easily equipped with the necessary technologies while new equipment could be redesigned for better integration of the necessary additional hardware.

The opening of trenches to bury sewer, water, and other utilities is an operation which can be observed on almost any highway construction project. Traditionally, a surveying crew will first stake out and mark the location of a planned trench. Later, a construction crew will begin excavating the trench to the desired depth using traditional surveying equipment and approximation to control depth and direction. Sometimes the stakes have been accidentally 
removed or damaged by the time the construction crew starts. Traditional excavation requires persons to enter the trench with shovels to even out the bottom, to lay pipe, etc.

The hazardous nature of construction work, especially that related to excavation work, is well documented. The fatality rate was estimated by OSHA at 50.8 deaths per 100,000 workers per year for $1984-1988$, whereas for construction work generally, it was estimated at 24.8 deaths per 100,000 employees. Similarly, trenching cave-in fatalities have been estimated by NIOSH at 75 per year, and lost workday injuries due to cave-ins at 1000 per year. In a recent report prepared by NIOSH, based on OSHA's inspection data, it was estimated that at least another 97 persons were killed as a result of all excavation-related accidents. The incidence rate for injury among construction workers, including those doing excavation work, is about two time the all industry average (i.e., 15.1 injuries per 100 workers in construction compared with 7.7 injuries per 100 workers in all industries. [Department of Labor]

The major occupational hazards of excavation work results from cave-ins, from exposure to underground utilities, and from material or equipment falling into the open trench. Precautions against cave-ins include bracing, sloping, benching, using of shields, or freezing. However the proper use of these techniques requires an understanding of the importance of such factors as excavation depth and width, soil type, hydraulic pressure, and other specific conditions present at the worksite.

The advent of computer integration which is able to link computer controlled machines to CAD systems on one hand and to hardened electronic sensors for real time control information provides many opportunities to reduce work hazards during trenching and pipe laying while at the same time increasing quality and productivity, similar to the tunnel boring machines in tunneling.

The capabilities of such automated and robotic devices would allow;

1) Advanced sensing devices directly mounted on the excavator boom allow not only the electronic detection of position of and forces within the manipulator and the hydraulic power system but also the detection of metals (e.g., pipes) and possibly other buried material which should not be damaged. The sensory system has the flexibility to be interfaced with on-board equipment monitoring devices (e.g., oil temperature) as well as CAD software providing data related to the trenching and/or pipe-laying operation (e.g., depth of trench) and electronic maps of underground utilities. These technologies would eliminate the need for crew members climbing into the hazardous trench. Also, many costly accidents due to 
the damage of buried utilities will be avoided.

2) Shared control between the operator and an intelligent and sensor based controller. Feedback of bucket position and encountered obstacles to the operator in 3-D. Presentation of virtual views of obstacles or positions which are presently not available to the operator.This operator augmentation technology will make the entire operation more efficient.

3) Real time position control through feedback from local positioning systems as well as laser guidance systems such as traditional beam and rotating plane lasers. This would eliminate the need for staking the trench out and possible delay of operations because of lost or dislocated stakes.The operator of the equipment would be supported by visual targets on a screen and actual positions for either robotic or manual control of trenching and pipe-laying operation. The control system also supports the automatic generation of as-built data to be directly fed to an electronic utility map.

4) Support of smart end-effector attachments which are able to connect themselves to the excavator boom/bucket without the need for detaching the bucket. Quick disconnects allow for easy hook-up of both electronic cables and hydraulic power. The smart end-effector for laying of pipes includes a set of specialized sensors, such as a laser receivers, that are directly integratable with the overall sensory system. The pipe-manipulator-attachment is capable to automatically grab and position the pipe supported by a remote positioning system (e.g., laser).

\section{Reference}

Department of Labor, 1989. "Occupational Safety and Health Standards-Excavation; Final Rule,"Occupational Safety and Health Administration, Federal Register/ Vol. 54, No. 209, October 31, Washington, DC. 


\section{ROBOTIC EXCAVATION}

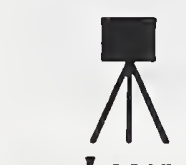

Laser

Transmitter A

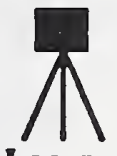

Transmitter B

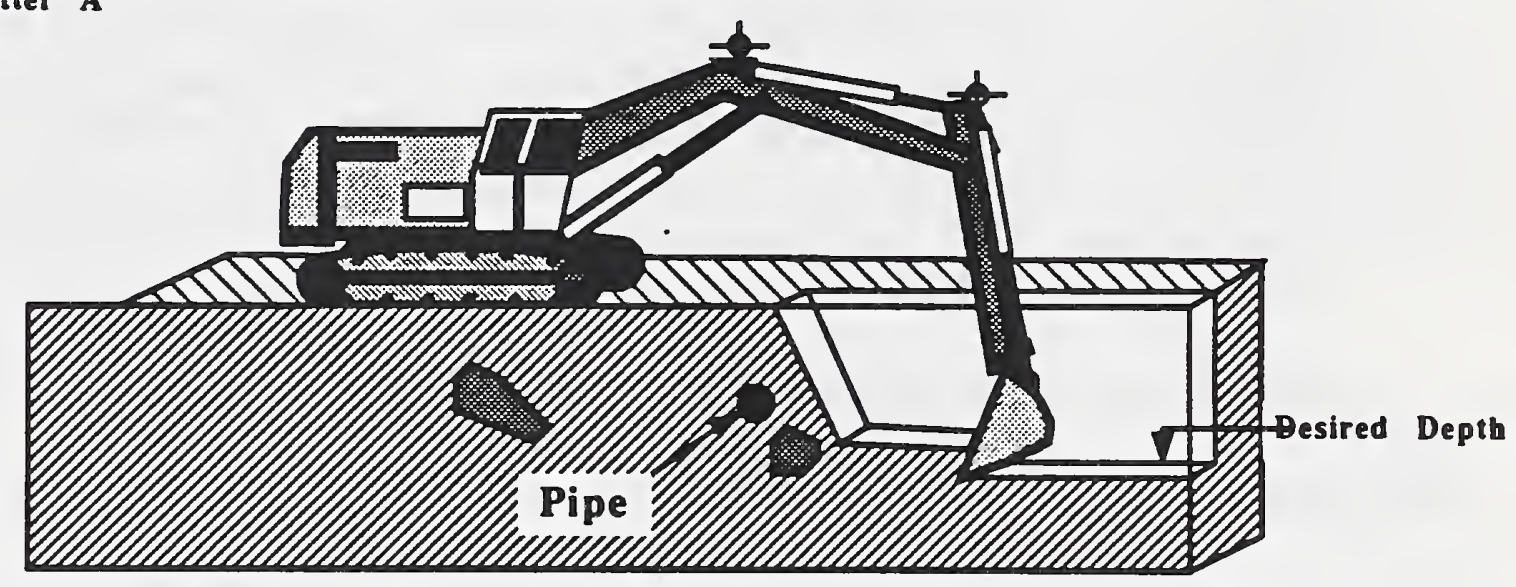




\section{ROBOTIC PIPE PLACEMENT}

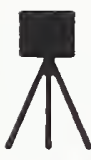

Laser

Transmitter A Control System

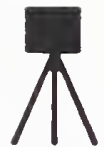

Laser

Transmitter B
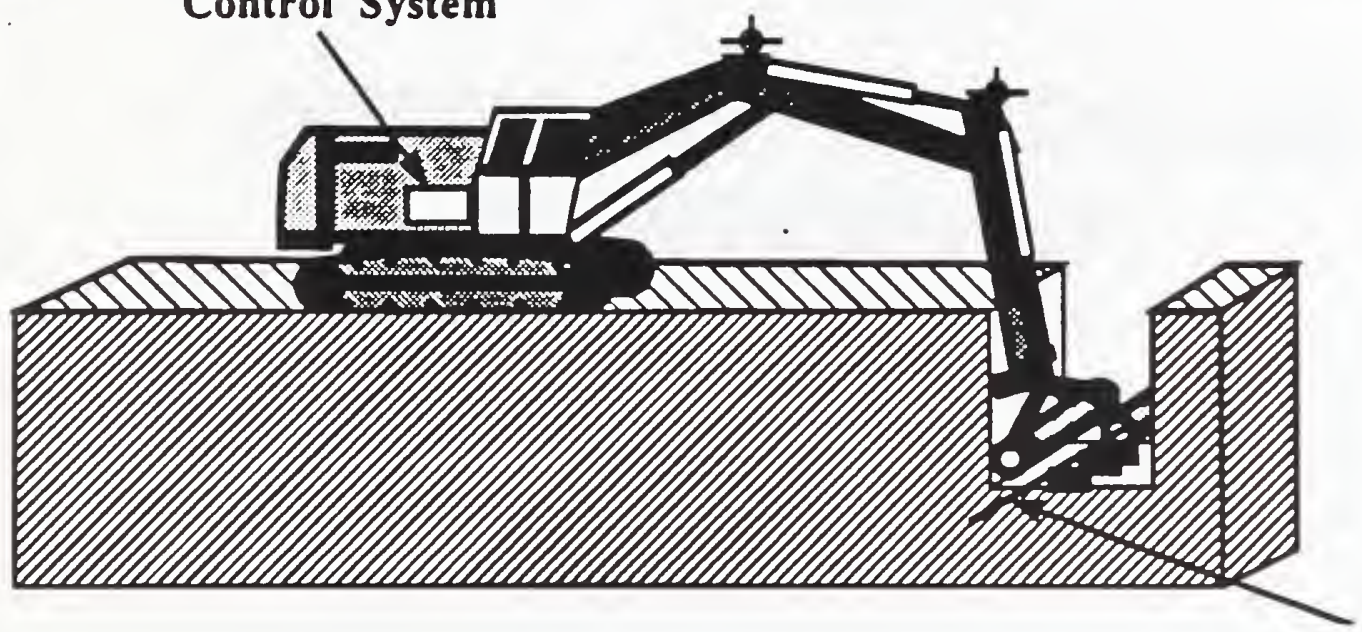

Laser Guidance 


\section{BRIDGE INSPECTION AND MAINTENANCE}


, 


\title{
Automating Bridge Inspection and Maintenance.
}

\author{
Kenneth Goodwin \\ Robot Systems Division, NIST.
}

May 27, 1993

Bridge inspection and maintenance offers a significant opportunity to reduce costs through automation while achieving enhanced environmental control. The current situation with respect to bridge maintenance is in fact so severe that many states cannot afford to attend to all of the bridges in need of repair, and are focusing only on the most severe cases. In consequence, any potential cost savings could be expected to contribute directly to public safety by extending available funds to increased numbers of bridges. A 1991 report from the Federal Highway Administration (FHWA) notes $40 \%$ of the bridges on the federal aid system were built in the 1950s and 60 s with minimum cover for reinforcing steel and no corrosion protection. More than a quarter million bridges are eligible for federal aid. Of these, FHWA estimates that 75,000 need work. In addition to the $\$ 16.1$ billion in Federal funding, state and local governments spend between $\$ 500$ million and $\$ 1$ billion a year on 1,500 to 2,500 bridges that receive no federal money. All levels of government will spend more than $\$ 4$ billion a year on bridge maintenance.

Increased environmental regulations have delayed maintenance, particularly in the stripping and repainting of highway overpass structures. Increased process restrictions and media waste disposal costs have been the primary cause of delays and additional costs. Environmental regulations now require the isolation of blast areas and have significantly increased waste disposal 
costs, especially for paints containing hazardous wastes such as lead. In past years, a contractor could remove an overpass's coating system through open air blasting. However open air blasting produces airborne contaminants which are harmful to personnel, equipment, and the environment. Workers must now operate equipment in limited visibility containment areas while wearing cumbersome protective suits. Containment areas are constructed with scaffolding and are enclosed by tents. The erection of the containment area is a slow and expensive process which adversely effects productivity. A North Carolina Department of Transportation case study of the stripping and primer application of two bridges in 1991 found that $50 \%$ of the time in a typical work day was spent on moving and sealing the containment enclosure and cleaning and vacuuming debris.

The automation projects proposed in this document would address these needs with a series of near-term and longer-term developments. Automated systems can remotely inspect bridge paint condition and the physical state of bridge members, erect shrouds, recover stripping media and paint with increased efficiency, and reduce the manpower and time required to strip and paint an overpass. The remote operation, the reduced operator contact, and the automated containment shroud will greatly reduce the time-consuming construction of staging and enclosures and eliminate the need for respirators and special clothing. This would provide the following key benefits:

- Increase speed and efficiency of inspection operations.

- Increase efficiency and reduce time to strip paint.

- Reduce and eventually eliminate time spent by workers on bridges.

- Reduce time required to place shrouding for painting.

- Improve quality of painting and decrease time required.

- Reduce hazardous waste through more efficient paint application.

- Reduce exposure of workers to harmful materials.

- Reduce environmental impact of paint stripping. 
- Automate generation of maintenance and inspection databases.

- Reduce manpower requirements.

For typical highway overpass bridges, it appears feasible to reduce the costs of stripping and painting by one quarter to one third, in addition to less easily-quantifiable environmental advantages.

\section{Near-Term and Longer-Term Approaches.}

Technology is available, or nearly available, today for automating the remote collection of imaging and other sensor data to assess bridge and paint condition. Similarly, automated tooling for stripping and applying paint is available. The principal problems to be addressed are the automated placement and manipulation of such sensors and tooling, the automated placement of shrouding, and ultimately the automated interpretation and logging of data and control of operations.

An initial, near-term, step is to develop improved alternatives to "Snoopers" for positioning and manipulating automated bridge inspection and maintenance operations. Advanced control techniques, already developed for industrial robots, can provide coordinated motion for devices adapted from exiisting machines, such as boom lifts. Two such concepts in highway overpass paint removal technology are presented in this proposal for the development of a prototype Robotic Highway Overpass Stripping (RHOS) System. These devices could begin to achieve a number of real benefits even with initial simple teleoperated modes of operation.

In the longer term, wholly-new forms of robotic devices could be designed for delivery of many inspection and maintenance services. Such machines would be programmed from databases describing each bridge. The bridge databases would be developed originally from "as-built" databases, which in turn would be developed during construction by noting deviations from "as-designed" databases generated during design. Each time a bridge is repaired or otherwise modified, an updated "as-is" database would be gener- 
ated. These "as-is" databases would constitute the input for planning and scheduling bridge repair, and for programming the robots to perform various functions such as inspection, paint stripping, and repainting.

Advanced robotic devices working from such databases could be developed able to craw along over and under bridges, automatically performing routine inspection aint stripping, and repainting chores. While large bridges might have custom-designed, dedicated robots, robots might also be specially designed for whole classes of smaller bridges. Such robots would be transported to bridge sites and deployed to crawl along a bridge and its associated support structures and monitor a number of parameters that are a measure of the health of the bridge, such as macro-scale deformations, acoustic emissions, ultrasonic echo examination, paint condition, and chemical detection of corrosion. The same robots, fitted with different apparatus, would then while still in place handle stripping, painting, and perhaps minor structural repair as indicated by the inspection.

\section{Near-Term Technical Objectives.}

Since bridge inspection and maintenance is a major activity, involving bridges and overpasses ranging from simple to complex and small to large, a variety of automation opportunities appear as alternatives to current use of Snoopers and scaffolding for manual operations.

The NIST Robot Systems Division has been developing flexible, intelligent control systems for over a decade. The foundation of these control systems lies in a control architecture which establishes a skeletal framework for building flexible controls for complex systems. This sensor based real-time control system architecture has been applied to numerous robot, vehicle, and factory control solutions. These systems include serial link robots, cooperative robots, coordinated robots, factory automation, automatic guided vehicles, autonomous underwater vehicles, teleoperated robots, tele-operated vehicles, and parallel link manipulators.

The Robotic Highway Overpass Stripping (RHOS) system could overcome 
many of the environmental barriers confronting highway overpass maintenance. RHOS would be an integrated set of manipulators, stripping devices, and containment shrouds under the coordinated control of a computer system. RHOS would provide rapid set up and use, complete containment of the blast media and paint debris, maximum recycling of the stripping media, and the exclusion of human workers from the blasting environment.

An overpass stripping operation using RHOS would consist of a robotized aerial lift capable of manipulating a blasting nozzle and containment shroud along structural members of highway overpasses. The containment shroud will transport media waste to a recovery system. The recovered blasting media will, to the extent possible, be re-used.

The goal of this near-term demonstration-effort would be to develop and demonstrate a robotically manipulated paint stripping system. This system would remove existing paint and prepare those surfaces for further painting. The system would recover the blasting media and chip debris generated in the blasting process and, when possible, recycle the media. The system initially would be largely teleoperated and would attempt to demonstrate ease of operation by current overpass maintenance contractors. The RHOS system would include an integral shroud subsystem, expected to contain a minimum of ninety five percent of the spent media and chip debris. The shroud subsystem will also transfer the debris to a recycling subsystem. RHOS would clean overpass metal structures to near white metal by media blasting, and produce an appropriate surface profile to receive new coatings. In its initial form, the RHOS system should be able to access surfaces routinely addressed by manual blasting.

The goal is a system usable by personnel presently engaged in highway overpass refurbishment, operating under common weather conditions. Maintenance requirements should be similar to those commonly required by standard industry manufacturers. The operator interface will be designed to minimize the operator's programming tasks and to support on-site diagnostics. 


\subsection{Technical Approach.}

The RHOS system will bring together many subsystems under unified computer control. Wherever possible RHOS will utilize commercially manufactured components in order to expedite the availability of commercial versions. The RHOS system has two major development areas. The first area is a computer controlled aerial lift to maneuver in and around the highway overpass structure. The second area is the processing equipment which includes all blasting, containment, and recovery subsystems.

A robotized aerial lift will be developed through coordinated efforts with a commercial aerial lift company. Currently available aerial lifts are not capable of making a smooth coordinated move, such as moving in a straight line along the surface of a bridge girder. Each joint must be controlled separately by the operator. Coordinated joint control has been well developed for industrial robots but has not yet been applied to aerial lifts.

Potential commercial suppliers with active development efforts in the area of coordinated motion have been identified. Cooperative research with agencies such as NIST would be required to enhance their efforts and move towards the development of an open architecture robotic aerial lift. These efforts would entail interface developments for additional mechanical joints and command, status, and sensor communications. Efforts would also include the development of computer, electronic, and sensor components needed for robotic control with minimal operator interaction.

The RHOS system controller will supervise both the aerial lift and the processing equipment. NIST could develop the controller in accordance with the NIST Real-time Control System architecture (RCS). The control system would have an easy to use operator interface, such that the operator will require neither specialized computer nor robotic training. The RCS hierarchal structure would ensure the RHOS control system remains open for future expansion.

Existing systems for acquiring sensory data and for maintaining camera fixation through coordination of camera motion with lift motion could easily be adapted to RHOS. NIST has already developed rapid camera gaze-control 
systems operating under the RCS hierarchical control system. The containment system must permit manipulation by the robotic aerial lift, must not restrict the blasting of overpass structural members, and must transfer the media waste to the recovery subsystem. The containment system must also conform to irregularities in surface to be stripped in order to insure adequate containment of the waste. This may entail multiple modular shroud components designed for rapid change or a single conformable device. Deployable shrouding might begin with a large emplacement within which the robot mechanisms could act over a large volume, as shown in Figure 1. Subsequently, current developments from the shipbuilding industry might be adapted to provide small, movable shrouding as shown in Figure 2.

Final system integration will entail the assembly, testing and demonstration of the complete RHOS system. The system integration phase of the project would conclude with field demonstrations of the RHOS system, in which various overpass structural members will be stripped.

\subsection{Specific Steps.}

Eleven tasks are proposed that could be accomplished over an 18 month term. These tasks are briefly outlined below.

1. Identify Overpass Features. Though cooperative efforts with the Federal Highway Administration and a State Department of Transportation, select a representative set of highway overpasses. The effort will identify common features or families of features which require periodic stripping from the selected overpasses. The RHOS system will then be developed to process all of the identified features.

2. Select Lift. Perform comparative analysis of available lifts.

3. Select Blasting System. Perform comparative analysis of available media blasting systems.

4. Develop Shroud Subsystem. The shroud subsystem is the highest risk element of the project. The shroud must fulfill the EPA requirements 
for level 3 paint stripping by containing and collecting the spent media and debris, and then transfer this material to the recycling subsystem. A comparative study will be conducted to determine the best shroud design to meet these requirements. The construction of the shroud should be contracted to industry in order to expedite the availability of commercial versions of the RHOS system.

A static-type shroud system design would remain fixed to the bridge structure while the blasting nozzle maneuvers within (see Figure 1). In this configuration some of the manipulator joints operate within the shroud while the others remain outside. The shroud will have a port which will seal about the manipulator and ensure its freedom of motion. Media waste will exit the shroud through another port primarily by means of gravity to be routed to the recycling system. With the dynamic shroud design, the shroud would be an integral part of the end effector carrying the blasting subsystem (see Figure 2). This form of shroud would enclose the blasting unit and move along a structure's surface via the robotic aerial lift. The dynamic shroud system would most likely consist of interchangeable modules, each able to conform to a different structural feature. A vacuum system will route the media waste to the recycling subsystem.

5. Select Computer Configuration. Perform comparative analysis of computer control systems. Select system based on availability, support, ease to interface, expandability, convenience of field maintenance, and cost.

6. Design Manipulator Extension. A standard aerial lift does not have sufficient degrees of freedom to access all of the required areas of an overpass. Additional degrees of freedom (joints) will be added to the end of the aerial lift, which will increase the dexterity of the manipulator to provide acceptable access.

7. Develop User Interface. The operation of the RHOS system will require minimal training for existing overpass maintenance personnel. The controls shall be intuitive with clear identification. The interface panel will also be portable such that the operator will be able to position himself at the most advantageous position to operate the system. 
8. Develop System Controller The system controller shall have a set of routines to perform all the functions required for RHOS system operation. Routines will be included which provide for stripping specific overpass features, stripping collections of features, performing diagnostics, and performing simple maintenance.

9. Integrate Aerial Lift and Extension. Integration consists of assembling mechanical components, establishing controller communications, and performing coordinated motion.

10. Integrate Stripping System. The stripping system shall be tested to ensure that the blasting subsystem can remove common overpass paints and that the recovery subsystem functions as required. Representative values will be derived from these tests which will establish the system's operating parameters. These parameters include such items as media flow rates, pressures, stand-off distances, linear feed rates, and overall processing rates.

11. Perform Field Tests. The final testing includes two phases. The first phase could be conducted at NIST. The RHOS system will be operated at the extremes of its design requirements. Tests will ensure the robustness of the controller, the thoroughness of the programming, and the convenience and completeness of the operator interface. The second phase will consist of paint stripping at one or more highway overpass sites. The sites will be selected by either FHWA, or an appropriate state highway department. The site should be scheduled for routine paint stripping maintenance and the regular contractor's employees should operate the RHOS system.

\section{Longer-Term Technology.}

Advanced robotic devices will be designed with the ability to perform inspection, paint stripping, and repainting operations under bridges by attaching themselves to the I-beams underneath the bridge and maneuvering using crawling as a means of locomotion. An example of such a robot is shown in 
Figure 3. This device consists of two crawling arms (or legs) and a work platform with a robot manipulator and containment shroud (shroud not shown in the figure).

\subsection{Advanced Automation.}

The initial test version of this device will be controlled by an operator using a joystick input. However, a fully operational system will have an automatic control system that will use a database describing the geometry of the particular bridge and a planned set of actions for performing a prescribed set of tasks. The bridge database will be developed originally from an "as-built" database, which in turn will be developed during construction by noting deviations from the "as-designed" database generated during design. Each time the bridge is repaired or otherwise modified, a new "as-is" database will be generated. This "as-is" database will provide the input for planning and scheduling bridge repair, as well as for programming the robot to perform the various functions required for inspection, paint stripping, and repainting.

The design envisioned would operate under the guidance of a general hierarchical control system, such as the NIST RCS design, which could accept at the site such a database describing a particular bridge, and adapt execution of operations to it under a generic task plan that would be applicable to all bridges of the same class. This would be a straightforward extension of current state-of-the-art industrial practice, for example robotic welding of automobiles in which new CAD designs are accessed to generate paths for robot welders. Since the nature of operations in the field is inherently less structured and less controlable than in factory situations, this level of operation would still require general guidance by an operator, but routine, detailed motion planning in real-time would be generated by the task-planning program.

In a later stage of development, the device would incorporate sensing for guidance (in addition to the initial, specialized sensing for inspection) which would allow it to adapt to errors in positioning and to new situations not contained in the data base (e.g., bird's nests, undocumented repair work.) 
Sensory-guided robotic systems of this sort, operating under general task plans and working from a priori databases exist today in laboratory settings and experimental operations. They can successfully adapt simple planned operations such as navigation and manipulation to minor discrepancies between their observed sensory data and expectations generated from riori databases. Experimental approaches to automatically updating the databases from the robot's sensory input also exist. The bridge-maintenance task presents an attractive target for applying and extending these experimental technologies to highway maintenance operations due to the relatively fixed nature of the task, the relatively structured environment, and the relative ease with which working databases could be produced.

\subsection{Mechanical Design.}

The device shown in figure 3 consists of two crawling arms and a work platform with a robot manipulator and containment shroud (not shown.) Each crawling arm consists of a gripper at the end of a telescoping pole with a set of six cables that control the $\mathrm{x}, \mathrm{y}, \mathrm{z}$ position, and roll, pitch, and yaw orientation of the gripper with respect to the robot base. The lengths of the six cables are controlled by six winches that are under computer control. This technology has been proven in the laboratory and the computer algorithms are well understood. The gripper attached to the end of the telescoping pole can be controlled by the computer so as to align with and grasp the bottom of any I-beam within the reach of the crawling arm. Simple magnetic sensors on the grippers can provide the computer with the feedback necessary to make the orientation and gripping operation completely automatic. The winches and cables are strong enough to support the weight of the robot, and by coordinating the motion of the winches, the robot can maneuver itself under the bridge.

The work platform is also equipped with clamping mechanisms that can grapple two I-beam flanges and support the weight of the robot against gravity. When the work platform is clamped to the I-beams, the crawling arms are free to release their grip and move to new gripping positions. When the crawling arms are clamped to the I-beams, the work platform can release 
its clamps and the arms can maneuver it to a new position. By alternating between the work platform and the crawling arms gripping and moving, the robot can thus maneuver throughout the under side of the bridge, and can position its work platform and containment shroud wherever required to perform the functions of inspection, paint stripping, and repainting.

This proposed design can be constructed almost entirely of light weight aluminum tubing and steel cables. It can therefore be both large in size and light in weight. Crawling arms of this design have been shown able to easily support more then five times their own weight. It is estimated that the entire structure including crawling arms, manipulator, and shroud will weigh less than 600 kilograms.

It is anticipated that a device similar to that shown in Figure 3 will be able to maneuver over the entire underside of a bridge, including crossing under cross-support beams and between supporting pillars. The device will be designed to be deployed, either by lifting it into position from underneath a bridge, or by suspending it over the side of a bridge from a truck equipped with a modified crane. 


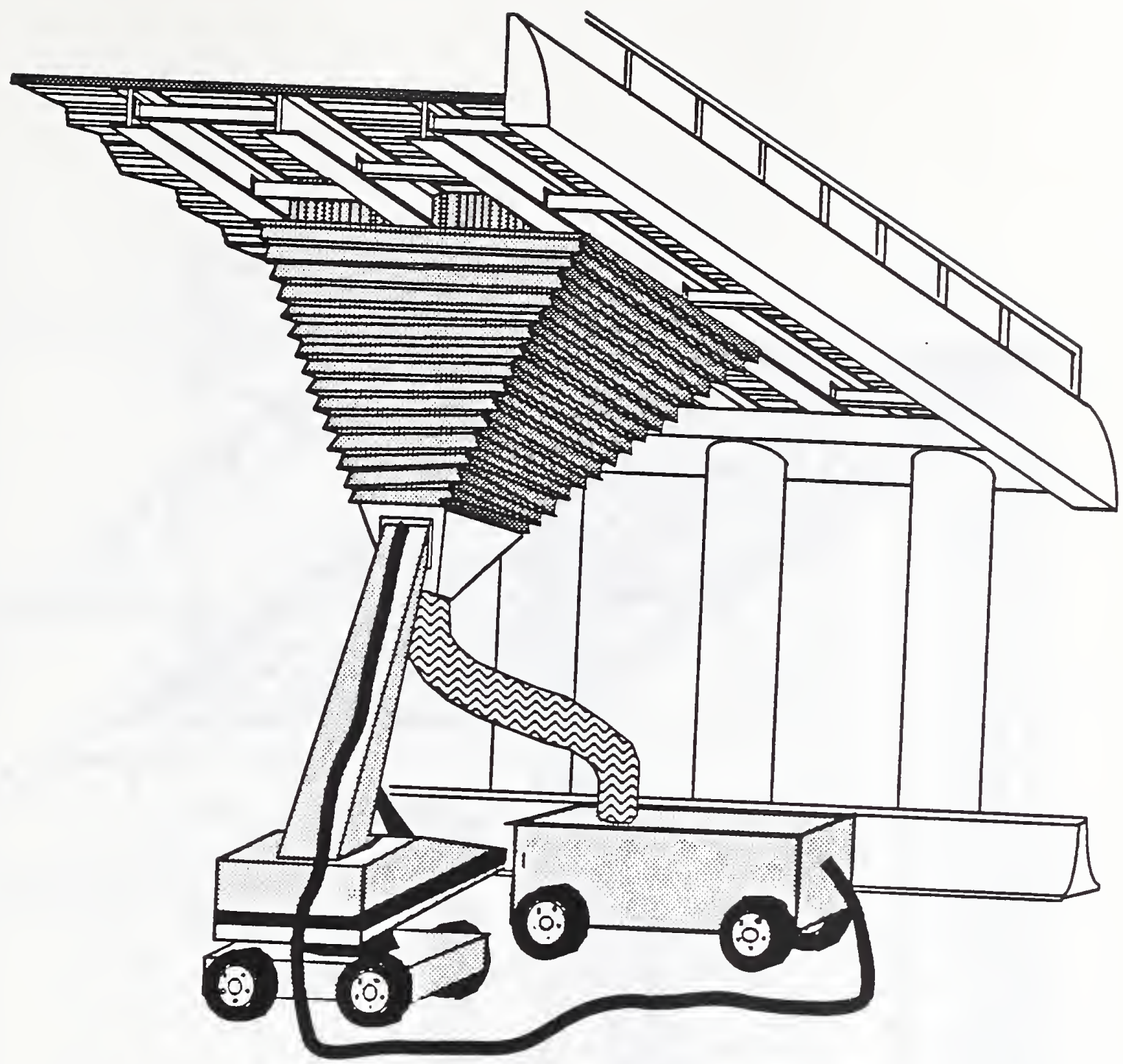

Figure 1 Possible Stationary Shroud Configuration

With the dynamic shroud design, the shroud would be an integral part of the end effecter clastying the blasting subsystem (see Figure 2). This form of shroud would enclose the shroud system would most likely consist of interchange robotic aerial lift. The dynamic to a different structural feature. A vacuum system will route modules, each able to conform recycling subsystem. 


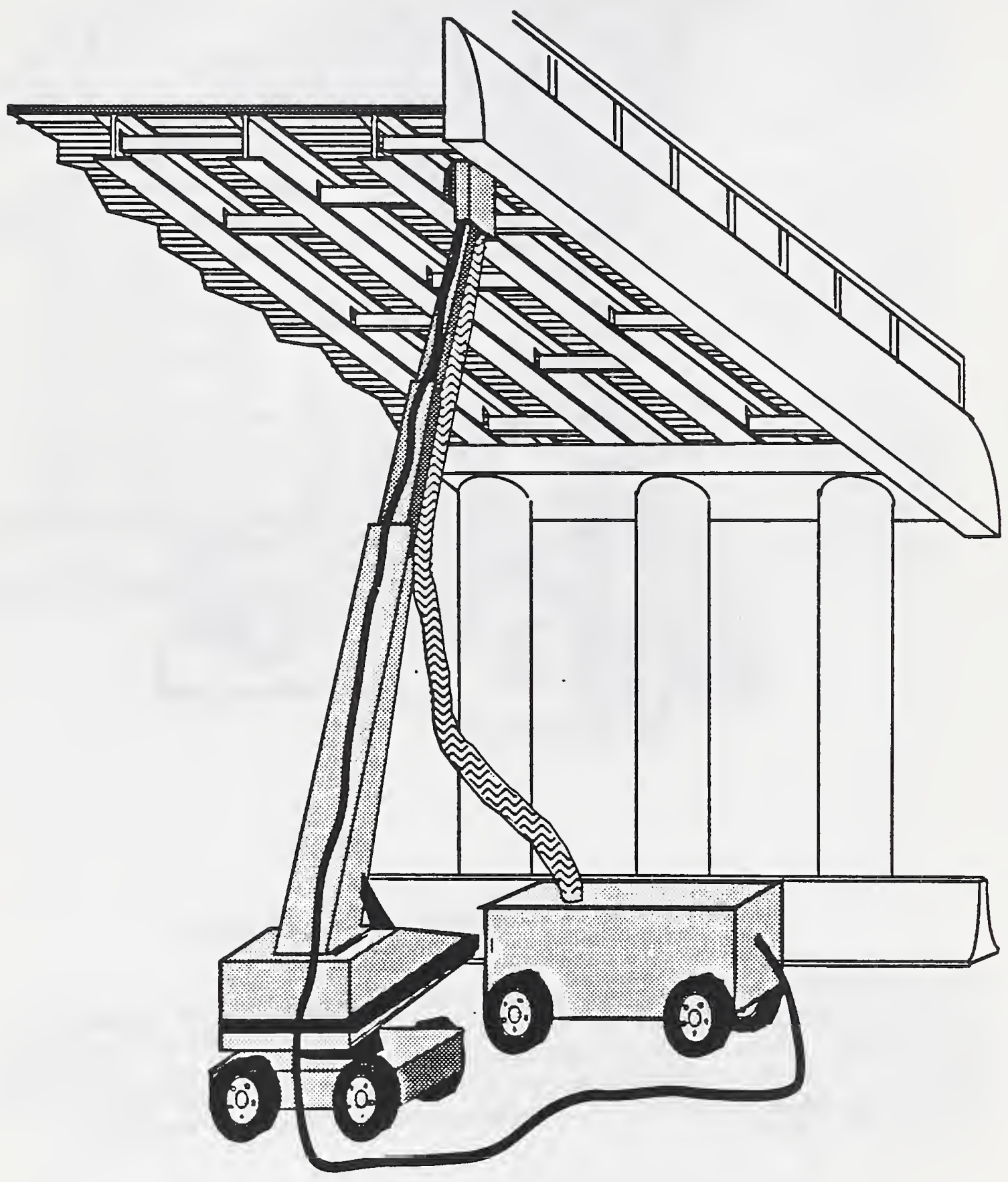

Figure 2 Possible Dynamic Shroud Configuration 


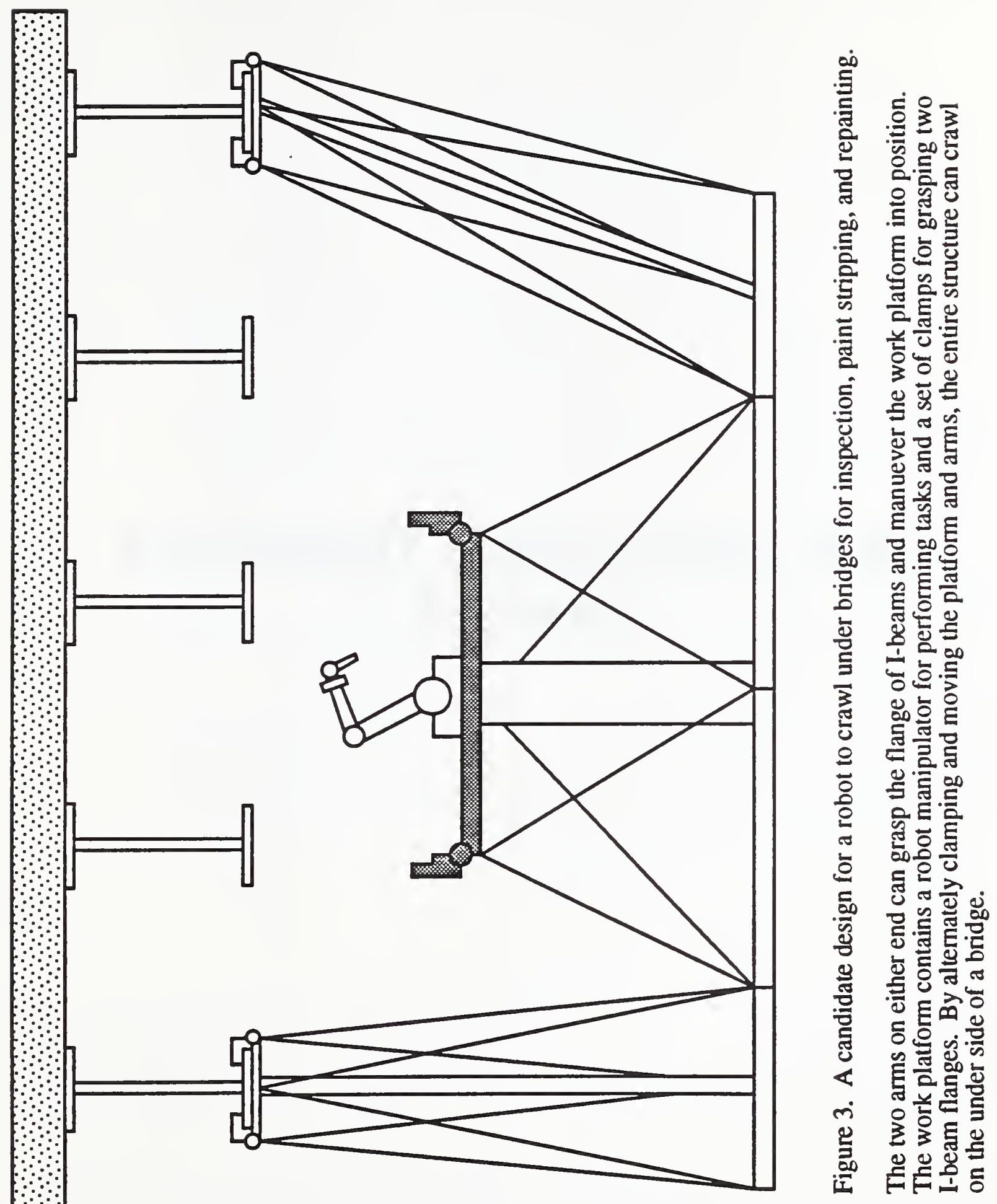




\section{PAVEMENT INSPECTION AND REPAIR}




\title{
A Proposal on Automated Crack Detection and Sealing
}

\author{
Avi Kak \\ Robert Cromwell \\ Robot Vision Lab \\ Purdue University
}

\section{Possible Payoffs from the Proposed Research}

In the following we describe a proposed roadway inspection system. If the objectives could be accomplished, the following benefits would be realized:

1) Roadway defects such as cracks would be detected by our system,with performance better than that of human inspectors. The minimum crack size would be less, meaning that preventive maintenance could be carried out earlier, leading to increased savings in repairs.

2) Quantitative measures of performance - detection rate, false-alarm rate, etc. - could be accurately characterized. This is not currently possible with the highly subjective human decision-making process.

3) As the inspection (and, for defects of limited severity, the repair) could be done at highway speeds, much more roadway than the currently limited sample could be inspected. What is more, if repair could be carried out simultaneously, inspection and repair would become a one-pass operation.There would be no need for road closing.

\section{Discussion}

Road surface inspection is a boring, repetitive task consisting of inspection and quantitative evaluation of a manufactured surface. As such, it is an ideal application of machine vision. In the following we propose methods for the automatic detection of roadway defects, and, where possible, their automatic repair.

Human experts recognize many distinct forms of road surface damage or deterioration(1); presents one of many classification schemes. However, all forms are presently detected by human inspectors who simply look at the road. This 
means that photometric and range measurements would possess adequate information for the detection of all currently recognized problems.

Figure 1 shows a cross-section of a road with some commonly recognized problems labeled. Since a pothole is the largest such structure, it is easy to detect. the aberrant profile exhibited in the range data clearly indicates its presence and accurately defines its boundaries. The exposed aggregate would be of a different color, and so a pothole would also be easily detected in photometric imagery.

We have turned our attention to a more difficult inspection problem, crack detection and repair. While cracks can grow quite wide, thus becoming easy to detect, it is best if they are detected early so that prompt repair can prevent further damage. This requires the detection of quite small cracks, which means that vision data must be gathered at a fine scale, so that features only 0.1 " wide or even narrower be detected. Since cracks may be transverse or longitudinal, or at any angle in between, it is necessary to gather data at similar sampling rates both across the road and along the direction of travel. The requirements for storing the amount of data associated with even a short segment of a road would be astronomical. The only solution is a system that analyzes the road as it travels over it, storing only the information needed to describe detected problems.

What sort of information would be useful for making this type of decision? We feel that both range and reflectance information should be used. Consider the highly schematic system shown in Figure 2. Imagine an array of balls, or wheels, of differing diameters, free to roll along the road and follow its contour. If there were a way to record the up-and-down motions of these individual sensors, the result would be a 3-D map of the road surface showing its texture and shape at varying scales. The larger balls or wheels would describe the overall shape of the road, and would be useful for the detection of such relatively large-scale phenomena as rutting. The smaller sensors would measure the surface at a finer scale, detecting narrow cracks.

We took a sample of slightly deteriorated road surface, and used a robotic manipulator with a force-torque sensor to drag a probe over the sample surface, attempting to maintain constant force/torque conditions. Records the paths of the robot arm as it moved the probe in a grid pattern over the sample yielded measurements of a form similar to those of our hypothetical system of Figure 2. Some of this data is plotted in Figures 3 and 4.

The problem is that electro-mechanical recording devices are too slow to gather data of the desired scale while the platform moves at a realistic speed. For this reason we suggest using range sensors of the general types commonly used in machine vision. Figure 5 shows a structured-light range sensor - a system in 
which a projector casts a distinctive pattern on a scene and a camera views the scene from an offset position. Knowledge of the optics and geometry of the system allow the (row,column) information gathered by the camera to be converted into $(x, y, z)$ measurements, building a range map of the road as the system travels over it. The range resolution characteristics are a function of the sensor design, it would need to be designed so that the structures of interest can be seen.

How, then, would the analysis be done? We suggest the application of morphological operators to the range map, among other techniques. Figure 6 shows the $\mathrm{z}$ component of the $(\mathrm{x}, \mathrm{y}, \mathrm{z})$ measurements for a sample of deteriorating asphalt, with greater values of $z$ represented by brighter pixels. The crack network leading from the left to the bottom, via the center, is very noticeable. Figure 7 shows a similar image for two samples of concrete, one of which is cracked. Again, the flaw is strikingly obvious. Morphological operators, which can be mathematical models of rolling balls, make such features more striking. Figure 8 shows the application of such an operator to the image of $z$ as intensity for the concrete samples. Other than the ends of the samples, the only noticeable feature is the crack.

For details that could be seen in simple photometric imagery, a system similar to that of Figure 9 would suffice. A camera with multiple light sources would view the road as the system was transported. Again, no attempt should be made to store the imagery. It should instead be interpreted as it is gathered, and only symbolic information about defects and their locations retained.

Figure 10 shows what is called registered intensity data for the asphalt sample - it is the intensity measurements made at the same locations for which $(\mathrm{x}, \mathrm{y}, \mathrm{z})$ values were measured, with $\mathrm{z}$ displayed in Figure 6. Similarly, Figure 11 shows registered intensity data for the concrete samples. Morphological operators can also be applied to the photometric data, as shown in Figure 12.

Our proposed system would thus make a large number of measurements of each visible segment of the road surface. What should be done with these multiple channels of information? We feel that an architecture similar to that shown in Figure 13 might produce optimal results. Morphological operators of differing characteristics would be applied to both range and photometric imagery, and the outputs applied as the input to neural networks.

Once the cracks had been detected in imagery, the information about the precise location of the sensor platform at the time the data was gathered would be used to drive machinery appropriate for sealing that type of surface. Our experience with mobile robotics indicates that it would be a mistake to rely on odometry to 
coordinate actions across several vehicles. If the sealing is done by a second vehicle, then some sort of accurate relative positioning method is needed to accurately drive a "blind" repair arm. We feel that the best solution would be to have the repair done from the same platform, so a rigid frame of reference between sensor and actuator is maintained. Some form of visual servoing might be needed to drive the end effector along the crack. That task is similar to the seam-tracking done by existing welding robots, and so a mature technology is available for application. Given that the robotic manipulators will be mounted on a moving platform, some work is obviously needed in the area of dynamic path-planning and in the coordination of the positioning of the end effector with respect to the motion of the vehicle.

\section{Performance}

An important question relevant to this proposal is: How fast can such inspection be carried out? In other words, what will be the speed of the vehicle on which this inspection system will be mounted? We believe that it will be possible to carry out such inspection at highway speeds. Our optimism is based on the fact that the entire inspection process can be carried out in a highly parallel fashion using a bank of rather inexpensive microprocessors. What we are saying is that each cross-section of the highway will be scanned not by a single laser fan beam, but by a large number of small fans, each fan covering a width of, say, 1 foot. Therefore, a 12 foot lane would be covered by 12 laser fans. In the system we are envisioning, each fan would be produced by a separate laser diode. The road surface illuminated by each fan would be digitized by a separate camera and the data analyzed by a separate microprocessor.

\section{References}

1.Road Surface Management (Pavement Condition Evaluation System), Georgia Department of Transportation, Atlanta GA, January, 1990. 


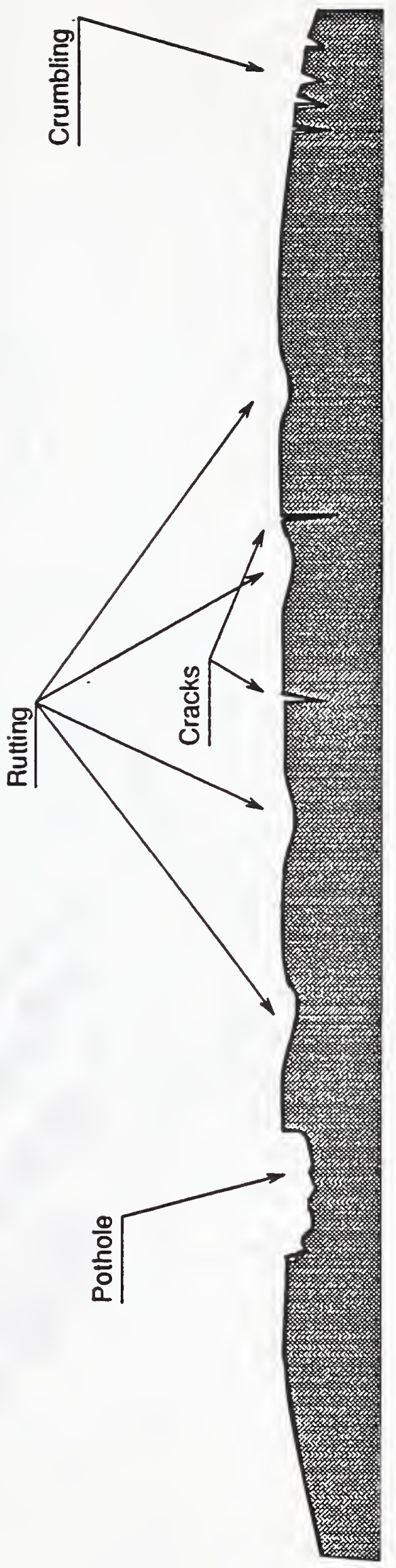

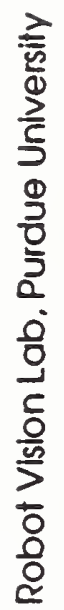

힌 


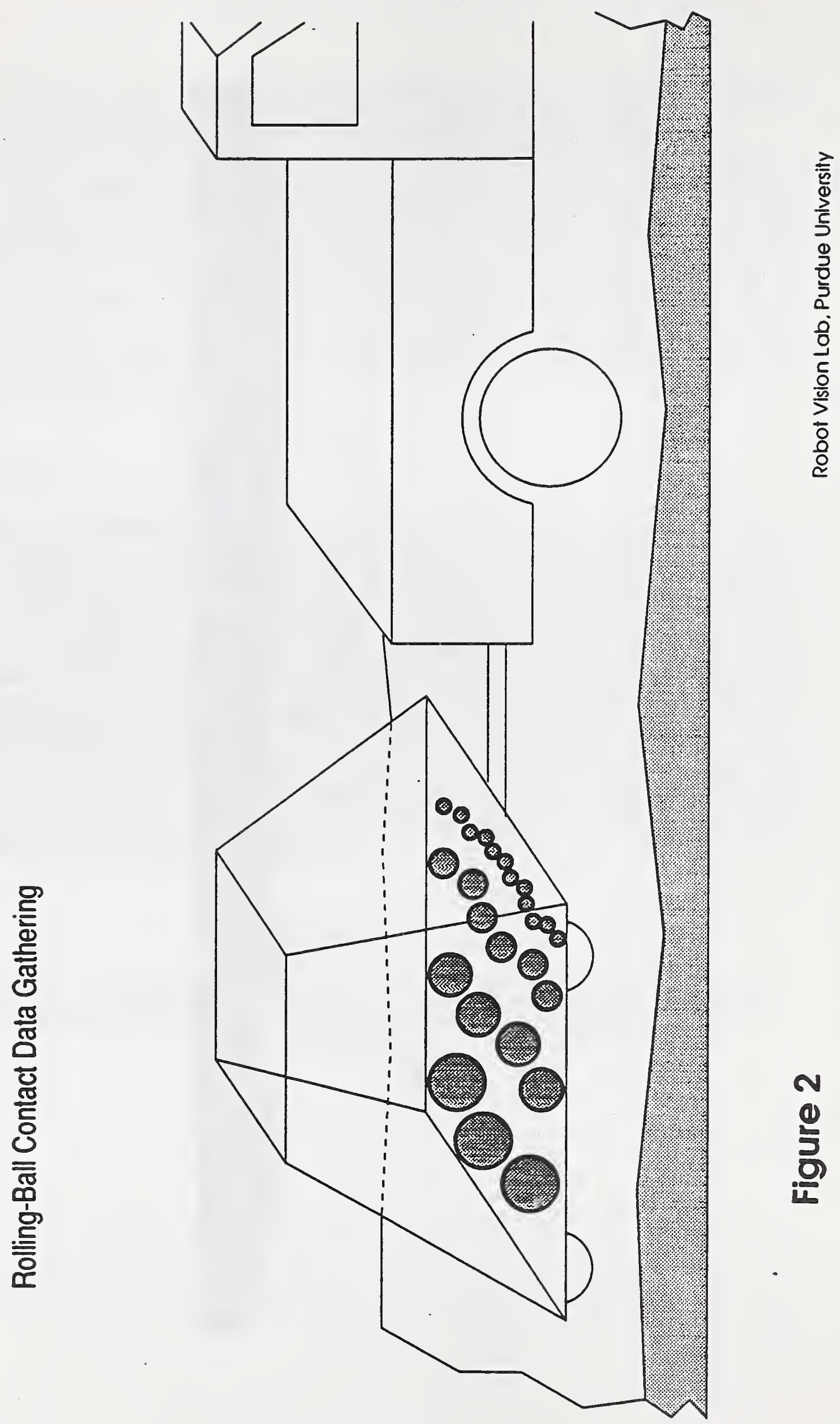




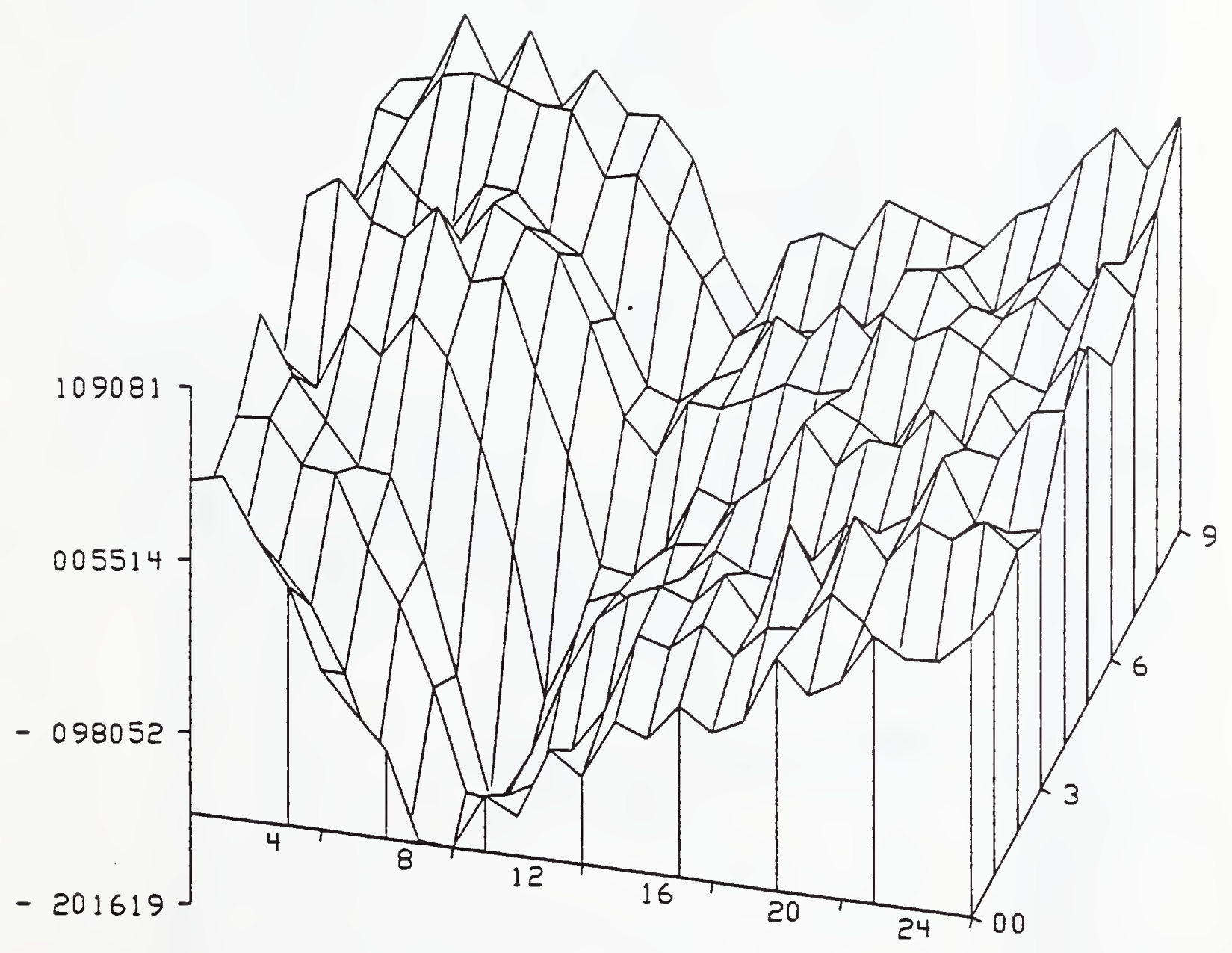

Figure 3 


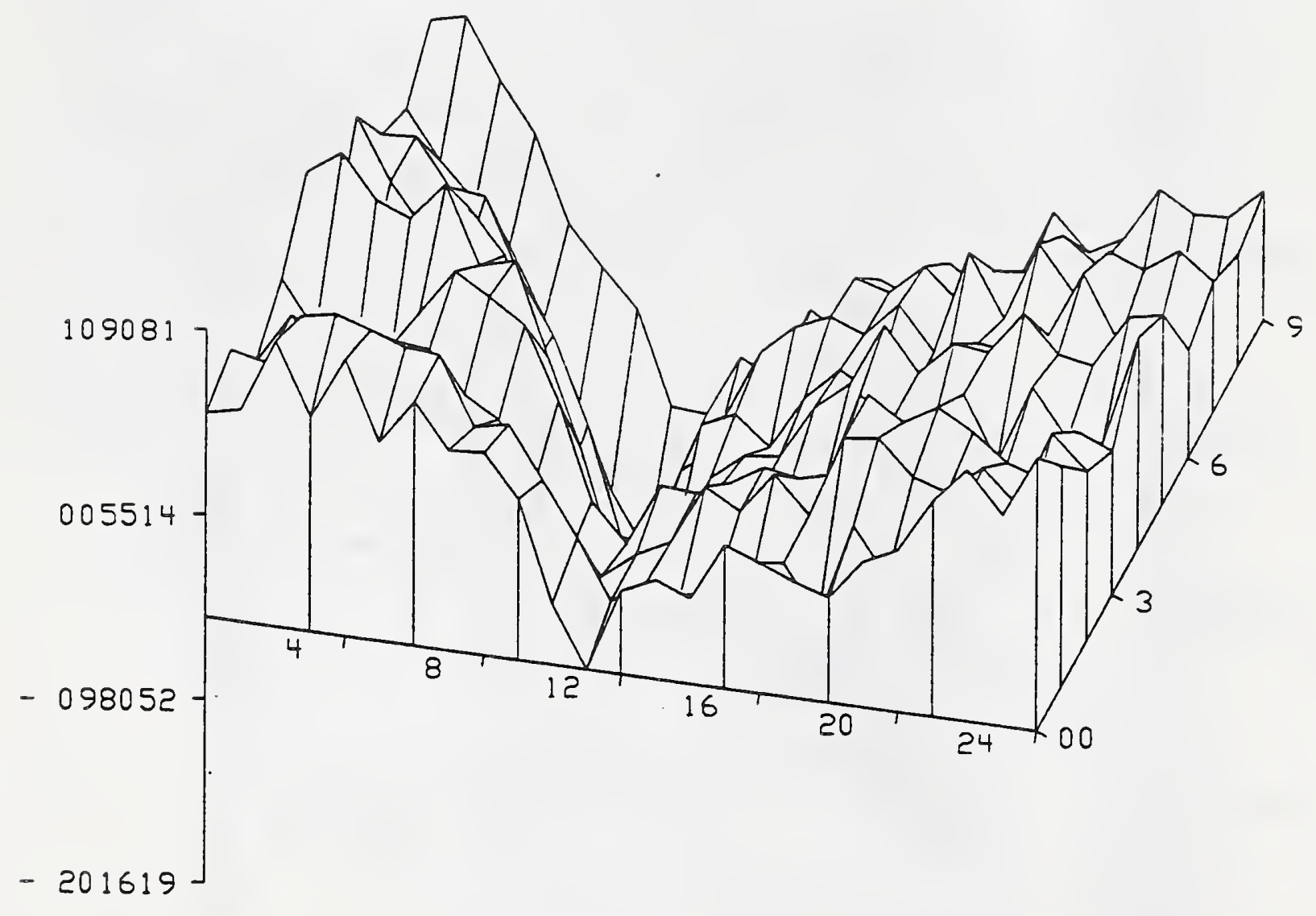

Figure 4 


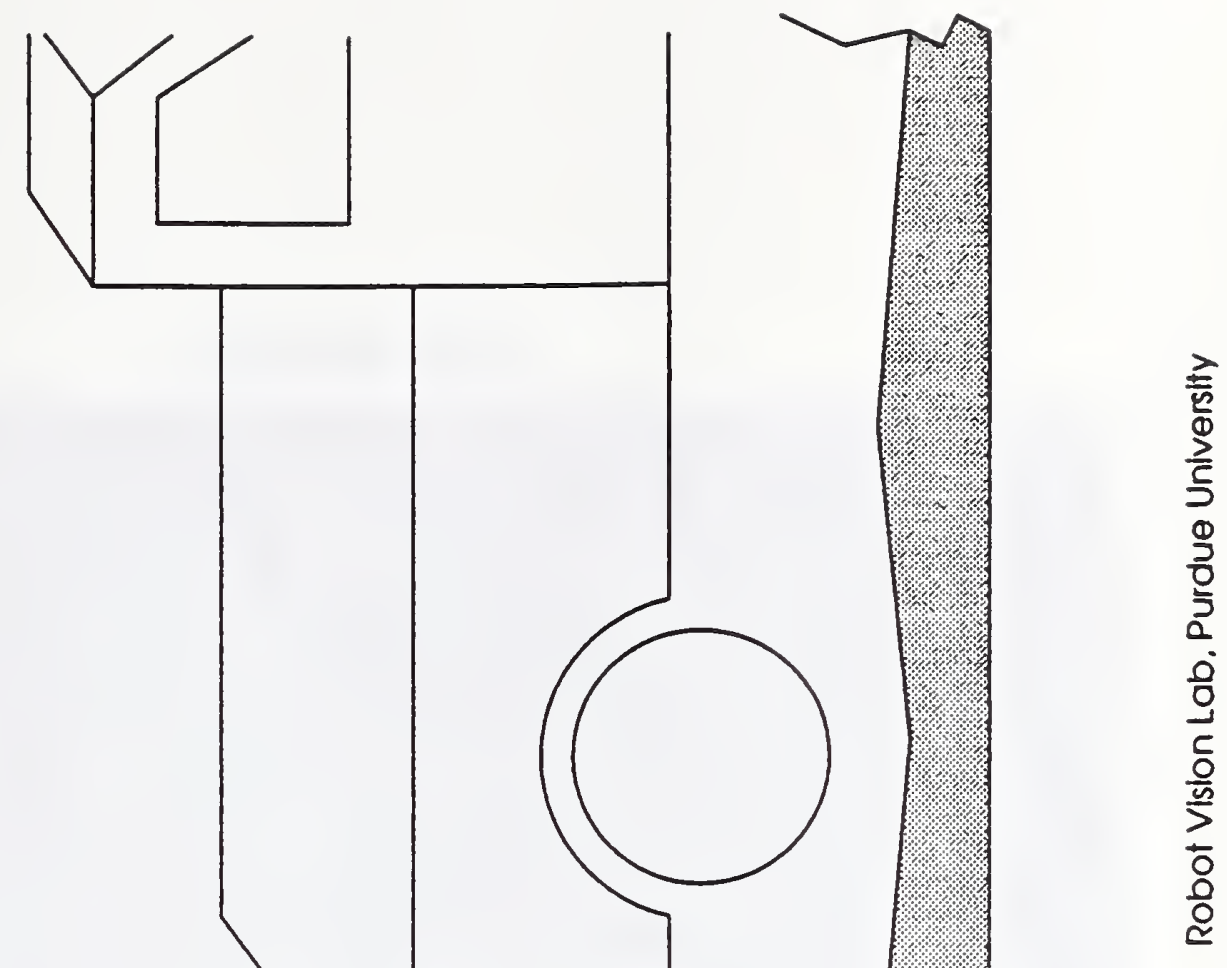

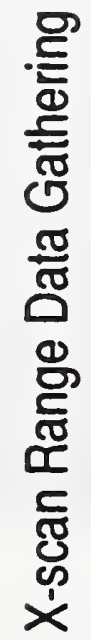




\section{$\mathrm{Z}$ as intensity}

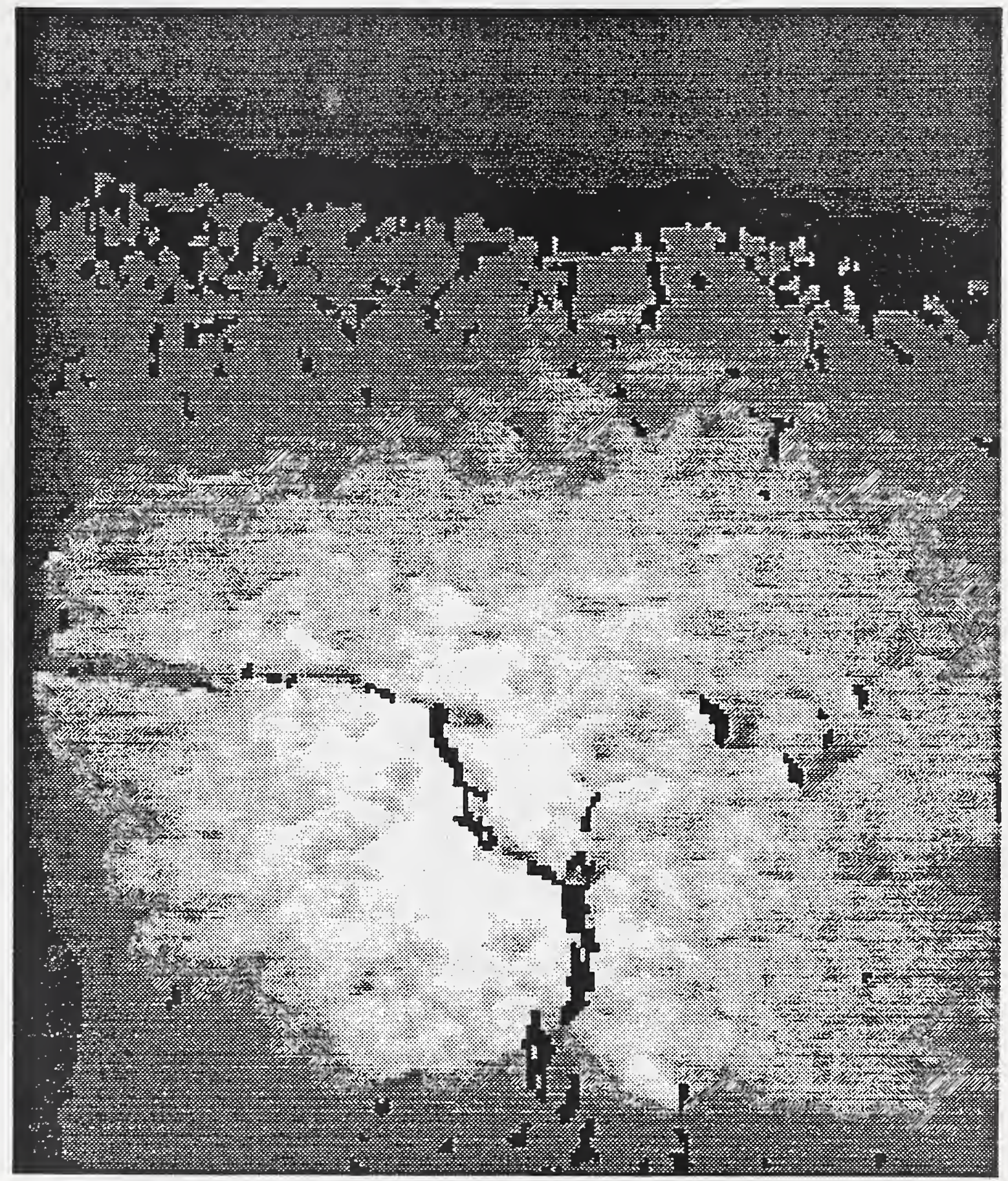




\section{$\mathrm{Z}$ as intensity}

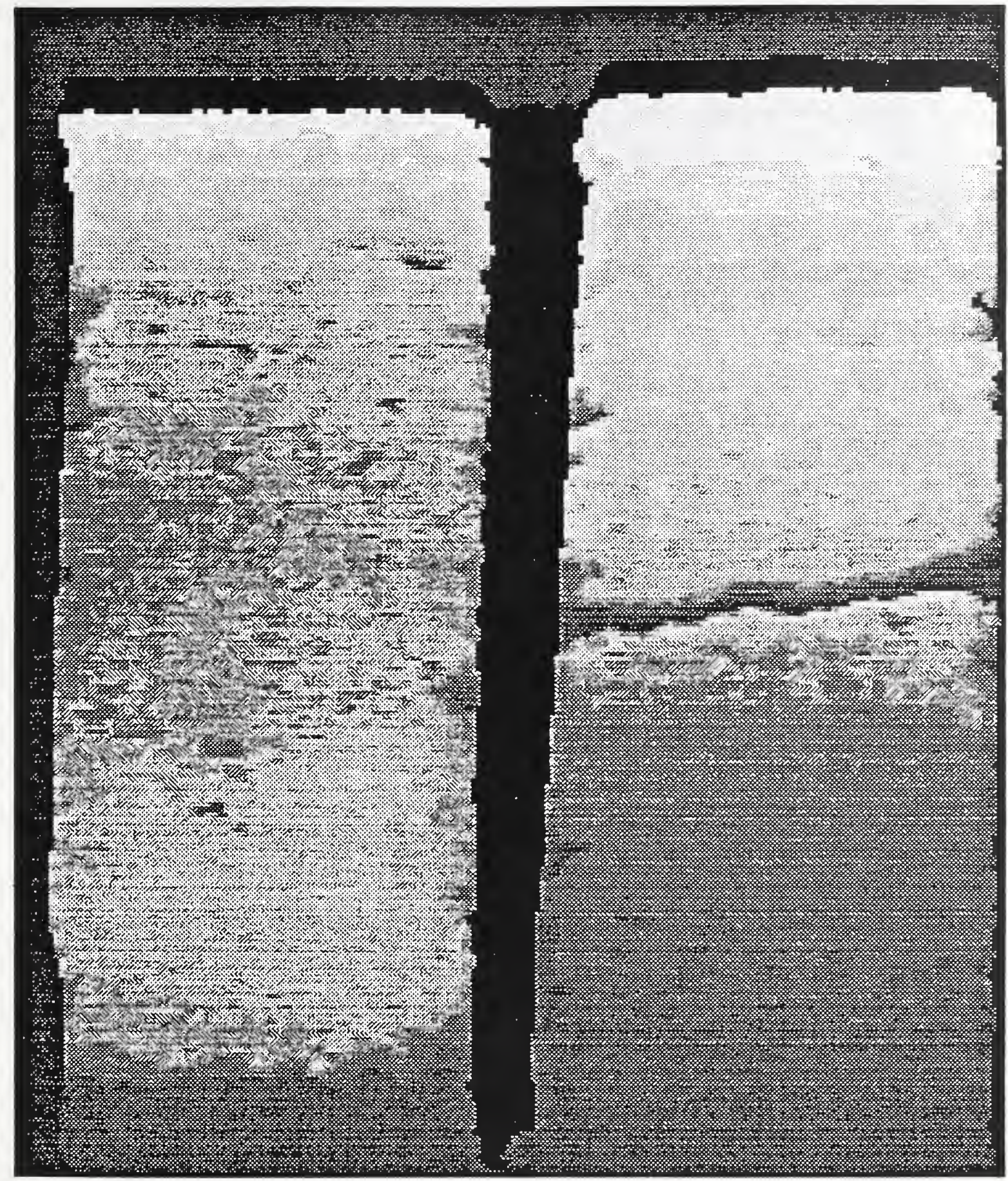




\section{rolling_ball(Z)}
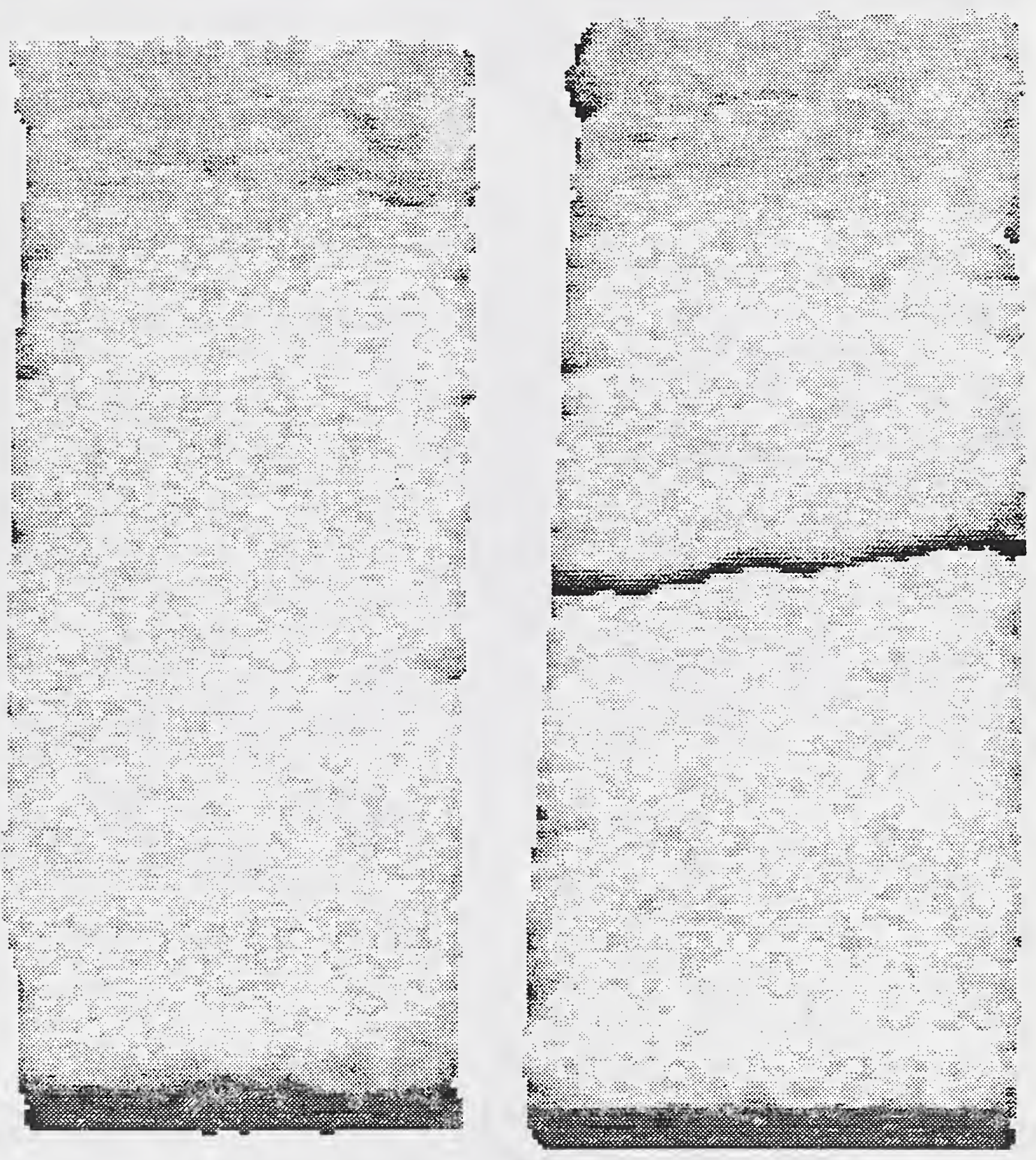

Figure 8 


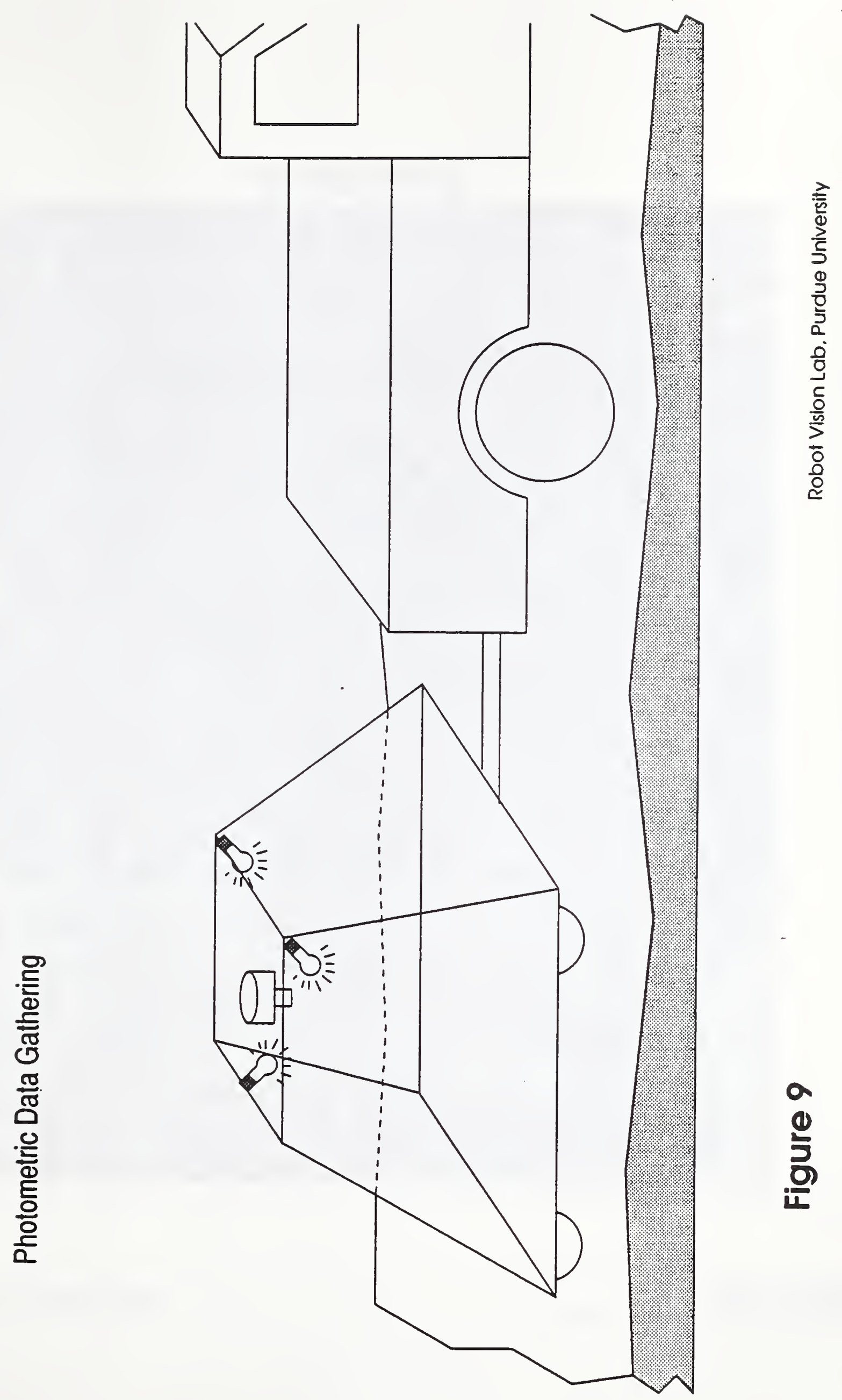




\section{Intensity image}



Figure 10

Robot Vision Lab. Purdue University 


\section{Intensity Image}

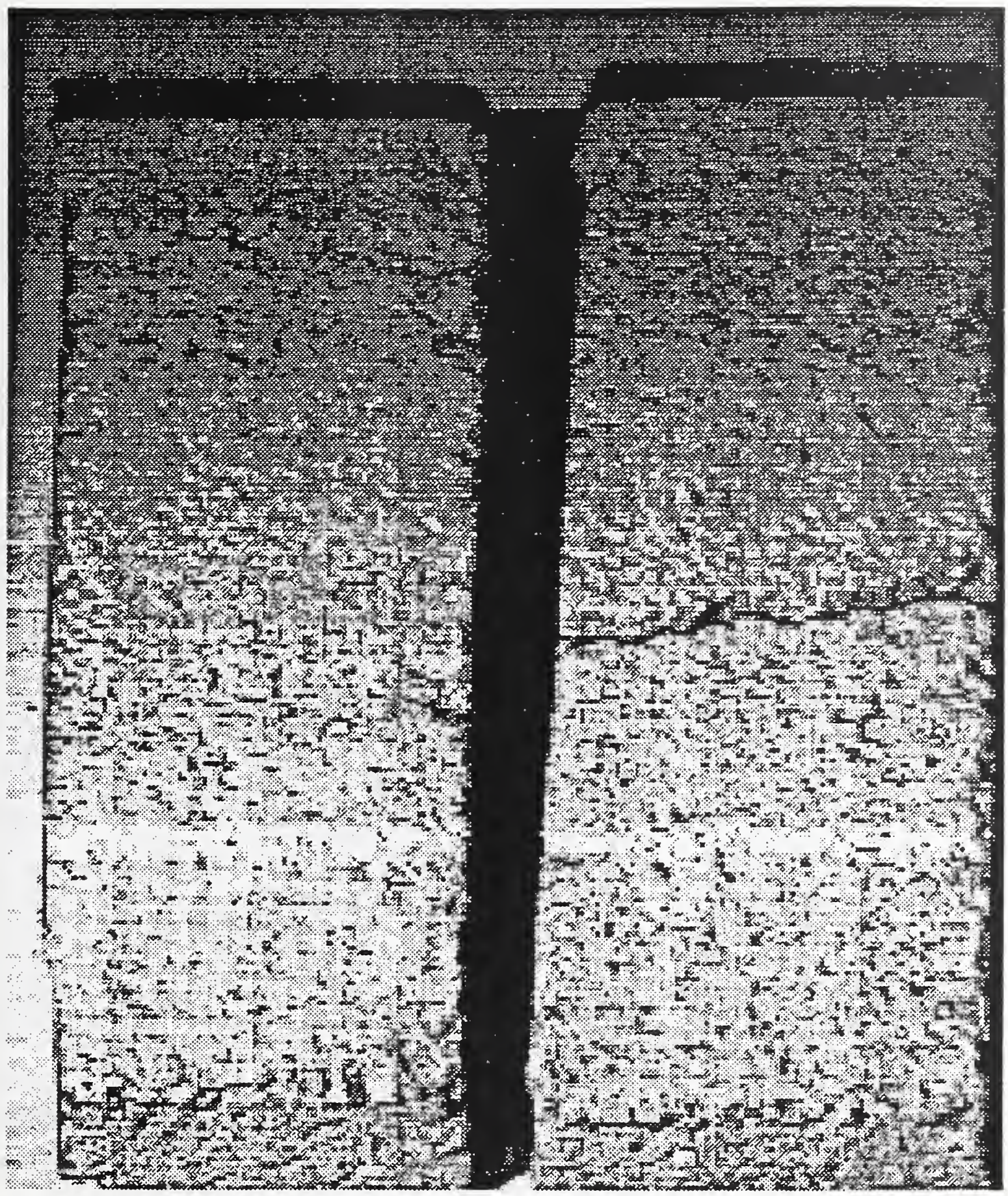




\section{rolling_ball(intensity)}

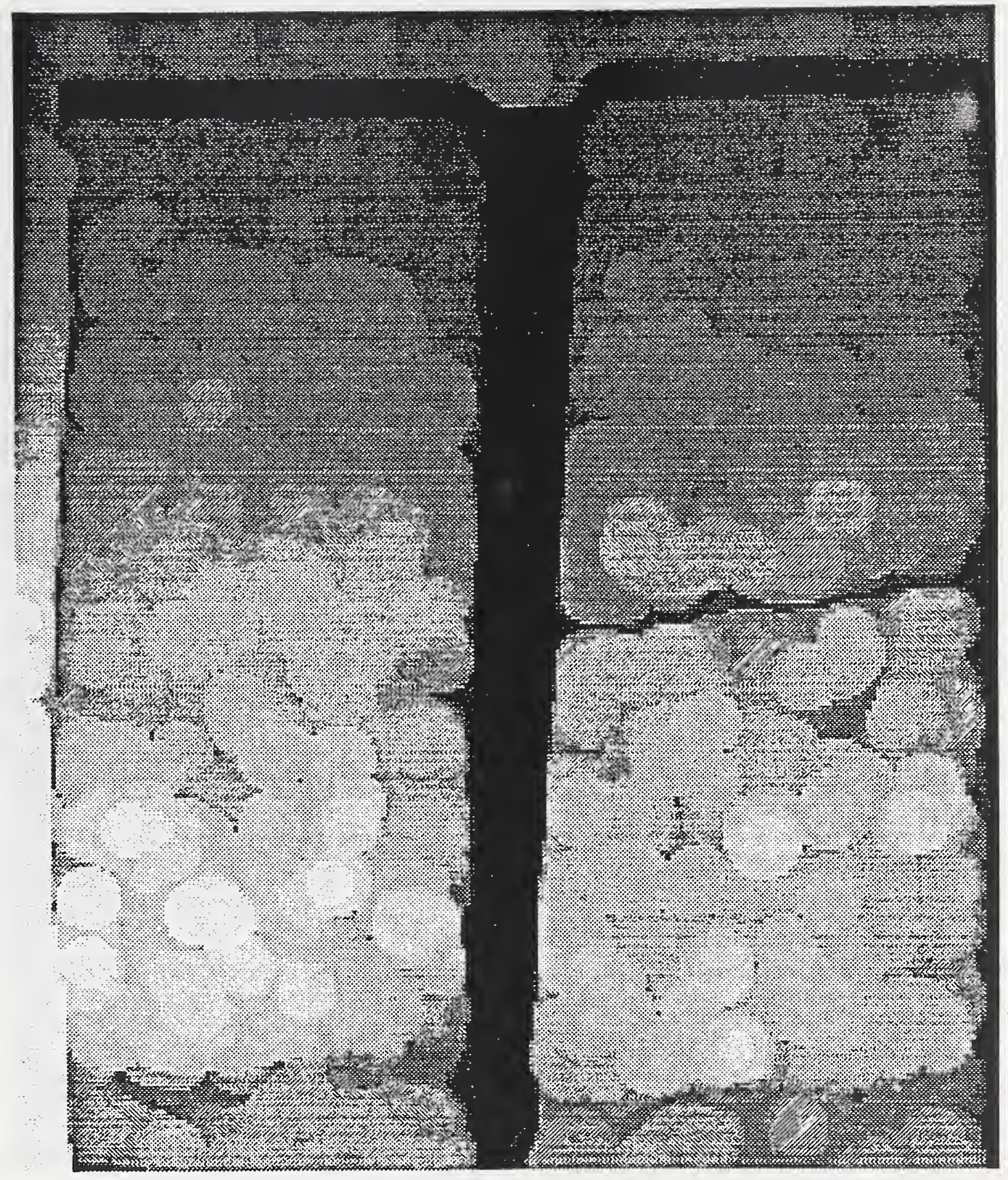


Purdue Robot Vision Lab's Neuro-Morph Architecture For Surface Inspection at Multiple Levels of Resolution

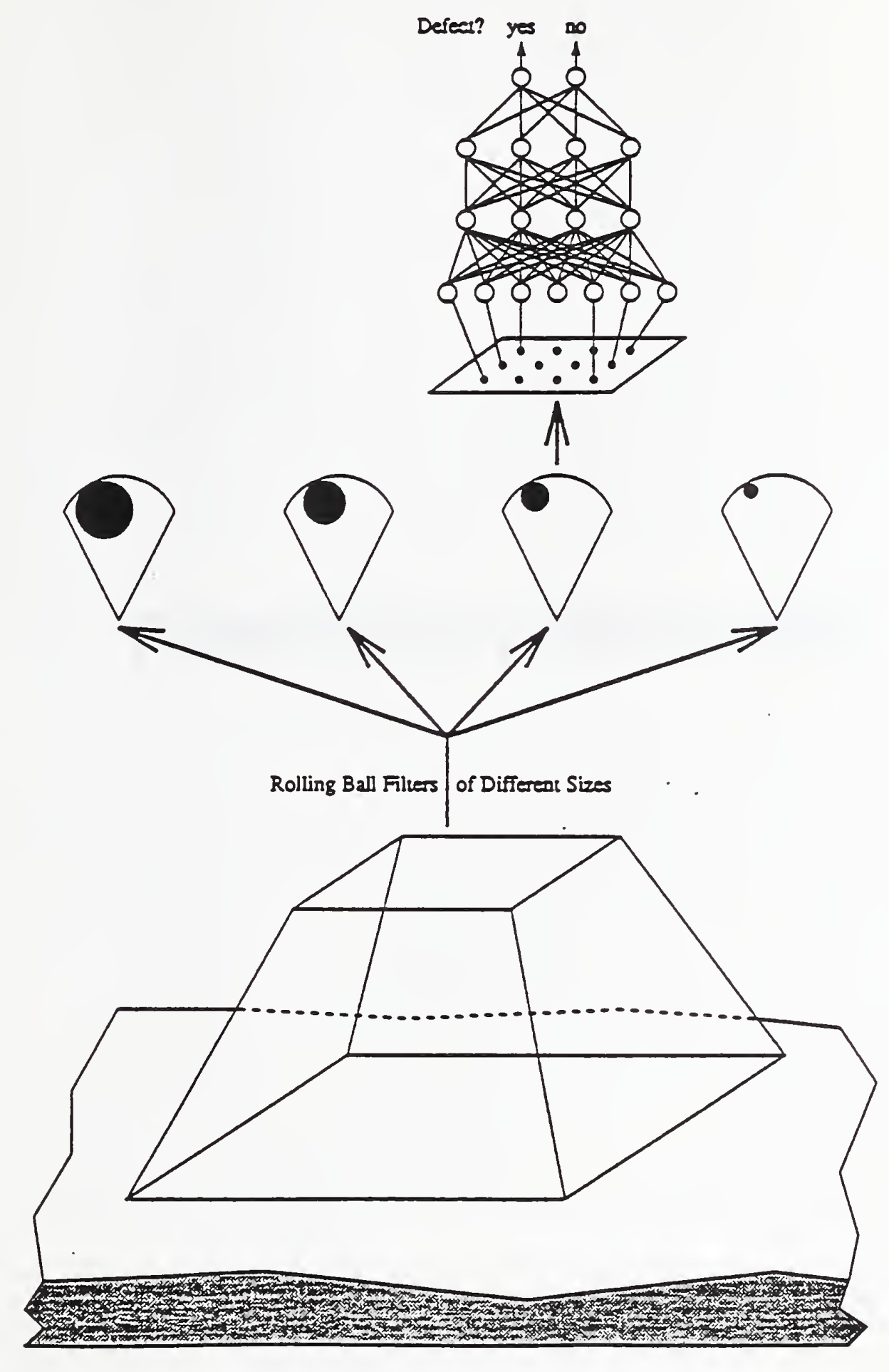

Figure 13 
TEMPORARY BRIDGING 


\title{
Rapid Temporary Bridge Construction
}

\author{
Mr. Ken Goodwin, NIST
}

Ma y 27, 1993

\begin{abstract}
Ma jor opportunities exist to develop and demonstrate construction of temporary bridges, causeways across wetlands, and bypasses for traffic management over repair sites. Modular bridge sections will be put in place by teleoperated, mobile, light weight cranes. The major thrust of this project will be the development and field demonstration of light weight modular bridge sections, put in place by innovative full scale prototype cranes. The key advantages over existing bridging systems are that the bridge sections and cranes will be much lighter, and the cranes will provide better control of loads, faster assembly, and less environmental disturbance.
\end{abstract}

Background.

The Department of Defense has developed over many years high strength, lightweight tactical bridges and causeways for military traffic, including tanks. Lightweight military bridging systems appear to be well suited for further application in civilian construction of temporary bridges, causeways over wetlands, and for traffic management over highway and bridge repair sites.

Recently, NIST has entered into a Cooperative Research and Development Agreement (CRADA) with Global Associates Ltd. of Arlington, Virginia to utilize a combination of a lightweight modular bridging system (10A MBS) with a lightweight, stable robotic crane (RoboCrane) in various commercial, military and space applications.

Global's 10A Modular Bridging System (Patented) is a unique lightweight modular highway bridging system. Figure 1 shows the basic element of this system. It has numerous attributes making it particularly viable for:

Rapid construction of temporary bridges used for traffic handling during bridge repair.

Construction of bridges over wetlands with minimum environmental impact.

Construction of bridges to handle emergency situations. 
The weight of the 10A MBS bridges, designed for HS 25 loads, is significantly less than any other style of highway bridges. It is transported fully assembled in large sections, in a nested configuration and can be constructed with the NIST RoboCrane technology in an extremely short time.

Due to the significantly reduced weight of the bridge, it can be installed with a lightweight RoboCrane. The crane weight is significantly less than any other existing lifting equipment, and it is within the standard capacity of the $10 \mathrm{~A}$ MBS load rating.

The Robot Systems Division of the National Institute of Standards and Technology (NIST) has been experimenting for several years with new concepts for robot mobility and cranes. These concepts utilize the basic idea of the Stewart platform parallel link manipulator. The unique feature of the NIST approach is to use cables as the parallel links and to use winches as the actuators. So long as the cables are all in tension, the load is kinematically constrained, and the cables resist perturbing forces and torques.

Based on this prior work, a revolutionary new type of robot crane has been developed that can precisely control the position, velocity, and force of tools, machinery, and loads, in all six degrees of freedom ( $x, y, z$, roll, pitch, and yaw). The basic configuration, shown in Figure 2, consists of a triangular work platform suspended from an upper support structure by six cables controlled by six winches.

In order to study the lifting and positioning capabilities of this design, NIST has constructed a midsize version, made from 6 meter lengths of 10 centimeter diameter aluminum tubing. It is capable of lifting 2,000 kilograms even though it weighs less than 500 kilograms. A photograph of this crane is shown as Figure 3.

The RoboCrane work platform can support large loads, is extremely stable, and is capable of exerting controlled forces and torques in six degrees of freedom. Its design gives it an extremely high strength-to-weight ratio. It is of lightweight construction, based on axially loaded compression elements and high strength cables. All structural members are either in pure compression or pure tension (except for supporting their own weight). As a result the RoboCrane can lift and manipulate loads many times its own weight. This is an order of magnitude improvement over conventional cranes which typically weigh (including counterweight) more than they can lift.

The RoboCrane scales easily to much larger sizes, such as would be required for highway construction and repair. Versions with dimensions of several hundred feet, made from cross-braced triangular trusses appear feasible. 
Bridge and road repair work involves closing of lanes and roads to carry out the repair work. The lane shifting and exposure of construction workers to passing traffic creates a hazardous situation. Lane closing slows the traffic and creates economical burden on local activities. The FHWA quantif ied the "loss to the public" due to traffic disturbance during road and bridge repair, and as a result new highway reconstruction, rehabilitation and even new bridge construction have incentive clauses for reducing the time for repair work.

Operations to erect highway bridges currently require the use of heavy truck, crawler, or barge supported boom cranes. For bridging streams, rivers, and wetlands, the temporary construction of coffer dams and islands supported on piles is of ten required to support the cranes.

In the process of bridge erection on wetlands, where environmental disturbance caused by construction equipment is highly undesirable, the crane has to be transported over the bridge. For commercially available cranes, the AASHTO HS- 25 loading capacity is insufficient and the bridge must be upgraded for this crane movement. This results in a heavier bridge, at greater cost.

The NIST RoboCrane, made of axially loaded compression elements and cables, which have the capacity required for the lightweight bridge construction, is expected to weigh less than the allowed AASHTO HS-25 loading.

Where highway or bridge repairs are to be made, there frequently does not exist sufficient room for a shoulder or construction of a temporary lane to maintain traffic flow. In such cases the repair contractor is required to stop operations and clear a lane, at least in commuting hours. This is very disruptive to the repair operations and greatly increases costs.

\section{Benefits.}

The benefits that will accrue from the automation program can be expressed in economic, efficiency, and environmental terms. Global's 10A Modular Bridging System combined with the NIST robocrane will result in reduction of construction time and cost.

The combined lightweight system is expected to result in significant weight and cost savings. The lightweight robotics construction will enable finishing a bridge within weeks and with minimum environmental impact upon wetlands and other nearby terrain.

The RoboCrane configuration appears to be suited for a wide variety of applications and of fers potential advantages in weight, cost, and speed of operation. Taking full advantage of the lightweight bridge sections and crane, the system can be optimized to yield minimum combined cost, fast erection, high degree of safety and reliability. 
For highway or bridge repair operations, temporary bridging could provide new lanes alongside a lane being repaired so that traffic flow could be maintained. This would be of great benefit to the motorist who would not be delayed by construction and to the repair contractor, who could carry on repair activities without the necessity of interrupting repair work to open lanes to traffic during commuting hours. Several states have reported that in many bridge repair contracts, traffic management accounts for over half the total project cost.

In the U.S alone there are $3-4000$ bridge rehabilitation projects every year. Using a temporary bridge which can be readily transported to the site, quickly erected to carry all traffic during the bridge repair and then removed and used at another site makes the rehabilitation process quicker, less costly, more ef ficient, safer and results in better product on the repaired permanent bridge.

It is estimated that at least $10 \%$ of the bridge rehabilitation projects would benefit from this approach.

Building a detour or bypass using a temporary bridge can save $20-50 \%$ of the required repair time. (in a recent project, using a temporary bridge based on the $10 \mathrm{~A}$ MBS design reduced the estimated project duration from 3 to 2 years). In addition to the time saving, the work zone is safer, the quality of the finished repair is better and the total cost of the project can be significantly reduced.

A typical bypass curved bridge that can be constructed with the combined $10 \mathrm{~A}$ Modular Bridging System - RoboCrane technology is presented in Figure 4. On this project, which is expected to have an incentive of $\$ 15,000$ per day, reduction in project time by more than a year will result in $\$ 5.5$ million saving, in addition to all other benefits.

We believe that in many situations where there does not exist room to use a shoulder or construct a temporary traffic lane, the costs of traffic management can be reduced by one half.

The main benefit of rapid, cantilevered construction of bridges over wetlands is environmental. The bridge can be built from one side with piling driven from the erected bridge without touching the ground (except for the pile location). There is no need for moving construction equipment and crew into the wetland area itself, thus greatly reducing the impact on the environment. It will speed up the approval of bridging projects over wetlands became a time consuming activity that typically results in delay of large economical development projects.

Bridge and highway repair in situations where there is a restricted available width of right-of-way, or restricted width due to topographical conditions (mountains, causeways) create a serious disturbance to traffic. In most cases, traffic handling by closing lanes is unacceptable and thus the repair work is delayed, resulting in unnecessary hazards to the public. 
Using the $10 \mathrm{~A}$ MBS - RoboCrane combination to rapidly install an overpass bridging, (as shown in Figure 5) can resolve those situations. An overpass bridge can be erected over a weekend, with part of the lanes remaining open to traffic during the temporary bridge construction time. When the overpass bridging is completed, traffic continue with the same number of lanes, while bridge repair is performed using another RoboCrane moving on rails hanging from the overpass bridge. As in the case of temporary bridging, once the repair of the existing bridge is done, the temporary overpass bridge is disassembled and moved to a new site.

4

Approach.

This proposal is to leverage military development of lightweight bridge systems with what NIST has done in crane development by developing a bridging system suitable for highway construction and repair applications and demonstrate its practical capabilities.

As shown in Figure 6, we propose to use a rectangular cantilever structure to provides the mechanical support for the suspension system. The top plane of the structure provides the support points for three Stewart platforms. By simultaneously controlling the six winches for each platf orm in a coordinated way, the placement of bridge sections can be precisely controlled.

A structural frame which provides support for two RoboCranes, will enable speeding the construction sequence. One RoboCrane can be used to assemble components, while the second would be used to position the completed subassemblies. Using the proposed system and construction sequence, shown in Figure 7 , it is estimated that a causeway, 1,100 feet long, could be erected in 24 hours, including the driving of piles.

For mobility, the gantry frame can provide gross horizontal motion to straddle loads such as modular bridge sections. The gantry can move from one section to another on wheels which traverse from one section of a causeway to another and can utilize sections of previously installed roadway as counter weights.

\section{$5 \quad$ Research Objective.}

The proposed research objective is to evaluate the technical feasibility and viability of constructing temporary bridges, causeways across wetlands, and traffic management bypasses through the use of modular bridge sections erected by light weight robotic cranes. 
To achieve the research objectives, the following development and demonstration phases or projects could be conducted:
Near-term:
Temporary bridging for traffic diversion around bridge repairs.
Medium-term: $\quad$ Construction of permanent bridges or causeways across wetlands.
Long-term: $\quad$ Construction of temporary traffic management by-passes over highway repair sites.

The near term project would involve integrating existing new technologies for modular bridging with recently-developed robot crane technology which provides stable control for lifting bridge sections. Construction of a temporary by-pass bridge along side a repair site would require the development of cantilever cranes and attachments so that the crane could be supported by existing bridges or overpasses. Figure 8 shows a concept for a cantilevered Stewart platform crane with a spine which could position modular bridge sections alongside an existing roadway, while the traffic continues to flow under the crane.

The medium term project would involve the development of a lightweight crane system for the placement of bridge sections without the need for conventional, heavy cranes and the construction of islands in wetlands to support them.

The long term project would demonstrate the construction of a temporary by-pass over a repair site. Figure 6 shows a temporary overpass bridge to carry traffic over a bridge repair site.

\section{$7 \quad$ Activities.}

Following is a list of the major activities required to carry out near, medium, and long term demonstration projects.

Near Term: $\quad$ Temporary Bridging Around a Repair Site

Conduct feasibility study and develop concept.

o define problem

- quantify requirements

- propose combined system modes of operation

- define construction procedures

o define cost model

o define the requirements for bridge sections and connectors

Design, simulate, analyze and model operations.

o propose alternative design concepts

o develop computerized 3D simulation/animation of the deployment 
and construction sequence

o determine and verify structural and operational behavior using finite elements analysis

Develop a $1 / 16$ scale working model crane system in the NIST laboratory.

o develop an advanced Stewart platform crane controller.

o develop and demonstrate a 1/16 scale laboratory working model crane.

o integrate controller with crane

Demonstrate performance of working model crane placing modular bridge sections in the laboratory.

- obtain scale model modular bridge section

0 install quick connect/disconnect

o demonstrate controlled positioning of bridge section

Design, construct and demonstrate full scale system at a field site.

- Develop and fabricate full scale components

- Test full scale assembly operations

- Perform field demonstration.

- Complete final report and evaluation.

Medium Term: $\quad$ Construction of permanent bridges or causeways across wetlands.

Conduct feasibility study and develop concept.

o define problem

- quantify requirements

o propose combined system modes of operation

o define deployment sequence

o define construction procedures

o define cost model

o define the requirements for bridge sections and connectors

Design, simulate, analyze and model operations.

- propose alternative design concepts

o develop computerized 3D simulation/animation of the deployment and construction sequence

- determine and verify structural and operational behavior using finite elements analysis

Develop a $1 / 16$ scale working model crane system in the NIST laboratory.

- develop an advanced Stewart platform crane controller.

o develop and demonstrate a $1 / 16$ scale laboratory working model crane.

o integrate controller with crane 
Demonstrate performance of working model crane placing modular bridge sections, piles, and pile driving in the laboratory.

o obtain scale model modular bridge section

0 install quick connect/disconnect

o demonstrate controlled positioning of bridge section

- demonstrate positioning and connection of pile guides

0 demonstrate positioning and connection of pile sections and pile drivers

o demonstrate pile driving

Design, construct and demonstrate full scale system at a field site.

- Develop and fabricate full scale components

- Test full scale assembly operations

- Perform field demonstration.

- Complete final report and evaluation.

Long Term: Construction of temporary traffic management bypasses around or over highway repair sites.

Develop system specifications.

Complete design, modeling and analysis.

Obtain structural components.

Fabricate crane structure.

Install sensors (tensiometers, encoders).

Develop displays for operator interface.

Assemble combined crane system for laboratory demonstration.

Integrate, test, tune and demonstrate $1 / 16$ scale working model crane.

Improve controller sof tware to provide:

o weight compensation position rate controller

o path planning

0 error detection and recovery

0 test and tune model and gains

Demonstrate complete system in the laboratory.

Scale up design for full scale demonstration.

Develop and fabricate full scale components.

Test full scale assembly operations.

Perform field demonstration.

Complete final report and evaluation. 


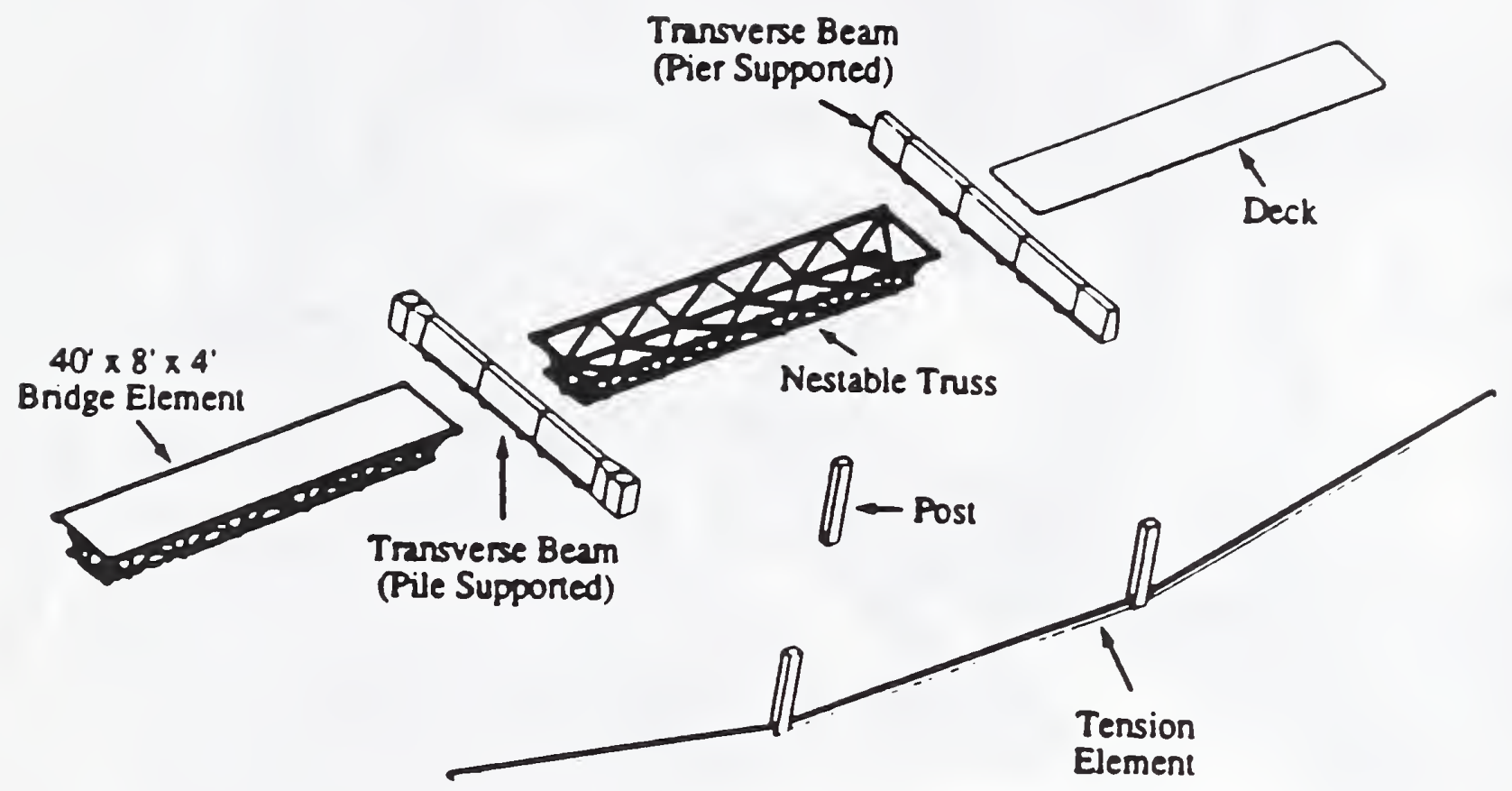

Figure 1: The 10A Modular Bridging System Basic Elements 


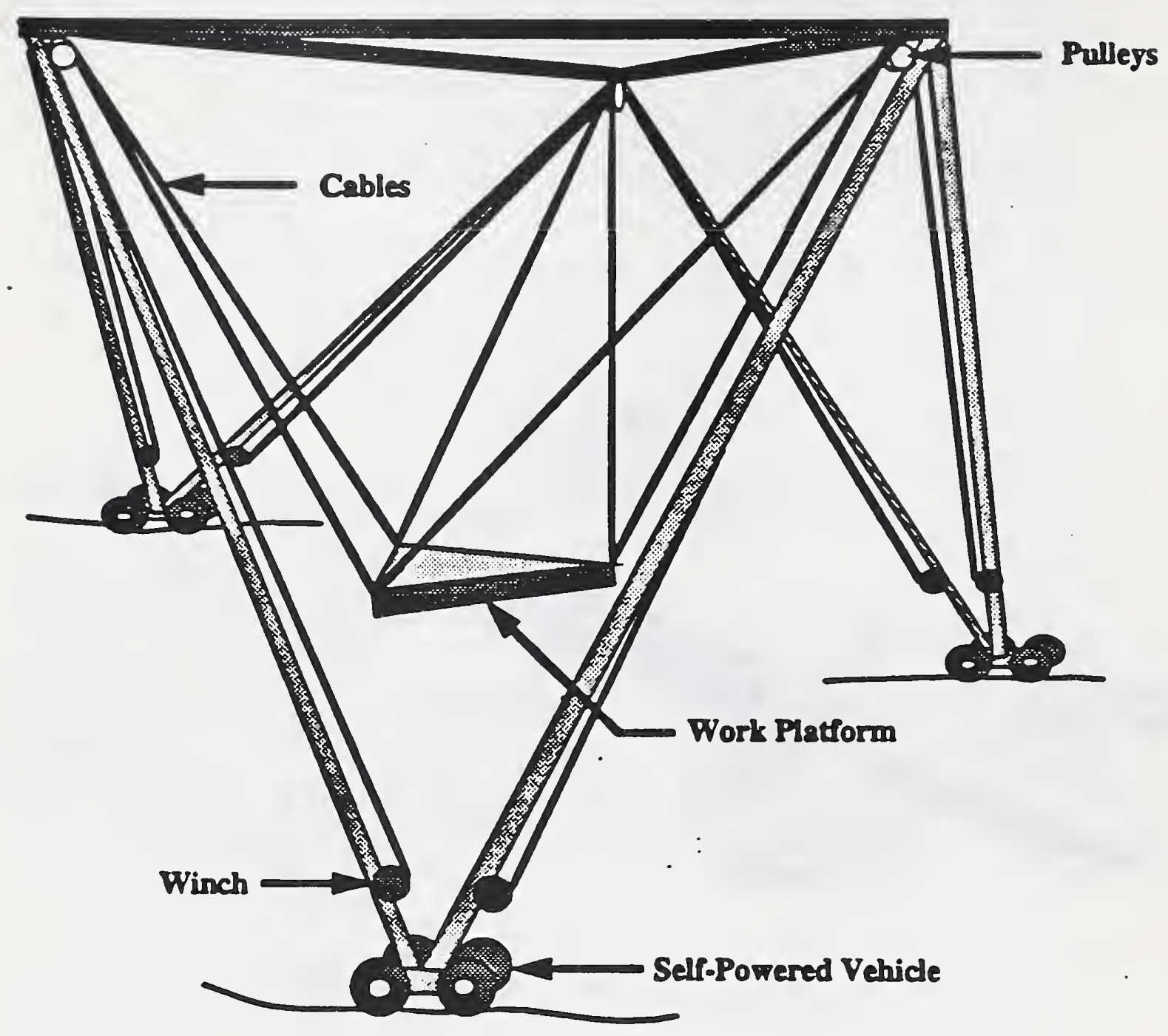

Figure 2: The NIST RoboCrane. 


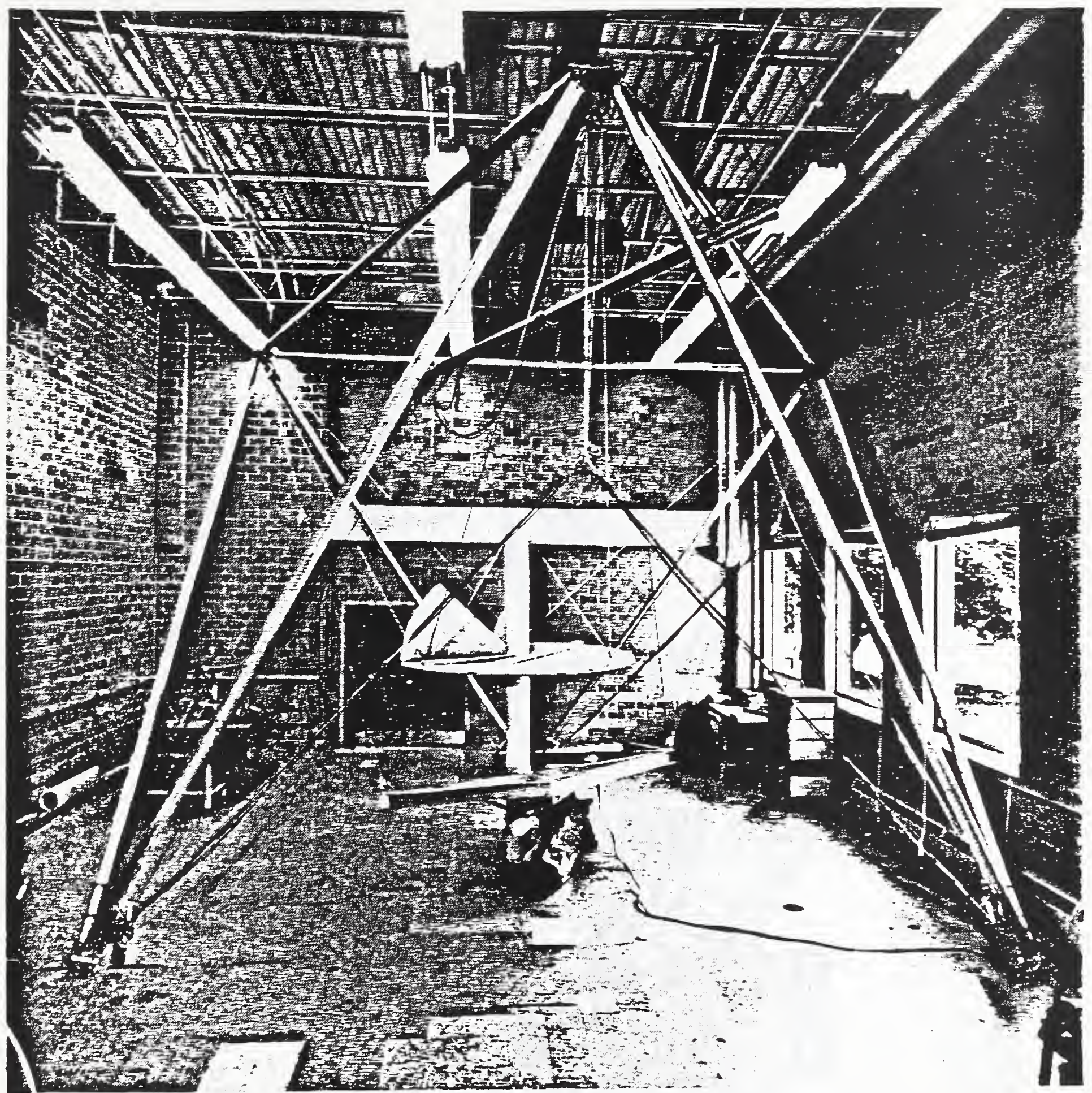

Figure 3: Photograph of the 6 meter RoboCrane. 


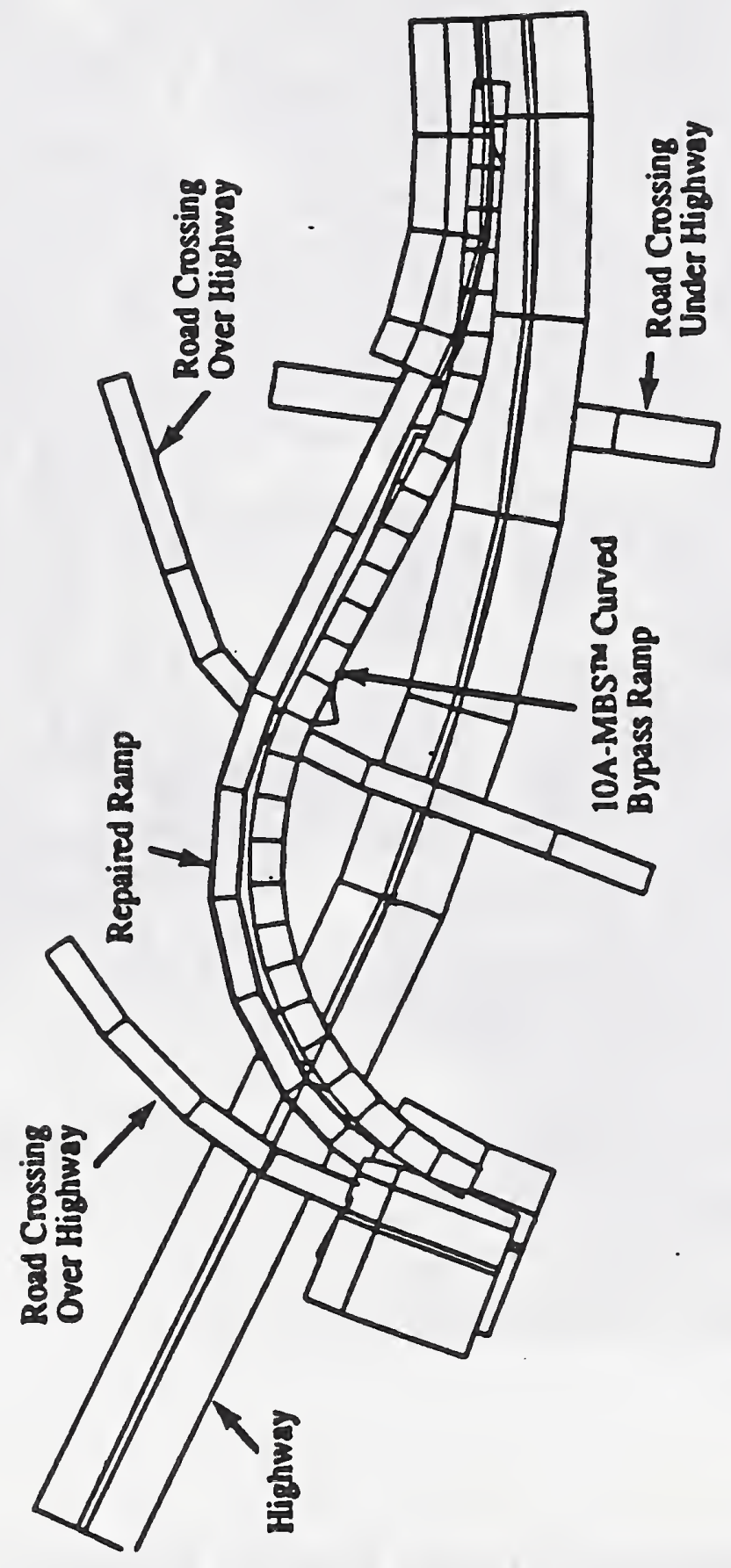

竞

5 0

บ.

- 0

을 은

ง

.

을

궁

$=0$

$2 \geq$

บ

s.

足

승 용

콩

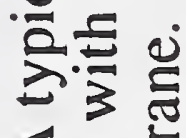

480

$\ddot{\nabla} \stackrel{0}{2}$ ?

는

이유. 


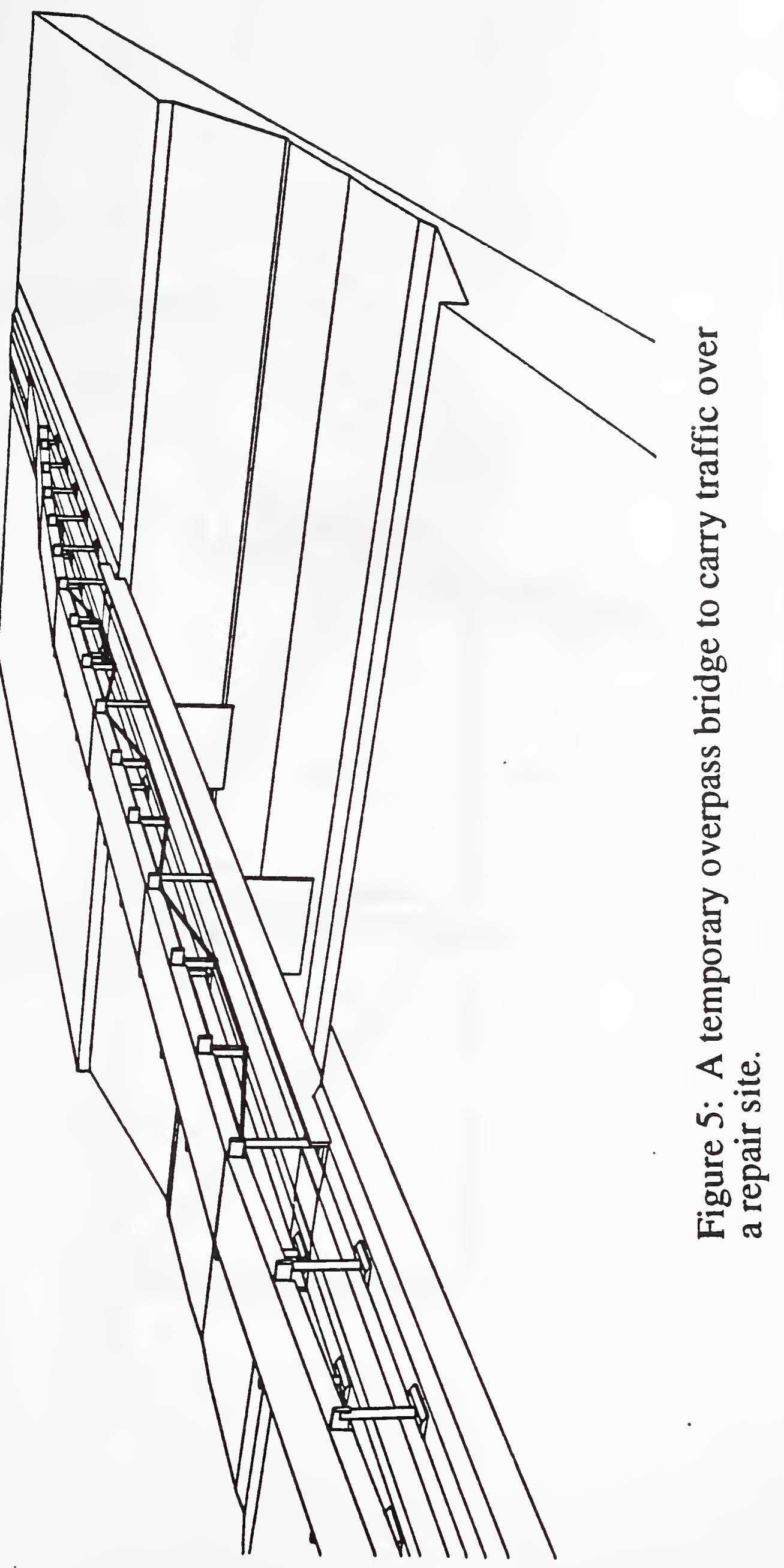




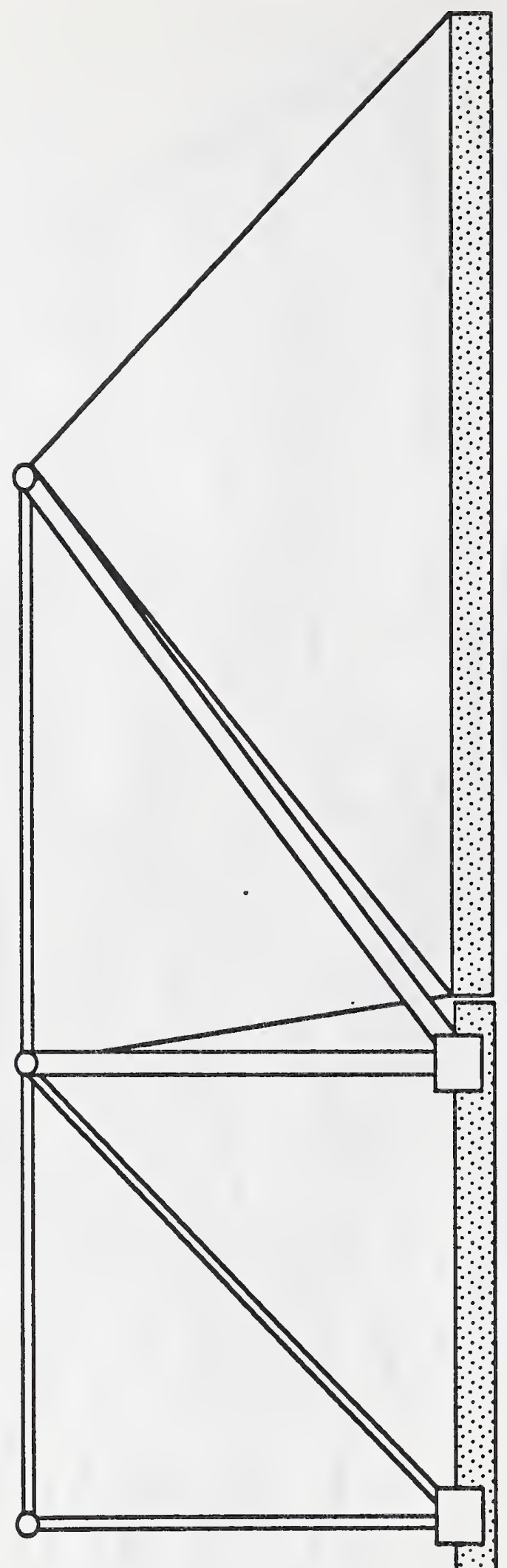

总

20

e

8

0

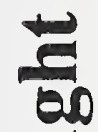

(4)

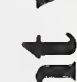

응

-

웅

里 


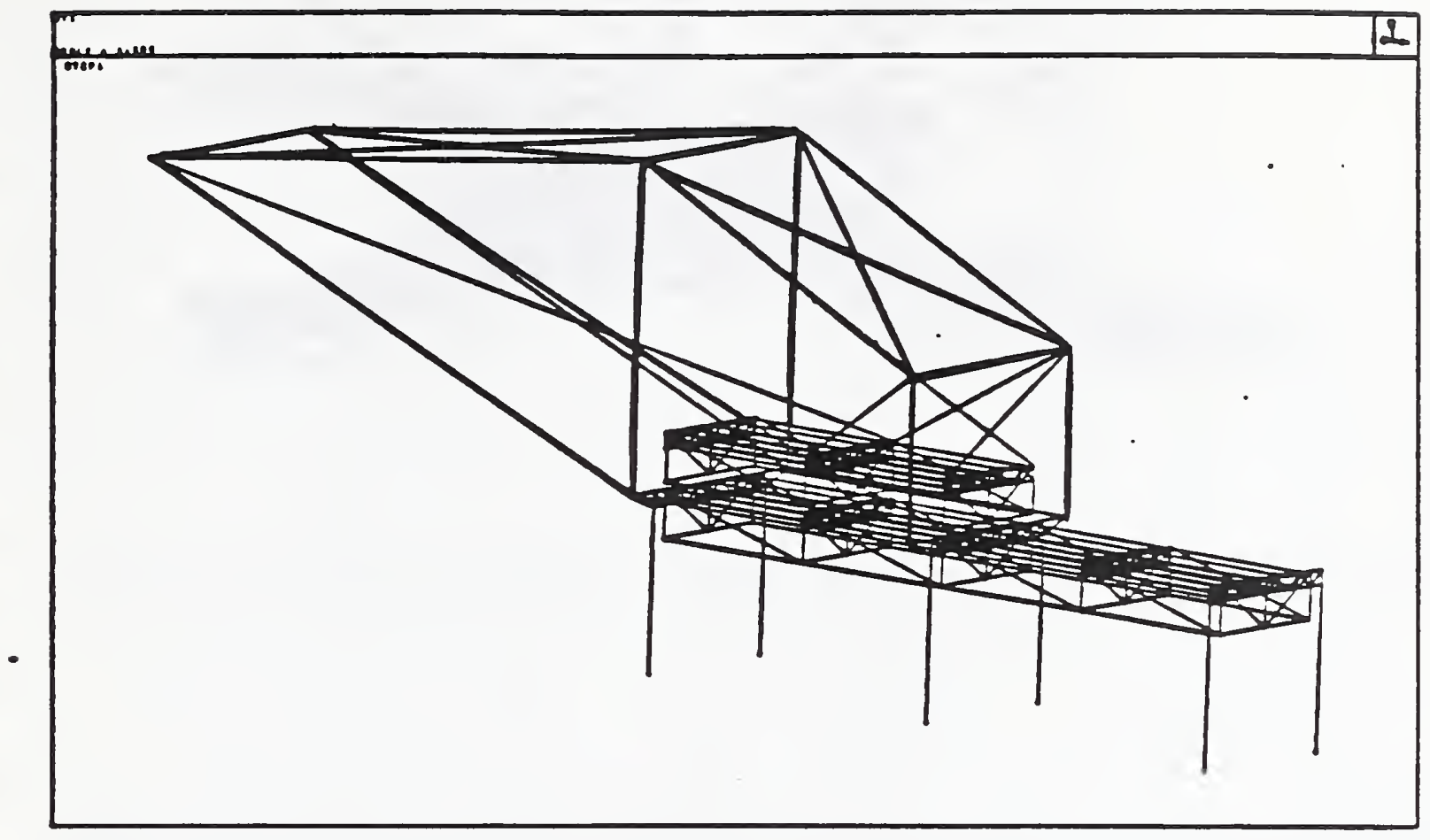

Figure 7: Modular Bridge Section PlacementConstruction Sequence. 

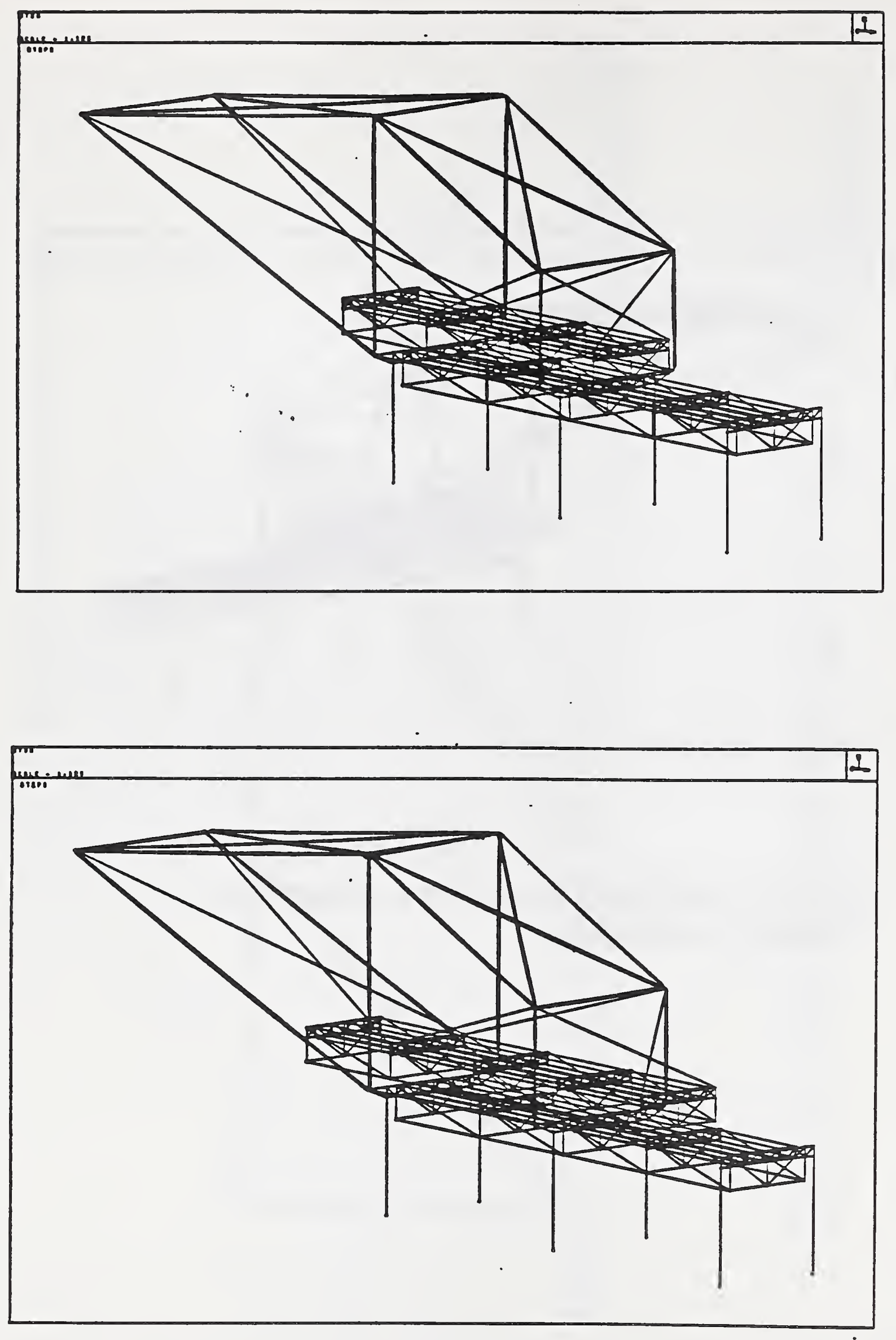

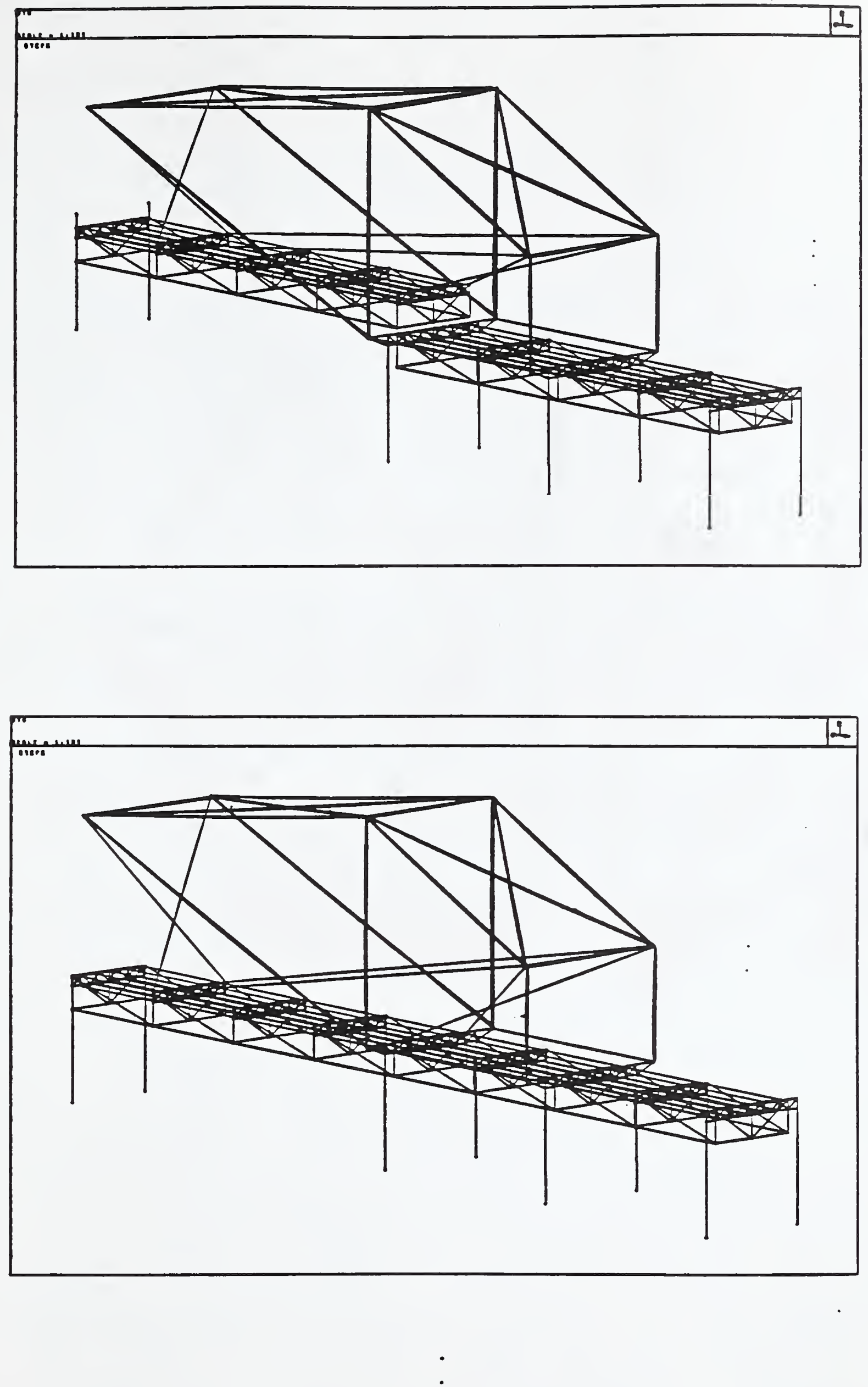

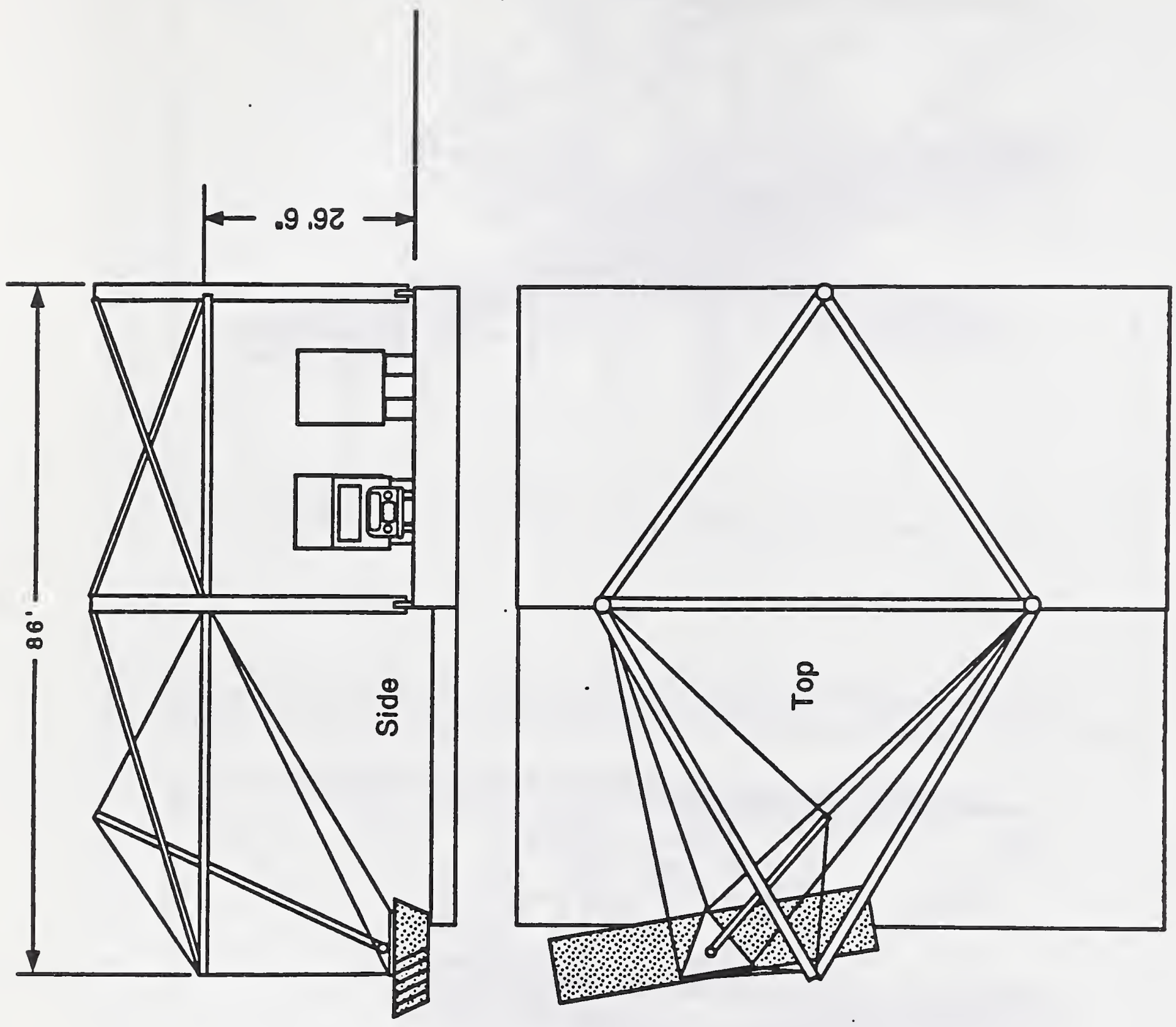
SECTION: 8

\section{CERF COST/BENEFITS ANALYSIS OF TECHNOLOGY PROPOSALS}

MEASURES OF MERIT - ROBOTIC TECHNOLOGY 



\section{IMPACT OF ROBOTICS/AUTOMATION APPLICATIONS IN HIGHWAY TRANSPORATION}

\section{Prepared By:}

\section{CERF}

Civil Engineering Research Foundation

1015 15th Street, N.W., Suite 600

Washington, DC 20005 
I 


\begin{abstract}
Six Robotics/Automation technologies proposed by the National Institute of Standards and Technology, dealing with construction, maintenance and construction/maintenance operations for use in the highway transportation industry, are examined. The technologies are evaluated to assess their potential impact in terms of efficiencies, cost, safety, operations, and in extending the service life of various highway components. Survey questionnaires requesting qualitative and quantitative assessments of the technology proposals were completed by highway industry experts in academia, state departments of transportation, and the construction industry. The survey responses are tabulated and summarized. A task force of representative industry experts, using the survey results as a start point, conduct detailed analysis of the technologies in the context of representative scenarios and develop quantified indicators of the technology impact.
\end{abstract}




\section{TABLE OF CONTENTS}

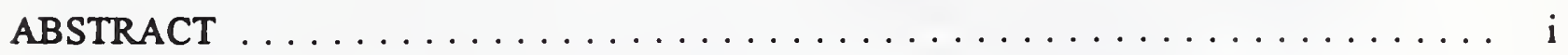

ACKNOWLEDGMENT $\ldots \ldots \ldots \ldots \ldots \ldots \ldots \ldots \ldots \ldots \ldots \ldots \ldots \ldots$ vii

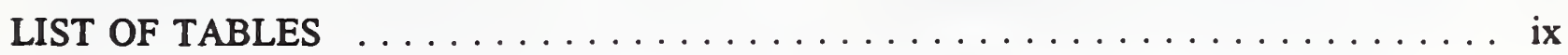

LIST OF FIGURES $\ldots \ldots \ldots \ldots \ldots \ldots \ldots \ldots \ldots \ldots \ldots \ldots \ldots \ldots \ldots \ldots$

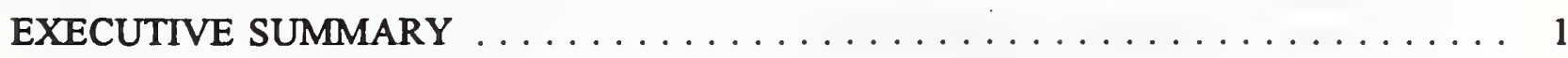

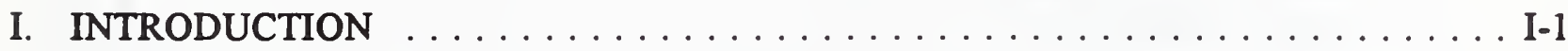

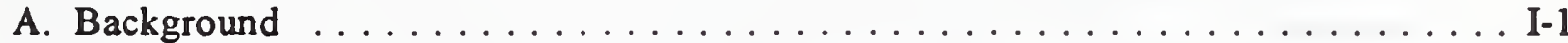

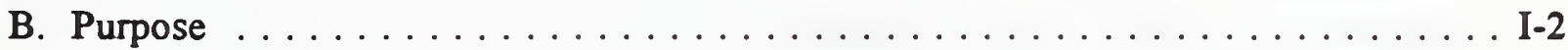

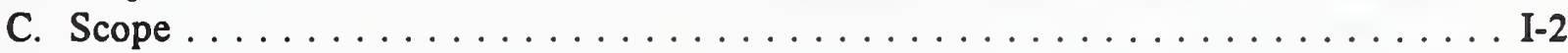

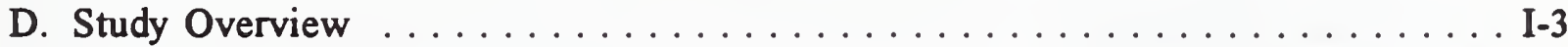

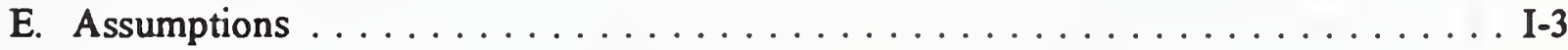

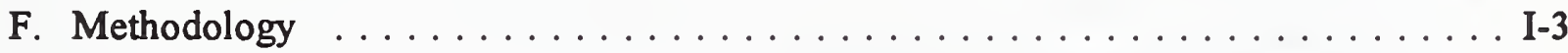

II. POTENTIAL AREAS OF RESEARCH $\ldots \ldots \ldots \ldots \ldots \ldots \ldots \ldots$ II.A-1

A. Site Integration Through Hierarchical Control $\ldots \ldots \ldots \ldots \ldots \ldots$ II.A-1

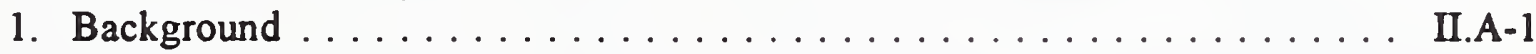

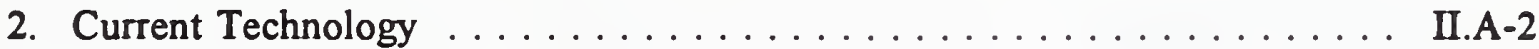

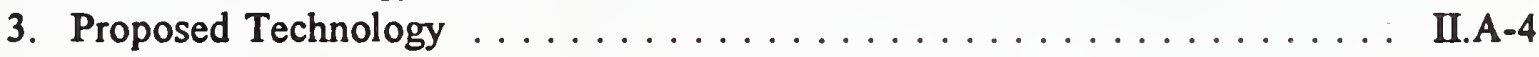

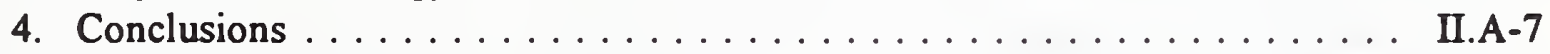

a. Benefits to highway construction $\ldots \ldots \ldots \ldots \ldots \ldots \ldots$ II.A-7

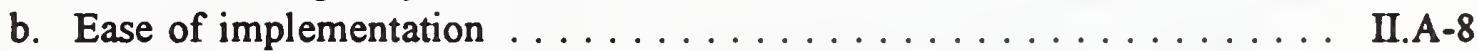

c. Industry acceptance $\ldots \ldots \ldots \ldots \ldots \ldots \ldots \ldots \ldots \ldots \ldots$ II.A-8

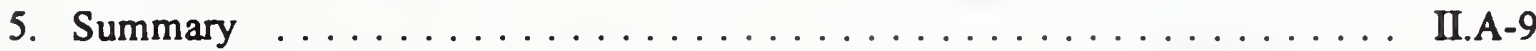

B. Automated Bridge Deck Construction $\ldots \ldots \ldots \ldots \ldots \ldots \ldots \ldots$ II.B-1

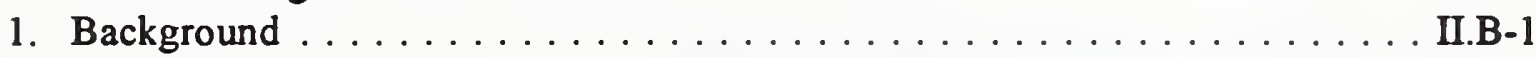

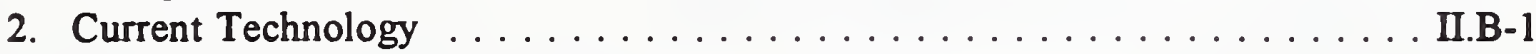

3. Proposed Technology $\ldots \ldots \ldots \ldots \ldots \ldots \ldots \ldots \ldots \ldots$ II.B-3

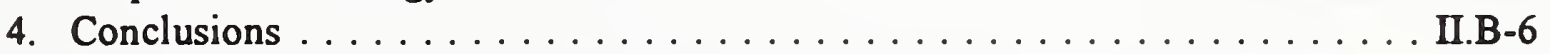

a. Benefits to highway construction $\ldots \ldots \ldots \ldots \ldots \ldots \ldots \ldots$ II.B-6

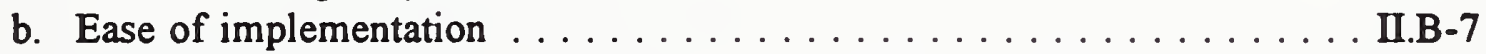

c. Industry acceptance $\ldots \ldots \ldots \ldots \ldots \ldots \ldots \ldots \ldots \ldots \ldots \ldots \ldots$ II.B-8 
5. Summary $\ldots \ldots \ldots \ldots \ldots \ldots \ldots \ldots \ldots \ldots \ldots \ldots \ldots \ldots \ldots$ II.B-9

C. Automated Trenching and Pipelaying $\ldots \ldots \ldots \ldots \ldots \ldots \ldots \ldots$ II.C-1

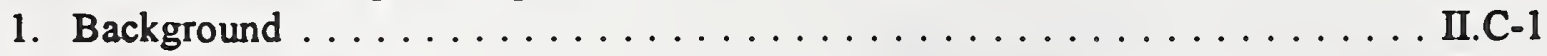

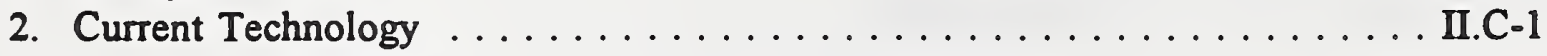

3. Proposed Technology . . . . . . . . . . . . . . . . . . . II.C-4

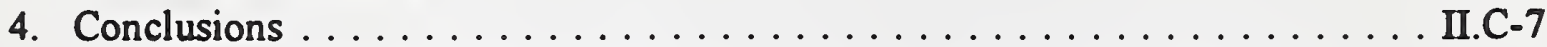

a. Benefits to highway construction $\ldots \ldots \ldots \ldots \ldots \ldots \ldots \ldots \ldots \ldots \ldots$ II.C-7

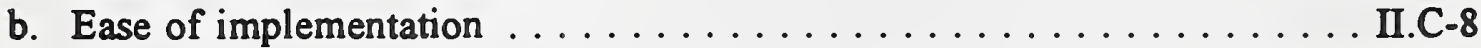

c. Industry acceptance $\ldots \ldots \ldots \ldots \ldots \ldots \ldots \ldots \ldots \ldots \ldots \ldots \ldots \ldots \ldots$ II.C-8

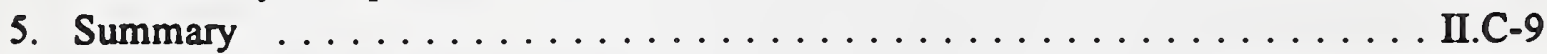

D. Bridge Inspection and Maintenance $\ldots \ldots \ldots \ldots \ldots \ldots \ldots \ldots \ldots$ II.D-1

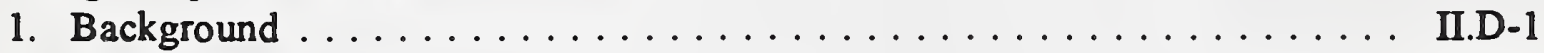

2. Current Technology $\ldots \ldots \ldots \ldots \ldots \ldots \ldots \ldots \ldots \ldots \ldots \ldots$ II.D-1

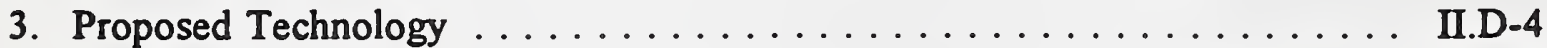

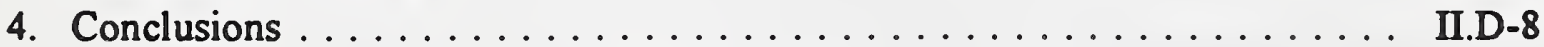

a. Benefits to highway construction $\ldots \ldots \ldots \ldots \ldots \ldots \ldots$ II.D-8

b. Ease of implementation . . . . . . . . . . . . . . . II.D-9

c. Industry acceptance $\ldots \ldots \ldots \ldots \ldots \ldots \ldots \ldots \ldots \ldots \ldots \ldots$ II.D-10

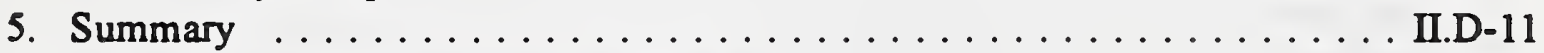

E. Automated Pavement Inspection and Repair . . . . . . . . . . . . II.E-1

1. Background . . . . . . . . . . . . . . . . . II.E-1

2. Current Technology . . . . . . . . . . . . . . . . II.E-1

3. Proposed Technology . . . . . . . . . . . . . . . . . . II.E-2

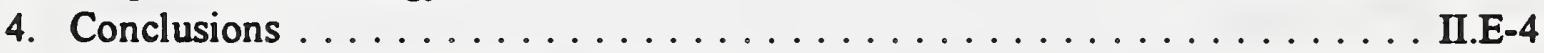

a. Benefits to highway construction $\ldots \ldots \ldots \ldots \ldots \ldots \ldots$ II.E-4

b. Ease of implementation . . . . . . . . . . . . . . . . II.E-5

c. Industry Acceptance $\ldots \ldots \ldots \ldots \ldots \ldots \ldots \ldots \ldots \ldots$ II.E-7

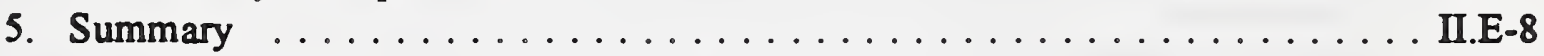

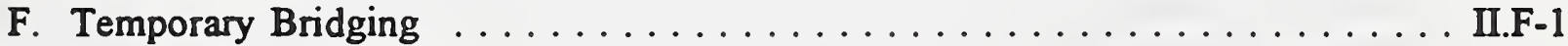

1. Background . . . . . . . . . . . . . . . .

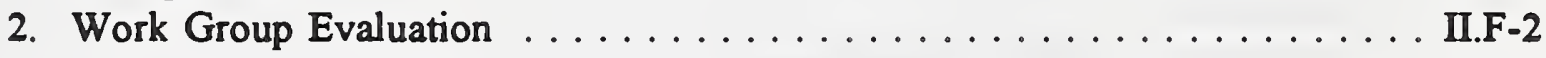

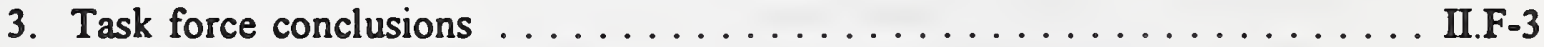

a. Benefits to highway construction $\ldots \ldots \ldots \ldots \ldots \ldots \ldots \ldots \ldots \ldots \ldots$ II.F-3

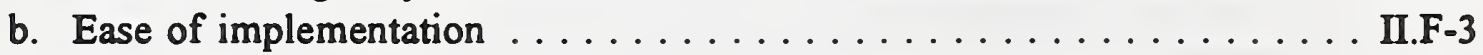

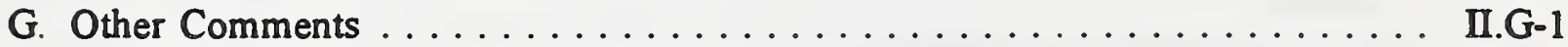

III. CONCLUSIONS AND RECOMMENDATIONS . . . . . . . . . . . III-1

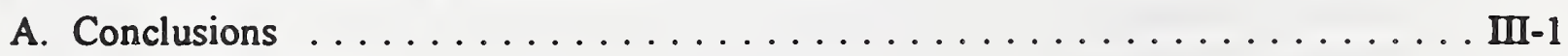

B. Recommendations . . . . . . . . . . . . . . . . . . III-3 


\section{APPENDIXES}

APPENDIX A - Survey Questionnaire . . . . . . . . . . . . . . . A A-1

APPENDIX B - Survey Response Summary - Site Integration . . . . . . . . . . . . B-1

APPENDIX C - Survey Response Summary - Automated Bridge Decking . . . . . . C.1

APPENDIX D - Survey Response Summary - Trenching and Pipelaying . . . . . . . D - 1

APPENDIX E - Survey Response Summary - Bridge Inspection and Maintenance .. E-1

APPENDIX F - Survey Response Summary - Pavement Inspection and Repair . . . . . F-1

APPENDIX G - Survey Response Summary - Temporary Bridging . . . . . . . . . . . G-1

APPENDIX H - Survey Response Summary - General Questions . . . . . . . . . . . H-1

APPENDIX I - Working Group Organization . . . . . . . . . . . . . . . I-1

APPENDIX J - References . . . . . . . . . . . . . . . . . . J J 1 


\section{ACKNOWLEDGMENT}

This report would not have been possible without the selfless dedication of many individuals who generously gave of their time to answer the survey questionnaire and participate in the August 31 workshop. The following individuals provided information and comments used to formulate the structure and content of the report.

Mr. Donn E. Hancher, P.E., C.E.

Chairman and Terrell-McDowell Chair Professor of Construction Engineering and Management

University of Kentucky

Mr. Charles Potts

President

APAC

Mr Pierri Domercq

Kasler Corporation

Mr. Mike Vorster

David H. Burrows Professor of Construction Engineering and Management

Department of Civil Engineering

Virginia Tech

Mr. George Herndon

State Highway Engineers Office

Florida Department of Transportation

Mr. Robert J. Benke

Director, Office of Research Administration

Minnesota Department of Transportation
Mr. Thomas R. Warne

Deputy Director

Arizona Department of Highways

Mr. John Chiaverini

Vice President, Special Projects

Perini Corporation

Mr. Dwight Bower

Deputy Director

Colorado Department of Transportation

Dr. Robert E. Maki, P.E.

Engineer of Traffic and Safety Division

Michigan Department of Transportation

Dr. Thomas D. White

Professor of Civil Engineering

Purdue University

Mr. Al Kosick

Traffic Management Section

Texas Department of Transportation

Thad Pirtle

Equipment Manager

Traylor Brothers

In addition, the following individuals volunteered to attend the workshop and assisted in the synthesis of the comments received from the survey. They provided the detailed analysis leading 
to the report conclusions. They devised the scenarios representative of a typical task to which the proposed robotics/automation technology could be applied and highlighted real world experience to make the concept assessment more representative of the true worth of the proposals. Their contribution is gratefully acknowledged.

Mr. Roozbeh Kangari

Associate Professor

School of Civil Engineering

Georgia Institute of Technology

Mr. Tom Iseley

Department of Civil Engineering

Louisiana Tech University

Dr. Carl Haas, P.E.

Assistant Professor of Civil Engineering

The University of Texas at Austin

Dr. Reid Brown

Vulcan Material Company

Birmingham, AL
Mr. Tom West

California Department of Transportation (CALTRANS)

Mr. William P. Carr

Technology Applications Manager

Washington State Department of Transportation

Mr. Steve Pageau

Arizona Department of Highways

The principal author of this report is Mr. Charles S. Nichols, with editing assistance from Ms. Meg Willett. Ms. Andrea Rudnick and Mr. Jay Etris helped in organizing and conducting the workshop and Mr. Ian Thomas provided background research. 


\section{LIST OF TABLES}

Table II.A-1. Work Breakdown Matrix for Current Site Integration Technology . . . II.A-4 Table II.A-2. Work Breakdown Matrix for Proposed Site Integration Technology . . I II.A-6 Table II.B-1. Work Breakdown Matrix for Current Bridge Decking Technology . . . . I..B-2 Table II.B-2. Work Breakdown Matrix for Proposed Bridge Decking Technology . . . . II.B-5 Table II.C-1. Work Breakdown Matrix for Current Trenching and Pipelaying . . . . . . I.C-3 Table II.C-2. Work Breakdown Matrix for Proposed Automatic Trenching and

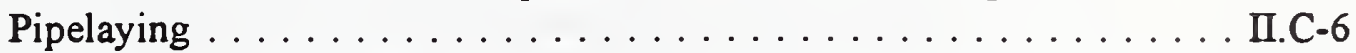

Table II.D-1. Work Breakdown Matrix for Current Bridge Inspection and Maintenance II.D-3 Table II.D-2. Work Breakdown Matrix for Proposed Bridge Inspection and Maintenance ... . . . . . . . . . . . . . . . II.D-7

Table II.E-1. Work Breakdown Matrix for Current Crack Sealing Technology . . . . . II.E-2

Table II.E-2. Work Breakdown Matrix for Proposed Crack Sealing Technology . . . . . II.E-4

Table II.G-1. Average Estimated Technology Savings in Percent . . . . . . . . . . II.G-4

Table II.G-2. Priority Ranking of 25 Application Areas to Automate . . . . . . . . II.G-5

Table III-1. Summary of Technology Comparisons . . . . . . . . . . . . . . III-2

Table A-1. Evaluation Criteria Table . . . . . . . . . . . . . . . . . . . A-4

Table A-2. Average Ranking for the Six Technologies by Survey Respondents . . . . A-5

Table A-3. Average Priority Ranking for the Six-Technologies by Survey

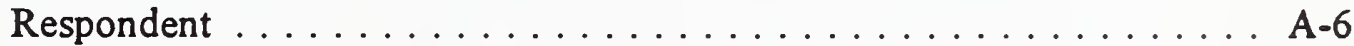

Table A-4. Priority Ranking of 25 Application Areas to Automate .......... A-7 
(1) 


\section{LIST OF FIGURES}

\section{LIST OF FIGURES}

Figure II.B-1 Concept Drawing for a Demonstration Project for the Automation of

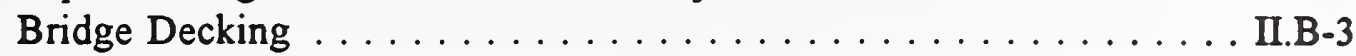

Figure II.C-1 Conceptual Drawing of Robotics Excavation . . . . . . . . . . . II.C-4

Figure II.C-2 Conceptual Drawing of Robotics Pipe Placement . . . . . . . . . . . . II.C-4

Figure II.D-1 Possible Stationary Shroud Configuration . . . . . . . . . . . II.D-4

Figure II.D-2 Possible Dynamic Shroud Configuration . . . . . . . . . . . . II.D-5

Figure II.E-1 Structured-light Range Sensor System for Crack Detection . . . . . . . . II.E-3

Figure II.E-2 Hypothetical Crack Layout on a Road Section . . . . . . . . . . . . . II.E-6

Figure II.G-1 Technology Priority Ratings - Average of all Ratings . . . . . . . . II.G-2

Figure II.G-2 Assessment of Technology Impact $\ldots \ldots \ldots \ldots \ldots \ldots$. . . . . . . . 


\section{EXECUTIVE SUMMARY}

Six Robotics/Automation technologies proposed by the National Institute of Standards and Technology (NIST) are evaluated for their potential impact on the highway transportation industry in terms of efficiencies, cost, safety, operations, and in extending the service life of various highway components. The technologies fall into three broad operational areas and are as follows:

\section{CONSTRUCTION}

Automated Bridge Deck Construction

Automated Trenching and Pipelaying

\section{MAINTENANCE}

Automating Bridge Inspectiony and Maintenance

Automated Crack Detection and Sealing

\section{CONSTRUCTION/MAINTENANCE}

Site Integration Through Hierarchical Control

Rapid Temporary Bridge Construction

The concepts were evaluated in a two-step process. Step one consisted of distributing 29 survey forms to a selected group of highway transportation industry experts in academia, state departments of transportation, the highway construction industry, and the highway materials industry. A $58.6 \%$ return rate was achieved with most respondents providing input on all questions. Step two involved assembling a seven-man panel of experts drawn from the same industry cross section to review the survey results, develop representative task scenarios, and evaluate the concepts in quantitative terms. Five of the six concepts are evaluated in this manner. The sixth, Rapid Temporary Bridge Construction was evaluated only in qualitative terms due to a lack of time and insufficient background and experience on the part of the panel to conduct a quantitative evaluation.

The report results must be viewed in the context in which the information was developed. Quantification was achieved by developing what the panel felt was a representative task scenario for each technology. The scenario selected does not necessarily represent the most frequent potential application of the technology or the application at which the technology would perform the best (or worst) in comparison to existing technologies. Assumptions were made concerning the concepts-principally in terms of acquisition, operation, and maintenance cost of the technology, and, in a few instances, the performance capabilities of the technology-which, if incorrect, could affect the outcome of the evaluation. It is therefore necessary to continually evaluate the concepts as they progress through the development phase to insure they still offer improvements over the current technologies which warrant expenditure of developmental funds. 
One concept, Automated Crack Detection and Sealing, showed the greatest potential cost savings when compared to the present technology. It also has the greatest potential for increased productivity. Crack Detection and Sealing does not represent a major expenditure of highway maintenance dollars so the potential direct saving from this technology is not as great as the percent improvements would lead one to believe. The major benefit offered by this technology is that a highway jurisdiction could maintain almost 100 times as many miles of highway surface for the same expenditure of maintenance funds. This would have a major impact on extending the service life of roads, thus leveraging the savings from this technology and realizing much greater indirect cost savings.

Site Integration Through Hierarchical Control, though ranked fourth in potential savings for the scenario evaluated, is considered the technology that offers the greatest overall savings to the highway transportation industry. It has the most universal application of the six technologies. If Site Integration realizes savings of $10 \%$ to $20 \%$, as indicated in the analysis, it has the potential of saving $\$ 8$ billion to $\$ 16$ billion (based on $\$ 78.3$ billion spent in 1991 for highway construction and maintenance) each year. The Consortium for Advanced Positioning Systems (CAPS) is recommended for incorporation into Site Integration to provide an early demonstration of this technology.

There are aspects of each technology that may inhibit their acceptance by industry. Industry does not perceive a need for Site Integration and does not use current technology (CPM, PERT) extensively. Capital outlay for Bridge Decking robotics, Bridge Inspection and Maintenance robotics, and Crack Detection and Sealing robotics may restrict their purchase and application to only the largest construction firms, thus limiting their overall impact. Automated Trenching and Pipelaying does not offer substantial savings in terms of cost or reduced project duration because this operation is inherently machine capacity dependent. The concept does not purport to improve machine productivity, and the safety benefit of eliminating personnel in the trench will not be realized until automated pipe section coupling is developed.

The panel of experts recommends that industry (academia, contractors, and state DOTs) continue to be involved as the research and development of robotics/automation applications to highway transportation progress towards useable tools for the industry. In addition, as a result of the concern expressed by survey respondents and the panel of experts concerning the feasibility of several concepts, it is strongly recommended that a technology risk assessment be conducted for concepts selected for further development. 


\section{INTRODUCTION}

This report estimates the potential impact of automation/robotics studies which were recommended as a result of an expert assessment of the feasibility of applying robotics to highway construction, maintenance, and operations. This assessment is part of a larger research program undertaken by the National Institute of Standards and Technology (NIST) under sponsorship of the Federal Highway Administration (FHWA), entitled "Robotics Application for Highway Transportation." The objectives of the overall program are the following:

- Assess present robotics knowledge;

- Identify on-going and planned robotics applications to highway transportation in the USA and other countries; and

- Recommend other cost-effective robotics applications.

This report assesses the potential impact of six automation/robotics studies recommended by technical experts from academia and industry as a result of a series of workshops (which included state high way construction and maintenance engineers and operations engineers); field visits to observe and document actual highway construction, maintenance, and operations, a; well as a final working group meeting. These activities produced a list of six recommended studies encompassing both near-term as well as medium- and long-term automation/robotics development, to include expected/desired performance objectives for each technology. This report assesses the potential impact of each technology in terms of efficiencies, cost, safety, operations, and extending the service life of various highway components.

Robotics, as used in this report, will include both robot and automation technologies.

\section{A. Background}

Productivity is decreasing in the U.S. construction industry, which is the opposite of the manufacturing segment, where productivity is improving. One reason for this is the use in manufacturing of advanced computer and machine technologies, whereas increased environmental and worker safety requirements have reduced total productivity in construction. The Japanese are considerably ahead of the United States and other countries in applied research for construction automation. They have applied various types of robotics systems and other modes of automation to design and construction in an effort to improve quality, increase productivity, and reduce costs. The technologies that have been successfully used in Japanese automotive and electronics industries are now being intensively researched for integration into the Japanese construction industry. Japan has led in this area due to the structure of their construction industry and contractor control of research and development, as well as other traditional reasons they have been successful in automotive, electronics, and other industries. 
Robotics has been used at an increasing rate in various fields. Robotics systems have been developed for coal mining, hazardous waste cleanup, and building construction. The military has used robotics for a variety of applications and has a major research program underway to develop robotics fighting vehicles. The technology is now sufficiently established to warrant accelerated consideration for use in the highway transportation industry. Robotics promises to increase safery and productivity while reducing costs and the safety hazards associated with work sites adjont to traffic.

The Fiscal Year 1991 Highway Trust Fund Authorization was $\$ 13.8$ billion dollars. The three major categories of expenditure: interstate construction, interstate $4 R$, primary roads, and bridge replacement and rehabilitation accounted for $\$ 9.9$ billion or almost $72 \%$ of the total expenditure [4]. According to a report published by The Road Information Program (TRIP), a backlog of $\$ 290$ billion exists in road and bridge needs on major routes, whereas the U.S. spent only $\$ 26.4$ billion in 1991 on improvements to these major routes. According to Department of Transportation estimates, the annual expenditures would have to be increased to $\$ 67$ billion to meet the backlog of needs [8].

During the period 1981 to 1991 , highway travel increased by $40 \%$ while actual capital expenditures for highways, in inflation adjusted dollars, decreased in 21 states. In 1991, the average American motorist spent more than $\$ 103$ on wasted fuel, added tire wear, and extra vehicle repairs as a result of driving on rough, rutted roads. This translates to nationwide waste of more than $\$ 17.4$ billion [8]. Clearly more needs to be done to improve and upgrade the highway system throughout the country.

Robotics and automation promise to increase productivity in new construction, maintenance and repair, and traffic flow through work sites. This report provides an objective evaluation of six robotics/automation proposals, assessing their impact on the highway system, and making a subjective judgement on their commercial value to the highway construction and maintenance industry.

\section{B. Purpose}

This research report was prepared under contract to the National Institute of Standards and Technology (NIST) to provide an independent evaluation and estimate of the potential impact of robotics/automation concepts. The concepts were recommended and undertaken as a result of an assessment of the feasibility of applying robotics to highway construction, maintenance, and operations.

\section{Scope}

The report assesses the potential impact of six robotics/automation technology concepts recommended as a result of a series of workshops (attended by state highway construction and maintenance engineers, operations engineers, academia, and industry), field visits to observe and 
document actual highway construction, maintenance, and operations, as well as a final working group meeting. On the premise that each concept leads to successful development of a robotics/automation technology, this report seeks to assess the potential impact of each technology in terms of efficiency, cost, safety, operations, and in extending the service life of various highway components.

\section{Study Overview}

Six specific proposals were evaluated by this study. The proposals have long-, mid-, and shortterm aspects, and in several cases the proposed work spans more than one time frame, with various benefits anticipated at each stage. The six proposals are as follows:

- Site Integration Through Hierarchical Control

- Automated Bridge Deck Construction

- Automated Trenching and Pipelaying

- Automated Bridge Inspection and Maintenance

- Automated Crack Detection and Sealing

- Rapid Temporary Bridge Construction.

A summary of each technology can be found in Section II.

\section{E. Assumptions}

This study has not attempted to assess either the feasibility or technical performance of the proposed robotics/automation systems. It is assumed that the technology will perform as stated by the proposal author, that there are no technical barriers which cannot be overcome in the time frame specified, and that the system proposed will be cost competitive (from a capital expenditure standpoint; e.g., purchase price, training, maintenance, etc.) with the existing technology. This did not prevent survey respondents and workshop participants from expressing their concern and/or skepticism about certain claims made by proposal authors. Whenever a consensus existed these concerns have been included in this report. Their inclusion is in no way a reflection on the merits of the proposal. Rather, they provide an insight to concerns held by the construction community. These concerns must be addressed by either a technical demonstration to dispel the doubt or an effective marketing strategy before the technology will become acceptable to the industry.

\section{F. Methodology}

The information contained in this report was developed in two steps. The first involved distribution of a survey form to 29 experts representing the spectrum of the highway construction industry. The respondents were selected for their technical knowledge and recognition as experts in their field. They represent some of the nation's most prestigious engineering schools, nationally and internationally recognized highway construction firms, suppliers of highway 
construction materials, and departments of transportation of states considered to be innovative leaders in highway construction technology. Appendix A contains an explanation of the survey form and the method by which the results were tabulated. A summary of each response is found in Appendixes B through $\mathrm{H}$.

In step two, a representative group of experts was brought together in a workshop setting to review the survey results and develop further the information needed for this report. Three work groups were formed to consider the broad technology headings of construction, maintenance, and construction/maintenance. Each was assigned two technologies to evaluate and report their findings to the entire group at the end of the day. A discussion of the workgroup organization, tasks, and schedule is found in Appencix I.

The workgroup participants reviewed the survey results. For each technology a typical task (scenario) was developed to serve as a basis for evaluating the benefits offered by the proposed technology. The tasks were planned and cost determined much the same as a contractor would in developing a bid proposal. Means cost datu, or expert knowledge from the work shop participants, were used for the current technologies. Assumptions were made when necessary for performance and cost of the proposed technologies. A similar "bid proposal" was developed so both technologies could be compared.

Conclusions were drawn regarding the proposed technologies from this analysis and the survey results. The conclusions fall into the three broad categories: benefits to highway construction, ease of implementation, and industry acceptance. 


\section{POTENTIAL AREAS OF RESEARCH}

\section{A. Site Integration Through Hierarchical Control.}

\section{Background}

a. General - Unforeseen events can idle equipment at the worksite, which wastes time and costs money. An event can occur which requires equipment not at the worksite. Normally, it is the job of the site foreman to deal with these events. The foreman can only oversee his "island" of activity and therefore is implementing a local rather than global optimization of a construction plan. The foreman's fundamental limitation is that he lacks information about what is happening at the other work sites of the project. Consequently, the key problems are the lack of global information and a method for using it effectively.

A site foreman does an excellent job in allocating resources at her work site, i.e., she does the best job she can with the information she has. However, this local optimization results in sub-optimal use of equipment, personnel, and planning for materials delivery. Theoretically, if the foreman knew about the state of all of the project work sites, resources could be allocated more effectively. As a result a degree of "slop" is incorporated in planning schedules to ensure adequate numbers of personnel, equipment, and supplies are available at all work sites on projects that have critical completion dates. When this is not done the completion date invariably slips because of unforeseen events. Site Integration Through Hierarchical Control is anticipated to provide the "tool" the foreman needs to optimally manage all resources at a multitude of project work sites.

b. Typical task (scenario) for this technology - A road resurfacing project was selected to evaluate this technology. The work group chose this project because it involved management of numerous resources and consisted of many sequential operations taking place at several locations. Scheduling of equipment and material is critical to timely completion of road resurfacing projects. Though road resurfacing is not the most complex highway construction project, it provided sufficient complexity to demonstrate the benefit of Site Integration while being simple enough to permit effective analysis.

The project consists of resurfacing ten miles of an eight-lane highway for 80 lanemiles of resurfacing. Two inches of the road surface are to be milled and the debris hauled away. A two-inch binder course followed by a one-inch wear surface is to be laid. Fifty-six thousand tons of milled surface will be removed and 85,000 tons of 
asphalt, consisting of 56,000 tons of binder course and 29,000 tons of wear surface is required.

The project is located in a metropolitan area with heavy traffic flow. The contract calls for the project to be completed within 90 days. Seven days a week and twentyfour hours a day are available for the project. Work is scheduled for twelve hours a day with ten hours devoted to paving operations. The rolling operation extends two hours beyond paving to finish the asphalt laid during the day. The asphalt plant is a 10-mile average haul distance away and is also the disposal site for the milled material.

A typical sequence of events for this project will consist of the following activities:

- Establish traffic control on two lanes for a five mile section of road

- Temporarily stripe the road for the lane diversion

- Mill the road surface to specification and back haul the milled material

- Apply a tack coat for the binder course

- Pave the binder course

- Apply a tack coat for the wear course

- Pave the wear course

- Strip the paved road section

- Move the traffic control to the next section of road to resurface.

This sequence is independent of whether or not Site Integration is utilized. Equipment capabilities are unchanged by Site Integration. Overall project efficiencies are expected to increase due to the elimination of most lost time.

\section{Current Technology}

a. Description - Work is normally scheduled using Critical Path Method (CPM) utilizing Gantt charts to determine the resources required and duration of each aspect of the project. The site foreman manages the resources for his particular segment of the entire project semi-independent of the other site foreman. Well run projects will require an after-action meeting at the end of each day among the various site foremen to coordinate plans for the following day. Little effective communication takes place between the various sites on the project during the day unless an emergency situation comes up.

b. Task Analysis - For this scenario the equipment requirements and duration of the project phase as well as total project duration were derived based on the experience of the workgroup participants. Cost of the equipment, labor, and materials was estimated using Means. Certain aspects of this project will be the same for both the current technology and the proposed technology and their cost is minimal compared 
to the total project cost. These functions are ignored in this analysis. This project consists of four separate work sites each with its own work site foreman. There are two milling sites and two paving sites. A project engineer is in charge of the overall project and responsible for coordination of the various site activities and allocation of resources.

Twelve-ton trucks are used to haul the asphalt and back haul the milled pavement. Each truck can make one round trip in an hour. The pacing element of this operation is laying the binder course. Two pavers and associated equipment are capable of laying two lane-miles of two-inch binder course a day (1,400 T/day) during a 10-hourday. Two millers and associated equipment will be required for an eight-hour work day to keep pace with the paving operation. The millers are capable of milling approximately $1,900 \mathrm{~T} /$ day ( 2.7 lane-miles) and will not work at their full efficiency. The wear course can be laid at the rate of 3 lane-miles per 10-hour day. Fourteen 12 ton dump trucks are required to haul the 117 loads of asphalt required per day for the binder course, 14 per day for back hauling the milled material and 12 per day for the wear course. These truck quantities represent a $15 \%$ to $20 \%$ excess haul capacity to account for equipment down time and lost time at the asphalt plant while waiting in a queue. It will take 40 days to mill all eight lanes, 40 days to lay the binder course, and 26.5 days to lay the wear course. Total project duration, not counting time required for lane closure and line painting, is 67 days.

c. Work breakdown - Table II.A-1 depicts the various functions which must be performed to resurface a road and shows the equipment, manpower, and material required to accomplish those functions.

Total project cost is $\$ 4,210,303$, and requires 35,774 man-hours of effort. The cost and man hours expended for each function are shown below:

Function

Milling

Back Haul

Paving - Binder Course

Haul - Binder Course

Paving - Wear Course

Haul - Wear Course

Rolling Binder and Wear

Asphalt
Cost

$\$ 511,144$

$\$ 409,640$

$\$ 324,080$

$\$ 409,640$

$\$ 214,703$

$\$ 210,672$

$\$ 297,544$

$\$ 1,832,880$
Man Hours

4,480 man-hr

5,600 man-hr

6,560 man-hr

5,600 man-hr

5,830 man-hr

2,880 man-hr

4,824 man-hr 


\begin{tabular}{|c|c|c|c|}
\hline Function & Resources Required & $\begin{array}{r}\text { Unit Cost } \\
\text { of Re- } \\
\text { source }\end{array}$ & $\begin{array}{l}\text { Units Re- } \\
\text { quired }\end{array}$ \\
\hline Milling & $\begin{array}{l}2 \text { ea B-71 Crew consisting of: } \\
1 \text { Foreman } \\
3 \text { Laborers } \\
3 \text { Equipment Operators } \\
1 \text { Pvmt. Profiler } \\
1 \text { Road Sweeper } \\
1 \text { F.E. Loader }\end{array}$ & $\begin{array}{r}\$ 6,389.30 \text { per } \\
\text { crew day }\end{array}$ & 80 crew days \\
\hline $\begin{array}{l}\text { Back haul of } \\
\text { milled material }\end{array}$ & Dump Trucks w/Drivers & $\begin{array}{r}\$ 731.50 \text { per } \\
\text { truck day }\end{array}$ & 560 truck days \\
\hline $\begin{array}{l}\text { Paving - Binder } \\
\text { Course }\end{array}$ & $\begin{array}{l}2 \text { ea Paving crews consisting of: } \\
1 \text { Foreman } \\
7 \text { Laborers } \\
1 \text { Equipment Operator } \\
1 \text { Asphalt Paver }\end{array}$ & $\begin{array}{r}\$ 4,051.00 \text { per } \\
\text { crew day }\end{array}$ & 80 crew days \\
\hline $\begin{array}{l}\text { Asphalt Haul for } \\
\text { Binder Course }\end{array}$ & $\begin{array}{l}\text { Dump Trucks w/ Drivers } \\
\text { Asphalt }\end{array}$ & $\begin{array}{r}\$ 731.50 \text { per } \\
\text { truck day } \\
\$ 20.84 / \text { ton }\end{array}$ & $\begin{array}{l}560 \text { truck days } \\
56,000 \text { Tons }\end{array}$ \\
\hline $\begin{array}{l}\text { Paving - Wear } \\
\text { Course }\end{array}$ & $\begin{array}{l}2 \text { ea Paving crews consisting of: } \\
1 \text { Foreman } \\
7 \text { Laborers } \\
1 \text { Equipment Operator } \\
1 \text { Asphalt Paver }\end{array}$ & $\begin{array}{r}\$ 4,051.00 \text { per } \\
\text { crew day }\end{array}$ & 53 crew days \\
\hline $\begin{array}{l}\text { Asphalt Haul for } \\
\text { Wear Course }\end{array}$ & $\begin{array}{l}\text { Dump Trucks w/ Drivers } \\
\text { Asphalt }\end{array}$ & $\begin{array}{r}\$ 731.50 \text { per } \\
\text { truck day } \\
\$ 22.96 / \text { ton }\end{array}$ & $\begin{array}{l}288 \text { truck days } \\
29,000 \text { tons }\end{array}$ \\
\hline $\begin{array}{l}\text { Rolling Binder and } \\
\text { Wear Course }\end{array}$ & $\begin{array}{l}\text { Rolling crew consisting of: } \\
6 \text { Equipment Operators } \\
1 \text { Tandem Roller, } 10 \text { Ton } \\
2 \text { Rollers, Pneumatic Wheel } \\
3 \text { Rollers, Steel Wheel }\end{array}$ & $\begin{array}{r}\$ 4440.35 \text { per } \\
\text { crew day }\end{array}$ & 67 crew days \\
\hline
\end{tabular}

Table II.A-1. Work Breakdown Matrix for Current Site Integration Technology

\section{Proposed Technology}

a. Description - The primary objective of this work would be to substantially reduce the construction time on highway projects, perhaps by as much as $50 \%$, through the use of automation techniques now employed in manufacturing. Computerized design 
databases exist today which can be used as the basis of automated planning, scheduling, and logistical control of materials and resources. Advanced control techniques can be used to dynamically reschedule the equipment on a site, as well as to coordinate the arrival of materials and relocation of men and equipment based on the current state of the site. In the short term, using design databases, survey databases, and on-site data entry, it is possible to do real-time global optimization of projects with man-in-the-loop interfaces, including equipment deployment and scheduling, and delivery of materials. Other advantages would include reduced materials waste and automated collection of data for as-built databases. The fundamental requirement is gathering and distributing information in a timely manner to optimize work for the entire site rather than just a small part of it. Longer-term efforts could extend to semi-automated control of grading and materials placement directly from plans and survey data through advanced operator interfaces, or to automated sensing and control of interactions between pieces of equipment, such as between trucks and concrete-spreaders/asphalt pavers, or between front-end loaders and bulldozers or graders.

b. Task Analysis - The major difference in how this project would be completed using site integration is that a separate fleet of trucks would not be allocated for the back haul of the milled material. With efficient scheduling and tracking of resources the trucks hauling the binder course of asphalt could back haul the milled material. Based on the experience of work group participants, the paving operation could be more productive when everything goes smoothly and materials arrive when scheduled. One of the participants has laid as much as 2,000 tons of binder course in a 10-hour day under ideal conditions. For the purpose of this analysis a rate of 1,750 tons per day binder course and 1,200 tons per day wear course is assumed possible through the efficiencies offered by Site Integration.

c. Work breakdown - Table II.A-2. depicts the functions which must be performed to resurface a road, and shows the equipment, manpower, and materials required to accomplish those functions using the proposed site integration technology. 


\begin{tabular}{|c|c|c|c|}
\hline Function & Resources Required & $\begin{array}{l}\text { Unit Cost } \\
\text { of Re- } \\
\text { source }\end{array}$ & $\begin{array}{l}\text { Units Re- } \\
\text { quired }\end{array}$ \\
\hline Milling & $\begin{array}{l}2 \text { ea B-71 Crew consisting of: } \\
1 \text { Foreman } \\
3 \text { Laborers } \\
3 \text { Equipment Operators } \\
1 \text { Pvmt. Profiler } \\
1 \text { Road Sweeper } \\
1 \text { F.E. Loader }\end{array}$ & $\begin{array}{r}\$ 6,389.30 \text { per } \\
\text { crew day }\end{array}$ & 64 crew days \\
\hline $\begin{array}{l}\text { Back haul of } \\
\text { milled material }\end{array}$ & Dump Trucks w/Drivers & \multicolumn{2}{|c|}{$\begin{array}{l}\text { Site Integration permits using as- } \\
\text { phalt trucks to remove milled ma- } \\
\text { terial on back haul. }\end{array}$} \\
\hline $\begin{array}{l}\text { Paving - Binder } \\
\text { Course }\end{array}$ & $\begin{array}{l}2 \text { ea Paving crews consisting of: } \\
1 \text { Foreman } \\
7 \text { Laborers } \\
1 \text { Equipment Operator } \\
1 \text { Asphalt Paver }\end{array}$ & $\begin{array}{r}\$ 4,051.00 \text { per } \\
\text { crew day }\end{array}$ & 64 crew days \\
\hline $\begin{array}{l}\text { Asphalt Haul for } \\
\text { Binder Course }\end{array}$ & $\begin{array}{l}\text { Dump Trucks w/ Drivers } \\
\text { Asphalt }\end{array}$ & $\begin{array}{r}\$ 731.50 \text { per } \\
\text { truck day } \\
\$ 20.84 / \text { ton }\end{array}$ & $\begin{array}{l}576 \text { truck days } \\
56,000 \text { tons }\end{array}$ \\
\hline $\begin{array}{l}\text { Paving - Wear } \\
\text { Course }\end{array}$ & $\begin{array}{l}2 \text { ea Paving crews consisting of: } \\
1 \text { Foreman } \\
7 \text { Laborers } \\
1 \text { Equipment Operator } \\
1 \text { Asphalt Paver }\end{array}$ & $\begin{array}{r}\$ 4,051.00 \text { per } \\
\text { crew day }\end{array}$ & 48 crew days \\
\hline $\begin{array}{l}\text { Asphalt Haul for } \\
\text { Wear Course }\end{array}$ & $\begin{array}{l}\text { Dump Trucks w/ Drivers } \\
\text { Asphalt }\end{array}$ & $\begin{array}{r}\$ 731.50 \text { per } \\
\text { truck day } \\
\$ 22.96 / \text { ton }\end{array}$ & $\begin{array}{l}288 \text { truck days } \\
29,000 \text { tons }\end{array}$ \\
\hline $\begin{array}{l}\text { Rolling Binder and } \\
\text { Wear Course }\end{array}$ & $\begin{array}{l}\text { Rolling crew consisting of: } \\
6 \text { Equipment Operators } \\
1 \text { Tandem Roller, } 10 \text { Ton } \\
2 \text { Roller, Pneumatic Wheel } \\
3 \text { Rollers, Steel Wheel }\end{array}$ & $\begin{array}{r}\$ 4440.35 \text { per } \\
\text { crew day }\end{array}$ & 66 crew days \\
\hline
\end{tabular}

Table II.A-2. Work Breakdown Matrix for Proposed Site Integration Technology

Total project cost is reduced by $14 \%$ to $\$ 3,610,626$, and man hours required to complete the job are reduced by almost $24 \%$ to 27,286 man-hours. Project duration is reduced from 67 days to 56 days. The cost and man hours expended for each function are shown below: 
Function

Milling

Back Haul

Paving - Binder Course

Haul - Binder Course

Paving - Wear Course

Haul - Wear Course

Rolling Binder and Wear

Asphalt
Cost

$\$ 408,915$

Done as part of binder haul

$\$ 259,264$

$\$ 421,344$

$\$ 194,448$

$\$ 210,672$

$\$ 293,103$

$\$ 1,832,880$
Man Hours

3,584 man-hr

5,888 man-hr

5,760 man-hr

4,422 man-hr

2,880 man-hr

4,752 man-hr

\section{Conclusions}

\section{a. Benefits to highway construction}

1) Cost - This technology holds the promise of providing large cost savings. The project analyzed in this study was somewhat simple compared to major highway construction projects accomplished every day. A highway widening project, for example, which involves grubbing and clearing, bridge widening, and an upgraded storm drain system would require much greater coordination and scheduling of resources and materials. The potential dollar savings for such a project could conceivably be as high as $20 \%$ to $25 \%$ compared to the $14 \%$ for the evaluated project. The general view of both survey respondents and work group participants is that savings as high as $50 \%$ are not realistic. The savings which should be achievable, however, are substantial and make this project worth pursuing. The cost of training and the additional equipment required to implement this technology were cited as potential detractors. There will be an unquantified cost savings to the traveling public resulting from the $16 \%$ reduction in project duration.

2) Safety - The general consensus was that this technology should contribute to worksite safety through more efficient scheduling and tracking of equipment and material. There should be fewer equipment delays and equipment could be scheduled in an optimum manner to minimize the inconvenience to the traveling public. Completing a project in a shorter time will reduce worker exposure. 
3) Time - The technology does offer time savings. For the project analyzed, duration was reduced by over $16 \%$ and man hours reduced by almost $24 \%$. Savings should be greater on more complex projects where increased worker productivity of $20 \%$ should be achievable.

4) Quality - There will be increased quality of the final project but the degree of increase is difficult to quantify. The major increase will result from the proper equipment and material being available when needed making it less likely that someone will "make do" with an effort less than specified.

\section{b. Ease of implementation}

1) Technical hurdles - No major technical hurdles are anticipated for this technology. If greater reliance is placed on sensors and tracking devices to implement this technology there may be a problem in radio frequency allocation to ensure sufficient channels are available for effective communication. Channel multiplexing may be a solution.

The Consortium for Advanced Positioning Systems, or CAPS, integrates the robust (but continually evolving) computer-aided design and computer-aided engineering environments with the recently developed capability for real-time site positioning measurement [6]. CAPS could be incorporated into site integration to provide an early demonstration of this technology.

2) Applicability - This technology has broad application to the highway construction industry. It is conceivable that various degrees of concept complexity could be implemented. In this manner, the small business which cannot afford the capital investment for a full-blown system-nor would the small business have need for all the capabilities-could purchase a system tailored to its need.

\section{c. Industry acceptance}

1) Priority/need - At present, industry does not perceive a need for site integration. One respondent cited the fact that, "Current methods available for project management (CPM, PERT) are seldom necessary for use on [State DOT] construction projects." It would be necessary to set up a demonstration project to demonstrate the savings a contractor could realize using site integration before the industry would perceive a need for this technology. Site integration was ranked fourth of six for priority/need in the survey.

2) Capital outlay - Insufficient information was provided in the concept description to assess capital outlay. The short-term implementation appears 
to involve only the purchase of the software (to be developed) and a computer(s) for on-site use. This should represent minimal capital outlay. The long-term implementation involves sensor and display systems to automatically communicate information to supervisor and worker alike. The cost for such a system could be substantial and deter many from using hierarchical control to manage a project.

3) Expected commercial value - The potential commercial value of this concept is great provided training and equipment costs can be kept within reach of the average contractor.

5. Summary - The comparative analysis of the current and proposed technology for this scenario is summarized below.

\section{Cost Project Duration Crew}

$\begin{array}{cccc}\text { Current } & \$ 4,210,303 & 67 \text { days } & \begin{array}{c}35,774 \\ \text { man-hours }\end{array} \\ \text { Proposed } & \$ 3,610,626 & 56 \text { days } & \begin{array}{c}27,286 \\ \text { man-hours }\end{array}\end{array}$


$\pm$ 


\section{B. Automated Bridge Deck Construction.}

\section{Background}

a. General Information - Bridge decking and bridge deck rehabilitation represent a considerable share of annual highway expenditures. The task is highly labor intensive, requiring workers to manually place and tie rebar, distribute the cement in the forms, and achieve the final finish. This work is subject to heavy lifting and other activities which can result in back injuries. Using robotics to construct bridge decks could increase productivity and reduce safety hazards.

b. Typical task (scenario) for this technology - A 40-foot-wide by 100-foot-long bridge is to be decked with an 8-inch reinforced concrete slab. Epoxy-coated rebar is utilized and the concrete is pumped in place. Number 5 rebar is used for the transverse bars and placed on 7 -inch centers. Number 4 rebar is used for the longitudinal bars and placed on average 10-inch centers with more being placed in the middle half of the slab span than over the beams.

\section{Current Technology}

a. Description - A visual inspection is conducted of the bridge substructure to insure it is properly installed and ready to receive the bridge deck. The first layer of primary reinforcement rebar is placed transverse to the longitudinal bridge girders one inch up from the form. Longitudinal rebar is placed on the transverse rebar and tied. The second layer of longitudinal rebar is placed and the transverse rebar tied on top so that the transverse rebar will be two inches from the finished concrete surface. It takes 10.7 man-hours to place one ton of epoxy-coated rebar. Forms are erected for a lane section which also serves as the track for the concrete paver. The area to be paved is wetted to prepare for the concrete. Concrete is pumped into the paver hopper which distributes and screeds the concrete into the form. Workers manually fill low spots in the concrete, vibrate it to remove voids and finish the concrete surface. The concrete is allowed to cure, using protective covering as appropriate, and the forms are removed. Final inspection is accomplished. Generally as much as $80 \%$ of bridge decks placed using this technique require milling of the surface to bring it into specification because of ineffective quality control during placing..

b. Task Analysis - Bridge decking is a sequential operation where the preceding operation must be finished before the next operation can be started. This is particularly true on small bridge projects such as the one used for this evaluation. On larger bridge projects, rebar can be assembled in one area of the bridge deck while the concrete is be placed in an area where rebar assembly has been completed. A small 
bridge project was selected to require both the current and proposed technology to proceed in a sequential manner. Also, bridges less than 100 feet long represent approximately $88 \%$ of all bridges built during the period 1950 to 1989 .

c. Work breakdown - Table II.B-1. depicts the various steps in the process of bridge decking and the resources required.

\begin{tabular}{|c|c|c|c|c|}
\hline $\begin{array}{c}\text { Performance } \\
\text { Element }\end{array}$ & Current Standard & Resources Required & $\begin{array}{l}\text { Unit Cost } \\
\text { of } \\
\text { Resource }\end{array}$ & $\begin{array}{c}\text { Units } \\
\text { Required }\end{array}$ \\
\hline Inspection & Visual & Inspector & $\$ 329 /$ day & 0.5 days \\
\hline Rebar Placement & Placed and tied manually & $\begin{array}{l}\text { Rebar Crew consisting of: } \\
1 \text { Foreman } \\
3 \text { Rodmen (Reinforc- } \\
\text { ing) } \\
\text { \#4 Rebar } \\
\text { \#5 Rebar }\end{array}$ & $\begin{array}{l}\text { \$544/ton } \\
\text { \$544/ton* }\end{array}$ & $\begin{array}{l}3.2 \text { tons } \\
7.2 \text { tons }\end{array}$ \\
\hline $\begin{array}{l}\text { Concrete place- } \\
\text { ment }\end{array}$ & $\begin{array}{l}\text { Concrete pumped and } \\
\text { placed } \\
\text { Vibration to remove voids } \\
\text { Screeding } \\
\text { Finishing }\end{array}$ & $\begin{array}{l}\text { Crew C-1 consisting of: } \\
3 \text { Carpenters } \\
1 \text { Laborer } \\
3 \text { Power Tools } \\
\text { Materials } \\
\text { Concrete } \\
\text { Crew C-20 consisting of: } \\
1 \text { Labor foreman } \\
5 \text { Laborers } \\
1 \text { Cement finisher } \\
1 \text { Eq. operator } \\
2 \text { Vibrators } \\
1 \text { Concrete pump }\end{array}$ & $\begin{array}{r}\$ 1,112.40 \\
/ \text { day } \\
\$ 27.05 / \text { day } \\
\$ 5.93 / \mathrm{sf} \\
\$ 48 / \mathrm{cy} \\
\$ 1,191.20 \\
/ \text { day }\end{array}$ & $\begin{array}{l}1 \text { day } \\
420 \mathrm{sf} \\
100 \mathrm{cy} \\
1 \text { day }\end{array}$ \\
\hline $\begin{array}{l}\text { QC of concrete } \\
\text { and slab }\end{array}$ & $\begin{array}{l}\text { Done manually by taking } \\
\text { samples of the concrete } \\
\text { and sending to testing lab- } \\
\text { oratory }\end{array}$ & \multicolumn{3}{|c|}{$\begin{array}{l}\text { This operation is done exactly the same using current and } \\
\text { the proposed technology. The cost is minimal compared } \\
\text { to other costs and is ignored in this evaluation. }\end{array}$} \\
\hline Concrete curing & Accomplished manually & & S0.30/sf & $4,000 \mathrm{sf}$ \\
\hline Final inspection & Visual & Inspector & \$329/day & 0.5 days \\
\hline
\end{tabular}

Table II.B-1. Work Breakdown Matrix for Current Bridge Decking Technology 
The initial inspection will take one-half day, and placing the rebar will require an additional three and one-half days. Forms will take one day and the placing of the concrete will take one day. The final inspection will take one-half day. Total project duration is six days, not counting curing time for the concrete.

The bridge decking operation will cost $\$ 22,687$ broken down as follows:

Labor

Materials

Curing

Equipment
$\$ 7,844$

$\$ 12,949$

$\$ 1200$

$\$ 695$

\section{Proposed Technology}

a. Description - The goal of this work would be to substantially reduce time and manpower required to deck or re-deck bridges, while improving quality and reducing the need for rework. The aim of this proposed national demonstration project would be to show that it is possible to incrementally add automated capabilities to today's technology in order to achieve this goal. Existing screeds used in bridge work already provide a basic, globally-referenced, physical platform. Figure II.B-1. is a concept drawing for a demonstration project for the automation of bridge decking. With existing screeds as the common integrating target, researchers at many institutions could work toward implementing automated functions such as:

- Subgrade inspection using photometric, range, and straingauge sensors.

- Computer-aided design, organization, and tracking of rebar.

- Laying down rebar, either individually or in sheets, including laying down the supports needed for the rebar.

- Automated tying rebar.

- Monitoring concrete supply flow with respect to the subgrade profile and the design specification by the use of optical, ranging, and strain-

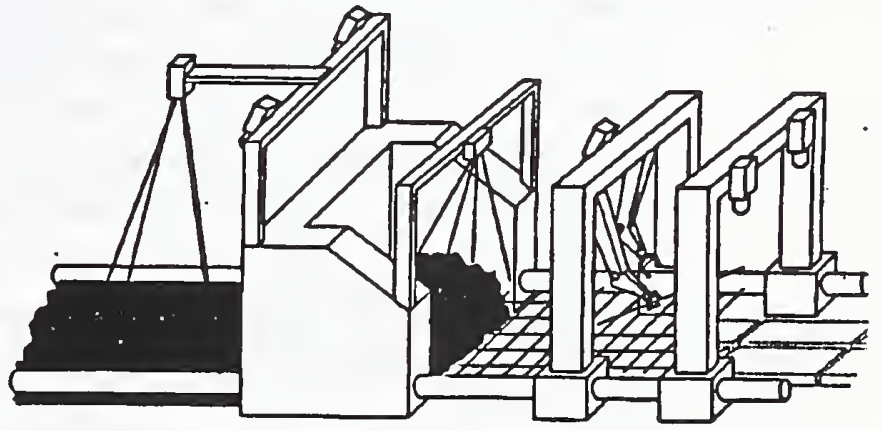

Figure II.B-1 Concept Drawing for a Demonstration Project for the Automation of Bridge Decking gauge sensors. 
- Inspection of the concrete slab immediately behind the screed to automatically correct pits or voids, and control overall deck profile to confirm to specifications.

- Other floating and tining operations automatically carried out and inspected.

b. Task Analysis - The proposed technology will be capable of conducting the sub-deck inspection, placing the transverse rebar and chairs and tie the rebar. It would also place, vibrate, and finish the concrete, possibly eliminating the need for a final inspection if it can achieve the desired level of quality control during the operation. Although the technology description indicates that the inspection is conducted simultaneously while placing the rebar, no mention is made of the affect problems with the sub-deck would have on the operation. The rebar, however, would have to be placed in two passes. On the first pass the bottom layer of transverse rebar and chairs are placed. The first and second layers of longitudinal rebar are manually placed using only a two-man crew. It may be possible for the transverse rebar to be placed as the robotics device completes placing rebar on another section of the bridge deck. Time savings from concurrent operation would be minimal because manual placement is the pacing function.

During the second pass of the robotics device the bottom layer of rebar is tied and the top layer of transverse rebar is placed and tied. It is questionable whether or not the concrete could be placed during this second pass as well or whether a third pass would be required. The concern revolves around possible conflict between delivery of concrete and feeding the rebar hopper. For the sake of analysis it is assumed that both operations could be conducted simultaneously.

Little information was provided in the proposal description to indicate either cost or productivity rates. It was therefore necessary to make some assumptions in order to develop productivity and cost comparisons with existing technology. It is assumed that the robotics device will be capable of $20 \%$ greater production than a trained, fourman crew, i.e., 3.6 tons of rebar placed and tied in a day. A two-man crew is still required to manually place the longitudinal rebar. It is assumed that their productivity is $35 \%$ higher placing the rebar than would be placing and tying rebar. Their productivity is therefore 7.0 man-hours per ton. The Robotics Bridge Decker is estimated to cost $\$ 500,000$. Bare cost is estimated based on a four-year depreciation period at a utilization rate of 2,000 hours per year. Total equipment cost is bare cost plus $10 \%$.

c. Work breakdown for recommended technology - The work breakdown is depicted in Table II.B-2. 


\begin{tabular}{|c|c|c|c|c|}
\hline $\begin{array}{c}\text { Performance } \\
\text { Element }\end{array}$ & Proposed Standard & Resources Required & $\begin{array}{l}\text { Unit Cost } \\
\text { of } \\
\text { Resource }\end{array}$ & $\begin{array}{c}\text { Units } \\
\text { Required }\end{array}$ \\
\hline Inspection & Mechanically & Robotics Bridge Decker & \multicolumn{2}{|c|}{$\begin{array}{l}\text { Included in Rebar Place- } \\
\text { ment }\end{array}$} \\
\hline Rebar placement & $\begin{array}{l}\text { Transverse rebar and } \\
\text { chairs placed mechanical- } \\
\text { ly in two passes and tied } \\
\text { Longitudinal rebar placed } \\
\text { manually }\end{array}$ & $\begin{array}{l}\text { Worker/Foreman* } \\
\text { Laborer } \\
\text { \#4 Rebar } \\
\text { \#5 Rebar }\end{array}$ & $\begin{array}{l}\text { \$400/day } \\
\$ 233 / \text { day } \\
\text { \$544/ton* } \\
\text { \$544/ton* }\end{array}$ & $\begin{array}{l}3.5 \text { day } \\
1.5 \text { day } \\
3.2 \text { tons } \\
7.2 \text { tons }\end{array}$ \\
\hline $\begin{array}{l}\text { Concrete place- } \\
\text { ment** }\end{array}$ & $\begin{array}{l}\text { Concrete pumped to Ro- } \\
\text { botics Bridge Decker, } \\
\text { placed, vibrated, screeded, } \\
\text { and finished }\end{array}$ & $\begin{array}{l}\text { Crew C-1 consisting of: } \\
\quad 3 \text { Carpenters } \\
\quad 1 \text { Laborer } \\
3 \text { Power Tools } \\
\text { Materials } \\
\text { Robotics Bridge Decker } \\
\text { Concrete } \\
\text { Concrete pump } \\
\text { Equipment operator }\end{array}$ & $\begin{array}{r}\$ 1,112.40 \\
/ \text { day } \\
\\
\$ 27.05 / \text { day } \\
\$ 5.93 / \text { sf } \\
\$ 550 / \text { day } \\
\$ 48 / \text { cy } \\
\$ 597 / \text { day } \\
\$ 294 / \text { day }\end{array}$ & $\begin{array}{l}1 \text { day } \\
420 \text { sf } \\
1 \text { day } \\
100 \text { cy } \\
1 \text { day } \\
1 \text { day }\end{array}$ \\
\hline $\begin{array}{l}\text { QC of concrete } \\
\text { and slab }\end{array}$ & $\begin{array}{l}\text { Done manually by taking } \\
\text { samples of the concrete } \\
\text { and sending to testing lab- } \\
\text { oratory }\end{array}$ & \multicolumn{3}{|c|}{$\begin{array}{l}\text { This operation is done exactly the same using current and } \\
\text { the proposed technology. The cost is minimal compared } \\
\text { to other costs and is ignored in this evaluation. }\end{array}$} \\
\hline Concrete curing & Accomplished manually & & S0.30/sf & 4,000 sf \\
\hline Final inspection & Accomplished manually & Inspector & $\$ 329 /$ day & 0.25 days \\
\hline
\end{tabular}

*Worker/Foreman also operates the Robotics Bridge Decker

**Conducted simultaneous with laying the second rebar tier

Table II.B-2. Work Breakdown Matrix for Proposed Bridge Decking Technology

The robotics device would complete the first pass inspecting and laying the transverse rebar in one day. The two-man crew would require an additional day and one-half to place the longitudinal rebar. The second tier of transverse rebar and concrete would be placed by the robotics device in one day. 
The bridge decking operation will take three and three-quarter days to complete using the proposed technology, and cost $\$ 19,111$, broken down as follows:
Labor
$\$ 3,238$
Materials
$\$ 12,949$
Curing
$\$ 1,200$
Equipment
$\$ 1,724$

\section{Conclusions}

\section{a. Benefits to highway construction}

1) Cost - This technology represents a cost savings of $16 \%$ over the present technology for the chosen scenario $(\$ 22,687$ for the present technology verses $\$ 19,111$ for the proposed). All cost savings come from increased productivity of the work force. The savings are partially offset by increased equipment cost (154\% increase). Uncertainties in the calculated savings include the cost of the robotics unit, rate of production, operating cost, and maintenance cost. An additional cost saving not included in the analysis is the probable elimination of post-construction milling of the bridge deck surface to achieve the required tolerance. Better quality control from robotics tying of the rebar and continuous QC placing the concrete is expected to produce a more durable product, reducing the life cycle cost. Survey respondents rated this technology next to last for potential cost savings of the six technologies evaluated.

2) Safety - Survey respondents rated bridge decking in a tie for fourth place for impact on safety. Based on the number of individuals involved in the operation (a maximum of seven at any given time) and the hazards associated with the functions performed, the analysis supports that rating. The most hazardous operation, carrying and placing the longitudinal rebar, is still accomplished by workers.

3) Time - The total project duration (not counting curing time) was reduced from six days to three and three-quarter days. The majority of time savings comes from being able to place the second tier of rebar and concrete at the same time. Rebar requires three and one-half days to place using either technology.

4) Quality - Quality is expected to be better in several areas. The rebar placement will be more accurate and quality of ties improved. There will be less possibility of damage to or misalignment of the rebar caused by people walking over the rebar either during the rebar placement phase or concrete 
pour. Once the second tier of longitudinal rebar is placed there would be no need for anyone to walk on the bridge deck until the concrete is cured. Because the concrete is poured immediately after the rebar is aligned and tied the possibility of inadvertent damage is reduced. Quality control of concrete placement would be greater with the ability of the robotics to sense and correct problems as they occur. The need for post construction milling should be eliminated, an expensive operation not estimated in this analysis.

\section{b. Ease of implementation}

1) Technical hurdles - This technology presents several technical hurdles. It is unlikely that the addition of an automatic inspection capability would provide a productivity advantage to offset the system cost. The present technology requires only one-half day of an inspector's time to complete this task. No other work is being done on the bridge deck while the inspection is being conducted. If problems are found which require correction no work need be stopped. The Robotics Bridge Decker on the other hand is laying rebar while conducting the inspection. It is likely that a problem in the sub-deck may be discovered which would require removal of rebar already placed before the problem could be rectified. This would only have to occur once or twice before a contractor would revert to manual inspection.

The sequence of placing rebar in a bridge deck indicates that at least two passes of the robot would be required to complete the task. It is conceivable that the technical problems presented by sorting first and second tier longitudinal rebar, aligning and tying first tier rebar and placing and tying second tier transverse rebar cannot be accomplished in one pass. There is also concern about effectively scheduling the arrival of concrete with the production rate of placing and tying the rebar. If a problem is encountered with the rebar that temporarily halts the operation, concrete trucks may be waiting with their drums filled with setting concrete.

Attempting to do all these operations simultaneously is analogous to the idea of having one office machine perform all the functions of scanning, printing, copying and faxing. It is technically feasible but no one would buy it. A fault in any portion of the machine would shut down all office operations.

The automated bridge decking technology, as described in the proposal, contains highly sensitive electronics equipment for sensing defects and positioning. The electronic equipment will be in close proximity to the hostile environment of rebar and concrete, and there is a question concerning this equipment's ability to survive in such an environment. 
2) Applicability - There is limited application for this technology. It would be more cost effective on longer span bridges than on the short span for which it was evaluated. Requirements to use small and/or minority contractors on smaller bridge projects would restrict use of this technology to only very large projects which comprise a small percent of bridge deck work. The technology could only be applied to bridge decks which use sub-deck panels. This method of bridge deck construction is restricted in some states. The time savings the technology affords could make it attractive to bridge deck rehabilitation where it is desirable to complete the project as quickly as possible to restore full traffic flow. Again, the limitation of bridge deck type applicability would have to be considered.

\section{c. Industry acceptance}

1) Priority/need - Survey respondents rated bridge decking last of the six technologies rated. One comment from a state department of transportation illustrates the general feeling of respondents. "This proposed machine could not adapt to 'unforeseen' changes, could only be used for certain bridge decks, and could not do soffit and girder stems of a structure. There are too many variables during construction to visualize this type of equipment as useful." Other technology developments on the horizon may make robotics rebar placing and tying obsolete before it can be developed. Work is under way to develop rebar from synthetics which are light weight and non-reactive with concrete. These are projected to be available in lightweight mats which could be placed by hand and contain both longitudinal and transverse reinforcement.

Some respondents expressed a need for higher, more consistent quality concrete and saw the robotics concrete placing, vibrating, screeding, and finishing as the answer. This alternative merits further consideration.

2) Capital outlay - No indication was given in the proposal on which to make an informed estimate of the initial cost of an automated bridge decking system. This device is complicated electronically and mechanically. It must be capable of sensing and identifying defects in the sub-deck, accurately positioning rebar, tying approximately 15 rebar joints every five to ten inches, dispensing concrete at a measured, uniform rate, sensing the height of concrete places, uniformly vibrating the placed concrete, and performing screeding and finishing operations. It was on this basis that an initial cost of $\$ 500,000$ was assumed. This may be low. The cost estimating also assumed maintenance of such a complex piece of equipment would be comparable to other construction - probably an over conservative assumption. The high capital 
outlay as well as the anticipated high operating cost of the proposed technology would place it out of reach for all but the largest construction companies.

3) Expected commercial value - There is definite commercial value to the concept if the technical hurdles can be overcome and the initial cost of the equipment can be kept reasonable. Productivity would be increased by $62 \%$ and total project completion time would be reduced by $38 \%$ (bridge deck portion only). The rapid acceptance of exodermic decks for bridge projects [Bettigole] may limit the applicability of automated bridge decking as envisioned in this concept.

\section{Summary}

\section{Cost Project Duration Man-days}

$\begin{array}{rccc}\text { Current } & \$ 22,687 & 6 \text { days } & 27 \\ \text { Proposed } & \$ 19,111 & 3.75 \text { days } & 10.25\end{array}$





\section{Automated Trenching and Pipelaying.}

\section{Background}

a. General information - The author cited several benefits for adopting the proposed new technology for trenching operations. The principal benefits addressed in this analysis include:

- Reduction of fatal accidents and lost workday injuries.

- Elimination of accidental damage of buried utilities

- Augmentation of operator efficiency

- Reduced survey requirements

- Use of "smart" excavator attachments

b. Typical task (scenario) for this technology - Because this technology is being proposed for highway construction and not utility installation, a storm drain system to handle runoff from the highway was selected. A five-mile section of 60 -inch diameter, 10 gauge, bituminous-coated, corrugated metal pipe is to be installed at an average depth of 15 feet in a sand and gravel soil. This requires an 8-foot-wide trench with a side slope of 0 to 1 . Total excavation required is 170,000 bank cubic yards. A rammer tamper will be used for compacting 8-inch lifts in two passes.

\section{Current Technology}

a. Description - A survey control for the project is established by a survey team and the trench right-of-way is surveyed and marked with stakes. A construction crew excavates the trench to the required depth using surveying methods and approximation to control depth and direction. Personnel enter the trench to finish the trench bottom profile to receive the pipe. The pipe is placed in the trench using a crane and connections are made either mechanically or by hand, depending on the diameter and type of pipe being laid. The pipe described in the scenario requires manual connection. The trench is backfilled in lifts and each lift is compacted to specification.

b. Task Analysis - An initial survey is conducted to establish the control for the storm drain right-of-way by a two-man survey. Control may be from a local benchmark or a takeoff from control established for the highway right-of-way. The storm drain line is surveyed and staked. It is assumed the right-of-way is cleared as part of the highway grubbing and clearing operation. Surveying can be completed in five days. Excavation commences and as sufficient trench is opened pipe laying follows as a concurrent operation. The trench must be shored using a trench box to prevent cave 
in and to protect the workers in the trench finishing the trench-bottom profile and making connections. A survey team is required periodically to reestablish grade stakes that have been knocked down and to check the depth and alignment of the pipeline. Because of the size of this job, four excavators and four pipe laying crews will be employed. Two front end loaders will be employed for the backfill. The project can be completed in 100 days with pipe laying lagging three days behind the start of excavation and backfill and compaction lagging three days behind pipe laying. The survey crew is required to be on site $25 \%$ of the time to verify alignment and depth of the trench.

c. Work breakdown - Table II.C-1 depicts the various steps in the process and the resources required.

Productivity of one 1.5 cy hydraulic in sand and gravel soil is $480 \mathrm{cy} /$ day. Total excavation for the project is $170,000 \mathrm{cy}$, requiring 354 equipment days to complete the project. Using four excavators reduces the total trenching time to 89 days. It is estimated that the survey crew will be required to verify alignment and replace survey stakes every other day. This will require one-half crew day for 44 days or $22 \mathrm{crew}$ days. One pipe laying crew can place 75 linear feet (lf) of pipe a day. 26,400 lf are required for a total duration of 352 days. Using four crews, the storm drain can be installed in 88 days. A 2.5 cy front end loader is capable of backfilling $600 \mathrm{cy} /$ day with minimal haul distance. One rammer tamper can compact $780 \mathrm{cy} /$ day so there will be a slight mismatch between the backfilling and compaction operations. Nightyeight thousand cubic yards of compacted backfill has to be placed in the trench. Assuming a compaction factor of $15 \%, 113,000$ cy of loose fill has to be moved by the front end loader, which will take 188 equipment days. Two loaders can complete the backfill operation in 94 days.

The total cost of the project is approximately $\$ 3.5$ million broken down as follows:

$\begin{array}{lr}\text { Survey crew + supplies } & \$ 15,430 \\ \text { Excavation Equipment } & \$ 282,200 \\ \text { Excavation Manpower } & \$ 195,500 \\ \text { Pipe Laying Equipment } & \$ 235,400 \\ \text { Pipe Laying Manpower } & \$ 612,480 \\ \text { Pipe } & \$ 1,883,640 \\ \text { Backfill Equipment } & \$ 104,000 \\ \text { Backfill Manpower } & \$ 76,800\end{array}$


Compaction Equipment

Compaction Manpotwer

TOTAL
$\$ 12,430$

$\$ 44.070$

$\$ 3,423,230$

\begin{tabular}{|c|c|c|c|c|}
\hline $\begin{array}{l}\text { Performance } \\
\text { Element }\end{array}$ & Current Standard & Resources Required & $\begin{array}{c}\text { Unit Cost } \\
\text { of } \\
\text { Resource }\end{array}$ & $\begin{array}{r}\text { Units } \\
\text { Required }\end{array}$ \\
\hline Initial Survey & $\begin{array}{l}\text { Survey in control from } \\
\text { existing control point }\end{array}$ & $\begin{array}{c}\text { Crew A-6 including } \\
\text { Chief of party } \\
\text { Instrument man }\end{array}$ & \$530/day & 1 day \\
\hline Excavation Survey & $\begin{array}{l}\text { Survey crew surveys and } \\
\text { stakes right-of-way }\end{array}$ & $\begin{array}{l}\text { Crew A-6 including } \\
\text { Chief of party } \\
\text { Instrument man } \\
\text { Survey stakes }\end{array}$ & $\begin{array}{l}\$ 530 / \text { day } \\
\$ 29.50 / \text { ctn }\end{array}$ & $\begin{array}{l}5 \text { days } \\
20 \mathrm{ctn}\end{array}$ \\
\hline Trenching & $\begin{array}{l}\text { Excavator operator using } \\
\text { survey stakes as guide } \\
\text { will dig rough trench. }\end{array}$ & $\begin{array}{c}\text { Crew B-12B including } \\
\text { Excavator Op. } \\
\text { Excavator Oiler } \\
1.5 \text { cy Excavator } \\
\text { Total excavation } \\
\text { Crew A-6 including } \\
\text { Chief of party } \\
\text { Instrument man }\end{array}$ & $\$ 2.81 / c y$ & $\begin{array}{r}170 \mathrm{k}-\mathrm{cy} \\
22 \text { days }\end{array}$ \\
\hline Pipe Laying & $\begin{array}{l}\text { Trench bottom finished by } \\
\text { hand. Pipe sections } \\
\text { placed by crane. Sections } \\
\text { joined by crew in trench. } \\
\text { Trench box used for safe- } \\
\text { ty. }\end{array}$ & $\begin{array}{l}\text { Crew B-13 including } \\
\text { Labor foreman } \\
4 \text { Laborers } \\
\text { Crane Operator } \\
\text { Crane Oiler } \\
25-T \text { Crane } \\
60^{*} \text { diam. pipe } \\
\text { Trench box }\end{array}$ & $\begin{array}{r}\$ 102 / \mathrm{f} \\
\text { (includes } \\
\text { cost of pipe) }\end{array}$ & $\begin{array}{r}4 \text { crews } \\
26,400 \text { lf }\end{array}$ \\
\hline Backfill & $\begin{array}{l}\text { Front end loader replaces } \\
\text { excavated material in } \\
\text { trench. } \\
\text { Equipment operator com- } \\
\text { pacts lifts. }\end{array}$ & $\begin{array}{l}\text { Crew B-10T including } \\
2.5 \text { cy loader } \\
\text { Loader Operator } \\
5 . \text { Laborer } \\
\text { Crew A-1 including } \\
\text { Laborer } \\
\text { Compactor }\end{array}$ & $\$ 1.60 / \mathrm{cy}$ & $\begin{array}{r}113 \mathrm{k}-\mathrm{cy} \\
\text { using } 2 \\
\text { crews }\end{array}$ \\
\hline
\end{tabular}

Table II.C-1. Work Breakdown Matrix for Current Trenching and Pipelaying 


\section{Proposed Technology}

a. Description - This proposal would attempt to automate most phases of the trenching and pipelaying process through the use of sensors, automation controllers, and smart end-effectors for equipment. The advantages which would result from accomplishing these objectives include the automation of all in-trench operations to remove humans from the trench which would greatly

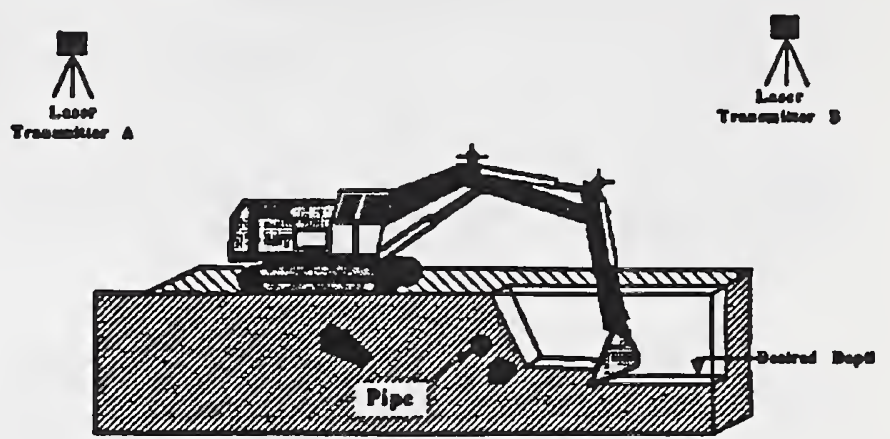

Figure II.C-1 Conceptual Drawing of Robotics Excavation increase safety, and permit the cutting of minimum-width trenches to reduce time and decrease interference with adjoining structures, utilities, or landscape; the reduction of damage to buried utilities; increased efficiency of machines and operators; reduction of survey and site-layout time, and automatic creation of as built databases for future utility maps. The

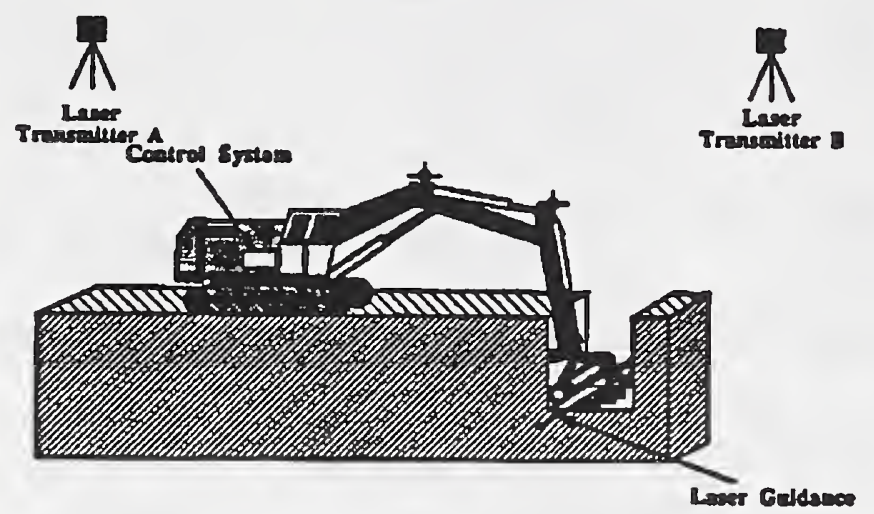

Figure II.C-2 Conceptual Drawing of Robotics Pipe Placement proposed research would bring together in one specific application area many of the automation concepts from manufacturing which can be applied to construction work in the field. In addition, it proposes specific retro-fittable devices which can be used to increase the versatility of traditional equipment such as backhoe excavators. The inherent safety problems of trenching operations suggest this as a highprofile area for potential demonstrations of automated technology. Figure II.C-1 depicts the automated trenching concept and the automated pipelaying technology is shown in Figure II.C-2.

b. Task Analysis - This technology does not inherently change the method or sequence by which the project is completed. A survey team would still be required to bring in control to establish the start point for each of the four sections of the storm drain. This is estimated to take an additional day of survey effort. The trench line right-of- 
way would not have to be surveyed or staked, nor would the survey crew be required verify trench depth and alignment. There would be no need to replace survey stakes. Twenty-seven survey crew days would be saved. The technology does not increase productivity. It does enhance the quality of the finished trench and provide for more accurate positioning of the pipe sections. It is estimated that two laborers could be eliminated from the pipe laying crew while still achieving the same level of daily productivity. All other functions would be identical to the present technology. Four sets of laser transmitters would be required; one for each excavation and pipe laying location. It is assumed the transmitters would be capable of controlling the excavation and pipe laying operations simultaneously.

c. Work breakdown - Table II.C-2 depicts the various steps necessary to lay the storm drain and the required resources.

Additional time would be required at the beginning and end of each day to secure the laser transmitters. No indication is given of setup time and it is not clear what the range might be. They would have to control a 6,600-foot-long construction site, or they would have to be relocated periodically. This may require additional survey effort. The up-front survey time would be reduced from six days to two, reducing the total project time from 106 days to 102 days.

Workers will still be required to enter the trench to make connections between pipe sections. Total worker exposure has been reduced from 5 to 3 at each site, or a $20 \%$ reduction in exposure to potential cave in. Trench boxes would still be required to protect the workers in the trench.

The pipeline would cost approximately $\$ 3.3$ million using this technology broken down as follows:

Survey Crew + Supplies

Excavation Equipment

Excavation Manpower

Pipe Laying Equipment

Pipe Laying Manpower

Pipe

Backfill Equipment

Backfill Manpower
$\$ 1,090$

$\$ 282,200$

$\$ 195,500$

$\$ 235,400$

$\$ 454,080$

$\$ 1,883,640$

$\$ 104,000$

$\$ 76,800$ 
Compaction Equipment

Compaction Manpower

TOTAL
$\$ 12,430$

$\$ 44.070$

$\$ 3,289,210$

\begin{tabular}{|c|c|c|c|c|}
\hline $\begin{array}{c}\text { Performance } \\
\text { Element }\end{array}$ & Proposed Standard & Resources Required & $\begin{array}{l}\text { Unit Cost } \\
\text { of } \\
\text { Resource }\end{array}$ & $\begin{array}{r}\text { Units } \\
\text { Required }\end{array}$ \\
\hline Initial Survey & $\begin{array}{l}\text { Survey in control from } \\
\text { existing control point to } \\
\text { include start point for } \\
\text { each of four excavation } \\
\text { operations }\end{array}$ & $\begin{array}{l}\text { Crew A-6 including } \\
\text { Chief of Party } \\
\text { Instrument man } \\
\text { Stakes }\end{array}$ & $\$ 530 /$ day & 1 day \\
\hline Excavation Survey & \multicolumn{4}{|c|}{$\begin{array}{l}\text { The centerline survey is done concurrently with the trenching operation using the } \\
\text { robotics guidance system following the CAD/CAM drawings of storm drain layout. }\end{array}$} \\
\hline Trenching & $\begin{array}{l}\text { Excavator operator, guid- } \\
\text { ed by the robotics system } \\
\text { digs the rough trench. } \\
\text { Quality of trench profile } \\
\text { much improved over cur- } \\
\text { rent technology. }\end{array}$ & $\begin{array}{l}\text { Crew B-12B including } \\
\quad \text { Excavator Op. } \\
\quad \text { Excavator Oiler } \\
1.5 \text { cy Excavator } \\
\text { Robotics sensors system } \\
\text { Total excavation }\end{array}$ & $\$ 2.81 / \mathrm{cy}$ & $\begin{array}{r}4 \text { each } \\
170 \mathrm{k}-\mathrm{cy}\end{array}$ \\
\hline Pipe Laying & $\begin{array}{l}\text { Pipe sections placed by } \\
\text { crane. Sections joined by } \\
\text { crew in trench. }\end{array}$ & $\begin{array}{l}\text { Crew B-13' including } \\
\text { Labor foreman } \\
2 \text { Laborers } \\
\text { Crane Operator } \\
\text { Crane Oiler } \\
25-T \text { Crane } \\
60^{n} \text { diam pipe } \\
\text { Trench box }\end{array}$ & $\begin{array}{r}\$ 96 / \mathrm{f} \\
\text { (includes } \\
\text { cost of pipe) }\end{array}$ & $\begin{array}{l}4 \text { each for } \\
88 \text { days }\end{array}$ \\
\hline Backfill & $\begin{array}{l}\text { Front end loader replaces } \\
\text { excavated material in } \\
\text { trench. }\end{array}$ & $\begin{array}{l}\text { Crew B-10T including } \\
\text { Loader Operator } \\
.5 \text { Laborer } \\
2.5 \text { cy Loader } \\
\text { Crew A-1 including } \\
\text { Laborer } \\
\text { Compactor }\end{array}$ & \$0.55/cy & $\begin{array}{r}2 \text { crews } \\
113 \mathrm{k}-\mathrm{cy} \\
\text { using } 2 \\
\text { crews } \\
113 \mathrm{k}-\mathrm{cy} \\
\text { using } 2 \\
\text { crews }\end{array}$ \\
\hline
\end{tabular}

Table II.C-2. Work Breakdown Matrix for Proposed Automatic Trenching and Pipelaying 
No estimate was made of the cost of the laser transmitters, sensors or operator augmentation technology. This equipment has the potential of being extremely expensive. By way of comparison, laser leveling systems rent for $\$ 102$ per day. Virtual reality technology costs tens of thousands of dollars for much less sophisticated systems than that envisioned by this proposal. The technology would have to cost less than $\mathbf{\$ 4 7 5}$ per day per site (excavator and crane) before overall savings could be realized on this project.

4. Conclusions - The workgroup made a rather strong statement regarding this technology as follows:

"On further examination of this proposal, Work Group \#1 sees no major impact to cost and safety. No equipment is being eliminated and expensive controls are added. While it is true that personnel are not needed during the actual excavation, they are still needed to install the pipe. This proposal does not address automated pipelaying systems. It must be pointed out that OSHA trench support systems will still be needed. Trenches will continue to cave-in as before.

"At the most, a 10\% improvement might be experienced in fatal trench cave-in accidents. This translates into about 7 lives saved per year.

"It is recommended that microtunneling be investigated for highway applications. It permits pipe to be installed without trenches resulting in no lives being lost in trenches."

\section{a. Benefits to highway construction}

1) Cost - It is questionable whether any direct cost savings will be realized from this concept. Ignoring the cost of the proposed technology, the total savings for this project is $\$ 172,740$ or less than $5 \%$ of the project cost. The technology would have to be on the project for 91 days at four work sites. Total allowable daily cost for the technology could not exceed \$475. Indirect cost savings may result from lower insurance premiums due to lower worker exposure in the trench. This has not been quantified.

2) Safety - Safety will be increased through reduced exposure of workers in the trench (estimated at 20\%). No attempt was made to estimate the potential safety hazard presented by digging in the vicinity of existing buried utilities or any savings which may result from avoiding accidental damage to them.

3) Time - Project duration is reduced by 4 days (less than $4 \%$ ) due to reduced survey requirements. The technology does not permit the time to complete any other functions to be reduced. 
4) Quality - The improved quality of the trench profile is reflected in the reduction of the pipe laying crew from 5 to 3. Increased pipe laying crew efficiency accounts for $92 \%$ of the cost savings. No other quality enhancement was claimed in this proposal nor are any envisioned.

b. Ease of implementation

1) Technical hurdles - No major technical hurdles are anticipated to implement this proposal for robotics guidance of excavation operations or to provide for more accurate placement of the pipe sections in the trench. The Consortium for Advanced Positioning Systems, or CAPS, integrates the robust (but continually evolving) computer-aided design and computer-aided engineering environments with the recently developed capability for real-time site positioning measurement [6]. CAPS could be incorporated into automatic trenching and pipelaying to provide an early demonstration of this technology.

Sensors to detect and discriminate buried utilities require further development to achieve a degree of reliability to realize their investment cost. For this reason, the claim of eliminating accidental damage of buried utilities is questioned.

2) Applicability - Lack of "as-builts" for existing utilities in CAD/CAM format may limit the applicability of this technology. The ability of this technology to produce accurate "as-builts" for the pipeline is an attractive feature for any utilities manager. The technology does partially address the safety problem associated with open-trench work but does not totally eliminate the need for workers to enter the trench to make pipe section connections.

\section{c. Industry acceptance}

1) Priority/need - Survey respondents ranked the impact of improved safety in trenching and pipe laying operations first of the six technologies. This is supported by the statistics quoted in the proposal. The proposal gave the impression that worker exposure in the trench would be totally eliminated. Until sensor and control technology, as well as pipe coupling, can be developed to the degree that personnel are not required to make connections between pipe sections, workers will be required in the trench. This may adversely affect the perceived need for this technology.

2) Capital outlay - The buy-in cost of the technology may be prohibitive considering the minimal improvement in efficiency. The proposal did not indicate the cost of sensors and lasers. The rental rate for current technology laser levels for the duration of this project would be $\$ 29,280$. Depending on 
the sophistication of the equipment-mounted sensors and the operator feedback system, any savings realized from increased productivity could be offset by new equipment costs. These costs require greater definition before this technology can be investigated further.

3) Expected commercial value - The expected commercial value of this technology is low. The savings to be realized from increased productivity are estimated to be small, less than $5 \%$ for the entire project. The survey indicated strong support for this technology for improved safety. The level of improved safety implied in the proposal may not be realized as indicated by the analysis. One respondent observed that most deaths resulting from trenching operations may be related to "small contractors where existing safety practices are not utilized." There will be reduced worker exposure to the hazard of in-trench operations which may be attractive to some.

5. Summary

\section{Cost Project Duration Crew}

$\begin{array}{cccc}\text { Current } & \$ 3,461,950 & 106 \text { days } & \begin{array}{c}3,702 \\ \text { man-days }\end{array} \\ \text { Proposed } & \$ 3,289,210 & 102 \text { days } & \begin{array}{c}2946 \\ \text { man-days }\end{array}\end{array}$





\section{Bridge Inspection and Maintenance}

\section{Background}

a. General information - The proposed technology is designed to overcome many of the drawbacks of the current method of inspecting, paint stripping, and repainting of steel bridges. The technology is proposed to provide the following key benefits:

- Increase speed and efficiency of inspection operations.

- Increase efficiency and reduce time to strip paint.

- Reduce and eventually eliminate time spent by workers on bridges.

- Reduce time required to place shrouding for painting.

- Improve quality of painting and decrease time required.

- Reduce hazardous waste through more efficient paint application.

- Reduce exposure of workers to harmful materials.

- Reduce environmental impact of paint stripping.

- Automate generation of maintenance and inspection databases.

- Reduce manpower requirements.

b. Typical task (scenario) for this technology - A four lane interstate overpass bridge crossing over a two lane highway with shoulder is to be inspected, cleaned, and repainted. The total steel area to be cleaned and painted is 4,600 sf. Current OSHA and EPA regulations concerning worker safety and clean air will be observed.

\section{Current Technology}

a. Description - A preliminary inspection is conducted to determine the scope of work required for scheduling of maintenance at a later date. The work crew arrives on-site and establishes lane control to permit access to the underside of the bridge. Scaffolding is erected, the area to be cleaned is draped, and workers begin the paint stripping operation using sand blasting. The blast material and old paint is collected for later disposal in an environmentally-acceptable manner. Painting follows the cleaning operation. Once the first section is completed the scaffolding and draping is removed and installed on the next section to be cleaned and painted. This operation is repeated until the entire bridge has been cleaned and repainted. Workers are required to wear protective clothing and breathing protection during the stripping and painting operations.

b. Task Analysis - The stripping and painting operation will be done on one-third of the bridge at a time. The road shoulders will be used to provide maximum traffic flow. The preliminary inspection is conducted by two trained technicians using a bucket 
truck for access to the underside of the bridge. They establish temporary traffic control to divert traffic around the bucket truck while they are inspecting. The inspection will take one day to complete.

The paint stripping crew arrives on-site and establishes traffic control. The stripping and painting can be accomplished in one of two ways. Scaffolding is erected from the ground up and canvas material hung on the scaffolding to enclose the work area. The second method is to hang scaffolding from the overpass and cover it with canvas. Either method cost approximately the same to emplace and move and restricts traffic movement under the draped portion of the bridge. Once the draped area is establisned, a sand blasting unit is used to clean rusted areas and remove chipped and flaking paint. In the case of bridges coated with lead-based paint, the minimum amount of paint is removed to provide a sound surface to receive the new paint. This is done for two reasons. First, lead-based paint provides superior protection to paints which meet current health and safety standards. Second, the paint debris is a hazardous waste and expensive to dispose. The amount of removal is therefore kept to a minimum. The same holds true for nonlead-based paint though the motivation for minimal removal is not as great.

Once the current section of bridge structure is cleaned and prepared a primer coat is applied and allowed to dry. This is followed by a topcoat. The draping and scaffolding is removed and erected on the next section of bridge to be cleaned and painted.

Because of the sequential nature of the operation there is considerable wasted time. The primer coat and topcoat take one-half day to apply. No additional work is done on that day to allow the paint to dry thoroughly. Total duration of dead time for this project is 2.5 days.

c. Work breakdown - Table II.D-1 depicts the various steps in the process and the resources required to accomplish them.

The preliminary inspection is completed in one day using a crew of two. Total cost is \$714. Manpower expended is 16 man-hours.

The scaffolding and drape must be erected and dismantled three times. Total erection and drape time for the three erections using a crew of three is 3 days or 72 manhours. Dismantling for the three cycles consumes 36 man-hours. The cost for both these operations combined is $\$ 5,432$. Manpower expended is 108 man-hours. 


\begin{tabular}{|c|c|c|c|c|c|}
\hline $\begin{array}{l}\text { Performance } \\
\text { Element }\end{array}$ & Current Standard & \multicolumn{2}{|c|}{ Resources Required } & $\begin{array}{l}\text { Unit Cost } \\
\text { of Re- } \\
\text { source }\end{array}$ & $\begin{array}{c}\text { Units } \\
\text { Required }\end{array}$ \\
\hline $\begin{array}{l}\text { Preliminary Inspec- } \\
\text { tion }\end{array}$ & $\begin{array}{l}\text { Visual inspection to deter- } \\
\text { mine the scope of work } \\
\text { for maintenance at a later } \\
\text { date. }\end{array}$ & $\begin{array}{l}2 \text { Inspection } \\
\text { Bucket Truck }\end{array}$ & $\begin{array}{l}\text { Techni- } \\
\text { cians }\end{array}$ & $\begin{array}{r}\$ 265 / \text { man- } \\
\text { day } \\
\$ 184 / \text { day }\end{array}$ & $\begin{array}{l}2 \text { man-days } \\
1 \text { day }\end{array}$ \\
\hline $\begin{array}{l}\text { Erect Scaffolding } \\
\text { and drape }\end{array}$ & $\begin{array}{l}\text { Tubular scaffolding is } \\
\text { erected by hand and } \\
\text { draped with canvas. } \\
\text { (Three cycles, } 8 \text { hrs per } \\
\text { cycle) }\end{array}$ & \multicolumn{2}{|c|}{$\begin{array}{l}\text { Crew consisting of: } \\
2 \text { Painters } \\
1 \text { Laborer }\end{array}$} & $\begin{array}{r}\$ 1,207.20 \\
/ \text { day }\end{array}$ & 1 day \\
\hline $\begin{array}{l}\text { Paint stripping and } \\
\text { cleaning }\end{array}$ & $\begin{array}{l}\text { Paint and rust is cleaned } \\
\text { using sand blasting in an } \\
\text { enclosed environment }\end{array}$ & \multicolumn{2}{|c|}{$\begin{array}{l}\text { Crew E-11 consisting of: } \\
2 \text { Painters } \\
1 \text { Laborer } \\
1 \text { Eq. Operator } \\
1-250 \text { CFM Air Com- } \\
\text { pressor } \\
\text { Sand Blaster } \\
\text { Sand Blasting acces- } \\
\text { sories } \\
\text { Materials }\end{array}$} & $\begin{array}{r}\$ 1350.75 \\
/ \text { day }\end{array}$ & 4.5 days \\
\hline Painting & Apply undercoat. & \multicolumn{2}{|c|}{$\begin{array}{l}\text { Crew E-15 consisting of: } \\
2 \text { Painters } \\
\text { 1-17 CFM Paint } \\
\text { Sprayer }\end{array}$} & $\begin{array}{r}\text { S0.09/SF } \\
\text { S714.95 } \\
/ \text { day } \\
\text { S0.36/SF }\end{array}$ & $\begin{array}{l}4,600 \mathrm{SF} \\
3 \text { days } \\
4,600 \mathrm{SF}\end{array}$ \\
\hline $\begin{array}{l}\text { Remove scaffold- } \\
\text { ing }\end{array}$ & $\begin{array}{l}\text { Scaffolding is taken down } \\
\text { by hand to either be re- } \\
\text { erected at another section } \\
\text { of the bridge or put into } \\
\text { storage. (Three cycles, } 4 \\
\text { hours per cycle.) }\end{array}$ & $\begin{array}{r}\text { Crew consisti } \\
2 \text { Painters } \\
1 \text { Laborer }\end{array}$ & & $\begin{array}{r}\$ 1,207.20 \\
/ \text { day }\end{array}$ & 0.5 days \\
\hline
\end{tabular}

Table II.D-1. Work Breakdown Matrix for Current Bridge Inspection and Maintenance

Paint stripping and cleaning costs $\$ 6,078$ for manpower and equipment and $\$ 2,116$ for materials. It requires 144 man-hours to strip and clean the entire bridge. The primer coat costs $\$ 1,072$ for manpower and equipment and an additional $\$ 414$ for materials. The topcoat costs $\$ 1,144$ for manpower and equipment with materials costing $\$ 1,656$. 
Manpower expended is: 144 man-hours for stripping, 24 man-hours for the undercoat, and an additional 25.6 man-hours for the topcoat. It should be noted that this project involves considerable dead time to allow paint to dry overnight between coats or before scaffolding can be dismantled. If the painting crew and equipment time is charged against the project during the dead time, the cost for undercoating would be $\$ 2,559$, topcoating would be $\$ 3,801$, and 48 man-hours would be charged for each.

The total cost for the project is $\$ 18,626$ ( $\$ 20,700$ if dead time is charged) broken down as follows:

$\begin{array}{lc}\text { Inspection } & \$ 714 \\ \text { Scaffolding } & \$ 5,432 \\ \text { Stripping } & \$ 8,194 \\ \text { Undercoat } & \$ 1,486 \\ \text { Topcoat } & \$ 2,800\end{array}$

\section{Proposed Technology}

a. Description - This technology proposes to develop improved alternatives to

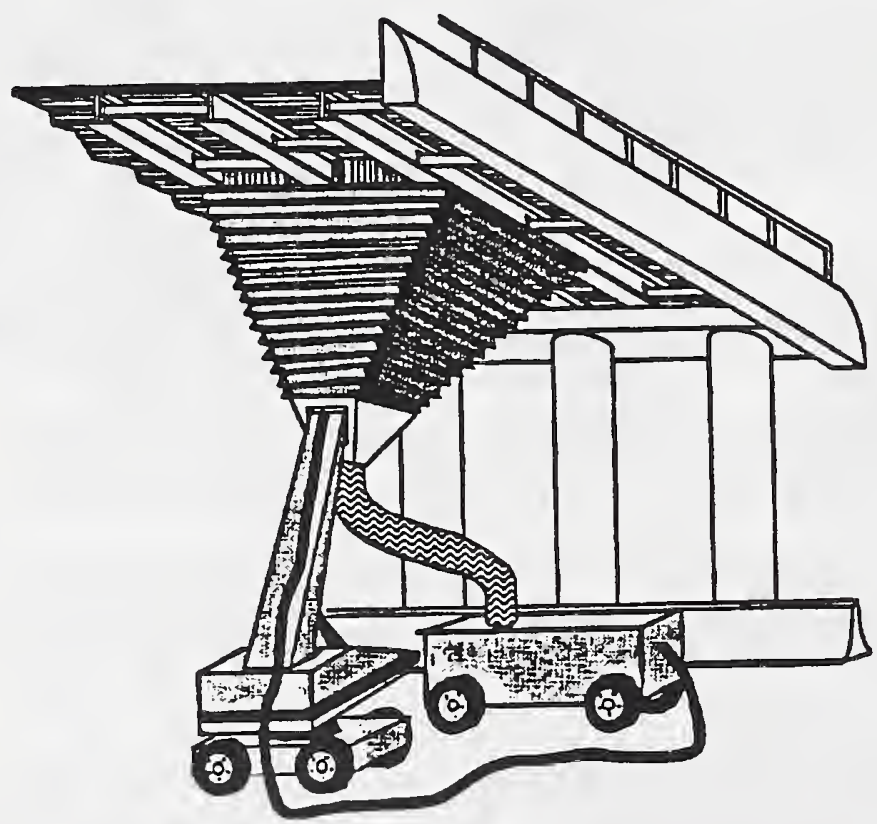

Figure IIDD-1 Possible Stationary Shroud Configuration
"Snoopers" for positioning and manipulating automated bridge inspection and maintenance operations. Elimination of workers from paint-stripping environments and improved containment of lead-based paint and shot are examples of potential advantages of automation. In the short term, advanced control techniques can provide coordinated motion for devices adapted from existing machines. In the longer term, wholly-new forms of robotics devices could be designed for delivery of many inspection and maintenance services. Such machines would be programmed from databases de- 
scribing each bridge. The bridge databases would be developed originally from "asbuilt" databases, which in turn would be produced during construction by noting deviations from "as-designed" databases generated during design. Each time a bridge is repaired or otherwise modified, a new "as is" database would be generated. These "as-is" databases would constitute the input from planning and scheduling bridge repair, and for programming the robots to perform various functions such as inspection, paint stripping, and repainting. Figure II.D-1 depicts a stationary shroud concept configuration while Figure II.D-2 depicts a possible dynamic shroud configuration.

Advanced robotics devices might be able to crawl along over and under bridges, automatically performing routine

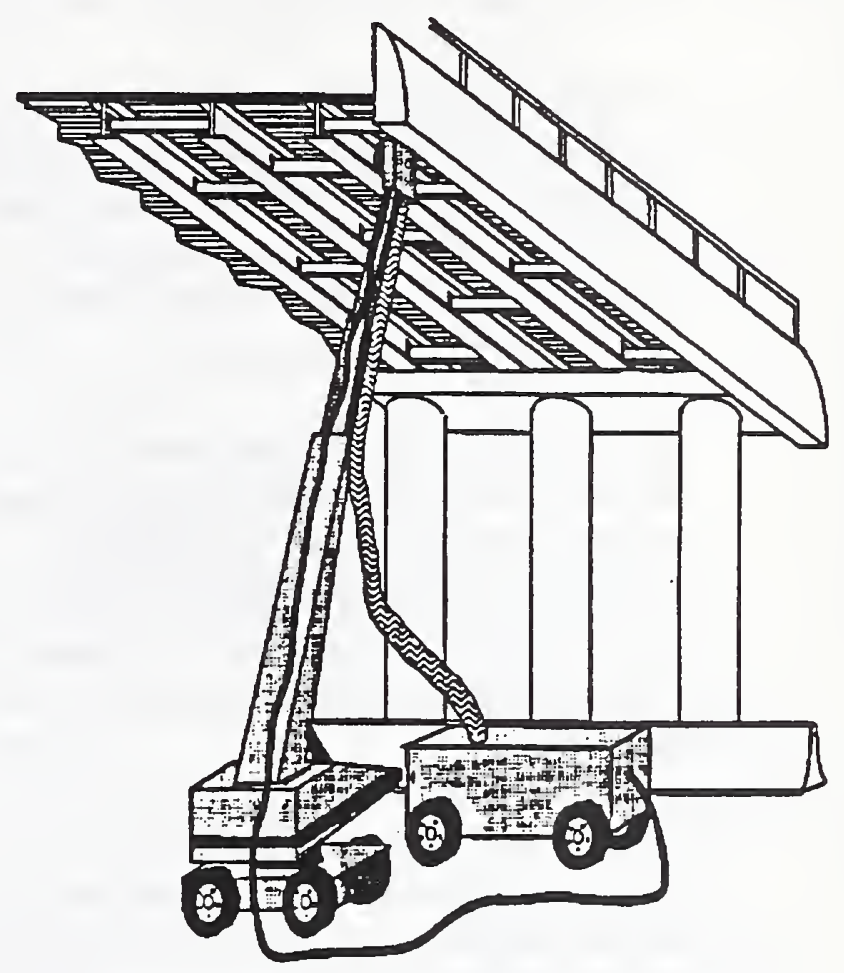

Figure II.D-2 Possible Dynamic Shroud Configuration inspection, paint stripping, and repainting chores. Large bridges might have specially designed robots. Robots might be especially designed for classes of smaller bridges. Such robots might crawl along a bridge and its associated support structures and monitor a number of parameters that are a measure of the health of the bridge, such as macro-scale deformations, acoustic emissions, ultrasonic echo examination, paint condition, and chemical detection of corrosion.

b. Task Analysis - This proposal will automate inspecting, shrouding, stripping, and painting operations. Based on the technology description, it does not appear that the technology offers a reduction in the time it takes to either strip or paint the bridge structure. Time savings do appear to be in order for both inspection and shrouding operations. Based on the description of the technology, it is difficult to determine how quickly inspection of a typical bridge could be conducted. For the purposed of this analysis it is assumed inspections using the Robotics Highway Overpass Stripping (RHOS) System could be done in $75 \%$ of the time. Shrouding, especially for the dynamic shroud configuration, is done "instantaneously." Lane closures are still 
necessary for inspection, shrouding, stripping, and painting. This technology offers no savings in this area. Lane closure, however, is a very incidental part of the entire operation and is ignored in this analysis.

A two-man crew will still be required for the inspection. One of the crew members can be a laborer/driver rather than a technician. The technology should allow the inspection to be completed quicker than by manual methods because the condition of the bridge would be sensed electronically and stored in a database. For the purposes of analysis it is assumed the RHOS could inspect a bridge in $80 \%$ of the time it currently takes.

The procedure for stripping and painting is identical to the current technology except for the need to erect scaffolding to drape the bridge. This will allow the crew to strip the entire bridge before beginning the primer coat. The entire bridge could be primed and the topcoat then applied. The lane closure would be moved each time to protect the workers and equipment. The work crew would be reduced to one painter and one laborer. One equipment operator to run the Air Compressor would be required for the stripping.

c. Work breakdown - Table II.D-2 depicts the various steps in the process and the resources required. This table assumes the inspection technician and the painter receive $10 \%$ more compensation because of the additional skill required to operate the RHOS. The RHOS is conservatively assumed to be twice the cost of a Bucket Truck to account for the robotics incorporated into the design.

The preliminary inspection is completed in 6.4 hours using a crew of two. Total cost is $\$ 713$ and 12.8 manhours are expended.

No scaffolding is required, and stripping can continue uninterrupted across the entire length of the bridge. It takes 4.5 days to complete the paint stripping, and the work crew can proceed directly to applying the undercoat. Total manpower required for paint stripping is 108 man-hours at a cost of $\$ 8,418$, including equipment and materials. The undercoat requires 1.5 days to apply and is left to dry overnight. Cost of the undercoating operation is $\$ 1,880$ and requires 24 man-hours. The topcoat is applied in 1.6 days at a cost of $\$ 3,220$, taking 25.6 manhours. 


\begin{tabular}{|c|c|c|c|c|}
\hline $\begin{array}{l}\text { Performance } \\
\text { Element }\end{array}$ & Proposed Standard & Resources Required & $\begin{array}{l}\text { Unit Cost } \\
\text { of } \\
\text { Resource }\end{array}$ & $\begin{array}{l}\text { Units } \\
\text { Required }\end{array}$ \\
\hline $\begin{array}{l}\text { Preliminary Inspec- } \\
\text { tion }\end{array}$ & $\begin{array}{l}\text { Robotics inspection using } \\
\text { the RHOS to determine } \\
\text { the scope of work for } \\
\text { maintenance at a later } \\
\text { date. }\end{array}$ & $\begin{array}{l}1 \text { Inspection Technician } \\
1 \text { Laborer/Driver } \\
\text { RHOS unit }\end{array}$ & $\begin{array}{l}\text { \$290/day } \\
\$ 233 / \text { day } \\
\$ 368 / \text { day }\end{array}$ & $\begin{array}{l}0.8 \text { days } \\
0.8 \text { days } \\
0.8 \text { days }\end{array}$ \\
\hline $\begin{array}{l}\text { Paint Stripping and } \\
\text { Cleaning }\end{array}$ & $\begin{array}{l}\text { The RHOS is used to es- } \\
\text { tablish its own shroud and } \\
\text { sand blast the paint. }\end{array}$ & $\begin{array}{l}\text { Crew E-11' consisting of: } \\
1 \text { Painter } \\
1 \text { Laborer } \\
1 \text { Eq. Operator } \\
1-250 \mathrm{CFM} \text { Air Com- } \\
\text { pressor w/Sand } \\
\text { Blaster and accesso- } \\
\text { ries } \\
\text { RHOS unit } \\
\text { Materials }\end{array}$ & $\begin{array}{r}\$ 1042.60 \\
/ \text { day }\end{array}$ & $\begin{array}{l}4.5 \text { days } \\
4,600 \mathrm{SF}\end{array}$ \\
\hline \multirow[t]{2}{*}{ Painting } & $\begin{array}{l}\text { Apply undercoat remotely } \\
\text { using RHOS }\end{array}$ & $\begin{array}{l}\text { Crew E-15' consisting of: } \\
\quad 1 \text { Painter } \\
1 \text { Laborer } \\
\text { RHOS unit } \\
\text { Materials }\end{array}$ & $\begin{array}{r}\$ 609.45 \\
/ \text { day } \\
\text { \$368/day } \\
\text { S0.09/SF }\end{array}$ & $\begin{array}{l}1.5 \text { days } \\
1.5 \text { days } \\
4,600 \mathrm{SF}\end{array}$ \\
\hline & $\begin{array}{l}\text { Apply topcoat remotely } \\
\text { using RHOS }\end{array}$ & $\begin{array}{l}\text { Crew E-15' } \\
\text { RHOS unit } \\
\text { Materials }\end{array}$ & $\begin{array}{r}\$ 609.45 \\
/ \text { day } \\
\$ 368 / \text { day } \\
\$ 0.36 / \text { SF }\end{array}$ & $\begin{array}{l}1.6 \text { days } \\
1.6 \text { days } \\
4,600 \mathrm{SF}\end{array}$ \\
\hline
\end{tabular}

Table II.D-2. Work Breakdown Matrix for Proposed Bridge Inspection and Maintenance The total cost for the project using the RHOS unit is $\$ 14,231$ broken down as follows:

Inspection

$\$ 713$

Stripping

Undercoat

Topcoat
$\$ 8,418$

$\$ 1,880$

$\$ 3,220$

This represents a cost savings almost $24 \%$ above the existing technology. 


\section{Conclusions}

\section{a. Benefits to highway construction}

1) Cost - The direct cost savings is $23.6 \%$. The major savings comes from elimination of scaffolding and the man-hours associated with its erection and dismantling. This is offset by the increased cost of the other operations due to of higher equipment cost. There will be additional cost savings not calculated in this analysis from reduced insurance premiums as a result of the reduced worker hazard. The workers remain on the ground in all phases of the operation, and the RHOS goes where the work needs to be accomplished. It must be noted that this cost savings is totally dependent on the accuracy of the estimate used for the RHOS unit. Time savings resulting from automation of this operation are realized in conducting the preliminary inspection (estimated at $20 \%$ ), elimination of lost time between sequential operations, and elimination of the need to erect scaffolding. The lost time occurs after each application of a paint coat. Using the current technology this operation takes only 0.5 days for each bridge section. The paint must be allowed to dry overnight causing the remaining half day to be lost. Using the proposed technology, the stripping and undercoating operations combined take 6 days. The undercoat is left overnight to dry, and topcoating is started the next day without lost time. There will be 2.5 days of dead time on this project using the current technology and no dead time using the proposed technology, which translates directly to reduced cost. Survey respondents ranked this concept three for cost savings of the six technologies reviewed.

2) Safety - Safety is enhanced in almost all phases of the operation. Workers are not required to erect scaffolding and work above the ground. The preliminary inspection team does not have to maneuver a bucket truck around the underside of the bridge to conduct their inspection nor use safety equipment to reach portions of the bridge inaccessible to the bucket.

There is greater exposure in moving the traffic control with the proposed technology. Using present technology, traffic control is established once for each of the three sections of bridge painted. The proposed technology completes one function (e.g., stripping) across the entire length of the bridge, requiring traffic control to be moved three times as often. The side benefit to the proposed technology, however, is that at the end of the work day all lanes can be opened to traffic. This is not possible with scaffolding in the travel way. 
Survey respondents ranked this technology second behind trenching and pipelaying for its improvement of worksite safety of the six technologies reviewed.

3) Time - Time represents the greatest savings presented by the proposed technology. Total project duration using the current technology is 14.5 work days. Using the proposed technology this is reduced to 7.6 work days, a savings of almost $48 \%$. The savings comes from eliminating dead time while paint is allowed to dry (2.5 days) and the time it takes to erect and dismantle the scaffolding (4.5 days). When evaluated against total man-hours to complete the project, this technology promises a $46.3 \%$ increase in productivity.

Considerable time will be saved by the traveling public because total lane closure hours are reduced from 716 hours to 60.8 hours. The current technology requires a lane to be closed 24 hours a day from the start to end of the project. The new technology takes less time and requires one lane to be closed only during working hours. Time savings to the traveling public could be further increased if work was scheduled at night, a procedure which would be possible using this technology. This technology was ranked fourth by survey respondents for time savings.

4) Quality - Based on experience in the manufacturing industry, quality is expected to be better. Robotics devices can control the rate of application more consistently than can most humans. This should result in a more uniform final product. It is unclear whether the sensor system envisioned would be able to discriminate sufficiently to leave sound old paint on the bridge or whether it would remove all old paint. If the latter is the case, this technology would create more hazardous waste by removing greater quantities of lead-based paint (where it existed), and the resultant paint job would not provide the level of protection that leaving the lead-based paint would. This technology tied for first along with site integration for quality.

\section{b. Ease of implementation}

1) Technical hurdles - A major technical hurdle is the lack of "as-built" databases on existing bridges. Of the steel bridges built between 1950 and 1989 , only $6 \%$ were built since the advent of widespread use of CAD/CAM for design. The cost of converting drawings on older bridges to create the database would be a major undertaking. The hostile environment in which the sensors (especially visual sensors) will be required to operate may present technical problems difficult to overcome. 
2) Applicability - This technology will have broad application, however, it will be necessary to develop further its performance characteristics and cost before a complete assessment of its applicability can be made. Survey respondents and workgroup participants expressed concern about the technology being able to address anything but simple I-beam girder bridges. One workgroup participant stated that a major maintenance problem in his state is maintaining the inside of steel box girders. He saw this technology as being able to address this problem with a robot able to "crawl" inside the girder and accomplish the work.

\section{c. Industry acceptance}

1) Priority/need - On average, survey respondents ranked bridge inspection second of twenty-five applications they thought were most beneficial to automate. Using a weighted average (giving preference to a concept rated second by several people over one ranked first by only one person), bridge inspection ranked first. This question did not limit the respondent to consider only steel highway bridges. With the large number of bridges in existence (over 300,000 constructed from 1950 to 1989), this represents a major expense item in a jurisdiction's highway maintenance program.

2) Capital outlay - For the purpose of this analysis, it was assumed that the RHOS would be twice the cost of a bucket truck. This is considerably more than current stripping and painting equipment, but not beyond the reach of most contractors who bid on this type work. The savings in time and the increased efficiency should make this technology attractive enough that capital outlay would not be a deterrent to adoption. If, however, the system's cost is considerably more than assumed, capital outlay may limit adoption of this technology.

3) Expected commercial value - Use of the RHOS would give a company a decided competitive advantage. Productivity per man-hour would be increased by $46.3 \%$. On-site safety would be improved by reducing the number of workers required, limiting their above-grade activities, and removing the worker from a hazardous environment. Lane-closure hours would be reduced from 716 hours for the present technology to 60.8 hours for the proposed. This should be a major incentive for highway jurisdictions specifying the use of this technology through performance criteria in their request for proposals. 
5. Summary

Cost Project Duration Crew

Current $\$ 18,626^{*} \quad 14.5$ work days 317.6 man-hours*

29.5 total days

Proposed $\$ \$ 14,231 \quad 7.6$ work days $\quad 170.4$ man-hours

10.6 total day

*These figures become $\$ 20,700$ and 364 man-hours, respectively, if lost time is included. 


\section{E. Automated Pavement Inspection and Repair.}

\section{Background}

a. General - Cracks develop in roadway surfaces over time for a variety of reasons. Thermal stress, inherent weakness in pavement structure, traffic loads, and frost action all contribute to develop cracks. Left unchecked, moisture will enter the pavement structure through the cracks, weakening the sub-base. This cycle will eventually result in total failure of the road. Crack sealing is a low cost method to keep moisture out of the pavement structure and extend the service life of the road.

b. Typical task (scenario) for this technology - Inspect and seal cracks between $1 / 2$ inch and 1 inch in width on one lane of a 4-lane divided highway. Twelve miles of roadway requires repair with 3,000 linear feet of crack per lane-mile. A total of 36,000 linear feet of crack will be cleaned and sealed.

\section{Current Technology}

a. Description - The current technology is manpower intensive. A preliminary survey of the roadway surface is conducted by trained personnel to determine current condition. The inspector visually looks for rutting, potholes, spalling, and cracks. In some cases, on-the-ground measurements are taken, providing quantitative information to serve as input to an automated prioritization system. Measurements are made of a representative sample section of road, and the results then used to characterize the entire road segment. In most cases, however, the evaluation and prioritization of the road segment is subjectively done by the inspector.

Work schedules are developed from the prioritization process and crews are assigned road repair tasks. Ideally, roads should be maintained when there is only minor surface cracking, and the subgrade has not begun to deteriorate due to water infiltration. Practically speaking, only those road segments in dire need of repair are addressed. Cracks are cleaned using compressed air, and sealant is applied manually.

b. Task Analysis - Traffic control is established using cones, typically closing one lane of approximately one-half mile of a road at a time. Visual inspection is performed by the foreman, and the cracks are cleaned and dried by one individual using an air compressor and a cleaning/drying wand. Cleaning is followed by manual placement of sealant by a two-man crew using applicators to distribute the sealant carried in a heating tank. The foreman inspects the quality of the crack sealing process as it progresses. Once the half-mile section of road is completed, the cones are picked up and a new traffic control is established for the next project location. Production rate 
is approximately 7,800 linear feet of crack per day.

c. Work breakdown for current technology - The work breakdown, resources required, and daily costs for the current method of crack sealing are shown in Table II.E.1. Project duration would be five days and requires a work crew of seven. Total project cost is $\$ 10,764$.

\begin{tabular}{|c|c|c|c|c|}
\hline $\begin{array}{l}\text { Performance } \\
\text { Element }\end{array}$ & Current Standard & Resources Required & Unit Cost & $\begin{array}{c}\text { Units } \\
\text { Required }\end{array}$ \\
\hline $\begin{array}{l}\text { Install traffic con- } \\
\text { trol }\end{array}$ & $\begin{array}{l}\text { Load truck with signs and } \\
\text { cones. } \\
\text { Set out signs and place } \\
\text { cones }\end{array}$ & $\begin{array}{l}\text { Pickup truck } \\
2 \text { laborers } \\
\text { Signs } \\
\text { Cones }\end{array}$ & $\begin{array}{r}\text { \$56/day } \\
\$ 465.60 / \text { day } \\
\$ 6 / \text { day } \\
\text { \$75/day }\end{array}$ & $\begin{array}{l}5 \text { days } \\
5 \text { days } \\
5 \text { days } \\
5 \text { days }\end{array}$ \\
\hline $\begin{array}{l}\text { Inspect cracks and } \\
\text { clean }\end{array}$ & $\begin{array}{l}\text { Truck pulls crack cleaner } \\
\text { with man and wand to } \\
\text { identify and clean cracks }\end{array}$ & $\begin{array}{l}\text { Foreman } \\
2 \text { laborers } \\
\text { Truck } \\
\text { Crack Cleaner }\end{array}$ & $\begin{array}{r}\$ 258 / \text { day } \\
\$ 465.60 / \text { day } \\
\$ 56 / \text { day } \\
\$ 102 / \text { day }\end{array}$ & $\begin{array}{l}5 \text { days } \\
5 \text { days } \\
5 \text { days } \\
5 \text { days }\end{array}$ \\
\hline Seal cracks & $\begin{array}{l}\text { Truck pulls heated tank } \\
\text { with filler material. La- } \\
\text { borer uses applicator to } \\
\text { fill cracks and a second } \\
\text { laborer strikes off the ex- } \\
\text { cess filler. } \\
\text { (NOTE: One laborer from } \\
\text { other operation) }\end{array}$ & $\begin{array}{l}2 \text { laborers } \\
\text { Truck } \\
\text { Heating tank with sealing } \\
\quad \text { material }\end{array}$ & $\begin{array}{r}\$ 465.60 / \text { day } \\
\$ 56 / \text { day } \\
\$ 146.95 / \text { day }\end{array}$ & $\begin{array}{l}5 \text { days } \\
5 \text { days } \\
5 \text { days }\end{array}$ \\
\hline $\begin{array}{l}\text { Remove and relo- } \\
\text { cate traffic control }\end{array}$ & \multicolumn{4}{|c|}{$\begin{array}{l}\text { The same resources allocated for installing the traffic control would be used for this } \\
\text { activity. }\end{array}$} \\
\hline
\end{tabular}

Table II.E-1. Work Breakdown Matrix for Current Crack Sealing Technology

\section{Proposed Technology}

a. Description - Currently human experts are required to visually inspect road surfaces. Many attempts have been made to apply machine vision to this process due to the large amount of inspection that must be performed, but none has yet been sufficiently successful. The objective of this proposal is to develop an inspection system for roadway defects such as cracks with performance better than that of human inspectors. The minimum detectable crack size would be less, so that preventive maintenance could be carried out earlier, leading to increased savings in repairs. Quantitative measures of performance, detection rate, and false-alarm rate, could be accurately characterized. The goal would be to carry out the inspection (and for defects of limited severity, the repair) at highway speeds. Much more roadway than the 
currently limited sample could be inspected, and if repair could be carried out simultaneously, inspection and repair would become a one-pass operation with no need for road closing. Figure II.E-1 shows a conceptual drawing of a possible crack detection technology.

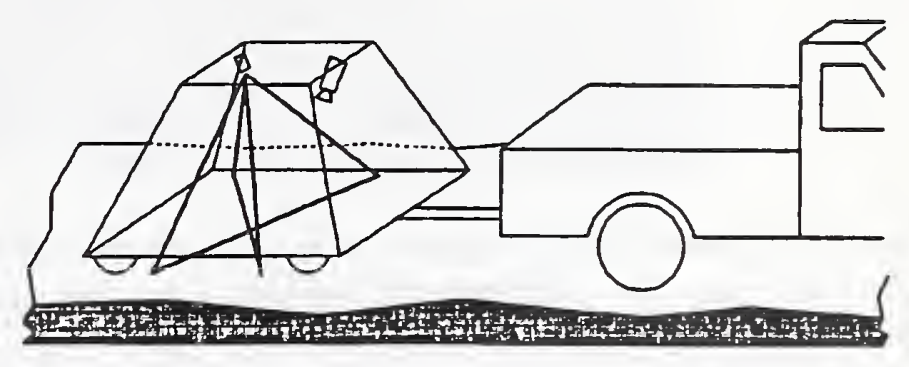

b. Task Analysis - It is anticipated that a preliminary survey would still be required to

\section{Figure II.E-1}

Structured-light Range Sensor System for Crack Detection prioritize the work areas and to identify road sections which require more intensive maintenance and repair than crack sealing. Although the survey could be performed by the proposed technology much quicker than presently done manually no assessment was made of potential savings of the proposed technology over current practice. Automating this process will improve its accuracy, increase productivity, and reduce accident exposure. No attempt was made, however, to assess automated inspection as a stand-alone technology.

Work schedules would be developed from the survey inspection and an Automated Crack Detection and Sealing Unit would be assigned to the project. The increased speed of the robotics system would permit use of a moving traffic control. A moving traffic control reduces traffic delay and is inherently safer than stationary traffic control. The operation of detecting, cleaning, drying, and sealing cracks is accomplished in one pass by the Unit. For the purpose of this study it is assumed that "highway speed" as stated in the proposal is 10 miles per hour. This is based on the fact that CALTRANS has developed a robotics crack sealer which is capable of sealing longitudinal cracks at a rate of 10 miles per hour. The CALTRANS crack sealer is unsophisticated by comparison to the description of this robotics proposal. The actual productivity rate would depend upon the linear feet of cracks per lane-mile of highway and the percent of transverse verses longitudinal cracks. The consistent quality expected to be achieved through automation of this function should eliminate the requirement for a foreman to provide quality control.

No cost information was provided in the proposal. For the purpose of this analysis it is assumed the unit could be produced for $\$ 300,000$. Bare cost is estimated based on a 4-year depreciation period at a utilization rate of 2,000 hours per year. Total equipment cost is bare cost plus $10 \%$. 
c. Work breakdown for recommended technology - The work breakdown, resources required, and daily cost for the proposed technology are shown in Table II.E-2. This project would cost $\$ 731$ per day using the proposed technology. The entire project could be completed in 1.2 hours for a cost of $\$ 110$. The total crew used to complete the project consists of the moving traffic control driver and Automated Crack Detection and Sealing Unit operator.

\begin{tabular}{|c|c|c|c|c|}
\hline $\begin{array}{l}\text { Performance } \\
\text { Element }\end{array}$ & Proposed Standard & Resources Required & Unit Cost & $\begin{array}{c}\text { Units } \\
\text { Required }\end{array}$ \\
\hline $\begin{array}{l}\text { Moving traffic } \\
\text { control }\end{array}$ & $\begin{array}{l}\text { Moving traffic control } \\
\text { unit }\end{array}$ & $\begin{array}{l}\text { Driver } \\
\text { Impact control truck } \\
\text { Signs }\end{array}$ & $\begin{array}{r}\$ 160 / \text { day } \\
\$ 75 / \text { day } \\
\text { \$6/day }\end{array}$ & $\begin{array}{l}0.15 \text { days } \\
0.15 \text { days } \\
0.15 \text { days }\end{array}$ \\
\hline $\begin{array}{l}\text { Inspect cracks and } \\
\text { clean. Seal cracks }\end{array}$ & $\begin{array}{l}\text { Automated inspection, } \\
\text { cleanup and sealing }\end{array}$ & $\begin{array}{l}\text { Operator } \\
\text { Automated Crack Detec- } \\
\text { tion and Sealing Unit }\end{array}$ & $\begin{array}{l}\$ 160 / \text { day } \\
\$ 330 / \text { day }\end{array}$ & $\begin{array}{l}0.15 \text { days } \\
0.15 \text { days }\end{array}$ \\
\hline
\end{tabular}

Table II.E-2. Work Breakdown Matrix for Proposed Crack Sealing Technology

Even if the automated crack detection and sealing unit was capable of only one and one-half miles per hour it could still complete the project in one day at a cost of only \$731, a major savings and a quantum increase in productivity.

\section{Conclusions}

\section{a. Benefits to highway construction}

1) Cost - This technology represents a cost savings of many orders of magnitude over the present technology; $\$ 110$ verses $\$ 7,236$. This is a cost reduction of over $98 \%$. Uncertainties in this calculated savings include the actual cost of the robotics unit, rate of production, operating cost, and maintenance cost. Other potential cost savings not considered in this analysis include reduction in the use of sealing material because of the inherent greater accuracy of robotics sealant placement and the longer life of the sealing process resulting from consistent quality control. These costs are expected to be minimal compared to savings offered by the enhanced productivity. Survey respondents ranked this technology second to site integration for potential cost savings of the six technologies evaluated.

2) Safety - This technology should greatly reduce accidents and injury during road inspection and crack sealing operations. From the standpoint of the traveling public, a moving traffic control is inherently safer than a traffic diversion where 
cones have to be repeatedly placed, picked up, and moved to the next location. Worker exposure is greatly reduced. Current technology requires at least four people to be on the road during the sealing operation: the foreman, the crack cleaner, and a two-man sealing crew. The proposed technology requires no one to be on the road during the sealing operation. When used for the prioritization survey, it eliminates the need for people on the road taking measurements.

No attempt was made to determine the number of people injured or killed each year conducting crack sealing operations. It is anticipated that reduced exposure would result in lower workman's compensation premiums for the contractor conducting the work. The exact amount of this savings was not estimated. The survey placed this technology third in safety.

3) Time - The proposed technology promises to reduce the time required to complete the scenario project from five days to just over an hour. This improved productivity is dependent on the technology achieving the assumed productivity rate of 10 miles per hour. Any productivity rate greater than the current three miles per day would be an improvement. Looked at in another way, current technology has a productivity rate of 0.043 lane-miles per man-hour (for the scenario conditions), whereas the robotics system produces five lane-miles per man-hour. This is a productivity increase of over $11,500 \%$. Survey respondents ranked this technology first for time.

4) Quality - Quality is expected to be enhanced. Robotics systems used in manufacturing processes have produced consistent high quality products. It is anticipated that same high quality could be achieved through the application of robotics to crack detection and sealing. Much greater control could be achieved in sealant placement accuracy and the quantity of sealant put in the crack. Overflow would be minimal or eliminated, and a consistently higher quality product would be produced. This technology was ranked third for quality in the survey.

\section{b. Ease of implementation}

1) Technical hurdles - There are a number of technical hurdles which must be overcome before this technology could be implemented. The first is development of a reliable detection system which could be operated and maintained by construction industry personnel. This would require retraining of present personnel and may entail them learning new skills they lack. The potential savings promised by this technology makes retraining an affordable option for a contractor because the potential rewards are so great.

Integration of the positioning data between the detector and crack sealer presents 
the next major technical challenge. This is viewed as more of a software problem if the detector and sealer are contained in one unit. If two units are employed a detector and a sealer - the problem of data integration is magnified.

By far the greatest technical challenge is development of the crack cleaning and sealant dispensing mechanism. The CALTRANS crack sealer consists of two robotics arms mounted on the front of a vehicle. This works well for longitudinal cracks where the arm needs only to trace the crack as the vehicle moves forward. Sealing both longitudinal and transverse cracks presents a much greater problem. Consider the complexity of placing sealant in the cracks shown in Figure DI.E-2 from a vehicle moving north to south.

Some possible techniques to overcome this technology hurdle discussed by the work group included an $x-y$ plotter mechanism that has a high degree of control and low dispensing head inertia. A second recommendation was analogous to an ink-jet or dot matrix printer. However, instead of having a

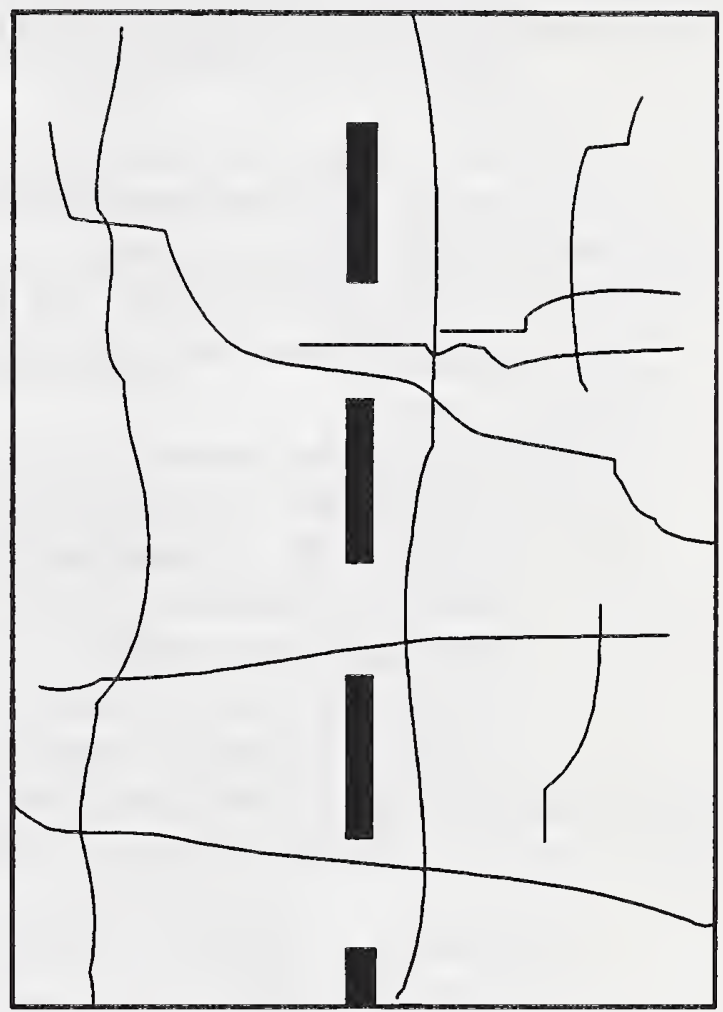

Figure II.E-2 Hypothetical Crack Layout on a Road Section "print head" move from side to side to dispense sealant it was suggested to have an array of overlapping dispenser nozzles, much as used in LED laser printers, which would dispense a measured amount of sealant when the nozzle lined up with the crack.

The general consensus of the work group and survey respondents was that the crack sealing portion of this proposal would govern the success or failure of the concept. It was felt that a technology demonstrator should be built early in the development process to prove the feasibility of sealing cracks at a speed sufficiently greater than the present three lane-miles per day to make the concept cost effective.

2) Applicability - This concept has universal applicability. Surface cracks in flexible pavements are the single biggest cause of pavement deterioration, especially in areas subject to freeze-thaw cycles. The cracks permit moisture to get into the 
road structure and weaken it. Traffic loads pump the moisture into the pavement through the cracks, causing spalling which then develops into potholes. Frost action causes frost heaves when moisture is present further distressing the road surface and creating more cracks. This vicious cycle continues until the road structure eventual fails. Crack sealing minimizes moisture intrusion in the road structure and has been shown to extend the useful life of a pavement. The major problem faced by road maintenance jurisdictions is the high cost and low productivity of the present methods. This technology promises to correct this shortfall.

\section{c. Industry Acceptance}

1) Priority/need - The general consensus of survey comments is that better crack detection by itself is not very useful. Comments such as, "After the pavement is inspected for cracks, then what? The area's maintenance funding determines when the cracks are fixed." "If the serviceability of the pavement is to last, cracks in the pavement must be sealed at the earliest possible time to prevent moisture from getting into the base." Automating the sealing process is the real need. Automated crack detection is needed to control sealant application.

The need to improve crack sealing productivity is great. Many road cracks are not sealed even annually because of the cost to put a work crew on the road. Most road maintenance jurisdictions do not conduct crack sealing operations until there are a sufficient number of cracks to make the process cost effective. Unfortunately, this approach reduces the useful life of a pavement and eventually requires rehabilitation measures sooner than would otherwise be required.

Based on the survey results this technology ranked third overall in its priority/need. It ranked third also in the technology impact based on the combined rankings for safety, cost, time and quality.

2) Capital outlay - Capital outlay will be a major impediment to industry acceptance of this technology. For the purposes of this study it was assumed the crack detection and sealing unit could be commercially produced for about $\$ 300,000$. This is a significant investment for a small construction company or municipality which typically does this type of work. Large companies could make this investment to realize the promised benefits. The net effect would be to drive many small companies out of business because they would be non-competitive.

3) Expected commercial value - The expected commercial value of this technology is the highest of the six concepts analyzed. A contractor with a unit could underbid its competition by half and still make considerably more profit than normal. Projected (preliminary) productivity increases of $11,500 \%$ and cost 
reductions of almost $99 \%$ are too tempting to be ignored. If an acceptable level of reliability and maintainability can be achieved, along with the promised productivity rates, this technology should be a major commercial success.

\section{Summary}

\section{Cost Project Duration Man-days}

$\begin{array}{rrrr}\text { Current } & \$ 10,764 & 5 \text { days } & 35 \\ \text { Proposed } & \$ 110 & 1.2 \mathrm{hrs} & 0.3\end{array}$




\section{F. Temporary Bridging}

\section{Background}

a. General - It is often necessary to construct temporary (in use less than a year) diversions to accommodate new construction or to facilitate rehabilitation of existing highways, bridges, and utilities. For bridge deck rehabilitation, for example, the bridge will be closed one lane at a time while the rehabilitation work is done. This is a time consuming sequential operation and does not efficiently use the resources required for the project. Jersey barriers are required to protect work crews and to provide a restraint for vehicles on the bridge which must be moved as each lane is completed. Current temporary bridge construction consists of using the Bailey Bridge, developed by the military for combat operations, or constructing a temporary bridge using more conventional construction methods.

b. Description of recommended technology - Deployment of modular temporary bridging systems by automated means could provide several classes of benefits associated with different time-frames of technological development.

NEAR TERM - Temporary bridging for traffic diversion around bridge repairs can be placed with increased speed and efficiency by integrating existing new technologies for modular bridging with recently-developed robot crane technology, which provides stable control of heavy lifting in six degrees of freedom.

MID TERM - Rapid and ecologically non-invasive bridging of wetlands during construction of new bridging could be accomplished with further extension of these technologies. The suspended Stewart platform crane technologies can emplace lightweight modular bridging over ecologically-sensitive sites with little or no footprint. The net benefit would include elimination of costly reconstruction of damaged habitats, as well as minimal ecological intrusion.

LONG TERM - Relocateable temporary bridging to carry traffic over highway repair sites is an idea with a long history. Until recently the technology to make such proposals realistic did not exist. It now appears that combinations of recent developments in deployable bridging structures and robotics lifting and positioning technology make it reasonable to attack this problem in a serious manner. If this can be achieved, very substantial benefits to the economy would result from minimizing lost commuter time and delay of goods and services due to traffic congestion at repair sites. 


\section{Work Group Evaluation}

The work grou, igned to evaluate this technology also evaluated the site integration technology. The $\&$ up decided at the outset that site integration was a more complex issue whici had mue universal application than temporary bridging. The work group members also felt that as a group they did not possess the technical expertise to evaluate : emporary bridging. They decided to devote their effort to evaluating the complex issue of site integration.

The group cid provide general comments which need to be considered in evaluating this proposal.

Military bridging is developed for portability, speed, and mobility. As such, design compromises must be made to achieve those characteristics which are most critical for military applications. To achieve portability and mobility the roadway width is restricted a - design life is compromised. Speed is achieved by having both large modular sections and loose fitting joints normally connected by pins. Curbs are minimal and do not provide any level of protection in preventing a vehicle from driving off the bridge. Although it is desirable to erect temporary bridging for highway construction quickly, the time constraints for it are not as demanding as for military applications. In the military environment it is critical to be able to emplace a portable bridge in minutes to lessen the likelihood of detection and subsequent engagement with indirect or direct fire. Crossing safety is sacrificed to achieve this level of speed. Highway construction requires greater emphasis be placed on safety and time is the usual trade-off to achieve it.

A major aspect of safety not addressed in the concept is an adequate side barrier to keep vehicles on the bridge. Is it possible to design a lightweight barrier that provides the same level of restraint as a Jersey barrier? If this is not possible then the temporary bridging concept would not meet basic safety requirements.

From the concept description a modular bridge designed for a military application is to be adapted for highway use. If this is the case, what is the design life of the bridge? Military bridges are normally designed with a limited design life, usually 10,000 crossings of the maximum design load. Highway bridges, on the other hand, are designed to withstand an "unlimited" number of crossings of the maximum design load with a substantial safety factor. Traffic on military bridges is strictly controlled for speed, load class, and vehicle spacing. The 10A MBS (Global's 10A Modular Bridging System-patented) would have to withstand unregulated traffic. The dynamic interaction between live loads at the maximum bridge rating and a lightweight bridge may substantially change the design of the 10A MBS. 
Further complicating an evaluation of this concept is the fact that no utilization or cost information was provided. The concept mixed many issues. It talked about the 10A MBS with the RoboCrane as a temporary bridge for use in place of a bridge under rehabilitation or for a traffic diversion, the $10 \mathrm{~A}$ MBS as a permanent bridge over a wetland where the RoboCrane would not be required because a crane would be needed to drive the piles, and the RoboCrane as a lifting device for general highway construction. The design criteria for a temporary bridge which needed to be erected and removed from a site are different from those of a modular-constructed, permanent bridge over a wetland. These two applications would appear to be mutually exclusive.

3. Task force conclusions - With the foregoing discussion in mind, some general comments can be made based on the survey feedback.

\section{a. Benefits to highway construction}

1) Cost - Temporary bridging was ranked third in the survey for life cycle cost savings to highway construction, maintenance, and operation. One of the principal benefits anticipated in this area was reduced delay time for the traveling public. When asked to "grade" temporary bridging for cost savings it was ranked last. There was considerable divergence of opinion in this area by survey respondents.

2) Safety - Survey respondents rated temporary bridging in a tie for fourth out of the six concepts for positive impact on safety. Concern was expressed about the safety of the concept. The liability issue associated with highway construction was cited. The traveling public was seen as the primary beneficiary of safety from using a 10A MBS based temporary bridge.

3) Time - This concept was ranked third for impact on time. There was considerable disagreement on this issue as this concept had the largest standard deviation in this category of the six concepts.

4) Quality - Temporary bridging was rated last in the survey for positive impact on quality.

\section{b. Ease of implementation}

1) Technical hurdles - Many concerns were voiced concerning the ability to meet the performance goals established for this concept along with the level of safety demanded of highway construction. The ability to use this concept on the multitude of sites encountered in construction is also a concern. Modular bridge sections have long been able to be rapidly assembled using materials handling equipment. It must be proved that modular bridge sections, 
as envisioned in this concept, will conform to all the highway safety requirements and still meet performance goals.

2) Applicability - This technology has limited applicability compared to the other concepts. It was ranked last for implementation and many respondents cited concern over it being a specialized technology with limited application. 


\section{G. Other Comments}

The survey questionnaire asked several general questions, which are located in Appendix $\mathrm{H}$ and summarized below.

When asked to identify other areas of highway construction, maintenance, and operations that would benefit from robotics/automation, one trend in the responses was evident. Most respondents suggested areas with high safety hazards. Tunneling headed the list, being suggested by four respondents followed by roadside maintenance (mowing, weed control, litter pickup, etc.) from three respondents. One respondent summarized the general thoughts when he said, "Any safety-related maintenance or operational devices that would remove workers from work zones or construction hazard areas."

Robotics/automation appears to be gaining acceptance throughout the industry. Laser control for grading and pavement operations was cited most often. Guidance systems for tunnel boring machines was also mentioned by two respondents. One respondent suggested the general reluctance on the part of the industry to accept robotics/automation was due to "the specialization of the equipment and thus low market appeal." This same idea was expressed in various forms as potential hurdles to accepting the technical proposals evaluated in the survey.

Another major concern expressed was the impact of robotics/automation on the work force. Training, labor relations, union concerns, job reductions, and minority hiring goals were all stated as non-technical, human hurdles to acceptance of robotics/automation in the construction industry. Similar arguments were voiced by the manufacturing industry two decades ago. International competition has forced many sectors of the manufacturing industry to embrace robotics/automation, though not without the impacts cited above.

A final trend in the comments received involved partnering. This was mentioned in reference to developing technologies. Respondents felt that industry participation in the selection process of concepts was critical. This same sentiment was voiced by the workshop participants. Partnering was also mentioned as important in the delivery of construction industry services to the customer. Partnerships should be established between the industry, highway jurisdictions, and the traveling public to make better use of construction dollars available. "More involvement of construction experts is needed in design: i.e., constructibility, value engineering, life cycle costing, and design-build contracts. Also, more designer involvement is needed in the construction phase, i.e., improved QA/QC and problem solving. Partnering is needed for both design and construction phases of projects."

Respondents were specifically asked to rank the six proposals based on their priority/need, 
ease of implementation, and life cycle cost savings to highway construction, maintenance, and operations. Figure II.G-1 shows the results of this ranking in the categories Priority/Need, Implementation, and Cost Savings. Bridge inspection and maintenance was rated highest priority overall. It was ranked first for both Priority/Need and Cost Savings. This was followed closely by pavement inspection and repair and trenching and pipelaying, in that order. The remaining three technologies, site integration, temporary bridging,

PRIORITY RATINGS FOR TECHNOLOGY (High Number thdicetes High Pricrity)

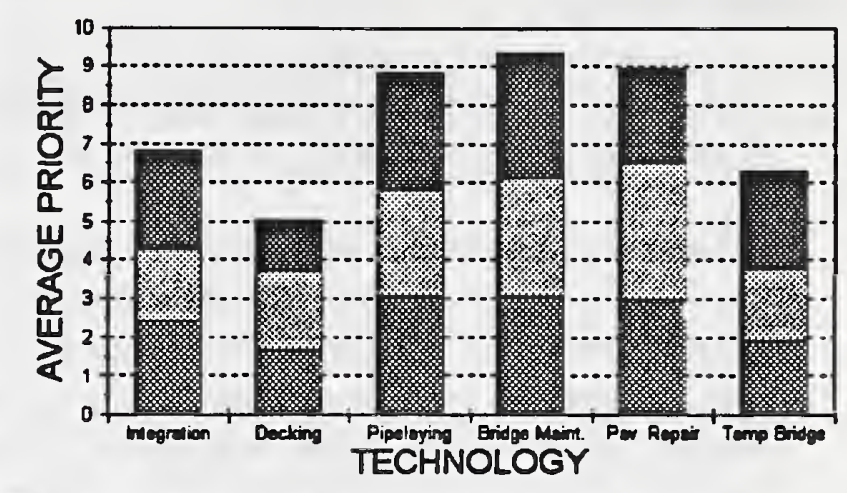

Priority/Need Implementation Cost Savings

Figure II.G-1 Technology Priority Ratings Average of all Ratings and automated bridge decking, completed the field respectively.

Respondents were also requested to "grade" the technologies on a scale of " $A$ " to " $E$ " with an " $A^{n}$ indicating the technology would have a positive impact on the factor making it "much better" and an " $E$ " would have a negative impact on the factor making it "much

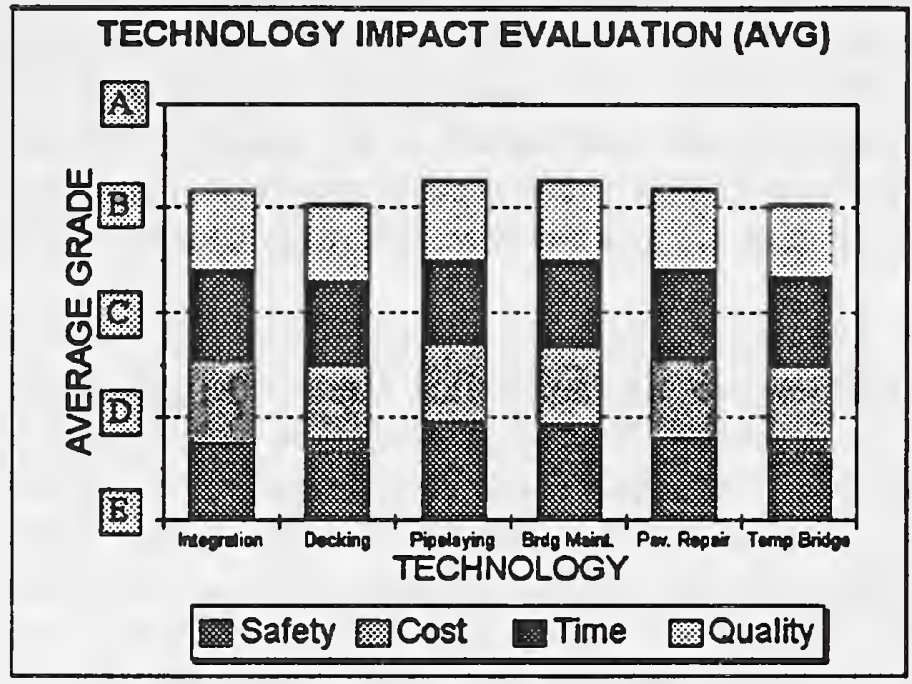

Figure II.G-2 Assessment of Technology Impact worse". The four factors respondents were asked to evaluate were Safety, Cost, Time, and Quality (see Appendix A for an explanation of what each factor included). Figure II.G-2 shows how the various technologies were rated. Respondents were not restricted on grade assignment. As a result there was less discrimination and the six technologies tended to be grouped much closer together than in the previous ranking. Analysis of the ratings shows that the respondents assessed automating trenching and pipe laying as having the greatest positive impact on safety. Site integration was ranked

highest for positive impact on cost. This is largely due to its almost universal application to any kind of highway construction or maintenance project. The fact that the proposer claimed a potential $50 \%$ savings (which was disputed by workshop participants) may have 
influenced this rating. Robotics pavement inspection and repair received the highest grade for time savings (an opinion supported by the analysis), while site integration and robotics bridge inspection and maintenance tied with the highest grade for improved quality. Considering all four categories, trenching and pipelaying received the highest overall average grade.

In the preceding analysis, the four factors were considered to carry equal weight. A preliminary analysis of a pair-wise comparison by a select group of experts indicates they ranked the four factors in the following order: Quality, Safety, Cost and Delay. The first three factors are evenly spaced with Delay running a distant forth. Applying normalized weighting values to the factors did not change the rank order of the concepts. Temporary bridging, however, did drop in relative importance from a tie for fifth to a definite last.

The survey asked the respondents to estimate the potential savings of the six concepts in eleven different areas (two concepts were evaluated in one additional area each). The responses for this portion of the survey reflected the claims of the concept proposers. Many respondents made no attempt to estimate, either in dollars or percent, the expected savings the technologies offered. Table II.G-1 lists the results of those ratings. The reader is referred to Appendixes B through $G$ for additional comments provided by the respondents for each concept (see question 4).

The survey listed 25 applications and asked the respondents to rank the top six in terms of the most beneficial to automate, given that the application could be automated. Table III.G-2 depicts the result of this question. Eleven applications were selected by at least one respondent as the most beneficial to automate and two were selected by nine respondents as among the top six. Those two were Trench/Pipes and Road Surface Inspection. 


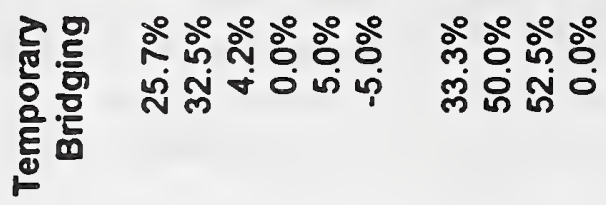
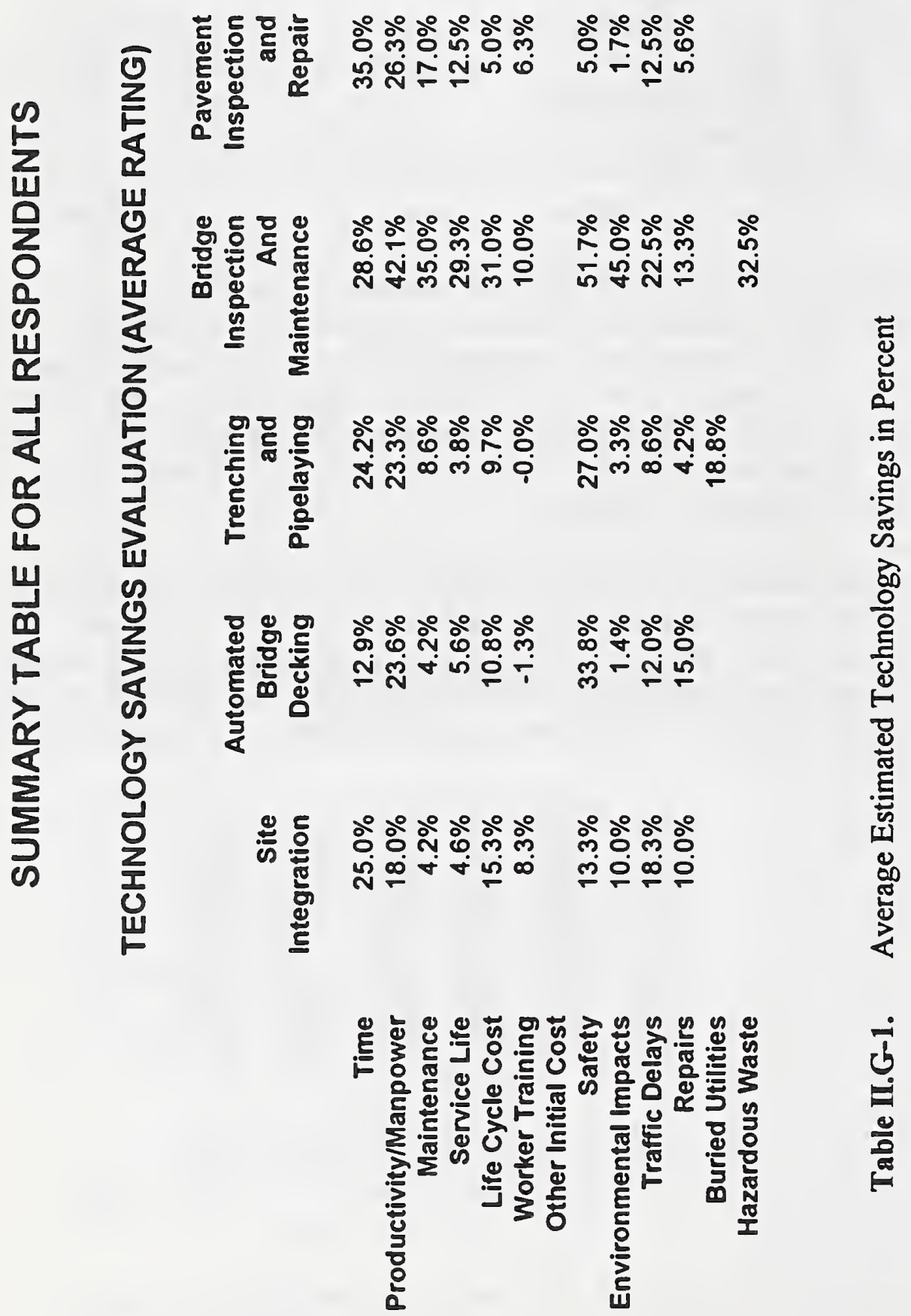


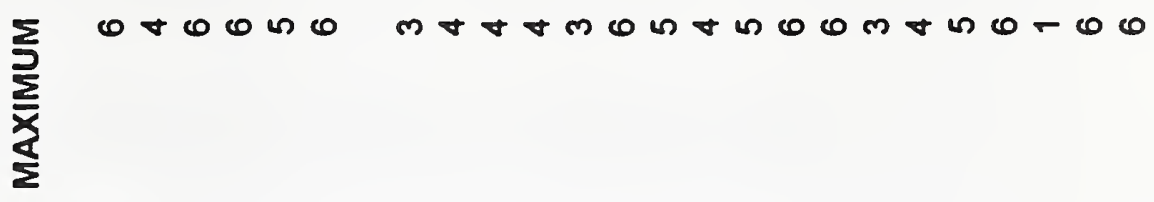

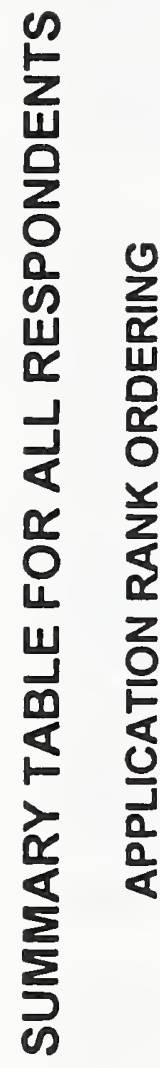
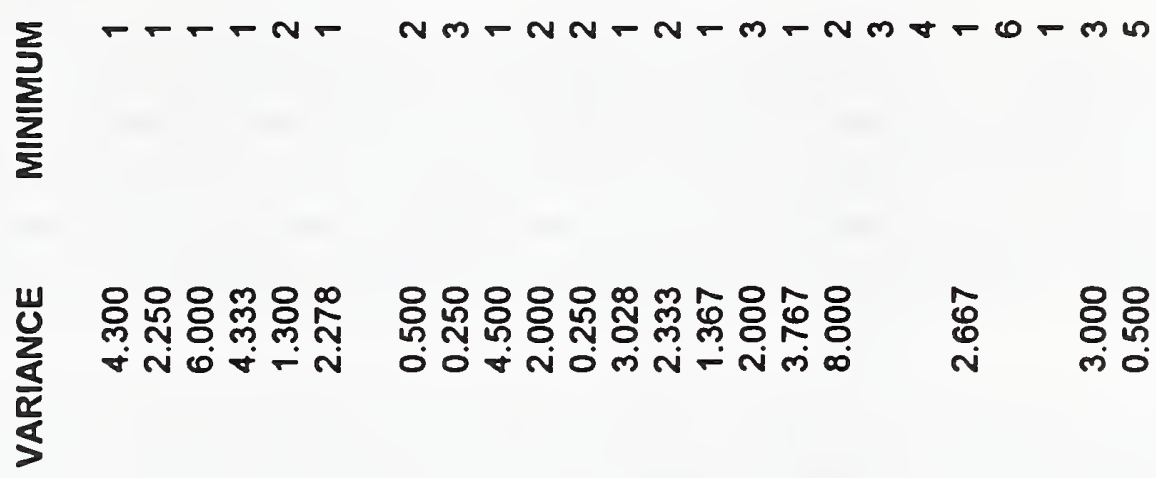

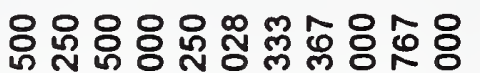

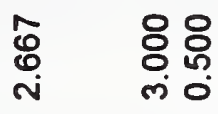

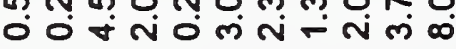

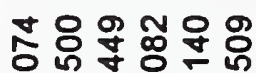
虫

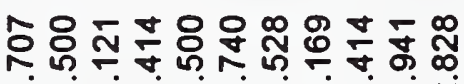
$\begin{array}{ll}m & N \\ \infty & N o\end{array}$ 虫

U

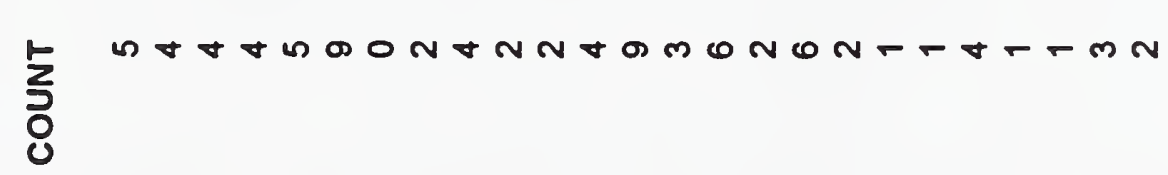

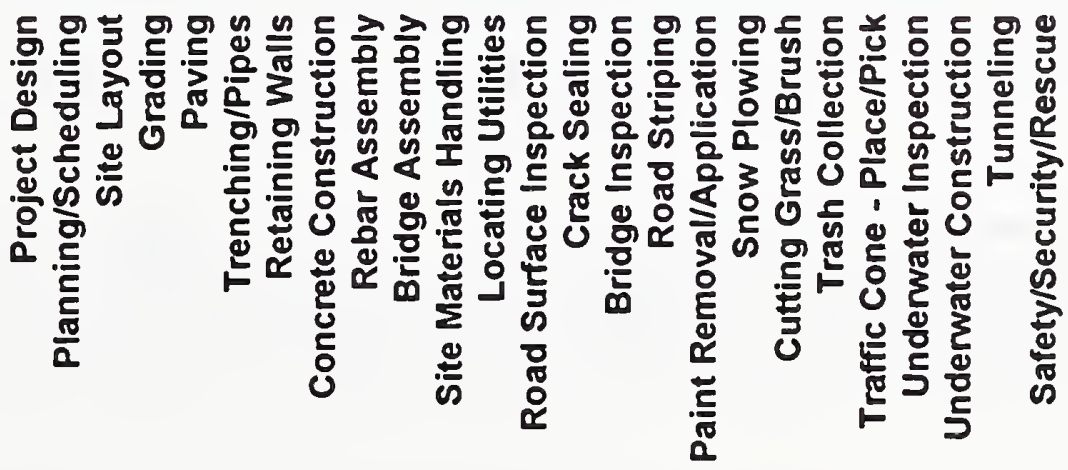




\section{CONCLUSIONS AND RECOMMENDATIONS}

\section{A. Conclusions}

Table III-1 summarizes the results of the analysis in Section II. In interpreting these results the reader is reminded to review the assumptions made in evaluating each technology and to keep in mind the specific scenario that was used to arrive at these figures. The results are not intended to represent the total or even average savings to be expected from a technology. Rather they represent only probable savings for a typical project provided the assumptions concerning performance and cost of the proposed technology are realistic.

The technology that promises the greatest savings in basic project cost and reduced delay to the traveling public is automated pavement inspection and repair. This technology is highly effective only if it can deliver on automating both pavement inspection and crack sealing. The potential success of this technology is less sensitive to variations in actual performance than the other technologies because the potential gains are so great. The technology can perform at considerably lower speeds than that assumed in the analysis $(10 \mathrm{mph})$ and cost considerably more than the $\$ 300,000$ estimated per unit and still be a cost effective technology. It does have a major technology hurdle to overcome: distributing crack sealing material at speeds up to 10 miles per hour in transverse and longitudinal cracks. This aspect of the concept should be the first to be demonstrated before money is spent developing the other technologies needed to make the overall concept a success. Although the concept can cost considerably more than the $\$ 300,000$ used in the analysis, capital expenditure to "buy into" the technology will be a major factor in its acceptance because small contractors usually conduct crack sealing operations and they are capital limited.

Automated bridge inspection and maintenance offers the next greatest percent gain in cost savings and productivity. It ranked second in project cost savings and project duration reduction and third in increased productivity. This technology promises to reduce the delay to the traveling public (i.e., the number of hours lane diversions are in effect during the project) by $91.4 \%$. A number of technology problems relating to the sensor systems to be employed must be solved before this concept will be viable. As with automated pavement inspection and repair, capital cost will be a major factor in industry acceptability.

Ranked third is automated bridge deck construction. It promises a substantial increase in worker productivity while offering moderate savings in cost and moderate to substantial savings in project duration. This concept, however, was felt to present the greatest integration problem in bringing together a number of fairly simple technologies into an integrated package. 


$\begin{array}{cccc}\text { TECHNOLOGY } & \text { COST } & \begin{array}{c}\text { PROJECT } \\ \text { DURATION } \\ \text { (days) }\end{array} & \begin{array}{c}\text { MANPOWER } \\ \text { (man-days) }\end{array} \\ \text { (m) } & & & \end{array}$

SITE INTEGRATION

$\begin{array}{rccc}\text { Current } & \$ 4,210,303 & 67 & 4,472 \\ \text { Proposed } & \$ 3,610,626 & 56 & 3,411 \\ \text { Savings } & 14.2 \% & 16.4 \% & 23.7 \%\end{array}$

BRIDGE DECKING

$\begin{array}{rccc}\text { Current } & \$ 22,687 & 6 & 27 \\ \text { Proposed } & \$ 19,111 & 3.75 & 10.25 \\ \text { Savings } & 15.8 \% & 37.5 \% & 62.0 \%\end{array}$

TRENCHING AND PIPELAYING

$\begin{array}{rccc}\text { Current } & \$ 3,461,950 & 106 & 3,702 \\ \text { Proposed } & \$ 3,289,210 & 102 & 2,946 \\ \text { Savings } & 5.0 \% & 3.8 \% & 20.4 \%\end{array}$

BRIDGE INSPECTION AND

MAINTENANCE

$\begin{array}{rccc}\text { Current } & \$ 18,626 & 14.5 & 317.6 \\ \text { Proposed } & \$ 14,231 & 7.6 & 170.4 \\ \text { Savings } & 23.6 \% & 47.6 \% & 46.3 \%\end{array}$

PAVEMENT INSPECTION AND

REPAIR

$\begin{array}{rccc}\text { Current } & \$ 10,764 & 5 & 35 \\ \text { Proposed } & \$ 110 & 0.15 & 0.3 \\ \text { Savings } & 99.0 \% & 97.0 \% & 99.1 \%\end{array}$

Table III-1. Summary of Technology Comparisons 
Site integration, though offering only the fourth best overall savings for the scenario evaluated, has the promise of widest application and realization of the greatest total dollar savings to the national highway system. The claimed $50 \%$ savings by the concept author is probably unrealistic as demonstrated in the analysis. However, saving $10 \%$ to $20 \%$ on every highway construction and maintenance project would amount to $\$ 8$ billion to $\$ 16$ billion (based on $\$ 78.3$ billion spent in 1991) saved each year. That would finance $39 \%$ to $78 \%$ of the current highway maintenance and operations bill.

\section{B. Recommendations}

Two technologies are highly recommended for further development:

- Site Integration; and

- Automated Pavement Inspection and Repair.

Site integration is recommended because of its almost universal application to all highway construction, maintenance, and repair projects. This concept offers the greatest total dollar savings of the six concepts considered. The Consortium for Advanced Positioning Systems (CAPS) could be incorporated into site integration to provide an early demonstration of this technology.

Automated pavement inspection and repair is recommended because of the overall savings it offers for that operation and the added benefit that properly maintaining the nation's roads will have on indirect costs such as fuel consumption, transportation costs, vehicle repair, and safety.

The work group of experts strongly recommended that industry (academia, contractors, and state DOTs) continue to be involved as the research and development of robotics/automation applications to highway transportation progress toward a useable tool for the industry. The August 16 issue of Business Week contained an article by Christopher Power, et al., with six suggestions to improve the success rate in new product launches. These suggestions bear repeating and adapting to the development and launch of robotics/automation for highway transportation applications. The suggestions are:

- ASK YOUR CUSTOMER - This has been done for the initial phase and the effort has been applauded by the industry. It is critical to consult the customer at every step, from the idea stage to rollout. The industry wants to contribute its part.

- SET REALISTIC GOALS - Performance characteristics need to be established that are attainable and represent savings over the present technology. Acceptability of several concepts will be dependent on the capital investment required. There will be a trade-off between performance and cost. ASK CUSTOMERS what they want.

- BREAK DOWN WALLS - Involvement of everyone who will be responsible for the 
final product from the researchers, to the manufacturer, to the using industry is critical. "Partnerships," as mentioned by several survey respondents, will facilitate this process.

- CREATE GATEWAYS - There is nothing worse than a research and development program that takes on a life of its own. Criteria need to be established and milestones set so the project can be evaluated and valid "go," "no-go" decisions made. The highest risk portions of the project must be identified early and attacked first. The tendency to attack the easy problem to demonstrate early success must be avoided at all cost or the credibility of the Federal R\&D program will again be subject to the criticism of waste.

- WATCH THOSE TESTS - "Test marketing" needs to be done as was for the concept stage. The tests must be continued at each stage of development to ensure the product still meets user needs and expectations. The tests must be of a long enough duration and cover sufficient depth of the market to give a real sense of product potential.

- DO YOUR POST-MORTEMS - Formal reviews must be done when the product does not meet expectations to answer the question, "Why?" The information gained from this review will be useful in determining appropriate corrective action for that product or will help prevent the same mistake being made on another product.

The work group and survey respondents expressed concern over the feasibility of several concepts, and they strongly recommended a technology risk assessment be conducted on concepts selected for further development. The risk assessment should focus on identifying and quantifying the factors essential to technical success, technical performance, and commercial performance. The risk (probability of success or failure) associated with each factor should also be assessed. The net commercial value, given technical success, should also be determined based on the variability of the technical and commercial performance of the concept. Through this rigorous methodology a valued judgement can be made of the return on R\&D dollar investment for the nation. 


\section{APPENDIX A - SURVEY QUESTIONNAIRE}

Section One of the survey asked the same five questions concerning each of the six concepts evaluated. The answers to Section One questions are reproduced in Appendixes B through G. Each answer is preceded by the letter " $A$ " through " $Q$ " which is keyed to the respondent. If there is no response following the letter it means that the respondent did not answer that question. The only exception to this convention is question 4. Since this question was soliciting a numerical response which was tabulated, only the non-numerical responses are recorded in this section to provide a complete picture of the survey response. The questions asked of each technology were:

1. Does the proposed technology address a critical problem area in highway construction, maintenance and operations? Please explain your answer.

2. Briefly describe the current procedures in highway construction, maintenance, and operations which the proposed robotics/automation technology will replace or change.

3. What are potential barriers to adoption of the proposed technology? What will it take to overcome these barriers?

4. Assuming that barriers to adoption are resolved and that the proposed technology achieves its stated performance goals, please estimate the potential savings (in dollars) for highway construction, maintenance, and operations projects for the following categories. [12 to 13 categories were listed for each technology. Refer to Appendixes B through $G$ for the specific categories.]

5. If automation/robotics could be applied to current highway construction, maintenance, and operations, do you think this proposed technology will meet the performance goals set forty in the proposal? Please explain your answer.

6. General comments concerning the proposed technology.

Section Two consisted of Table A-1. The respondents were asked to "grade" each technology on a scale of A to E for their impact on four categories: Safety, Cost, Time, and Quality. The categories are defined in the table. The result of this "grading" is shown in Table A-2.

Section Three asked eight additional general questions. The answers to questions 2 through 5 are tabulated in Tables A-3 and A-4. The questions are as follows:

1. What other areas of highway construction, maintenance, and operations would benefit from robotics/automation? 
2. Please rate the following six proposed technologies in their order of priority/need for the highway construction industry (1-6):

SITE INTEGRATION

AUTOMATED BRIDGE DECKING

TRENCHING AND PIPELAYNGG
BRIDGE INSPECTION AND MAINTENANCE

PAVEMENT DNSPECTION AND REPAIR

TEMPORARY BRIDGING

3. Please rate the following six proposed technologies based on the ease of implementation in highway construction, maintenance and operations (1-6):

SITE INTEGRATION

AUTOMATED BRIDGE DECKING

TRENCHING AND PIPELAYING
BRIDGE INSPECTION AND MAINTENANCE

PAVEMENT INSPECTION AND REPAIR

TEMPORARY BRIDGNG

4. Please rate the following six proposed technologies based on life cycle cost savings to highway construction, maintenance, and operations (including potential benefits to the environment, traffic, safety, etc.) (1-6):

SITE INTEGRATION

AUTOMATED BRIDGE DECKING

TRENCHING AND PIPELAYING
BRIDGE INSPECTION AND MAINTENANCE PAVEMENT INSPECTION AND REPAIR TEMPORARY BRIDGING

5. For the application areas listed below, please rate the top 6 in terms of the most beneficial to automate, given that the application can be automated:

Project Design
_Planning and
Scheduling
Site Layout
_ Grading
Paving
_Trenching/Pipes
_Retaining Walls
_Concrete Construction
_Rebar Assembly

Project Design

Planning and

Scheduling

Site Layout

Grading

Paving

Trenching/Pipes

Retaining Walls

Rebar Assembly
Bridge Assembly

Site Materials Handling

Locating Utilities

Road Surface Inspection

Crack Sealing

Bridge Inspection

Road Striping

Paint removal and

Application
Snow Plowing

Cutting Grass and Brush

Trash Collection

Traffic Cone - Place Pick

Underwater Inspection

Underwater Construction

Tunneling

Safety/Security/Rescue 
6. Do you use robotics/automation on construction projects? Please explain the current usages and the benefits of robotics/automation and note the problems you have encountered.

7. Please provide any additional comments or recommendations concerning automation and robotics.

Appendix $\mathrm{H}$ contains the responses to questions 1,6 and 7 . 


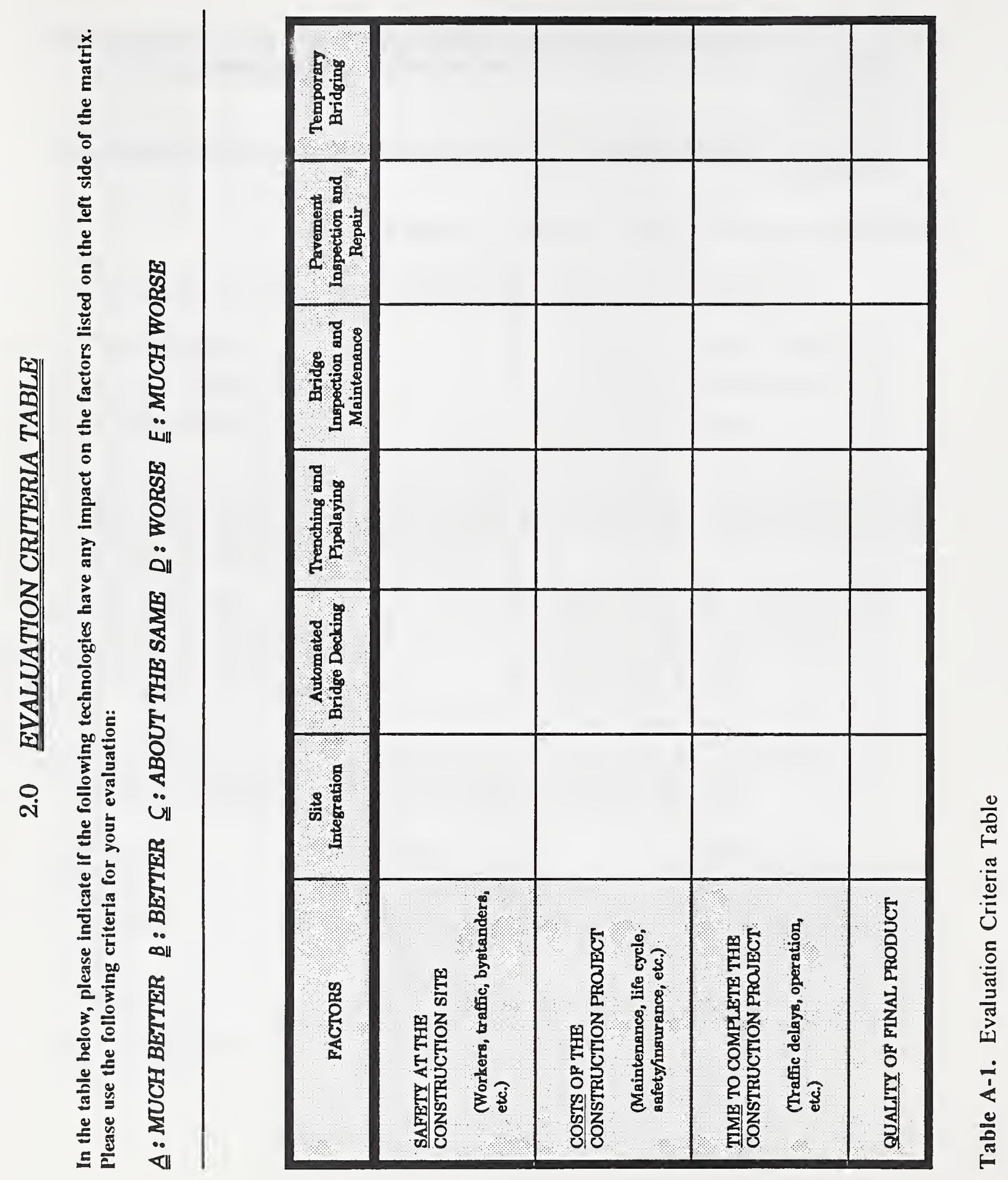




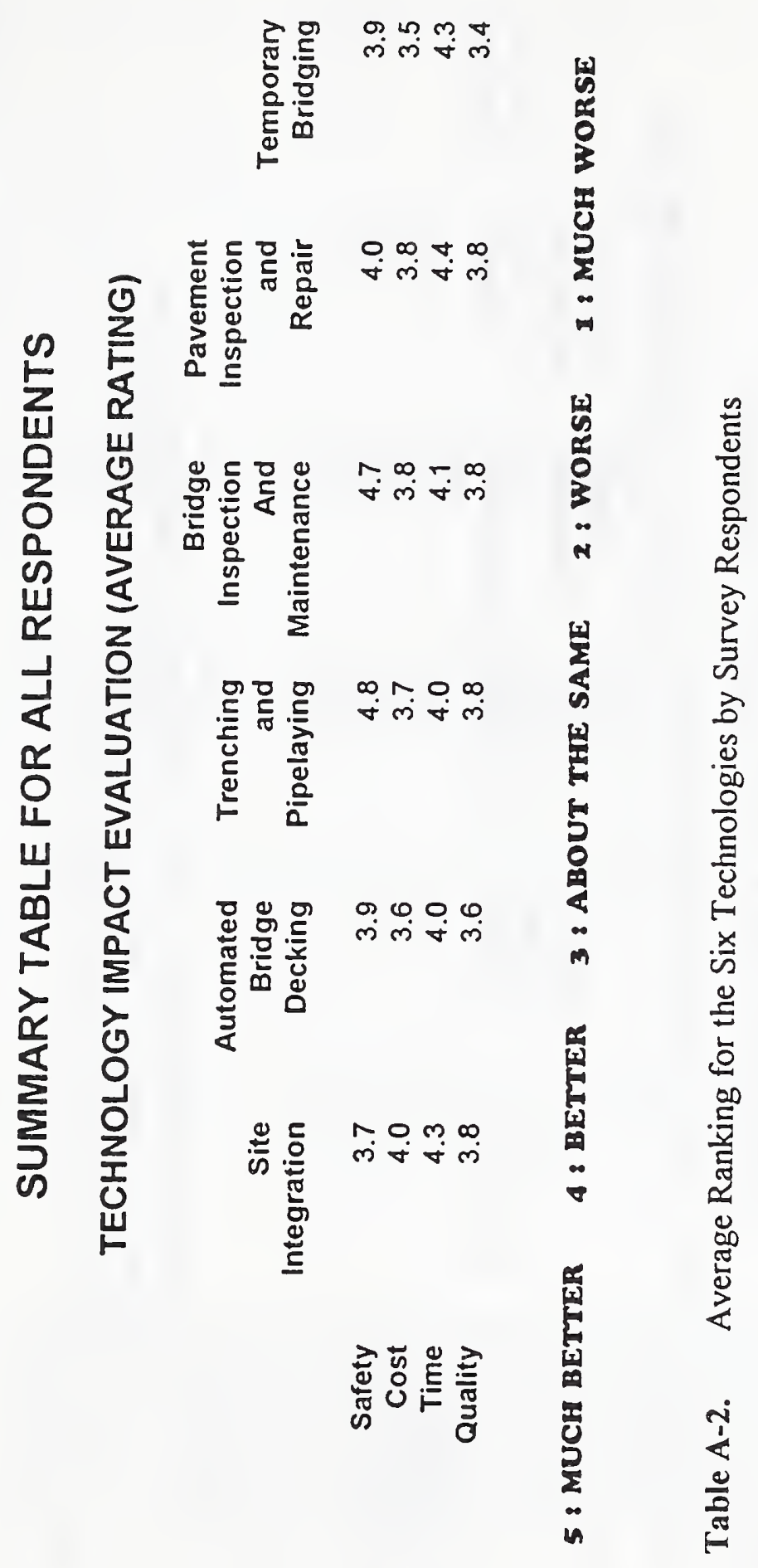




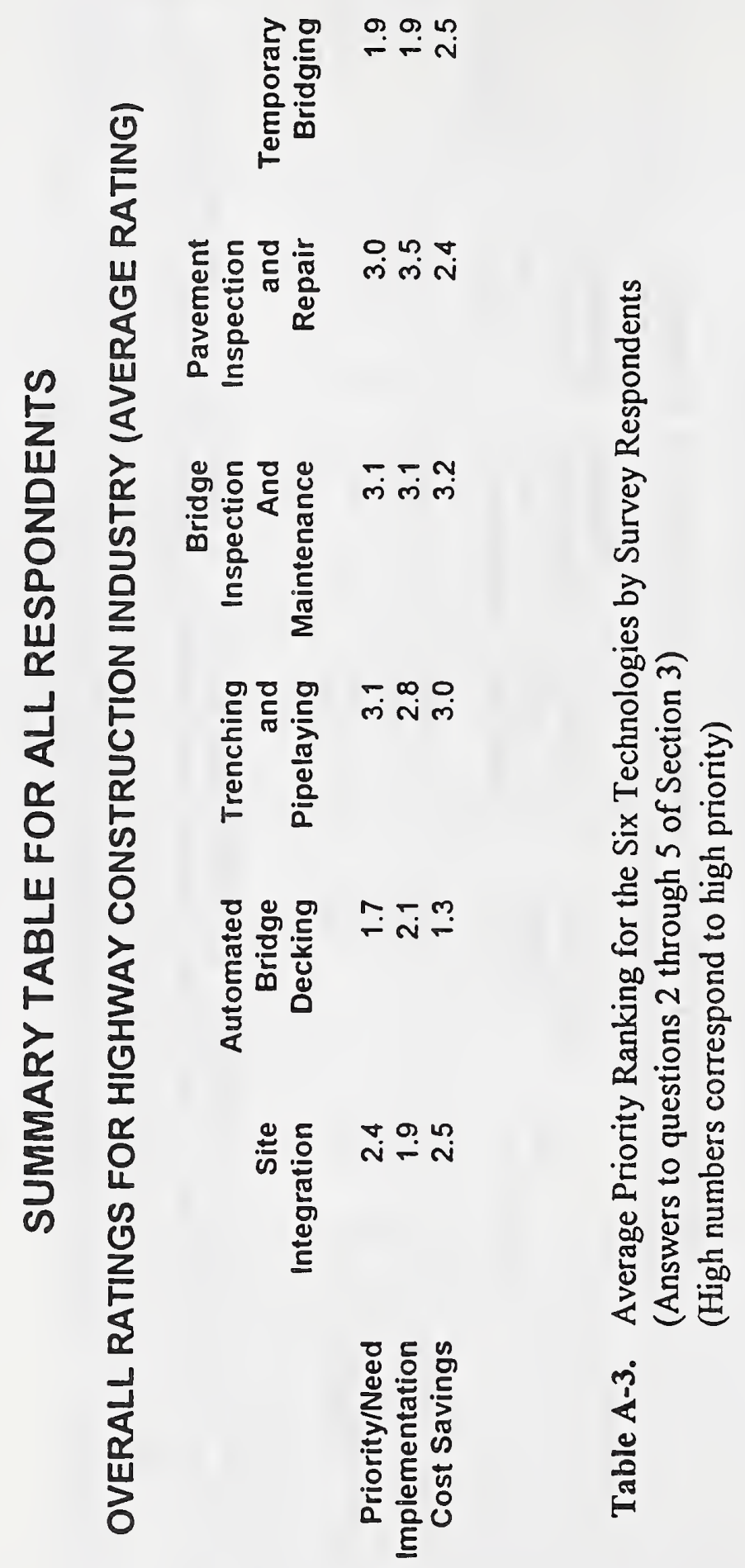




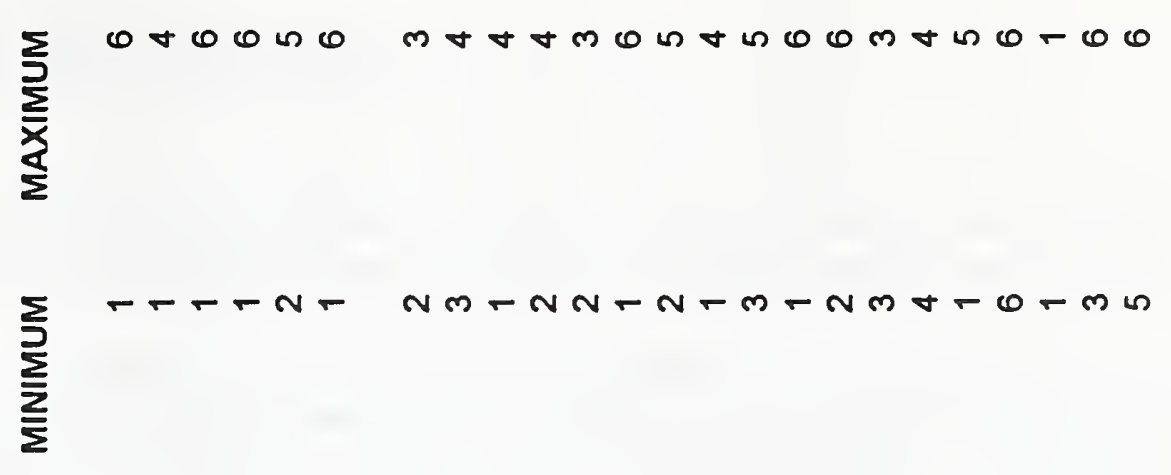

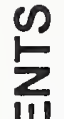

응 Uूu

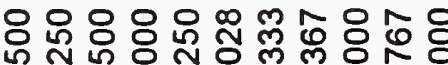

요용

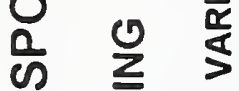
ó

i mo

$\ddot{\sim}$

$\simeq \quad$ 㟧

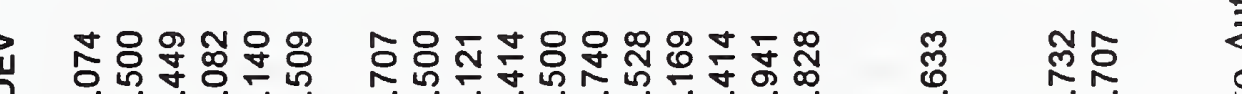
」) 㰻

芯

$\alpha \geq \frac{0}{2}$ nin

o.

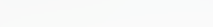$$
\text { (1) }
$$

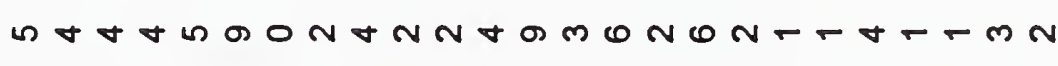

Ł
3
0
0

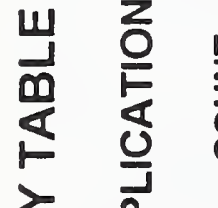

3

$2 \frac{2}{2}$

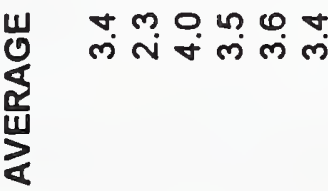

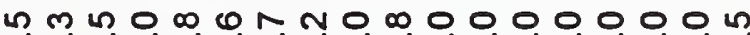

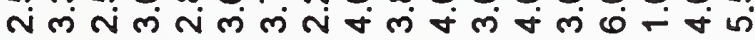
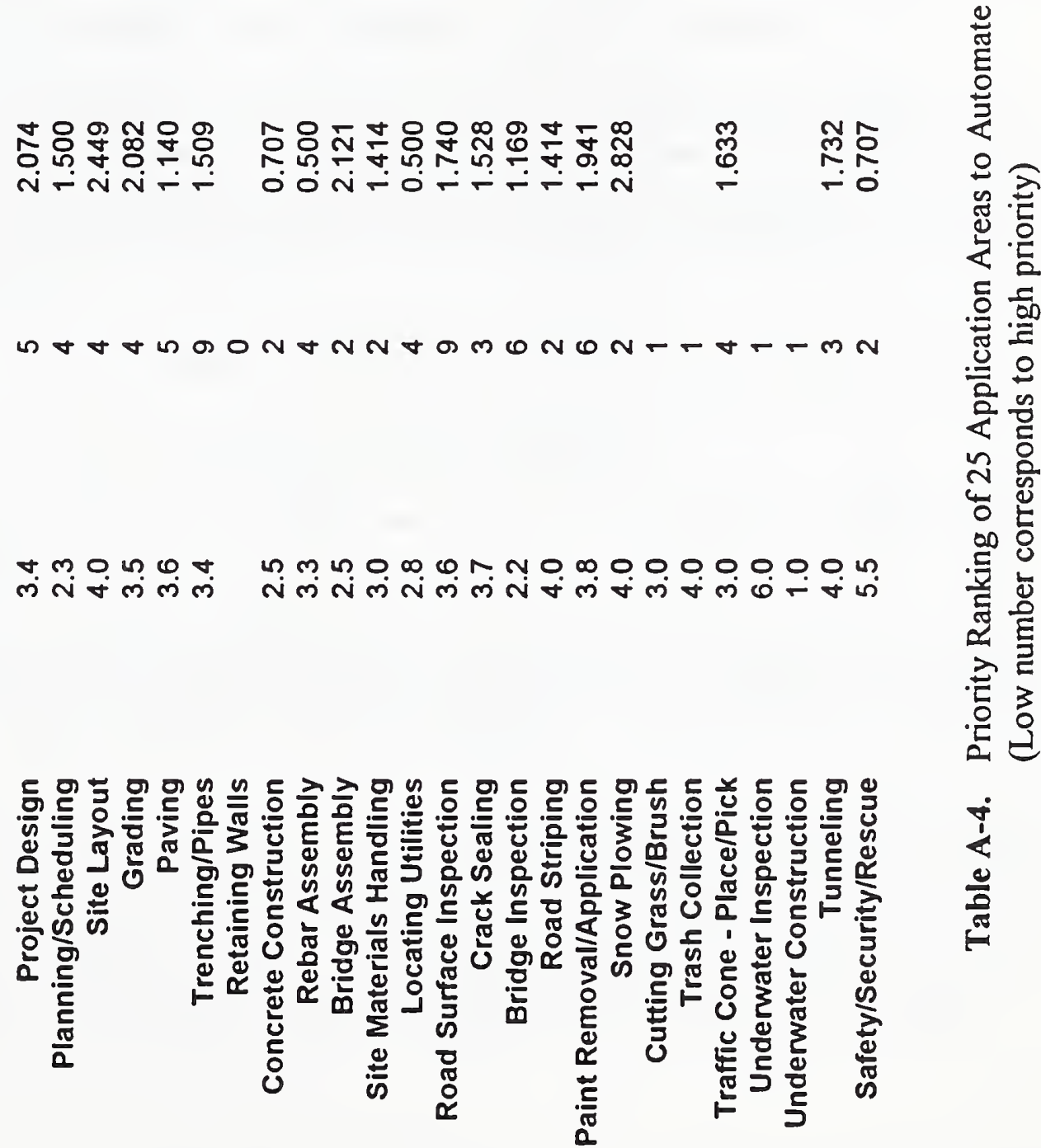

$\frac{1}{0}$ 


\section{APPENDIX B - SURVEY RESPONSE SUMMARY}

\section{SITE INTEGRATION}

\section{Does the proposed technology address a critical problem area in highway}

construction, maintenance and operations? Please explain your answer.

A. Yes. Although I think the proposed potential of reducing construction time by $50 \%$ is unrealistic, there is a need for better planning on today's highway projects. This is especially true for renovation projects in populated areas. Current efforts are very slow and troublesome to all involved. Much better long term integrated planning tools and methods could be very beneficial. The weak link is the human link in the management system.

B. This proposal addresses a critical problem in highway construction.

C. Yes. The greatest loss on construction projects is related to poor planning, lack of communication and proper coordination of effort to ensure that duplication is removed from the process. Updating work schedules and identifying equipment, material and labor requirements through each phase of the process is essential to good project management.

D. Yes, labor time is the highest variable in the construction of a finished product.

E. Yes: many, if not all, phases of work can be improved.

F. Yes. Day to day scheduling of the work site by the Contractor is challenging and time consuming.

G. Would not consider the problem "critical." Current methods available for project management (CPM, PERT) are seldom necessary for use on [State] DOT construction project. Present technology is more than adequate to meet the need for most projects.

H. This project does address a critical area within highway construction, maintenance, and operations. It has been documented on several occasions that the ability to influence the cost of a project is the greatest nearer the front end of the project. Decisions made during the conceptual and design phase can drastically impact the construction cost of a project. Therefore, any effective way of being able to integrate the vast amount of information which must be accessible to various levels of personnel is critical. 
I. The proposed technology does address a need in the highway construction area. Hierarchial integration and control of all site activities is currently accomplished through the job foreman and his assistants. Of course this is prone to human error, misjudgments based on lack of information, and less than optimal integration due to human limitations and lack of time.

Computerized systems are used to some degree away from the site to track critical path progress, scheduled deliveries, check material lists, etc. Integration of all of these subsystems into a central hierarchical management system as a tool for the job foremen currently does not exist.

Some state of the art tools and techniques are used for site assessment and "as-built" plans for new projects reside on the CADCAM system. Integration of these technologies for real time tracking of project progress currently does not exist.

K. Yes. Anytime the "unknown" or "unforeseen" can be anticipated with a pre-conceived thought out plan, there is bound to result a cost benefit. This proposed Hierarchical Control process presents the opportunity (whether it be short, medium or long term) to exercise a pre-planning process to overcome and improve upon inherent inefficiencies in the execution of our work tasks. However, I do not believe that the Hierarchical Control methodology will improve upon all of the examples listed in pages 7.9, nor required in all.

L. This would have a positive impact on some large projects, but many smaller projects would benefit only marginally. Bridge projects would probably benefit the most.

M. The proposed hierarchical control technology addresses a very critical area of highway construction. Use of technology allows an approach which minimizes costs associated with construction delays that occur because of unplanned events, such as weather and congestion. This technology also allows better construction project planning. In this sense, planning then becomes a dynamic function that can occur throughout the construction process.

This approach fits in with the new "open systems architecture" development currently underway at Michigan Department of Transportation.

Yes. Many opportunities exist for automation techniques in the scheduling of project resources and the use of disparate data to optimize the use of resources. However, there is a great deal of inertia to overcome. "We've never done it that way before." While there are several potential areas for improvement, $50 \%$ reduction is high and development of the databases and integration of all possible alternatives may be too cumbersome. 
N. Time is a critical factor and having a better system to control the elements of construction that can be controlled probably would be a major help. However, I don't believe that a $50 \%$ reduction in time is possible. Weather is the most critical factor controlling project completion and little can be done to control the weather. Without a doubt contractors could be efficient but I would be surprised if the reduction due to better scheduling and/or automation exceeded $20 \%$.

O. I do not think that it is critical. It does present the next step in a logical progression forwards more automation of the construction site. The main reason that it is not considered critical is that less than a majority of contractors currently use simple scheduling to its full advantage. There is a serious lag of technology and implementation in construction. It is a timely research project because sensor technology, data acquisition and processing, and implementation protocol needs to be research now so that these advancements can be incorporated into construction, If the proposed $50 \%$ improvement is based on nonscheduled construction then it is achievable. However, if the $50 \%$ improvement is based on fully scheduled (current technology) then the improvement is more likely to be 10 to 15 percent. Too much material and equipment has to occupy the same space.

P. Certainly project scheduling and coordination is important but I am not sure it is critical. I do not believe that construction time could be reduced by half. Also, I believe that we should be concentrating on quality and costs, not necessarily time.

The short term efforts could certainly be helpful for project coordination and scheduling. However, generating plans from automated survey data is already being done. Also, databases for logistics and scheduling (project planning) are already being used.

Long term efforts for semi-automated control may require very large, complex computer systems, which could easily cost more than the time saved. Data input needs could also be overwhelming.

2. Briefly describe the current procedures in highway construction, maintenance, and operations which the proposed robotics/automation technology will replace or change.

A. Current efforts on large and/or complicated projects often result in serious delays and cost overruns due to unforeseen sight conditions which take much effort to resolve with current planning and management approaches. Quick access to accurate data sources would allow for vastly improved project schedules and reduced interruptions to the general public. This is especially true for construction and maintenance activities. 
B. Currently such a system is not used. The goal of the proposed research is to utilize advanced control techniques to dynamically reschedule the equipment on a site, as well as to coordinate the arrival of materials and relocation of men and equipment based on the current state of the site.

C. Computer aided design systems can be utilized to sequence and then track both large and small scale construction projects.

D. Scheduling on the jobsites are currently controlled by Prima Vera systems. It is difficult to control last minute changes which upsets the schedule.

E. All information dissemination and coordination procedures.

F. Optimization of the placement of delivered materials as well as the timely scheduling of those materials could be very beneficial. Knowing the exact quantity of material removed from or placed in a site could be very useful for figuring pay quantities.

G. Since CPM and PERT are seldom used by [State] DOT construction personnel, this technology could replace an essentially non-existent (not needed) procedure.

H. Current procedures are fragmented and techniques are inconsistent. CAD tools are often not utilized to their maximum potential. In some cases they are still only viewed as a drafting tool. In other cases they are used in the preliminary costing and assessment, but not in the planning and operations. Even though CPM and PERT have been around for many years, they still are not used to their maximum potential. Some contractors only develop them because it is a specific requirement. They do not use them as a planning or decision making tool.

I. Currently it is the job of the site foreman to deal with unforeseen and changing events. However, the site foreman can only foresee his local activities, and therefore lacks information about events at adjacent or other worksites. This lack of global information makes the current procedure somewhat inefficient.

Site integrations should also promote the use of some advanced techniques and equipment that might otherwise not be used. An example of this might be the realtime update and distribution of CAD/CAM "as-builts" due to unforeseen changes. Another example might be the increased use of advanced metrology techniques for real-time monitoring of the worksite progress.

K. I am enclosing a copy of pages 7-9 wherein I have noted a matrix of A, B, C, or D. I have also designated my definition of this matrix which will enable you to analyze my response to this question. 
L. Some "site integration" is already done on our projects with our project tracking techniques. This technology would improve on our current techniques and complement the critical path method on some projects. Some projects would not need this new technology because solutions are intuitive.

M. Currently projects are developed and managed without the use of hierarchical controls.

There is considerable variation in the level of automation and it is difficult to generalize. However, it may be safe to say that we still operate in a proper system with little useful data interchange and we rely on skilled foremen of superintendents working with the project engineer's staff to get the job done.

N. The proposed system would make maintenance and construction operations more efficient just by mandating more thorough planning. Hopefully all work that could or should be done during an operation would be done. No more duplication of effort because all requirements or needs weren't known.

O. Assuming that certain features are required.

1. It would force contractors to utilize scheduling.

2. The term maintenance maybe misapplied. It is likely that reconstruction is the correct and more general term.

P. Project scheduling, coordination, delivery, and project planning in the short term. Actual equipment operations (grades, trucks, pavers, loaders, etc.) in the long term.

3. What are potential barriers to adoption of the proposed technology? What will it take to overcome these barriers?

A. Accurate data of existing highways, especially underground obstacles, odes not exist. Also, convenient tools which are user friendly for field personnel do not exist, at least are not readily available. There will be natural resistance of current managers to adopt automated technologies over their time-honored approaches of supervision and planning.

B. No major potential technological barriers.

C. As with any new technology, the resistance to deviating from the standard "old" approaches will probably create barriers to acceptance of the new technology. Training and demonstration of success will increase the confidence levels and at the same time make the user a part of the changed process. 
D. Training of personnel to adopt to the latest technologies.

E. Very serious barriers due to fragmentation of industry.

F. I don't see the need for moment to moment communication with the operator. From a safety standpoint this could be dangerous and distracting. Although the idle time of an equipment operator is expensive and wasted, the costs incurred through robotics to minimize the delays would be high.

Delays caused by utility disruptions are usually unforeseen due to poor utility location. For the robotics system to function properly, prior knowledge of the exact location of all utilities would be needed. This is very seldom the case in the field.

G. Proposed technology vastly exceeds the need for such a system. Examples cited in the proposal are not at all realistic to typical highway construction site. Technology should be tested in factory type environment before even being considered for highway construction site. Even if practical to use, the overhead cost of system development operation and maintenance would add significantly to construction in management cost due to "high tech" systems used \& technical skills needed.

H. The greatest barrier to the adoption of the technology once it is developed is to get the potential users to try to utilize it. For example, examine how long it has taken for CPM to be utilized at today's level, and it is still not being utilized to its maximum potential. Now, this proposal is interested in developing a much more comprehensive technology.

In order to overcome this barrier the end users must be involved in the development process. They must play an active role. This is important to insure that the real problems are addressed.

I. Development and integration of a hierarchical control system architecture for site integration will depend on availability and integration of many different subsystem technologies. many of the technologies may not have been time tested at construction sites. Many of the technologies may not be accepted and used by the construction industry. It would therefore be necessary to perform detailed evaluation, testing and demonstration of these technologies prior to overall integration. it is necessary to understand the risk envelopes associated with each technology and the overall development of the architecture. This will help minimize risks during deployment of this technology. Are there enough proven technologies that can be integrated at a site to be of some benefit to the end user? If so, this might be a first step. If not, the technologies to be integrated might be introduced and used independently prior to integrations. 
Cost/benefit at particular construction sites might be a barrier to implementation. Skepticism to the new technology and reliance on proven methods will also prove to be tough barriers to implementation.

K. The most visible barriers to me would be the various trade unions, and more, what do we do, what's the "Labor Force" that will be replaced with these "Robots"?! With the existing underutilized work force, both skilled and unskilled, we will be improving productivity and safety plus, but compounding an existing national problem. Can this system be "Sold"??! Also, can we train our existing "unskilled", i.e., non professional, work force to manipulate all of these sophisticated new "tools"?

L. 1. People that don't want to change methods and give some of their management responsibilities over to a machine.

Explain benefits of using this technique.

2. "Urgent" situations that seem to override the suggestions that come from the information system.

Reassessment of what really is urgent and important.

M. Potential barriers to adaption of hierarchical control include: (1) lack of resources to collect and store data required for such a system; (2) lack of resources to train staff in using this system; (3) lack of acceptance of this system by departmental personnel. Devoting resources to develop system means that funding would be cut from construction budgets. Additional resources must be acquired. The resolution of problem \#3 will come only when staff is fully trained not only on this type of system, but on computers in general. This will greatly enhance public acceptance of this approach.

Technology will likely not be a barrier, rather traditional practices and mindsets as well as established procurement practices, etc. Once a few examples of efficiencies can be demonstrated, competition will force changes.

N. Cost/Benefit. The technology needs to be demonstrated on actual projects to prove the benefits possible, without actual field tests I don't see much chance of acceptance.

O. 1. Sensor and data acquisition and processing technology.

2. Work-force not just education of existing work-force but a work-force trained in electronics and computers. 
P. Project planning is already being done.

The cost and complexity of the computer system for the long term effort may cost more than the time saved. For both the short term and long term efforts, much data would have to be input into the system. If this requires manual input, personnel time won't be saved. Computer software for long term effort is significant.

4. Assuming that barriers to adoption are resolved and that the proposed technology achieves its stated performance goals, please estimate the potential savings (in dollars) for highway construction, maintenance, and operations projects for the following categories. Please refer to Attachment 1, "Site Integration Present Cost Data" for background information on the average estimated costs associated with highway construction projects. If you have better cost data or information available, please use it and explain how and/or where you obtained the information.

NOTE: Please label N/A if you feel a category does not apply to the proposed technology

a. More efficient use of time

Significant decrease likely due to systems support costs.

I do not think any time will be saved during the design phase. Data acquisition and input will be very time consuming. In my opinion, it will probably take more time on the front end of the project. The exception would be if the system were extremely user friendly. My comments are based on what it takes to get a CAD system up and running effectively for a specific project.

Yes.

b. Increased productivity and reduction of manpower requirements

Significant decrease

I think overall, especially on extremely complex projects, if all parties are working as a partner, then the savings would be substantial.

Less redundancy of equipment and manpower $10 \%$ cost savings, may be $15 \%$

c. Maintenance costs

On complex projects the maintenance cost could be substantial because of the quality and quantity of information which could be available.

d. Increased service life of final product

This is largely related to quality

e. Life Cycle Costs

I do not feel comfortable trying to estimate "LCC" for this technology. The acceptance rate will be very slow. LCC savings could possibly be in the $10 \%$ 
range.

$2 \%$ savings overall on project $(\$ 5,000,000$ per year in [State]) savings

Somewhat related to quality, type of materials, design etc.

\section{f. Worker training}

Increased training required

Expected increase in worker's training time and cost

Huge increase in worker training demands plus add new people with high tech.

skills for support.

Worker training will be a problem. It will take a formal program with a high level of effort and a lot of expense. This comment is made based on my knowledge and experience with training personnel to operate automated micro-tunneling machines. As mentioned above a new work-force will need to be educated (electronics, computers, and construction)

$10 \%$ savings - less duplication. $\$ 10,000$ per job or so.

g. Other factors associated with initial cost

Initial cost of hardware and software

The learning curve. Do not underestimate the level of resistance.

$\$ 10,000$ extra in start-up costs to get it going

Mobilization would be less.

h. Safety (eg. insurance costs, liability, workman compensation, etc.)

Safety should be enhanced with the total system as it is described. This should at some time in the distant future impact insurance costs. However, I do not think the influence or impact will be substantial.

Some improvement

\section{i. Environmental impacts}

Positive impact

Very little

Less equipment, less time both would have to have a positive impact.

j. Less traffic delays (ie., how it effects the productivity for people in traffic, productivity for the delivery of goods, etc)

Major impact on traffic delays (less delays)

Increased

Traffic delays could be decreased if it is used extensively and effectively.

Less equipment would reduce traffic delay, but really traffic delays not addressed in most positive way. If traffic delays reduce would have tremendous impact on cost to user. 
k. Less repairs due to an improved quality of final product

l. Other (please specify)

Overall savings $5 \%$ on some projects

5. If automation/robotics could be applied to current highway construction, maintenance, and operations, do you think this proposed technology will meet the performance goals set forth in the proposal? Please explain your answer.

A. I feel that significant improvements in performance would be possible -- but not as much as proposed by authors.

B. This is an excellent proposal. Very practical. It clearly defines the objectives. The methodology and proposed technology are well defined.

C. Yes. To some degree, portions of the proposed technology is already being used. The drive of competition alone will cause the adoption and development of the technology.

D. No, the goal of saving half the time seems idealistic. Most construction projects have built in time conflicts which would not allow those proposed savings.

E. Yes, but barriers will be hard to overcome.

F. It may meet the performance goals but I don't think it would be cost justifiable.

G. Such automation should be tested in factory/manufacturing environment before any consideration is given to applications at job site.

H. No, I think it is unreasonable to think that $50 \%$ of construction time could be saved just on hierarchical control for the integration of all activities at the worksite.

I. Yes, assuming that the technology is accepted and used correctly by the site manager or foreman. This type of technology has the capability to ultimately speed up project delivery, make more efficient use of resources, help to provide for a better end product, and relieve the pressure often associated with managing large projects.

Another benefit, just as important, is the development and use of the technologies that will build the foundation of this ultimate site integrations system. Often times it takes a major integration project to push the "state of the art" in some technology arenas. An example of this is the advances in computer technology over the last ten years sparked in a large part through military buildup. 
$\mathrm{K}$. Yes, but not by as much as $50 \%$. There is no question that there will result a reduction in lost time, idle time, equipment down time, re-work, and labor inefficiencies. Also there is no question that the resulting end product will be of better quality.

L. Do not feel a $50 \%$ reduction in time is possible on most projects. Some savings will be achieved.

M. The technology has high potential for meeting the performance goals set in the proposal if the necessary resources are put into system development and user training. This type of system is currently being developed at the Michigan Department of Transportation and these concerns are being addressed. The importance of accurate information, user-friendly interfaces and reliable system operation should not be understated.

N. No. Weather, changed conditions and design errors will reduce the available benefit.

0. No. I think the potential savings is overstated. There are existing scheduling techniques that contractors are not fully utilizing. One of the big problems is that a certain volume of material has to go into a given location in a timed sequence. "wo pieces of equipment cannot be operating in the same space. It would appear that contractors would reduce equipment and staff to reduce overhead first. General contractors depend and in many cases are required by law to use subcontractors that control construction events. Their technological abilities are limited. The proposed research area would be more feasible if a master format were proposed and areas rigorously developed and then integrated.

P. No, I don't believe time can be reduced by half. Also, computer and automation costs must be considered.

I would rather this project concentrate on a better quality and reduced costs, not just reduced time.

\section{General comments concerning the proposed technology.}

A. The proposed technology is feasible to develop. It will take time to develop and implement, but it can be useful if designed practically.

B. High impact on highway construction.

C.

D. The focus should be very specific for each phase of the site. 
E. Most potential of those identified.

F.

G.

H. There are too many planning and evaluation tools available at the present time which are not being fully utilized. I am concerned about funding more research to address a problem which the industry does not see as the real issues impacting productivity and cost.

I think that the question needs to be asked and research conducted as to why current programs such as computer simulation, etc., are not being utilized.

I. It is important to recognize that while there may be some similarities between highway construction sites and building construction sites, there are also many differences. A technology that may work in the building construction industry may not withstand the hostile highway construction environment. Highway sites are typically adjacent to other lanes of high speed traffic and there is a constant potential for a workzone penetration. Theft and vandalism is a constant concern as most sites are not secure.

Previous work in the area of site integration has occurred previously and needs to be thoroughly investigated including the basic technologies utilized and end user acceptance.

K. I would predict that the industry will be very supportive of the majority of the program and that the end result will have to have a positive effect on the demands of the diminishing availability of public funding for our required infrastructure.

L.

M. None.

N. Definitely on the more complicated projects a thorough and dynamic scheduling system would be a benefit. For the smaller projects with few activities, doubt that the benefit gain from the technology is worth the effort. Today we don't require CPM's on all projects. Even though they are simple to construct, it doesn't change the completion date or bottom line.

O. I do not think that the panel understands the construction process well. Overall this is not a short term project.

- Implement current scheduling technology is short term. 
Who would do research?

Might have UPS, Fed-Express to do early integration they seem to have first or second generation system operating.

P. 



\section{APPENDLX C - SURVEY RESPONSE SUMMARY}

\section{AUTOMATED BRIDGE DECKING}

1. Does the proposed technology address a critical problem area in highway construction, maintenance and operations? Please explain your answer.

A. Yes. Many bridges in our highway system need replacing or repairing. A major problem is the inconvenience to motorists caused by long project durations. More effective and efficient methods of bridge decking would be very beneficial.

B. Not a critical problem. Although, an automated bridge deck construction can increase productivity of deck construction.

C. Yes. The repair of bridges under traffic is a very difficult process that causes major traffic control problems as well as high safety risks. The proposed technology should improve the quality of the finished deck, reduce construction time and employee risks.

D. Yes. The quality finishing of bridge decks still remains an "art form" dependent on the expertise of the operators.

E. Yes, it is a critical area, but I am not sure of the total value of the work.

F. No. Most of our trouble is with the cutting process.

G. Nationwide there is a bridge deck cracking problem which could be due to many factors such as various concrete mix properties, environment, construction methods. The referred project could increase consistency and some Quality control issues such as preparation, rebar size \& spacing. However, there are some issues that will be difficult for the robot to react to and adjust the process. There are sometimes concrete mix \& grade adjustments made during construction which is done by humans. -Also bridge construction is not a production effort. All bridges differ in geometry \& complexity. Can robots be adjusted for these changes?

-Many states don't use precast panels for their slab construction. This process assumes using the panels for alignment. Slab construction does require consistent \& good construction method and it is critical \& costly problem, however I don't believe Automation can help the problem.

H. This happens to be out of my area of expertise. however, I am certain that bridge decking and rehabilitation of bridge decks are critical areas. 
I. No. Bridge deck construction is not seen as a critical problem. if done properly, current techniques will yield a satisfactory product. Current construction techniques work well. this proposed machine could not adapt to "unforeseen" changes, could only be used for certain bridge decks, and could not do soffit and girder stems of a structure. There are too many variables during construction to visualize this type of equipment as useful. Most reviewers believed the complexity of the machine necessary to accomplish all of the necessary work tasks for a deck pour would not be cost effective.

\section{All reviewers stopped evaluation at this point.}

J. No. The proposal only address a small portion of the overall bridge deck placement operation. More savings would be available thru better steel detailing. The layout of the bottom steel mat controls accuracy of top deck \& proposal ignores this. Most delays in bridge deck operations are due to poor steel detailing, cutting or installation of embedded item this proposal does nothing to address these.

K. Of the several steps enumerated in SECTION ONE: OVERVIEW, I see a very definite need $\&$ advantage in the application of automation/robotics to the laying of rebar, placing of chairs and tying of rebar. This same comment and to the same degree would apply to monitoring the flow of concrete, mechanical vibration, monitoring the supply of concrete, monitoring the constructed deck and floating and finishing of concrete. As far as automating the inspection of subgrade is concerned, my opinion would be that the cost/benefit would not improve enough to warrant the added effort (required). We should insist on better quality control of the existing methodology to obtain more economical results. Overall, automation of the various steps enumerated above would also reduce if not eliminate many of the existing unsafe work practices and unsafe work areas.

L. There may be lower risk/higher payoff issues in highway construction which would benefit from the application of high technology. Automating bridge construction may increase efficiency during construction but may also tend to give the bridge designer less flexibility and tend to foster "standard" designs which facilitate construction. It may be more feasible to develop several pieces of equipment which could be used at stages of bridge construction.

M. The needs in these areas can be better defined, if these issues are discussed in the Bridge Engineering meetings under auspices of the Federal Highway Administration (FHWA) and the American Association of State Highways and Transportation Officials (AASHTO). 
I do not believe the proposed technology addresses a critical problem area. Our critical area is maintenance. I am skeptical of a high technology solution to such a specific problem. I question at what point we would see a return on an investment of this magnitude.

Automation of process of placing reinforcement in the bridge deck seems do able, but what are the increased costs associated with this.

N. [State] DOT views the bridge deck as one of the most critical areas of design and construction of bridges. Over the life of the structure (assuming no major seismic events are encountered), the bridge deck receives the most abuse from traffic loads and environmental effects. It appears that this technology requires the use of sub-deck panels. Currently, this method of bridge deck construction is allowed only on a very limited basis by the[State] DOT.

O. Not really. There may be some benefits. However, placing materials is not time consuming. There could be some time benefit but not much. Material technology is reasonably good. The biggest problem is in locating deteriorating areas and preparing them for repair.

It would seem more beneficial to develop new bridge designs so that inspection is facilitated and decks can be replaced as modular units.

P. Although I am not familiar with bridge deck construction, I do not believe that this is a very critical problem area. Bridge deck construction procedure seem to be well established.

Q. Yes. Manual placement and tying of rebar could readily be replaced with machinery for cost savings in reduced labor, efficiency of placement and tying due to human fatigue

- Measurement of the finished product (deck) while it is in a stage which would lend it to being changed if not conforming to specification. Prevent grinding, this process would improve over all quality of the deck.

2. Briefly describe the current procedures in highway construction, maintenance, and operations which the proposed robotics/automation technology will replace or change.

A. Current bridge decking operations are very labor-intensive and often very slow, except for concrete placement. The proposed technology would eliminate some of the labor required and would speed up the whole process. 
B. Bridge decking is done at site or by prefabrication. The goal of the proposed research is to show how incremental automated capabilities can be added to today's technology.

C. Greatly improve inspection process and reduce the number of inspectors needed during construction. Reduce the number of laborers needed and reduce the amount of materials needed by more accurately controlling additives and material placement.

D. From the grading of the last deck, screed pipe, setting the finishing machine, placing the concrete and finishing the traveled surface, particularly at the start and end of the concrete placement, could all benefit from improvement.

E. Deck construction using traditional methods.

F. The hiring of minority contractors. Requirement of large investment would not be justified. If system worked, use would be limited to very large project which composes a very small percent of work.

G. Currently bridge deck construction is performed by humans. All inspection is done by a human prior to steel laying and concrete pour. All quality assurance tests are done by humans at the site.

H. Rebars are placed manually, but the placement of, screeding, and finishing operations of concrete are mechanized. manual labor is needed to assist the equipment such as spotting uneven areas, etc.

I.

J. The substructure/girders are profiled and marked for installation of bottom deck forming. Deck forms installed and approved. Iron workers lay out \& place bottom deck steel. Any imbeds placed, then top matt of steel placed. Bidwell rails set \& girded and deck thickness checked. Concrete then placed, skreeded, tined \& [?].

K. My answer here I believe would only be redundant, given the written description in most cases of the now "labor" intensive operation, which would be replaced, as I have outlined above in replacing the various "manual" operations with Robotically controlled disciplines. I would also emphasize the vast improvement, over time, in labor cost and to a lesser extent, material cost.

L. Construction practices will be dramatically different using the proposed automation. The largest difference will be during the deck pour with the robotics/automation performing many tasks in a much shorter period than current methods. This will most 
likely reduce the labor content of bridge construction and compress the construction schedule.

Should the automated deck construction prove to deliver a higher quality product, maintenance activities will be affected. Typical maintenance operations on bridge decks are to fix delaminations and cracks as a result of the application of deicing chemicals. Higher control of the materials going in to the bridge and better curing procedures could reduce maintenance operations.

The design process will have to adapt to the use of robotics/automation in bridge construction. The designs will have to be simplified and standardized so that the new technology can be used in as many instances as possible.

M.. Bridge deck inspection, using the radar and automated measurement ability, will be great.

Monitoring scour conditions of important water course crossings can be attempted by using the robotics/automation technology.

Construction inspectors would not have to spend as much time with depth checks, steel placement, etc., during construction. Most of the cost savings (if any) would be from the reduction in construction personnel.

N. Bridge deck construction is very labor intensive. There are many elements with many variables that must be dealt with. In multiple span bridges, the deck reinforcing varies considerably due to high negative moment stresses at interior piers. Stage construction of bridge decks (not continuous construction of the deck) is very typical of our current designs. The effects of varying girder camber and adjustment for minor construction deficiencies must also be accounted for. It is assumed that all falsework and formwork will be constructed with conventional methods.

O. Not much. Some minimal savings of material and fine.

P. Not familiar with current procedures.

Q. Manual tying of rebar Manual placement of the concrete in front of the finishing machine.

- Manipulation of screed controls and adjustments

- Manual placement of rebar

- Deck grinding

- Programming of the screed for different configuration of the deck. 
3. What are potential barriers to adoption of the proposed technology? What will it take to overcome these barriers?

A. The development of cost effective equipment may take time and much money to develop. There will be much skepticism about eliminating human resources from these operations. Also, better design procedures must be developed to accommodate uniform equipment dimensions with respect to final bridge dimensions if cost effective methods are to be developed.

B. Potential barriers are: current state of the technology in such areas as sensor systems, and hardware development $\&$ cost.

C. Changes will be needed in specifications and acceptance of automated inspection and control processes.

D. Training of current personnel.

E. None really

F. Large investment would not be competitive with methods now use.

G. -Justification of increase in productivity. It is difficult to prove the productivity advantages when most bridges are different in geometry $\&$ other characteristics. -possible job elimination

-Capability of adjusting \& reacting to problems during construction.

-This project should be tried out in a controlled environment several times and tested and compared to projects built by humans.

H. I see nothing in what is being described that does not seem doable. The barriers are simply in selecting the components and ensuring that it is designed to be sued in the field and that it is compatible with the typical contractor's overall operation.

I recommend that contractor involvement be a fundamental part of the research process.

I.

J. Length of paving train. From description would require a 6 or 7 piece train. There is simply not enough room around most bridge pours to accommodate this much equipment.

Cost would be very high with little if any benefit in final product. 
$\mathrm{K}$. Once more, the most difficult Barrier to overcome, is the same as previously mentioned, i.e., Organized Labor Unions - Difficult because the success of automation would be compounding an existing problem which I don't see be alleviated in the near future, i.e., an under utilized workforce. One other Barrier, to a lesser extent, in my opinion, but one that has impact, is the time/\$ req'd "to get there." This is difficult to analyze because there were no "goals (time wise")

L. One of the greatest potential barriers is the reluctance to change in the highway construction industry. This technology would be a radical departure and not without posing some financial risks to the contractor.

It may be possible to overcome this barrier by using the new product in several highly visibility demonstration projects and making all construction details available to contractors and highway agencies.

M. Increased cost, training and update: are barriers. Get right people involved (bridge engineers) and construction engineers from the start, right from the beginning.

Proven prototype in all weather situations.

As with the any unproven technology, I question how long it will take to get the bugs out of this system.

N. a) Flexibility of the technology.

This technology must be able to accommodate numerous factors including:

- Varying geometric conditions (i.e., [?], curves, skews, varying crossslopes).

- Varying reinforcing in bridge deck.

- Differential girder camber.

- Adjustment for minor dimensional deficiencies.

- Stage Construction.

- Varying concrete consistency, interrupted concrete placement, finishing \& curing of concrete.

b) The technology should be user friendly. The construction industry must view this technology as cost-effective to assure acceptance for use. It is suggested that the construction industry participate in some manner in development of this research.

c) Cost.

The technology should be developed to address these barriers.

O. There will be some training required, but no major problems. 
P. There still seems to be a large number of manual steps in the described project.

Q. Automation must be cost effective - verses manual labor - cost of labor/hour insurance cost, etc. Architectural changes which will lend themselves to automation repetitive design - involving architects in the automation process.

4. Assuming that barriers to adoption are resolved and that the proposed technology achieves its stated performance goals, please estimate the potential savings (in dollars) for highway construction, maintenance, and operations projects for the following categories. Please refer to Attachment 1, "Site Integration Present Cost Data" for background information on the average estimated costs associated with highway construction projects. If you have better cost data or information available, please use it and explain how and/or where you obtained the information.

NOTE: Please label N/A if you feel a category does not apply to the proposed technology

\section{a. More efficient use of time}

- None - could not be used on $95 \%$ of projects

- Time could be used more effectively if more of the process were automated.

- No.

- I have no problem agreeing with your conclusion of an average $30 \%$ increase in production. And relative to re-bar operations this figure would be in the $40-50 \%$ range -- consequently, the stated labor costs would reduce accordingly.

- Since this technology could compress the construction schedule, bridges could be built in a more timely fashion. thereby reducing motorist delays. No information on costs.

- No idea of potential benefits. However, the goal of the research should be to reduce construction time by a minimum of $25 \%$.

- Minor

b. Increased productivity and reduction of manpower requirements

- The savings here could be substantial and the contractor could optimize its utilization.

- No. Would take more time to set up yet not shorter production times.

- Both of these stated would occur without doubt. Productivity in the areas mentioned above would probably increase $25-30 \%$ whereas manpower req'ments decrease by $10-15 \%$ with exception of re-bar ops. -- this maybe as much as $25 \%$.

- Agree with $30 \%$ estimate for lack of better knowledge.

- No idea of potential benefits. However, the goal of the research should be to reduce construction time by a minimum of $25 \%$.

- Minor 


\section{c. Maintenance costs}

- I have no idea, but probably will not be impacted.

- Depends on increase in bridge deck quality.

- If quality of construction can be improved, the life of the structure would be increased, thereby reducing maintenance costs. No idea how much.

- Minor

\section{d. Increased service life of final product}

- Probably will not affect the service life.

- Not much or N/A

- Depends on increase in bridge deck quality.

- If quality of construction is improved, yes. No idea of cost savings.

- Some. Related to material.

\section{e. Life Cycle Costs}

- LCC could be decreased if the construction costs are decreased. In some cases automation does not result in lower LCC. It depends on many variables. This is why some tunnels are still executed by hand even though sophisticated "high tech" tunneling methods exist.

- If product is constructed at lower initial cost and is of equal or better quality, this technology will lower the life cycle costs of bridges.

- Improved if quality of construction is improved. No idea of cost savings.

- Some. Related to material.

\section{f. Worker training}

- Additional worker training is required

- Would require highly trained personnel that could not be retained

- Worker training will be a key factor to the success of the system and amy cost savings.

- Would require more operators trained on wire controlled equipment. Inspector training costs associated with setting up \& interpreting [?] data.

- Would become initially more expensive due to the necessity to teach new methodology.

- More worker training will be required. Most construction workers have little formal education.

- More technical training required. No idea of cost.

- Some

g. Other factors associated with initial cost

- Major initial cost of hardware \& software

- Only one use - most bridge construction equipment can be used under any site condition 
- Equipment cost \& setup

- Commercialization costs will be high. It will probably require many demonstrations across the country.

- An effect similar to "re-tooling"

- Most likely this will be an expensive machine to purchase and maintain.

- Increased equipment cost and maintenance.

h. Safety (eg. insurance costs, liability, workman compensation, etc.)

- Safety could be enhanced.

- May increase insurance costs \& liability to extra equipment. Since it reduces handling of rebar may reduce workman's comp claims in this [?].

- Should have a considerable decrease on cost however to a great extent on the competitiveness of the insurance dependent market place.

- This technology should improve worker safety by automating several hazardous tasks that workers perform.

- Safety to workers should be improved. No idea of cost savings.

- Some

i. Environmental impacts

- Positive impact

- Minor

j. Less traffic delays (ie., how it effects the productivity for people in traffic, productivity for the delivery of goods, etc)

- There is no question, I believe, that there would be positive impact resulting from automation on services delivery as well as people in traffic.

- Some

k. Less repairs due to an improved quality of final product

- Not a major change

- Absolutely affirmative. This dovetails with " $e$ " above.

- Depends on increase in bridge deck quality.

- Valid if quality is improved.

- Some

l. Other (please specify)

- Waste of money for development. R\&D money could be better spent on materials and construction (design) that allow for off sit production. 
5. If automation/robotics could be applied to current highway construction, maintenance, and operations, do you think this proposed technology will meet the performance goals set forth in the proposal? Please explain your answer.

A. The improvement could be close to that proposed, but more likely $20-25 \%$ increase in productivity than $30 \%$ to $50 \%$ mentioned.

B. It would be difficult to reach the goals set by the PI.

C. Yes. Would appear to have a high potential for producing a uniformly higher quality deck with less risk and disruption of traffic.

D. The goal of $30 \%$ time savings might possibly be met in the grading portion. However, in placing the reinforcing steel by automation, the existing savings of using truss bars would be eliminated.

E. Yes. The system can be developed.

F. Yes. If it works it works.

G. The equipment could meet the performance goals, however, cost savings and advantages are not as high because I don't believe it can help the cracking problems that we have.

H. Yes, I think there are some situations which could result in a $30 \%$ savings. However, I feel that overall this is optimistic.

I.

J. No - setting of bottom deck controls the quality of deck. This proposal does nothing to assist in setting it.

K. I would say yes. I believe the goals stated - i.e., $30 \%$ overall \& $50 \%$ in re-bar are doable objectives.

L. The performance goal seems reasonable. However, what will this cost?

M. Yes, if we make use of incremental approaches for innovations and implementation of the new automation. The proposed technology must go through peer engineering review first. 
N. I have serious doubts that this technology can be effectively applied. With [State] DOT restricted use of sub-deck panels, typical stage construction requirements, tapers and other geometric variables, it is doubtful that this technology will work for [State] DOT bridges. It might be of some value for short-span bridges with minor skew and simple geometry.

O. No. Construction process will not realize the cost savings proposed. The process as proposed can be achieved without major developments. Some system integration will be needed.

P. Cameras in a construction area could have problems with dirt and dust. Performance would degrade significantly if not kept clean.

Q. Yes. This area of deck construction - organization of rebar material could be greatly enhanced with the proposal. Bar coding in this area would work.

- No. Adding the rebar tying and placement to the concrete placing process would be a mistake. This puts the process in series - any one process stops and all stop, should be parallel procession.

- Concrete placing does not lend itself to lengthily shutdown - keep it simple and separate from another process which would interrupt it.

6. General comments concerning the proposed technology.

A. This technology is feasible to develop, some it already exists.

B.

C.

D. Need as much improvement in this area of construction as can be attained.

E. Set up time for system will be too high.

F. We would have no objection if the contractor chose to use this method of construction as long as the final product was in accordance with our Plans and Specifications.

G. -Needs to be tried in a laboratory environment prior to application -increase in productivity is questionable.

-efficiency concern when or if an adjustment is required.

H. 
I.

J. Do not see a need. The large paving train will complicate site access, increase costs greatly \& do nothing to produce a better product.

K. My only hesitation that require more thought is as I've stated, the potential nonacceptance by Labor Unions and some additional statements relating to anticipated short- medium- long-term plans.

L.

M. As indicated in Question \#1, I do not feel the automated bridge decking addresses a critical problem. The precision bundling required for the resteel will negate some of the proposed efficiency produced by mechanical decking. Part width construction and widenings may be too difficult for this procedure.

N. The concept will have limited benefit for [State] DOT. I have doubts about the quality of the final product.

o.

$\mathbf{P}$.

Q. Architects and designer will be the key element in the success to automate rebar placement due to the configuration in which it must be placed. 



\section{APPENDIX D - SURVEY RESPONSE SUMMARY}

\section{TRENCHING AND PIPELAYING}

1. Does the proposed technology address a critical problem area in highway construction, maintenance and operations? Please explain your answer.

A. Yes. Trenching and pipelaying, especially in urban areas and poor soils, are very costly and dangerous operations. Better and safer methods would be very beneficial.

B. Not a critical problem. However, an important research area.

C. Yes. Trenching and pipelaying from the standpoint of safety alone is one of the most challenging problems facing the construction industry.

D. Yes. Any reduction in exposure of safety problems is always of a benefit and cost savings.

E. No, there is very little trenching in highway work, it is not a big ticket item.

F. Problem not particularly critical. Sensors would prevent damaging existing pipes etc..:

a) Would they work underwater?

b) Cost of computer recording probably would be prohibitive to average small utility contractor.

c) Would reduce occurrence of fatal accident if trench workers eliminated.

G. Yes. Worker safety and efficiency would be improved.

H. Yes, the intersection of utility and piping systems with transportation systems is critical and will become more significant as more systems are put underground.

I. The proposed technology does address several problem areas in highway construction in the application of trenching for excavation and conduit installation. Without exact location of existing buried utilities such as conduits, wires, pipes, etc. the potential to break a connection is highly probable. This often creates a costly and timely delay to the operation. As stated in the proposal, safety is a tremendous concern although I could not easily track specific death or injury data from trenching operations for [name]. A , technology that eliminates dangerous tasks for either [name] workers or contractors is worth pursuing so long as the product is reliable enough to be used. 
Contacts in maintenance felt the technology more appropriate to construction where longer trenching operations typically occur. Maintenance trenching operations are typically over as quickly as they begin, replacing broken conduit, etc. Usually the problem area is identified and very quickly unearthed with minimal use of "as-built" information.

J. Yes. The proposed technology will have a very positive effect on safety. The more efficient use of equipment will reduce costs in the long term.

K. One of the most accident producing construction operations in the industry is related to trenching \& pipe laying. There is little doubt in my mind that automation/Robotics would prove very useful as a cost saving and accident/lost time saving tool.

L. Yes, as the report states the injury and death rate in this phase of construction is relatively high. Checking and re-checking grades and dealing with cave-in threats are very time consuming.

M. The use of this technology provides benefits in terms of improved job safety and more precise trenching. Application of sensor technologies reduces risk and associated delays of hitting underground cables and pipes. System can be integrated into the hierarchial control system explained in section 1.1 Site Integration to provide a comprehensive planning and construction program. All these factors are important consideration.

N. The potential problem area would be in the construction area. However, most of our trenching and pipe laying are done at relatively shallow depths - less than 6 feet deep. Also, safety regulations require shoring, sloping of trench slides, or other measure for trenches over 4 feet deep.

O. Yes. There is potential for the proposed technology. The application is broader than just highway construction there area number of installations and repairs of utilities not related directly to highway construction. It just so happens that it usually occurs on roadway right-of-way. I think safety will be improved but deaths referenced may be related to individual to small contractors where existing safety practices are not utilized.

P. Yes, safety in trenches is a very real problem.

Q. Yes. Safety in and around the trench. The location and disturbance of underground utilities.

- Operator working in the blind and little or no feeling of contact with utilities or object. 
2. Briefly describe the current procedures in highway construction, maintenance, and operations which the proposed robotics/automation technology will replace or change.

A. The proposed technology would replace human resources with automated equipment and control tools.

B. Current procedure is to use not automated construction equipment. The proposed technology is expected to automate trenching operations in highway construction.

C. Without a doubt, removing the worker from the trench or minimizing the workers' time in the trench would be a major change. Proper implementation of the technology will change the procedures used to excavate for and lay pipe.

D. Any method which would check on the quality of soil stability to safely excavate a trench would be a benefit.

E. Conventional trenching.

F. a) Could possibly eliminate labor in the trench, thus eliminating the need for a trench box.

b) Could find adjacent pipes and cables already in place (would eliminate guesswork).

c) Compaction could be remotely done.

d) Augment production by elimination of measuring depths manually.

e) Automatic pipe connection would be widely accepted in the industry under certain conditions. This would probably not be used on projects with large diameter pipes.

G. Fully described in proposal

H. Excavate a trench, install pipe, and backfill.

I. Some human intervention is supposed to be relieved through automation, although it is difficult to see how much can be replaced through what was proposed. Traditional operations rely on human interpretation of "as-built" plans that may or may not be accurate. Integration of "as-builts" into CAD/CAM and the trenching operation could eliminate potential human error. Automation of redundant trenching (i.e., a mile of trench at the same depth, etc.) could increase efficiency. Accuracy of the trench might be better in terms of alignment, etc. Documentation may be better if a dead reckoning sensor is used. Automated re-tooling is an important aspect, improving efficiency and safety substantially in some cases.

J. Current construction practices require the operator and grad man to work in concert to maintain line and grade. The automation of the trencher would allow for the 
programming of a pipe run referenced from one control point. The operator would be free to monitor progress and material supply. Current procedures for measurement of pipe installed could be incorporated into the placement process since the alignment should exactly correspond to the plans.

K. I don't believe I can improve on the very capable description of replacing existing methodology with automation/robotics that has been described by Dr. Bernold in the "Proposed Research Topic" hand out.

L. This will get most of the personnel out of the trenches where they are in danger. This would replace the manual shoring up of the trench and manual alignment and backfill of the pipes.

M. The current system uses manually-surveyed layouts, manually-operated heavy equipment. Mapping system may vary from manually-surveyed maps to aerial photographed topographical maps. Data is not currently input into a comprehensive hierarchal system.

N. This technology would reduce the exposure of workers inspectors to potential trench failures - although that risk is already low due safety regulations. Surveying workload might also be reduced after control work is complete.

Pipe often requires that the pipe bedding material be shaped to allow the pipe to be cradled in the bedding. I'm not sure how this technology can do that work. If it can't then workers would still have to be in the trench to do hand work.

O. I think the problem statement does a reasonable job of identifying these.

P. The most important aspect of this project will be to remove personnel from trenches. Present procedures require workers to be located in trenches.

Q. Survey for trench excavation and pipe laying. The quality of the operator currently on an excavator. lessen the manpower need (manual/abor) which in turn lowers insurance cost and supervision.

3. What are potential barriers to adoption of the proposed technology? What will it take to overcome these barriers?

A. The controls to operate heavy machinery electronically do not exist. The use of such technology would be very difficult in congested urban areas or on projects with difficult site conditions. I am not certain this technology will be successful unless close human 
monitoring is included. Such technology will be very difficult to use in poor soil conditions.

B. The sensor technology required for the proposed system is not advanced for practical use at construction sites. CMV's lessons should be investigated by the PI.

C. Develop the confidence in laser controlled excavation operations. This should not be a major hurdle to overcome.

D. Training; confidence in any methods to produce the quality results required.

E. None

F. Barriers:

a) Location and existence of utilities.

b) Possibility of computer malfunction or downtime.

Overcoming the barriers:

a) Barriers can't be overcome. This technology would be severely limited in urban intersection.

b) Use a backup power source and equipment.

G. 1. Initial cost and training costs would likely be significant. Low cost equipment requiring little training would be beneficial.

2. Accuracy of sensing/measuring systems critical to success. Question ability to totally clean site \& place/compact without manual involvement.

H. Existing level of technology with the sensing equipment. The proposal does not adequately explain the proposed sensing technology.

I. The scope of the proposed project is very broad which may require several stages of development to complete. The author is vague about how to proceed with the project as well as having failed to identify technical issues that must be addressed. One obvious issue is about the limits of laser sensors, 3-D sensing, and position coordinate system determination of various sensed information. The excavators attitude, pitch, roll, yaw is also important, but how is this information obtained? If other sensors are to be proposed, some time needs to be given to sensor fusion. This is not a trivial task.

The use of "as-built" plans may be difficult as most older plans are not on the $\mathrm{CAD} / \mathrm{CAM}$. It is usually not cost effective to update paper plans to CAD/CAM unless necessary for current work. Additionally, these plans are not always correct or up to date, so reliance on this utility mapping technique alone would probably not be sufficient. This is why real-time sensor data becomes so important. 
Finally, the cost of retrofitting or modifying existing equipment, versus the cost of new equipment is very important. Benefits of cost savings will be a very important aspect in the acceptability of implementing the new technology. cost/benefit will be to the manager what reliability will be to the end user.

J. 1) The placement and compaction of backfill in the narrow trenches will have to be addressed. compatible automated compaction equipment would be needed.

2) Vast improvements in the location of existing utilities would be necessary in the short term for use in design.

3) Overcoming the mentality "we've always done it like this" through reporting a successful demonstration project.

4) Getting utility companies to buy into the new technology by illustrating the cost of facility repairs vs improved utility mapping.

5) Equipment rental companies may be hesitant to incur costly retro fitting without measurable market demand.

6) Testing of backfill in trenches will be an issue.

K. The potential barriers continue to be, in my opinion, the potential opposition of Labor Unions augmented by the additional impact by compounding the current underutilized labor market. It will take a concerted effort on the part of industry management to assist Labor Unions in re-training the displaced labor market for other skills/crafts.

L. 1. Keeping small contractors in business.

Solution: Maybe provide some equipment or shared equipment with other contractors.

2. Questions regarding whether or not the equipment is efficient enough to provide time savings.

Solution: Test several prototypes.

3. Is the equipment simple enough to use.

Solution: Provide good user interface.

M. Barriers to adoption include need for capitol equipment investment into new technologies at a time of reduced operating budgets, need for resources for data acquisition and limited resources for training operators and users, which is necessary for both user acceptance and efficient operation.

N. One potential barrier would be cost of equipment and training of equipment operator especially for small contractors.

I'm doubtful that small contractors can become effective users of this technology. Forced use could drive small contractors out of business.

O. 
P. Development of appropriate sensors, hardened computer equipment located on machinery, and positioning equipment to lay pipe, etc.

Q. Cost of equipment for automation and accuracy and durability of equipment. The cost of a force feed back system on a conventional excavator is far out of reach today, approximately $\$ 500,000$. New technology and mass production will lessen this. Supply of inexpensive labor is a factor which lessens the need for automation.

4. Assuming that barriers to adoption are resolved and that the proposed technology achieves its stated performance goals, please estimate the potential savings (in dollars) for highway construction, maintenance, and operations projects for the following categories. Please refer to Attachment 1, "Site Integration Present Cost Data" for background information on the average estimated costs associated with highway construction projects. If you have better cost data or information available, please use it and explain how and/or where you obtained the information.

NOTE: Please label N/A if you feel a category does not apply to the proposed technology

- Because utilizing automation/robotics methodology would have a major impact on existing procedures, I believe estimating cost savings would be very subjective at best -an exercise I do not believe I can predict.

a. More efficient use of time

- Minimum

- $20 \%$ overall savings (not effective with pipes larger than $24 "$.

- Increase in efficiency

- This capability could impact the time taken to complete a project.

- Efficient use of time can be achieved if incidents are avoided to prevent delays. One estimate of $10 \%$ to $20 \%$ efficiency increase was given with no detail to references used.

- Absolutely yes.

- Should cut time in half, thus labor in half.

- Excavation equipment would be more efficient, but how much is uncertain.

b. Increased productivity and reduction of manpower requirements

- Minimum

- Increase in efficiency

- This area could be enhanced.

- Currently, construction operations are contracted out. To ensure that contractors are complying with state standards and specifications, engineers are assigned to monitor contractors and inspect actual work performed on a daily basis. Implementation of the proposed technology would ensure contractor compliance without requiring additional personnel. 
- Absolutely affirmative

- Should require $1 / 3$ less personnel.

- I doubt that manpower requirements would change significantly.

c. Maintenance costs

- Not a major change

- High impact

- Could be much higher than conventional equipment.

- No change - to keep equipment operating efficiently, in my opinion requires a "given" number of man hours per operating hour - there may be a small savings.

- Should save dollars by about $1 / 3$ when trenching and repairing existing pipe.

- Maintenance cost of the equipment would probably increase.

\section{d. Increased service life of final product}

- Same as traditional systems

- Probably not. The exception might be by-products of this automated operation.

Generation of "as-built" plans is beneficial for all intentional purposes. Future maintenance and construction operations will rely on this information to avoid unexpected damage to existing buried utilities during operations.

- Should increase service life by 5 to $10 \%$ by more accurate alignment (less stress on joints).

- I doubt that service life would be affected.

- Minor

e. Life Cycle Costs

- LCC - I don't see a tremendous effect on this area.

- Higher based on potential cost of equipment, sensors, etc. and skilled manpower to operate and maintain the equipment. this of course will have to be weighed against potential increases in efficiency.

- Very definitely a lower life cycle cost given the more efficient installation cost.

- When technology is well established, should give life cycle cost savings of $33 \%$.

- I doubt that service life would be affected.

- Minor

\section{f. Worker training}

- Requires operators training

- Would cost more

- Worker training will be high.

- Much more worker training not only to operate, but to maintain the equipment.

- $20 \%$ short-term increase. $30 \%$ long-term reduction

- More per "unit" of work given training required to learn the new technology.

- May cost $30 \%$ more, $50 \%$ more at first. 
- More training would be required for equipment operators. Cost unknown.

- Knowledge and training will need to change

g. Other factors associated with initial cost

- Major cost for hardware \& software

- Could save on surveying expenses and operations.

- Set up cost and insuring that equipment is programmed properly.

- Additional cost for equipment change over but reduced by the greater efficiency of the overall operation and better safety records.

- High cost for first models of equipment. Loss of jobs. Lack of competition.

- Equipment and its maintenance.

h. Safety (eg. insurance costs, liability, workman compensation, etc.)

- Very large

- Safety dramatically increased

- Major impact on safety of workers

- One less worker on the job could mean a small reduction in cost of insurance. Also no in trench operations could reduce insurance costs.

- Safety will be enhanced.

- While this might appear lower at first glance, the potential for equipment failure in early versions may increase the cost of insurance and/or liability.

- A great savings given the much safer work place and the lost time eliminated by the reduction of accidents.

- Should save $1 / 3$ in insurance and liability costs.

- If exposure of workers is decreased naturally these costs would be decreased.

- Maybe reduce by $5-15 \%$

\section{i. Environmental impacts}

- Positive impact

- None to speak of other than better community relations due to fewer accidents, safer project completion but negatively compounded due to smaller labor force.

- Construction site would be less extensive

- Less potential for damage to existing utilities.

j. Less traffic delays (ie., how it effects the productivity for people in traffic, productivity for the delivery of goods, etc)

- Project could possibly be completed faster, therefore shorter maintenance of traffic times.

- Based on the greater efficiency producing a shorter project life span (installation) the negative effect on traffic should also be reduced.

- Time should be cut in half, since most jobs now have adequate rerouting. There would be an overall savings of $20 \%$. 
- Traffic delays might be less, but to what extent is unknown.

- less conflict because of reduced extent of construction site.

- less fine on construction site.

k. Less repairs due to an improved quality of final product

- Not a major change

- Some improvement

- This will be enhanced.

- Maybe, al though the trench is usually temporary.

- Completed work would not be affected.

- I'm not sure that final product - i.e., the pipeline, sewer, etc., would be any better.

- The quality may or may not be improved

\section{l. Elimination of accidental damage of buried utilities}

- Very large

- Major impact

- Dramatic improvement

- This should be prevented.

- This is a benefit since "as-builts" may not be accurate. Costs incurred by unexpectedly striking and damaging an existing buried utility would ensure increased costs and may cause delay to the traveling public (i.e., striking an existing water main).

- $10 \%$ short term. $50 \%$ long-term.

- Greatly enhanced- therefore great cost reduction in producing final product.

- I think this is more of a function of accurately locating existing utilities. If location is known there is little chance of damage using current methods.

- Yes

m. Other (please specify)

5. If automation/robotics could be applied to current highway construction, maintenance, and operations, do you think this proposed technology will meet the performance goals set forth in the proposal? Please explain your answer.

A. Except for rural project sites and good soil conditions, I have serious doubts that the goals proposed can be accomplished. There are just too many unknowns in utility work to use open trench methods. Pipe jacking and tunnelling are much more feasible.

B. Methodology to accomplish this research is not clearly defined. It is not likely that the performance goal set can be achieved.

C. Yes. It will greatly reduce jobsite risk and improve excavation efficiency. 
D. If pipes could be laid without anyone entering the trench, a definite cost savings would be achieved. The potential difficulties for this to be attained are to numerous to list.

E. Yes. It is a simple system.

F. Time will tell.

G. Significant increase in training and costs would be increased but goals could be met.

H. Yes.

I. Yes, if it is approached correctly. There are many different ways to address the proposed automation problem as discussed in 6 .

J. Application of automation/robotics in these areas will meet the performance goals for safety, equipment utilization and the as-built data bases for utilities. Time savings in field survey will most likely be offset by increased needs in the design details.

K. I did not see any specific goals mentioned in the proposal.

L. Yes, because of the danger of the operation and because of the time consuming nature of getting the proper alignment, grade and backfill. This technology has tremendous potential.

M. The proposed technology has the potential to completely meet the goals set forth. In fact the purely technological constraints are easily overcome. It is the problems associated with collecting and storing the necessary accurate data required by a completely integrated system and the user acceptance and efficiency of this system that are the constraining factors. Adaption of this technology, therefore, must be done from the "problem-solving technology" perspective rather than from the "technology looking for problems to solve." The flow of inputs must start from the bottom up, with as much emphasis on data inputs as there is on the mechanical/electrical end. End users (field technicians) and management must be thoroughly trained, at different levels of training, to facilitate adaption.

N. No. If construction of a utility system were starting from scratch, it might be beneficial, but in areas where there may be several existing utilities - above, below, and crossing - I don't think the benefit is there.

O. Yes. Based on my experience with equipment/sensors a significant proportion of the goals can be achieved. 


\section{APPENDIX D - SURVEY RESPONSE SUMMARY: Trenching and Pipelaying}

P. If appropriate sensors could be developed, the proposed technology should be able to meet the performance goals.

Q. Yes. Current technology is very close to excavator automation and force feed back.

6. General comments concerning the proposed technology.

A. I do not feel this technology offers as much benefit as others may in utility construction.

B.

C.

D. Tremendous cost saving possibilities, if the problems can be overcome.

E. It is more of an issue for utility companies.

F. Average [State] "pipelayer" labor rate is $\$ 8.75$ per hour Average [State] "laborer" labor rate is $\$ 6.50$ per hour.

G.

H. More utilities and pipelines are being installed without trenches utilizing trenchless techniques. It seems effort and research need to be placed in this area as it basically removes the backhoe form the loop. Why automate a tool that will have limited use in the future?

By far the safest pipe project is one which does not put personnel in a trench and where the operator sits in a control cabin at a computer screen.

I. The general idea of automation is good although success of this type of project depends on a host of variables. Approach is very important. As this proposal addresses the integration of many different technologies, some unproved, it is important to minimize the risk of failure of the total integrated package. Perhaps the first step in the automation process would be the development and testing of each sub-technology (sensor, etc.) for this specific operation. An obvious second step would be the integration of these technologies for remote operation of the excavation equipment. Following successful demonstration, automated, man-in-the-loop techniques could be performed perhaps leading to some autonomous operation in the long-term. 
As stated earlier, the proposal is too vague to provide in-depth review. Additionally, reference of previous work in this area might help to alleviate concerns on the enormity of the integration or sensor fusion process at hand.

Of course success of this type of project depends heavily on the competence of the research team and their knowledge of leading edge technologies for this specific application.

J. Although greatly reduced, I don't foresee the total removal of workers from trench conditions. The addition of backfill placement and compaction needs to be addressed in this proposal. These activities expose workers to the same hazards as the pipelaying process.

K. I know it will produce more economic \& safer results. Some years ago Perine Corp developed a pipe laying system (not robotically motivated) but small diameter pipe laid in trench with water table 1-2 ft below surface with no labor in trench. All work hydraulically controlled. System currently patented.

L.

M.

N. None.

O. There will need to be development in sensor technology to realize the potential for this topic. Unlike construction involving surface obstacles, obstacles in trenching are buried.

P. This would probably be the most worthwhile use of automation technology. If the dangers to human life could be decreased significantly, this project would be very beneficial.

Q. Need an advanced type of centralized transmitter - excavator and or operator would know where the excavator was in relation to the immediate surroundings above and below the ground. Onboard computers could then be preprogrammed with hazard zones, elevations, etc. 



\section{APPENDIX E - SURVEY RESPONSE SUMMARY}

\section{BRIDGE INSPECTION AND MAINTENANCE}

\section{Does the proposed technology address a critical problem area in highway construction, maintenance and operations? Please explain your answer.}

A. Yes. Bridge inspection and maintenance is a critical issue in maintaining a safe highway system. Current human inspection techniques are slow and costly, as are current bridge maintenance procedures.

B. This is an important and very critical problem in highway maintenance and inspection. The proposed technology can assist many states with sever bridge problems.

C. Yes. Bridge deterioration is a major problem and the proposed technology would definitely be an asset both in construction and inspection. Current procedures are not able to reduce the percentage of bridges needing repair.

D. Yes. The containment of the blasting residue has been difficult problem for years.

E. Yes. It may not be a big ticket item, but it is very important and time critical.

F. I have read the proposal on a robotics system for inspecting and painting bridge structures. The proposal is using data on all bridges to quantify the problem and proposing a solution that appears to address only steel bridges. [State] is a concrete state, we have a limited number of steel bridges.

The proposal highlights the systems strong point of being able to protect workers from lead base paint hazards. [State] does not have a real lead base paint problem on bridges. When the robotics system is developed (assume 5 years), the Department will have 83 bridges (22,355 tons of steel) with lead base paint. Half of the steel is on the Hart bridge in Jacksonville. It is a truss with lots of lattice work and is not conducive to a robotics system for painting. Most of the remaining steel is on small bridges with limited space. It would be quicker to clean and paint them manually than to try to set up a robotics system.

Many of the steel bridges without lead base paint are not conducive to robotics system. How do you get a robot in a steel box girder which has $3^{\prime}$ diameter access hatches? Can it traverse the inside of a steel box girder that has $3^{\prime}$ of vertical clearance which is periodically bisected diagonally and horizontally with cross bracing? Can it access the inside of built up truss members which are boxed with lattice work? Is it practical on small remote girder bridges with 10 to 20 tons of steel and limited under clearance? Is it 
practical to set up a robot on $15^{\prime}$ to $30^{\prime}$ spans? How will the robot function on the 107 moveable bridges with constantly varying cross section and bracing? Will it accommodate the machinery and drive trains?

We have some concerns on robotics inspection of bridges. Let's consider economics. Inspectors will be needed to inspect the bridges which are not conducive to the robotics. As a minimum 2 people with additional equipment will be required to haul, install and run the robot. Additional personnel will be required to interpret and evaluate the data collected. In many cases, clarification of the data will require another trip to the bridge. When the robot is being used on a bridge over a roadway extra maintenance of traffic may be required unless the robot is programmed to watch out for traffic. If 2 people are required to operate and others to interpret data, wouldn't it be more economical to continue sending the 2-man bridge inspection team that collects and clarifies data while on the site. They also enter data into an electronic file while at the bridge site. Less people and less equipment are required to get down loadable data files.

How practical is robotics inspection? Will it clean dirt and debris from recesses and critical parts of the bridge or just give you a picture of what is exposed? Will the robotics system clean and check all fatigue prone details for fracture cracks? Can it use the dye penetrant spray and interpret results? Will it check the tension on bolts? Will it chip rust and deteriorated steel away to determine actual thickness of good steel? The proposal only addresses superstructures. Will the system evaluate substructures, pilings, drilled shafts, slope protection, fenders systems, electrical systems, moveable bridge drive trains, box culverts that are half filled with muck, and metal arch bridges? Will it check stream beds for scour? If it will not address each of these, the inspectors will still be needed to complete the inspection, Frequently travel time to a bridge site exceeds the time required to inspect. If inspectors are required to complete an inspection, they could reduce cost by doing the complete inspection without the robot and its support personnel. Will the system separate first line supervisors from the bridges so that they don't know each one as a family member? This could weaken the supervisors ability to properly prioritize the work needs.

Apparently the system will compare the current inspection images against the previous inspection images to determine changes. Storing large quantities of imagery electronically eats up tremendous storage space in the computer system. Is it economical to store electronic imagery of all components of all bridges just to identify the few bridges that need repair or replacement. If the system does not store all the imagery electronically, it does not provide any more data than the existing inspection system.

In summary, because of [State's] flat terrain, most bridges in the state can be accessed by inspectors for a hands on inspection with ladders, [?] boats, barges with scissors lifts or the underbirdge inspection machine. Access is not a major problem. In the urban areas, 
public safety and maintenance of traffic become the major concerns. On moveable bridges, the ability to move inspectors off the moveable span quickly to allow the spans to open for marine traffic is a major concern. On all bridges the major concern is to ensure the bridges are cleaned and inspected as required to ensure all deficiencies are identifies. Any system that cannot accommodate these concerns should not be pursued by the Department.

G. Yes. As stated in the proposal lead paint stripping \& containment is serious problem and a danger to the personnel \& environment.

Also consistent painting procedures are desirable but not always available. A Robot with sufficient accurate sensors can perform efficiently \& effectively.

H. Yes.

I. The proposal does address a problem, mainly the containment of lead based paints. The system described does not look feasible though. Current practice includes water blasting of paint and then encapsulating the structure with a water based paint. The lead paint is kept on the structure as much as possible because it is a great corrosion protection covering. Furthermore, most repaint jobs are for "spot blasting". Very, very few are for total removal of paint. Thus this machine would be very limited for use in spot cleaning.

Development of technologies to eliminate the use of "man-in-the-bucket" hydraulic lifts is very important having both cost and safety implications. The over-pass paint stripping however, seems to be the least of the bridge maintenance problems. Inspection of bridges for cracks and defects seems to have a much higher priority. This is especially true following natural disasters such as earthquakes. Rapid and thorough inspection is imperative prior to opening structures to traffic following seismic activity. Conventional operations will not accommodate both rapid and thorough inspections.

\section{All reviewers stopped evaluation at this point.}

J. Using robotics devices and automation for bridge inspection and maintenance and development of bridge data bases does address a critical problem. Automation reduces costs, manual work, and mistakes in bridge data. it does not appear that paint stripping and repainting is a critical problem area in our State.

$\mathrm{K}$. Where will the $\$$ come from? The "Feds" have been downsizing their budget allocation continually over the last 3-4 years. The program as outlined by Kenneth Goodwin certainly addresses both the near and longer term approaches as well as defining the objectives of each. There is no question that there are critical problems caused by a combination of neglect of our infrastructure coupled with the impact resulting from our changing environmental considerations. 
L. Yes, there is a lot of concern regarding lead based paint, and the safety and accuracy of inspection techniques.

M. Yes. Concerns for the health of the workers and for the environment have caused substantial changes in the operations of stripping and repainting of highway overpass structures. The changes which have taken place have had such a significant impact on the cost of the work that allowing structures to deteriorate in an unpainted condition, with early replacement, is now considered a variable alternative to stripping and painting.

N. To a certain extent, yes, cleaning and painting existing steel structures is becoming an expensive item of work, due to environmental safety and health requirements.

O. It does address a problem in the area of maintenance and operation. It may not be critical but development of the technology could have significant and beneficial effects.

P. Bridge inspection and maintenance is a critical problem area. Use of automation technology to assist any tasks in this area would be helpful.

Paint stripping should be one of the easier tasks.

Q. To a certain extent, no doubt the automation and robotics technology will greatly enhance the painting/stripping of bridge due to hazardous material, but as technology advances with new water base paint, a large portion of this work will be dissolved.

- I do think inspection and maintenance of existing highways is important, not only from extending the life of the road, but also to discover new technology in these areas for new construction. The automation of maintenance and inspection data bases is probably one of the most important aspects of this series. it will provide information to compare and measure.

2. Briefly describe the current procedures in highway construction, maintenance, and operations which the proposed robotics/automation technology will replace or change.

A. The proposed technology would eliminate much of the human resources required today for bridge inspection and maintenance. Hand methods would be replaced by automated equipment processes.

B. Currently done by expert inspection. The proposed research will develop improved alternatives to snoopers for positioning and manipulating automated bridge inspection and maintenance.

C. The proposed process should reduce labor and reduce delays to the travelling public. The process will create a safer work zone for both workers and the public. 
D. The containment devices which were outlined in the proposal.

E. Current procedures are very random and fractured.

F.

G. Currently all paint stripping, containment and repainting are done by humans.

H. Manual

I.

J. The current procedure of painting of bridges will be changed with automation. The procedure of performing bridge inspection, managing bridge inspection data, and scheduling of bridge repair work will be changed depending on the degree of automation.

$\mathrm{K}$. I believe that Mr. Goodwin has done an excellent job in outlining current practices and procedures in existing operations. He has also very clearly expressed the objectives that would be achieved through automation of existing procedures. My writing would be redundant.

L. Shrouding large areas for removal of paint. Using boom trucks and snoopers.

M. -- A single efficient containment can protect the workers and the environment.

-- Workers can operate the robot from remote locations: thereby, improving worker safety.

-- Improved efficiency of operation will reduce the time the roadway under the structure is out of operation.

N. A contractor performs the following operations:

1. Installs rigging and shrouding

2. Cleans structural components with high pressure water blast

3. Removes corrosion by abrasive blasting, collecting spent blast material

4. Applies paint to structure

5. Removes rigging and shrouding.

0 . The main effect would be in worker safety, time reduction for inspection and maintenance and traffic delays. Also a more accurate information data base for bridges will be possible. 
P. Current procedures are hazardous and deal with an environmentally sensitive subject. Automated bridge inspection and maintenance will change a manually intensive operation. This could replace the paint stripping/painting crew and bridge inspectors.

Q. Record keeping as to condition, life of components and data gathering for future studies. The process will be automated entirely. The inspection and repair of minor defects will change to a large degree.

- It will enable maintenance and construction officials to repair defects and damage before destruction.

3. What are potential barriers to adoption of the proposed technology? What will it take to overcome these barriers?

A. It is unclear if the equipment needed is available; if not, such development could be very expensive. Many bridges are over water or rugged terrain, thus the equipment pictured in proposal will not work. Equipment is needed that must be supported form the bridge structure which may be difficult to adopt for the many sizes of bridges.

B. No major barriers are expected. Hardware development at practical stage may become an issue.

C. First cost investment and education will probably be the largest blocks to adoption of this technology.

D. Training. If people are not at the immediate site, who will accept the quality of the finished product.

E. None

F.

G. -Government agencies \& regulations (i.e. FHWA, States, EPA, etc.)

-Prototype testing in controlled atmosphere is recommended prior to application due to unknown performance.

H. Technical details that will need to be resolved in order to make equipment which can work on various types of bridges.

I.

J. I do not see any potential barriers on the adoption of the proposed technology if it is feasible and cost effective. 
K. Given the existing "state of the art" I do not envision any "Barriers" which will not be overcome, excepting that as "process" continues to be developed $\&$ refined to the next plateau, if it does not prove cost effective and beneficial then this will become the barrier which will not be overcome.

L. 1. Cost to contractors, capital cost of equipment.

Solution: Subsidize initially.

2. EPA questions about proper removal of lead paint.

Solution: Demonstrate and take careful measurements.

M. Barriers - the proposed technology should be easy to operate, as efficient and effective as the current system, and have an overall cost effectiveness.

$\mathrm{N}$. This system will be operating in an environment consisting of fine metallic dust, which will cause damage to electrical components; adequate seals will have to be provided to protect circuits.

O. I do not think that there will be too many barriers for cost. At this point equipment and crews for inspecting, sand painting, and painting are minimal at least for small bridges and overpasses. The set up time for such structures may be prohibitive for more elaborate equipment. Large bridges are another story. The set up time be minimal relative to the time of inspection and added safety.

P. Shrouding could be a real problem and may need some manual inspections. also, developing a robotic device to crawl along bridges might require that additional railings or other components be built into bridges.

The development of an "as is" data base may be much more difficult than it appears.

Q. Robotics equipment being built to withstand an adverse environment of sandblast and paint.

- New technology in paint removal.

- Very few bridges being built the same and with repair and maintenance in mind.

- Integration of designers, architects and construction.

4. Assuming that barriers to adoption are resolved and that the proposed technology achieves its stated performance goals, please estimate the potential savings (in dollars) for highway construction, maintenance, and operations projects for the following categories. Please refer to Attachment 1, "Site Integration Present Cost Data" for background information on the average estimated costs associated with highway construction projects. If you have better cost data or information available, please use it and explain how and/or where you obtained the information. 
NOTE: Please label N/A if you feel a category does not apply to the proposed technology

a. More efficient use of time

- Will be enhanced.

$-\$ 9,000 / y r$.

- Less preparation and setup and takedown of shrouds and equipment. 50\% time savings.

- Efficiency was not addressed in the proposed except to say that an objective is to reduce the time required to strip and paint an overpass. Certainly, the elimination of temporary environmental housing would substantially improve efficiency and result in a substantial cost reduction.

- Depends on size of bridge, could be substantial would expect 20 to $30 \%$

b. Increased productivity and reduction of manpower requirements

- Should be enhanced.

$-\$ 3,000 / y r$.

- It appears that the crew size can be reduced to an operator and a laborer. comparing this to an E-11 crew at $\$ 684 /$ day, this would represent a savings of $\$ 1350$ - (304 + $232.80)=\$ 814.20 /$ day. A savings is realized for eliminating an environmental containment area for each bay of an overpass. Using a F-5 crew level or \$1216.05/day, plus move in cost, this can be prorated and added to the stripping and painting crew cost. Additionally, the cost of personal protective suits for blasting and cleaning operations would be saved. The cost savings appears to be in excess of $\$ 1000 /$ day of operation.

- Increased productivity with 30 to $50 \%$ manpower reduction

c. Maintenance costs

- Should be reduced.

- $\$ 3,000 / y r$.

- Estimated potential overall savings for a simple steel beam bridge is $15 \%$ to $20 \%$ of current costs.

- Would probably come from being able to inspect and maintain more often.

d. Increased service life of final product

- Will be increased

$-\$ 4,000 / y r$.

e. Life Cycle Costs

- Lowered

- Definitely improved.

- Reduce 
f. Worker training

- Requires operators training

- Training will be an important factor.

- $\$ 6,000 / y r$.

- Not greatly affected

- Some training will be required

g. Other factors associated with initial cost

- Hardware \& software

- Equipment \& Mobilization

- None

- Higher equipment costs

h. Safety (eg. insurance costs, liability, workman compensation, etc.)

- High impact on safety

- Increase in safety

- Safety will be enhanced greatly.

- $\$ 9,000 / y r$.

- A very definite positive impact.

- Reflected in reduction of labor cost.

- Improved safety which should translate into reduction of insurance and workman's compensation

i. Environmental impacts

- Very big

- Very positive impact

- Positive impact on environment

- Environmental effects will be improved.

- $\$ 1,000 / y r$

- Greatly enhanced.

- Requirements for controls of pollutants should not change.

- Some improvement, how much will depend on effectiveness of design for media collection.

j. Less traffic delays (ie., how it effects the productivity for people in traffic, productivity for the delivery of goods, etc)

- Large

- $\$ 3,000 / y r$.

- Considerable increase in productivity.

- Each system requires lane controls because of heights restrictions; therefore, it is difficult to determine the effects on traffic delays.

- Some improvement. 
k. Less repairs due to an improved quality of final product

- Large

- Possible quality improvement

$-\$ 3,000 / y r$.

- Not sure this applies-benefits will be in areas of decreased time and environmental impact.

1. Reduction of hazardous waste due to more efficient paint application

- Large

- Yes

- This is certainly a possibility.

- $\$ 3,000 / y r$.

- Not as much in application as in stripping. Maybe as much as 30-40\%.

- I believe this would be insignificant.

- Yes.

m. Other (please specify)

5. If automation/robotics could be applied to current highway construction, maintenance, and operations, do you think this proposed technology will meet the performance goals set forth in the proposal? Please explain you answer.

A. Yes, this technology has good potential for land bridges. However, I do have doubts about technology proposed handling bridges over water or rugged terrain.

B. The basic work is already done by the PI. The methodology is clearly defined. Most likely the performance goals will be accomplished.

C. Should exceed current performance standards with more efficiency and complete inspection. The repairs will be more effective than the current methods being used.

D. Yes. If an automated camera device could be utilized for visual inspection.

E. System can be developed and implemented.

F.

G. Yes. A definite need in testing in a lab environment prior to real application can answer many questions.

H. Yes 
I.

J. The performance goals will be met assuming the automation/robotics is successfully developed. However, I have reservations on the time frame set forth in the proposal for the successful development of such a system.

K. Yes. I think the stated goals are not "pie-in-the-sky" but rather modest and attainable. The proposed program is well thought out and phased development giving ample opportunity to succeed.

L. Yes, this has tremendous potential, and is an extension of some of the existing technology. there are numerous worker safety and exposure concerns, as well as an inability to detect some problems as soon as this technology would hopefully be able to.

M. I think the proposed technology can meet the performance goals for most of the work in stripping and repainting of highway overpasses. However, each bridge has unique features that may be difficult to access and it seems reasonable to anticipate that each bridge will require some follow-up stripping and painting by hand, but this could be minimal.

N. No, see responses to number 3 and number 6 .

O. In general yes. I do have some concern about application to cost benefits for smaller bridges. However, more restrictive environmental laws and competition should out weigh such costs. The projected cost savings are reasonable.

P. The proposed technology should be appropriate for the goals of the application. Instrumentation (sensors) would have to be developed to provide feedback for the paint stripping operation, in order to do it automatically. An automated device that "crawled" over a bridge might require guiderails or some other device to be built into a bridge. This added feature would require a detailed analysis.

Q. No. Eighteen months is a tight time frame for this proposal although much of the proposed technology is currently available.

6. General comments concerning the proposed technology.

A. Good potential for success.

B. Bridge inspection is an important area for automation.

C. 
D. The problem could also be solved by relaxing the environmental standards. Studies were not made on the original standards.

E. It is a good idea but only impacts a small cost component.

F.

G. Beneficial project.

H. I feel that this is an excellent area in which to invest research.

I.

J. The proposed technology seems to put a lot of emphasis on paint stripping and repainting. Research on automation/robotics for routine bridge inspection should be emphasized also.

K. Yes. I think the stated goals are not "pie-in-the-sky" but rather modest and attainable. The proposed program is well thought out and phased development giving ample opportunity to succeed.

L.

M. The concept addresses a new and difficult problem area so the opportunity for success is substantial. The unit illustrated in Figure 2 appears to offer flexibility that is needed if containment and control can be achieved.

N. This is an extremely complicated system doing multiple tasks, and more than likely depending on fiber optics for operation. It has been our experience that these systems never perform to expected levels. The savings are generally not realized due to "down time $^{n}$ and maintenance costs keep the system operational.

O. More restrictive environmental laws may be the driving force for development of this type of technology.

P. See above.

Q. Automation must be cost driven. Neither regulation nor cost are strong enough to propel this technology. 


\section{APPENDIX F - SURVEY RESPONSE SUMMARY}

\section{PAVEMENT INSPECTION AND REPAIR}

1. Does the proposed technology address a critical problem area in highway construction, maintenance and operations? Please explain your answer.

A. Yes, pavement inspection and repair is a major problem.

B. Pavement inspection and repair are important areas in highway maintenance. it could be considered as a critical problem.

C. Yes. Pavement condition surveys are the primary method used by the highway agencies to determine maintenance needs and to schedule rehabilitation projects.

D. No. After the pavement is inspected for cracks, then what? The area's maintenance funding determines when the cracks are fixed.

E. Yes. Manpower is limited.

F. This technology would be used for Pavement Management and maintenance. Pavement Management could be used to prioritize rehabilitation, predict deterioration rates, predict budget needs, distribute rehabilitation funds to District.

Maintenance groups could use to determine maintenance needs, location, and distribute funding.

The Pavement Condition Survey is presently used for the functions listed under Pavement Management.

G. To some degree. Technology is already available to very accurately detect cracks, potholes, etc. through use of videotape and other means. This proposal identifies yet another method of detecting such roadway deficiencies. However, better detection methods do nothing to remedy the problem. The real question is how can these deficiencies be corrected without disrupting traffic - i.e. repairs at highway speeds. I suspect that more than $90 \%$ of all pavement inadequacies are detectable with the human eye - improvements in detection don't solve the real problem.

H. Yes, this is a critical area.

I. Worldwide, a tremendous amount of resources are expended annually maintaining highway pavement, and crack and joint sealing are two critical maintenance tasks. These activities are generally labor-intensive and dangerous to both the workers and the traveling 
public. It is quite evident to most travelers that improved materials and procedures including the sue of more advanced technologies are severely needed. The Strategic Highway Research Program (SHRP) has had the improvement of pavement maintenance as it pertains to crack and joint sealing as one of its primary goals. The SHRP project H107A, Fabrication and Testing of Maintenance Equipment Used for Pavement Surface Repairs - Crack and Joint Sealing, has obviously addressed this problem. This study was performed in parallel to SHRP H-107B which is aimed at the development of equipment for pothole repairs. Additionally, through the SHRP-IDEAS program, work was funded at Carnegie-Mellon University which investigated automated crack filling. Furthermore, pavement distress survey systems, aimed at evaluating the pavement at high speeds, have been the subject of numerous additional studies. As such, the proposed technology is important as evidenced by the numerous other studies that have been, and are still being performed in this area (none of which have been referenced in this proposal).

J. Cracking is a critical problem for highway maintenance and operation. The detection of cracks is not at present a critical problem. Cracks generally take years to develop and there is usually ample time to detect them and repair them.

K. I do not feel qualified to respond to this particular application of automation/robotics program. I do not have any experience in problem resolution in this field.

L. Crack detection and sealing is a critical problem in highway maintenance. If the serviceability of the pavement is to last, cracks in the pavement must be sealed at the earliest possible time to prevent moisture from getting into the base.

M. Yes. Preventive maintenance programs rely on timely detection and repair of surface defects and/or deteriorations. A unit that can accomplish this at highway speeds would allow for preventative maintenance to occur on busy highways without disruption to traffic and the associated costs to the user and maintaining organization. The consideration for interference with the flow of traffic and related cost currently preclude a timely preventative maintenance program.

N. What this technology does is identify cracks. I'm not sure what this does for us. We can usually identify cracks during maintenance procedures, clean them and patch them. How would this technology translate to pavement rating?

O. Yes. However, the proposal as described does not indicate an understanding of the basic problem of visual distress identification which is a well defined process. Also, significant research has been conducted on 2 D (NCHRP) and Stero (Univ. of Florida/Florida DOT). Maintenance at Highway speeds seems unreasonable. 
P. Pavement inspection is an important, time consuming operation. The proposed technology for pavement crack inspection would help solve a significant problem in highway maintenance.

Q. Yes. Any type of preventative measures extend the life expectancy of anything and an accurate method of measurement/inspection would accomplish this.

2. Briefly describe the current procedures in highway construction, maintenance, and operations which the proposed robotics/automation technology will replace or change.

A. Human visual observations would be replaced by an automated equipment system. Pavement repair operations would be replaced by automated methods with much less labor required.

B. This is an automated system which will replace current human expert visual inspection of road surfaces.

C. Most of the inspection programs are labor intensive, and as a result, are slow. They also are limited in the size of the sample, that is, it is not practical to evaluate all the roadway surface.

D. An automated device will eliminate the exposure of personnel to traffic exposure.

E. Very labor intensive and dangerous.

F. The Pavement Condition Survey is presently conducted on an annual basis. The Flexible Pavement Survey consists of ride and rut depth measurements using a South Dakota Profiler, and subjective measurements of surface deteriorations (cracking, raveling, and patching). The Rigid Pavement Survey consists of ride measurements (South Dakota Profiler), fault measurements, surface deterioration, spalling, patching, transverse cracking, longitudinal cracking, corner cracking, shattered slabs, pumping and joint condition.

The Survey is used for the purpose listed under Pavement Management (see question 1). Maintenance conducts a separate survey to determine their needs.

G. Visual human surveys, videotape surveys with video image processing.

H. Visual inspection

I. Current operations are highly labor intensive. Approximately $2 / 3$ of overall crack sealing costs are attributed to labor. Conventional inspection techniques are performed by personnel trained to recognize many distinct forms of pavement damage and deterioration. 
Thus, pavement inspection is also very subjective. The technologies developed under the earlier and on-going studies that this proposal does not reference have the potential to vastly improve the crack sealing field. The non-contact inspection technologies addressed in this proposal are similar to ongoing pavement inspection research and my have merit. The use of morphology appears to be a good idea. Tactile sensors will have significant problems at highway speeds.

J. Automated crack detection could speed up crack inventories. Robotics could possibly reduce manpower needs.

$\mathbf{K}$.

L. The technology described would eliminate the need for a maintenance crew that closes a lane of roadway. locates, cleans, and seals cracks. The crew uses compressed air to remove loose debris and dry the crack. Sealer is then applied by hand to seal the crack so moisture cannot pass through to the base.

M. A maintenance foreman schedules a crack sealing operation when he determines the work appropriate. Crack sealing operations require that a lane of traffic is closed. The individual who seals the cracks generally is also responsible for finding the cracks to be sealed. Depending upon the sealant, it is blotted with another material (sand sawdust, tissue paper, etc.), before traffic is allowed to use the lane. Other materials require a cure time.

N. Maintenance procedures, whereas a crew drives down the road, identifies and fills cracks, it might be used as an estimating tool. It's best application would be in pavement rating of crack correlation to: Fatigue, alligator cracking, block cracking could be differentiated as they all have different meanings to us in the pavement management system.

O. It is felt that there is a need for Automatic pavement distress survey capability. Recent and current research has progressed as far or farther then the scope of the proposed research topic.

P. Most pavement inspection is done manually by trained employees who rate pavement. Several research projects have been completed regarding this topic.

The results of these projects should be reviewed.

Q. It will change the time lapse from inspection to repair and the inaccuracies. It will reduce amount of labor and supervision needed for both. 
3. What are potential barriers to adoption of the proposed technology? What will it take to overcome these barriers?

A. It must be proven that the proposed inspection process will work efficiently and cost effectively. It is difficult to develop automated equipment for pavement repair since the deficiencies are irregular. Automation works best when the work is uniform. Technicians will be needed to use the equipment effectively.

B. There is not a major technological barrier. Similar systems are developed in other robotics centers such as CMU. Vision systems may become a problem at practical implementation stage.

C. Training and correlation of results to currently accepted standards will probably cause the greatest barriers to acceptance.

D. Training of people to have confidence in the results of the automated devices.

E. None

F. a) The new technology would have to work

b) Data analysis would have to be standardized to compare between states as well as reporting, presently different methods are used.

c) Cost would have to be reasonable.

d) Management approval.

G. Technology far exceeds the need. Solution looking for problem. Currently available commercial equipment adequately detects conditions. It is highly unlikely that highway speed maintenance is feasible due to materials available and the nature of repairs needed.

H. Developing the technology

I. The barriers to the adoption of the proposed technology are the general skepticism of the end-users, the relatively high cost such machinery will bear, concerns about the training and set-up costs, concerns about displacing workers, and anxiety with regard to high tech equipment in general. The only way these barriers can be overcome is by demonstration of actual prototype hardware, and detailed cost benefit analysis based on the prototype's performance.

More specifically, assuming that inspection can be done at highway speeds (not a trivial task,but subject to the extent of pavement cracking and the proportional data processing requirements), the application of the sealant material at speeds higher than a few miles per hour begin to be a significant bottleneck (again based on severity, extent and direction of 
cracking). Furthermore, the amount of material used at higher speeds can be tremendous posing a material supply problem.

Separating the inspection operation from the repair operation has serious problems as identified in the proposal. Dynamic path planning and coordination of the end effector with the inspection information on a single moving vehicle is very difficult problem in itself without contemplation of complex transformations between multiple vehicles.

Cost of the suggested methods might become very prohibitive. A recently purchased offthe-shelf laser with a 4 inch field of view was $\$ 25,000$. The authors contemplate an array of these sensors. Parallel processing may satisfy some real-time processing requirements, but raise serious maintenance, repair and calibration problems.

In other words, one has to look cautiously at all aspects of the total operation and identify all potential bottlenecks or barriers to final implementation.

J. Costs could be too much for state DOT's to afford. Level of equipment complexity may be too great to find competent operators. Maintenance of equipment may be too costly.

To overcome barriers will take a technology that can be practically applied. Also, training and education very important as well as good marketing.

K.

L. Cost of purchasing and maintaining the equipment and the ability of the equipment to accurately identify and seal all cracks are potential barriers. To overcome these barriers it will be necessary to demonstrate that the equipment can be obtained and operated in a cost efficient manner and that it will do what is required to seal cracks completely and reliably.

M. A potential barrier to the use of the technology is the unavailability of a satisfactory performing sealant that can be placed at the proposed speed. To overcome this barrier, a special sealant will be required.

N. It has to have a good practical-proven application correlated and validated against existing systems.

O. No barriers. The problems are coast and technology. Film as a record media has been used with subsequent visual analysis. Current video does not have adequate definition. New high definition video technology may. Real fine processing seems a future goal. Cracks must be detected in the range of width of a few $\mathrm{mm}$. girder cracks indicate maintenance would not be effective. 
P. To perform pavement inspection at highway speeds, data will have to be collected and processed very quickly. Sensors will have to be developed for this, plus if the data is stored, a large data storage medium will be required.

No discussion of automatic pavement repair was presented.

Q. Becoming too technical for repairs, such as pot holes, at a late stage of failure. maybe emphasis should be directed toward early stage repair. Locating the cracks is only half of the problem. The repair of the cracks usually require $90 \%$ of the time. New technology in this area is needed. Information from the crack detection could be pushed in this direction.

4. Assuming that barriers to adoption are resolved and that the proposed technology achieves its stated performance goals, please estimate the potential savings (in dollars) for highway construction, maintenance, and operations projects for the following categories. Please refer to Attachment 1, "Site Integration Present Cost Data" for background information on the average estimated costs associated with highway construction projects. If you have better cost data or information available, please use it and explain how and/or where you obtained the information.

NOTE: Please label N/A if you feel a category does not apply to the proposed technology

a. More efficient use of time

- This would provide much more efficient use of time.

- Yes. Crew size is significantly smaller and somewhat more efficient at identifying, preparing and sealing cracks.

- $\$ 10,000 /$ year.

- This is difficult to estimate. It would vary with the actual speed that the equipment could travel (highway speeds do not often mean traffic speeds) and the density of the cracks. However, as proposed, efficiency improvements probably represent a major portion of potential available in the labor and equipment costs currently estimated at $\$ .50$ to $\$ .72$ per lineal foot.

- Yes. Visual distress surveys are time consuming.

b. Increased productivity and reduction of manpower requirements

- Greatly increased

- Manpower requirements might be decreased from a crew of 8 persons to a crew of 2.

Labor cost per lane mile $=\$ 18,000$.

- $\$ 50,000-\$ 75,000 /$ year. 
- Labor should be reduced to approximately one-eighth of crew size and a lane closure will not be required.

Reduction in cost $\quad=9 / 10 \times \$ 0.16$ labor cost $/ \mathrm{ft}$

$=\$ 0.14 / \mathrm{ft}$

- Yes.

c. Maintenance costs

- Maintenance cost would be increased at first.

- While maintenance costs of the equipment might rise significantly, the overall cost of the operation will decrease substantially due to reduction in labor force. $(66 \%$ of conventional operation is tied up in labor).

- $\$ 100,000 /$ year.

- Would develop from better maintenance timing

d. Increased service life of final product

- No increase due to this technology

- Service life will be increased due to better maintenance.

- An initial study (unidentified) indicated that a proper sealing operation including proper preparation and application could increase the service life of the seal by up to seven times the current life.

- $\$ 25,000 /$ year.

- Yes, but not as much as one would believe

e. Life Cycle Costs

- No increase due to this technology

- With better maintenance practices, the LCC should be improved.

- An initial study (unidentified) indicated that a proper sealing operation including proper preparation and application could increase the service life of the seal by up to seven times the current life.

- Maybe

f. Worker training

- Operators training is required

- Worker training should not be a problem.

- The type of maintenance worker for the new operation would be considerably different from that of the conventional operation. The automated operation would probably require technicians schooled in computer operation, robotics, etc.

- This would generally be a new technology

g. Other factors associated with initial cost

- Hardware \& software costs

- Cost of equipment 
- Initial cost of using this type of automated machine may prove to be prohibitive to many private and small public sector organizations (based on initial marketing research performed in previous research).

- Expensive

h. Safety (eg. insurance costs, liability, workman compensation, etc.)

- Very high

- Higher safety

- Small decrease

- Safety will be enhanced from the standpoint of the public as well as from those using the system.

- Safety would increase substantially. The workers performing this task are now located on-board the vehicle rather than next to adjacent high speed traffic. Workmen

compensation should reduce drastically with the use of this equipment.

- $\$ 2,500 / y e a r$.

- There would be less danger in making surveys.

\section{i. Environmental impacts}

- Positive impact

- Increased service life means less rehabilitation/reconstruction

j. Less traffic delays (ie., how it effects the productivity for people in traffic, productivity for the delivery of goods, etc)

- High

- Small

- Overall traffic delays should be less.

- This operation may be performed at speeds allowing for a moving lane closure.

Conventional operations require a standard lane closure operation. Moving lane closure typically has less effect on the traveling public.

- Major consideration but difficult to estimate.

- Yes

k. Less repairs due to an improved quality of final product

- High

- Yes. An initial study (unidentified) indicated that a proper sealing operation including proper preparation and application could increase the service life of the seal by up to seven times the current life.

- This would come from better timing

l. Less commuter delays

- Very small - current surveys conducted during non-rush hours

- This operation may be performed at speeds allowing for a moving lane closure. 
Conventional operations require a standard lane closure operation. Moving lane closure typically has less effect on the traveling public.

- Yes

m. Less repairs and improved quality of final product

- High

- Yes. An initial study (unidentified) indicated that a proper sealing operation including proper preparation and application could increase the service life of the seal by up to seven times the current life.

- This would come from better timing

n. Other (please specify)

5. If automation/robotics could be applied to current highway construction, maintenance, and operations, do you think this proposed technology will meet the performance goals set forth in the proposal? Please explain your answer.

A. If the equipment can be developed, the performance goals can be achieved.

B. The research goals are clearly defined. Most likely the research will reach to its performance goals.

C. This technology, when perfect, should far exceed current performance standards and would result in major changes to the way highway agencies establish and control their maintenance budgets.

D. The goal of checking for cracks seems to be attainable, however, how will the cracks be fixed? That seems to be the primary problem.

E. Yes

F. Several organizations are working in technology to measure cracks at highway speeds in real time.

G. Performance goals would be met, however, benefit is still very small.

H. Yes

I. The authors propose to inspect the pavement for cracks at highway speeds. In the not too distant future, I believe that it will be possible to perform pavement distress surveys at relatively high speeds. The author's approach of using lasers and vision is not unique. A system is already in existence (that has also been reported in the literature) that can 
extract features of pavement including cracks as small as $1 \mathrm{~mm}$ in addition to rutting and other larger features at speeds as high as $450 \mathrm{~m} / \mathrm{h}$. Since this system has been developed a few years ago, I would expect that its performance has been greatly improved. The authors of this proposal discuss both the detection and the sealing of cracks at highway speeds; the sealing of cracks at these speeds is not possible. The limitations of mechanical devices to follow cracks and perform the requires preparation and sealing prevent operations at such high speeds.

J. Detecting smaller cracks is NOT a problem. Plenty of quantitative performance measures exist today. Typically roads are NOT closed for crack sealing repairs, only an individual lane is closed. Robotics in this area would be better suited to safety issues.

K.

L. The ability of the proposed equipment to function at highway speeds seems questionable. Cracks that are encountered that contain moisture and/or loose debris will have to be cleaned and dried before sealing. The proposal does not explain how the equipment will be able to identify or deal with these types of variation in conditions.

M. I believe a major barrier is the development of a satisfactory sealant that can be used with the technology.

N.

O. No, the proposal has yet to factor in current research. Also, it does not appear that the proposers appreciate the significance of cracking.

P. I think proposed technologies for pavement inspection has a good chance for success. I am not sure if inspection could be done at highway speeds. Also, roadway repairs was not discussed, therefore the proposed technology is unknown.

Q. Yes. But I feel more emphasis should be directed to why the cracks are there to begin with.

6. General comments concerning the proposed technology.

A. This proposal has a lot of potential.

B.

C. 
D. The repair of the pavement should receive the maximum emphasis.

E. System could be developed.

F. Lasers have not worked for measuring cracks. Cracks fill with dirt so depth and width can not be measured.

Would system do anything with raveling?

G. See question \#1

H. None

I. It is quite concerning that the authors of this proposal are totally unaware of the large amount of work that has already addressed pavement distress survey systems and automated crack sealing and filling. While the sensing problem is formidable, several groups have already developed systems to locate cracks/joints in the pavement. Furthermore, SHRP has invested into much work in this area. The authors seem to lack an understanding of the crack sealing process, and they are quite naive to expect crack sealing operations to occur at highway speeds. For a generally transverse crack across a lane, the sealant dispenser will need to move at an incredible rate in order for the vehicle to be traveling at highway speeds, and it is necessary for the sealant applicator to follow the crack to meet seal specifications. Furthermore, the authors speak of the need to identify cracks smaller than what is recognized by a human. All studies on the crack sealing operation note that minute cracks are not worth sealing, and furthermore, extraneous sealant on the pavement is highly undesirable due to the difference in coefficients of friction between sealant and pavement.

J. It would appear research is directed toward the wrong problem. Prevention of cracks, reduction or control of cracks would appear to be more beneficial.

K.

L. One of the main problems in the use of automated machinery is designing the machine to recognize changes in conditions. The conditions encountered on a highway surface can be infinitely variable in very short distances. Can this equipment deal with changes in the surface temperature, moisture, the presence of debris in cracks?

M.

N. Again, if this technology can be correlated against existing methods for pavement rating and can be proven against existing methods for pavement rating and can proven consistent and efficient [authors underline] at reduced costs [authors underline] then it may be valid 
[authors underline]. I don't think simulations detection and repair is as important as is a good analytical system for programming needs.

O. There needs to be continued research to insure that if and when technology is available to make automated distress surveys that it is developed. Highway agencies do need such technology

$\mathbf{P}$.

Q. I feel more research is needed on this subject. 


\section{APPENDIX G - SURVEY RESPONSE SUMMARY}

\section{TEMPORARY BRIDGING}

1. Does the proposed technology address a critical problem area in highway construction, maintenance and operations? Please explain your answer.

A. When a temporary bridge is needed, a cost effective process would be very beneficial. I am not certain how critical this need is compared to other problems.

B. The proposed technology is not a major critical problem. Although, it would increase speed of traffic.

C. Yes. Major source of cost and delay when repairing or replacing existing bridges.

D. If a project requires traffic control, this method, under certain conditions, maybe beneficial.

E. No - it's not an issue.

F. Partially. The critical portion of handling heavy volumes of traffic including repeated heavy truck loads has not been addressed. The noise factor has also not been addressed.

G. Yes. The critical problem might be traffic control costs; in that case construction of a temp. bridge might be cost effective. Also work zone safety issues \& environment.

H. I do not have any background in this area.

I. Yes. Currently highway new alignment construction through existing physical obstructions, widening of existing highways and bridges and big bridge repair jobs require detour of traffic and/or the installation of protective barriers for separating the construction site from the traveling public. These measures are often found expensive, inconvenient to the traveling public and still not a fool proof method for safety. Construction of a new bridge over a wetland area require strict permit requirement approval from the Department of Fish and Game: expansive inspection, costly construction scheduling for protecting the species in the wetland and restoration cost of the wetland after construction. For Temporary crossing, [name] currently uses simple span construction or Bailey bridge launching construction. These methods are effective in situations such as straight alignment, span length up to 200 feet, relative big launching site and high labor costs. 
J. Yes this is a critical area of need. Studies need to determine what standard items are available for use:

Example:

1) [State DOT] recently replaced a bridge by using precast slabs for deck with asphalt overlay. Standard loading design; 52 days from beginning to completion; design build construction.

2) Use of discarded railroad flat cars for temporary haul road bridges. To be the property of [State DOT] for future use.

Care needs to be taken that these temporary bridges or materials can be transported and relocated by standard equipment. Fancy robotics cranes are not available everywhere and rural construction is much more prominent nationwide than urban.

Temporary bridges for haul road crossings to eliminate traffic interruptions should provide considerable savings and great improvements in public safety.

$\mathrm{K}$. With the possible exception of construction of bridges over wetlands and in emergency situations, I am not sure a critical need exists as for example, in the other five thrust areas. I believe the "abstract" on page one verifies this thought. On the other hand, I do certainly agree that the present closing of lanes and re-routing traffic to effect repair work or even phases construction/re-construction does create hazardous situations which could possibly be alleviated with this automated system.

L. Yes, when roads are closed the financial and political consequences are often large. It is often difficult to provide an inexpensive and convenient detour.

M. Not at all. The use of temporary bridges has very limited application at [State] DOT. One of the major selling points of the subject system is its rapid deployment. While this essential in the military situation cited, it is not as important in highway applications since the existing bridge can carry traffic while a temporary bridge is erected.

N. The proposed temporary bridging would address primarily an operational need. This technology would be to provide traffic access around a damaged bridge. The technology could also be used for detour structures used as temporary replacements while existing old bridges are demolished and replaced. This technology is viewed as appropriate for permanent structures at this time.

O. There are actually two technologies in this proposal. The first is the use of temporary bridging and the second is a light weight crane. The crane appears to address a need for lifting that may apply to a number of areas of construction. The bridging concept would also seem to have application by itself, for emergency and temporary bridging. 
P. Except for temporary bridging around construction sites, I am not convinced this is a critical problem area. The only application with possible merit could be bridging over environmentally sensitive areas. This proposal has less to do with robotics than the others.

Q. Yes, to a certain extent, traffic control and congestion can contribute to a substantial cost to the contractor and the public.

- Access to wetlands is a critical problem with cost and environmental issues.

- New lifting technology would be a breath of fresh air.

- We continue to utilize lifting technology of 100 years.

2. Briefly describe the current procedures in highway construction, maintenance, and operations which the proposed robotics/automation technology will replace or change.

A. The current processes for construction of temporary bridges are very labor intensive and slow. Some efficient systems exist for run around systems on land, but not bridges.

B. Currently, temporary bridging is done by conventional methods of construction. However, prefabricated systems are also becoming more common. The proposed system will not have a major change over the prefabricated systems.

C. It will replace the current slow process of constructing temporary replacements and will reduce construction time, thus totally altering project scheduling.

D. Temporary bridging in certain limited conditions may replace traffic detours. These detours are difficult for the traveling public.

E. Not an issue.

F. The main portion of work being replaced or changed would be surveying, form work and concrete placement. Also, the maintenance of traffic would greatly be reduced. Reduce the use of MBE's.

G. Currently, both methods are used. Traffic control on the subject bridge and also construction of temporary bridge depending on conditions.

H.

I. The proposed robotics/automation technology will provide an alternative solution of the problems described in answer \#1. It might eliminate detours and properly divert traffic at the job site. It could eliminate some unnecessary disturbance in the wetland areas. It appears to provide curve type and lengthy temporary crossing and could be launched in a 
tight launching area. If automation is possible, worker and public safety could be improved.

J. Robotics ideas can be supplementary to current procedures of all bridges being custom designed and reduce design costs and time of construction.

Standards need to be developed for "second generation" Bailey type bridges.

K. Here again I thing Mr. Goodwin does an excellent job in relating the construction procedures which currently exist in executing project requirements. (see page $3 \& 4$ )

L. During dry seasons roads are sometimes rerouted through creek beds during bridge repair. This presents safety hazards. An inexpensive temporary bridge would be better. In urban areas there is often not room for a conventional temporary bridge or detour. Some roads are closed altogether during bridge repair. New relatively simple and inexpensive temporary bridges and construction could have lots of uses.

M. Not applicable.

N. Temporary bridges are frequently used in transportation work. They are occasionally used on an emergency basis when bridge failures occur or bridges are in manger of failure. Temporary detour or construction site access bridges are frequently used.

O. A light weight crane as shown would provide precise stand off lifting capability. This capability would be of benefit in highway construction at constrained sites and where traffic has to be maintained. The temporary bridging with and without the light weight crane could speed bridge repair or reconstruction.

P. Present bridge construction techniques would be replaced with lightweight bridge panels.

Q. The building of temporary work platforms and causeways to permit conventional hoisting equipment access to the work. It will change design criteria from which permanent bridges are built from traffic control and deferred repair schedules due to conflicting traffic congestion.

3. What are potential barriers to adoption of the proposed technology? What will it take to overcome these barriers?

A. Safety is critical for bridges. This new technology will not be accepted until proven safe to carry vehicles during its use.

B. Compatibility of the proposed systems may become a barrier at practical stage. 
C. The primary barrier to acceptance would most likely be demonstration of success and inclusion as an alternative in standard contracts.

D. The economics of the bridging construction compared to a detour and the political upheaval which usually results.

E. None

F. The potential barriers would be the greatly reduced traffic speeds through the temporary structure which would cause congestion and adverse public reaction.

G. State \& Federal agencies.

It will take time.

H.

I. Construction of a temporary by-pass bridge alongside a repair site - If the launching crane and modular bridge system are launched from the existing bridge with vehicle traffic running on the existing bridge, it would impose extra live load and dead load which the existing bridge might not be able to handle. The existing bridge might be strengthened for the extra load capacity, temporary shoring could be used to support the existing bridge, temporary reduction of permissible vehicle load traveling on the existing structure while the launching is in progress, or detouring the public traffic temporarily from the existing bridge for the launching period are potential solutions to this problem.

Construction of a temporary crossing on wetland - Could this (10A MBS) carry a heavy pile driving equipment, pile load and driving impact load. Might need to develop light weight pile driving equipment and light weight pile (aluminum!)

A temporary overpass to carry traffic over a repair site - It requires a lengthy clear approach area for the on and off ramps of the temporary overpass bridge. The modular bridge system should provide sufficient vertical clearance to accommodate the construction equipment and vehicle for performing repair work underneath. Existing structure might need to be strengthened or shored for extra (10A MBS) loads.

Some concern over seismic resistance.

J. In our state, transportation to worksite due to terrain and limited repetitive number of uses may be a barrier in maintaining cost efficiency.

Overcoming the barriers will take care in planning in design to assure units are transportable in terms of weight, length and placement to different worksites. Many 
bridge sites have poor access and limited work space which must be given consideration in selection of bridge type construction.

K. Since all phases, i.e., near, medium, and long term objectives require feasibility studies, I believe is a detriment to industry adaption until this question is answered. Also as Mr. Goodwin states on page 4 , if only a $10 \%$ benefit ration will result via use of temporary bridges, I doubt "universal" adaption will be achievable.

L. 1. Cost may be prohibitive on smaller jobs.

Solution: Share equipment and combine technologies.

2. Too individualized in some cases to use standard equipment.

Solution: Combine different methods.

3. Time to obtain equipment may be too short.

Solution: Lots of sets of equipment in lots of different locations.

M. Cost, lack of application.

A natural or manmade disaster that severely damaged several bridges requiring raped replacement.

N. a) Flexibility of the Technology

This technology must be able to accommodate numerous factors including:

- Varying site conditions

- Varying geometry

- Lateral load resistance capability (kind, EQ)

- Different foundation types.

b) The technology should be user friendly. The construction industry must view this technology as cost-effective to assure acceptance for use. It is suggested that the construction industry participate in some manner in development of this research.

c) Cost

The technology should be developed to address these barriers.

O. Do not see any significant barriers other than demonstration of the technology. Flexibility of the systems (bridging and/or crane) suggest that a user friendly design system be provided so that an appropriate configuration is applied to a given site. Each configuration of both the crane and bridging may require special assembly sequences and operation plans.

P. The robotic crane concept is not well described. This technology would have to be successful in order for the bridging techniques to be useable. The lightweight bridge panels may not withstand heavy highway traffic. 
Q. Who accepts liability of the temporary bridge? The fear of liability exposure with temporary bridging - A change of atmosphere US lawyers have created.

Type of piling and style of installation - new technology to drive long and heavy piling for temporary and permanent bridges.

- Design and styles of substructures - more innovation is this area.

- Work is set up in a series configuration, everything must be done at one point, access for men, machines and material will be bottlenecked.

4. Assuming that barriers to adoption are resolved and that the proposed technology achieves its stated performance goals, please estimate the potential savings (in dollars) for highway construction, maintenance, and operations projects for the following categories. Please refer to Attachment 1, "Site Integration Present Cost Data" for background information on the average estimated costs associated with highway construction projects. If you have better cost data or information available, please use it and explain how and/or where you obtained the information.

NOTE: Please label N/A if you feel a category does not apply to the proposed technology

a. More efficient use of time

$-\$ 100,000$

- \$2-5 Million (Based on \$50 Million annual bridge program)

- Unquestionably a plus.

- No idea of potential benefits. However, the goal of the research should be to reduce construction time by a minimum of $25 \%$.

- There are a number of applications that construction and rehabilitation would be accelerated. Perhaps in the range of 30 to 50 percent depending onsite

b. Increased productivity and reduction of manpower requirements

- $\$ 50,000$

- Yes, if traffic is diverted to allow unlimited work progress on existing structure.

- Precast or manufactured saves labor. \$2-4 Million.

- Productivity would be increased which would either result in reduction of manpower or a shorter time frame to complete a given scope with no change in manpower.

- No idea of potential benefits. However, the goal of the research should be to reduce construction time by a minimum of $25 \%$.

- Time savings appear to be where most benefit would be derived

c. Maintenance costs

- Not a major change

$-\$ 200,000$

- I think would be reduced overall given a reduction in equipment requirements.

- Do not think this applies. 
d. Increased service life of final product

- Perhaps, assuming a compromised conventional method due to traffic demand.

- NO

e. Life Cycle Costs

- Not a major change

- Perhaps, assuming a compromised conventional method due to traffic demand.

- Some savings if replacement by uniform components is needed. Cost undeterminable at present.

- Would be decreased.

- NO

\section{f. Worker training}

- Operators training are required

- Yes - unknown

- Yes, for setup and operation of Robo-Crane.

$-\$ 100,000 \pm$

- I believe this would be a manageable and of relatively little consequence.

- No change. Seems like this technology would require higher than average technical worker training.

- Some worker training required

g. Other factors associated with initial cost

- Hardware and software costs

- Cost of equipment

- Planning and design for implementation of temporary structure.

- The feasibility studies may prove to be a major impact which could affect the overall cost benefit.

h. Safety (eg. insurance costs, liability, workman compensation, etc.)

- Safety will improve, however, major improvement is not expected.

- Doesn't appear to decrease workman exposure.

- Some reduction

- Potential liability problem due to temporary structure.

- Small dollar savings. Improved productivity.

- A huge plus, given the major change resulting in avoidance of "lane changing."

- Should be improved. No idea of cost savings.

- For temporary bridging may be increase liability

i. Less traffic delays (ie., how it effects the productivity for people in traffic, productivity for the delivery of goods, etc)

- Major impact on reducing traffic delays 
- Would not work on widening projects and phase construction.

- Dramatic reduction in traffic delays. And speed up construction time.

- Less, assuming use in wetland areas.

- Extensive motorist delay savings when used to handle haul vehicles.

- No idea of potential benefits. However, the goal of the research should be to reduce construction time by a minimum of $25 \%$.

- Decrease in traffic delays could be significant

j. Less repairs due to an improved quality of final product

- Not a major change

- Potential major positive impact on traffic congestion assuming similar travel speeds and patterns on temporary structure.

- May be a factor if work site is isolated

k. Environmental impacts

- Very positive impact by eliminating costly reconstruction of damaged habitats as well as minimal ecological intrusion

- Wetland applications beneficial

- Environmental damage would be greatly reduced.

- N/A - Similar structures are currently used.

- This could be a significant benefit

l. Other (please specify)

Segmental construction does the same as this development. (Note Blue Ridge Parkway.)

5. If automation/robotics could be applied to current highway construction, maintenance, and operations, do you think this proposed technology will meet the performance goals set forth in the proposal?

A. If the final structure will carry the traffic safely, the performance will be much better than current temporary bridges.

B. It is questionable whether the performance goals can be achieved.

C. There appears to be no reason why this technology could not be used and should equal the performance of current alternatives at a much lower cost.

D. If the economics present a cost/benefit ratio, then the goals may be achieved.

E. Yes, but what is the objective? 
F. No. Bridge decks are critical in preventing accidents. The lack and/or reduced friction in a steel deck would create a safety hazard. This would be unacceptable from a safety viewpoint.

G. Yes.

H.

I. Yes! Assuming the Robo-Crane has the capability to deploy such a temporary structure, and the structure will support specified traffic loads, then it appears the proposed technology does indeed have some benefit. Use of military technology (Temporary structure) is a big plus, potentially saving the highway community many research dollars.

J. Possibly a test site could be located in [State].

Overall use of this technology would be small in [State].

K. If the feasibility studies and balance of the program do result in the benefits stated by Mr. Goodwin on pages 3,4 and 5, I do believe this program could be considered a success.

L. Yes, all three areas would benefit, but the long term solution would not have that much use in [State] since most places don't have that severe of a space constraint problem that the temporary bridge would have to go overhead.

M. No, I believe it will increase costs, save no (practical) time (i.e. inconvenience to the traveling public will not be reduced) and has no application to [State] DOT.

N. I have doubts that this technology can effectively deal with the multitude of variables encountered in construction. To gain industry acceptance, this issue will have to be accommodated along with ease of use and cost.

0.

P. The robotic crane is not described well enough to determine.

Q. No.

6. General comments concerning the proposed technology.

A. This proposal has good potential, but may be very expensive to test full size structure.

B. 
C.

D. Offers a limited area of application.

E. Not an issue.

F. The proposed technology can be used only in rural areas with light traffic where reduced speeds is acceptable by the public.

G. -DOD \& Fed. government partnership in developing the idea.

-Could prove to be very beneficial in cost savings of traffic control, work zone safety \& environment.

H.

I. It seems the automation/robotics technology could reduce the required labor cost during the launching as compared with conventional methods. Planning, material storage, maintenance and transportation are as critical as ever - for the margin of error would also approach to the cutting edge. These conditions shall also apply to the stage of dismantling the crossing system. This technique could well be the answer to specific sites that have seemingly insurmountable traffic problems.

J.

K. Without question, a well thought out approach but I believe requires additional research, as I have previously stated, before expecting embracing by the industry.

L.

M.

N. The concept has merit.

0.

P. This does not seem to be a typical robotic project.

Q. We have used temporary bridging (trestle) to work our cranes from for the past 6 years with success. We have worked in shallow, deep water and wetlands. Current bridge design require the sue of large conventional cranes for substructure work. If the robocrane is to be sued, current design would need altered or new technology introduced. 



\section{APPENDIX H - SURVEY RESPONSE SUMMARY}

\section{GENERAL QUESTIONS}

1. What other areas of highway construction, maintenance, and operations would benefit from robotics/automation?

A. Pre-assembly of components (on-site if volume sufficient)

Tunnelling and Pipe Jacking (less disruptive)

Paving operations

*QA/QC during construction or maintenance operations [CRITICAL NEED]

B. Recycling of materials.

C. A) Automated Invoicing

B) Automated Inventory Controls

C) Rapid Field Testing

D. A. Highway pavements

B. Highway operations; large traffic volumes

E. The expensive ones! Earthwork, paving, foundations, materials, work zone safety.

F. Perhaps truck weighing away from fixed scales or work sites.

G. Materials testing concrete, bituminous see \#5

H.

I. - Projects to automate pavement delineation including paint striping, placement of raised pavement markers, and the stenciling of arrows, stop signs, surveying marks, etc..

Other technologies could be used to determine the retro-reflectivity of the old markings prior to application of new markings.

- Automated pavement inspection and repair techniques.

- Remote sampling, identification and cleanup of hazardous material spilled in the highway right of way.

- Worker safety related projects including workzone penetration indicators.

- Remote operation of heavy construction or maintenance equipment in dangerous areas.

- Methods for automated removal of graffiti.

- Structure inspection techniques to eliminate worker exposure to traffic including the use of teleoperation, telerobotics, machine vision inspection tools, bridge mounted instrumentation, etc. 
- Regional monitoring and control of maintenance tasks such as bridge mounted instrumentation, irrigation, etc.

- Roadside cleanup devices such as litter pickup and containment vehicles.

- Automated control of roadside vegetation.

J. The most beneficial would be an automated pavement inventory system insuring early effective maintenance.

Continued application of laser technology to line and elevation control.

K. Tunnel construction definitely, particularly where going through gaseous ground or highly fractured ground. Using robots in place human workers would greatly reduce the accidents resulting from this type environment.

L. Roadside maintenance--shouldering, weed control, rockfall hazard mitigation, tunneling, pothole patching, snow and ice removal.

M. Traffic Control

Mowing

Planting Flowers \& Trees

Fencing

Inventories

Maintenance Records/Documentation

N. Any safety related maintenance or operational devices that would remove workers from work zones or construction hazard areas.

O. Original Design concepts should be revised so that prefabricated modular units (r.e. bridge decks) can be set into place. Anything that would reduce traffic delays and there by lower costs. User costs of highways outweigh cost of rebuilding.

P. Traffic management

Product testing

Q. Tunneling

Subgrade placement \& prep. - stabilized earth - pugmill, etc.

Hazard analysis - equipment, utilities, site conditions.

Automate equipment usage reporting $\&$ location on site for better utilization of equipment and operation and work crews. 
6. Do you use robotics/automation on construction projects? Please explain the current usages and the benefits of robotics/automation and note the problems you have encountered.

A. NO - not in construction business.

B.

C. A) Laser controlled graded

B) Automatic controls on paving equipment

C) Automatic controls on plants

D) Automatic invoicing systems

D. Yes. Pavement placement, roadway grading, concrete mixing, scheduling, and distance measuring layout. Most of the difficulties are encountered in the application of the programs by project personnel.

E.

F.

G. No

H.

I. No. [Name] actually contracts most new construction to the private sector. There are no provisions in the specifications to date that require contractors to use new technology concepts. [Name] on the other hand performs most of its own maintenance. Through the joint [Name]/University of [State] Advanced highway Maintenance and Construction Technology (AHMCT) program, prototype robotics and automated equipment has been developed for maintenance. Some of this equipment has been tested in the field by the end user. Other equipment is still under development.

The biggest hurdle appears to be the commercialization and subsequent availability to [Name] of ruggedized equipment developed from the AHMCT program prototypes. The primary problem cited by industry appears to be the specialization of the equipment and thus low market appeal.

J. Starting to use laser control in pipe construction and constant grade situations. Automated grade control on paving equipment. Automation in mixing of concrete and asphalt.

Problem: Establishing smooth grade when replacing and overlaying old pavements. 
K. Only on a limited basis.

L. Dowel inserters on concrete pavements. Will probably save money. No problems yet.

M. To varying degrees, surveying, grading, paving and management.

N. No.

O. Sensor technology for details and buried or hidden features appear to be the biggest problem that I have encountered.

P. Project design is automated to a large extent. Roadway construction is still more traditional, except for surveying.

Q. Yes. Guidance systems for tunnel boring machines. Problems w/componentry to withstand the adverse environment in tunnel applications. The advantage - Auto steer on target.

Grade control - Crawler tractors \& motor graders. Operators \& foreman not wanting to accept the benefits.

Q. Yes. Guidance systems for tunnel boring machines. Problems w/componentry to withstand the adverse environment in tunnel applications. The advantage - Auto steer on target.

Grade control - Crawler tractors \& motor graders. Operators \& foreman not wanting to accept the benefits.

7. Please provide any additional comments or recommendations concerning automation and robotics.

A. The key to success is automation -- man/machine coordination. The cost, potential problems and difficulty to develop of robotic systems are just not practical for many operations. However, automated systems with human monitoring and control have great potential.

B.

C.

D. 
E. We need to be much more focused in our approach.

F. 1. One respondent suggested the FHWA would be better off spending its funds on improving construction/maintenance materials.

2. Robotics avoids the issue of meeting minority hiring goals.

3. Need for training not addressed; could be substantial.

G. -Human job reduction could be a concern

-Difficult to apply in real world \& construction

H.

I. [Name] has always tried to employ new technology into its operations wherever possible, but has not kept current with advances in industrial robotics or automation applications until the last 4-5 years. Application of advanced technologies to many maintenance operations appears obvious in many instances, often appears to have a high likelihood for success, and is technologically workable. This does not ensure that the end user will except the advancement with open arms. In fact, many promising projects may not get started due to lack of support from the end users.

If the project appears to satisfy the goals and objectives (i.e., improved safety, reduced traffic congestion, etc.), the technology is available to accomplish it, has a high likelihood for success, and there appears to be some market for the product, but suffers from low support from the end user, [Name] will proceed with the project. Use of the new equipment has actually been mandated by management in some cases. An example of this was the elimination of bogies for paint striping and the replacement with a new, high technology paint striping vehicle. This met with tremendous resistance from the end user initially, but there is now not an end user that would switch back to the use of bogies. The new vehicle has prevented countless injuries and fatalities since its employment.

J. Automation should be directed toward routine repetitive activities. Robotics should be directed at safety issues.

The Goal should be simplicity of application and operation.

K. The U.S. industry needs to embrace automation to regain its leadership role on the international market place. We need to get all parties to the table to arrive at an acceptable "road to travel" to achieve objectives.

L.

M. 
N. There needs to be some trial field demonstrations and trials.

O. Prototype development costs will be significant. Implementation will reveal design flaws that have to be corrected. Expectations should factor in these problems. Most of the proposers would have benefited from participation of someone with specific highway construction and inspection experience. It is important that automation and robotics be given priority for research. This will benefit our own infrastructure and economy as well as maybe our construction industry competitive.

P. - Care should be taken that the cost of the automated/robotic procedure doesn't exceed the traditional methods.

- Roadway construction offers jobs to many unskilled workers. Should we be concerned with the elimination of unskilled workers?

- Find solutions to problems, don't find a solution and then search for a problem.

Q. I feel both should be introduced \& pursued in the market place as enhancements to labor and equipment for the improvement of quality and production, not as direct replacements. Product support for both must parallel the advancement of new technology. Especially w/quality technicians. We have consistently failed to accomplish this in the past.

8. Do you feel there is a need to improve current methods of project delivery systems and/or contracting practices in the highway construction industry? If yes, how can they be improved and/or what do you think should be researched?

A. More involvement of construction experts is needed in design: i.e., constructibility, value engineering, life cycle costing, design-build contracts. Also, more designer involvement is needed in the construction phase, i.e., improved QA/QC and problem solving. Partnering is needed for both design and construction phases of projects.

B.

C.

D. There is always room for improvement, as we are far from perfect. Research should focus on methods to have construction personnel make intelligent decisions more quickly.

E. Yes, information flow, high cost equipment intensive operations, all labor intensive operations.

F. Yes, but discuss this with the private sector of the industry. 
G. Yes.

-Better \& consistent construction methods

-Better quality assurance

H.

I. No answer.

J. Continued improvements are needed in contractor responsibility for quality and teamwork approach to project management.

"The Partnering Process" is working exceptionally well in [State].

Continuing practice of low bid is costing everyone money. Need to adopt new system.

Either drop high and low, then take one closest to average or calculate rental costs to account for time.

K. Very definitely yes. With the limited public funding, I believe more should be done/utilized in the Public Private partnership concept. Ways to make risk sharing by public sector a viable discipline in areas controlled and the responsibility of the public sector need immediate researching. Private sector has underutilized resources available to break gridlock to create jobs, provide tax income, and get stalled economy off dead center.

L. Yes. Give contractor more flexibility and responsibility. Use warranties where possible so the contractor must back up his work.

Give dollar incentives to encourage innovation on the contractor's part. This will save dollars down the road.

M. Yes.

N.

O. Quality Currently contractors have no inventive to do anymore than meet specifications.

P. Advanced technology may require revised procurement procedures. Traditional competitive bidding procedures do not work when purchasing development-related equipment or advanced technology.

Q. There should be more integration/partnering of architect - designers - contractor - Owners. 



\section{APPENDIX I - WORKING GROUP ORGANIZATION}

A working group was convened on August 31, 1993 to review the survey results and develop an industry based assessment of the six robotics/automation technologies evaluated in this report. The product of this workgroup formed the bases of Section II of this report. For each of the technologies the work group was asked to develop a scenario for the technology, detail how the scenario would be accomplished using present technology and develop a cost estimate. The work groups were provided sample tables with which to tabulate their work.

The work group were tasked to: Estimate the potential impact of six automation/robotics technology proposals on highway construction, maintenance, and operations in terms of efficiencies, cost, safety, operations, and in extending the service life of various highway components. They were asked to develop a representative task scenario within which the proposed technology would be evaluated. Using the scenario, the work group was instructed to determine how the task would be accomplished using current technology, the cost to accomplish the task, and how long it would take to complete. They were also instructed to perform the same analysis using the proposed technology. Sample work sheets were provided on which to record the results of the analysis. The specific instructions for the workgroups follow:

\section{Tasks for Workgroup Impact of Robotics/Automation Applications to Highway Transportation}

\section{A. Objective}

Estimate the potential impact of proposed automation/robotics applications to highway construction, maintenance, and operations.

\section{B. Scope}

Assess the potential impact of automation/robotics studies in terms of efficiencies, cost, safety, operations, and in extending the service life of various highway components.

C. Tasks

1. Document Present Highway Procedures for each proposed automation/robotics application.

Determine the various procedures now used in the United States to accomplish the work proposed for automation/robotics. This task includes identifying various procedures and 
obtaining baseline data regarding costs, efficiency, operational parameters, and safety.

2. Analysis of Present Highway Procedures for each proposed automation/robotics application.

Factually assess the various existing methods in use to accomplish the highway applications proposed for automation/robotics. The product from this task will be a performance template against which the proposed automation/robotics applications will be evaluated.

3. Develop Matrix of Performance Parameters for the proposed automation/robotics applications.

Develop a matrix that correlates projected performance for each recommended automation/robotics application.

4. Assess potential of proposed automation/robotics applications

Identify the potential benefits of each proposed automation/robotics application. Attempt to estimate upper and lower bounds of potential benefits and establish a rank ordering for the set of automation/robotics applications under consideration.

\section{Conclusions/Recommendations}

Develop appropriate conclusions regarding the potential benefit of each proposed application. Frankly assess and discuss those automation/robotics applications that appear to have the greatest commercialization potential. 


\section{WORKGROUP ORGANIZATION}

Workgroups are based on major applications of the proposed Robotics/Automation application. Three workgroups will examine technologies dealing principally with construction, maintenance, and a mix of construction and maintenance. The workgroups are as follows:

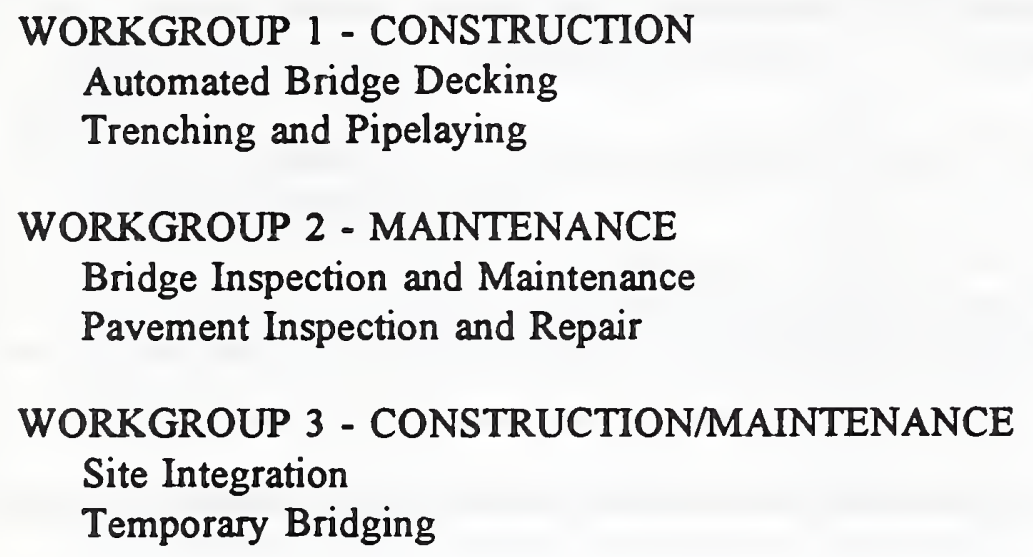

The workgroups will accomplish their work in two steps. Step 1 will involve an analysis of the present technology used to accomplish the function proposed for the Robotics/Automation application. Step 2 will develop projected/desired performance characteristics for the Robotics/Automation application along with anticipated costs.

\section{STEP 1}

For each proposed technology, the workgroup will develop and use a representative scenario to evaluate the technology. The workgroups will develop matrices which depict the various procedures now used in the United States to accomplish the work proposed for robotics/automation in the context of the scenario adopted. To the extent possible, the current standard, resources required, unit cost of resources, and the number of resource units required to accomplish each procedure will be determined for the scenario. The suggested headings for the matrix are shown below. The workgroup may develop a different set of headings provided the headings facilitate a comparison of current technologies with the proposed technologies in the areas of cost, efficiency, quality (service life), and safety. 
PRESENT SYSTEM FOR

Technology

Description of typical task for this technology:

Describe how this task is currently accomplished:

\begin{tabular}{|l|l|l|l|l|}
\hline $\begin{array}{l}\text { Performance } \\
\text { Element }\end{array}$ & Current Standard & Resources Required & $\begin{array}{l}\text { Unit Cost } \\
\text { of } \\
\text { Resource }\end{array}$ & $\begin{array}{l}\text { Units } \\
\text { Required }\end{array}$ \\
\hline & & & & \\
\hline & & & & \\
\hline & & & & \\
\hline & & & & \\
\hline
\end{tabular}

\section{STEP 2}

Using a similar table, the workgroup will evaluate the potential of the proposed technologies to accomplish the same performance elements identified in Step 1. Relying upon their extensive knowledge and experience, the workgroup members will develop the estimated performance characteristics for the proposed technologies rather than accepting the statements in the research proposals at face value. A suggested matrix headings follows.

PROPOSED ROBOTICS/AUTOMATION APPLICATION FOR Technology

\begin{tabular}{|l|l|l|l|l||}
\hline $\begin{array}{l}\text { Performance } \\
\text { Element }\end{array}$ & Proposed Standard & Resources Required & $\begin{array}{l}\text { Unit Cost } \\
\text { of } \\
\text { Resource }\end{array}$ & $\begin{array}{l}\text { Units } \\
\text { Required }\end{array}$ \\
\hline & & & & \\
\hline & & & & \\
\hline & & & & \\
\hline & & & & \\
\hline
\end{tabular}

Table shown for illustrative purposes only. 


\section{APPENDIX J - REFERENCES}

1. Bettigole, Robert A., P.E. "Exodermic Deck Boosts Bridge Load Rating," Roads \& Bridges, August 1993, pp 44-45.

2. Card, Andrew H., Jr. The Status of the Nation's Highways, Bridges, and Transit:

Conditions and Performance, Report of the Secretary of Transportation to the United States Congress, U.S. Government Printing Office, Washington: 1993.

3. Harrington-Hughes, Kathryn. "Highway Research," The Construction Specifier, July 1993, p 78.

4. Institute of Transportation Engineers. Highway Facts: 1991 Edition, Publication Number PP-021, Washington: 1991.

5. Larson, Thomas D. Highway Statistics 1991, (Publicaiton No. FHWA-PL-92-025), U.S. Department of Transportation, Federal Highway Administration, Washington, D.C.: 1992.

6. Magnell, Carl O. "The Construction Site: Automation's Last Frontier," American Consulting Engineer, Vol 4, No 2, pp 21 - 23: 1993.

7. R.S. Means Company, Inc. Means Heavy Construction Cost Data, 7th Annual Edition, Kornelis Smit, ed., Kingston, MA: 1993.

8. The Road Information Program. 1993 State Highway Funding Methods, Washington: 1993. 



\begin{abstract}
MEASURES OF MERIT
FOR AUTOMATION/ROBOTICS SYSTEMS FOR

ROAD CONSTRUCTION, MAINTENANCE, AND OPERATIONS
\end{abstract}

\author{
Prepared By: \\ Robert Finkelstein \\ Robotic Technology Inc. \\ 10001 Crestleigh Lane \\ Potomac, Maryland 20854
}

August 1993 



\section{TABLE OF CONTENTS}

\section{section}

1.0 PURPOSE.

2.0 BACKGROUND.

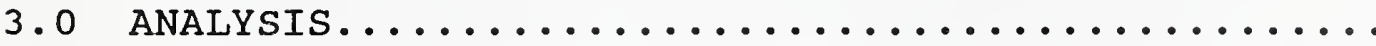

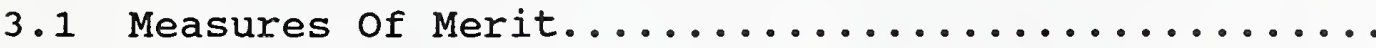

3.2 Evaluation of MoM And System Alternatives........

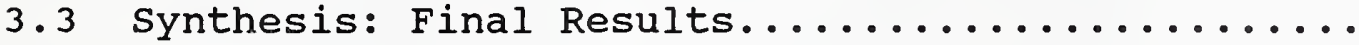

3.4 Sensitivity Analysis.....................

AHP BIBLIOGRAPHY ....................... 



\subsection{PURPOSE}

The purpose of this task is to define and weight measures of merit (MoM) suitable for use in the cost/benefit analysis of automation/robotics for road construction, maintenance, and operations. The task will also provide an example of a method for evaluating alternative systems against the weighted MoM.

\subsection{BACKGROUND}

A cost/benefit analysis of prospective automation/robotics systems for road construction, maintenance, and operations is to be performed as part of a project at the National Institute of standards and Technology (NIST). Suitable MoM are usually defined and weighted as part of a cost/benefit analysis, against which the various alternative systems are then evaluated.

There are various techniques available which may be used for evaluating alternative choices. Commercially available software may be used as tools to support the evaluation process. Examples of the software are: Expert Choice (available from the Decision Support Software Co.), and HIPRE 3+ Decision Support Software (available from Santa Monica Software Inc.). Both of these programs use the Analytic Hierarchy Process (AHP), but HIPRE 3+ also includes Multiattribute Value Function Techniques, which can be used in conjunction with the AHP. Both programs have been favorably reviewed by the operations research community. The AHP is also gaining popularity in the defense community (U.S. and Canada) for aiding in the evaluation of weapons systems (please see the bibliography for relevant papers, books, and documents concerning AHP theory and applications). The following is a brief description of the AHP.

Making decisions about complex problems involving conflicting criteria and several alternatives is not a simple process. Psychological research has demonstrated that, although the human mind is a wondrous thing, it is indeed limited. The AHP enables one to transcend such limitations by visually structuring a complex problem in the form of a hierarchy. Each factor and alternative can be identified and evaluated with respect to other related factors. This ability to structure a complex problem, and then focus attention on individual components, amplifies one's decision making capabilities. A person's capacity for making judgements is expanded beyond the limits imposed by what psychologists call the limited channel capacity and short term memory of the human mind.

The AHP makes it possible to look at the elements of a problem in isolation: one element compared against another with respect to a single criterion. This is the decision process reduced to its simplest terms - pairwise comparisons. The AHP helps the decision maker structure the problem (so he can focus on its 
elements), and synthesizes all judgements into a unified whole in which the alternatives are clearly prioritized from best to worst.

The decision maker's judgements form the basis of the AHP process. Judgements are made about pairs of elements relevant to a criterion or property which they have in common. For example, one might look at two telerobotic control system video displays and notice that the first is clearer than the second. In addition to observing this, we have an ability to say that the first display is much clearer than the second, or just moderately clearer, or that the clarity of the two displays is the same. It is from a multiplicity of these pairwise comparisons that we build our knowledge of the variability of a criterion that interests us.

The number of criterion considered in a particular decision is often large. For example, two robots may be compared according to size, weight, reliability, maintainability, accuracy, development risk, precision, flexibility, and so on. The criteria may be top-level MoM or submeasures. In either case, the AHP makes it easy to organize complex problems with a large number of criteria.

We usually perform measurements using scales with units such as pounds, seconds, miles, or dollars. But these scales, developed slowly by people over the years, limit the nature of ideas we can deal with. Social, political, and other qualitative factors can in no reasonable way be assessed in terms of physical or economic measurement. What then can we do to incorporate these seemingly non-measurable factors? Just as we distinguish and measure physical quantities, such as meters for length, or seconds for time, we are able to do the same with our perceptions of qualities, such as comfort, style, and political influence. We have the capacity to experience a wide range of feelings and discriminations. This permits us to develop relationships among the elements of a problem and to determine which elements have the greatest impact. The AHP is unique in that it can accommodate both quantitative and subjective inputs, and merge them into a single overall measure to determine which alternative is most desirable.

The AHP does this by devising a scale that enables us to measure tangible qualities. To be credible, this new approach should work in areas where we already know the unit of measurement. In fact, it has been validated in hundreds of experiments that the method underlying the AHP does indeed generate results conforming to classic ration scale measurements in physics, economics, and other fields where standard measures already exist. one can express the relative importance of one element over another, with respect to a given criterion, either verbally or numerically. When making comparisons in a social, psychological, or political 
context, the verbal comparison mode of the AHP can be used. When comparing economic or other measurable factors, the numerical comparison mode may be preferred. Table 1 below explains both scales and their relationship.

When comparing properties that lend themselves natural y to a numerical scale, one could use the numerical mode to e ter the judgements (values 1.0 through 9.0 are allowed). On this scale, 1.0 implies that the elements are equally important, 2.0 that one element is twice as important as the other, and 9.0 that one element is nine times as important as the other. These are absolute numbers that tell us, for example, which of two robots (functionally equivalent) is the heavier and how much heavier is it. Thus, assigning the value 5.0 says that the first robot is five times heavier than the second.

If the disparity between elements is so great that they are not of the same order of magnitude, an extra level should be added to the AHP tree, and the elements should be put into different clusters. Experience has confirmed that a scale of nine units is reasonable and reflects the degree to which we can discriminate the intensity of relationships among elements. (The numerical mode allows for more gradations of judgements within the basic nine units.) Not only does the AHP calculate priorities based on human judgement, it also produces a measure of inconsistency. This measure is useful in identifying possible errors in expressing judgements as well as actual inconsistencies in the judgements themselves. The Expert Choice software allows the user to request suggestions for improving consistency. (discussed below). However, it is important that the methodology does not preclude inconsistencies in judgements. On the contrary, many decisions must be made while recognizing inconsistencies that exist in the real world.

A typical scenario might be as follows: The decision maker would, as usual, build an AHP model that might contain criteria, sub(criteria), game-players and scenarios. However, the model would not include the alternatives. Instead, he would enter sets of ratings, (i.e. levels of performance such as outstanding, Above Average, Average, Below Average and Unsatisfactory) as leaf nodes.

After the judgement process is completed, the Ratings module, in the Expert Choice software, would be used to enter and evaluate the alternatives of choice. This would be accomplished by assigning a rating to each alternative with respect to each criterion or subcriterion.

When using Expert Choice with the Ratings module, one will observe a similarity to the classical weights and scores approach used to prioritize alternatives. The weights and scores approach is deficient in that it violates what scientists call the proper 
use of "scales of measurement". For example, in a classical weights and scores approach, the ratings would be given (ordinal) numbers, such as 1 for Unsatisfactory, 2 for Below Average, 3 for Average, 4 for Above Average, and 5 for Outstanding. If an alternative were considered above average with respect to a specific criterion, its score would be incremented by the weight for that criterion, multiplied by 2. Thus, an implicit and incorrect assumption that above average is twice as good as below average is introduced in the decision. This is an obvious error, one that is avoided when using the AHP because the AHP uses ration scale numbers.

NUMERICAL SCALE
VERBAL SCALE

\section{EXPLANATION}

Two elements contribute equally to

the property

Experience and judgement favor one element over another

An element is strongly favored

An element is very strongly dominant

An element is favored by at least an order of magnitude of difference

Used for compromise between two judgements judgements

Intermediate values in

0.1 increments of .1

(Example: 6.3)
Used for even finer gradations of judgements 


\subsection{ANALYSIS}

The automation/robotic systems in our example evaluation were selected previously by a joint NIST and Federal Highway Administration (FHWA) study group, in conjunction with the civil Engineering Research Foundation (CERF). The system alternatives are described in detail in the document: Proposed Research Topics For Evaluation, FHWA/NIST Study Group, May 27, 1993, and, therefore, they are not described in this report. It is a given, by the initial selection process, that all of the systems are technically feasible on an equal basis, so that no measures of merit relating to technical feasibility need be defined and used in the analysis.

The ultimate evaluation and prioritization of the system alternatives will be performed by expert panels in concert with CERF.

\subsection{Measures of Merit}

For the analyses of the MoM and system alternatives, we used Expert Choice Version 8, available from Decision Support Software Inc.

Figure 1 shows the hierarchical decision tree (going from left to right) for the problem at hand. The goal, as titled at the top, is to select a robotic/automation system for development and demonstration. We defined three first level measures: Functional Importance (FUNC.IMP), Operational Benefits (OP.BENEF), and System Characteristics (SYS.CHAR). Each of the first level measures has second level measures, or submeasures, associated with it. And the (pre-defined) set of automation/robotic system alternatives are associated with each of the submeasures.

The MoM of Functional Importance provides a larger context for the system selection. It includes, as submeasures, the potential national economic impact (ECON.IMP) of adopting the system; and the importance of the proposed system to the well-being of the highway infrastructure (INFR. IMP). The two measures may overlap for a particular system, but there is a useful distinction between the two. For example, a site integration system may have a relatively large national economic impact because it could lead to significant increases in productivity on a large number of worksites for roadwork, as well as job sites for building construction and other construction projects. But it is not as critical to the well-being of the highway infrastructure as, for example, an automated bridge inspection and repair system.

The Operational Benefits (OP.BENEF) measure is a relative MoM: the potential enhancement of the proposed system compared with the current way in which the same function is performed. Its submeasures include: the potential reduction in life cycle cost 
SELECT A ROBOTIC/AUTOMATION SYSTEM FOR DEVELOPMENT/DEMONSTRATION
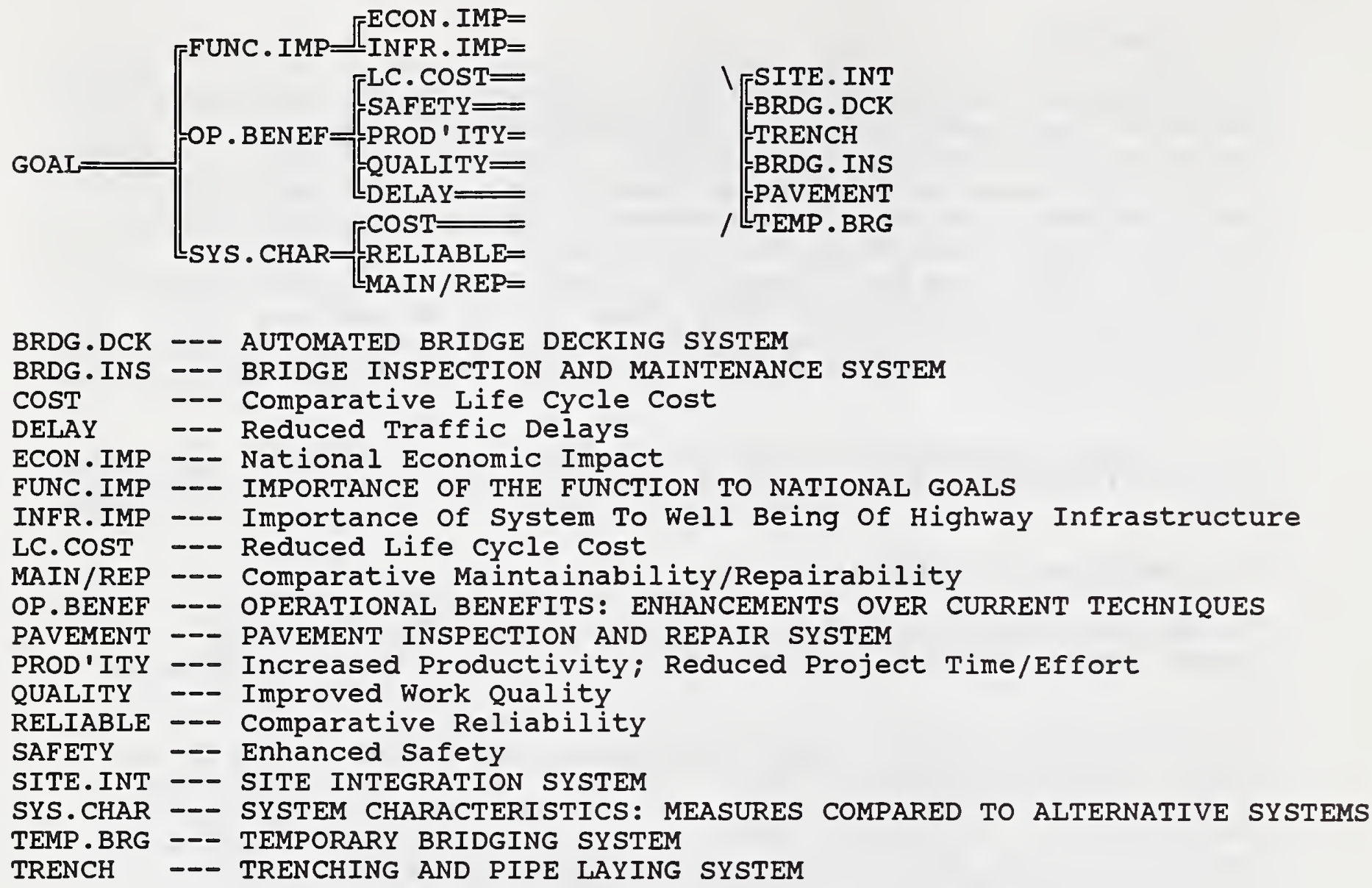
(LC.COST); the potential increase in safety (SAFETY); the potential increase in productivity, or reduction in project time or effort (PROD'ITY); the potential improvement in the quality of the work performed (QUALITY); and the potential reduction in traffic delays (DELAY).

The final first level measure is system Characteristics (SYS.CHAR), where the system alternatives are now compared with each other in terms of the submeasures: comparative life cycle cost (COST); comparative reliability (RELIABLE); and comparative maintainability and reliability (MAIN/REP).

The system alternatives, which are to be evaluated against the various MoM, are: an automated site integration system (SITE.INT); an automated/robotic bridge decking system (BRDG.DCK); a robotic trenching and pipe laying system (TRENCH); an automated/robotic bridge inspection and maintenance system (BRDG.INS); an automated/robotic pavement inspection and repair system (PAVEMENT); a robotic temporary bridging system (TEMP. BRG) •

Figures 2 through 15 show the details of the decision tree, in vertical format, including the final numerical results of the exercise (which will be discussed below). Figure 2 diagrams the goal at the top and the first tier of measures; the component submeasures are listed under each measure. Figure 3, and the subsequent Figures through Figure 15, focus on various parts of the tree; nodes not under consideration are represented by "O" to show the rest of the tree symbolically.

Each measure and submeasure, in the figures, has a weight, or priority, (the derivation of which will be described below). There are local priorities (L), which are relative to each parent node; and there are global priorities (G), which are relative to the ultimate goal (stated at the top of Figures 1 and 2 ). The value of both priorities are, of course, the same (equal to 1.000) at the goal node. They are also the same for each of the measures. They differ at the submeasures, however, where the submeasure $L$ add to 1.000 for each of the parent measures, but the submeasure $G$ add only to the value of $G$ (or $L$ ) for the corresponding parent measure.

\subsection{Evaluation of MoM And system Alternatives}

Figures 16 to 36 illustrate the evaluation process, which is performed automatically by the Expert Choice software, based on the pairwise comparisons made by the analyst (i.e., the program calculates the eigenvalues of matrices formed from the analyst's pairwise evaluations). In Figure 16, the three measures were evaluated, pairwise, as shown. The resulting priorities (weights) are shown in bar graph form at the bottom of the figure, with the numerical values to the left of the bars. 
SELECT A ROBOTIC/AUTOMATION SYSTEM FOR DEVELOPMENT/DEMONSTRATION

$$
\begin{array}{|l|c|c|}
\hline & \text { GOAL } \\
\text { L } 1.000 \\
\text { G } 1.000
\end{array} \mid
$$
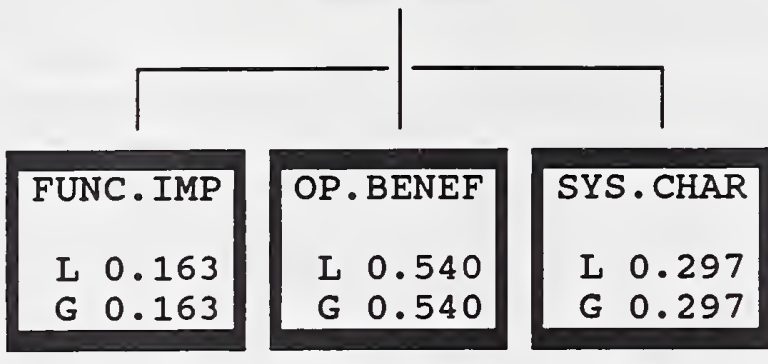

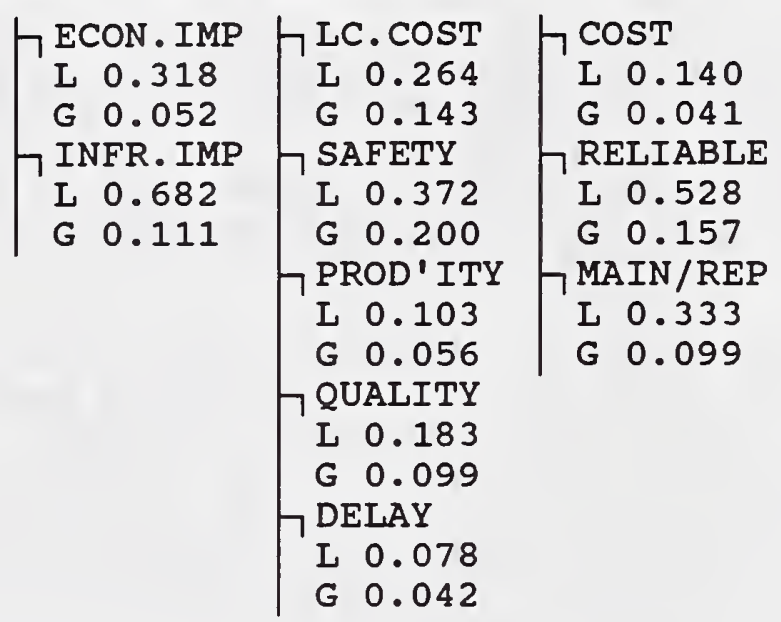

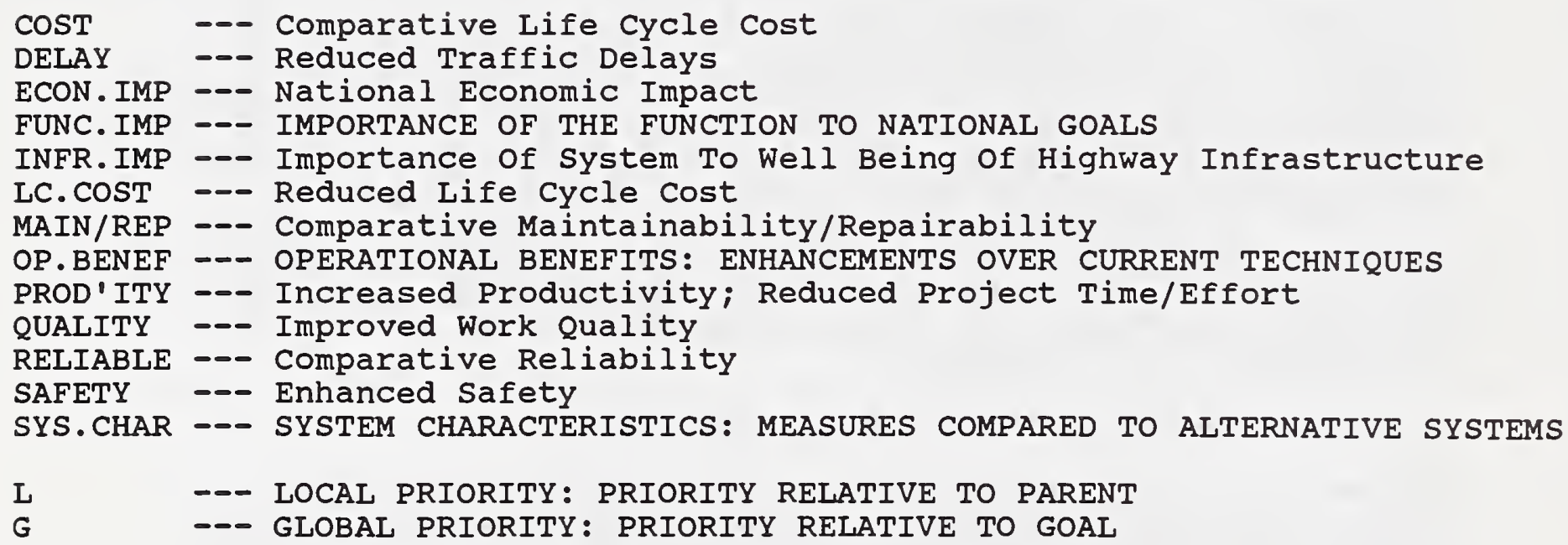



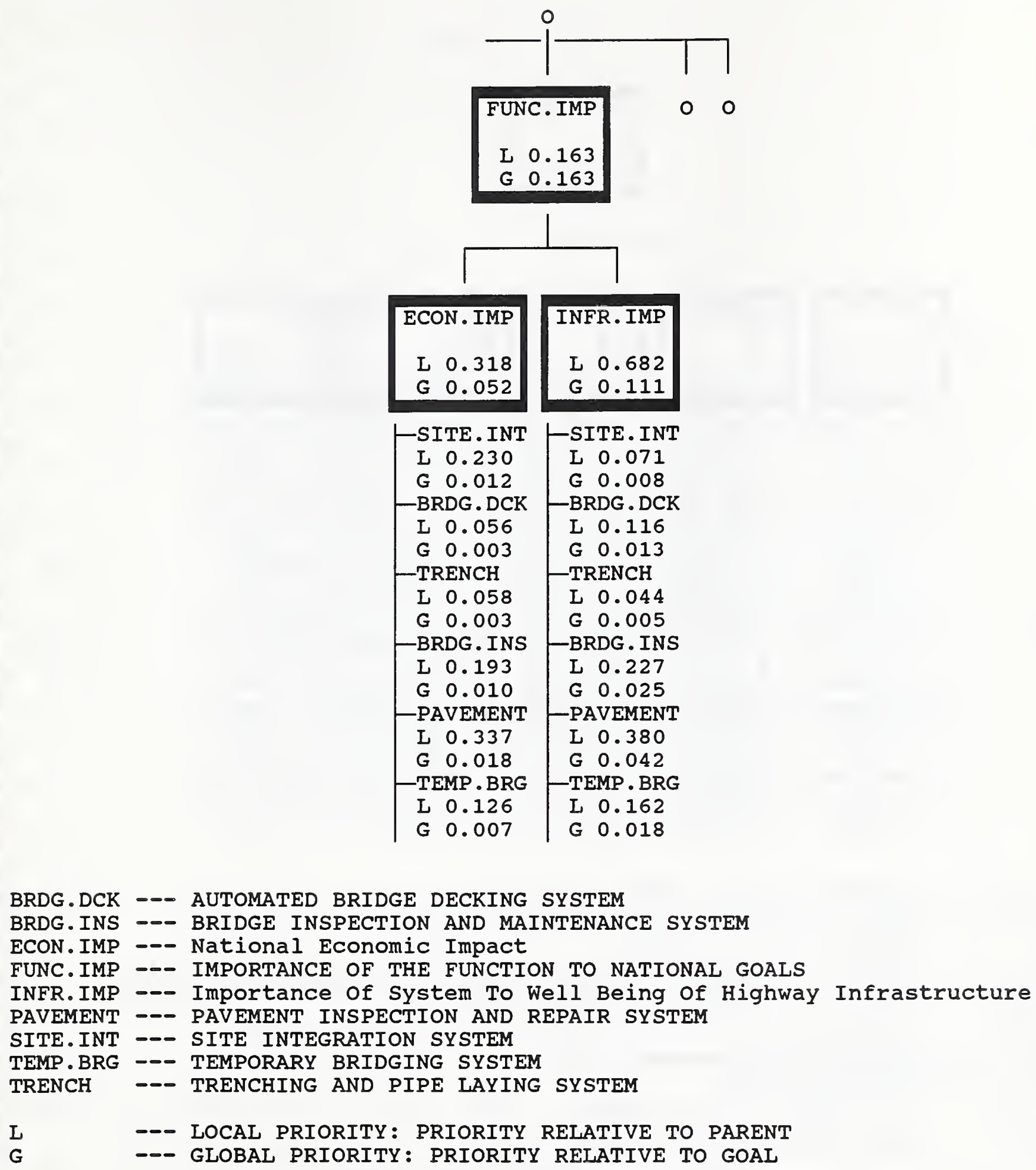


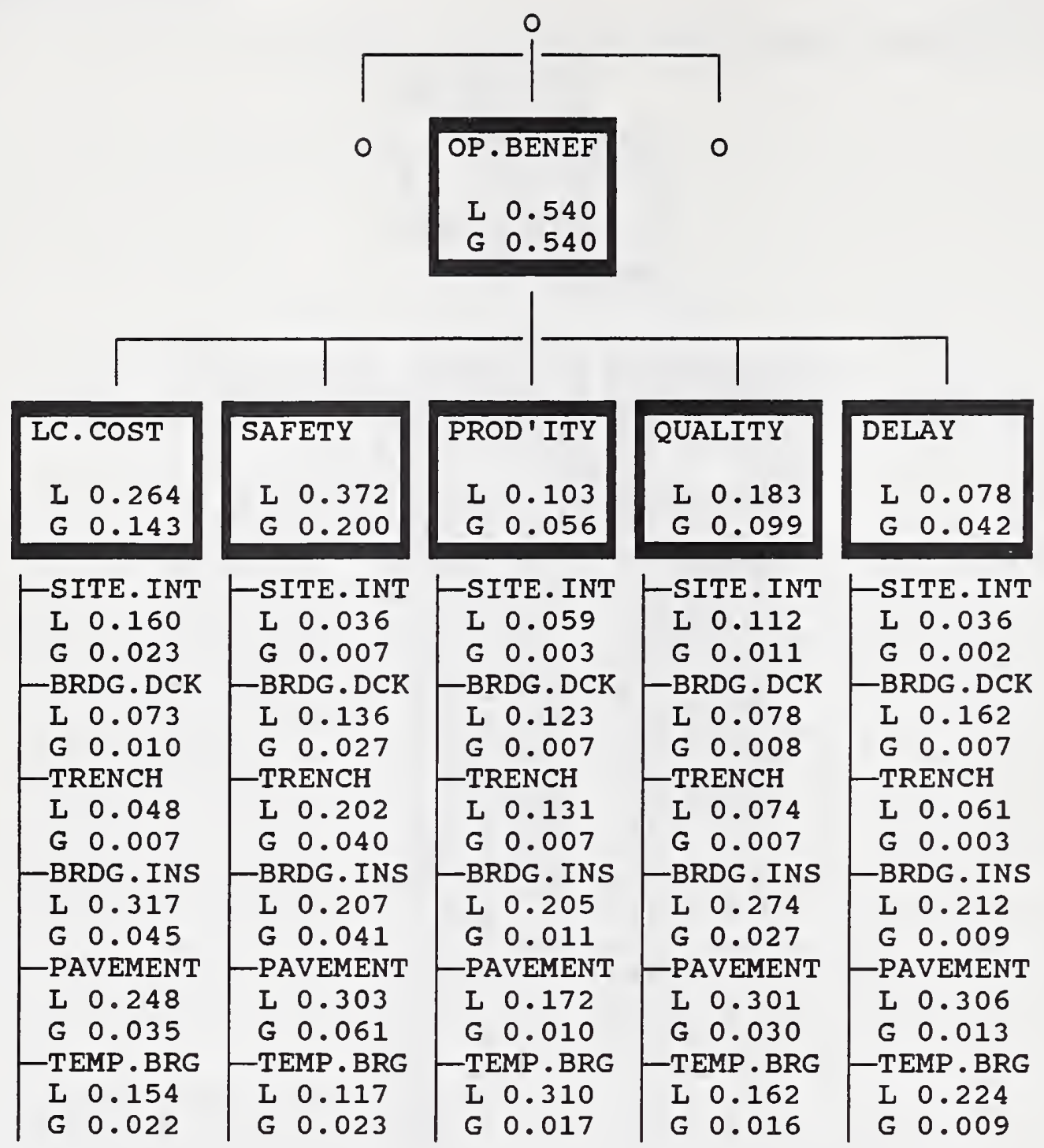

\footnotetext{
BRDG.DCK -- AUTOMATED BRIDGE DECKING SYSTEM

BRDG.INS --- BRIDGE INSPECTION AND MAINTENANCE SYSTEM

DELAY -- Reduced Traffic Delays

LC.COST --- Reduced Life Cycle cost

OP.BENEF -- OPERATIONAL BENEFITS: ENHANCEMENTS OVER CURRENT TECHNIQUES

PAVEMENT - - PAVEMENT INSPECTION AND REPAIR SYSTEM

PROD'ITY -- - Increased Productivity; Reduced Project Time/Effort

QUALITY --- Improved Work Quality

SAFETY -- Enhanced Safety

SITE.INT -- SITE INTEGRATION SYSTEM

TEMP.BRG -- TEMPORARY BRIDGING SYSTEM

TRENCH -

L -- LOCAL PRIORITY: PRIORITY RELATIVE TO PARENT

G - - GLOBAL PRIORITY: PRIORITY RELATIVE TO GOAL
} 


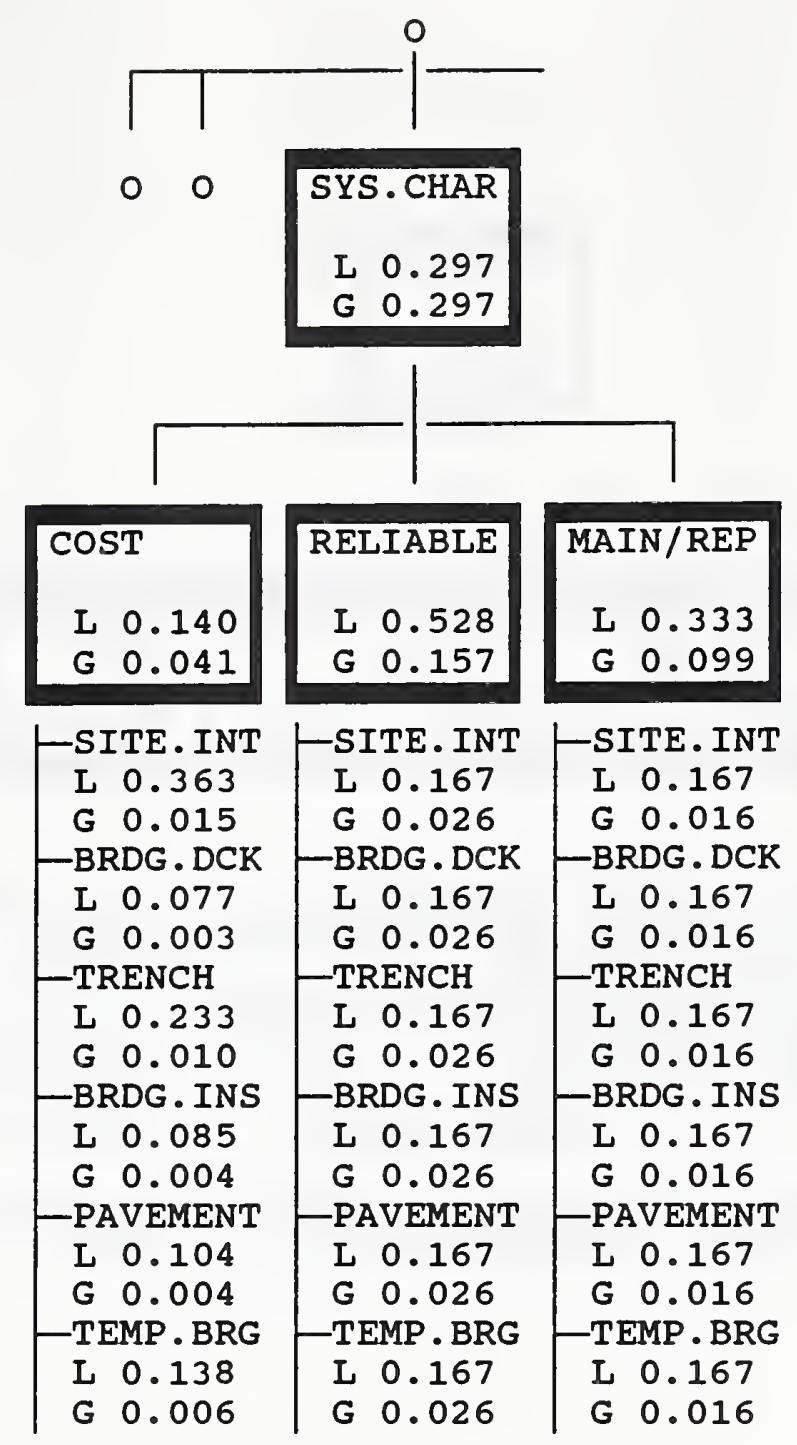

BRDG.DCK --- AUTOMATED BRIDGE DECKING SYSTEM

BRDG. INS - - BRIDGE INSPECTION AND MAINTENANCE SYSTEM

COST -- Comparative Life Cycle cost

MAIN/REP -- Comparative Maintainability/Repairability

PAVEMENT - - PAVEMENT INSPECTION AND REPAIR SYSTEM

RELIABLE --- Comparative Reliability

SITE. INT -- SITE INTEGRATION SYSTEM

SYS.CHAR -- SYSTEM CHARACTERISTICS: MEASURES COMPARED TO ALTERNATIVE SYSTEMS

TEMP.BRG - - TEMPORARY BRIDGING SYSTEM

TRENCH -- TRENCHING AND PIPE LAYING SYSTEM

L -- LOCAL PRIORITY: PRIORITY RELATIVE TO PARENT

$G \quad \cdots$ GLOBAL PRIORITY: PRIORITY RELATIVE TO GOAL 


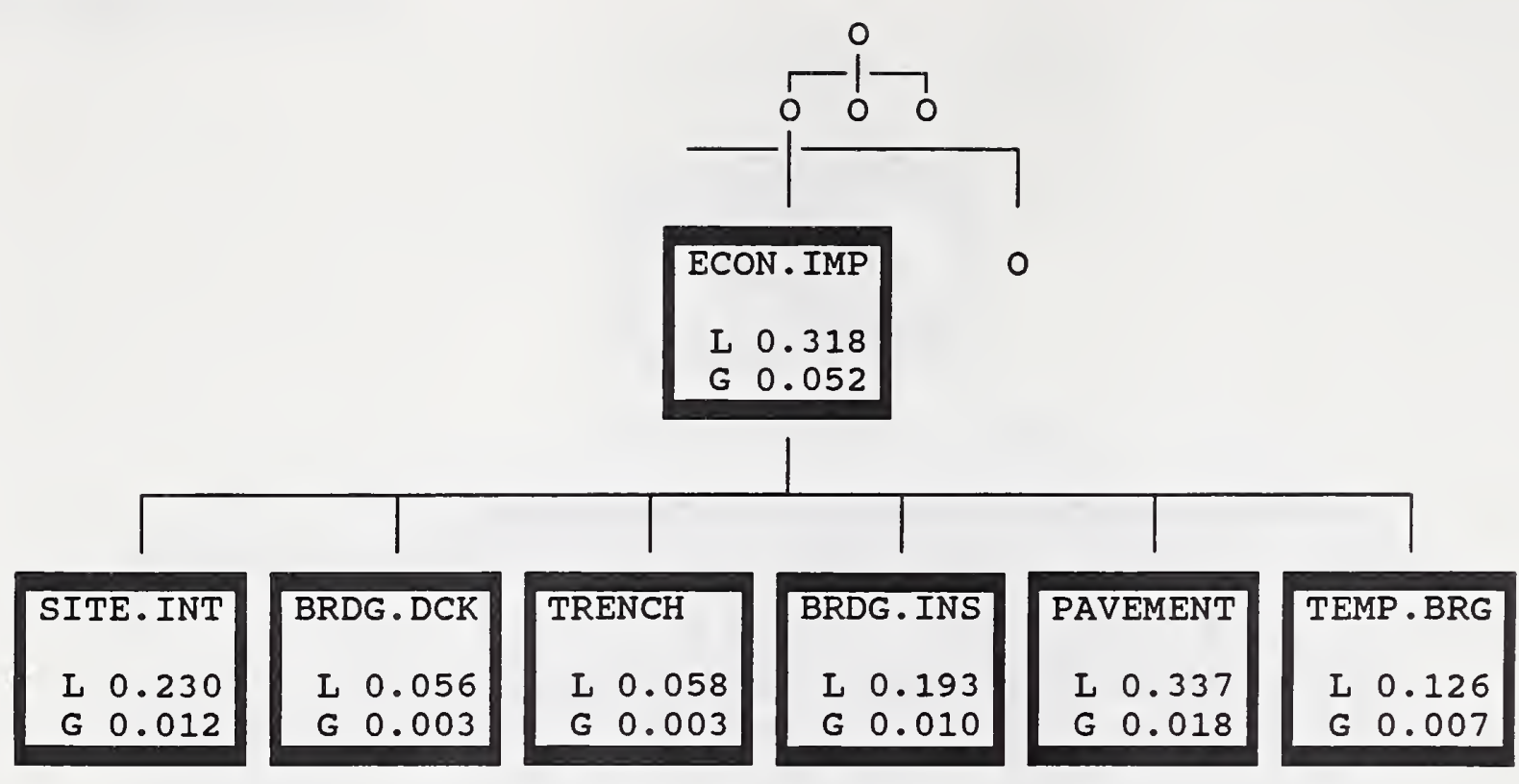

\footnotetext{
BRDG.DCK -- AUTOMATED BRIDGE DECKING SYSTEM

BRDG.INS --- BRIDGE INSPECTION AND MAINTENANCE SYSTEM

ECON.IMP -- National Economic Impact

PAVEMENT -- PAVEMENT INSPECTION AND REPAIR SYSTEM

SITE. INT -- - SITE INTEGRATION SYSTEM

TEMP.BRG -- TEMPORARY BRIDGING SYSTEM

TRENCH

-- TRENCHING AND PIPE LAYING SYSTEM

L

-- LOCAL PRIORITY: PRIORITY RELATIVE TO PARENT
-- GLOBAL PRIORITY: PRIORITY RELATIVE TO GOAL

G
} 


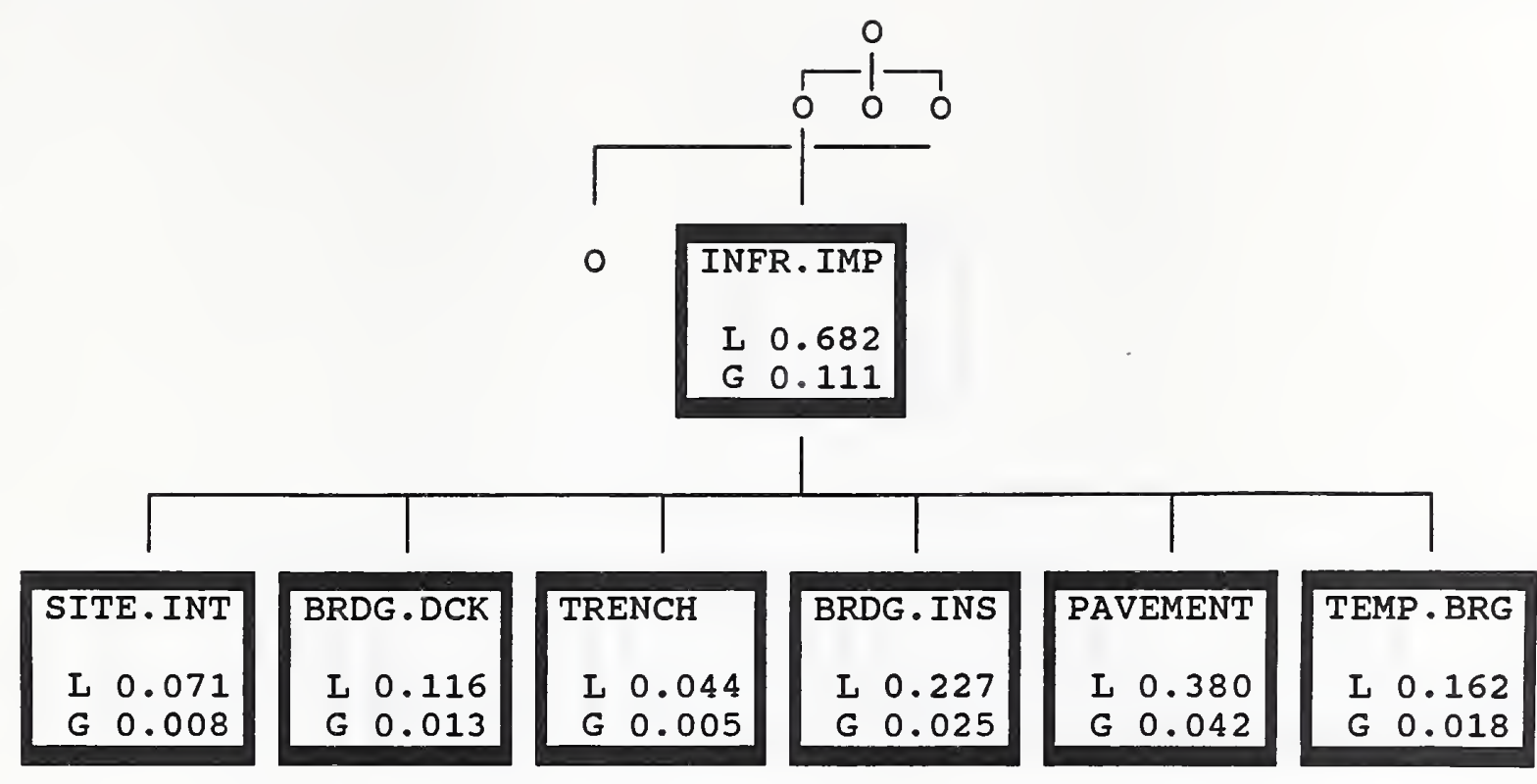

BRDG.DCK -- AUTOMATED BRIDGE DECKING SYSTEM

BRDG.INS -- BRIDGE INSPECTION AND MAINTENANCE SYSTEM

INFR. IMP - - Importance of system To Well Being of Highway Infrastructure

PAVEMENT -- PAVEMENT INSPECTION AND REPAIR SYSTEM

SITE.INT -- - SITE INTEGRATION SYSTEM

TEMP.BRG -- TEMPORARY BRIDGING SYSTEM

TRENCH - - TRENCHING AND PIPE LAYING SYSTEM

L -- LOCAL PRIORITY: PRIORITY RELATIVE TO PARENT

G -- GLOBAL PRIORITY: PRIORITY RELATIVE TO GOAL 

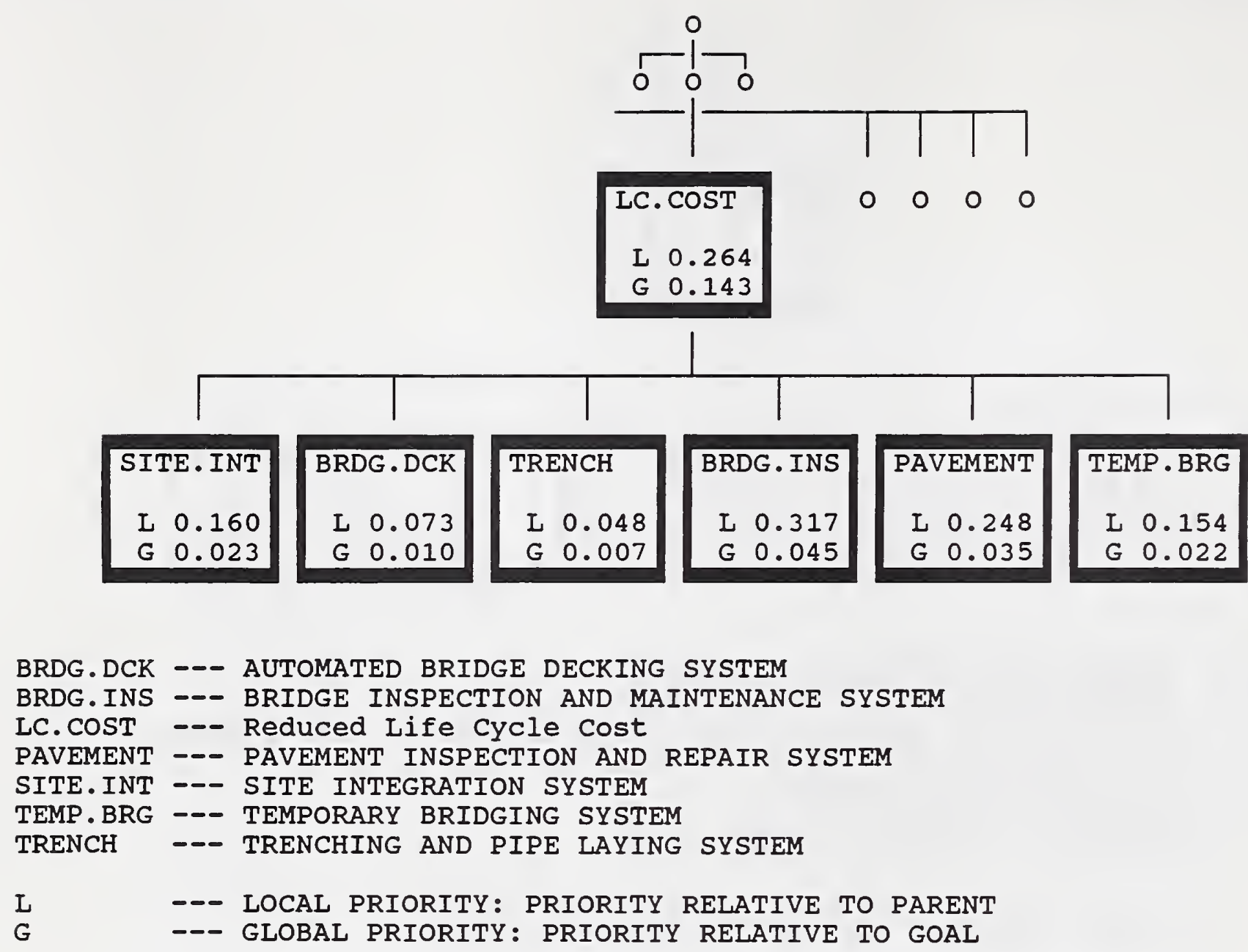

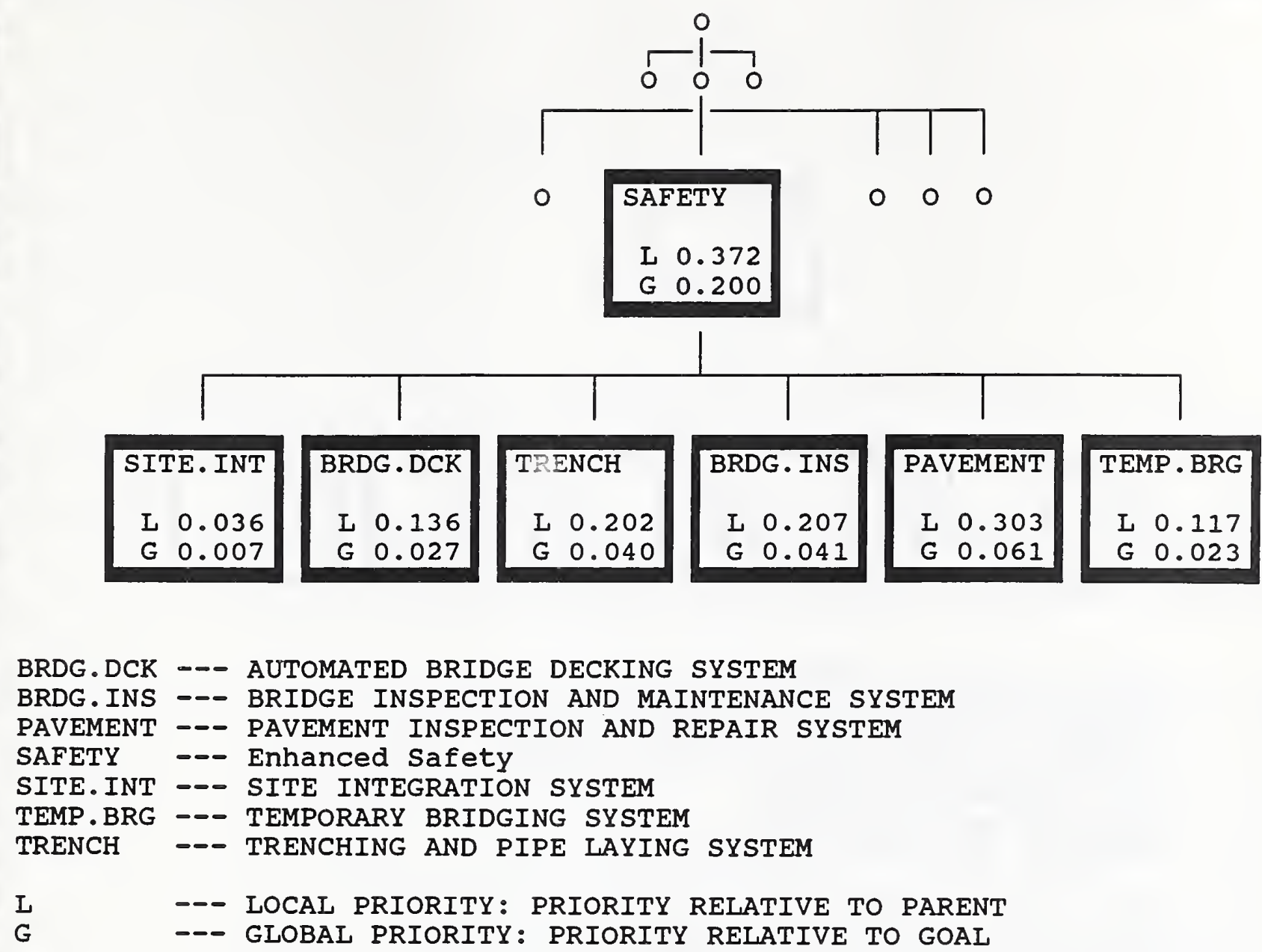

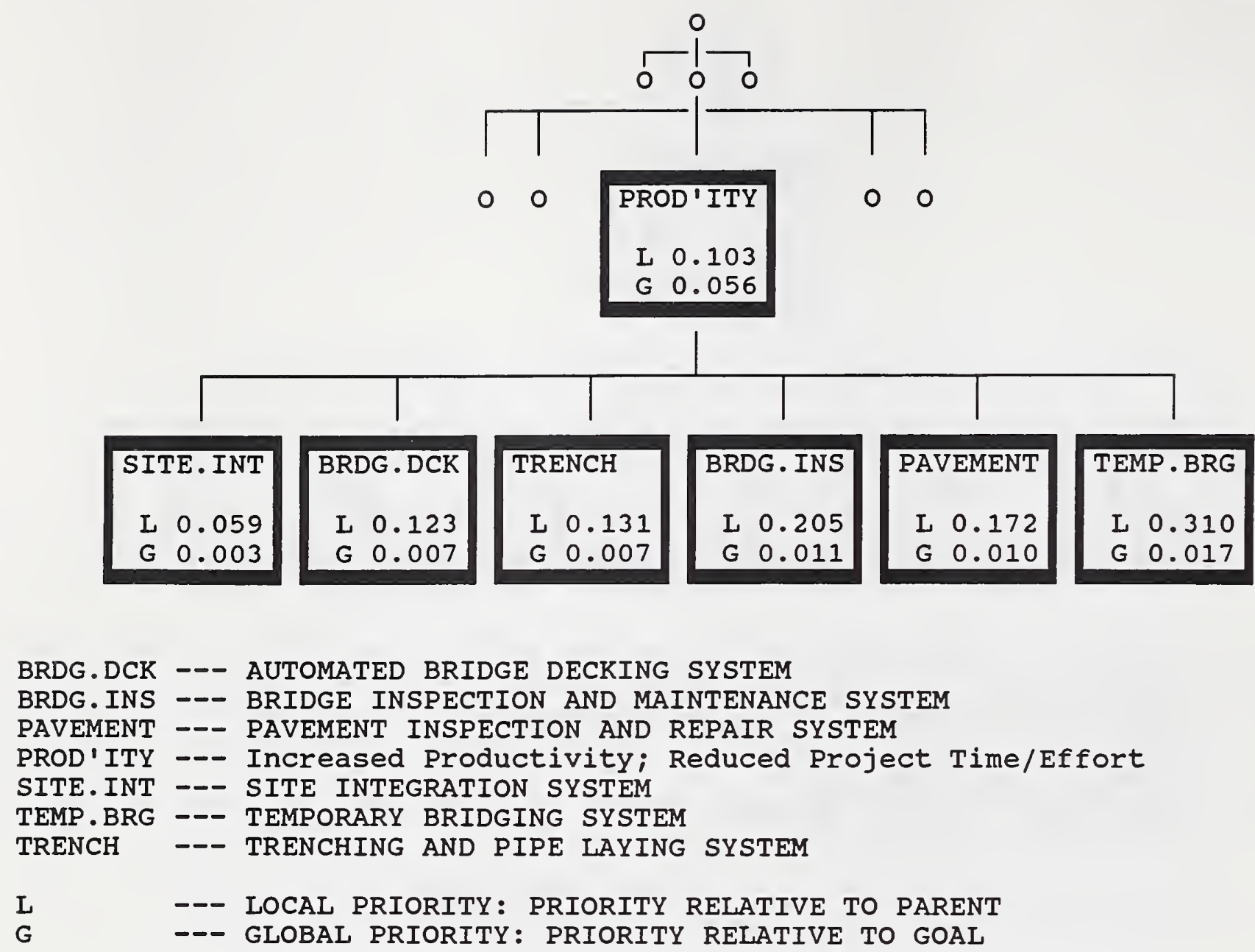


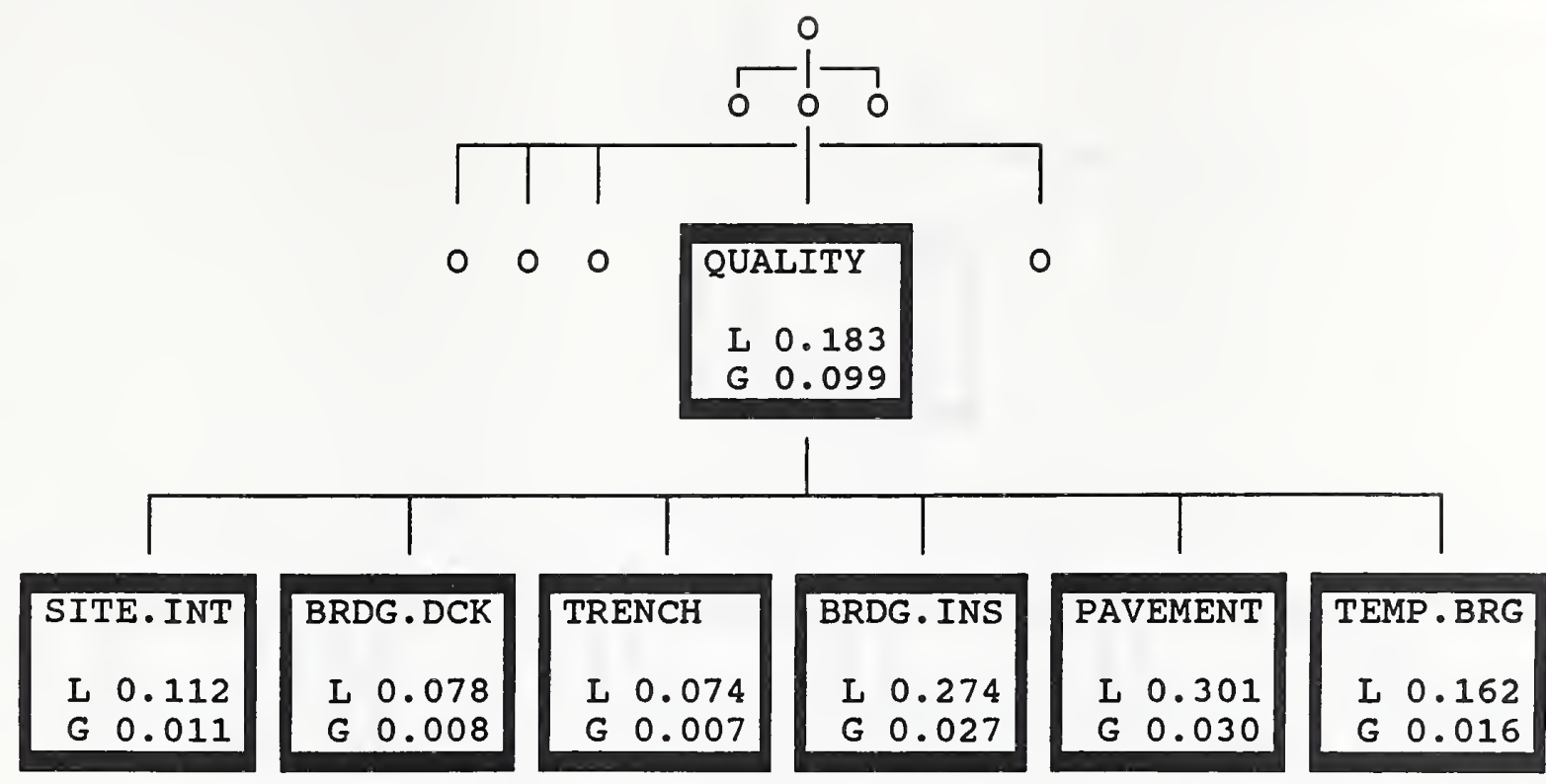

BRDG.DCK -- AUTOMATED BRIDGE DECKING SYSTEM

BRDG. INS -- BRIDGE INSPECTION AND MAINTENANCE SYSTEM

PAVEMENT -- PAVEMENT INSPECTION AND REPAIR SYSTEM

QUALITY --- Improved Work Quality

SITE. INT -- SITE INTEGRATION SYSTEM

TEMP.BRG -- TEMPORARY BRIDGING SYSTEM

TRENCH -- TRENCHING AND PIPE LAYING SYSTEM

L - LOCAL PRIORITY: PRIORITY RELATIVE TO PARENT

G $\quad$ GLOBAL PRIORITY: PRIORITY RELATIVE TO GOAL 

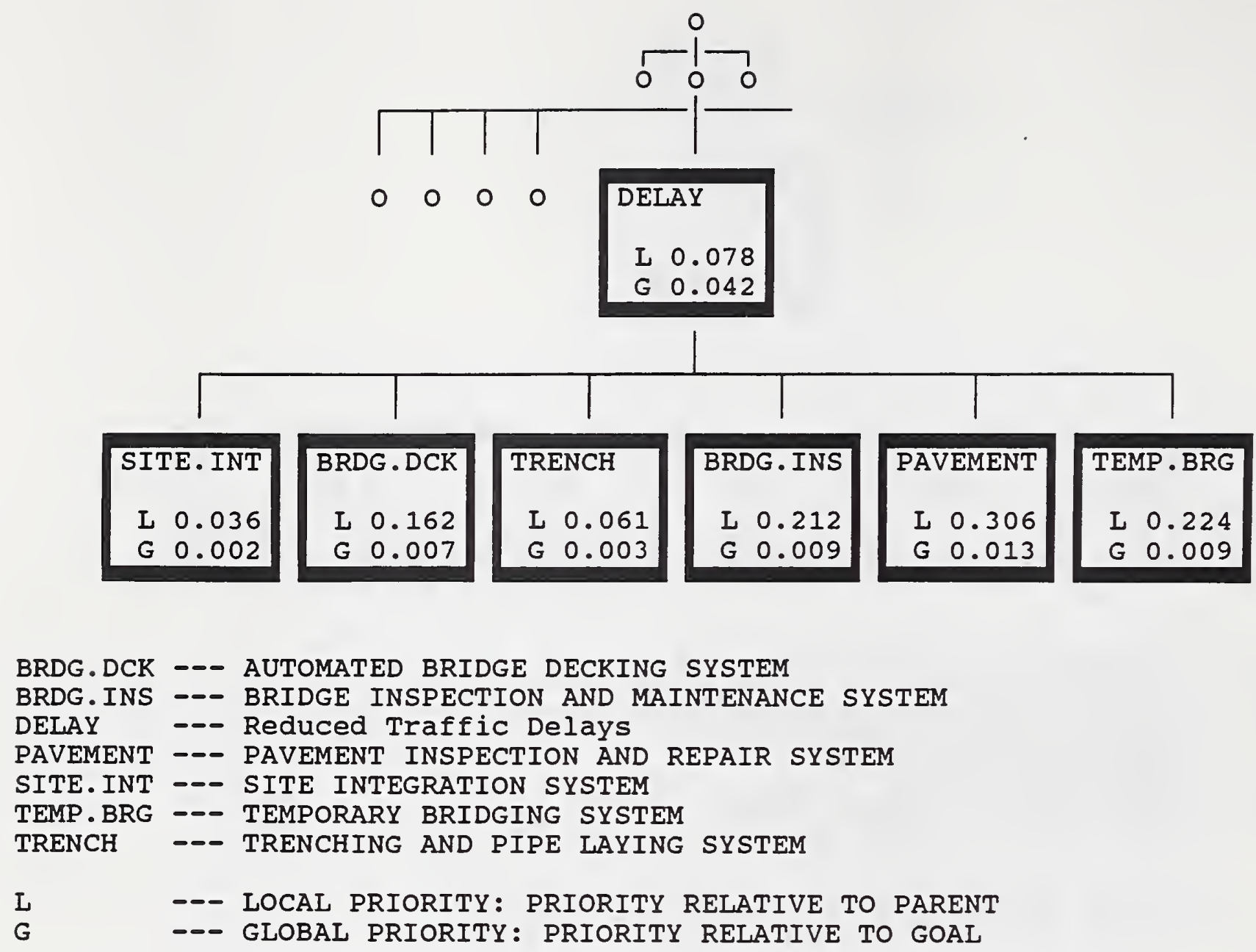

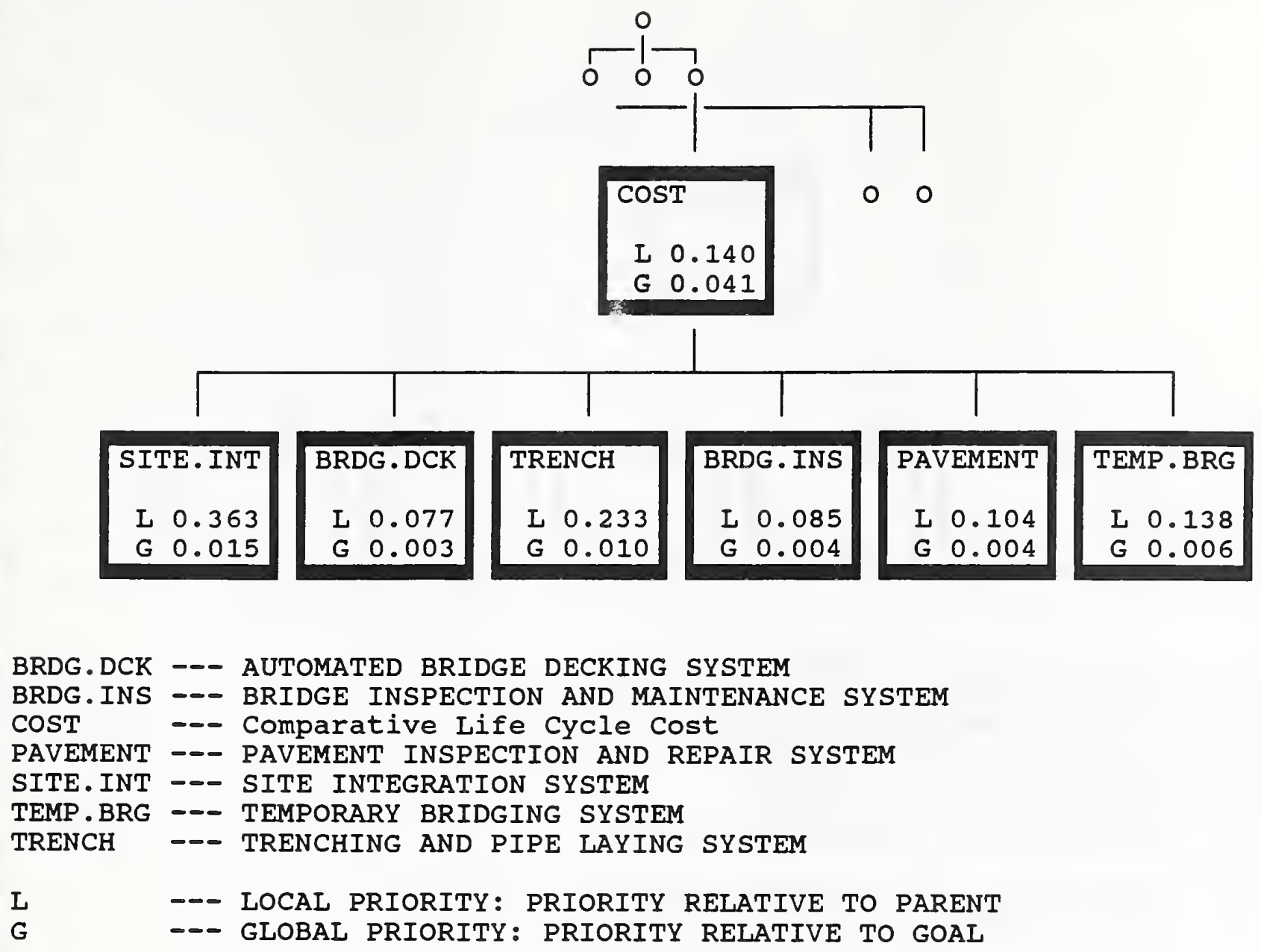

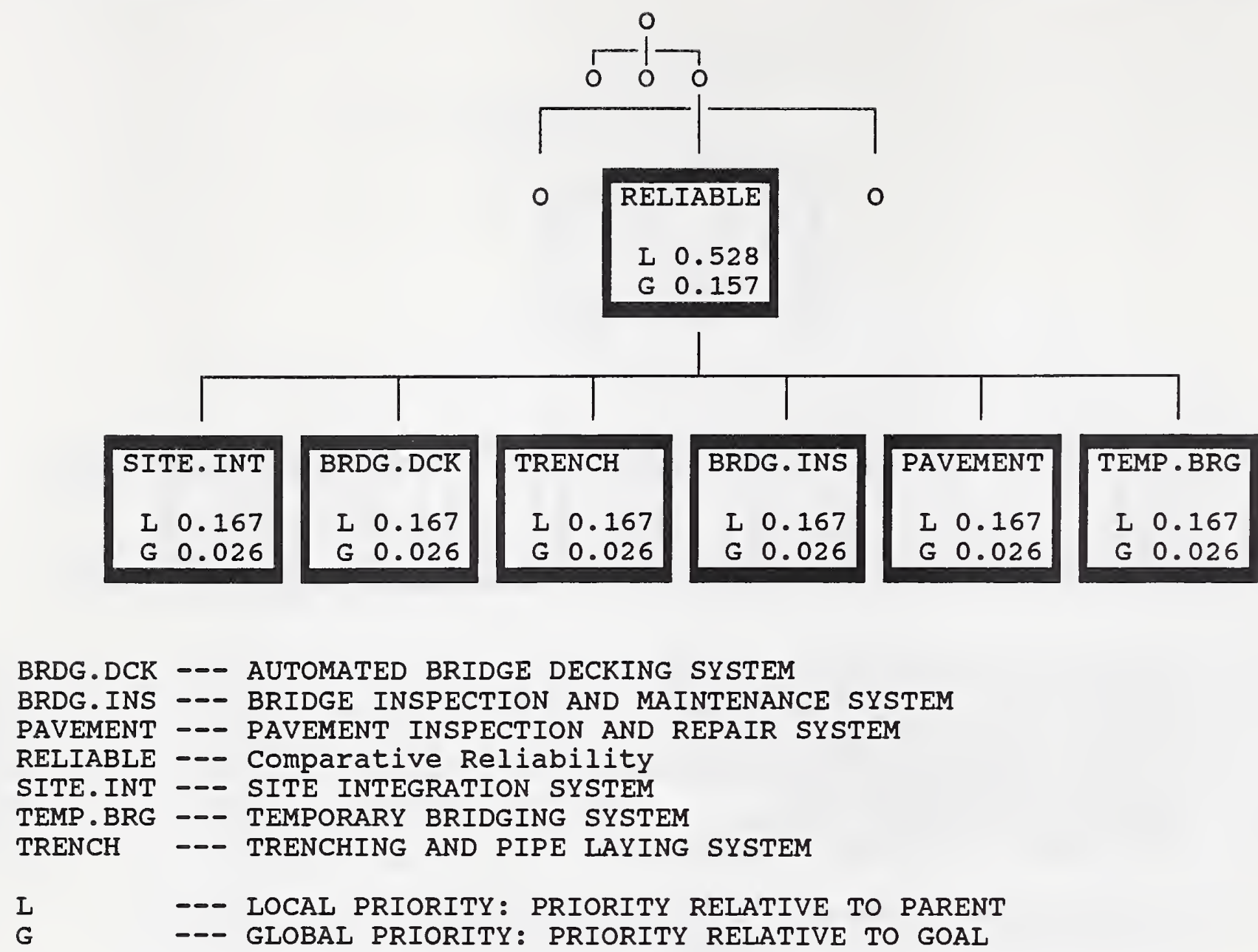


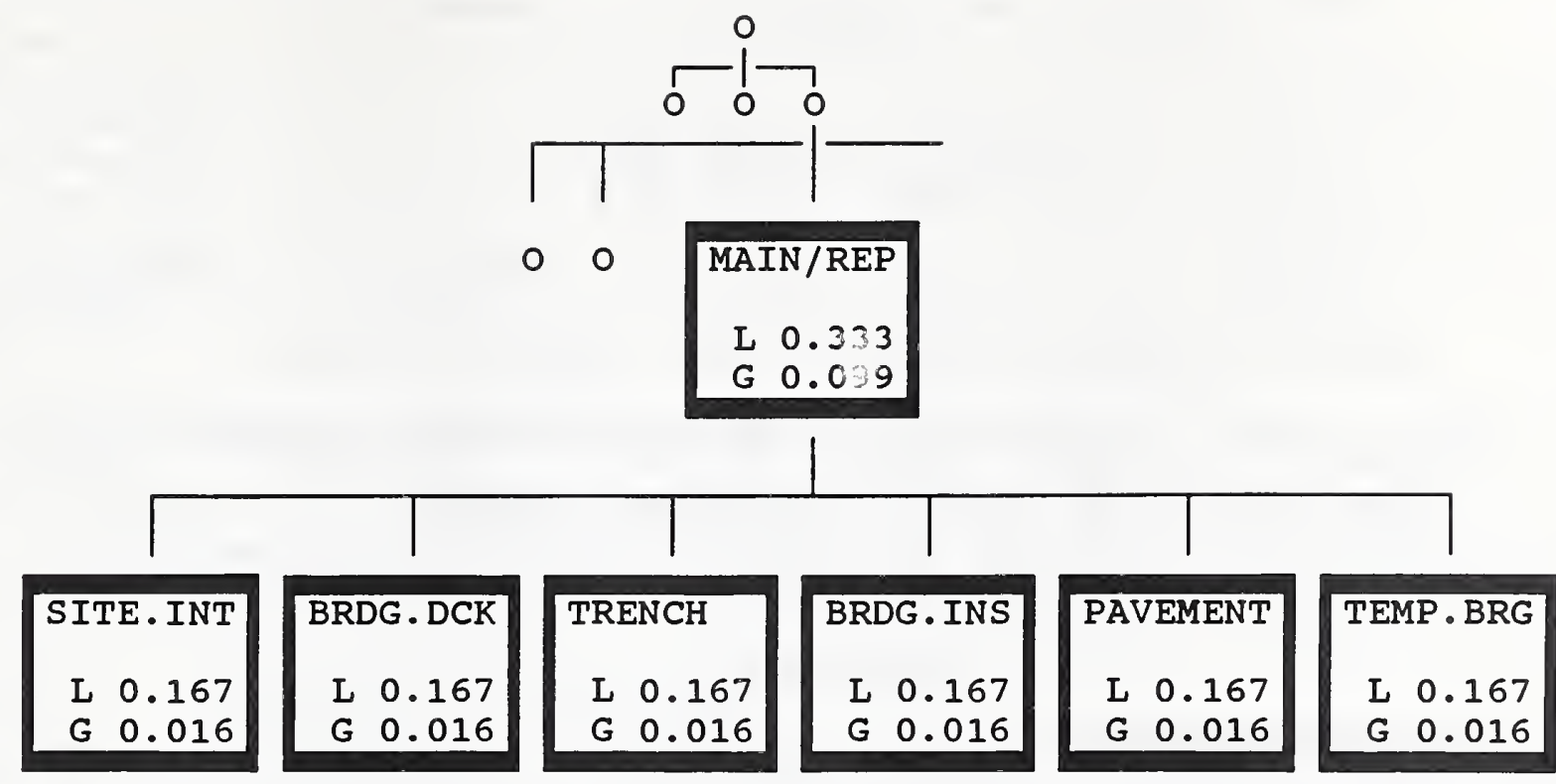

BRDG.DCK - - AUTOMATED BRIDGE DECKING SYSTEM

BRDG. INS -- BRIDGE INSPECTION AND MAINTENANCE SYSTEM

MAIN/REP -- Comparative Maintainability/Repairability

PAVEMENT -- PAVEMENT INSPECTION AND REPAIR SYSTEM

SITE.INT - - SITE INTEGRATION SYSTEM

TEMP.BRG -- TEMPORARY BRIDGING SYSTEM

TRENCH -- TRENCHING AND PIPE LAYING SYSTEM

L - LOCAL PRIORITY: PRIORITY RELATIVE TO PARENT

G -- GLOBAL PRIORITY: PRIORITY RELATIVE TO GOAL 
Verbal judgments of IMPORTANCE with respect to: GOAL

Node: 0

\begin{tabular}{|l|llllllllll|l|llllllllll|}
\hline 1 & FUNC.IMP & 9 & 8 & 7 & 6 & 5 & 4 & 3 & 2 & 1 & 2 & 0 & 4 & 5 & 6 & 7 & 8 & 9 & OP.BENEF \\
\hline 2 & FUNC.IMP & 9 & 8 & 7 & 6 & 5 & 4 & 3 & 2 & 1 & $\square$ & 3 & 4 & 5 & 6 & 7 & 8 & 9 & SYS.CHAR \\
\hline 3 & OP.BENEF & 9 & 8 & 7 & 6 & 5 & 4 & 3 & 0 & 1 & 2 & 3 & 4 & 5 & 6 & 7 & 8 & 9 & SYS.CHAR \\
\hline
\end{tabular}

1=EQUAL 3=MODERATE 5=STRONG 7=VERY STRONG 9=EXTREME

GOAL: SELECT A ROBOTIC/AUTOMATION SYSTEM FOR DEVELOPMENT/DEMONSTRATION

FUNC.IMP -- IMPORTANCE OF THE FUNCTION TO NATIONAL GOALS

OP.BENEF - - OPERATIONAL BENEFITS: ENHANCEMENTS OVER CURRENT TECHNIQUES

SYS.CHAR -- SYSTEM CHARACTERISTICS: MEASURES COMPARED TO ALTERNATIVE SYSTEMS

0.163

PRIORITIES

FUNC.IMP

0.540

OP.BENEF

0.297

SYS. CHAR

INCONSISTENCY RATIO $=0.009$. 
JUDGMENTS WITH RESPECT TO

FUNC. IMP < GOAL

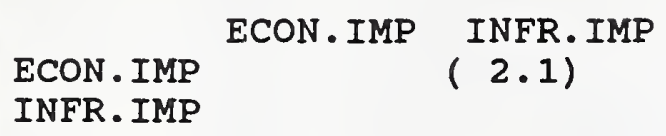

Matrix entry indicates that ROW element is

1 EQUALLY 3 MODERATELY 5 STRONGLY 7 VERY STRONGLY 9 EXTREMELY more IMPORTANT than COLUMN element unless enclosed in parenthesis.

GOAL: SELECT A ROBOTIC/AUTOMATION SYSTEM FOR DEVELOPMENT/DEMONSTRATION

ECON.IMP - - National Economic Impact

FUNC. IMP - - IMPORTANCE OF THE FUNCTION TO NATIONAL GOALS

INFR. IMP - - Importance of System To Well Being of Highway Infrastructure

0.318

PRIORITIES

ECON.IMP

0.682

INFR. IMP

INCONSISTENCY RATIO $=0.000$. 
Verbal judgments of IMPORTANCE with respect to: OP.BENEF < GOAL

Node: 20000

\begin{tabular}{|l|llllllllll|l|llllllllll|}
\hline 1 & LC.COST & 9 & 8 & 7 & 6 & 5 & 4 & 3 & 2 & 1 & 0 & 3 & 4 & 5 & 6 & 7 & 8 & 9 & SAFETY \\
\hline 2 & LC.COST & 9 & 8 & 7 & 6 & 5 & 4 & 0 & 2 & 1 & 2 & 3 & 4 & 5 & 6 & 7 & 8 & 9 & PROD ITY \\
\hline 3 & LC.COST & 9 & 8 & 7 & 6 & 5 & 4 & 3 & 0 & 1 & 2 & 3 & 4 & 5 & 6 & 7 & 8 & 9 & QUALITY \\
\hline 4 & LC.COST & 9 & 8 & 7 & 6 & 5 & 4 & 0 & 2 & 1 & 2 & 3 & 4 & 5 & 6 & 7 & 8 & 9 & DELAY \\
\hline 5 & SAFETY & 9 & 8 & 7 & 6 & 5 & 0 & 3 & 2 & 1 & 2 & 3 & 4 & 5 & 6 & 7 & 8 & 9 & PROD'ITY \\
\hline 6 & SAFETY & 9 & 8 & 7 & 6 & 5 & 4 & 3 & $\square$ & 1 & 2 & 3 & 4 & 5 & 6 & 7 & 8 & 9 & QUALITY \\
\hline 7 & SAFETY & 9 & 8 & 7 & 6 & 5 & 4 & 0 & 2 & 1 & 2 & 3 & 4 & 5 & 6 & 7 & 8 & 9 & DELAY \\
\hline 8 & PROD'ITY & 9 & 8 & 7 & 6 & 5 & 4 & 3 & 2 & 1 & 0 & 3 & 4 & 5 & 6 & 7 & 8 & 9 & QUALITY \\
\hline 9 & PROD'ITY & 9 & 8 & 7 & 6 & 5 & 4 & 3 & 1 & 1 & 2 & 3 & 4 & 5 & 6 & 7 & 8 & 9 & DELAY \\
\hline 10 & QUALITY & 9 & 8 & 7 & 6 & 5 & 4 & 0 & 2 & 1 & 2 & 3 & 4 & 5 & 6 & 7 & 8 & 9 & DELAY \\
\hline
\end{tabular}

1=EQUAL 3=MODERATE 5=STRONG 7=VERY STRONG 9=EXTREME

GOAL: SELECT A ROBOTIC/AUTOMATION SYSTEM FOR DEVELOPMENT/DEMONSTRATION

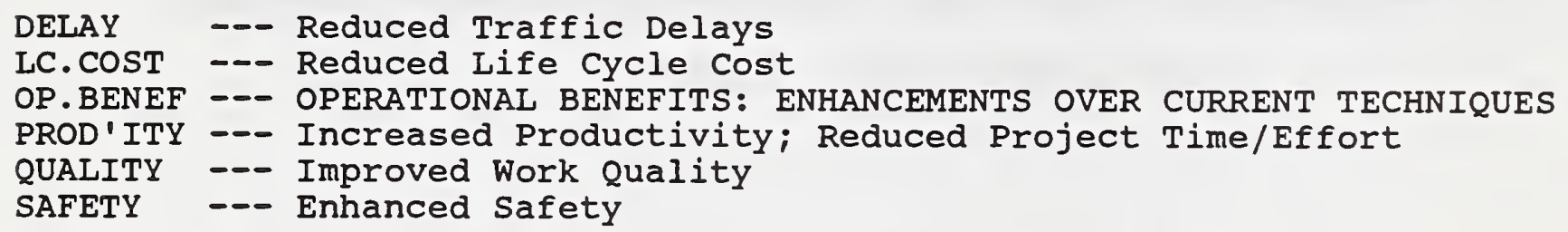


Verbal judgments of IMPORTANCE with respect to: SYS. CHAR < GOAL

\begin{tabular}{|l|rrrrrrrrr|l|lllllllll|}
\hline 1 & COST & 9 & 8 & 7 & 6 & 5 & 4 & 3 & 2 & 1 & 2 & 0 & 4 & 5 & 6 & 7 & 8 & 9 & RELIABLE \\
\hline 2 & COST & 9 & 8 & 7 & 6 & 5 & 4 & 3 & 2 & 1 & 2 & 0 & 4 & 5 & 6 & 7 & 8 & 9 & MAIN/REP \\
\hline 3 & RELIABLE & 9 & 8 & 7 & 6 & 5 & 4 & 3 & $\square$ & 1 & 2 & 3 & 4 & 5 & 6 & 7 & 8 & 9 & MAIN/REP \\
\hline
\end{tabular}

1=EQUAL 3=MODERATE 5=STRONG 7=VERY STRONG 9=EXTREME

GOAL: SELECT A ROBOTIC/AUTOMATION SYSTEM FOR DEVELOPMENT/DEMONSTRATION

Cost -- Comparative Life Cycle cost

MAIN/REP -- Comparative Maintainability/Repairability

RELIABLE -- Comparative Reliability

SYS.CHAR -- SYSTEM CHARACTERISTICS: MEASURES COMPARED TO ALTERNATIVE SYSTEMS

0.140

PRIORITIES

CosT

0.528

RELIABLE

0.333

MAIN/REP

INCONSISTENCY RATIO $=0.051$. 
Verbal judgments of PREFERENCE with respect to: ECON.IMP < FUNC.IMP < GOAL

Node: 11000

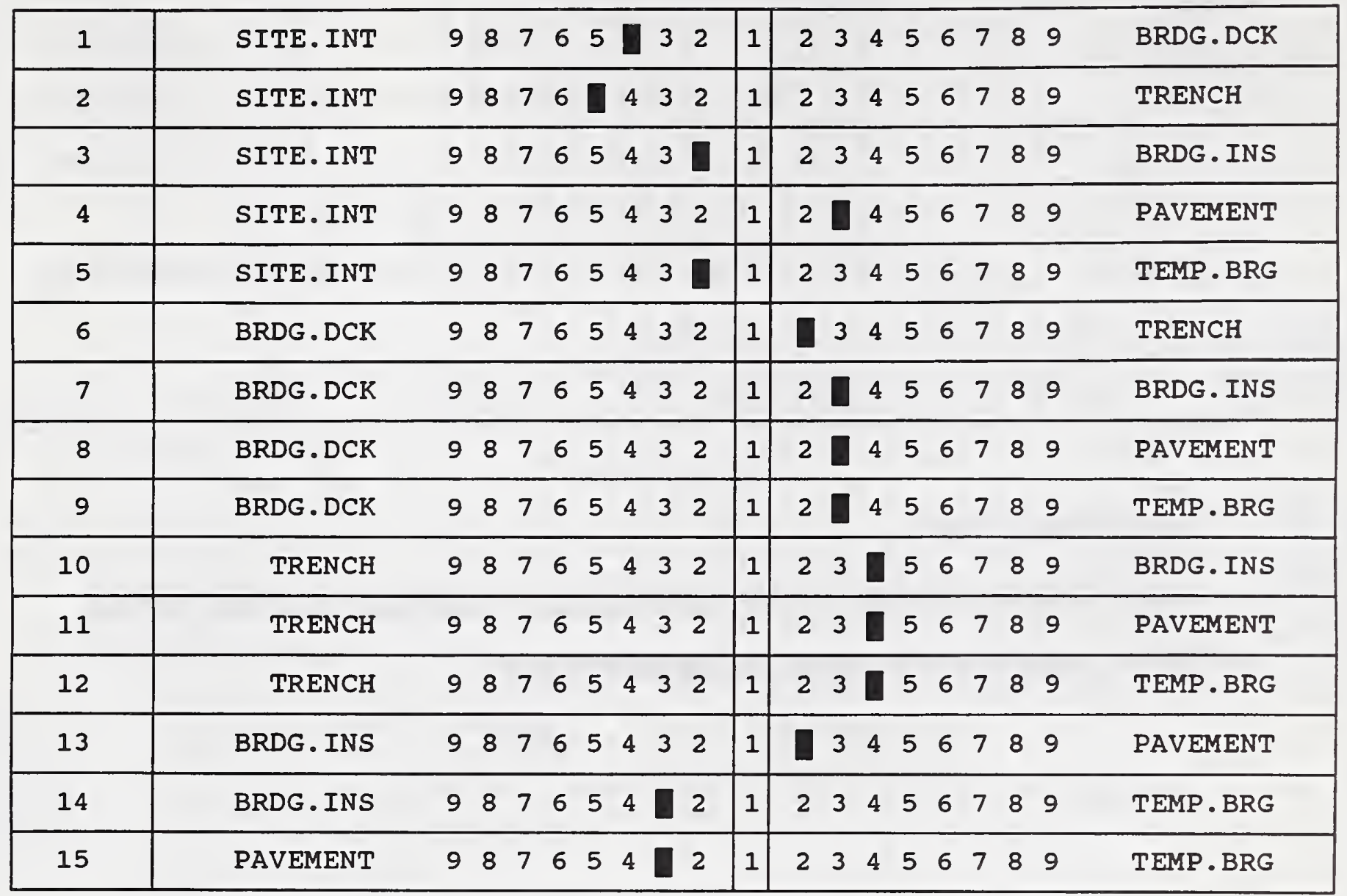

1=EQUAL 3=MODERATE 5=STRONG 7=VERY STRONG 9=EXTREME

GOAL: SELECT A ROBOTIC/AUTOMATION SYSTEM FOR DEVELOPMENT/DEMONSTRATION

BRDG.DCK - - AUTOMATED BRIDGE DECKING SYSTEM

BRDG.INS -- BRIDGE INSPECTION AND MAINTENANCE SYSTEM

ECON.IMP - - National Economic Impact

PAVEMENT -- PAVEMENT INSPECTION AND REPAIR SYSTEM

SITE. INT -- SITE INTEGRATION SYSTEM

TEMP.BRG - - TEMPORARY BRIDGING SYSTEM

TRENCH -- TRENCHING AND PIPE LAYING SYSTEM 


\section{PRIORITIES}

0.230

SITE. INT

0.056

BRDG.DCK

0.058

TRENCH

0.193

BRDG. INS

0.337

PAVEMENT

0.126

TEMP.BRG

INCONSISTENCY RATIO $=0.079$. 
Verbal judgments of PREFERENCE with respect to:

INFR. IMP < FUNC.IMP < GOAL

Node: 12000

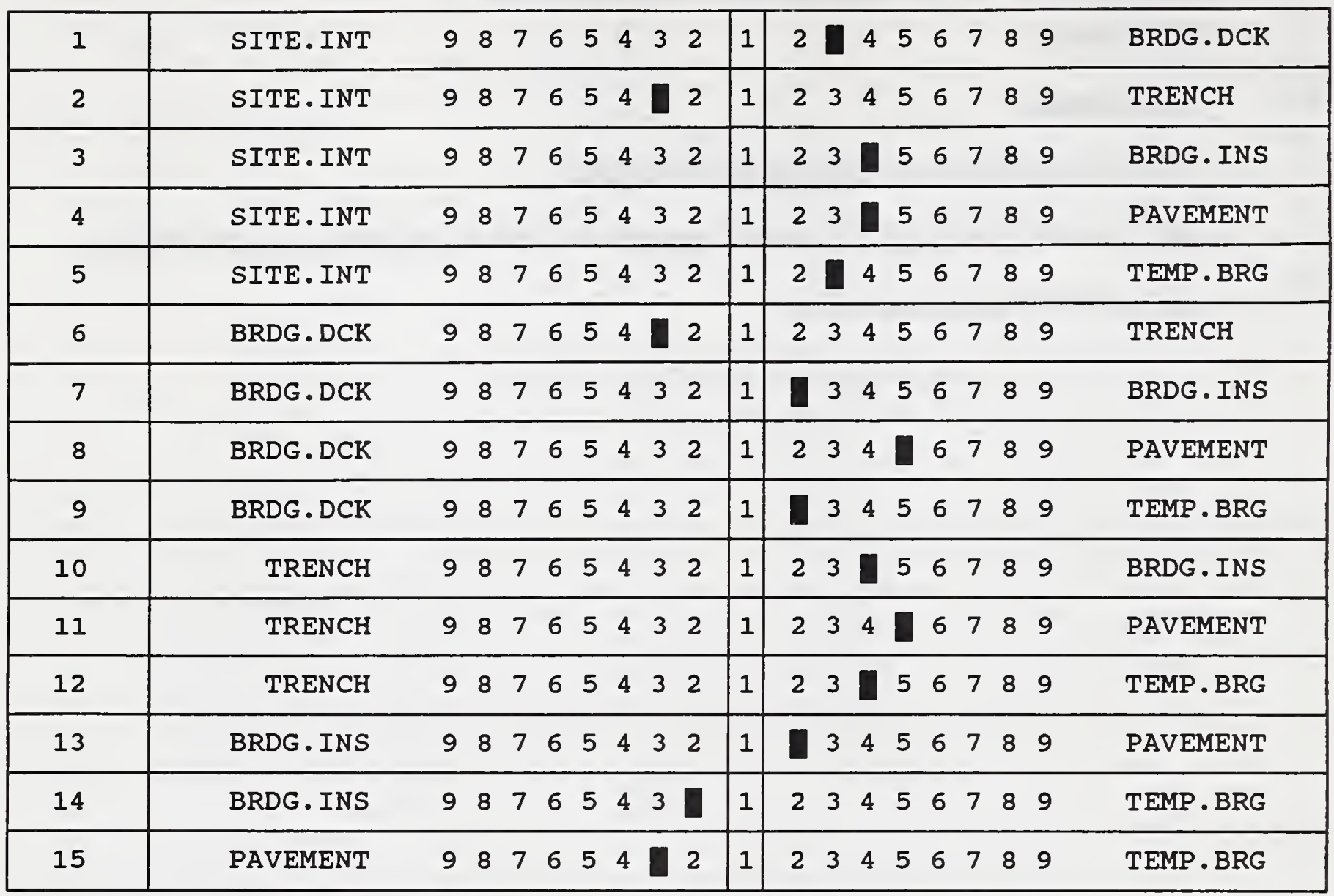

1=EQUAL 3=MODERATE 5=STRONG 7=VERY STRONG 9=EXTREME

GOAL: SELECT A ROBOTIC/AUTOMATION SYSTEM FOR DEVELOPMENT/DEMONSTRATION

BRDG.DCK -- AUTOMATED BRIDGE DECKING SYSTEM

BRDG. INS -- BRIDGE INSPECTION AND MAINTENANCE SYSTEM

INFR. IMP -- Importance of system To well Being of Highway Infrastructure

PAVEMENT --- PAVEMENT INSPECTION AND REPAIR SYSTEM

SITE. INT --- SITE INTEGRATION SYSTEM

TEMP.BRG --- TEMPORARY BRIDGING SYSTEM

TRENCH -- TRENCHING AND PIPE LAYING SYSTEM 
0.071

SITE. INT

0.116

BRDG.DCK

0.044

TRENCH

\subsection{7}

BRDG. INS

0.380

PAVEMENT

0.162

TEMP.BRG

INCONSISTENCY RATIO $=0.051$.

Figure 24 
Verbal judgments of PREFERENCE with respect to: LC. COST < OP.BENEF < GOAL

Node: 21000

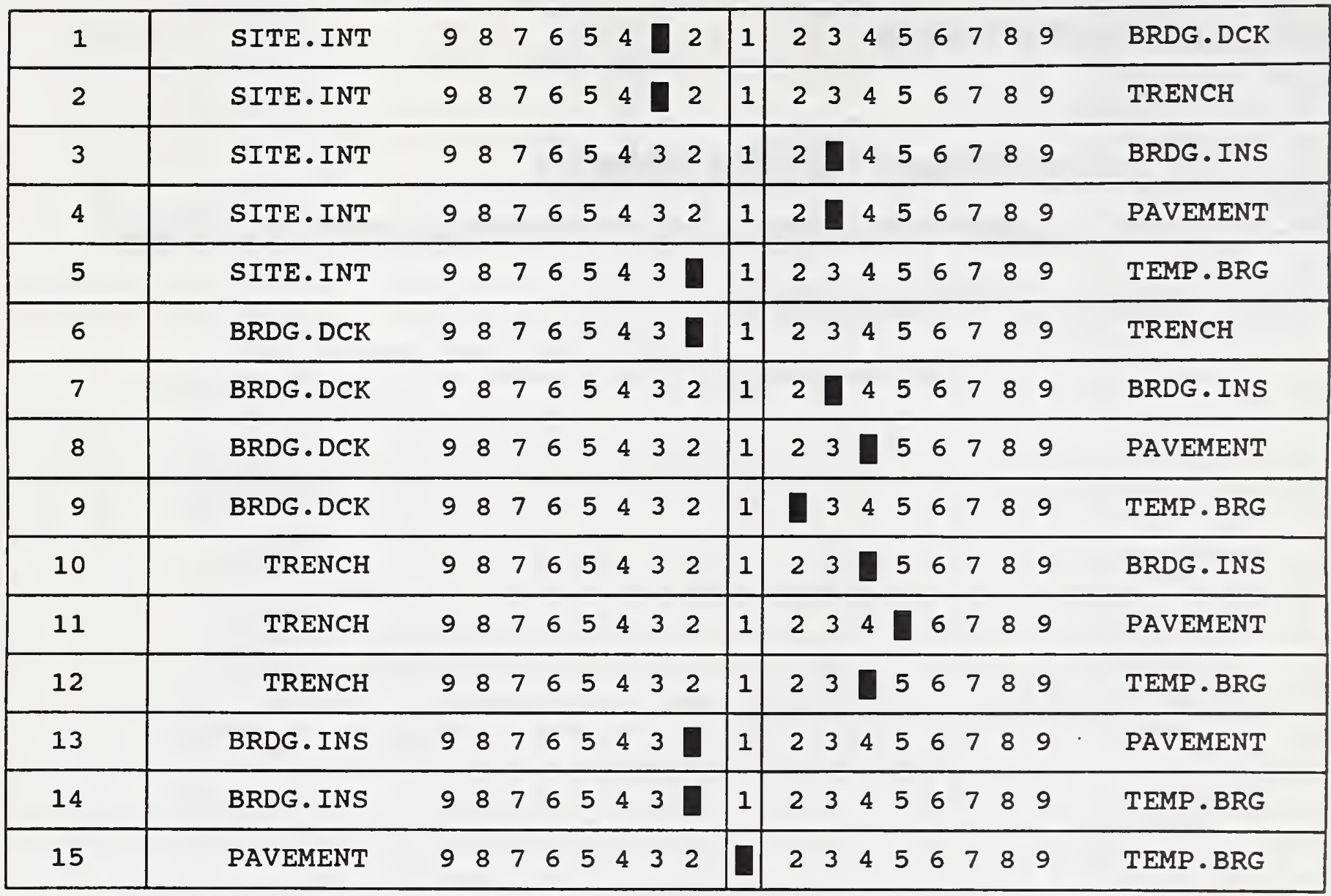

1=EQUAL 3=MODERATE 5=STRONG 7=VERY STRONG 9=EXTREME

GOAL: SELECT A ROBOTIC/AUTOMATION SYSTEM FOR DEVELOPMENT/DEMONSTRATION

BRDG.DCK -- AUTOMATED BRIDGE DECKING SYSTEM

BRDG.INS -- BRIDGE INSPECTION AND MAINTENANCE SYSTEM

LC. COST -- Reduced Life Cycle cost

PAVEMENT - - PAVEMENT INSPECTION AND REPAIR SYSTEM

SITE.INT -- SITE INTEGRATION SYSTEM

TEMP.BRG -- TEMPORARY BRIDGING SYSTEM

TRENCH - TRENCHING AND PIPE LAYING SYSTEM 
0.160

PRIORITIES

SITE. INT

0.073

BRDG.DCK

0.048

TRENCH

0.317

BRDG. INS

0.248

PAVEMENT

0.154

TEMP.BRG

INCONSISTENCY RATIO $=0.058$.

Figure 26 
Verbal judgments of PREFERENCE with respect to: SAFETY < OP.BENEF < GOAL

Node: 22000

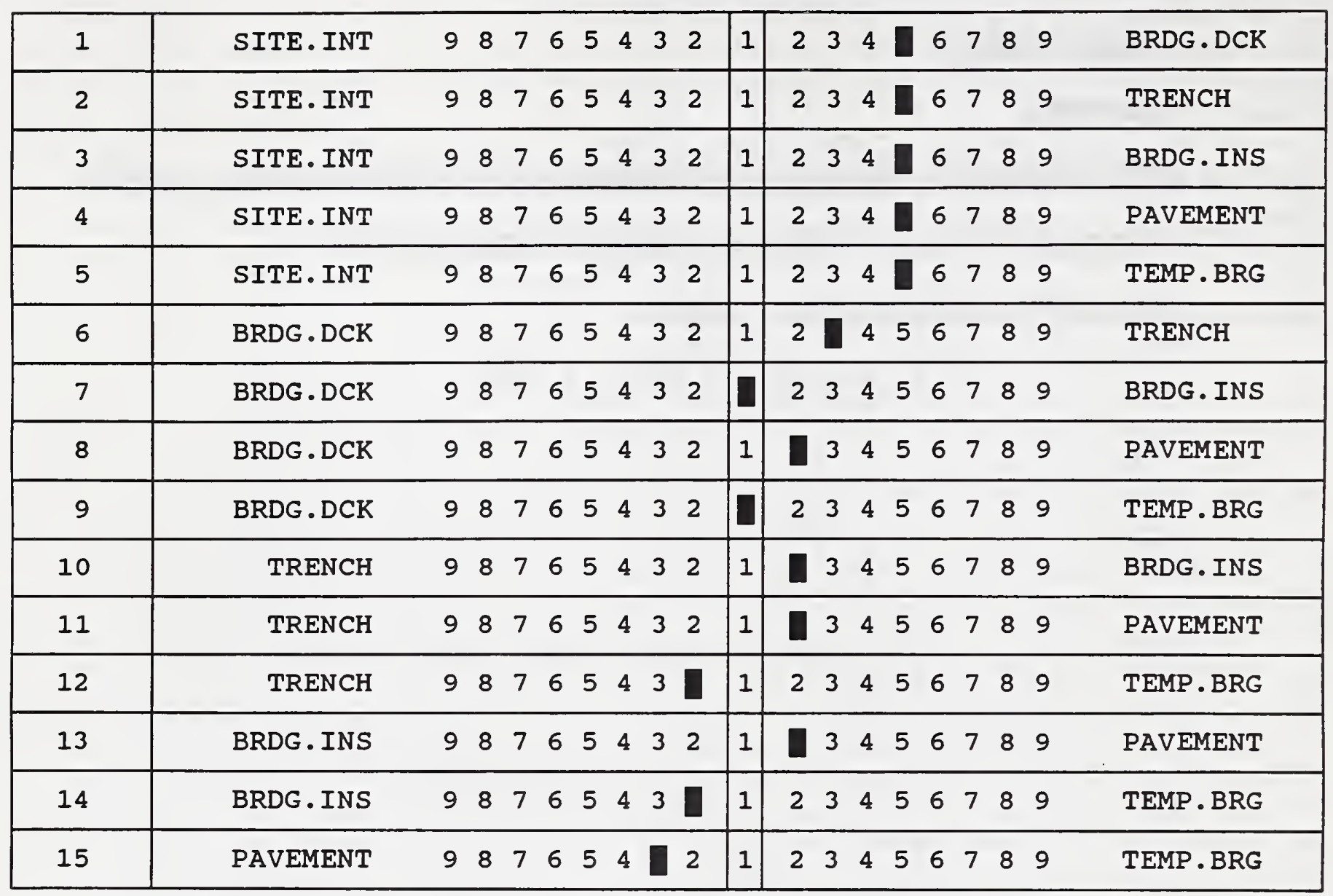

1=EQUAL 3=MODERATE 5=STRONG 7=VERY STRONG 9=EXTREME

GOAL: SELECT A ROBOTIC/AUTOMATION SYSTEM FOR DEVELOPMENT/DEMONSTRATION

BRDG.DCK -- AUTOMATED BRIDGE DECKING SYSTEM

BRDG.INS -- BRIDGE INSPECTION AND MAINTENANCE SYSTEM

PAVEMENT -- PAVEMENT INSPECTION AND REPAIR SYSTEM

SAFETY --- Enhanced Safety

SITE.INT --- SITE INTEGRATION SYSTEM

TEMP.BRG -- TEMPORARY BRIDGING SYSTEM

TRENCH -- TRENCHING AND PIPE LAYING SYSTEM 
0.036

PRIORITIES

SITE.INT

0.136

BRDG.DCK

0.202

TRENCH

0.207

BRDG. INS

0.303

PAVEMENT

0.117

TEMP.BRG

INCONSISTENCY RATIO $=0.053$.

Figure 28 
Verbal judgments of PREFERENCE with respect to: PROD'ITY < OP.BENEF < GOAL

Node: 23000

\begin{tabular}{|c|c|c|c|c|c|c|c|c|c|c|c|c|c|c|c|c|c|}
\hline 1 & SITE.INT & 98 & 7 & 6 & 5 & 4 & 3 & 2 & 1 & $2 \square$ & 4 & 5 & 6 & 7 & 8 & 9 & BRDG . DCK \\
\hline 2 & SITE.INT & 98 & 7 & 6 & 5 & 4 & 3 & 2 & 1 & 2 & 4 & 5 & 6 & 7 & 8 & 9 & TRENCH \\
\hline 3 & SITE.INT & 98 & 7 & 6 & 5 & 4 & 3 & 2 & 1 & 2 & 4 & 5 & 6 & 7 & 8 & 9 & BRDG.INS \\
\hline 4 & SITE.INT & 98 & 7 & 6 & 5 & 4 & 3 & 2 & 1 & 2 & 4 & 5 & 6 & 7 & 8 & 9 & PAVEMENT \\
\hline 5 & SITE.INT & 98 & 7 & 6 & 5 & 4 & 3 & 2 & 1 & 2 & 4 & 5 & 6 & 7 & 8 & 9 & TEMP . BRG \\
\hline 6 & BRDG.DCK & 98 & 7 & 6 & 5 & 4 & 3 & 2 & a & 23 & 4 & 5 & 6 & 7 & 8 & 9 & TRENCH \\
\hline 7 & BRDG.DCK & 98 & 7 & 6 & 5 & 4 & 3 & 2 & 1 & 3 & 4 & 5 & 6 & 7 & 8 & 9 & BRDG.INS \\
\hline 8 & BRDG.DCK & 98 & 7 & 6 & 5 & 4 & 3 & 2 & 1 & 3 & 4 & 5 & 6 & 7 & 8 & 9 & PAVEMENT \\
\hline 9 & BRDG.DCK & 98 & 7 & 6 & 5 & 4 & 3 & 2 & 1 & 3 & 4 & 5 & 6 & 7 & 8 & 9 & TEMP.BRG \\
\hline 10 & TRENCH & 98 & 7 & 6 & 5 & 4 & 3 & 2 & 1 & $2 \square$ & 4 & 5 & 6 & 7 & 8 & 9 & BRDG. INS \\
\hline 11 & TRENCH & 98 & 7 & 6 & 5 & 4 & 3 & 2 & D & 23 & 4 & 5 & 6 & 7 & 8 & 9 & PAVEMENT \\
\hline 12 & TRENCH & 98 & 7 & 6 & 5 & 4 & 3 & 2 & 1 & 3 & 4 & 5 & 6 & 7 & 8 & 9 & TEMP.BRG \\
\hline 13 & BRDG.INS & 98 & 7 & 6 & 5 & 4 & 3 & 2 & D & 23 & 4 & 5 & 6 & 7 & 8 & 9 & PAVEMENT \\
\hline 14 & BRDG.INS & 98 & 7 & 6 & 5 & 4 & 3 & 2 & 1 & 2 口 & 4 & 5 & 6 & 7 & 8 & 9 & TEMP.BRG \\
\hline 15 & PAVEMENT & 98 & 7 & 6 & 5 & 4 & 3 & 2 & 1 & 3 & 4 & 5 & 6 & 7 & 8 & 9 & TEMP.BRG \\
\hline
\end{tabular}

1=EQUAL 3=MODERATE 5=STRONG 7=VERY STRONG 9=EXTREME

GOAL: SELECT A ROBOTIC/AUTOMATION SYSTEM FOR DEVELOPMENT/DEMONSTRATION

BRDG.DCK --- AUTOMATED BRIDGE DECKING SYSTEM

BRDG.INS --- BRIDGE INSPECTION AND MAINTENANCE SYSTEM

PAVEMENT -- PAVEMENT INSPECTION AND REPAIR SYSTEM

PROD'ITY -- Increased Productivity; Reduced Project Time/Effort

SITE. INT -- - SITE INTEGRATION SYSTEM

TEMP.BRG --- TEMPORARY BRIDGING SYSTEM

TRENCH -- TRENCHING AND PIPE LAYING SYSTEM 
0.059

PRIORITIES

SITE.INT

0.123

BRDG. DCK

0.131

TRENCH

0.205

BRDG. INS

0.172

PAVEMENT

0.310

TEMP.BRG

INCONSISTENCY RATIO $=0.050$.

Figure 30 
Verbal judgments of PREFERENCE with respect to: QUALITY < OP.BENEF < GOAL

Node: 24000

\begin{tabular}{|c|c|c|c|c|c|c|c|c|c|c|c|c|c|c|c|c|}
\hline 1 & SITE.INT & 98 & 7 & 6 & 54 & 43 & & 1 & 23 & 4 & 5 & 6 & 7 & 8 & 9 & BRDG.DCK \\
\hline 2 & SITE.INT & 98 & 7 & 6 & 54 & 43 & $\square$ & 1 & 23 & 4 & 5 & 6 & 7 & 8 & 9 & TRENCH \\
\hline 3 & SITE.INT & 98 & 7 & 6 & 54 & 43 & 2 & 1 & 2 & 4 & 5 & 6 & 7 & 8 & 9 & BRDG.INS \\
\hline 4 & SITE.INT & 98 & 7 & 6 & 54 & 43 & 2 & 1 & 2 & 4 & 5 & 6 & 7 & 8 & 9 & PAVEMENT \\
\hline 5 & SITE.INT & 98 & 7 & 6 & 54 & 43 & 2 & 1 & 3 & 4 & 5 & 6 & 7 & 8 & 9 & TEMP . BRG \\
\hline 6 & BRDG.DCK & 98 & 7 & 6 & 54 & 43 & 2 & $\square$ & 23 & 4 & 5 & 6 & 7 & 8 & 9 & TRENCH \\
\hline 7 & BRDG.DCK & 98 & 7 & 6 & 54 & 43 & 2 & 1 & 2 & 4 & 5 & 6 & 7 & 8 & 9 & BRDG.INS \\
\hline 8 & BRDG.DCK & 98 & 7 & 6 & 54 & 43 & 2 & 1 & 2 & 4 & 5 & 6 & 7 & 8 & 9 & PAVEMENT \\
\hline 9 & BRDG.DCK & 98 & 7 & 6 & 54 & 43 & 2 & 1 & 3 & 4 & 5 & 6 & 7 & 8 & 9 & TEMP . BRG \\
\hline 10 & TRENCH & 98 & 7 & 6 & 54 & 43 & 2 & 1 & 2 & 4 & 5 & 6 & 7 & 8 & 9 & BRDG.INS \\
\hline 11 & TRENCH & 98 & 7 & 6 & 54 & 43 & 2 & 1 & 2 & 4 & 5 & 6 & 7 & 8 & 9 & PAVEMENT \\
\hline 12 & TRENCH & 98 & 7 & 6 & 54 & 43 & 2 & 1 & 2 & 4 & 5 & 6 & 7 & 8 & 9 & TEMP . BRG \\
\hline 13 & BRDG.INS & 98 & 7 & 6 & 54 & 43 & 2 & D & 23 & 4 & 5 & 6 & 7 & 8 & 9 & PAVEMENT \\
\hline 14 & BRDG.INS & 98 & 7 & 6 & 54 & 43 & $\square$ & 1 & 23 & 4 & 5 & 6 & 7 & 8 & 9 & TEMP.BRG \\
\hline 15 & PAVEMENT & 98 & 7 & 6 & 54 & $4 \square$ & 2 & 1 & 23 & 4 & 5 & 6 & 7 & 8 & 9 & TEMP . BRG \\
\hline
\end{tabular}

1=EQUAL 3=MODERATE 5=STRONG 7=VERY STRONG 9=EXTREME

GOAL: SELECT A ROBOTIC/AUTOMATION SYSTEM FOR DEVELOPMENT/DEMONSTRATION

BRDG.DCK -- AUTOMATED BRIDGE DECKING SYSTEM

BRDG.INS -- BRIDGE INSPECTION AND MAINTENANCE SYSTEM

PAVEMENT --- PAVEMENT INSPECTION AND REPAIR SYSTEM

QUALITY --- Improved Work Quality

SITE.INT -- - SITE INTEGRATION SYSTEM

TEMP.BRG -- TEMPORARY BRIDGING SYSTEM

TRENCH -- TRENCHING AND PIPE LAYING SYSTEM 
0.112

PRIORITIES

SITE.INT

0.078

BRDG. DCK

0.074

TRENCH

0.274

BRDG. INS

0.301

PAVEMENT

0.162

TEMP. BRG

INCONSISTENCY RATIO $=0.025$.

Figure 32 
Verbal judgments of PREFERENCE with respect to: DELAY < OP.BENEF < GOAL

Node: 25000

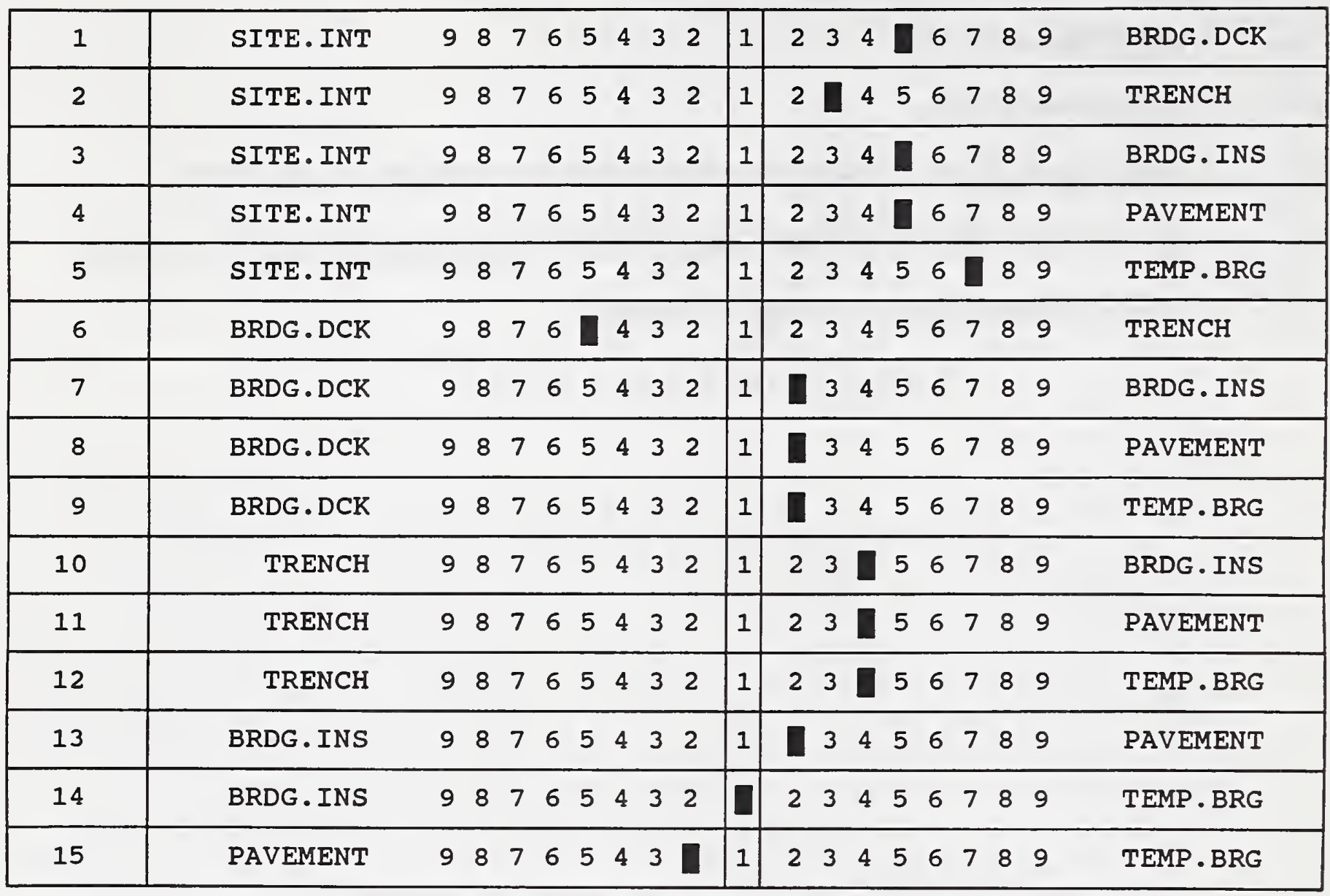

1=EQUAL 3=MODERATE 5=STRONG 7=VERY STRONG 9=EXTREME

GOAL: SELECT A ROBOTIC/AUTOMATION SYSTEM FOR DEVELOPMENT/DEMONSTRATION

BRDG.DCK -- AUTOMATED BRIDGE DECKING SYSTEM

BRDG.INS -- BRIDGE INSPECTION AND MAINTENANCE SYSTEM

DELAY -- Reduced Traffic Delays

PAVEMENT -- PAVEMENT INSPECTION AND REPAIR SYSTEM

SITE.INT -- SITE INTEGRATION SYSTEM

TEMP.BRG -- TEMPORARY BRIDGING SYSTEM

TRENCH - - TRENCHING AND PIPE LAYING SYSTEM 
0.036

PRIORITIES

SITE. INT

0.162

BRDG . DCK

0.061

TRENCH

\subsection{2}

BRDG. INS

0.306

PAVEMENT

0.224

TEMP . BRG

INCONSISTENCY RATIO $=0.046$.

Figure 34 
Verbal judgments of PREFERENCE with respect to: COST < SYS. CHAR < GOAL

Node: 31000

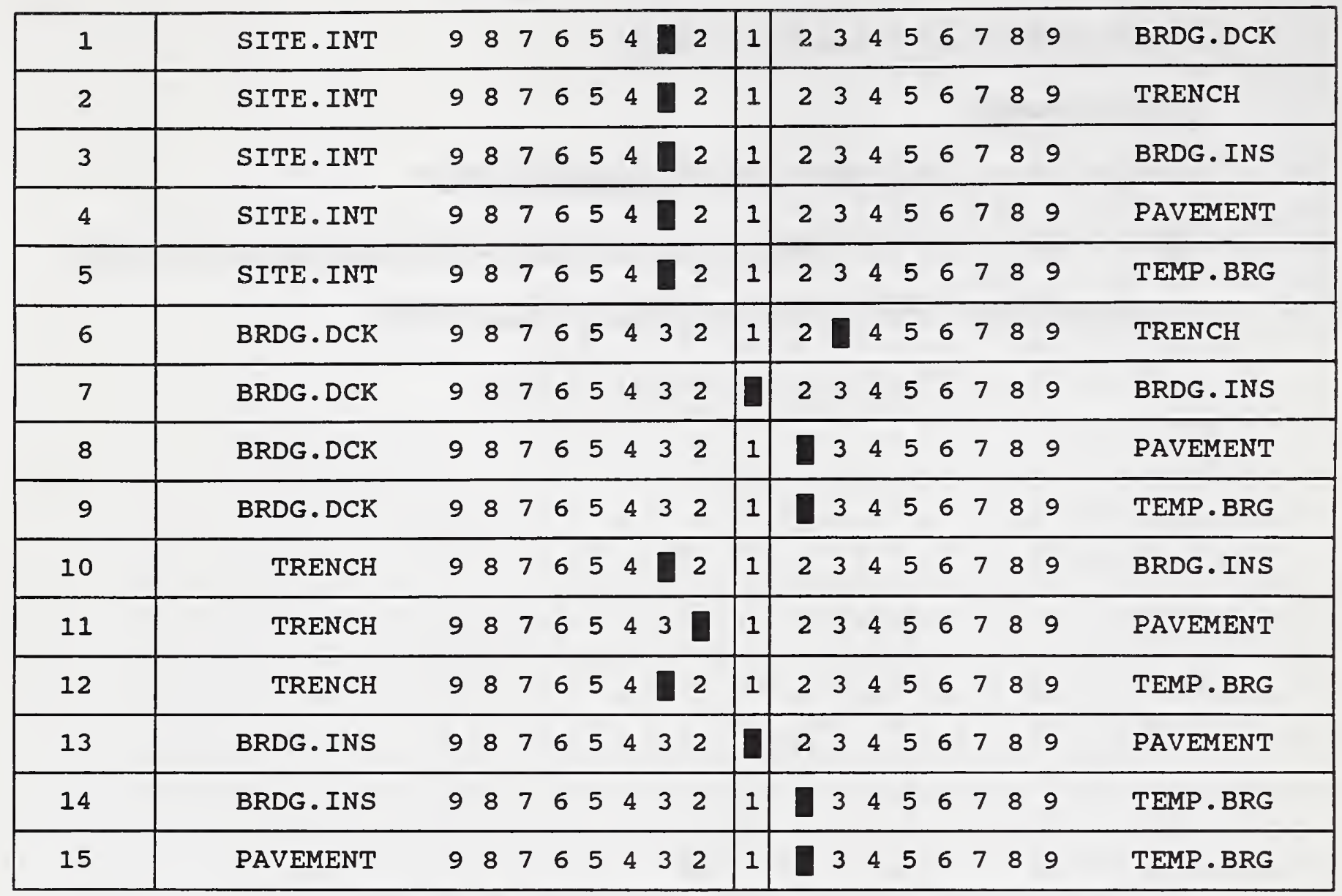

1=EQUAL 3=MODERATE 5=STRONG 7=VERY STRONG 9=EXTREME

GOAL: SELECT A ROBOTIC/AUTOMATION SYSTEM FOR DEVELOPMENT/DEMONSTRATION

BRDG.DCK --- AUTOMATED BRIDGE DECKING SYSTEM

BRDG.INS -- BRIDGE INSPECTION AND MAINTENANCE SYSTEM

COST -- Comparative Life Cycle cost

PAVEMENT -- PAVEMENT INSPECTION AND REPAIR SYSTEM

SITE.INT -- SITE INTEGRATION SYSTEM

TEMP.BRG -- TEMPORARY BRIDGING SYSTEM

TRENCH - 
0.363

SITE. INT

0.077

BRDG.DCK

0.233

TRENCH

\subsection{5}

BRDG.INS

0.104

PAVEMENT

0.138

TEMP.BRG

INCONSISTENCY RATIO $=0.043$. 
The inconsistency ratio is a measure of inconsistency in making pairwise comparisons (i.e., if $A$ is preferred to $B$, and $B$ is preferred to $C$, then $A$ should be preferred to $C$, to be consistent). Perfect consistency over all selections generates an inconsistency ratio of 0 . If the inconsistency ratio is greater than 0.10 , then the decision-maker should re-examine his choices. In Figure 16, the ratio is well below 0.10 , at 0.009 .

The evaluation of measures in Figure 16 is with respect to the goal (Node 0). It shows that the analyst (decision-maker) thought that the operational benefits of the systems are moderately more important than their functional importance; that the system characteristics are equal-to-moderately more important than their functional importance; and that the operational benefits are equal-to-moderately more important than the system characteristics. The rational for these judgements is that: (1) the usual driver for the introduction of any new technology is improvement over existing methods for performing the comparable function; (2) it is easier to compare quantitatively the benefits of a new technology with an older technology (to accomplish the same task), than to compare the relative benefits of two different technologies designed to accomplish different tasks; (3) it is difficult to quantify the importance of a technology with respect to national goals. So operational Benefits garners more than half $(0.540)$ of the weight of the three measures on the basis its intrinsic importance (because of the way technology is usually introduced into society) and practical importance (i.e., the relative ease of quantifying it).

The judgements in Figure 17 are to determine the importance of the submeasures of the Functional Importance measure. Because there are only two of them, they were evaluated graphically (with manipulation of a pie chart in the program), leading to the $2 \times 2$ matrix in the figure, where impact on the infrastructure is valued equally-to-moderately more important than impact on the national economy. This translated to a value of 2.1. Because there are only two submeasures, the consistency ratio is always 0.000 because it is impossible to choose inconsistently with only two items from which to choose.

The verbal judgements for the operational Benefits (enhancements over current techniques) submeasures are given in Figure 18. Improvement in safety has the highest weight (importance) with a final value of 0.372 , with reduced life cycle cost in second place with 0.264 , and the others as shown in the figure. Inconsistency is well within bounds.

Likewise, the system Characteristics submeasures are weighted in Figure 19, with reliability the most important submeasure (with a weight of 0.528 ). The systems are not functionally comparable (because the perform different roadwork functions), so their life cycle costs are less important as a MoM. For example, system A 
may cost an order of magnitude more than system $B$, but its benefits (for performing function $X$ ) may be comparably more than those of system B (for performing function $Y$ ). But constraints on capital investment costs (which are part of the life cycle costs) might favor the less costly system. If we were comparing functionally identical (but differently designed) systems, such as comparing one type of pavement inspection system with another, system cost might be a more important measure. Maintainability and repairability (0.333), while important, are less desirable than high re ability; avoiding failure is better than repair and maintenance.

The alternative systems are evaluated against the various submeasures, and preferences (weights) calculated in Figures 20 to 36. As an example, consider Figure 27. The systems are evaluated against the submeasure Safety (SAFETY), which has the parent measure operational Benefits (OP.BEN), which has the parent Goal (GOAL) of selecting a robotic/automation system for development/demonstration. Row 2 shows that the Trenching and Pipe Laying system is strongly preferred to the site Integration System for enhanced safety over current techniques for accomplishing the respective roadwork functions. Row 7 shows indifference (equality) between automated bridge decking and automated bridge inspection and repair in terms of enhance safety over current techniques. Row 13 shows an equal-to-moderate preference for automated pavement inspection and repair over automated bridge inspection and repair (with respect to enhanced safety) because pavement work is a more commonly performed function than bridge work (there is more pavement than bridges). All of the other system choices are comparably judged. Figure 28 displays the result of the system evaluations against the Safety submeasure. The automated/robotic pavement inspection and repair system scored best $(0.303)$ for Safety, with the trenching and bridge inspection/repair systems neck and neck in second and third places. An automated site integration system is the least valuable for enhancing safety, with a score of 0.036 .

The system alternatives are likewise evaluated against all of the submeasures, through Figure 36 .

\subsection{Synthesis: Final Results}

Figures 37 to 40 illustrate the final results obtained after scoring all of the system alternatives against the weighted submeasures and measures (i.e., synthesis of the leaf nodes [system alternatives] with respect to the Goal). The overall inconsistency index for the process is well within bounds, at 0.03 .

Figure 37 summarizes the weights of the measures and submeasures (with additional trees in the previously given Figures 2 to 15 ). Figures 38 and 39 summarize the values of the alternative systems 
SELECT A ROBOTIC/AUTOMATION SYSTEM FOR DEVELOPMENT/DEMONSTRATION
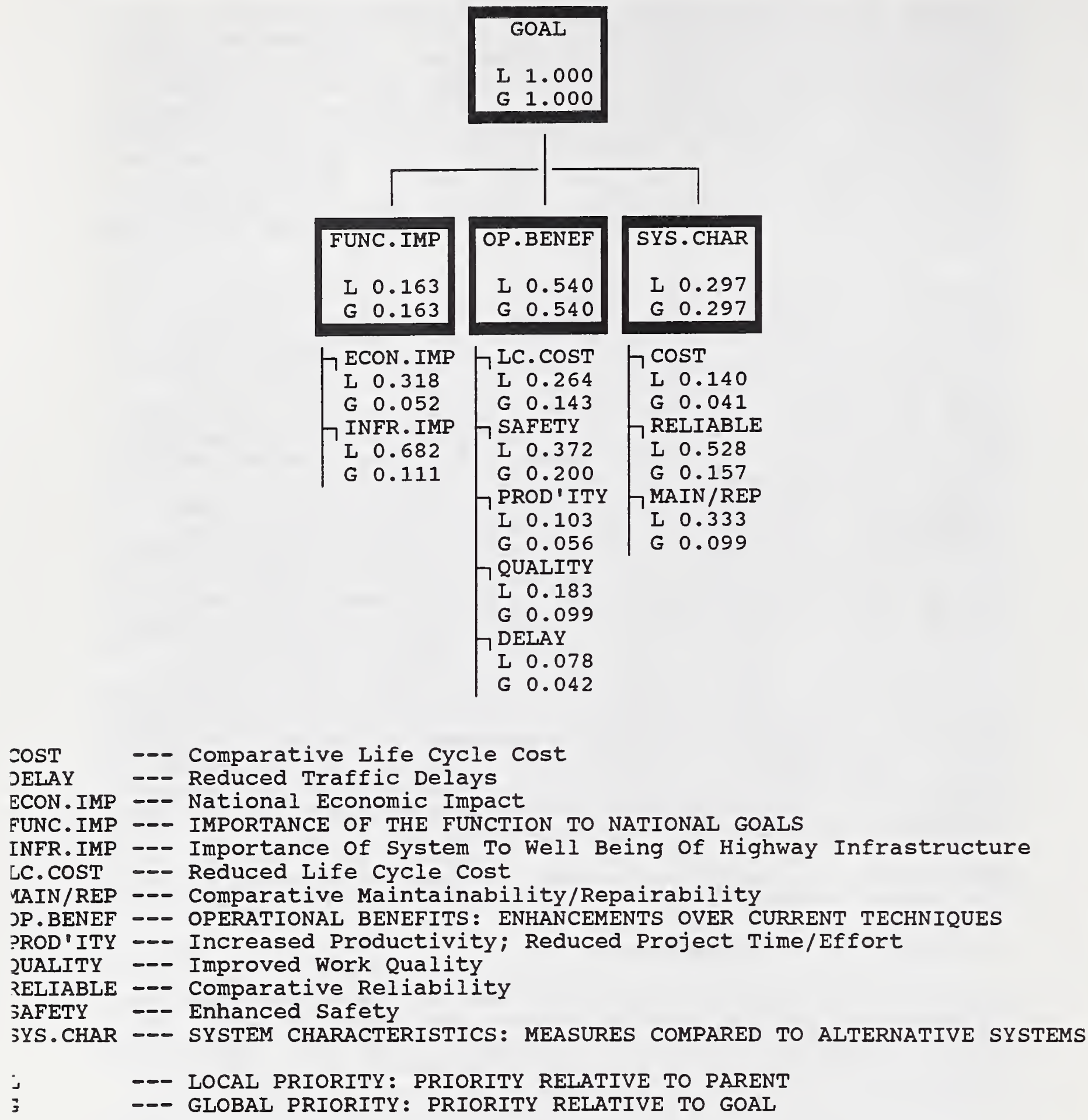


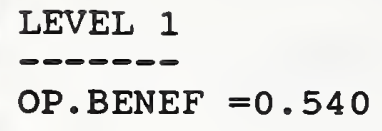

$\mathrm{OP} \cdot \mathrm{BENEF}=0.540$
LEVEL 3

$-\infty-\infty-\infty$

SAFETY $\quad=0.200$

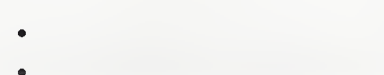

PAVEMENT $=0.061$

BRDG. INS $=0.041$

TRENCH $\quad=0.040$

BRDG. DCK $=0.027$

TEMP. BRG $=0.023$

SITE. INT $=0.007$

LC. $\cos T=0.143$

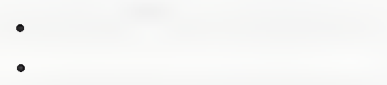

BRDG. INS $=0.045$

PAVEMENT $=0.035$

SITE. INT $=0.023$

TEMP.BRG $=0.022$

BRDG. DCK $=0.010$

TRENCH $=0.007$

QUALITY $=0.099$

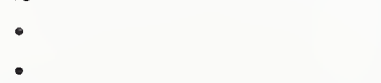

- 1

-

-

PROD ' ITY $=0.056$

PAVEMENT $=0.030$

BRDG. INS $=0.027$

TEMP.BRG $=0.016$

SITE. INT $=0.011$

BRDG. DCK $=0.008$

TRENCH $\quad=0.007$

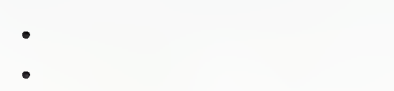

TEMP.BRG $=0.017$

BRDG. INS $=0.011$

PAVEMENT $=0.010$

TRENCH $=0.007$

BRDG. DCK $=0.007$

SITE. INT $=0.003$

DELAY $=0.042$

PAVEMENT $=0.013$

TEMP.BRG $=0.009$

BRDG. INS $=0.009$

BRDG. DCK $=0.007$

TRENCH $=0.003$

SITE. INT $=0.002$

SYS. CHAR $=0.297$

RELIABLE $=0.157$

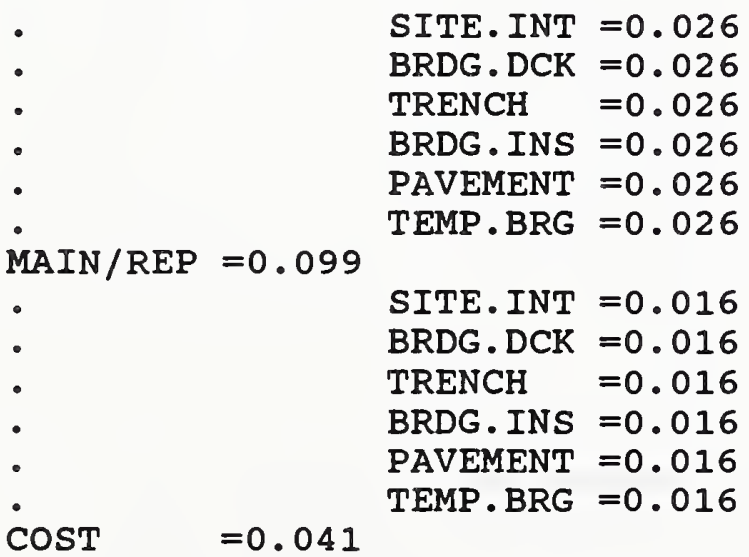

Figure 38
LEVEL 4 LEVEL 5

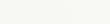


SELECT A ROBOTIC/AUTOMATION SYSTEM FOR DEVELOPMENT/DEMONSTRATION Sorted Details for Synthesis of Leaf Nodes with respect to GOAL DISTRIBUTIVE MODE

\begin{tabular}{|c|c|c|c|}
\hline LEVEL 1 & LEVEL 2 & LEVEL 3 & \\
\hline . & - & SITE.INT & $=0.015$ \\
\hline - & - & TRENCH & $=0.010$ \\
\hline & - & TEMP . BRG & $=0.006$ \\
\hline - & - & PAVEMENT & $=0.004$ \\
\hline • & - & BRDG. INS & $=0.004$ \\
\hline & - & BRDG. DCK & $=0.003$ \\
\hline$I M P=0.163$ & & & \\
\hline - & INFR. IMP $=0.111$ & & \\
\hline - & - & PAVEMENT & $=0.042$ \\
\hline - & - & BRDG.INS & $=0.025$ \\
\hline • & - & TEMP. BRG & $=0.018$ \\
\hline • & - & BRDG.DCK & $=0.013$ \\
\hline • & - & SITE.INT & $=0.008$ \\
\hline & - & TRENCH & $=0.005$ \\
\hline & ECON.IMP $=0.052$ & & \\
\hline & - & PAVEMENT & $=0.018$ \\
\hline & - & SITE.INT & $=0.012$ \\
\hline & - & BRDG.INS & $=0.010$ \\
\hline & - & TEMP.BRG & $=0.007$ \\
\hline & - & TRENCH & $=0.003$ \\
\hline & & BRDG . DCK & $=0.00$ \\
\hline
\end{tabular}


SELECT A ROBOTIC/AUTOMATION SYSTEM FOR DEVELOPMENT/DEMONSTRATION

Synthesis of Leaf Nodes with respect to GOAL DISTRIBUTIVE MODE

OVERALL INCONSISTENCY INDEX $=0.03$

PAVEMENT 0.255

BRDG.INS 0.215

TEMP.BRG 0.161

TRENCH 0.125

SITE.INT 0.123

BRDG.DCK 0.121

BRDG.DCK - - AUTOMATED BRIDGE DECKING SYSTEM

BRDG.INS - - BRIDGE INSPECTION AND MAINTENANCE SYSTEM

PAVEMENT -- PAVEMENT INSPECTION AND REPAIR SYSTEM

SITE.INT -- SITE INTEGRATION SYSTEM

TEMP.BRG -- TEMPORARY BRIDGING SYSTEM

TRENCH - TRENCHING AND PIPE LAYING SYSTEM 
against the measures and submeasures (while the software allows for a goal plus 5 levels, we are using 3 levels).

Figure 40 displays the final results, with the automated/robotic pavement inspection and repair system in first place with a score of 0.255 , and the automated/robotic bridge inspection system in a close second place with a score of 0.215 . The final three systems are closely ranked, between 0.125 and 0.121 , essentially equal in value.

There is nothing sacrosanct about these results - they reflect the preferences, rationale, and judgement of one analyst, performing an exemplar exercise and having no access to actual cost data, or other field data. It is the method, the analytical tool, that is important here, not the results of this exercise.

The AHP method and the MoM that we defined and weighted are recommended for use by the panel of experts for evaluating the alternative systems.

\subsection{Sensitivity Analysis}

After obtaining weights for the MoM and evaluating the alternative systems, the analyst should examine the degree to which small changes in judgement might affect the outcome by performing a sensitivity analysis. Figures 41 to 81 illustrate the results, for our example analysis, of a sensitivity analysis of all of the alternative systems versus the MoM, and the MoM versus each other. The results are displayed in several different graphic formats as an aid in visualizing the results.

For example, Figure 41 shows, in bar graph format, the relative contribution of each of the two submeasures (criteria) to the evaluation of the alternative systems. The economic impact MoM has a smaller affect on the pavement system than the infrastructure impact MoM, but it has a larger affect on the site integration system. The software allows the analyst to vary the MoM dynamically, so the affects on the alternative system choices can be tracked in real-time. A snapshot of this can be seen by comparing Figures 45 and 46 . Figure 45 has the calculated submeasures values for the operational Benefits MoM; it shows the pavement system with the highest score. In Figure 46, the weight (importance) of the life cycle cost submeasure has been increased dramatically (from 0.264 to 0.821 ), and the result is a first place edge for the bridge inspection system. However, a modest increase in the weight of the life cycle cost submeasure has no affect on the original outcome for the top-rated system (although lower-rated systems change order, such as increased priority for the site integration system).

A second method of investigating sensitivity is with gradient sensitivity, shown in Figure 42. In the graph, the weight value 


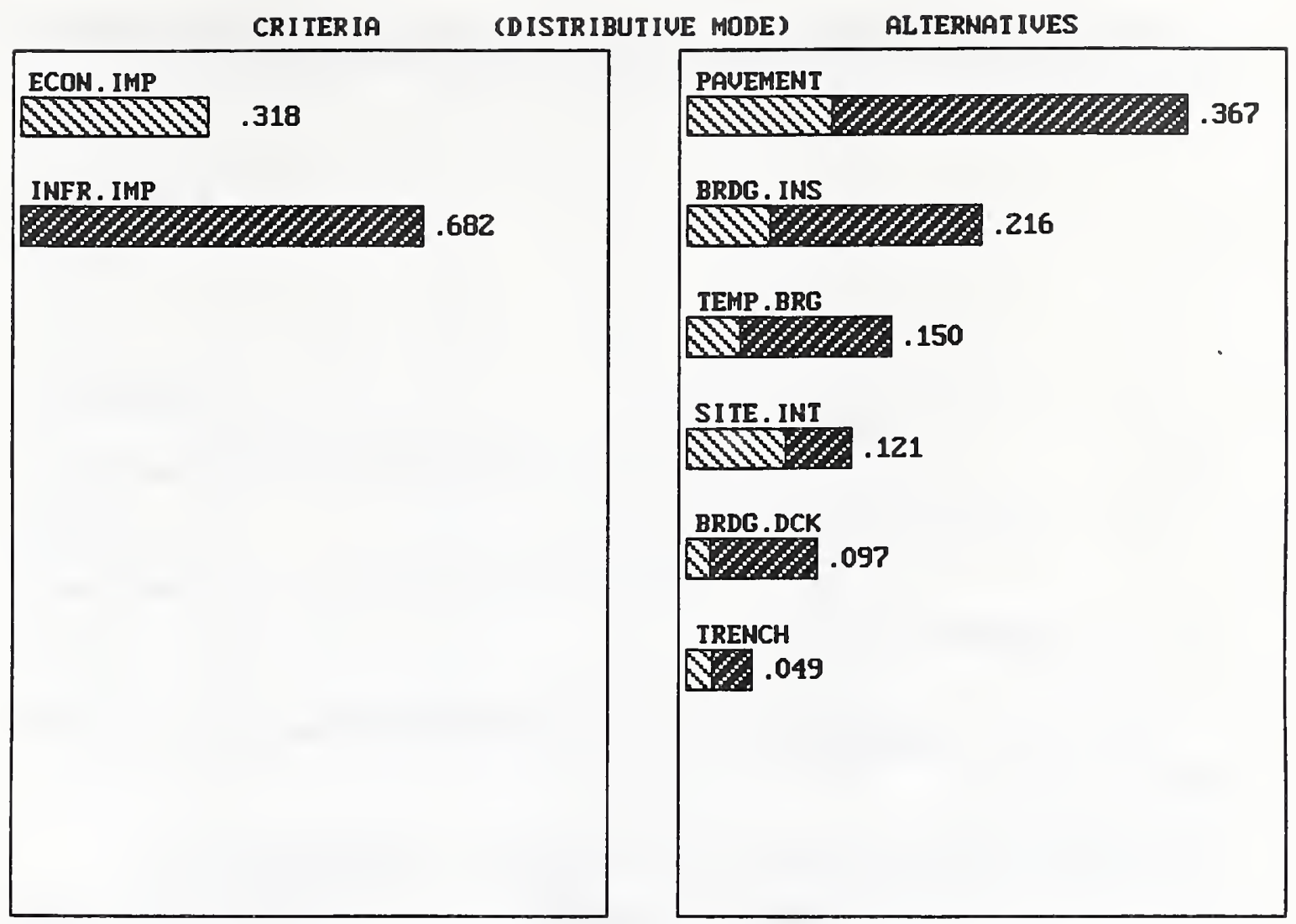

RTI

Figure 11 


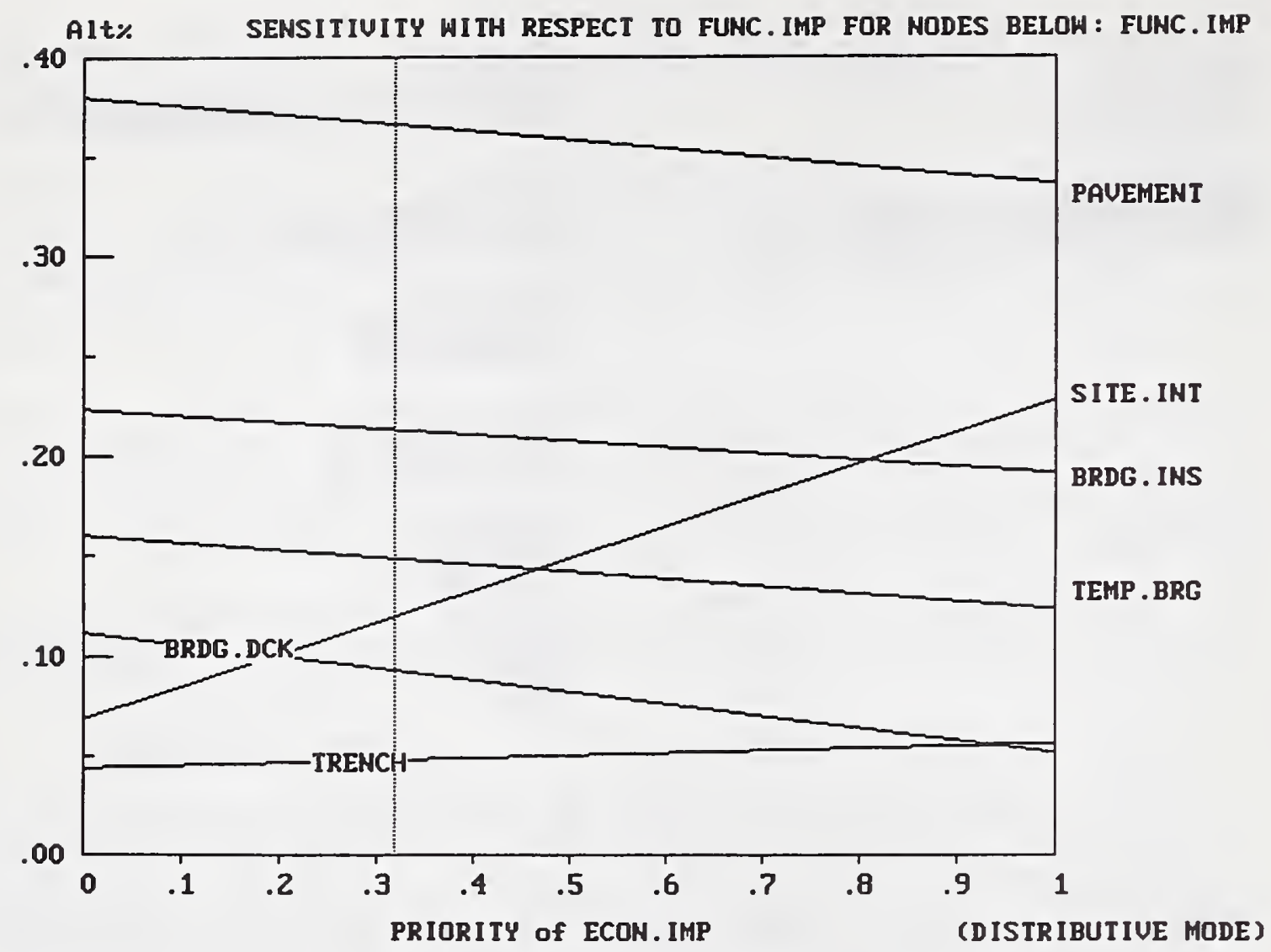

RTI 


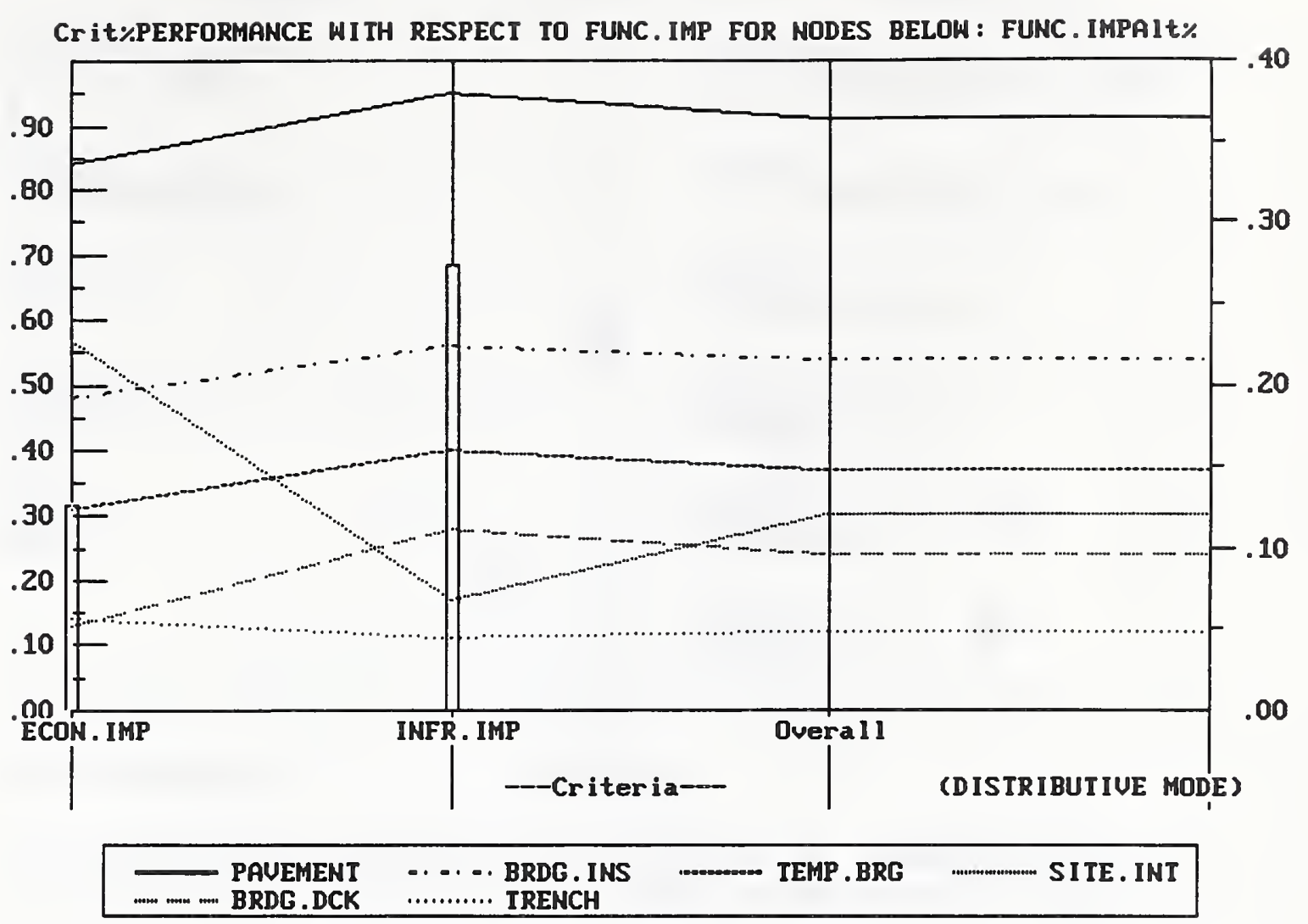

RTI

Figure 43 
INFR . IMP

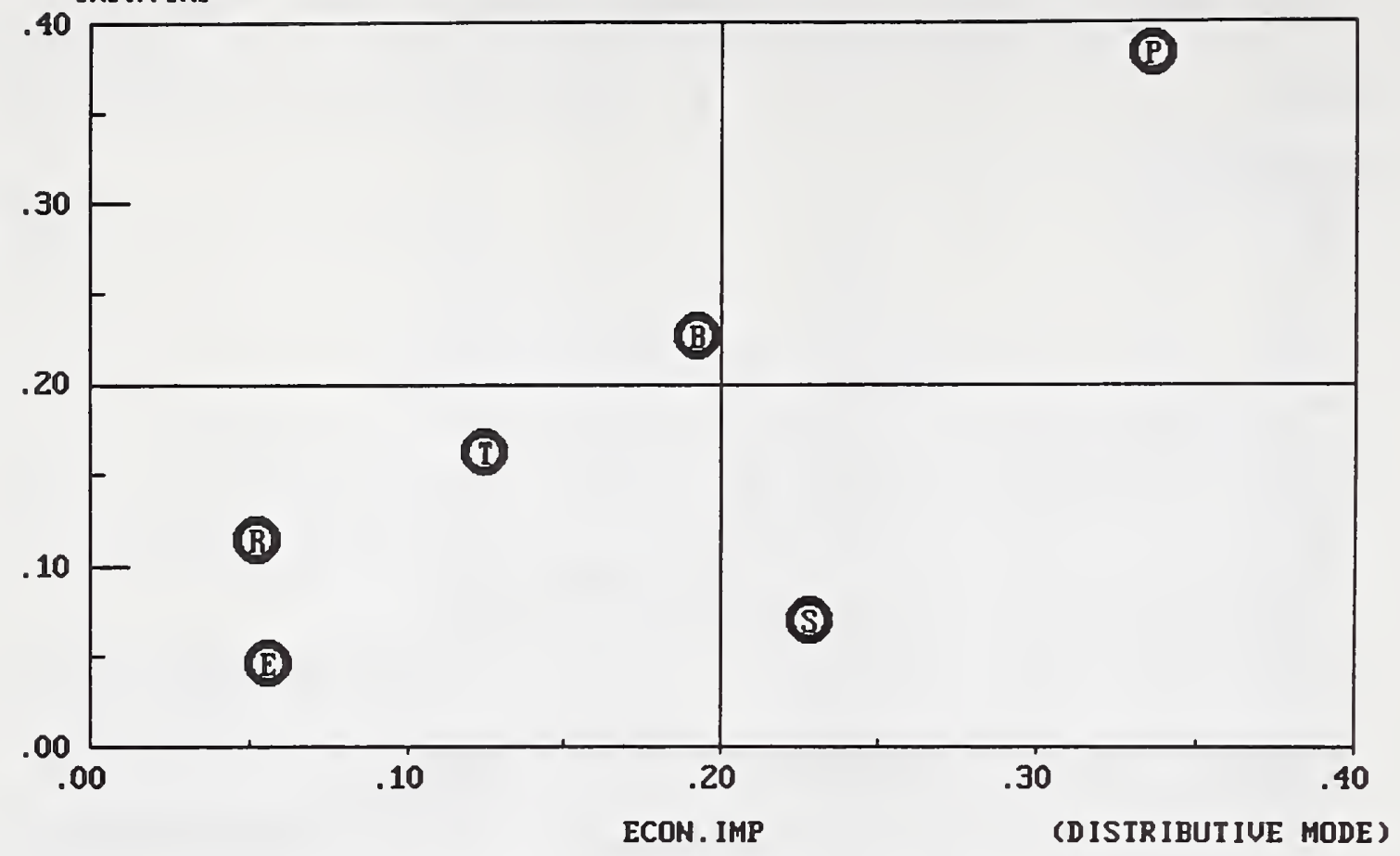

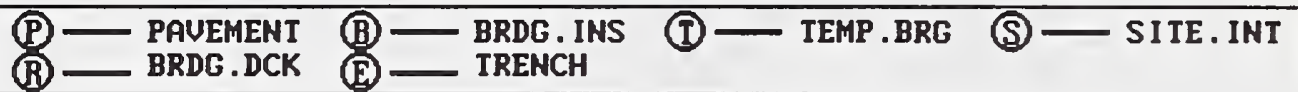

RTI 


\section{CRITERIA (DISTRIBUTIUE MODE)}

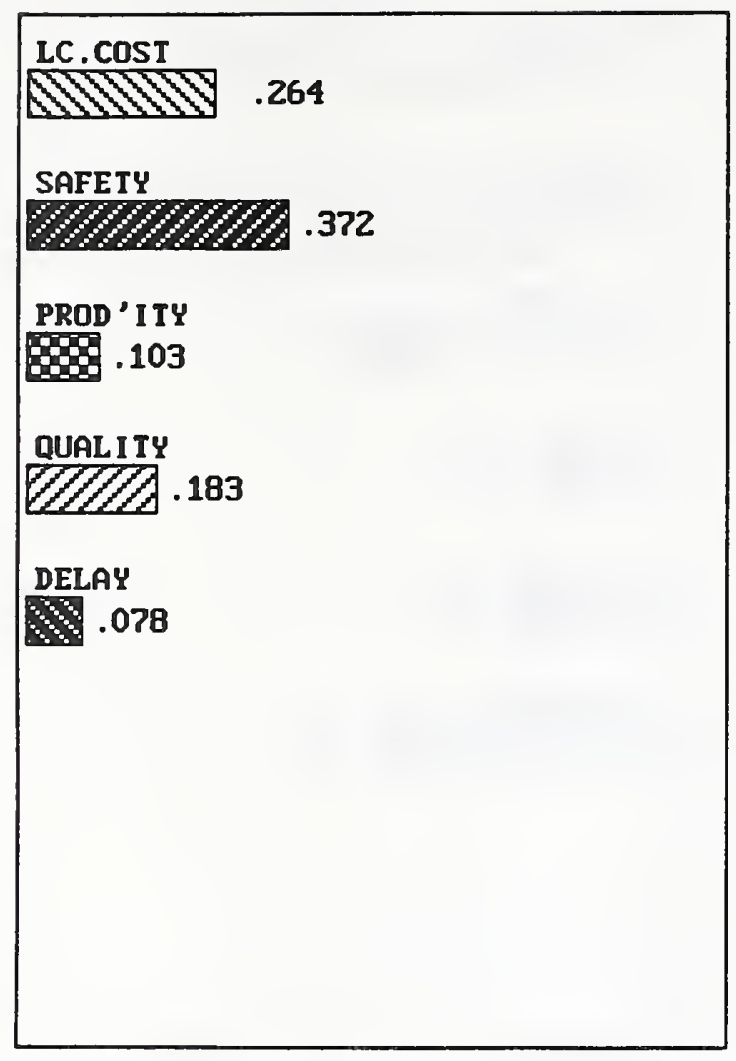

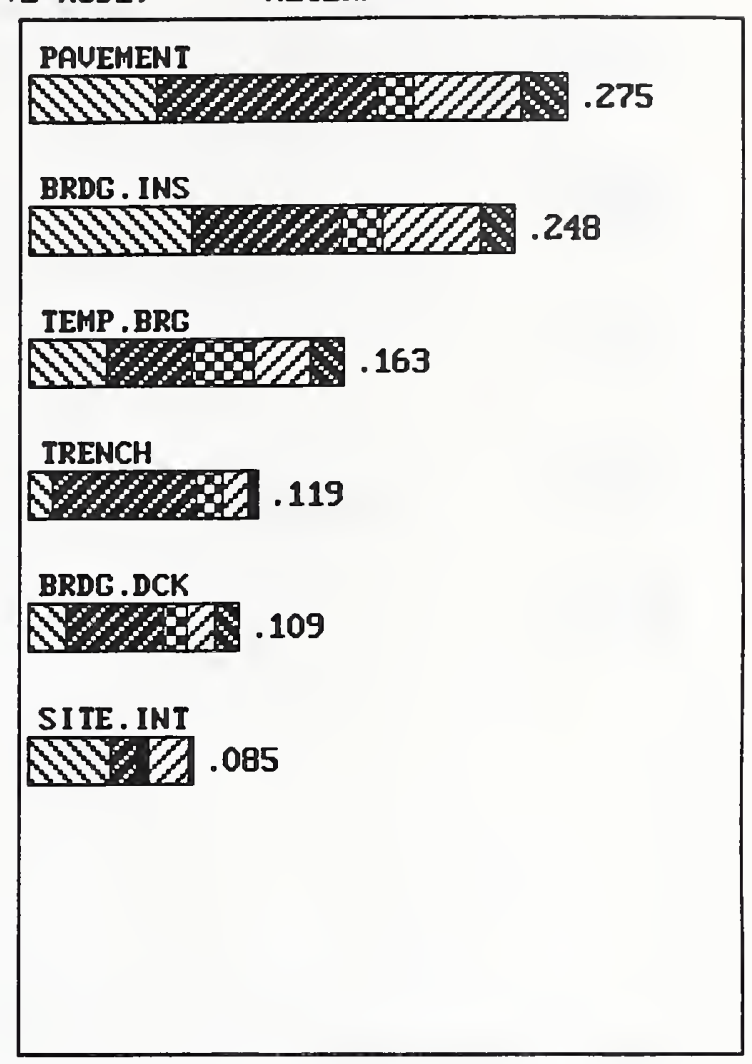

RTI

Figure 45 


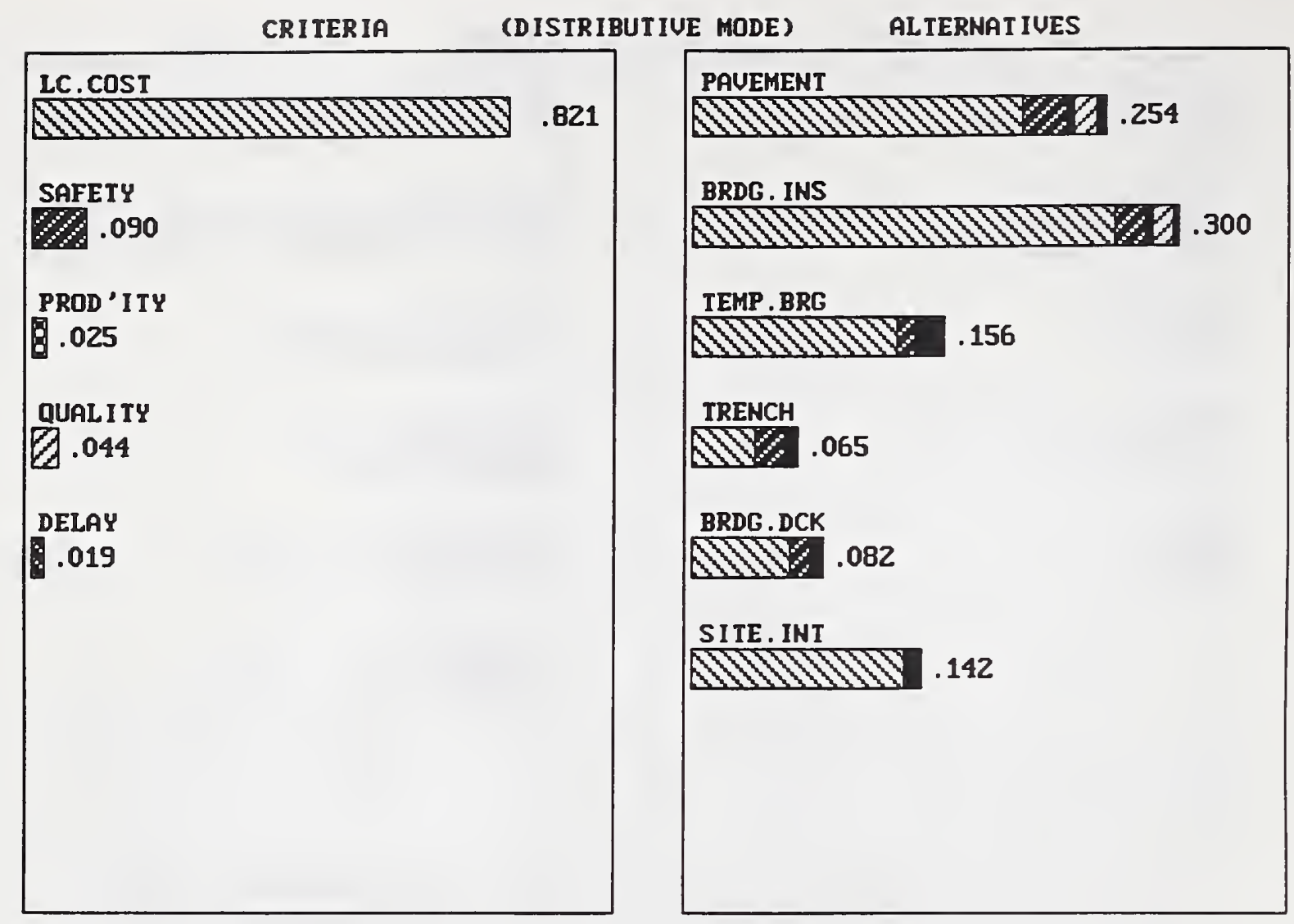

RTI

Figure 46 


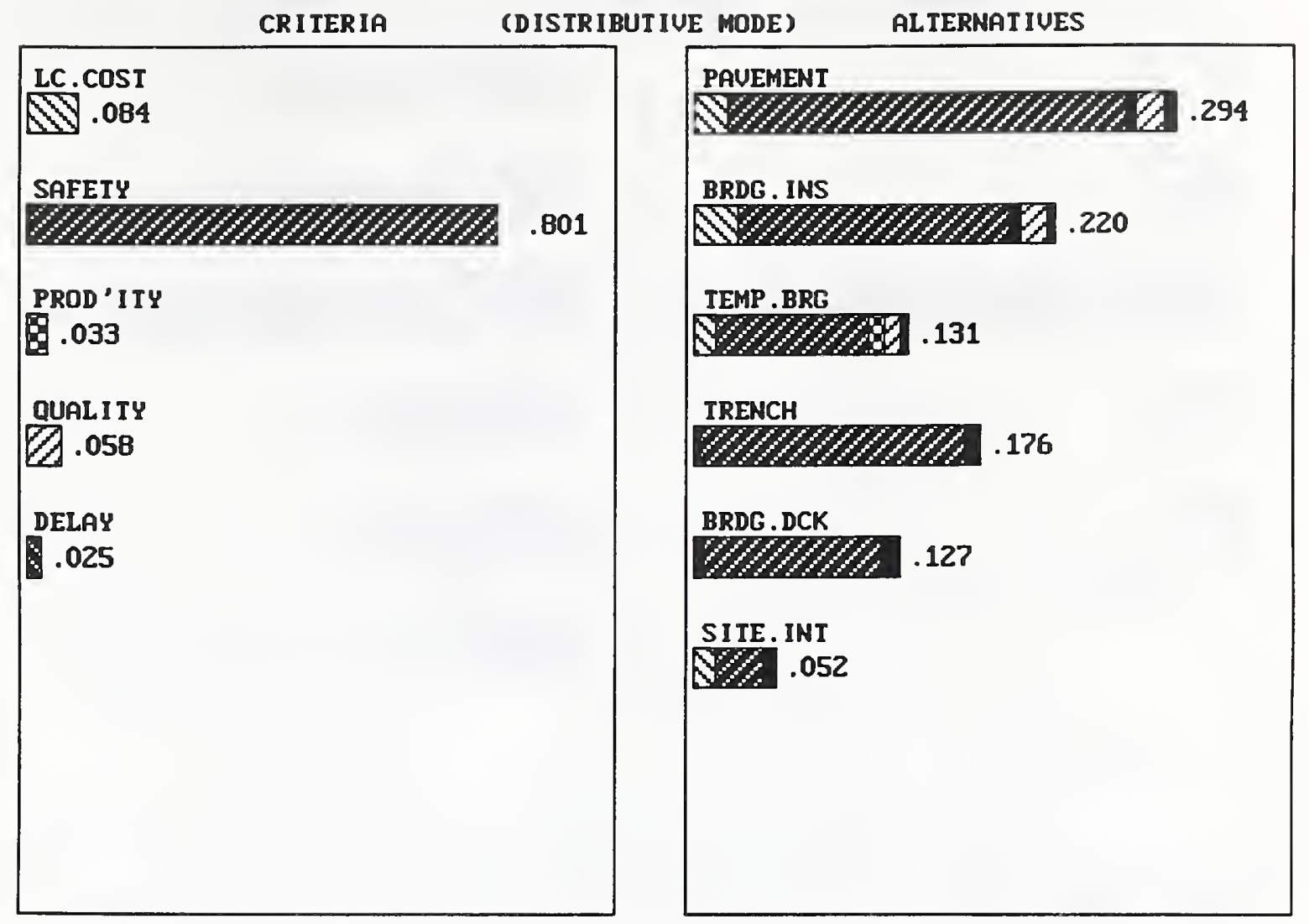




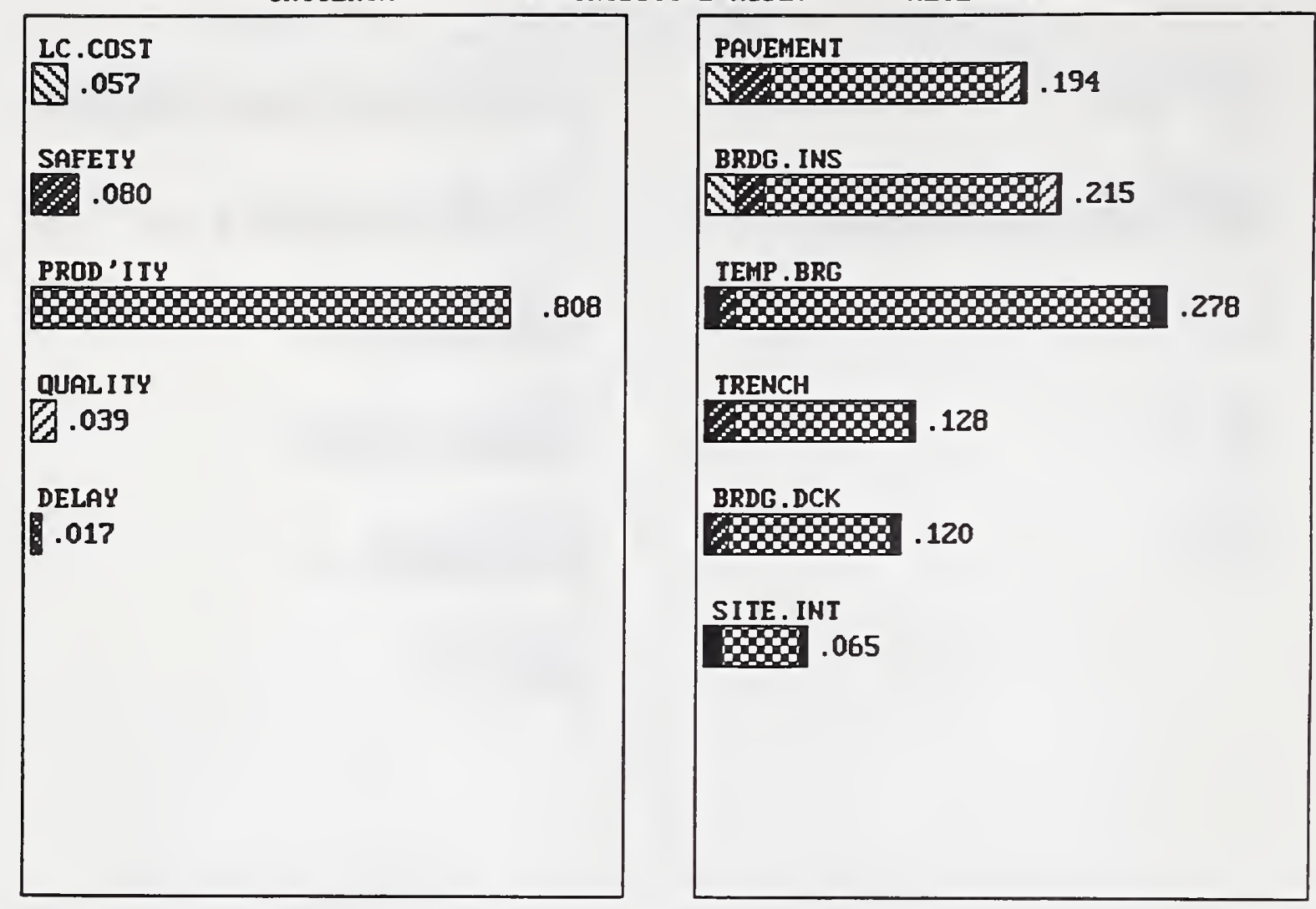

RTI 


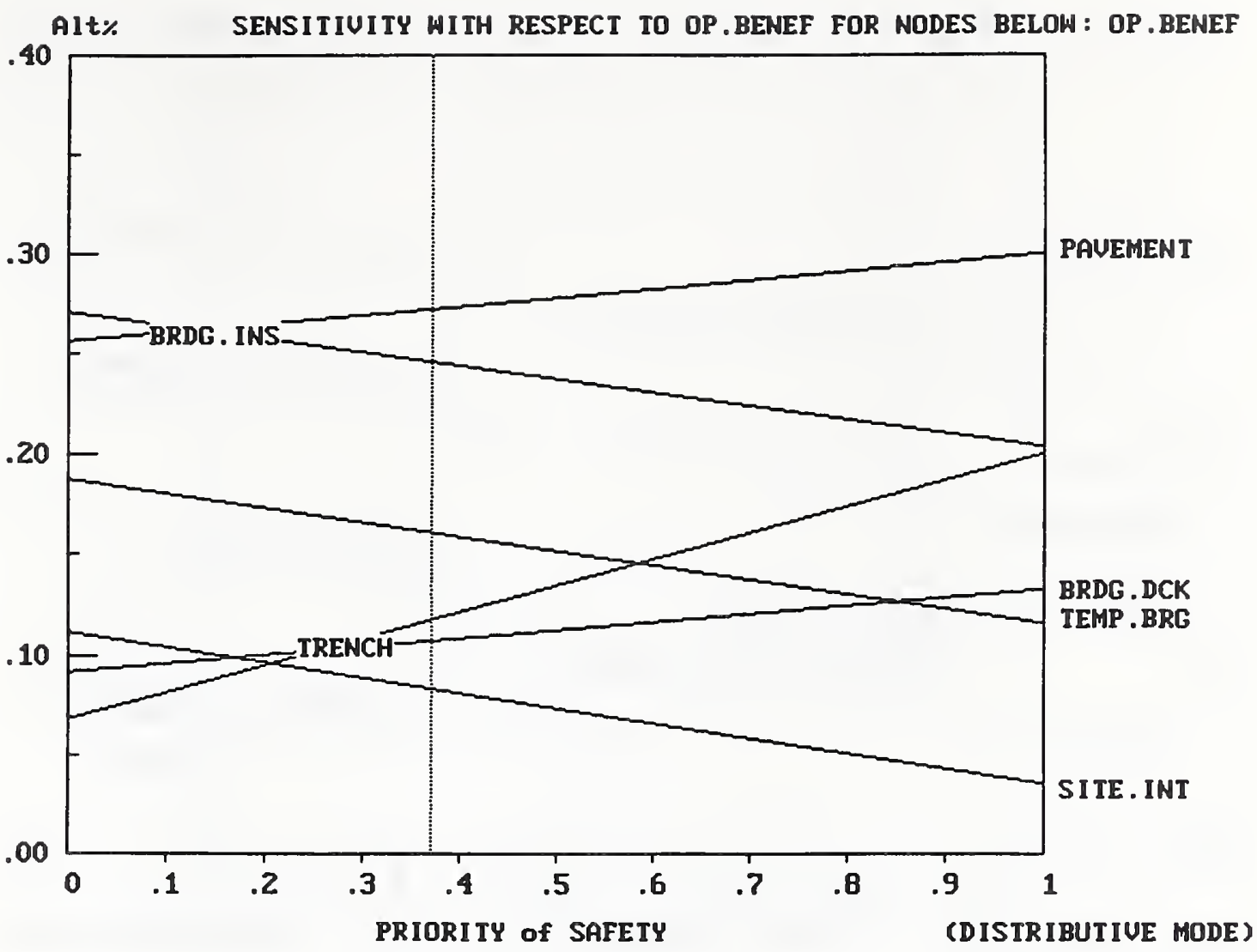

RTI

Figure 49 


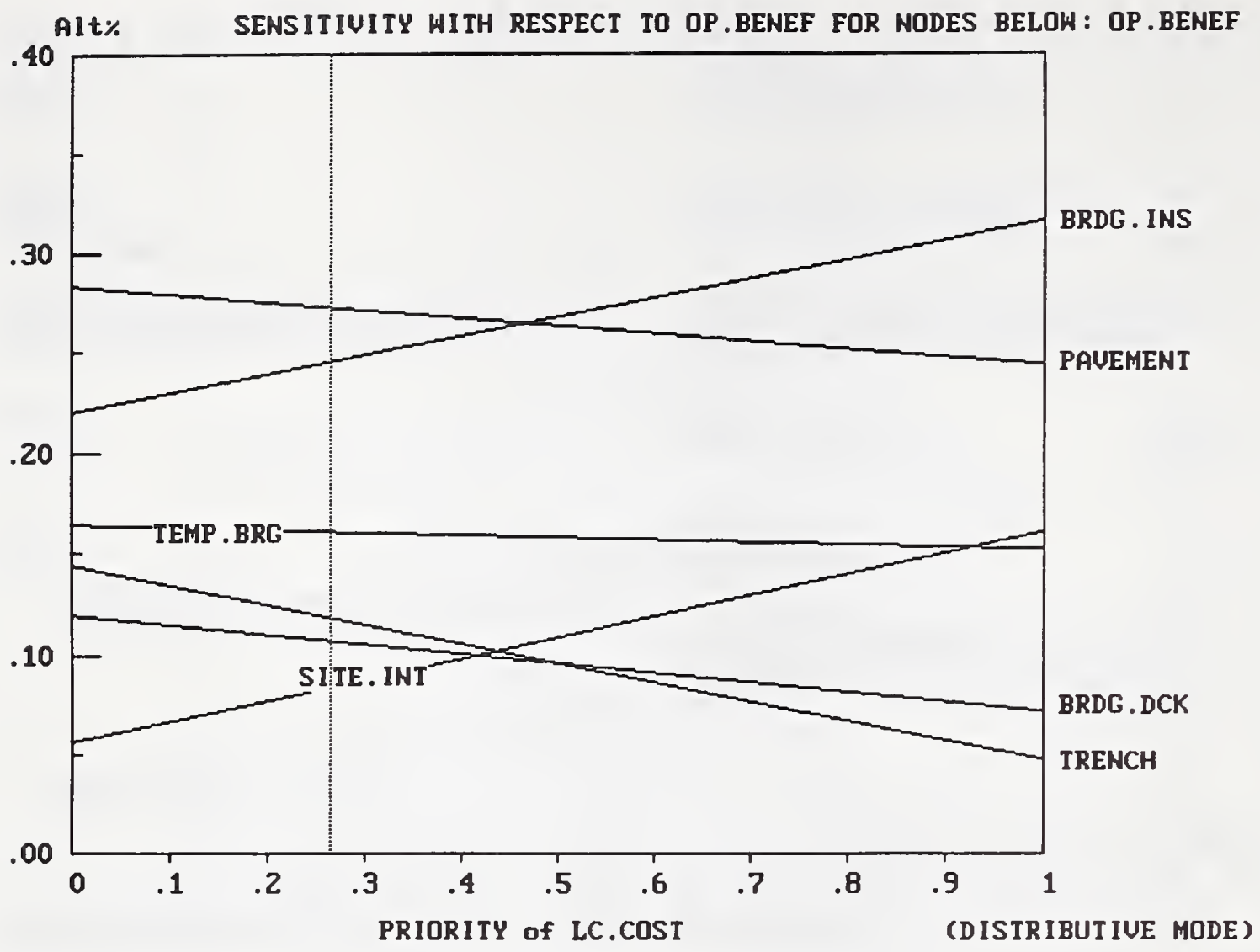

RTI

Figure 50 


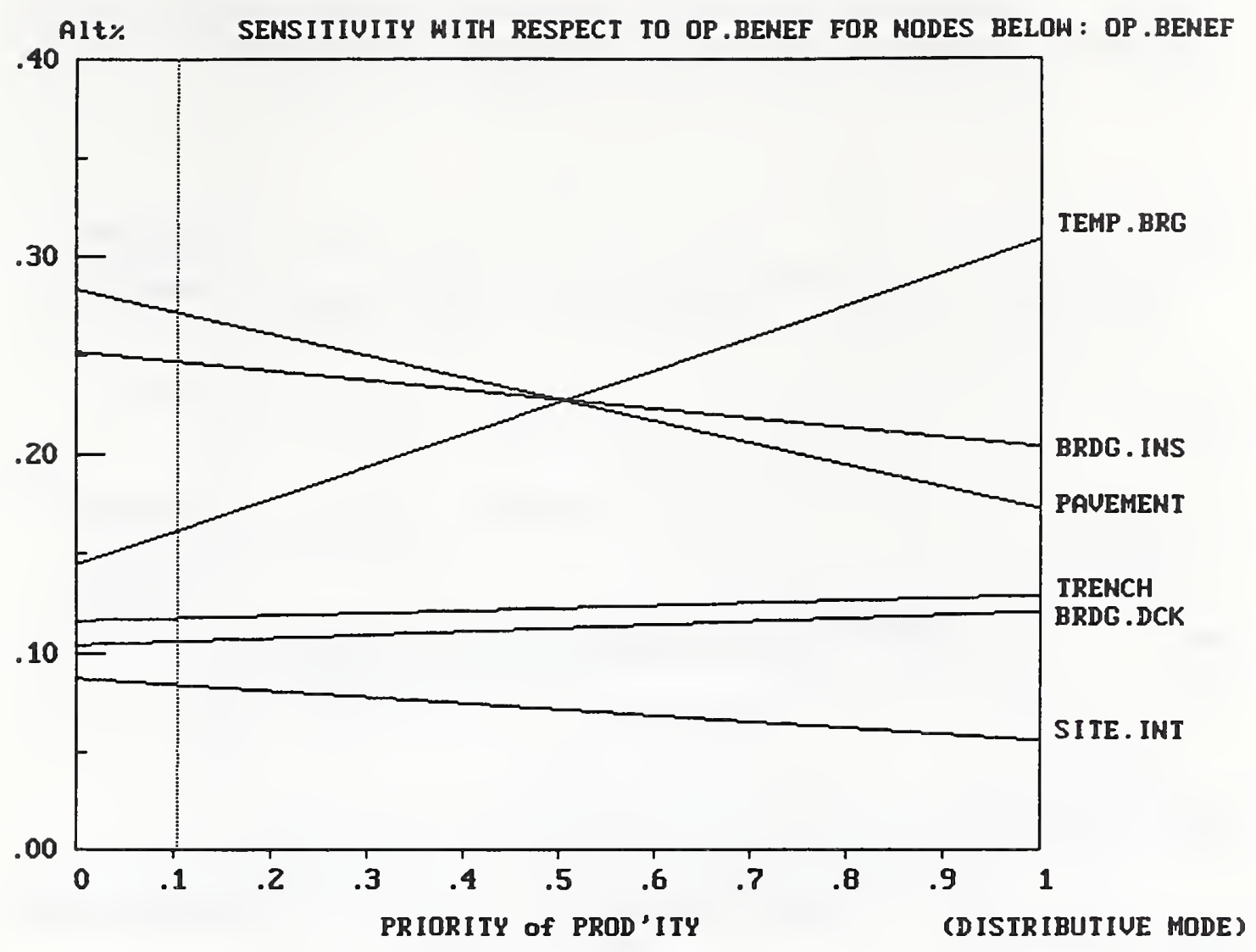




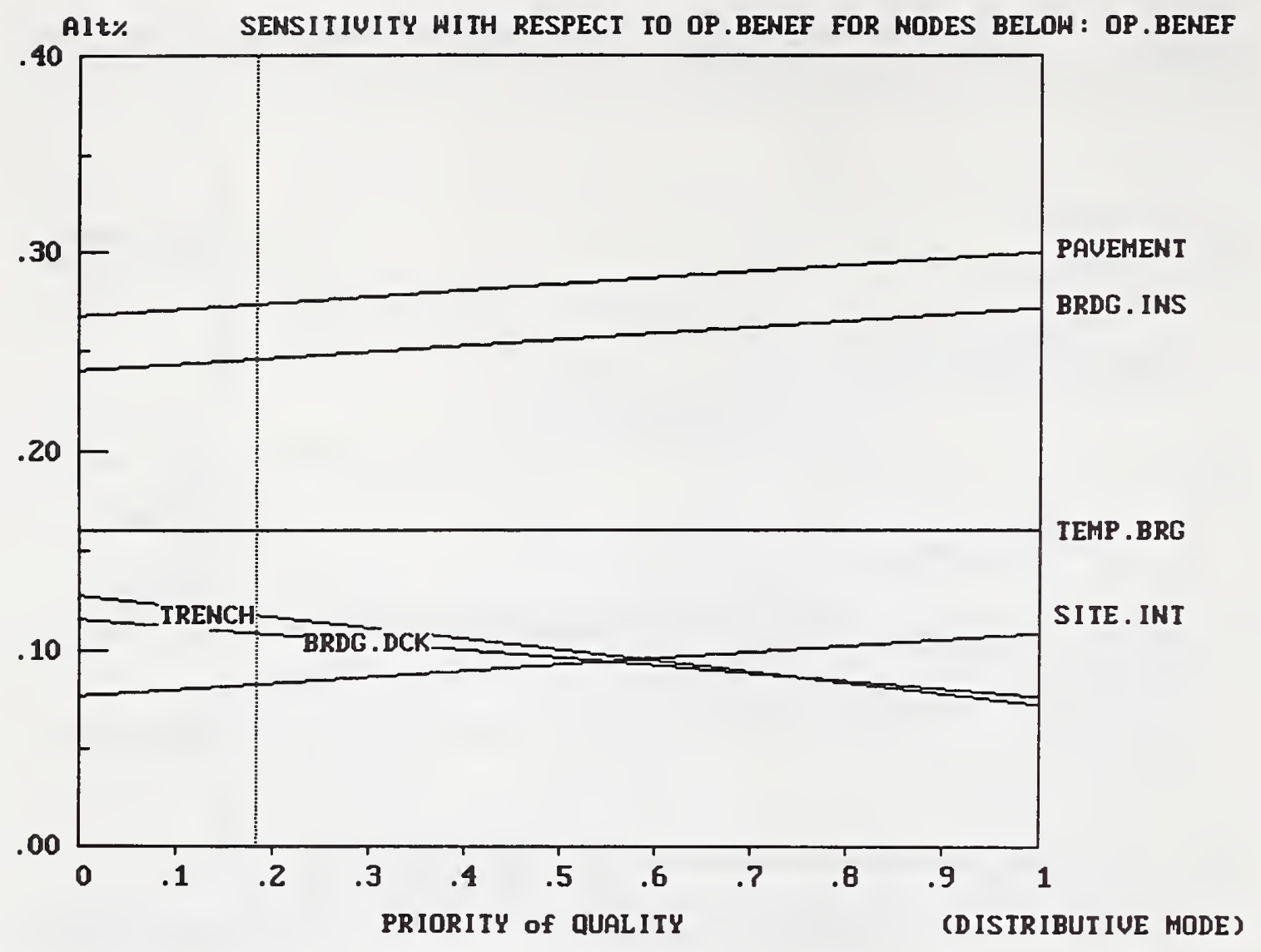

RTI

Figure 52 


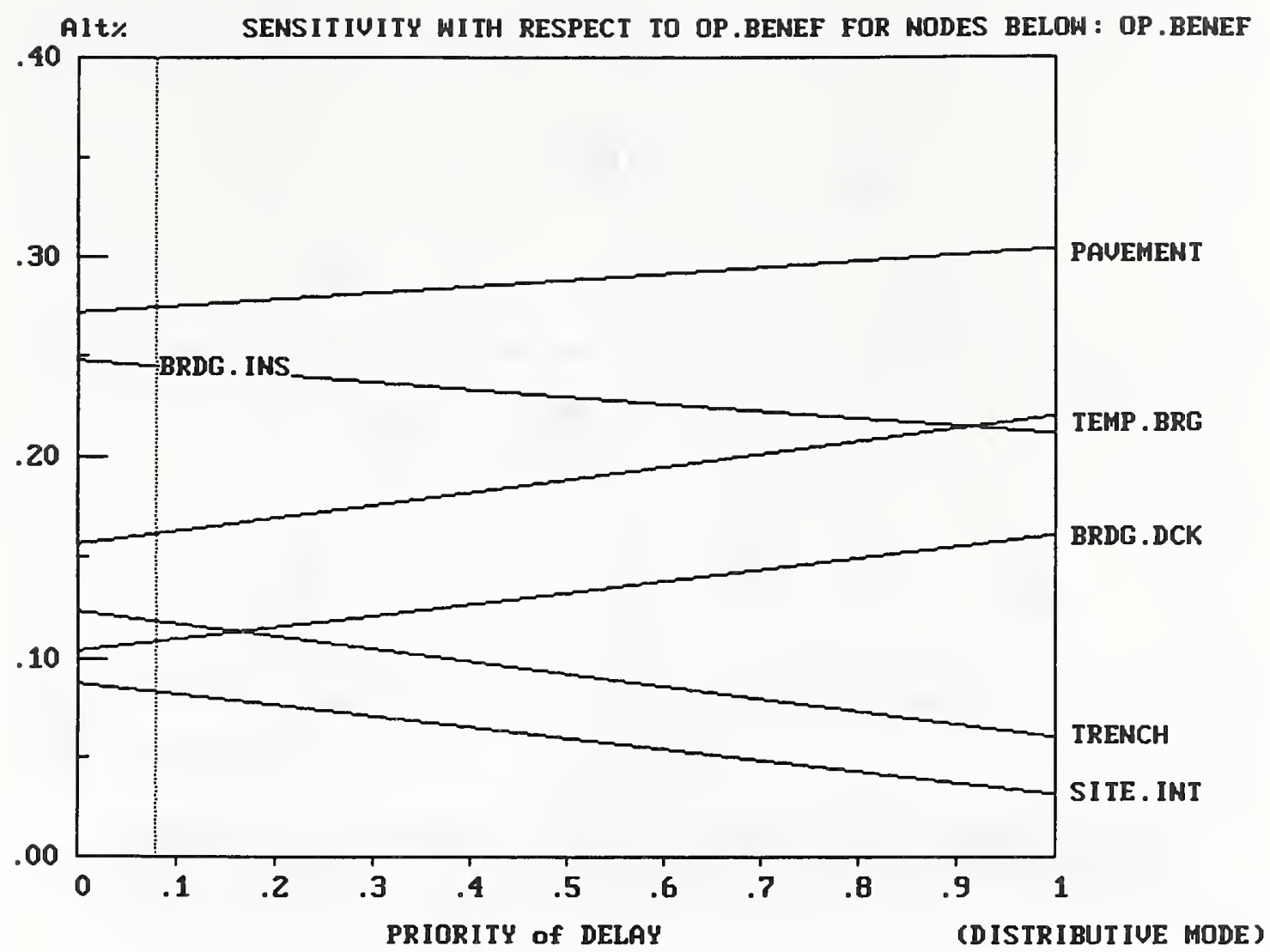

RTI

Figure 53 


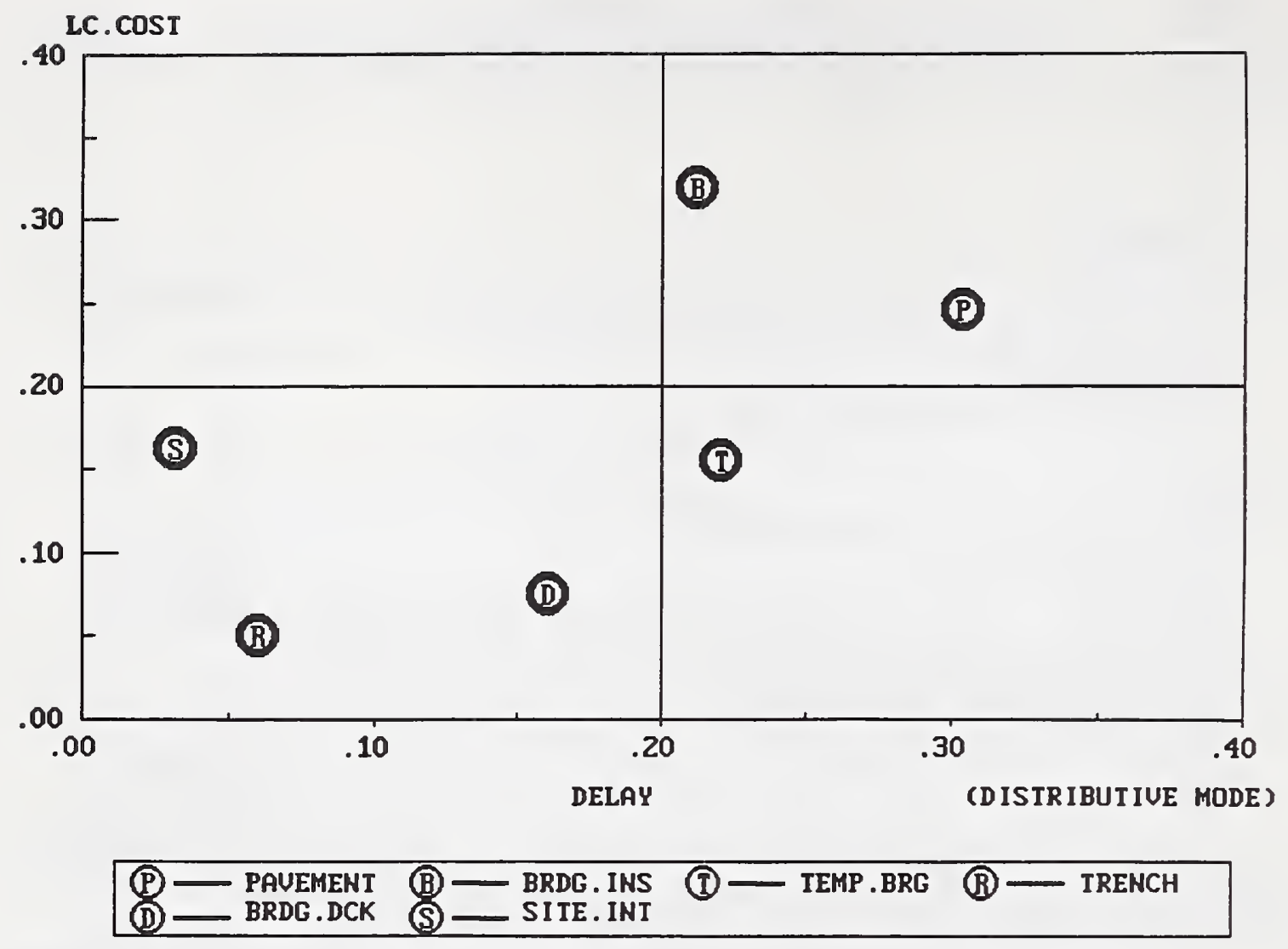

RTI 


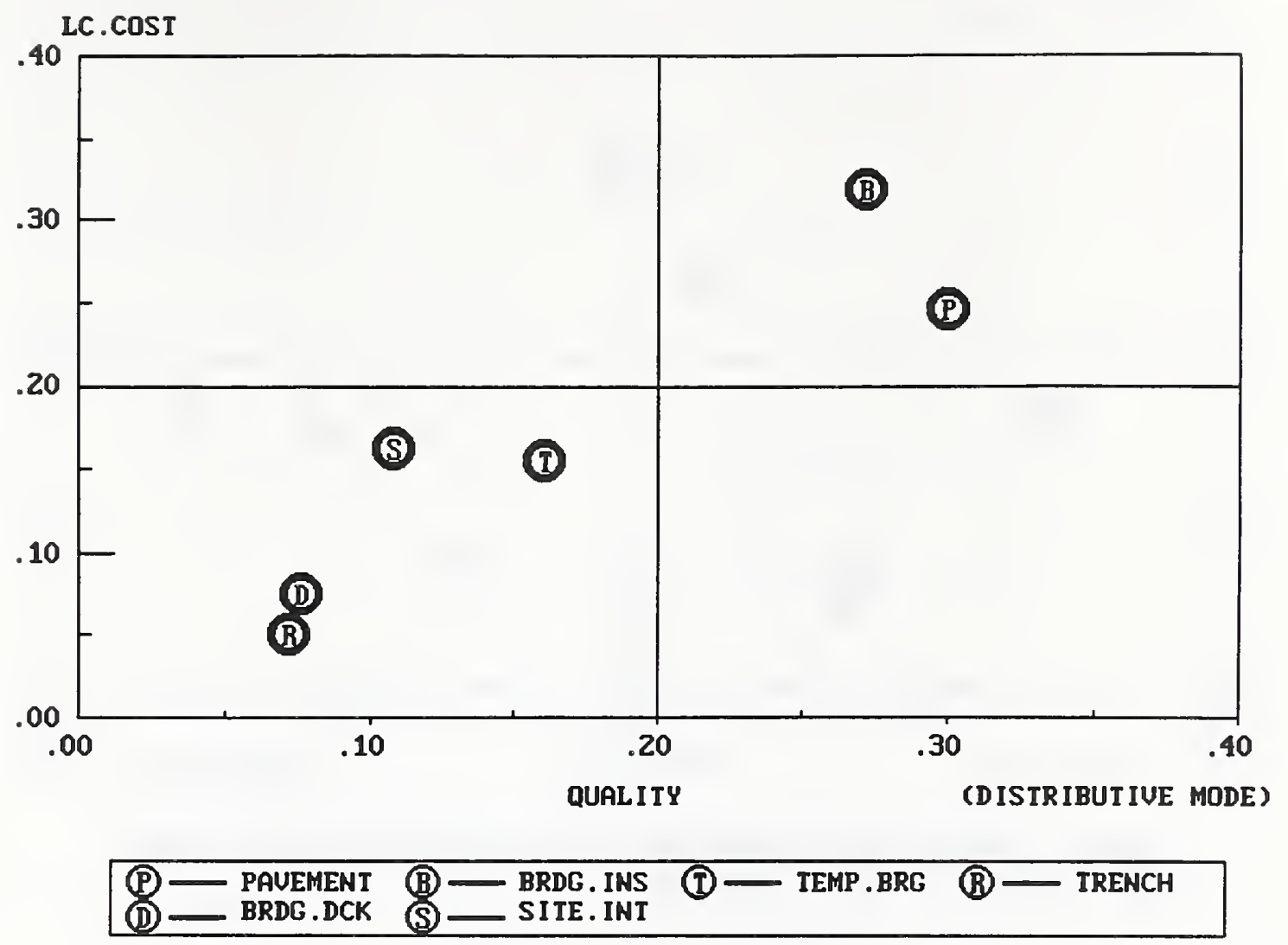

RTI

Figure 55 


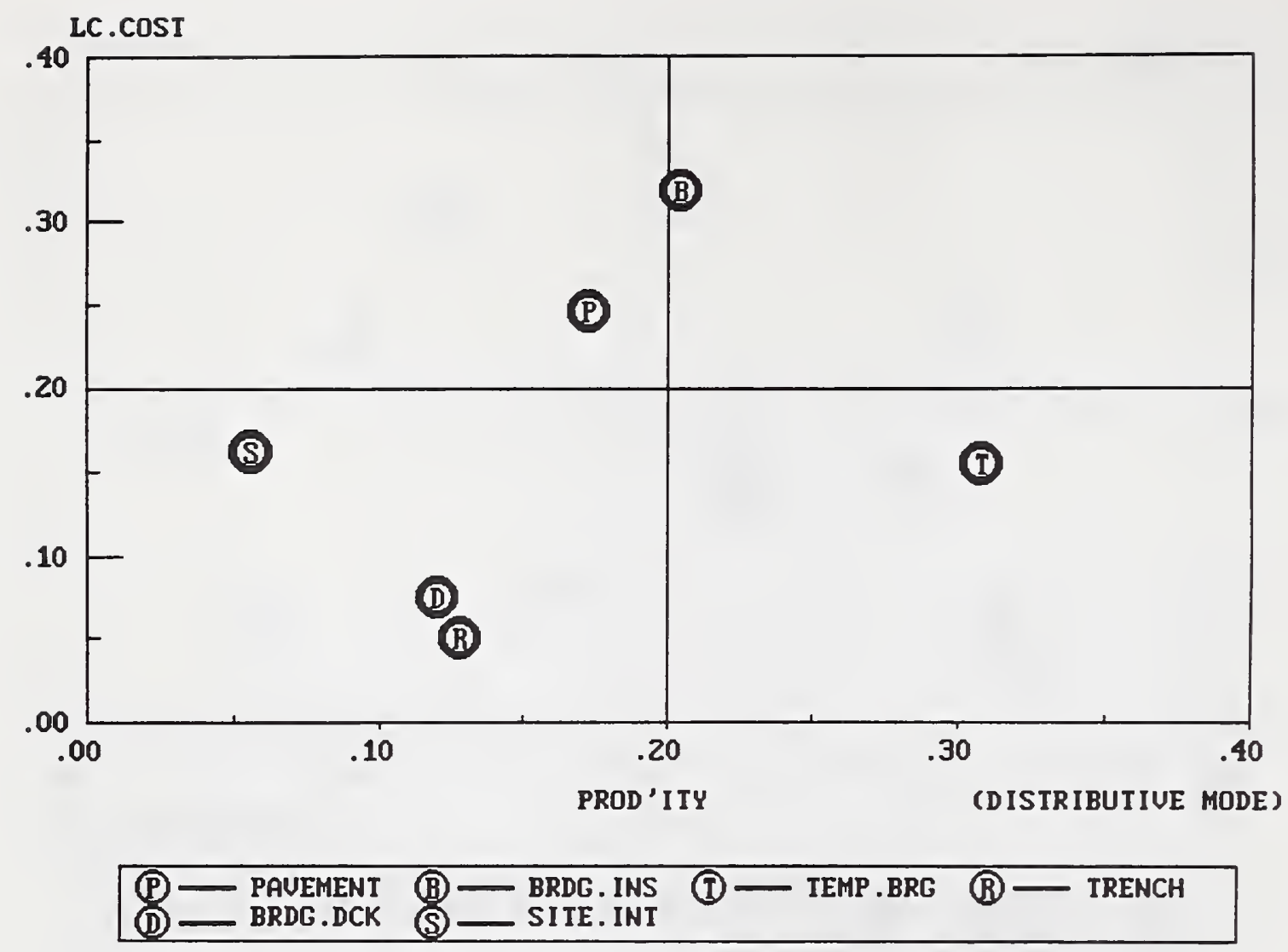

RTI

Figure 56 


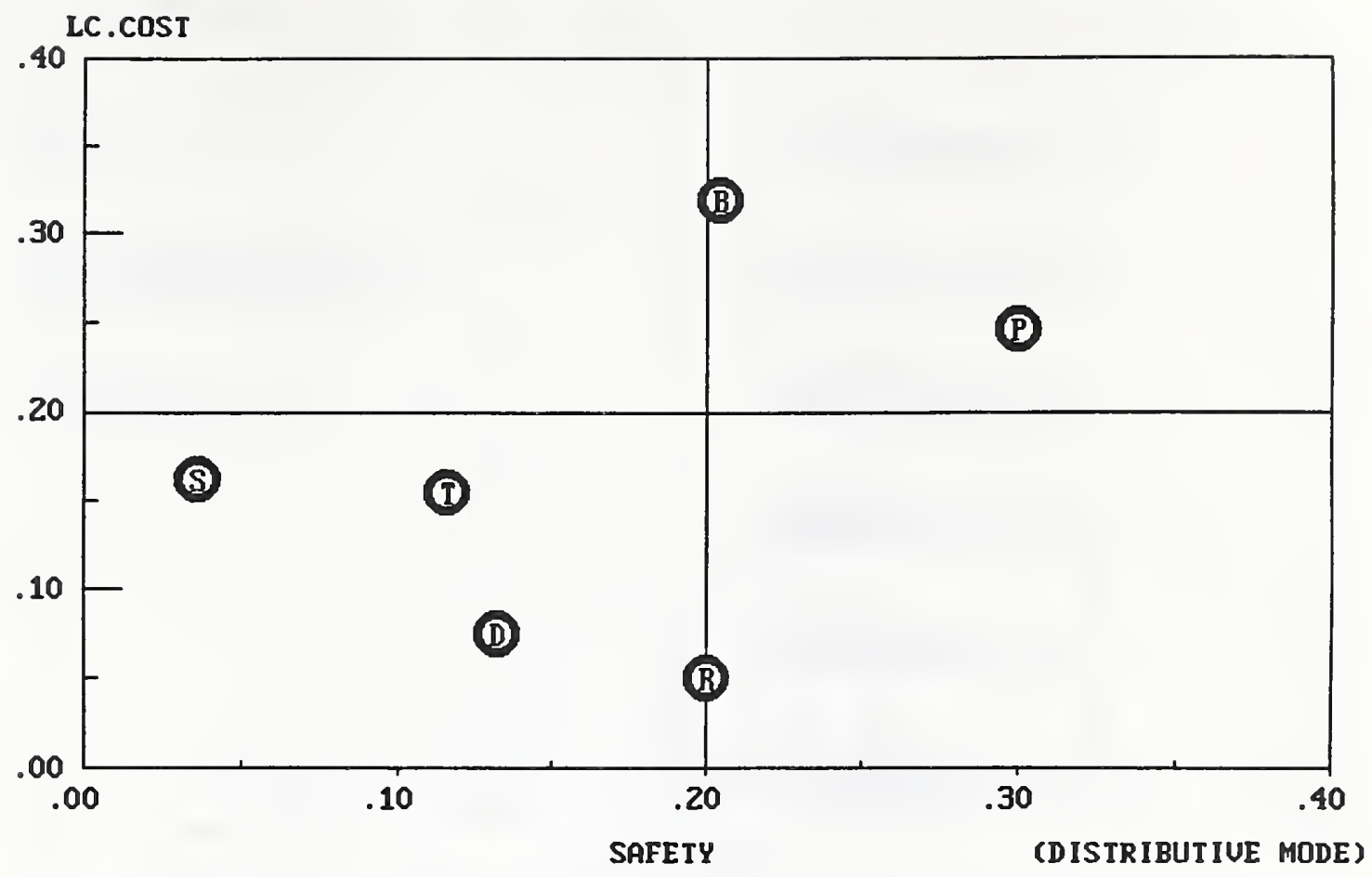

P - PAUEMENT
$(\mathrm{D})-$ BRDG.DCK

RTI 


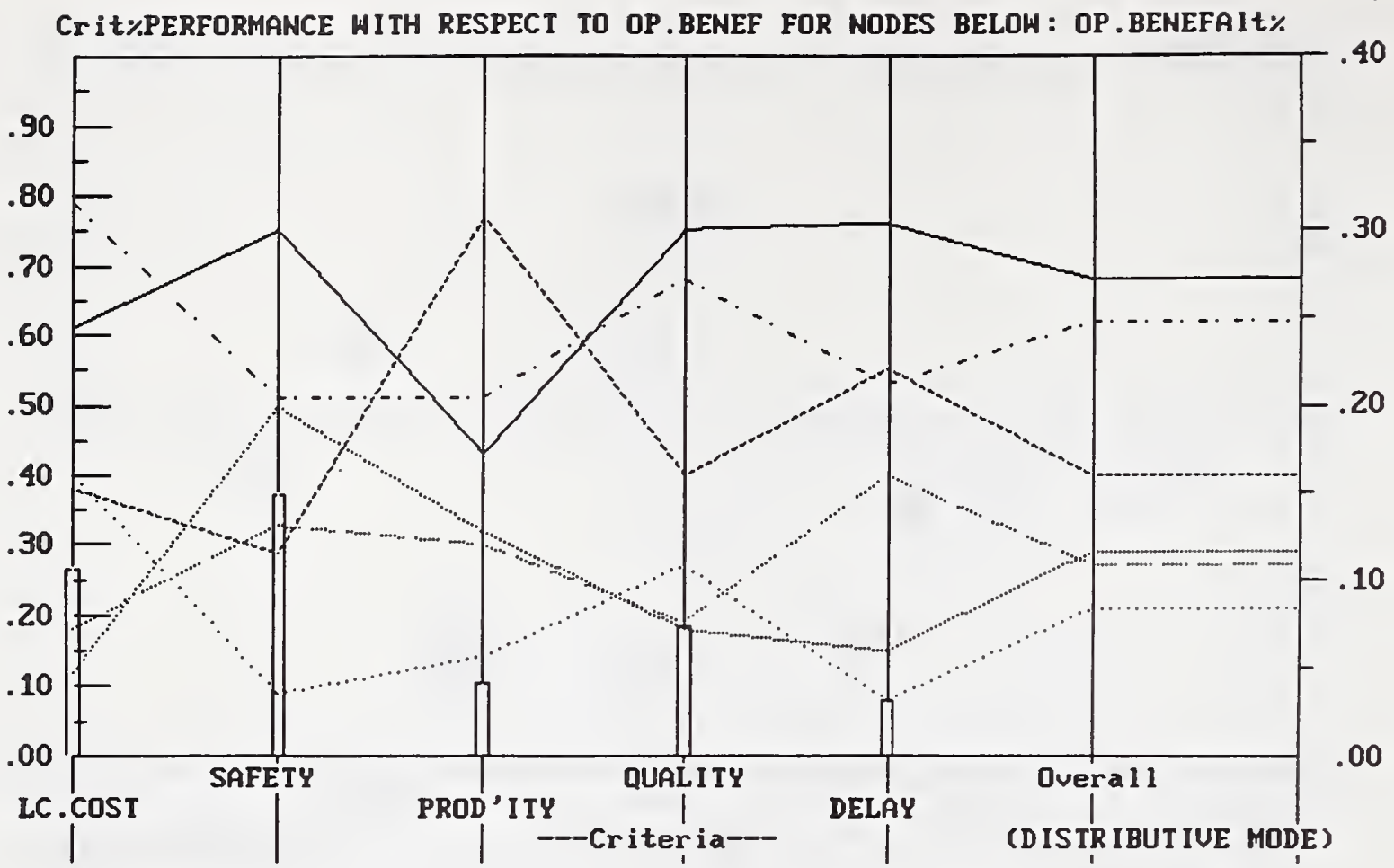




\begin{tabular}{|c|c|}
\hline CRI TER IA & (DISTRIBUTIUE MODE) \\
\hline 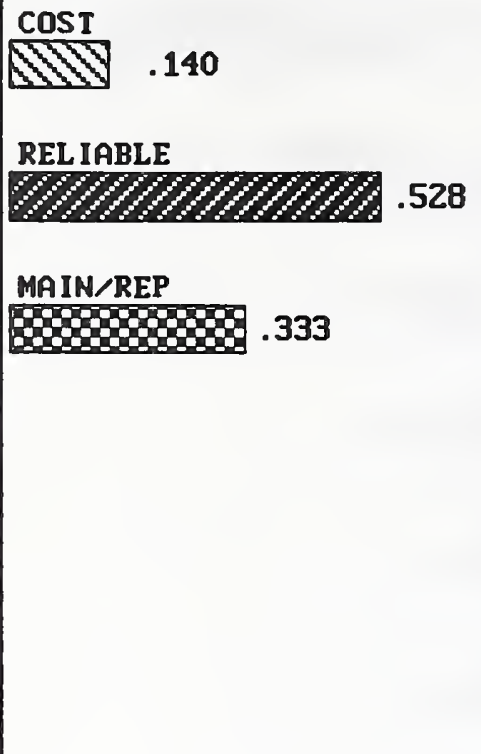 & 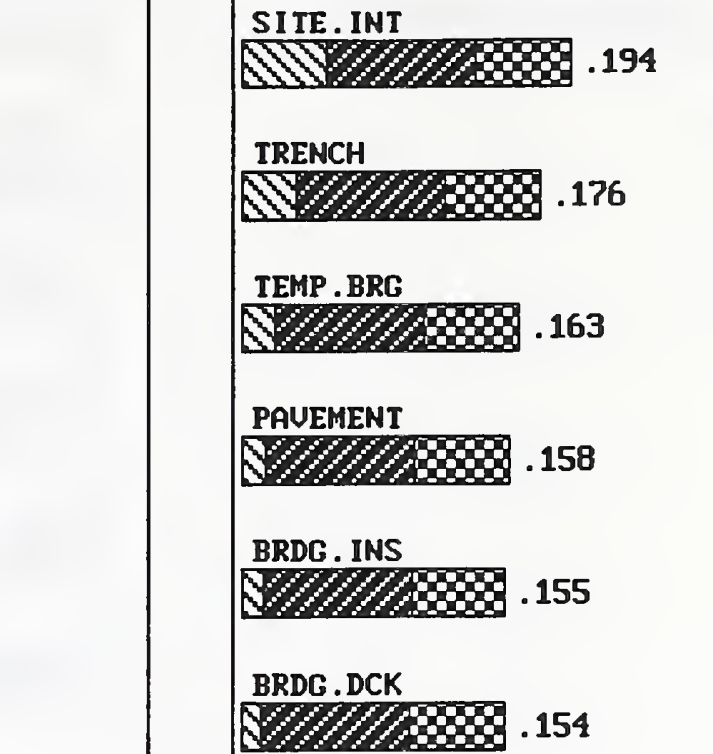 \\
\hline
\end{tabular}

RTI

Figure 59 


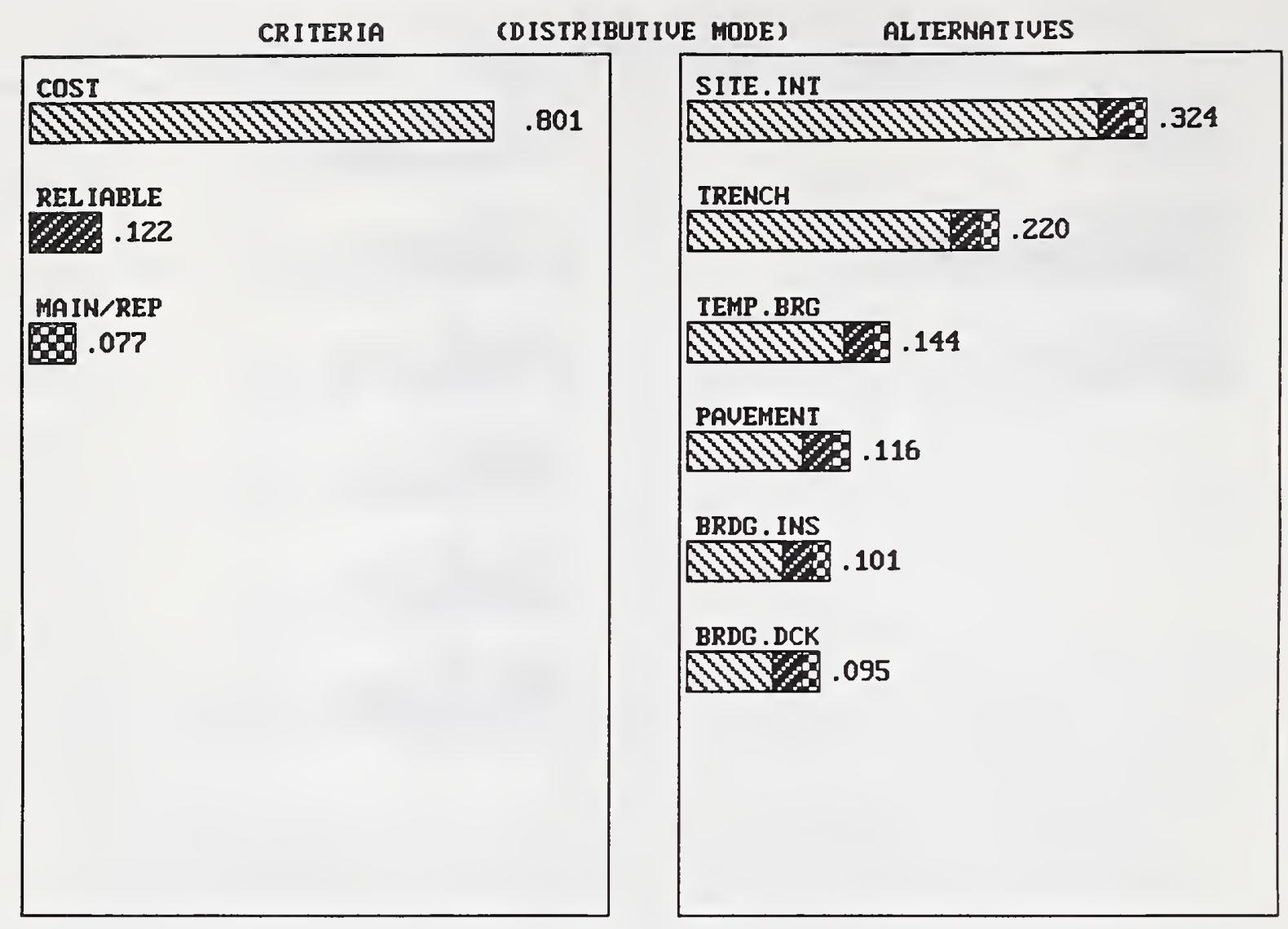




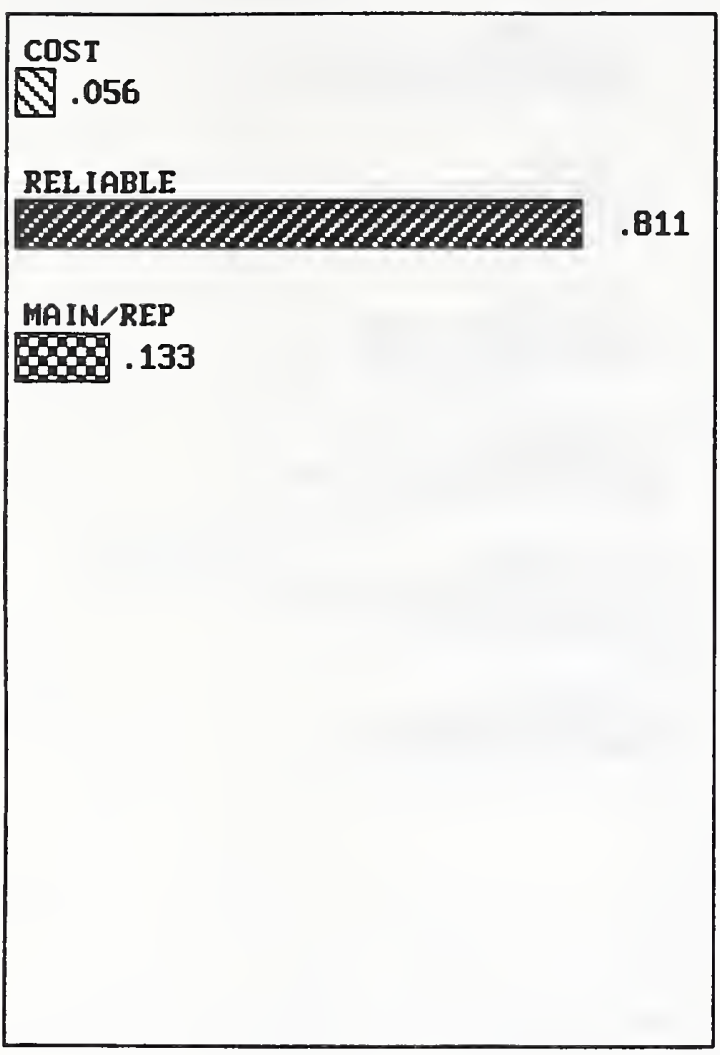

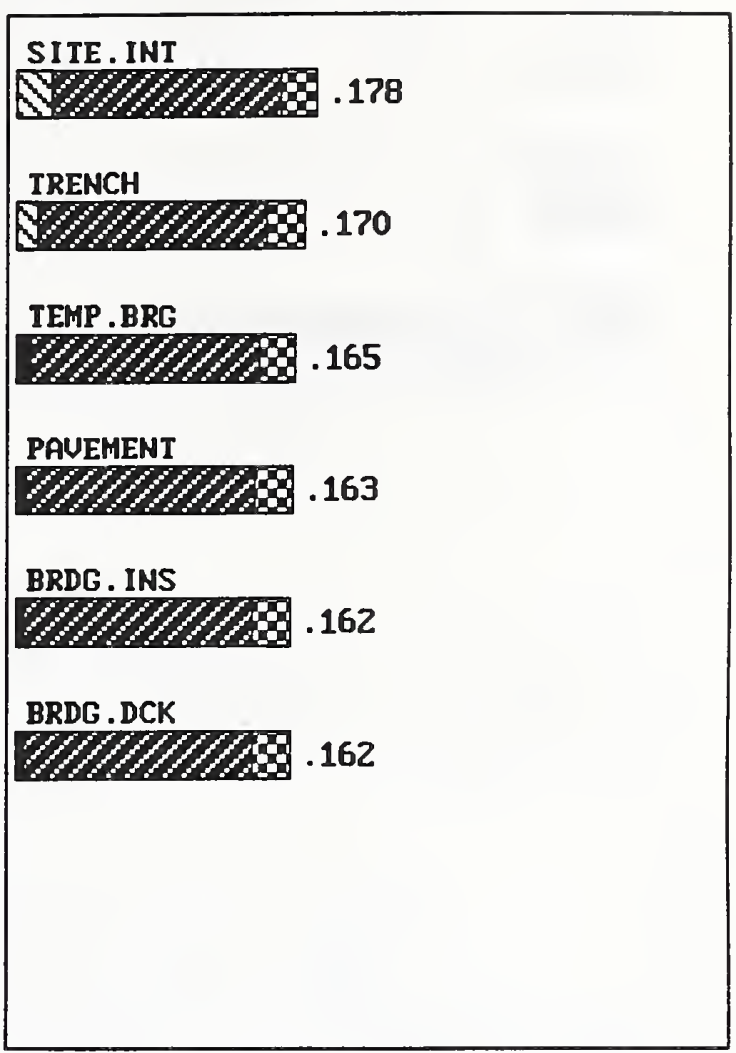




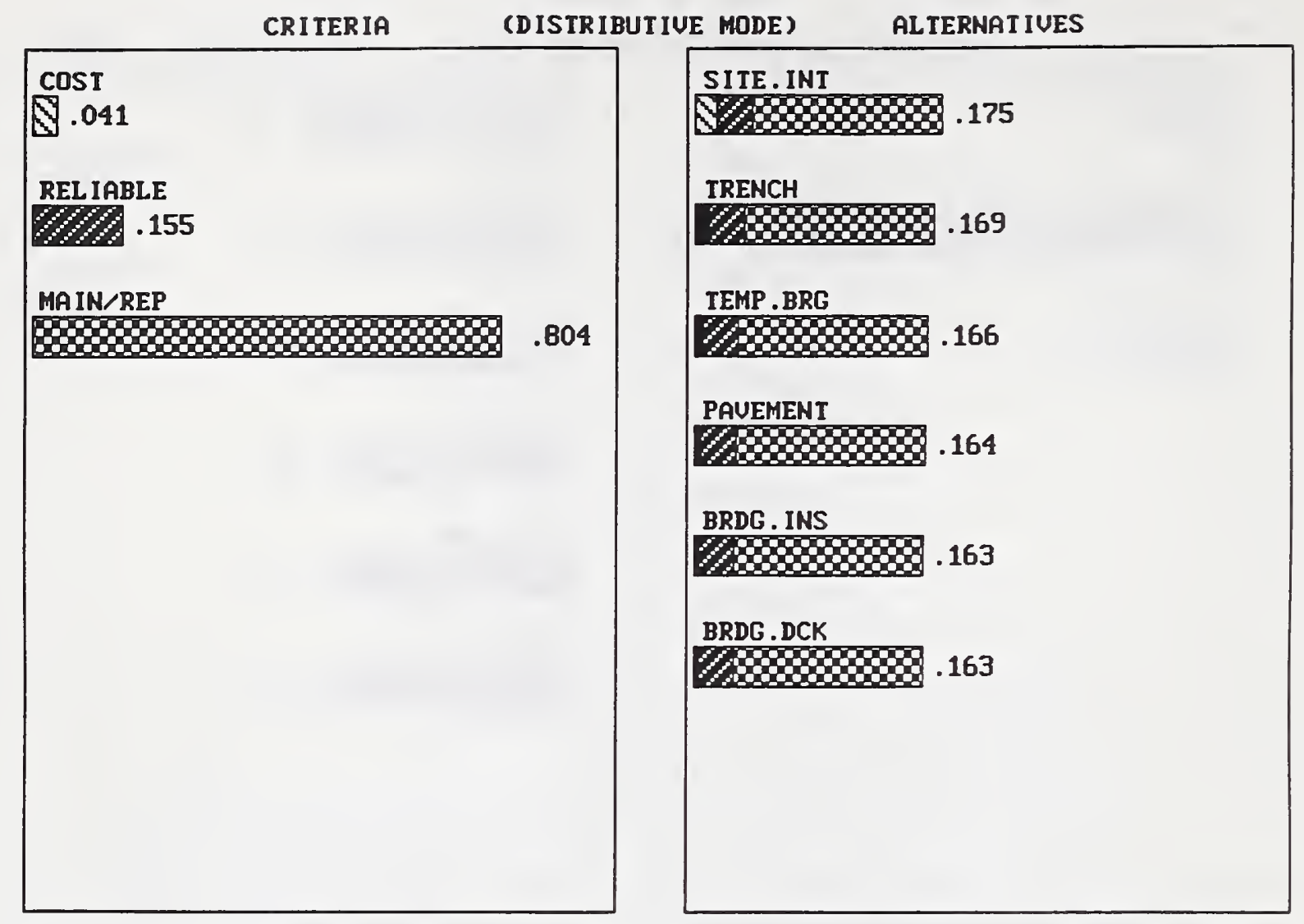

RTI 


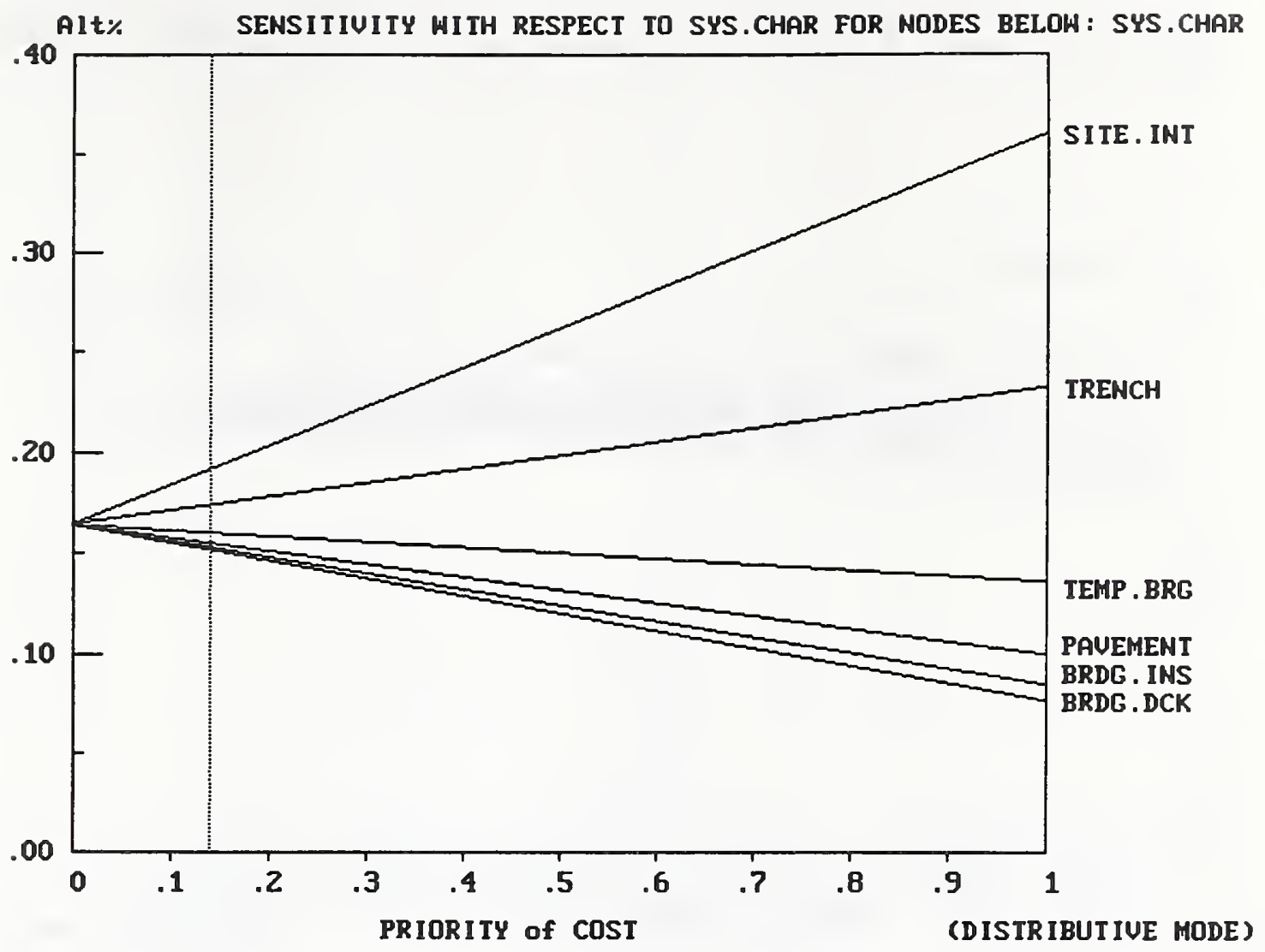

RTI

Figure 63 


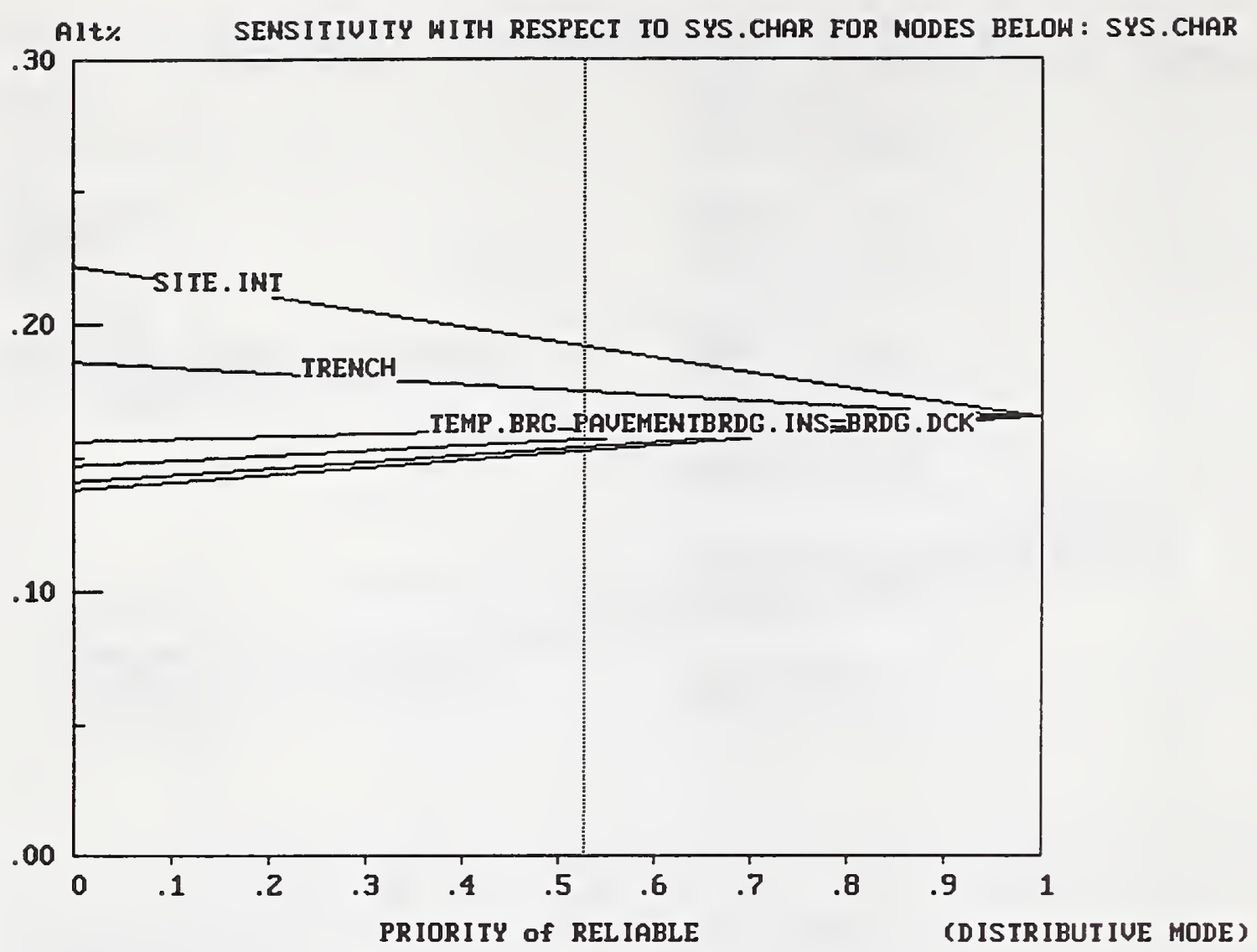

RTI 


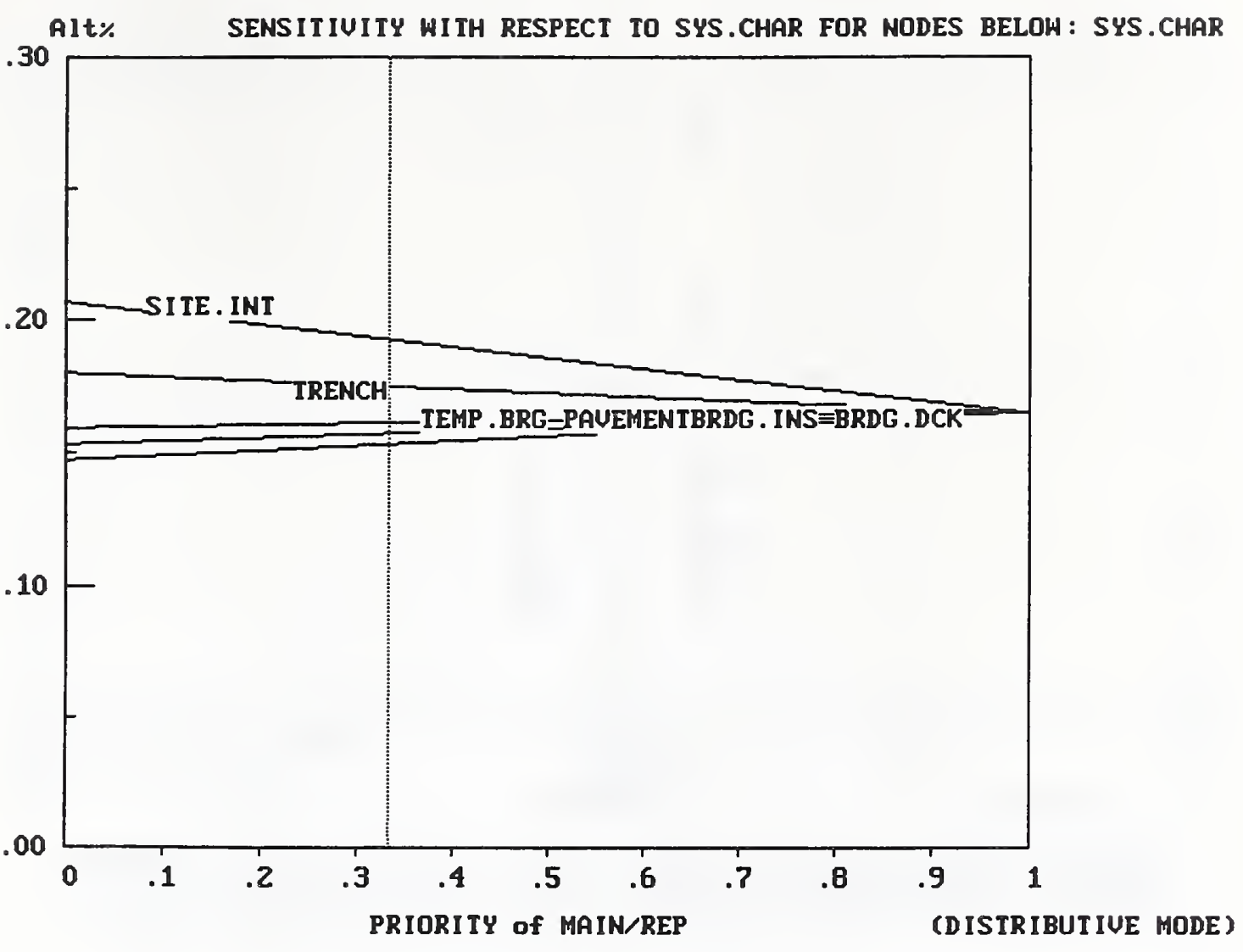

RTI

Figure 65 


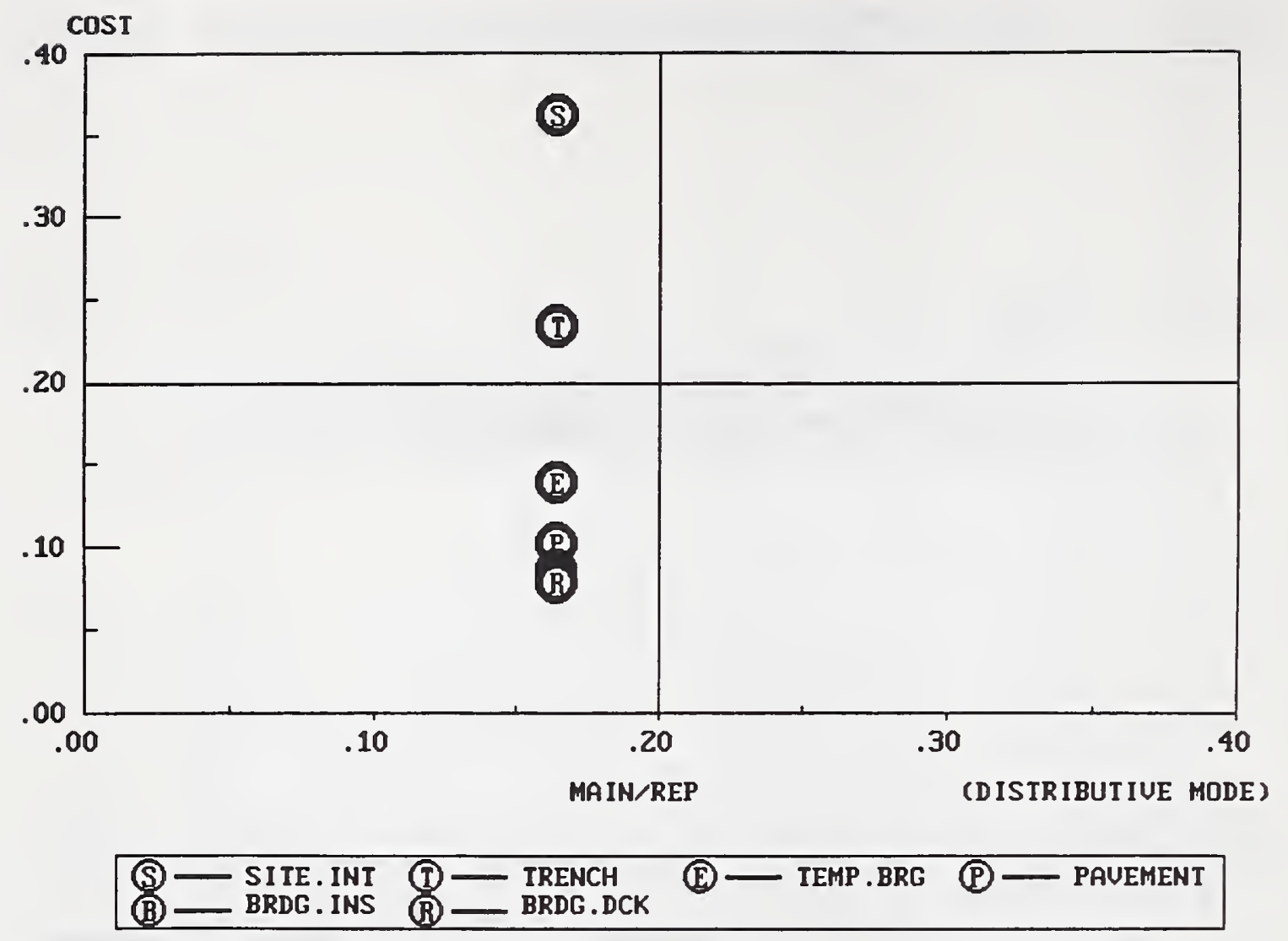

RTI

Figure 66 


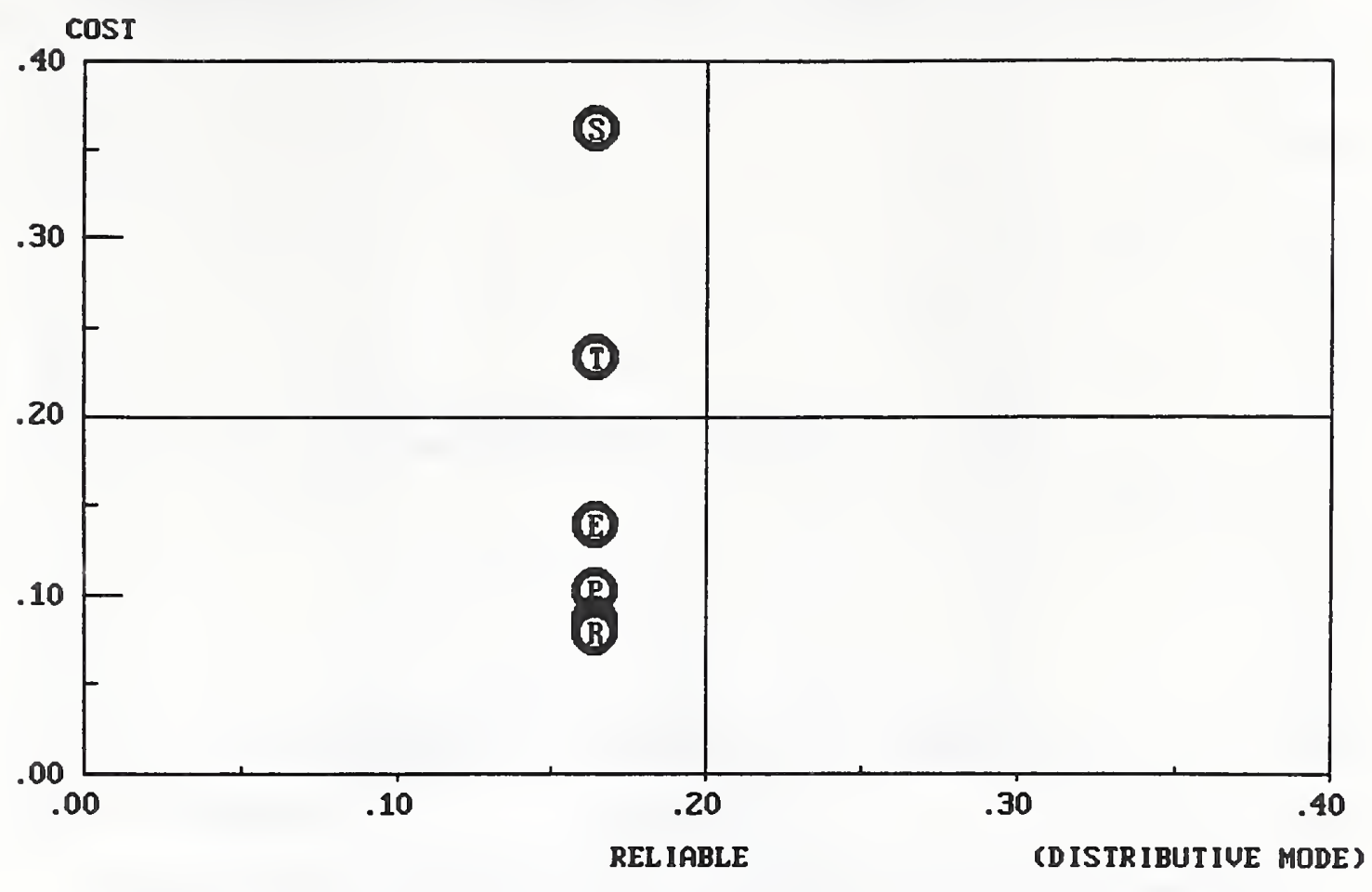

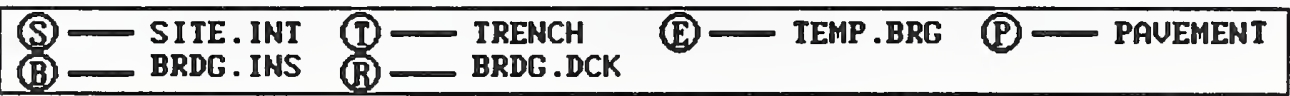


Crit\%PERFORMANCE WITH RESPECT TO SYS.CHAR FDR NODES BELOH: SYS.CHARAIt\%

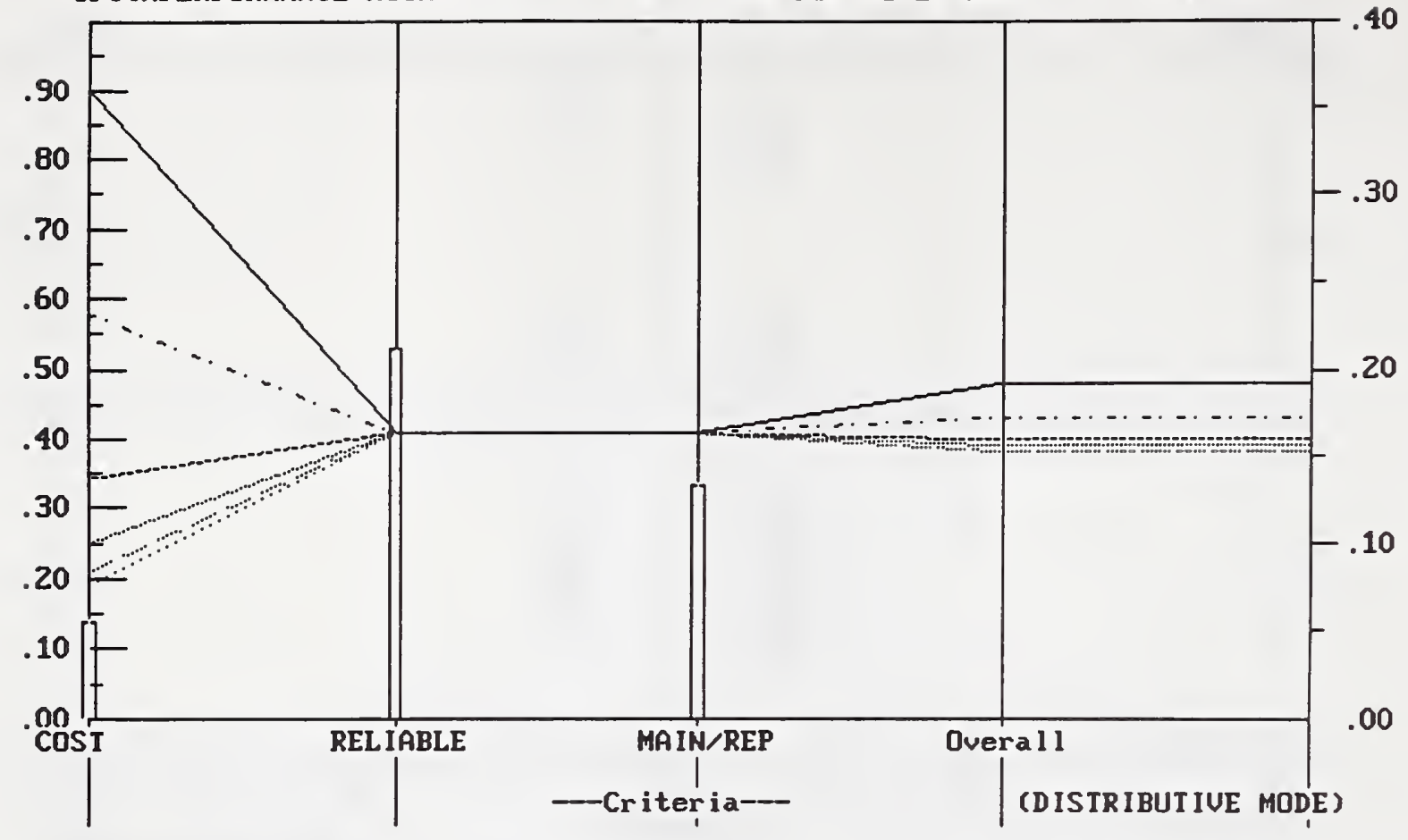




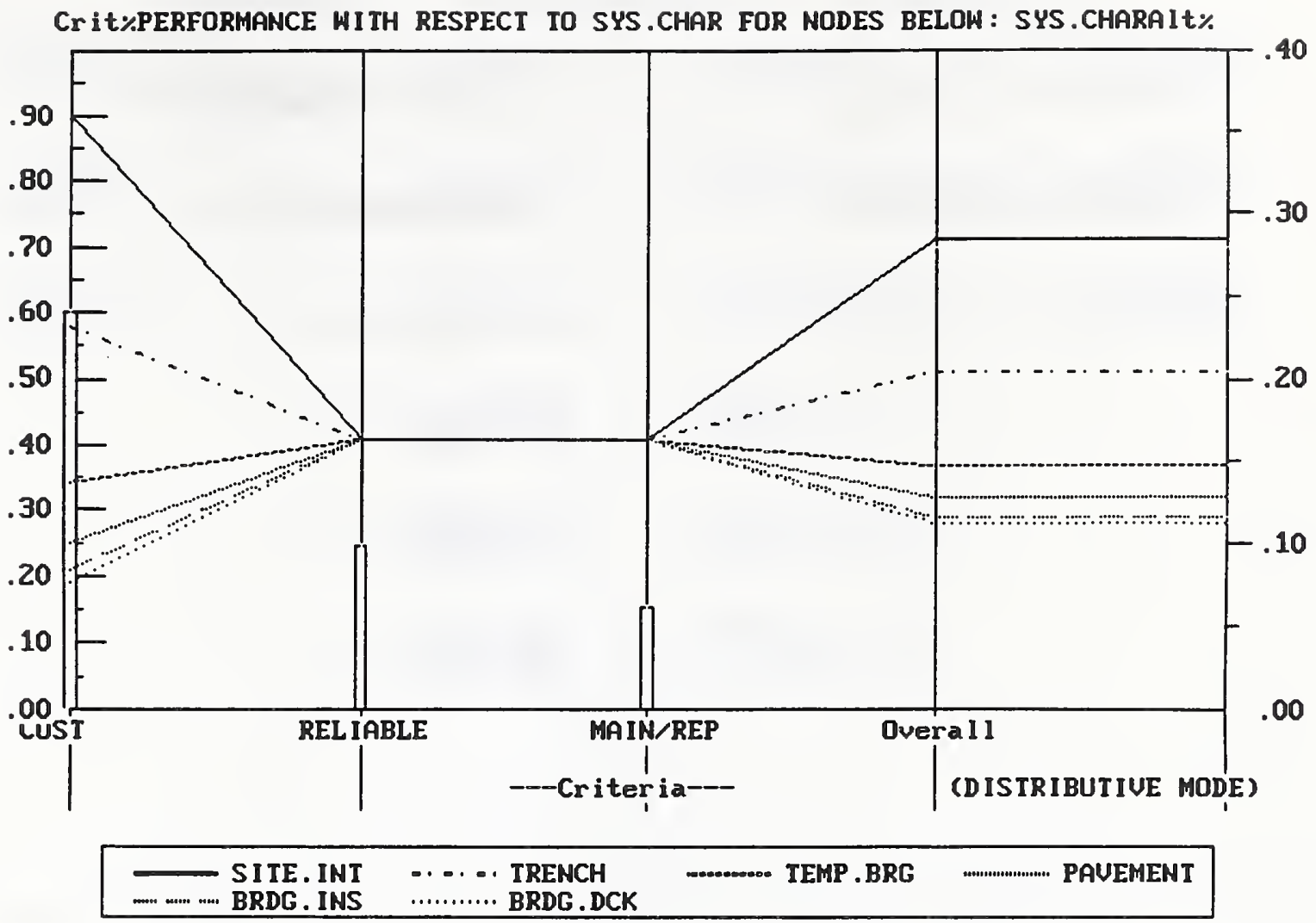

RTI 


\begin{tabular}{|c|c|}
\hline CRITER IA & (DISTRIBUTIUE MODE) \\
\hline 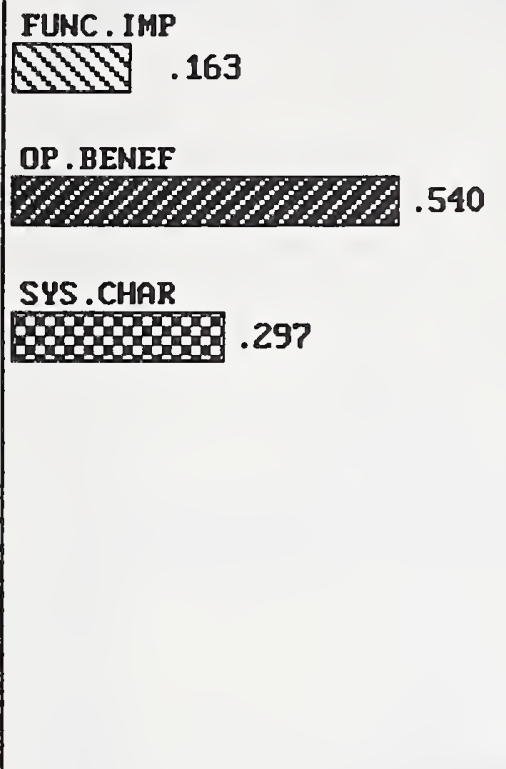 & 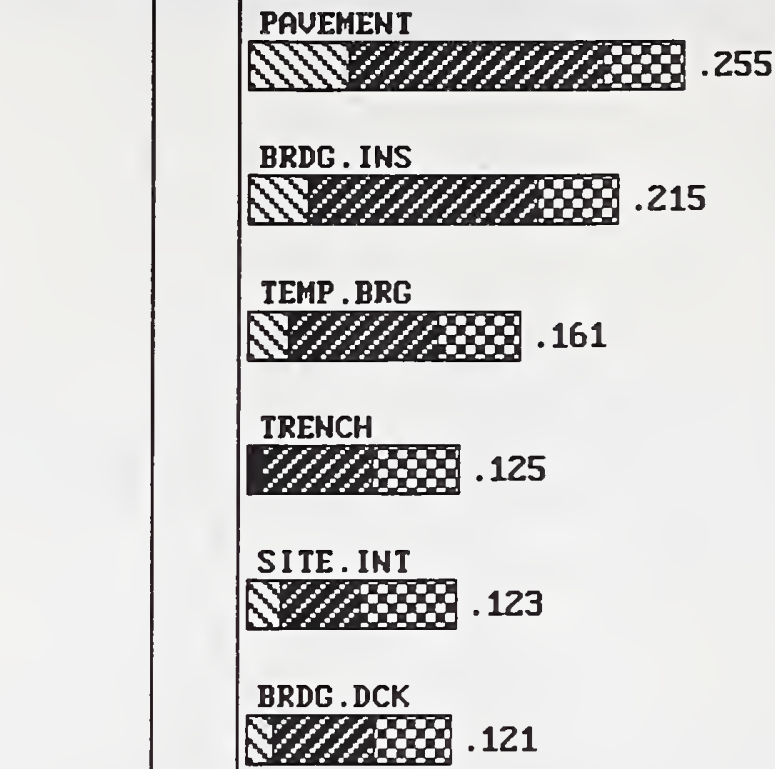 \\
\hline
\end{tabular}

RTI

Figure 70 


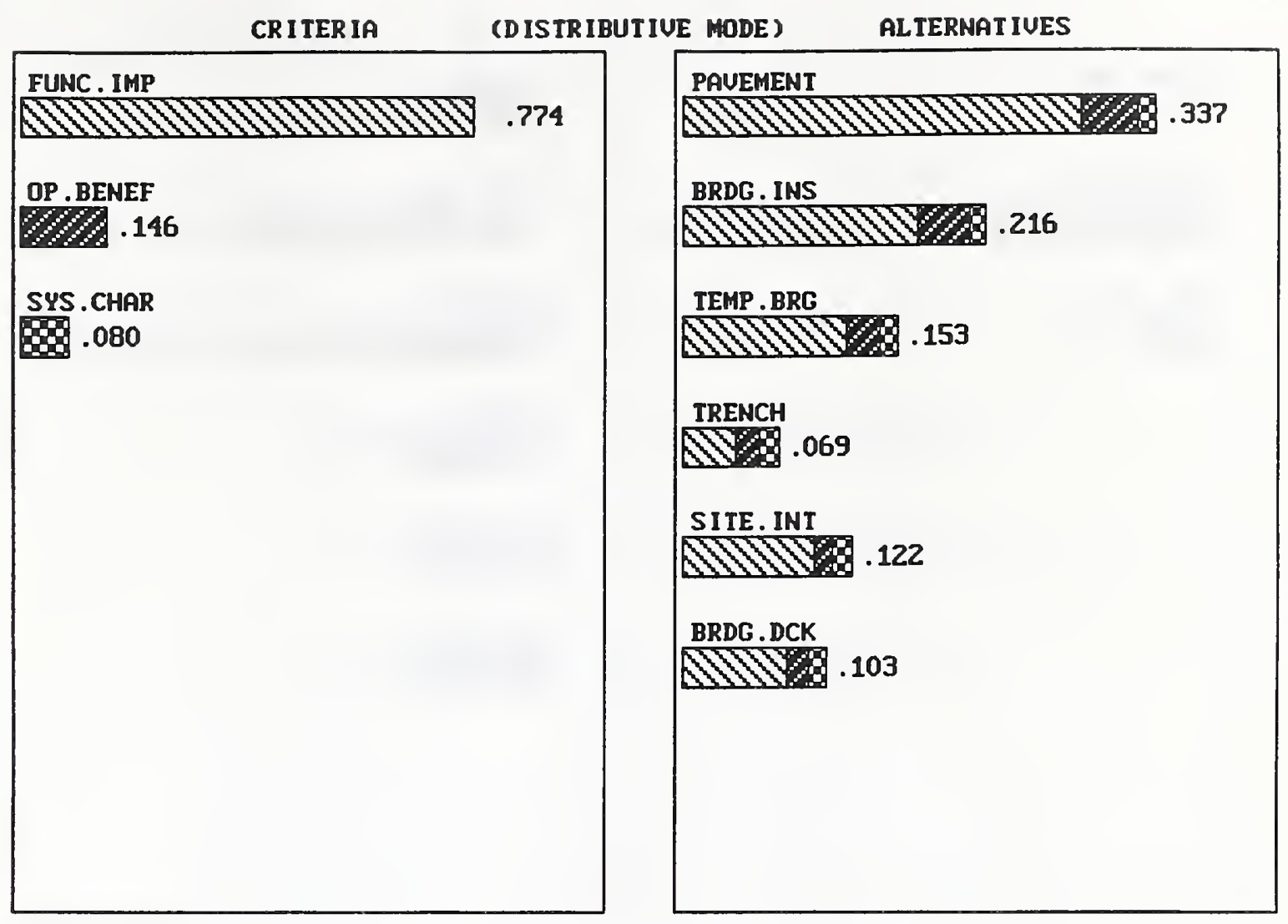


FUNC. IMP

W. .068

DP . BENEF

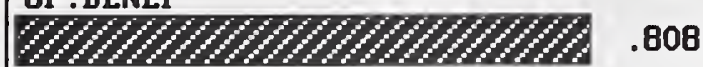

SYS. CHAR

Bg8g. 124

\section{PAUEMENT}

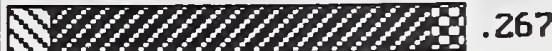

BRDG. INS

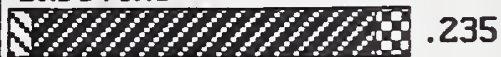

TEMP . BRG

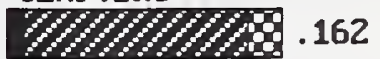

TRENCH

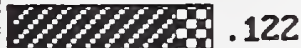

SITE. INT

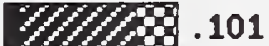

BRDG . DCK

P2PYPA . 114

RTI

Figure 72 


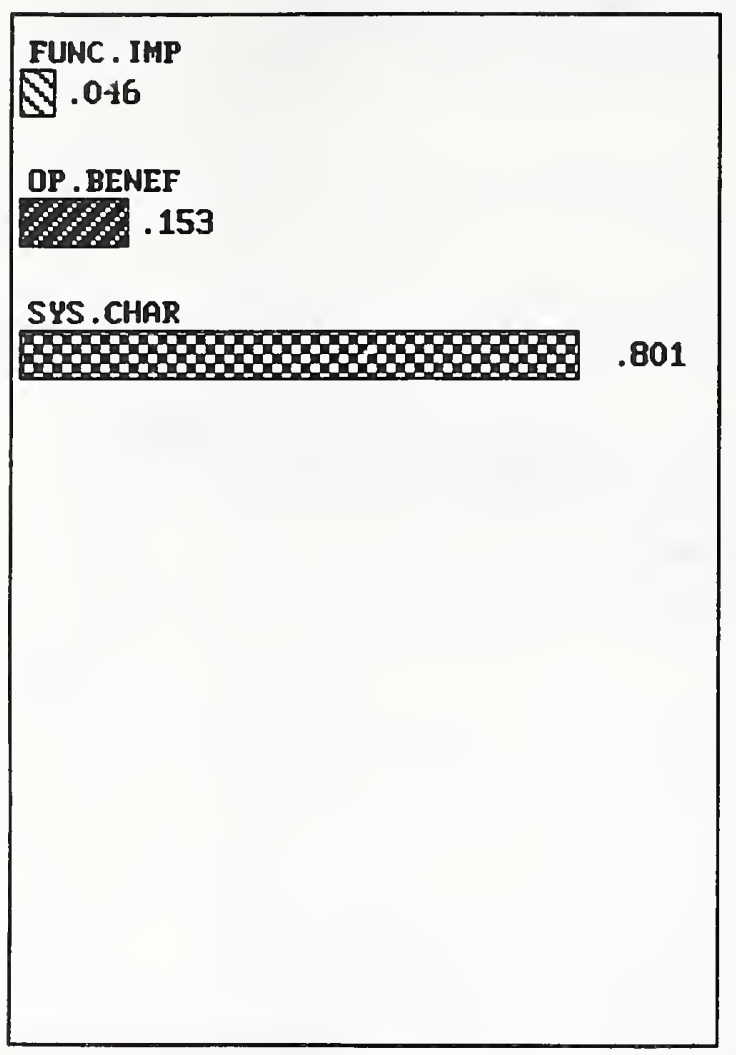

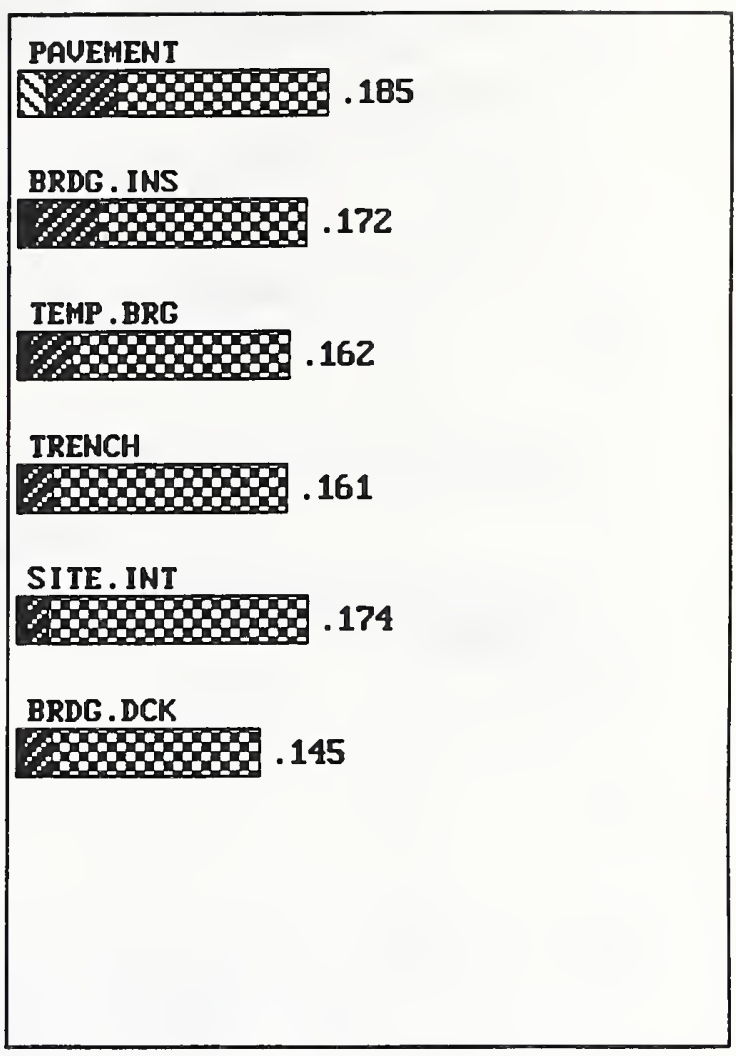




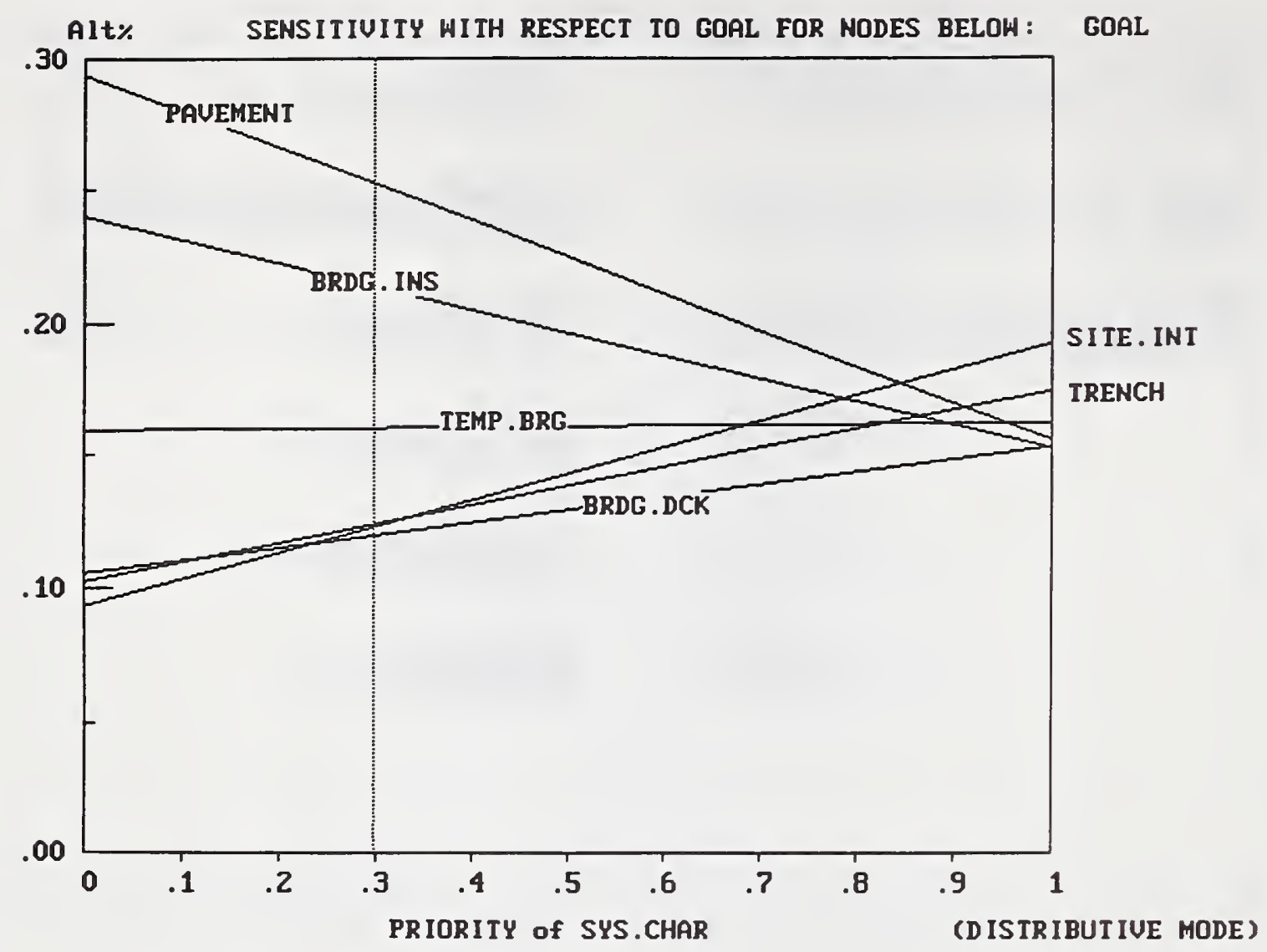

RTI 


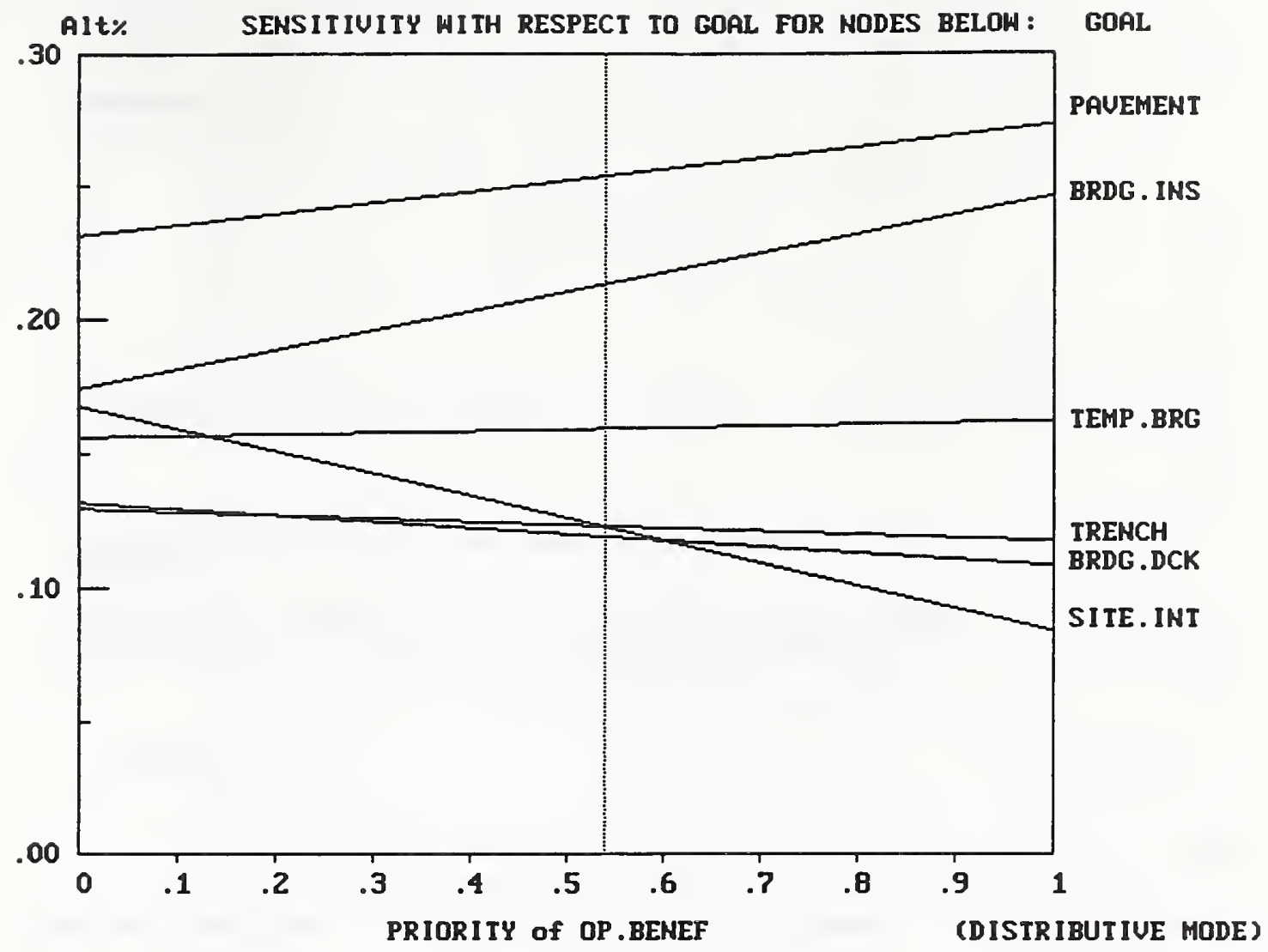

RTI 


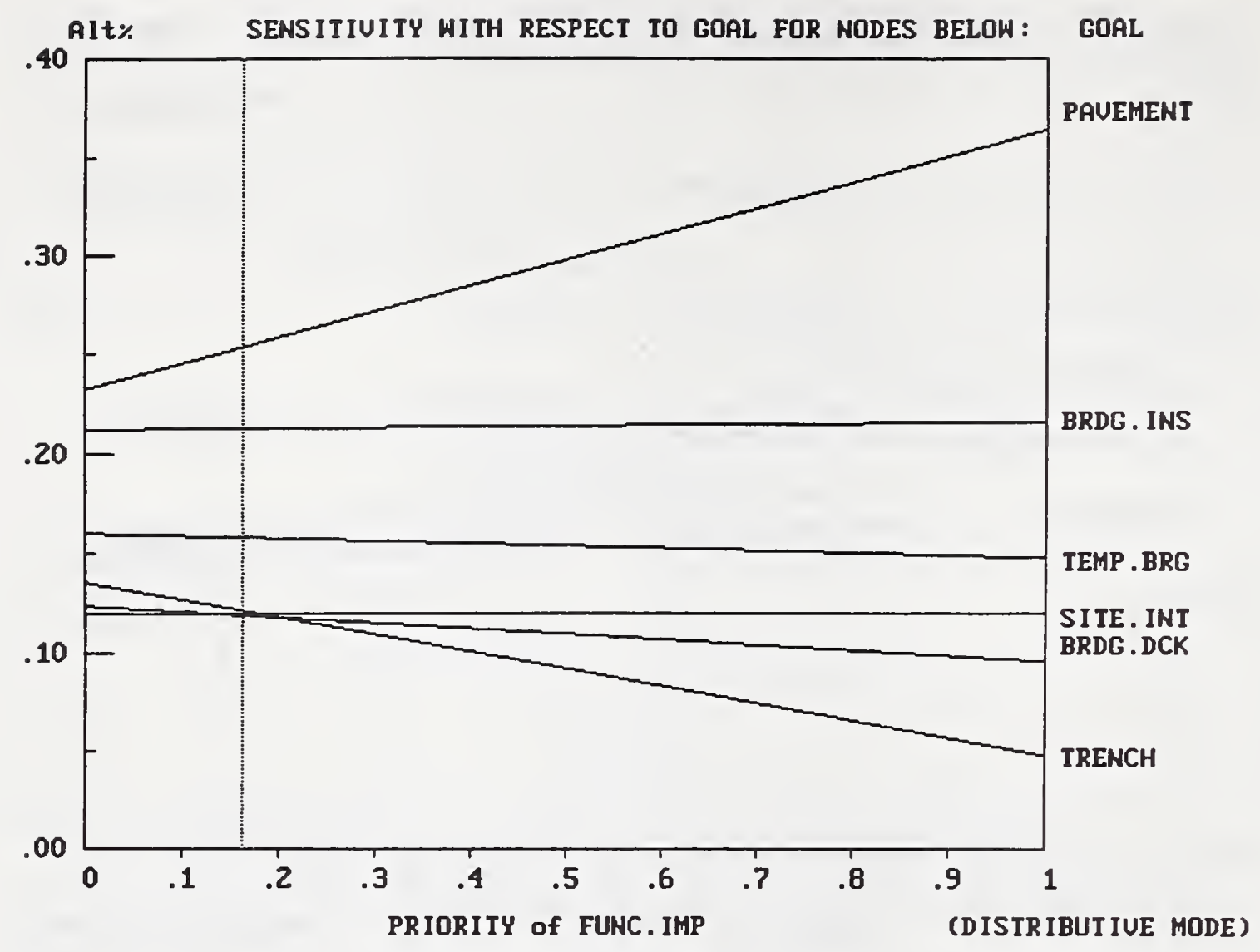

RTI

Figure 76 


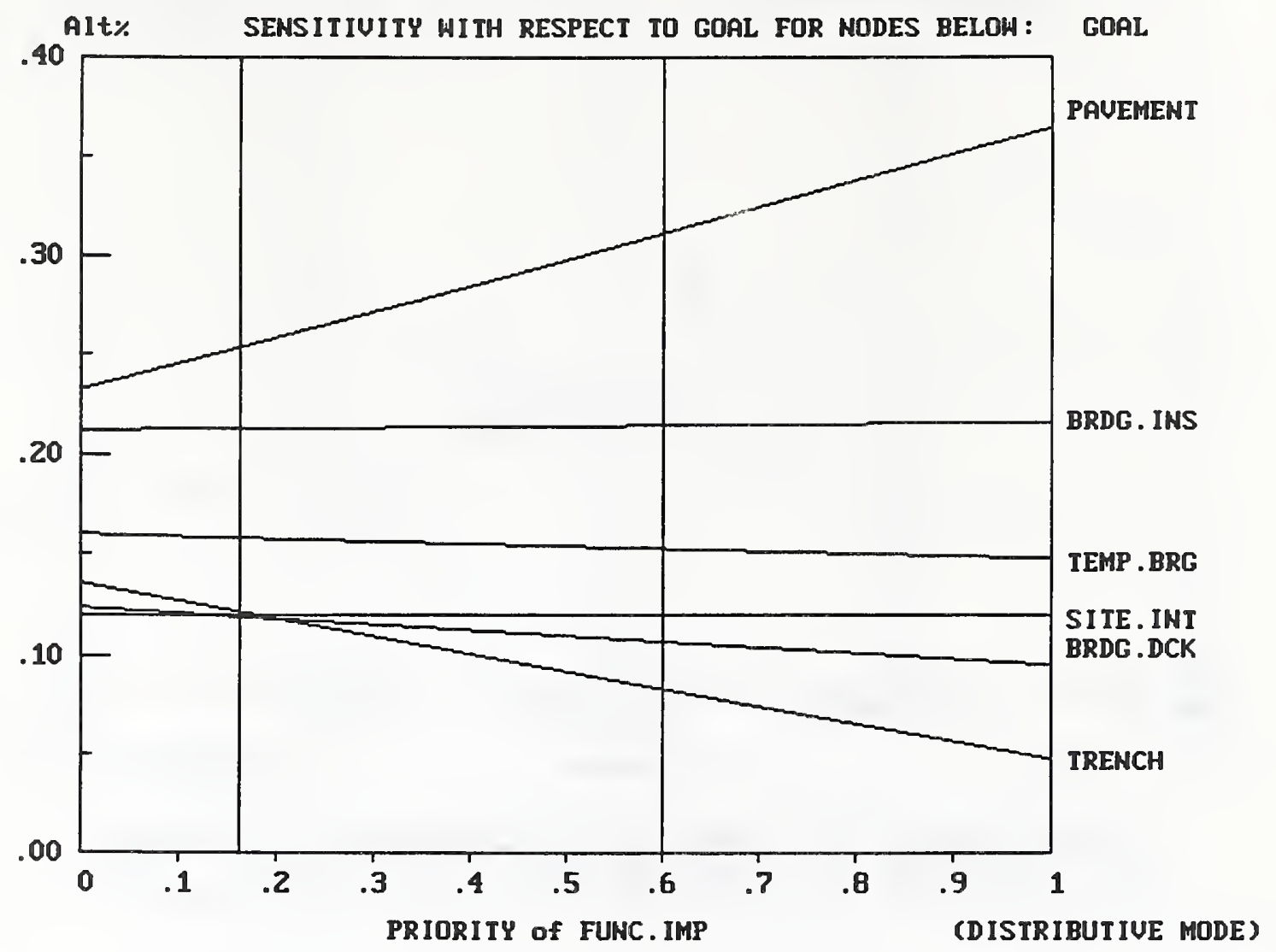

RTI

Figure 77 


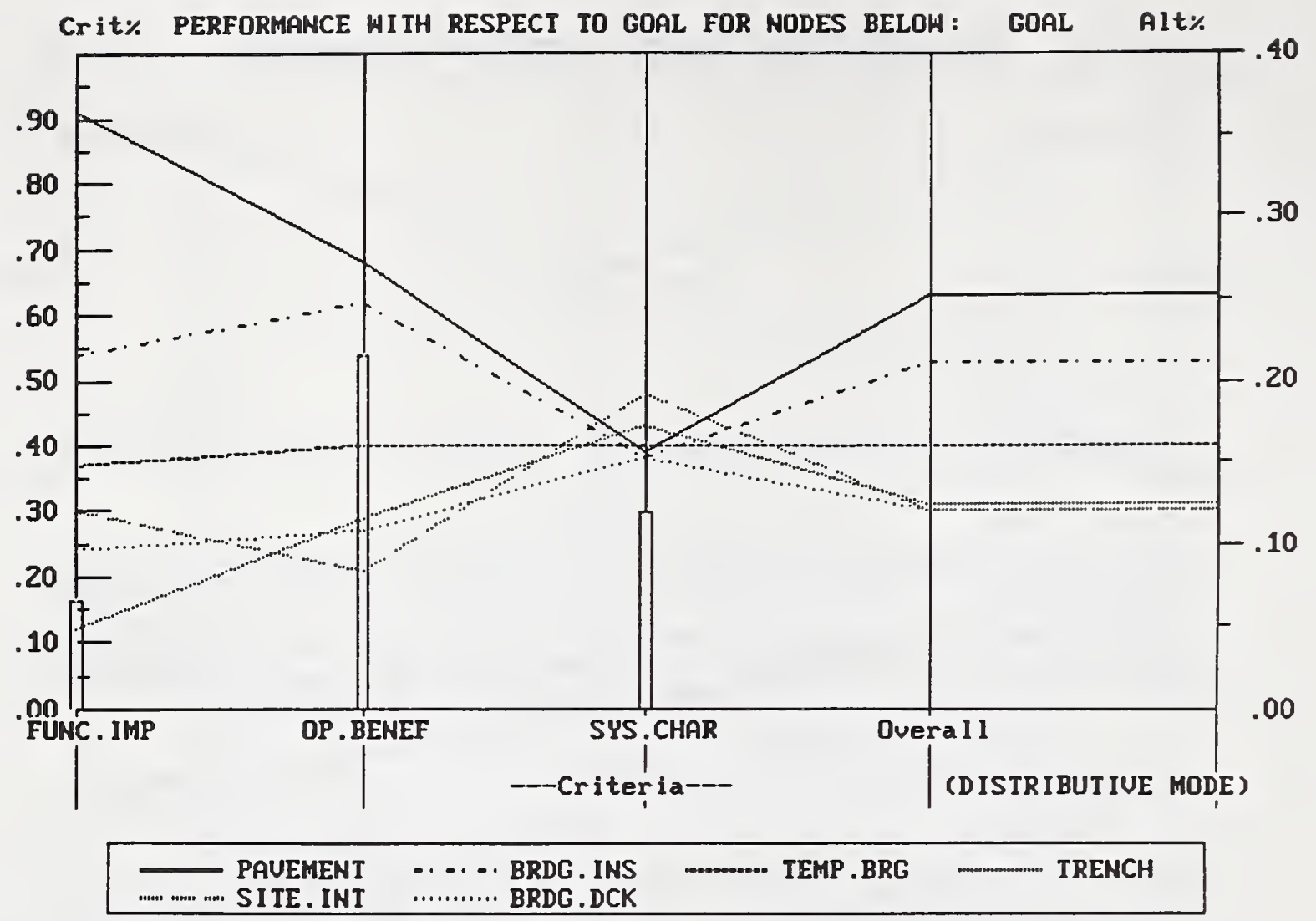

RTI 


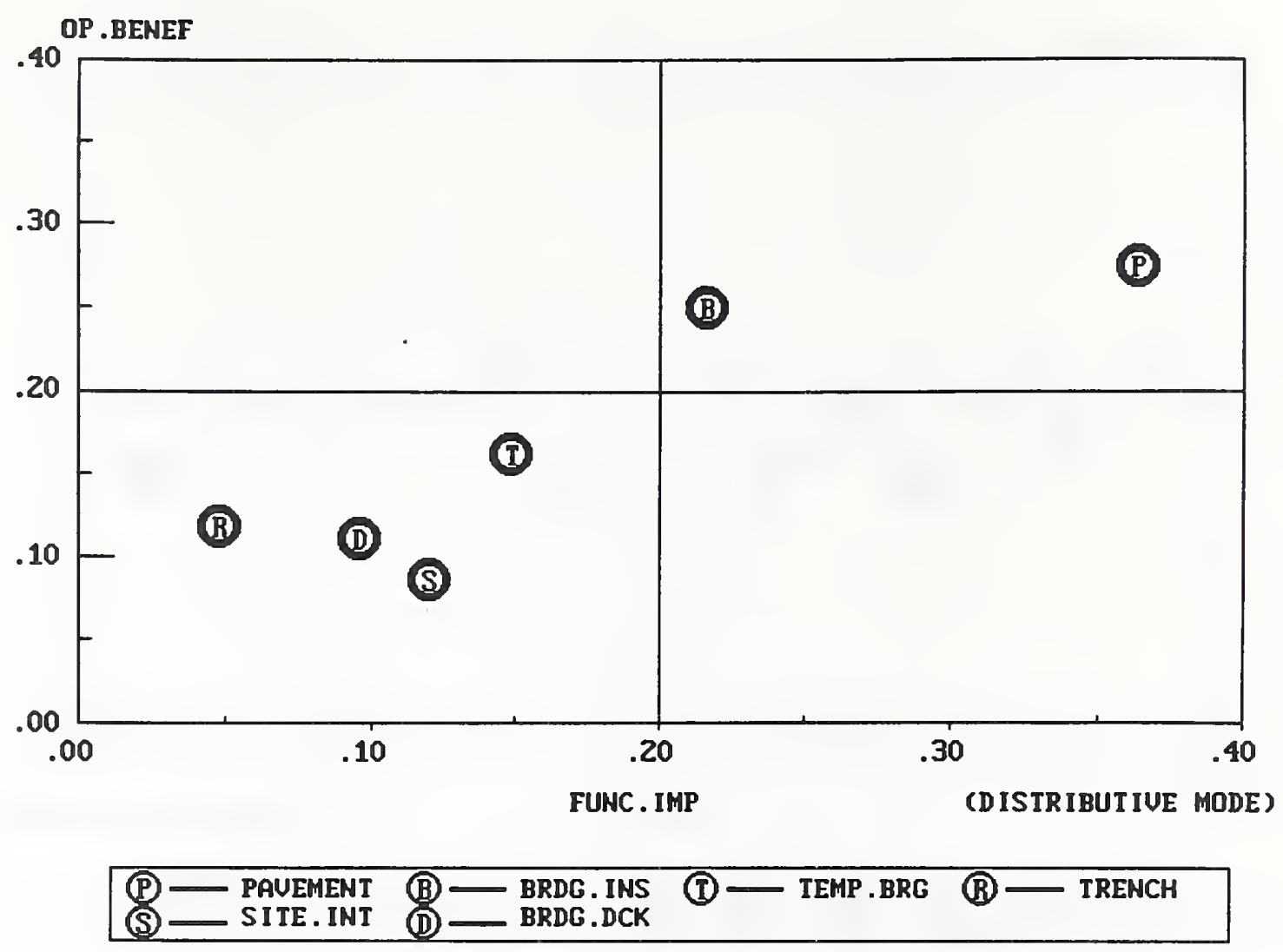

RTI

Figure 79 


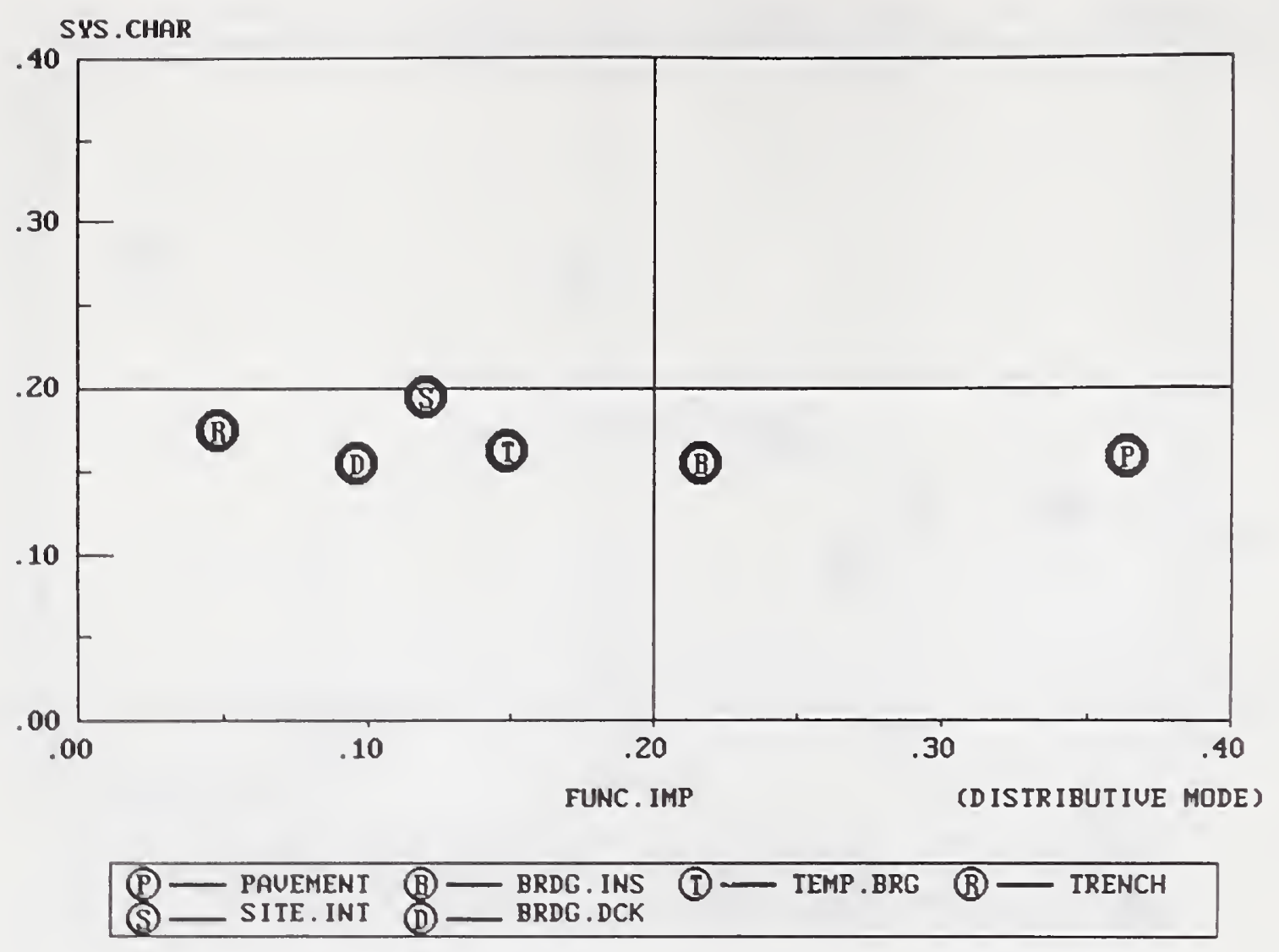

RTI 


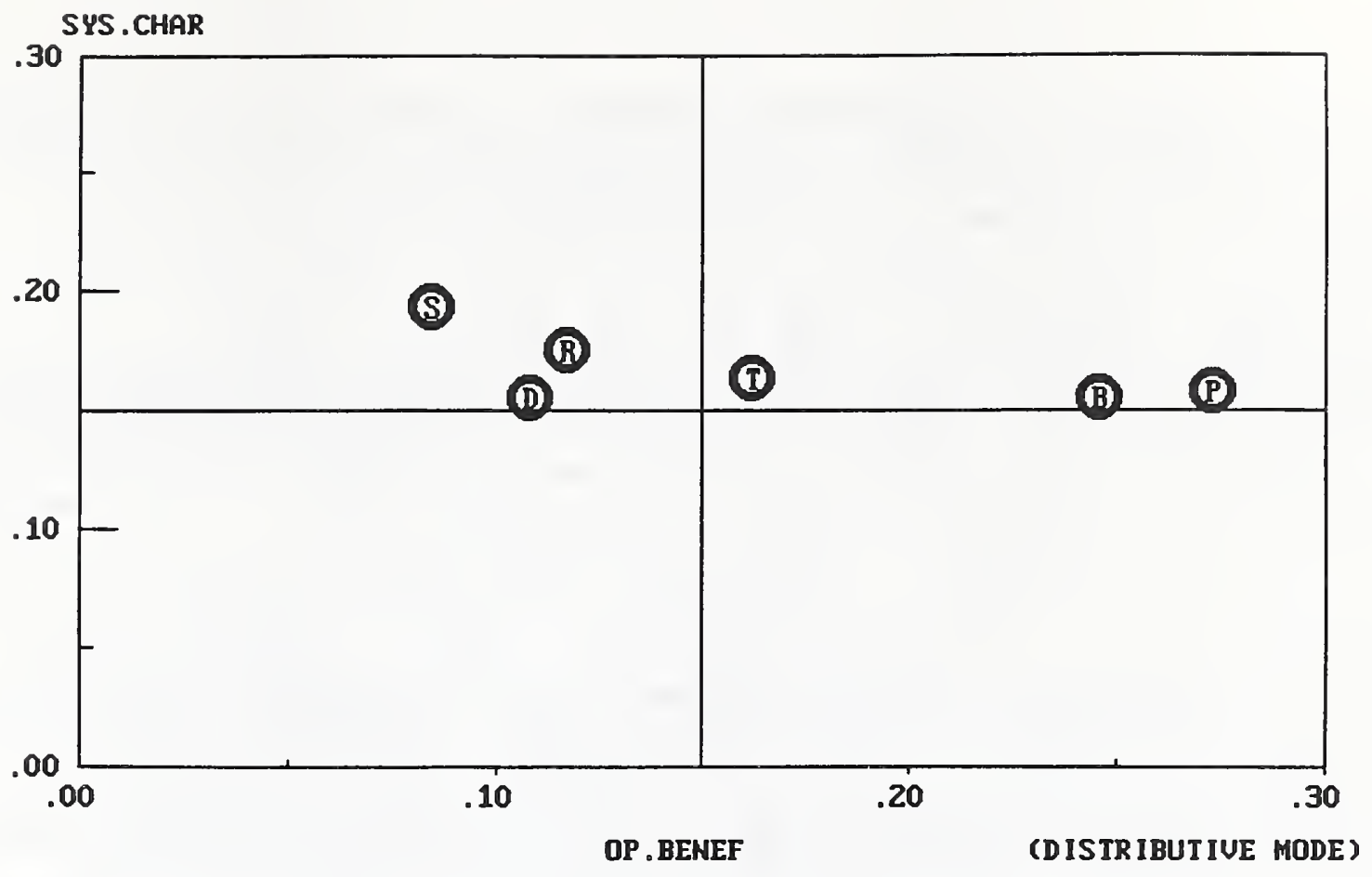

$(\mathrm{P}-$ PAUEMENT
$(\mathrm{S})-$ SITE.INT


for the measure of Functional Importance is fixed at its computed value, while the measure for Economic Impact is allowed to vary (the vertical line at 0.318 shows its computed value). By sliding the vertical line across the ECON.IMP axis, one can easily see how the values (weights) for the systems, and their priority ranking (with respect to the submeasures under

consideration) vary. In the case of Figure 42 , the site integration system increases in value with increasing importance of economic impact, while everything else (except for the trench system) declines. Figure 77 shows where the vertical line, representing the value of Func. Imp, was moved from its calculated value of 0.163 to a value of 0.6 to see the affect on the system priorities: there is no affect in this case.

A third way to investigate sensitivity is with a performance analysis graph, as shown in Figure 43. The two measures under consideration are shown as thin vertical bar graphs, with their values read from the left vertical scale. The scores for the systems are shown by the variously constructed lines across the graph (with the key for the lines representing the systems located below the graph). The system values are read from right vertical scale. The overall scores for the system are read vertically along the line marked "overall." The analyst can vary the values of the measures by varying the heights of the vertical MoM bars, and the system curves will vary accordingly. For example, the value for Cost, given in Figure 68 as 0.140 , was increased in Figure 69 to 0.600 . This caused a significant spread in the values of the systems in Figure 69, which were previously closely spaced in Figure 68. Site integration becomes a stronger candidate.

The two dimensional plot is a way to show how well the alternatives perform with respect to any two criteria (measures), as illustrated in Figure 44. Plots that tend to go from the upper left to the right indicate key tradeoffs. The key to the plot symbols is located below the graph. There are no key tradeoffs in Figure 44 .

There are sensitivity graphs for all of the cases. Because this is an example, and not the results of an "official" analysis, there is no reason to belabor the graphs, except to peruse them as an example of sensitivity analysis for the analytic hierarchy process. The sensitivity analysis for the final results are illustrated in Figures 70 to 92 . Figure 81 shows the calculated system values against the weighted MoM (which were given in various previous figures, including Figure 40). In Figure 71, the functional importance measure was increased considerably but did not alter the relative ranking of the top three systems. In Figure 72, the operational benefits measure was increased considerably, again not altering the ranking of the top three systems. Increasing the value of systems characteristics measure does alter the outcome: the systems become more equal in value. 


\section{ANALYTIC HIERARCHY PROCESS}

\section{Bibliography}

Accola, W.L., 1992, "An Empirical Investigation of the Effects of a Capital Budgeting Computerized Decision Aid and Cognitive Style Differences on Investment Decisions", University of Kentucky, DAI-A 53/04, p. 1205 .

Aczel J. and C. Alsina, 1987, "Synthesizing Judgments: a Functional Equations Approach," Mathematical Modelling 9/3-5, 311-320.

Aczel J. and C. Alsina, 1986, "On Synthesis of Judgments", Socio-Economic Planning Sciences 20/6, pp. 333-339.

Aczel, J. and T.I. Saaty, 1983, "Procedures for Synthesizing Ratio Judgments," Journal of Mathematical Psychology 27, 93-102.

Al-Awadi, M.A., 1989, "The Use of the Analytical Hierarchy Process in Conflict Analysis: Application to the Iraq-Iran War" , The George Washington University, DAI-A 50/05, p. 1360.

Al-Tassan, A.M., 1987, "An Analytic and Evaluation Study of Government Employee Housing Programs in Saudi A rabia: Using the Analytic Hierarchy Process", The University of Michigan, DAI-A 47/10, p. 3591.

Alexander, J.M., 1989, "An Analysis of Conflict in Northern Ireland", in: B.L. Golden, E.A. Wasil and P.T. Harker (eds), The Analytic Hierarchy Process, Springer-Verlag, New York, 225-241.

Alexander, J. and T.L. Saaty, 1977, "Stability Analysis of the Forward-Backward Process", Behavioral Science 22, 375-392.

Alexander, J.M., 1982, "Priorities and Preferences in Northern Ireland: An Update", Proceedings of the 10th IMACS World Congress on System Simulation and Scientific Computation, Montreal, Canada, 308-310.

Alexander, J. and T.L. Saaty, 1977, "The Forward and Backward Process of Conflict Analysis", Behavioral Science 22, 87-98.

Amin, H.A., 1985, "Evaluating the Appropriateness of Microcomputers for Litigation Document Management Using the Analytic Hierarchy Process", The George Washington University, DAI-A 45/10, p. 3018 .

Anderson, D.R., D.J. Sweeney and T.A. Williams (eds.), 1992, "The Analytic Hierarchy Process", in: ch. 18, Quantitative Methods for 
Business (5th Ed.), West Publishing, 763-775.

Apostolou, B.A. and J.M. Hassell, 1993, "An Empirical Examination of the Sensitivity of the Analytic Hierarchy Process to

Departures from Recommended Consistency Ratios", Mathematical and Computer Modelling 17/4-5, 163-170.

Apostolou, B.A., 1989, "An Investigation of Internal Auditor Judgment on the Importance of Indicators of Potential financial Fraud: An Analytic Hierarchy Process Approach", DAI-A 49/12, 3779 .

Arbel, A. and A. Seidmann, 1982, "Selecting an FMS: A Decision Framework", Department of Industrial Engineering, Tel-Aviv University, Israel.

Arbel, A. and A. Seidmann, 1985, "Designing a Multimicro Distributed Accounting Information System", Human systems Management (Netherlands) 5/4, 283-91.

Arbel, A., 1989, "Approximate Articulation of Preference and Priority Derivation," European Journal of Operational Research $43 / 3,317-326$.

Arbel, A. and A. Seidmann, 1984, "Performance Evaluation of Flexible Manufacturing Systems", IEEE Transactions on Systems, Man and Cybernetics SMC/14/4, 606-617.

Arbel, A., 1991, "A Linear Programming Approach for Processing Approximation Articulation of Preference", Collection: Multiple Criteria Decision Support (Helsinki, 1989), 79-86.

Arbel, A. and A. Seidmann, 1984, "Selecting a Microcomputer for Process Control and Data Acquisition", IIE Transactions 16/1, 7380 .

Arbel, A. and Y. Shypira, 1986, "A Decision Framework for Evaluating Vacuum Pumping Technology", J. Vac. Sci. Technol., A $4(2), 230-236$

Arbel, A., 1993, "A Weighted-Gradient Approach to Multiobjective Linear Programming Problems Using the Analytic Hierarchy Process", Mathematical and Computer Modelling 17/4-5, 27-40.

Arbel, A., T.L. Saaty and L.G. Vargas, 1987, "Nuclear Balance and the Parity Index: The Role of Intangibles in Decisions," IEEE Transactions in systems, Man and Cybernetics, September.

Arbel, A., J.R. Payne and R.M. Tong, 1981, "Decision Aids Derived from HARPOON/TOMAHAWK Targeting Considerations", Advanced Information and Decision Systems, Mountain View, CA. 
Arbel, A. and S.S. Oren, 1986, "Generating Search Directions in Multiobjective Linear Programming Using the Analytic Hierarchy Process", Socio-Economic Planning Sciences 20/6, 369-373.

Arbel, A., 1983, "A University Budget Problem: A Priority Based Approach", Socio-Economic Planning Sciences 17/4, 181-189.

Arbel, A. and Y.E. Orgler, 1990, "An Application of the AHP to Bank Strategic Planning: The Mergers and Acquisitions Process", European Journal of Operational Research 48/1, 27-37.

Arbel, A., 1987, "Venturing Into New Technological Markets," Mathematical Modelling 9/3-5, 293-298.

Armacost, R.L., J.C. Hosseini and R.G. Javalgi, 1990, "Using the Analytic Hierarchy Process for Small Business Decision Making", Akron Business \& Economic Review 21/1, 75-89.

Arrington, C.E., W. Hillison and R.E. Jensen, 1984, "An Application of Analytical Hierarchy Process to Model Expert Judgments on Analytical Review Procedures", Journal of Accounting Research 22/1, 298-312.

Arrington, C.E., R.E. Jensen and M. Tokutani, 1982, "Scaling of Corporate Multivariate Performance criteria: subjective Composition Versus the Analytic Hierarchy Process", Journal of Accounting and Public Policy 1/2, 95-123.

Aupetit, B. and C. Genest, 1993, "On Some Useful Properties of the Perron Eigenvalue of a Positive Reciprocal Matrix in the Context of the Analytic Hierarchy Process", European J. of Operational Research 67 , in press.

Austin, J.S., R.N. Braswell, J. Ostrominski and C.R. White, 1983, "Productivity Measurement: An Analytic Approach", Leadership and Management Development Center, Maxwell AFB, AL.

Avenhaus, R., 1981, "Game Theoretic Analysis of Inventory Verification", Mathematical and Statistical Methods in Nuclear Safeguards, Lectures from Joint Research Centre, Ispra (Italy), 317.

Aziz, I.J., 1990, "Analytic Hierarchy Process in the Benefit Cost Framework: A Post-evaluation of the Trans-Sumatra Highway Project", European Journal of Operational Research, 48/1, 38-48.

Baas, S.J., and Kwakernaak, H., 1977, "Rating and Ranking of Multi-aspect Alternatives Using Fuzzy Sets," Automatica 13, 47-58.

Badiru, A.B., B.L. Foote and J. Chetupuzha, 1991, "A Multiattribute spreadsheet Model for Manufacturing Technology 
Justification", Computers and Industrial Engineering 21/1-4, 2933.

Baesh, S. and C. Grady, 1991, "1980 Elections", section 7.2 in: T.L. Saaty and L.G. Vargas, Prediction, Projection and Forecasting, Kluwer Academic Publishers.

Bagchi, P.K., 1989, "Carrier Selection", Logistics \& Transportation Review 25/1, 63-73.

Bagranoff, N.A., 1989, "Using an Analytic Hierarchy Approach to Design Internal Control Systems", Journal of Auditing and EDP, $37-41$.

Bahmani, N., D. Yamoah, P. Basseer and F. Rezvani, 1987, "Using the Analytical Hierarchy Process to Select Investment in a Heterogeneous Environment", Mathematical Modelling 8, 157-162.

Bahmani, N. and H. Blumberg, 1987, "Consumer Preference and Reactive Adaptation to Corporate Solution of the OTC Medication Dilemma", Mathematical Modelling 9/3-5, 293-298.

Bahmani, N., G. Javalgi and H. Blumberg, 1986, "An Application of the Analytic Hierarchy Process for a Consumer Choice Problem," Marketing Science 9, 402-406.

Bahouth, S.B., 1993, "Expert Choice - Version 8 of DecisionMaking Software is Easier to Learn", Software review, OR/MS Today, June, 62-65.

Baldauf, S. and S. Kulkki, 1983, "International Divestments as the Reallocation Process of Productive Assets - A Managerial Approach", 9th Annual Conference of the European International Business Association (EIBA), Norweigian School of Management, Oslo.

Banai-Kashani, A.R., 1987, "Dominance and Dependence in Input-Output Analysis", Mathematical Modelling, 9/3-5, 377-380.

Banai-Kashani, R., 1988, "Discrete Mode-Choice Analysis of Urban Travel Demand by the AHP", Reprints of the International Symposium on The Analytic Hierarchy Process, pp. 445-452, Tianjin University, Tianjin, China, Sept. 6-9.

Banai-Kashani, A.., 1983, "Multidimensional Scaling in Simulation of Location: an Analytic Hierarchy Systems Approach", DAI-A $44 / 03,888$.

Banai-Kashani, A.R., 1988, "Probabilistic Dimension of the AHP Approach to Input-output Analysis: A Note", Reprints of the International Symposium on The Analytic Hierarchy Process, pp. 442-444, Tianjin University, Tianjin, China, Sept. 6-9. 
Banai-Kashani, A.R., 1984, "The Padagogical and Practical Use of a New Paradigm for Planning", Association of Collegiate Schools of Planning 26th Annual Conference, New York.

Banai-Kashani, A.R., 1988, "Toward a Synthetic Measure of Good Settlement Form", Environment and Planning B: Planning and Design $15 / 4,399-412$.

Barbeau, E., 1986, "Perron's Result and a Decision on Admissions Tests", Mathematics Magazine 59/1, 12-22.

Barbeau, E., 1987, "Reciprocal Matrices of Order 4", Mathematical Modelling 9/3-5, 321-326.

Bard, J.F., 1992, "A Comparison of the Analytic Hierarchy Process with Multiattribute Utility Theory: A Case Study", IIE

Transactions 24/5, 111-121.

Bard, J.F. and S.F. Sousk, 1990, "A Tradeoff Analysis for Rough Terrain Cargo Handlers Using the AHP: ...", IEEE Transactions on Engineering Management 37/3, 222-228.

Bard, J.F., 1986, "A Multiobjective Methodology for selecting Subsystem Automation Options", Management Science 32/12, 16281641 .

Bard, J.F., 1985, "User's Manual for AHP (The Analytic Hierarchy Process)", Austin: University of Texas, Department of Mechanical Engineering.

Barnthouse, L.W., D.L. DeAngelis, R.H. Gardner, R.B. O'Neill and C.D. Powers, 1982, "Methodology for Environmental Risk Analysis", Oak Ridge National Lab., TN, Department of Energy Report \# ORNL/TM-8167.

Bartoszynski, R. and M.L. Puri, 1981, "A Note on Predicting the Results of Chess Championship Matches", Behavioral Science 26/1, 85-87.

Barzilai, J., et al, 1986, "Axiomatic Foundations for the Analytic Hierarchy Process", Working paper No. 44, School of Business Administration, Halhousie University, Halifax, Canada.

Barzilai, J., W.D. Cook and B. Golany, 1987, "Consistent Weights for Judgments Matrices of the Relative Importance of

Alternatives", Operations Research Letters 6/3, 131-134.

Barzilai, J. and B. Golany, 1991, "An Axiomatic Framework for Aggregating Weights and Weight-Ratio Matrices", Proceedings of the 2nd International Symposium on The Analytic Hierarchy Process, Pittsburgh, PA, 59-70. 
Barzilai, J., et al, 1986, "The Analytic Hierarchy Process: Structure of the Problem and its Solutions", Working paper No. 45, School of Business Administration, Halhousie University, Halifax, Canada.

Basak, I., 1990, "Testing for the Rank ordering of the Priorities of the Alternatives in Saaty's Ratio-Scale Method", European J. of Operational Research 48/1, 148-152.

Basak, I., 1988, "When to Combine Group Judgments and When Not to in the Analytical Hierarchy Process: A New Method", Mathematical and Computer Modelling 10/6, 395-404.

Basak, I., 1993, "Incorporating Within-Pair Order Effects in the Analytic Hierarchy Process", Mathematical and Computer Modelling $17 / 4-5,83-92$.

Basak, I., 1991, "Inference in Pairwise Comparison Experiments Based on Ratio Scales", Proceedings of the 2nd International Symposium on The Analytic Hierarchy Process, Pittsburgh, PA, 173184 .

Basak, I. and T.L. Saaty, 1993, "Group Decision Making Using the Analytic Hierarchy Process", Mathematical and Computer Modelling $17 / 4-5,101-110$.

Basak, I., 1991, "Inference in Pairwise Comparison Experiments Based on Ratio Scales", Journal of Mathematical Psychology 35, 80-91.

Batty, S.E., 1982, "Book Review: The Analytic Hierarchy Process", Environment and Planning A 14/7, 986-987.

Baumann, J.L., 1990, "A Mixed Input Decision Model for Hierarchically Decomposable Complex Problems", DAI-B 50/07, 3089.

Beaumariage, T.G., 1991, "A Decision Model for Cognitive Task Allocation", DAI-B 51/07, 3517.

Belton, V. and T. Gear, 1984, "On a Shortcoming of Saaty's Method of Analytic Hierarchies", Omega 11, 228-230.

Belton, V., 1986, "A Comparison of the Analytic Hierarchy Process and a Simple Multi-Attribute Value Function", European Journal of Operational Research 26/1, 7-21.

Belton, V. and A.E. Gear, 1986, "Assessing weights by means of pairwise", VII-th International Conference on Multiple Criteria Decision Making, August 18-22, Kyoto, Japan

Benjamin, C.O., I.C. Ehie and Y. Omurtag, 1992, "Planning Facilities at the University of Missouri-Rolla", Interfaces 22/4, 
95-105.

Bennett, J.P. and T.L. Saaty, 1993, "Knapsack Allocation of Multiple Resources in Benefit-Cost Analysis by Way of the Analytic Hierarchy Process", Mathematical and Computer Modelling $17 / 4-5,55-72$.

Bernhard, R.H. and J.R. Canada, 1990, "Some Problems in Using Benefit/Cost Ratios with the Analytic Hierarchy Process", Engineering Economist 36/1, 56-65.

Blair, A.R., R. Nachtmann, J.E. Olson and T.L. Saaty, 1987, "Forecasting Foreign Exchange Rates: An Expert Judgment Approach", Socio-Economic Planning Sciences 21/6, 363-369.

Blankmeyer, E., 1987, "Approaches to Consistency Adjustment", Journal of Optimization Theory and Applications 54, 479-489.

Bombay Metropolitan Region Development Authority, 1985, "Regional Investment Plan for Bombay Metropolitan Region - 1985-86 to 198990 "'

Booker, J.M., M.C. Bryson and T.P. MCWilliams, 1984, "Decision Analysis Package for R\&D Project Selection and Evaluation", Los Alamos National Laboratory, Los Alamos, NM.

Borthick, A.F., 1982, "Selection of Computers for Small Accounting Systems: An Interactive Multi-Criteria Approach", The University of Tennessee, DAI-A 43/06, 2009.

Bosch, J.M. and K. Von Gadow, 1990, "Regulating Afforestation for Water Conservation in South Africa", South African Forestry Journal 0/153, 41-54.

Boucher, T.O. and E.L. McStravic, 1991, "Multi-Attribute Evaluation Within A Present Value Framework and its Relation to the Analytic Hierarchy Process", The Engineering Economist 37/1, 55-71.

Bowen, W.M., 1990, "The Nuclear Site Selection Decision - A Comparison of Two Decision-Aiding Models", DAI-A 51/05, 1725.

Boyer R. and D. Savageau, 1985, "Places Rated Almanac", Rand McNally, Chicago.

Brice, H. and T. Wegner, 1989, "A Quantitative Approach to Corporate Social Responsibility Programme Formulation", Managerial \& Decision Economics 10/2, 163-171.

Bridges, P.D. and V.C. Pelletier, 1991, "Planning the Future of the Social Security system in the United States: an Example in control", Ch. 11 in: Prediction, Projection and Forecasting, 
Kluwer Academic Publishers.

Brown, K.W., 1993, "Key Indicators of a College's conditions and Performance", Accounting Enquiries: to appear, Canisius college, Buffalo, NY.

Brown, K.W., 1993, "Key Trend Indicators Determined Through the Analytic Hierarchy Process", Working paper, Southwest Missouri state.

Buckley, J.J., 1985, "Fuzzy Hierarchial Analysis", Fuzzy Sets and Systems $17,233-247$.

Buckley, J.J., 1984, "The Multiple Judge, Multiple Criteria Ranking Problem: A Fuzzy set Approach II", Fuzzy sets and systems $13 / 2$, 107-124.

Buckley, J.J., 1984, "The Multiple Judge, Multiple criteria Ranking Problem: A Fuzzy Set Approach I", Fuzzy Sets and systems $13 / 1,25-37$.

Budescu, D.V., 1984, "Scaling Binary Comparison Matrices: A Comment on Narashimhan's Proposal and other Methods", Fuzzy sets and Systems 14, 187-192.

Budescu, D.V., R. Zwick and A. Rapoport, 1986, "A Comparison of the Eigenvalue Method \& and the Geometric Mean Procedure for Ratio Scaling," Applied Psychology Measurement 10/1, 69-78.

Caldwell, J.L., 1991, "Parallel Benefit/Cost Models for Improving Accessibility for Persons with Disabilities", Proceedings of the 2nd International Symposium on The Analytic Hierarchy Process, Pittsburgh, PA, 463-474.

Calhoun, K.J., 1989, "Automated Objectivity for Subjective Business Decisions", Information Strategy: The Executive's Journal 6/1, 21-25.

Calhoun, K.J., 1989, "Automated Objectivity for Subjective Hiring Decisions", Computers in Personnel, Winter, 5-10.

Cambron, K.E. and G.W. Evans, 1991, "Layout Design Using the Analytical Hierarchy Process", Computers \& IE 20/2, 221-229.

Canada, J.R., E.H. Frazelle, R.K. Koger and E. MacCormac, 1985, "How to Make a Career Choice: The Use of the Analytic Hierarchy Process", Industrial Management 27/5, 16-22.

Carriere, J. and M. Finster, 1992, "Statistical Theory for the Ratio Model of Paired Comparisons", Journal of Mathematical Psychology 36, 450-460. 
Castellano-Bohorquez, A.A., 1985, "Application of Analytical Methods to Institutional Research Findings", The Florida state University, DAI-A 45/11, p. 3460 .

Chan, Y.L. and B.E. Lynn, forthcoming, "Performance Evaluation and the Analytic Hierarchy Process", The Journal of Management Accounting Research, 1-50.

Chen, S.C., E.F. Pu and Z.Y. Zhou, 1988, "Structure of Decision Maker from the Evaluation Viewpoints of a Decision Making Software", Reprints of the International Symposium on The Analytic Hierarchy Process, pp. 620-625, Tianjin University, Tianjin, China, sept. 6-9.

Chen, B., G. Liu and Q. Chai, 1988, "The Revision of the Judgment Matrix", Reprints of the International Symposium on The Analytic Hierarchy Process, pp. 91-97, Tianjin University, Tianjin, China, sept. 6-9.

Cheng, M., 1988, "Modification of Developing Economic Forecast by AHP", Reprints of the International Symposium on The Analytic Hierarchy Process, pp. 232-236, Tianjin University, Tianjin, China, sept. 6-9.

Cheng, S.T., L.Z. Wen and W.Q. Fan, 1989, "AHP and Research of the Strategic objective system" Decision \& The Analytic Hierarchy Process (China) 1, 21-29.

Chou, Y.C., 1992, "An Intelligent Decision Support System for Naval Ship Design", DAI-B 53/01, 539.

Chu, A.T.W., and Kalaba, R.E., 1979, "A Comparison of Two Methods for Determining the Weights Belonging to Fuzzy Sets," Journal of Optimization Theory and Applications 27/4, 531-538.

Chui, S., 1988, "A Method to Solve Multiple Objective Decision Making with the Analytic Hierarchy Process", Reprints of the International Symposium on The Analytic Hierarchy Process, pp. 110-114, Tianjin University, Tianjin, China, Sept. 6-9.

Clayton, W.A., M.W. Dailey and W.W. Snodgrass, 1993, "Benefit Cost Analysis of Riverboat Gambling", Mathematical and Computer Modelling 17/4-5, 187-194.

Cogger, K.O. and P.L. Yu, 1983, "Eigen Weight Vectors and Least Distance Approximation for Revealed Preference in Pairwise Weight Ratios", School of Business, University of Kansas, Laurence, Kansas.

Cook, C.R., 1986, "Expert support systems for Competitive Procurement", Telematics $3 / 4,273-288$. 
Cook, D.R., S. Staschak and W.T. Green, 1990, "Equitable Allocation of Livers for Orthotopic Transplantation: An

Application of the Analytic Hierarchy Process", European Journal of Operational Research $48 / 1,49-56$.

cook, P.A. and R.D. Walmsley, 1990, "Evaluation of a Computer Model for the Selection of Candidate Species for Aquaculture", Southern African Journal of Aquatic Sciences 16/1-2, 90-100.

Cook, T., P. Falchi, and R. Mariano, 1984, "An Urban Allocation Model Combining Time Series and Analytic Hierarchy Methods", Management Science $30 / 2,198-208$.

Cosenze, T., 1989, "Analyzing the Priorities of JIT Activities", DAI-A 49/08, 2301 .

Coulter, H.B., 1991, "A Multiple Attribute Decision Theoretic Approach to a Two-class Discrimination Problem", DAI-B, 52/05, 2756.

Cousens, D.W.H., 1986, "Strategic Management: The Formulation of objectives and Priorities with the Aid of the Analytic Hierarchy Process," Unpublished MBL Dissertation, School of Business

Leadership, University of South Africa, Pretoria, South Africa.

Crawford, G. B., 1987, "The Geometric Mean Procedure for

Estimating the Scale of a Judgment Matrix", Mathematical

Modelling $9 / 3-5,327-334$.

Crawford, G.B. and C. Williams, 1985, "A Note on the Analysis of Subjective Judgment Matrices", Journal of Mathematical Psychology $29,387-405$.

Crawford, D., 1984, "Software support for the Intuitive Thinker", Wall street Computer Review 2/1, 53-58.

Crosbie, L.P. and J.H. Kravitz, 1991, "Horse Racing", section 10.4 in: T.I. Saaty and L.G. Vargas, Prediction, Projection and Forecasting, Kluwer Academic Publishers.

Curry, B. and L. Moutinho, 1992, "Environmental Issues in Tourism Management: ...", International Journal of Service Industry Management 3/1, 57-69.

Dadkhah, K.M., and Zahedi, F., 1993, "A Mathematical Treatment of Inconsistency in the Analytic Hierarchy Process", Mathematical and Computer Modelling 17/4-5, 111-122.

Dalal, M. and R. Thammaneewong, 1989, "Business School Ranking (by Analytic Hierarchy Decision Process", Proceedings of the International Conference on Multiple Criteria Decision Making: Applications in Industry and Service, Asian Institute of 
Technology, Bangkok, 849-864.

Datta, V., K.V. Sambasivarao, R. Kodali and S.G. Deshmukh, 1992, "Multi-Attribute Decision Model Using the Analytic Hierarchy Process for the Justification of Manufacturing Systems", International Journal of Production Economics 28/2, 227-234.

Davidson, D., 1986, "Decision Support System for Database Management System Selection", School of Engineering, Air Force Inst. of Technology, Pub. No. AD-A179 339/7/HCW, 76pp.

Davies, LG., 1988, "Senior Managerial Perceptions of the Foreign Direct Investment Decision", DAI-A 49/01, 109.

De Jong, P., 1984, "A Statistical Approach to Saaty's Scaling Method for Priorities", Journal of Mathematical Psychology 28/4, 467-478.

De Graan, J.G. 1980, "Extensions of the Multiple Criteria Analysis Method of T.L. Saaty", Technical Report M.F.A. 80-3, National Institute for Water Supply, Leidshcendam, the Netherlands, presented at EURO IV, Cambridge, July 22-25.

Debeljak, C.J., Y.Y. Haimes and M. Leach, 1986, "Integration of the surrogate worth trade-off method and the analytic hierarchy process", Socio-Economic Planning Sciences 20/6, 375-385.

Deland, D., M.R. Holloway and M. Ohlrich, 1982, "Evaluating Plant Locations by Analytic Hierarchy Process", Proceedings - 14th Annual Meeting of the American Institute for Decision Sciences, San Francisco, CA.

Dennis, S.Y., 1985, "A Probabilistic Model for Analyzing Hierarchically Structured Multi-Criterion Decision Problems", paper presented in the Joint National Meeting ORSA/TIMS, Boston, April 29-May 1.

Dennis, S.Y., 1985, "A Probabilistic Approach to Priority Assignment in Hierarchically structured Decision Problems", University of Florida, DAI-A 45/09, p. 2916.

Dennis, S.Y., 1987, "A Probabilistic Model for the Assignment of Priorities in Hierarchically structured Decision Problems," Mathematical Modelling 9/3-5, 335-344.

Dennis, S.Y., 1986, "A Probabilistic Analysis of the Eigenvector Scaling Problem", Working paper.

DeTurck, D.M., 1987, "The Approach to Consistency in the Analytic Hierarchy Process," Mathematical Modelling 9/3-5, 345-352.

Diao, H. and W. Zhou, 1991, "The AHP of Group Multiple Round 
Feedback Judgment", Proceedings of the 2nd International Symposium on The Analytic Hierarchy Process, Pittsburgh, PA, 135148 .

Diao, H. and Y. Diao, 1988, "The Dynamic Analysis of Rail Freight Transport Planning", Reprints of the International symposium on The Analytic Hierarchy Process, pp. 453-460, Tianjin University, Tianjin, China, Sept. 6-9.

DiNardo, G., D. Levy and B. Golden, 1989, "Using Decision Analysis to Manage Maryland's River Herring Fishery: an Application of AHP", Journal of Environmental Management 29, 193213.

Ding, C. and F. Duan, 1988, "The Application of AHP setting up New Using Energy Structural Sort in Rural", Reprints of the International Symposium on The Analytic Hierarchy Process, pp. 518-523, Tianjin University, Tianjin, China, Sept. 6-9.

Dobias, A.P., 1990, "Designing a Mousetrap Using the Analytic Hierarchy Process and Expert Choice", European Journal of Operational Research 48/1, 57-65.

Dolan, J.G., 1987, "Clinical Decision Making Using the Analytic Hierarchy Process: Choice of Antibiotic Treatment for communityAcquired Pyelonephritis", Clinical Research 35/3, 738 .

Dolan, J.G., 1990, "Can Decision Analysis Adequately Represent Clinical Problems?", Journal of Clinical Epidemiology 43/3, 277284 .

Dolan, J.G. and D.R. Bordley, 1991, "Should Concern Over Gastric Cancer Influence the Choice of Diagnostic Tests in Patients with Acute Upper Gastrointestinal Bleeding?", Proceedings of the 2nd International Symposium on The Analytic Hierarchy Process, Pittsburgh, PA, 391-404.

Dolan, J.G., 1989, "Choosing Initial Antibiotic Therapy for Acute Pyelonephritis", in: B.L. Golden, E.A. Wasil and P.T. Harker (eds.), Applications of the Analytical Hierarchy Process, Springer-Verlag, New York, 213-224.

Dolan, J.G. and D.R. Bordley, 1992, "Using the Analytic Hierarchy Process (AHP) to Develop and Disseminate Guidelines", Qualitative Review Bulletin 18/12, 440-447.

Donegan, H.A and F. Dodd, 1991, "A Note on Saaty's Random Indices, Mathematical Computer Modelling 15/10, 135-137.

Donegan, H.A. and T.B. McMaster, 1992, "A New Approach to AHP Decision Making", The Statistician 41/3, 295-302. 
Dongkui, M., 1988, "An Application of the AHP to the study of the Strategy and Game for Development of New Technologies in Ningxia Through the Year 2000", Reprints of the International symposium on The Analytic Hierarchy Process, pp. 366-370, Tianjin

University, Tianjin, China, Sept. 6-9.

Dorani, M.B., 1987, "Benefits and Constraints in Establishing and Maintaining a Multi-country computer and Information Network System for the Gulf Corporation Council's (GCC) Community", The George Washington University DAI-A 48/03, p. 693.

Dorweiler, B.P., 1987, "Legal Case Planning via the Analytic Hierarchy Process," Mathematical Modelling 9/3-5, 251-264.

Doryan-Garron, E., 1989, "Explaining Development Strategy Choice by State Elites", DAI-A 49/10, 3150 .

Dougherty, J.J., 1991, "Volleyball", Section 10.3 in: T.L. Saaty and L.G. Vargas, Prediction, Projection and Forecasting, Kluwer Academic Publishers.

Dougherty, J.J. and T.L. Saaty, 1977, "A Hierarchical Approach to Optimum Determination of Hospital Requirements", in: T.L. Saaty and L.G. Vargas (eds), The Logic of Priorities, Kluwer-Nijhoff, Boston, 165-181.

Driscoll, D.A., W.T. Iin and P.R. Watkins, 1984, "Cost-VolumeProfit Analysis Under Uncertainty: A Synthesis and Framework for Evaluation", Journal of Accounting Literature 3, 85-115.

Dyer, R.F., E.H. Forman and M.A. Mustafa, 1992, "Decision Support for Media Selection Using the Analytic Hierarchy Process", Journal of Advertising 21/1, 59-72.

Dyer, J.S., T.L. Saaty, P.T. Harker and L.G. Vargas, 1990, "Remarks on the Analytic Hierarchy Process: ...", Management Science $36 / 3,249-275$.

Dyer, J.S. and H.V. Ravinder, 1986, "A Rationale for the Decomposition of a Hierarchy of objectives", VII-th International Conference on Multiple Criteria Decision Making, August 18-22, Kyoto, Japan.

Dyer, R.F. and E.H. Forman, 1992, "Group Decision Support with the Analytic Hierarchy Process", Decision Support Systems 8/2, 99-124.

Dyer, J.S. and R.E. Wendell, 1985, "A Critique of the Analytic Hierarchy Process," Working Paper 84/85-4-24, Department of Management, The University of Texas, Austin, TX.

Dyer, R.F., et. al., 1988, "Case studies in Marketing Decisions 
Using Expert Choice", McLean, Decision Support Software.

Ehie, I.C., 1990, "An Integrated Multi-Objective Decision Model for Industry Planning in a Developing Country", DAI-B 50/11, 5190 .

Elsayed, E.A. and T.C. Hsiang, 1985, "The Analytic Hierarchy Process in the Supplier and Product Quality Rating Programs", paper presented at the Joint National Meeting of ORSA/TIMS in Boston, April 30-May 1.

Emshoff, J.R. and T.L. Saaty, 1982, "Applications of the Analytic Hierarchy Process to Long Range Planning Processes", European Journal of Operational Research 10/2, 131-143.

Epstein, B.J. and W.R. King, 1982, "An Experimental study of the Value of Information", Omega 10/3, 249-258.

Erkut, E., and S.R. Moran, 1991, "Locating Obnoxious Facilities in the Public Sector: An Application of the Analytic Hierarchy Process to Municipal Landfill Siting Decisions", Socio-Economic Planning Sciences 25/2, 89-102.

Erkut, E. and M. Tarimcilar, 1991, "On Sensitivity Analysis in the Analytic Hierarchy Process", IMA Journal of Mathematics Applied in Business and Industry $3 / 1,61-83$.

Evered, L.E., 1985, "The Use of Analytic Decision Techniques for the Selection of Elective Mathematics Courses in Secondary Schools", DAI-A 45/10, 3087 .

Expert Choice Software, produced by Expert Choice, Inc., 4922 Ellsworth Avenue, Pittsburgh, PA.

Fan, B., Y. Qian and Y. Gao, 1988, "An AHP Approach to the Assessment of the Comprehensive Capability of the Microelectronic Science and Technology of China in Comparison with other Countries", Reprints of the International symposium on The Analytic Hierarchy Process, pp. 330-337, Tianjin University, Tianjin, China, Sept. 6-9.

Farr, R.C., 1987, "A Comparison of the Analytical Hierarchical Process with Two other Decision Making Methods", Brigham Young University, DAI-A 47/08, p. 3095.

Fatti, L.P., 1989, "Water Research Planning in South Africa", in: B.L. Golden, E.A. Wasil and P.T. Harker (eds), Applications of the Analytic Hierarchy Process, Springer-Verlag, New York, 122137.

Federov, V.V., V.B. Kuz'min and A.I. Vereskov, 1982, "Membership Degrees Determination from Saaty Matrix Totalities", in: M.M. 
Gupta and E. Sanchez (eds.), Approximate Reasoning in Decision Analysis, North Holland, NY, 23-30.

Fedrizzi, M., 1990, "On a Consensus Measure in a Group MCDM Problem", Multiperson Decision Making Models Using Fuzzy Sets and Possibility Theory, 231-241.

Fichtner, J., 1986, "On Deriving Priority Vectors From Matrices of Pairwise Comparisons", Socio-Economic Planning Sciences 20/6, $341-345$.

Fichtner, J., 1983, "Some Thoughts About the Mathematics of the Analytic Hierarchy Process", Hochschule der Bundeswehr, Munich (Germany).

Flanagan, G.F., V.M. Florsberg and V.R.R. Uppuluri, 1984, "R\&D Task Prioritization of Breeder Technology Programs for FY-1985", Martin Marietta Energy Systems, Inc., Oak Ridge, Tennessee.

Flores, B.E., D.L. Olson and C.J. Wolfe, 1992, "Judgmental Adjustment of Forecasts: ...", International Journal of Forecasting $7 / 4,421-433$.

Forman, E.H., 1988, "Integrating AHP and Traditional OR/MS Methodologies", Reprints of the International Symposium on The Analytic Hierarchy Process, pp. 44-61, Tianjin University, Tianjin, China, sept. 6-9.

Forman, E.H. and R. Soyer, 1989, "Applications of the Analytic Hierarchy Process", Proceedings of the International Conference on Multiple Criteria Decision Making: Applications in Industry and Service, Asian Institute of Technology, Bangkok, 833-848.

Forman, E.H., 1993, "Facts and Fictions about the Analytic Hierarchy Process", Mathematical and Computer Modelling 17/4-5, 19-26.

Forman, E.H., 1990, "Random Indices for Incomplete Pairwise Comparison Matrices", European Journal of Operational Research $48 / 1,153-155$.

Forman, E.H., 1985, "Decision Support for Executive Decision Makers", Information Strategy: The Executive's Journal 1/4, 4-14.

Forman, E.H., 1991, "Determining Certainty Factors with the Analytic Hierarchy Process", Proceedings of the 2nd International Symposium on The Analytic Hierarchy Process, Pittsburgh, PA, 283302 .

Forman, E.H., 1990, "AHP is Intended for More than Expected Value Calculations", Decision Sciences 21/3, 670-672. 
Forman, E.H., 1987, "Relative vs. Absolute Worth", Mathematical Modelling, 9/3-5, 195-202.

Frazelle, E., 1985, "Suggested Techniques Enable Multi-Criteria Evaluation of Material Handling Alternatives", Industrial Engineering $17 / 2,42-48$.

Fuller, S.K., 1991, "Evaluating Fire Protection Investment Decisions for Homeowners", Socio-Economic Planning Sciences 25/2, 143-154.

Gass, S.I., 1986, "A Process for Determining Priorities and Weights for Large-Scale Linear Goal Programs," Journal of operational Research Society $37 / 8,779-785$.

Gass, S.I., 1988, "On Setting Goal-Programming Weights Using the AHP", Reprints of the International symposium on The Analytic Hierarchy Process, pp. 32-36, Tianjin University, Tianjin, China, sept. 6-9.

Gass, S.I., 1991, "Model Accreditation: A Rationale and Process for Determining a Numerical Example", Proceedings of the 2nd International Symposium on The Analytic Hierarchy Process, Pittsburgh, PA, 247-268.

Gass, S.I. and S.R. Torrence, 1991, "On the Development and Validation of Multicriteria Ratings: A Case study", SocioEconomic Planning Sciences 25/2, 133-142.

Gass, S.I., 1986, "The Analytic Hierarchy Process", Chap. 24, in Decision Making, Models and Algorithms, John Wiley \& Sons.

Ge, C., 1986, "Analysis of the Rural Energy Development strategy in Henan Province Using the AHP", Research Report, Inst. Energy Research, Academy of Henan Province.

Genest, C., F. Lapointe and S.W. Drury, 1993, "On a proposal of Jensen for the Analysis of Ordinal Pairwise Preferences Using Saaty's Eigenvector Scaling Method", Journal of Mathematical Psychology 37 , in press.

Gensch, D.H. and J.A. Svestka, 1979, "An Exact Hierarchical Algorithm for Determining Aggregate statistics From Individual Choice Data", Management Science 25/10, 939-952.

Gerrish, W., 1983, "Pain in Creative Writing: Quick Relief Using the Analytic Hierarchy Process", Mathematics and Computers in Simulation $25 / 2,120-124$.

Golden, B.L. and Q. Wang, 1989, "An Alternate Measure of Consistency", in: B.L. Golden, E.A. Wasil and P.T. Harker (eds), The Analytic Hierarchy Process, Springer-Verlag, New York, 68-81. 
Golden, B., A. Hevner and D. Power, 1984, "Decision Insight Systems for Microcomputers: A Critical Evaluation", College of Business and Management, University of Maryland.

Golden, B.L. And Q. Wang, 1989, "An Alternate Measure of Consistency", College of Business and Management, University of Maryland, College Park.

Golden, B.L. and E.A. Wasil, 1987, "Ranking Outstanding Sports Records" Interfaces $17 / 5,32-42$.

Golden, B.L., E.A. Wasil and D.E. Levy, 1989, "Applications of the Analytic Hierarchy Process: A Categorized, Annotated

Bibliography", in: B.L. Golden, P.T. Harker and E.A. Wasil (eds.), Analytic Hierarchy Process, Springer-Verlag, New York, $37-58$.

Gomes, L. and M. Lima, 1991, "Evaluating the Environmental Impacts of Roads by a Multicriteria Method", TIMS XXX - SOBRAPO XXIII Joint International Meeting, Rio de Janeiro.

Gong, X., 1991, "Haulage Mode-Choice of Chinese Railway Traffic by the Analytic Hierarchy Process", Proceedings of the 2nd International Symposium on The Analytic Hierarchy Process, Pittsburgh, PA, 507-520.

Gray, P., 1984, Book Review: The Analytic Hierarchy Process and Decision Making for Leaders, Interfaces 14/3, 97-99.

Grizzle, G.A., 1985, "Priority-Setting Methods for Plural

Policymaking Bodies", Administration and Society 17/3, 331-359.

Grizzle, G.A., 1987, "Pay for Performance: Can the AHP Hasten the Day in the Public Sector?" Mathematical Modelling 9/3-5, 245-250.

Growney, J.S., 1983, "Personal Decisions/Medical Decisions:

Consider the Analytic Hierarchy Process", UMAP Journal 5/4, 7-35.

Gu, J.F. and B.D. Liu, 1989, "Summary: The Ways of Evaluation", Decision \& The Analytic Hierarchy Process (China) 1, 7-20.

Guan, J., J. Chen and S. Li, 1988, "The Sensitivity Analysis Method for composited Priorities in the Hierarchic systems", Reprints of the International symposium on The Analytic Hierarchy Process, pp. 212-216, Tianjin University, Tianjin, China, Sept. 6-9.

Guo, F., S. Xu, Z. Gao and L. Chu, 1988, "The Application of Hierarchical Structure with Inner Dependence to the Evaluation of Key Products Made in Tianjin", Reprints of the International Symposium on The Analytic Hierarchy Process, pp. 247-154, Tianjin University, Tianjin, China, Sept. 6-9. 
Guo, B., 1988, "A Simple Algorithm of the Dynamic Priorities and an Approach to China's Forestry Production Structure for the Future", Reprints of the International Symposium on The Analytic Hierarchy Process, pp. 461-464, Tianjin University, Tianjin, China, sept. 6-9.

Guo, Y., J. Li, X. Gao and J. Jia, 1991, "Application of AHP and Fuzzy sets to the Development of a Scale to Measure Urban

Growth", Proceedings of the 2nd International symposium on The Analytic Hierarchy Process, Pittsburgh, PA, 535-544.

Guo, B., 1991, "Iformation Synthesis of Principal Right and Left Eigenvectors", Proceedings of the 2nd International symposium on The Analytic Hierarchy Process, Pittsburgh, PA, 211-214.

Gupta, S. and P.C. Wilton, 1986, "A Systematic Approach to the Measurement and Control of Bias in Managerial Judgments", XXVII International TIMS Conference, Australia.

Hachadorian, G.E., 1987, "Hierarchical Determination of the Risk of Forced Divestment to Foreign Owned Enterprises in LDC's", Mathematical Modelling 8, 163-166.

Hack, L.M., 1982, "Health Care Practitioners' Perceptions of Credentialing: The Purposes of Accreditation, Certification, and Licensure", University of Pennsylvania, DAI 43/03, 931.

Haedrich, G., A. Kuß and E. Kreilkamp, 1986, "Der Analytic Hierarchy Process", Ein neues Hilfsmittle Zur Analyse und Entwicklung von Unternehmens-und Marketingstrategien, wist. Wirtshaftswissenschaftliches studium 15/3, 120-126.

Haedrich, G. and T. Tomczak, 1988, "Analyse von Konfliktpotentialen im Hersteller - und Handelsmarketing mit HIlfe des Verfahrens 'Analytic Hierarchy Process' (AHP)", Die Betriebswirtschaft 48/5, 635-650.

Haimes, Y.Y., "A Review of the Analytic Hierarchy Process", Case Western University.

Hamalainen, R.P., 1990, "A Decision Aid in the Public Debate on Nuclear Power", European Journal of Operational Research 48/1, 66-76.

Hamalainen, R.P. and T.O. Seppalainen, 1986, "The Analytic Network Process In Energy Policy Planning," Socio-Economic Planning Sciences 20/6 399-405.

Hamalainen, R.P. and R. Karjalainen, 1988, "NETPRE - A Decision Support System for Analyzing Preferences in a Network Setting", Reprints of the International Symposium on The Analytic Hierarchy Process, pp. 626-633, Tianjin University, Tianjin, China, Sept. 
6-9.

Hamalainen, R.P., 1991, "Facts or Values - How Do

Parliamentarians and Experts see Nuclear Power?", Energy Policy, 464-472.

Hamalainen, R.P., 1988, "Computer Assisted Energy Policy Analysis in the Parliament of Finland", Interfaces 18/4, 12-23.

Hamalainen, R.P., A.A. Salo and K. Poysti, 1992, "Observations about Consensus seeking in a Multiple Criteria Environment", Proceedings of the 25th Annual Hawaii International Conference on System Sciences.

Hamalainen, R.P., Seppalainen, T.O., and Ruunsunen, J., 1986, "A Microcomputer-based Decision Support Tool and Its Application to a Complex Energy Decision Problem," Proceedings of the 19th Annual Hawaii Int. Conference on Systems Science, 494-502.

Hanratty, P.J., 1992, "Expert System Applications in Chemical Engineering", DAI-B 53/03, 1498.

Hao, G. and L.G. Vargas, 1991, "Using Neural Networks for Priority Derivation with Interval Judgments", Proceedings of the 2nd International Symposium on The Analytic Hierarchy Process, Pittsburgh, PA, 227-242.

Harker, P.T., 1987, "Incomplete Pairwise Comparisons in the Analytic Hierarchy Process," Mathematical Modelling 9/11, 837-848.

Harker, P.T., 1984, "Analytic Hierarchy Approach for the Determination of Human Migration", Dept. Geography, University of California, Santa Barbara, CA, Association of American Geographers Annual Meeting.

Harker, P.T., 1986, "Editor's Introduction", Socio-Economic Planning Sciences $20 / 6,325$.

Harker, P.T., Ed., 1986, Special Issue on the Analytic Hierarchy Process, Socio-Economic Planning Sciences 20/6.

Harker, P.T., and L.G. Vargas 1987, "The Theory of Ratio Scale Estimation: Saaty's Analytic Hierarchy Process", Management Science, 33/11, 1383-1403.

Harker, P.T. 1987, "Alternative Modes of Questioning in the Analytic Hierarchy Process," Mathematical Modelling 9/3-5, 353-360.

Harker, P.T., 1987, "Derivatives of the Perron Root of a Positive Reciprocal Matrix: with Application to the Analytic Hierarchy 
Process," Applied Mathematics and Computation 22/2-3, 217-232.

Harker, P.T. 1988, "The Art and Science of Decision Making: The Analytic Hierarchy Process," Working Paper 88-06-03, Decision Sciences Department, Wharton School, University of Pennsylvania, Philadelphia.

Harker, P.T., 1986, "The Use of Expert Judgments in Predicting Interregional Migration Patterns: An Analytic Hierarchy Approach," Geographical Analysis 18/1, 62-80.

Harper, R.M., 1984, "Internal Control in Local Area Networks: Consensus of Auditor's Judgments", The Florida state University, DAI $45 / 01,218$.

He, Q. and J. Zhao, 1988, "Application of AHP in Tool Design", Reprints of the International symposium on The Analytic Hierarchy Process, pp. 524-530, Tianjin University, Tianjin, China, Sept. 6-9.

He, X. and H. Liu, 1988, "An Application of AHP in the Traffic Planning", Reprints of the International symposium on The Analytic Hierarchy Process, pp. 465-468, Tianjin University, Tianjin, China, sept. 6-9.

He, J, H. Zhao and X. Du, 1985, "A Method for Comprehensive Evaluation of Achievements in Scientific Research Using the AHP", Theory Pract. Syst. Engng. 5/1, 33-38.

He, G., 1991, "Some Applications of AHP to the Urban Traffic system", Proceedings of the 2nd International Symposium on The Analytic Hierarchy Process, Pittsburgh, PA, 521-534.

Hedge, G.G. and P.R. Tadikamalla, 1990, "Site selection for a 'Sure Service Terminal'", European Journal of Operational Research $48 / 1,77-80$.

Heitz, J.H. and M.C. Miller, 1993, "Selection of Best Reorganizational Arrangement for the Research and Technology Directorate Using the Expert Choice Decision Program", Edgewood Research, Development \& Engineering Center, U.S. Army Chemical and Biological Defense Agency.

Hihn, J.M. and C.R. Johnson, 1988, "Evaluation Techniques for Paired Ratio-Comparison Matrices in a Hierarchical Decision Model", In: W. Eichhorn (ed.) Measurement in Economics, PhysicsVerlag, Heidelberg, 269-288.

Hoffman, D.B., 1984, "Using an Electronic Spreadsheet to support the Analytic Hierarchy Process", Proceedings of the 16th Annual Meeting of the American Institute for Decision Sciences, Toronto Canada. 
Holder, R.D., 1990, "Some Comments on the Analytic Hierarchy Process", Journal of the Operational Research Society $41 / 11$, 1073-1076.

Hong, S. and R. Nigam, 1981, "Analytic Hierarchy Process Applied to Evaluation of Financial Modeling Software", 1st International Conference on Decision Support Systems, Atlanta, GA.

Hope, R.P. and J.A. Sharpe, 1989, "The Use of Two Planning Decision support systems in Combination for the Redesign of an MBA Information Technology Programme", Computers \& operations Research $16 / 4,325-332$.

Hrbacek, K, 1978, "On the Complexity of Analytic Sets", Zeitschrift fur Mathematische Logik und Grundlagen der Mathematik $24 / 5,419-425$.

Hu, Y.Q. and G.M. Qian, 1990, "An AHP Application in Research of the Industrial Structure Rationalization", Decision \& The Analytic Hierarchy Process (China) 2, 58-64.

Hu, Z., 1988, "Fuzzy AHP and Its Application", Reprints of the International symposium on The Analytic Hierarchy Process, pp. 309-313, Tianjin University, Tianjin, China, Sept. 6-9.

Hu, Z., 1985, "Fuzzy AHP", Electric Power Research Inst., Qinghe, Beijing.

Hu, Z., 1991, "Application of Fuzzy Analytic Hierarchy Process to Group Decision Making", Proceedings of the 2nd International Symposium on The Analytic Hierarchy Process, Pittsburgh, PA, 157169.

Huang, Z., 1988, "Study in Estimation of Course Teaching Plan", Reprints of the International Symposium on The Analytic Hierarchy Process, pp. 338-343, Tianjin University, Tianjin, China, sept. 6-9.

Huang, X., 1988, "A General Principle of Rank Preservation for Adding Elements", Reprints of the International symposium on The Analytic Hierarchy Process, pp. 98-103, Tianjin University, Tianjin, China, sept. 6-9.

Hughes, W.R., 1993, "Consistent Utility and Probability Assessment Using AHP Methodology", Mathematical and Computer Modelling 17/4-5, 171-178.

Hughes, W.R., 1986, "Deriving Utilities Using the Analytic Hierarchy Process," Socio-Economic Planning Sciences 20/6, 393-95.

Hussain, H.B., 1990, "An Experimental Investigation of the 
Interaction Between Displays and Models in Multiple-criteria necision Support", DAI-B 51/01, 289.

wang, H.J., 1991, "An Application of the Analytic Hierarchy rocess to the Evaluation of Statistical Expert systems for Social Science Research", DIA-A 51/11, 3818.

Hwang, C.L. and K. Yoon, 1981, "Multiple Attribute Decision Making Methods and Applications", Lecture Notes in Economics and Mathematical systems, Springer-Verlag, New York.

Ikeda, H., et. al., 1992, "On a Selection Method of Imaging Condition in Scintigraphy: Study Using Analytic Hierarchy Process", Radioisotopes 41/10, 499-506.

Imber, S., E. Wasil, B. Golden and C. Stagg, 1991, "Selecting a Survey Design to Monitor Recreational Angling for striped Bass in the Chesapeake Bay", Socio-Economic Planning Sciences 25/2, 113122 .

Inoue, K., T. Moriyasu and U. Masage, 1986, "Evaluation of Cardinal Utility Based on Weighted Comparisons", VII-th

International Conference on Multiple Criteria Decision Making, August 18-22, 1986, Kyoto, Japan.

Islei, G. and A.G. Lockett, 1986, "An approach to preference vector derivation using least squares distance", VII-th

International Conference on Multiple Criteria Decision Making, August 18-22, 1986, Kyoto, Japan.

Islei, G. and A.G. Lockett, 1988, "Judgmental Modelling Based on Geometric Least Square", European Journal of Operational Research $36 / 1,27-35$.

Isser, S., 1991, "Baseball", Section 10.2 in: T.L. Saaty and L.G. Vargas, Prediciton, Projection and Forecasting, Kluwer Academic Publishers.

Jabri, M.M., 1990, "Personal Selection Using INSIGHT-C: An Application Based on the Analytic Hierarchy Process", Journal of Business and Psychology 5/2, 281-285.

Javalgi, R.G., et. al., 1989, "Using the Analytic Hierarchy Process for Bank Management: Analysis of Consumer Bank Selection Decisions", Journal of Business Research 19/1, 33-49.

Javalgi, R.G., R.L. Armacost and J.C. Hosseini, 1989, "Using the Analytic Hierarchy Process for Bank Management", Journal of

Business Research 19/1, 33-49.

Javalgi, R.G., S.R. Rao and E.G. Thomas, 1991, "Choosing a Hospital: ...", Journal of Health Care Marketing 11/1, 12-22. 
Jeck, T., 1983, "The Ranking of Incomplete Tournaments: A Mathematician's Guide to Popular Sports", American Mathematical Monthly 90, 246-266.

Jensen, R.E., C.E. Arrington and W.A. Hillison, 1984, "An Application of Analytical Hierarchy Process to Model Expert Judgments on Analytical Review Procedures" J. Acctg. Res. 22, 298-312.

Jensen, R.E. and R. Spencer, 1986, "Matrix scaling of subjective probabilities of economics forecasts", Economics Letters 20 , 221-225.

Jensen, R.E., 1986, "Comparison of Consensus Methods for Priority Ranking Problems", Decision Sciences 17, 195-211.

Jensen, R.E., 1982, "Reporting of Management Forecasts: An Eigenvector Model for Elicitation and Review of Forecasts", Decision Sciences 13, 15-37.

Jensen, R.E., 1983, "Review of Forecasts: Scaling and Analysis of Expert Judgments Regarding Cross-Impacts of Assumptions on Business Forecasts and Accounting Measures", Studies in Accounting Research \#19, American Accounting Association.

Jensen, R.E., 1987, "International Investment Risk Analysis: Extensions for Multinational Corporation Capital Budgeting Models," Mathematical Modelling 9/3-5, 265-284.

Jensen, R.E., 1981, "Scenario Probability Scaling: An Eigenvector Analysis of Elicited Scenario Odds ratios" Futures 13, 489-498.

Jensen, R.E., 1986, "Extension of consensus method for priority ranking problems: eigenvector analysis of 'pick-the-winner' paired comparison matrices", Decision sciences, forthcoming.

Jensen, R.E. and T.E. Hicks, 1993, "Ordinal Data AHP Analysis: A Proposed Coefficient of Consistency and a Nonparametric Test", Mathematical and Computer Modelling 17/4-5, 135-150.

Jensen, R.E., C.E. Arrington and M. Takutani, 1982, "Scaling Multivariate Performance Criteria: Subjective Composition Versus The Analytic Hierarchy Process", Journal of Accounting and Public Policy 1, 95-125.

Jensen, R.E., 1987, "A Dynamic Analytic Hierarchy Process Analysis of Capital Budgeting Under Stochastic Inflation Rates, Risk Premiums, Liquidity Preferences: Theory," Advances in Financial Planning and Forecasting 2, 269-302.

Jensen, R.E., 1983, "An Alternative Scaling Method for Priorities in Hierarchical Structures", Journal of Mathematical Psychology, 
Jensen, R.E., 1983, "Aggregation (composition) Scheme for Eigenvector Scaling of Priorities in Hierarchical structures", Multivariate Behavioral Research Vol. 18/1, 63-84.

Jia, H, G. Wang and M. Gong, 1988, "The Application of AHP to the Evaluation of General Performance Engineering Machinery", Reprints of the International Symposium on The Analytic Hierarchy Process, pp. 531-540, Tianjin University, Tianjin, China, Sept. 6-9.

Jia, H., 1989, "Applied Research of Group Decision", Decision \& the Analytic Hierarchy Process (China) 1, 43-50.

Jiang, S., B. He and Z. Wu, 1988, "Discussion and Practice on Determination of the Weight by AHP for Development of Water Resources", Reprints of the International symposium on The Analytic Hierarchy Process, pp. 541-548, Tianjin University, Tianjin, China, Sept. 6-9.

Jiang, M., 1985, "A System Analysis of the Reasonable Structure of the Commercial Energy Supply in Tianjin Region Using the AHP", Masters Thesis, Tianjin Science and Technology Training College, Tianjin.

Jiang, Z. and Y. Wei, 1988, "Some Notes on Pairwise Comparison Matrices", Reprints of the International symposium on The Analytic Hierarchy Process, pp. 181-186, Tianjin University, Tianjin, China, sept. 6-9.

Johnson, R.A., V. Srinivasan and P.J. Bolster, 1990, "Sovereign Debt Ratings: ...", Journal of International Business Studies $21 / 1$, 95-117.

Johnson, C.R., Beine, W.B. and Wang, T.J., 1979, "A Note on Right-left Asymmetry in an Eigenvector Ranking Procedure," Journal of Mathematical Psychology 19/1, 61-64.

Johnson, C.R., 1980, "Constructive Critique of a Hierarchical Prioritization Scheme Employing Paired Comparisons", Proceedings of the International conference of the Cybernetics society, IEEE, Piscataway, NJ.

Johnson, R.A., V. Srinivasan and B.J. Bolster, 1987, "A Sovereign Government Ratings Model Based on the Analytic Hierarchy Process", Working paper, Northeastern University.

Johnson, S.J., 1987, "Attributes Perceived as Essential for Hiring Football and Men's Basketball Coaches at NCAA Division I-A Schools by University officials", Oregon State University, DAI-A 47/09, p. 3355. 
Kalaba, R. and K. Springarn, 1979, "Numerical Approaches to the Eigenvalues of Saaty's Matrices for Fuzzy Sets", Computers and Mathematical Applications 4, 369-375.

Kamenetzky, R.D., 1982, "The Relationship Between the Analytic Hierarchy Process and the Additive Value Function, "Decision Sciences $13 / 4,702-713$.

Kameyama, Y., et. al., 1988, "Subjective and Quantitative Analysis of Fault Tree by Use of AHP", Reprints of the International Symposium on The Analytic Hierarchy Process, pp. 549-556, Tianjin University, Tianjin, China, Sept. 6-9.

Karacal, S.C., 1992, "The Development of an Integrative Structure for Discrete Event Simulation, object Oriented Modelling and Embedded Decision Processes", Oklahoma State University, DAI-B $52 / 08$, p. 4402 .

Karayalcin, I.I., 1982, "The Analytic Hierarchy Process -Planning, Priority Setting, Resource Allocation", European Journal of Operational Research 9/1, 97-98.

Karlson, G.L., 1993, "Designing the Best Catamaran", Mathematical and Computer Modelling 17/4-5, 179-186.

Karnes, C.I., 1991, "Measuring the Value of Quality for Apparel Manufacturing", DAI-A 52/06, 2204 .

Karni, R., et. al., 1990, "A Comparative Study of Multiattribute Decision Making Methodologies", Theory \& Decision 29/3, 203-222.

Karsan, D.I., 1989, "Development of Analytical Hierarchy Process (AHP) Models for Ranking and Selecting Research and Development Projects", Report \#107-1715-1-89, Conoco, Inc., Production Engineering and Research Dept., Marine Division, Houston, TX.

Kaynama, S.A., 1991, "Comparing the Analytic Hierarchy Process with a Modified Fishbein Behavioral Intention Model: An Application in Consumer Decision-Making", DAI-A 52/08, 2993.

Kechris, A., 1978, "The Perfect Set Theorem and Definable Wellorderings of the Continuum", Journal of Symbolic Logic 43/4, 630-634.

Khaksari, S., R. Kamath and R. Grieves, 1989, "A New Approach to Determining optimum Portfolio Mix", Journal of Portfolio Management $15 / 3,43-49$.

Khan, M.A., 1982, "Policy Prioritization and Critical Choices for Fiscally Distressed Cities: A Hierarchical Search", University of Pittsburgh, DAI-A 43/03, p. 949. 
Khorramshahgol, R. and V.S. Moustakis, 1988, "Delphic Hierarchy Process (DHP): A Methodology for Priority setting Derived from the Delphic Method and Analytical Hierarchy Process", European Journal of Operational Research $37,347-354$.

Khorramshahgol, R. and J.P. Ignizio, 1985, "Single and Multiple Decision-Making in a Multiple Objective Environment", Advances in Management studies.

Khurgin, J.I. and V.V. Polyakov, 1986, "Fuzzy Analysis of the Group Concordance of Expert Preferences, Defined by Saaty Matrices", Fuzzy Sets Applications, Methodological Approaches and Results, Akademie-Verlag, Berlin, 111-115.

Kim, C.S., 1988, "A Formal structure for the Evaluation of Decision Support System Generators: The systems Approach", Texas Tech University, DAI-A 48/08, p. 2095.

King, P.W., et. al., 1988, "Foundations, systems and Software to Support Decision-Making in Managerial and Research Environments", Parts I and II, In: Information and Technology: Planning for the Second Fifty Years, Proceedings of the 51st Annual Meeting of the American Society for Information Science, Atlanta, GA, 232-233.

King, Y. and S. Xu, 1986, "High performance medical expert system based on reasoning model using the AHP. Beijing Redcross Chaoyang Hospital, Beijing.

Kinoshita, E., 1987, Chapter 12 in: Introduction to the Analysis of Complex Environments, Keigaku Press.

Kinoshita, E., 1990, "A study on Determining Priority of Improvement for Road Using AHP", Traffic Engineering 25/2, 9-16.

Kinoshita, E., 1991, "A Study on Determining the Priorities of Expressway Construction Using AHP and LP", Proceedings of the 2nd International symposium on The Analytic Hierarchy Process, Pittsburgh, PA, 495-506.

Kinoshita, E. and T. Sasaki, 1988, "Evaluation of Route Choice Characteristics of Expressway Using AHP", Reprints of the International Symposium on The Analytic Hierarchy Process, pp. 469-476, Tianjin University, Tianjin, China, Sept. 6-9.

Kivijarvi, H. and M. Tuominen, 1991, "Logistics Management: A Method for Evaluation of Production-Distribution Investments", International Journal of Production Economics.

Kivijarvi, H. and M. Tuominen, 1989, "Computer-Based MultiAttribute Simulation of Production and Financial strategies", Engineering Costs and Production Economics 17 (Netherlands), 331341 . 
Ko, S.K., 1990, "Optimizing Reservoir systems operation With Multiobjective Decision Analysis", DAI-B 51/02, 884 .

Koger, R.K., J.R. Canada and E.R. MacCormac, 1985, "Decision Analysis Applied to Electric Utility Rate Design", The National Regulatory Research Institute, The Ohio State University, Occasional Paper No. 9.

Koger, R.K., 1984, "Goals for Ratemaking: A National Survey", in: Technology and Values: Decision Theory and Electric Rates, by: The Alfred P. Sloan Foundation, The IBM Corporations and Davidson College, NC.

Koger, R.K., 1984, "Decision Analysis Applied to Electric Utility Rate Design", North Carolina state University at Raleigh, DAI $45 / 12,3897$.

Kok, M. and F.A. Lootsma, 1985, "Pairwise-Comparison Methods in Multiple objective Programming", European Journal of operational Research 22/1, 44-55.

Konno, H., 1986, "Application of AHP to Evaluating a New Energy System", Operations Research of Japan 31/8, 481-487.

Korhonen, P.J. and J. Wallenius, 1990, "Using Qualitative Data in Multiple objective Linear Programming", European Journal of Operational Research 48/1, 81-87.

Korhonen, P.J., 1987, "The Specification of a Reference Direction Using the AHP", Mathematical Modelling, 9/3-5, 361-368.

Krovak, J., 1987, "Ranking Alternatives - Comparison of Different Methods Based on Binary Comparison Matrices", European J. of Operational Research 32, 86-95.

Kuong-Lau, K.K., 1986, "Quality Assurance Resource Allocation Using Expert Opinion and Optimization", DAI-B 47/01, 331.

Lahiri, S.B., 1992, "Skill-Sets Migration Planning via Analytic Hierarchy Process", Computers and Operations Research 19/5, 313320 .

Lai, S.K., 1991, "A Comparison of Multiattribute Decision-Making Techniques Using an Iterative Procedure to Derive A Convergent Criterion", DAI-A 51/12, 4300.

Lambert, J.B., 1991, "The Extended Analytic Hierarchy Decision Method", Mathematical and Computer Modelling 15/11, 141-151.

Lambert, J.M., 1992, "The Analytic Hierarchy Decision Method; Consistency Related to Finding a Closest Consistent Matrix", Department of Computer Science, The Pennsylvania state 
University, University Park, PA.

Landes, M.M. and D.R. Pescitelli, 1989, "Using the Analytical Hierarchy Process in NEPA-Based Public Involvement: A Profile of Success", Illinois Department of Transportation, Bureau of Location and Environment, Springfield, Illinois.

Lane, E.F., 1989, "Implications of Objective Function Type on Multiobjective Decision Making for Project Selection", DAI-A $51 / 01,10$.

Lane, E.F. and W.A. Verdini, 1989, "A Consistency Test for AHP Decision Makers", Decision Sciences 20/3, 575-590.

Lanoue, M.R. and J.J. Revetta, Jr., 1993, "An Analytic Hierarchy Approach to Major League Baseball Offensive Performance Ratings", Mathematical and Computer Modelling 17/4-5, 195-209.

Lauro, G.L., and A.P.J. Vepsalainen, 1986, "Assessing Technology Portfolios for Contract Competition: An Analytic Hierarchy Process," Socio-Economic Planning Sciences 20/6, 407-415.

Lee, Y. and B. Ahn, 1991, "Static Valuation of Combat Force Potential by the Analytic Hierarchy Process", IEEE Transactions on Engineering Management 38/3, 237-244.

Lee, H.K., 1992, "North-South Korean Reunification Policies (1988-1991), Options, and Models (Maslow's Theory)", University of Hawaii, DAI-A 53/06, 2099.

Lewis, M.T., 1985, "Ex Ante Evaluation of Audit Evidence", University of Southern California, DAI 46/09, 2741.

Lewis, R. and D.E. Levy, 1989, "Predicting a National Acid Rain Policy", in: B.L. Golden, E.A. Wasil, and P.T. Harker (eds), Applications of the Analytic Hierarchy Process, Springer-Verlag, New York, 155-170.

Li, Z. and H. Huang, 1992, "The Contribution Rate Analysis: Economic Increment from Scientific and Technological Innovation to Forest Management Industry", Forest Research 5/3, 335-341.

Li, S. and J. Chen, 1988, "The Application of AHP to Evaluate Teacher's Performance in China", Reprints of the International Symposium on The Analytic Hierarchy Process, pp. 344-348, Tianjin University, Tianjin, China, Sept. 6-9.

Li, G. A. Hu and X. Yuan, 1988, "Study on the Reasonable Division of Labour Among Rail Marshalling Yards Based on AHP", Reprints of the International Symposium on The Analytic Hierarchy Process, pp. 477-484, Tianjin University, Tianjin, China, Sept. 6-9. 
Li, J.L., 1990, "The Application of Mathematical statistics in Converging Investigation Data of AHP", Decision \& The Analytic Hierarchy Process (China) 2, 40-43.

Li, S. and B. Chen, 1988, "A Software of AHP", Reprints of the International Symposium on The Analytic Hierarchy Process, pp. 634-637, Tianjin University, Tianjin, China, Sept. 6-9.

Li, W., et. al., 1988, "Reprints of the International symposium on The Analytic Hierarchy Process, pp. 349-365, Tianjin University, Tianjin, China, Sept. 6-9.

Li, W. and R. Tan, 1991, "The Optimization Model of SubjectProportion of Higher Education and its Application", Proceedings of the 2nd International Symposium on The Analytic Hierarchy Process, Pittsburgh, PA, 475-480.

Li, Z. and S. Zang, 1991, "Feasibility on New Product Development: Application of the AHP to Decisions on Product Development", Proceedings of the 2nd International symposium on The Analytic Hierarchy Process, Pittsburgh, PA, 329-336.

Liang, T.C. and C.L. Sheng, 1990, "Comments on Saaty's Consistency Ratio Measure and Proposal of a New Detecting Procedure", International Journal of Information Management Science $1 / 2,55-68$.

Liang, B.G., L.Z. Li and P. Lizheng, 1989, "A Coordinative Model of the Social System", Decision \& The Analytic Hierarchy Process (China) 1, 51-59.

Liberatore, M.J., 1987, "An Extension of the Analytical Hierarchy Process for Industrial R\&D Project Selection and Resource Allocation", IEEE Transactions on Engineering Management EM-34/1, $12-18$.

Liberatore, M.J., 1989, "A Decision Support Approach for R\&D Project Selection", in: B.L. Golden, E.A. Wasil and P.T. Harker (eds), The Analytic Hierarchy Process, Springer-Verlag, New York, 82-100.

Liberatore, M.J. and R.I. Nydick, 1990, "An Analytic Hierarchy Approach for Evaluating Product Formulations", in: Computer Aided Formulation: A Manual for Implementation, A. Bohl. (ed).

Liberatore, M.J., R.L. Nydick and P.M. Sanchez, 1992, "The Evaluation of Research Papers (Or How to Get an Academic committee to Agree on Something)", Interfaces 22/2, 92-100.

Liberatore, Matthew J., 1988, "A Decision Support System Linking Research and Development Project Selection with Business Strategy", Project Management Journal 19/5, 14/21. 
Lin, W.T., T.J. Mock and A. Wright, 1984, "Evaluation of Audit Evidence: A Multiple Criteria Decision Approach", Proceedings and Abstracts - American Institute for Decision Sciences, Thirteenth Annual Meeting.

Lin, W.T., T.J. Mock and A. Wright, 1984, "The Use of the Analytic Hierarchy Process as an Aid in Planning the Nature and Extent of Audit Procedures", Auditing -- A Journal of Practice and Theory $4 / 1,88-99$.

Liu, B. and S. Xu, 1987, "The Applications of AHP in China and its Development", Mathematical Modelling, 9/3-5, 179-183.

Liu, Q. and Q. Wang, 1988, "Product Method of AHP", Reprints of the International Symposium on The Analytic Hierarchy Process, pp. 225-231, Tianjin University, Tianjin, China, Sept. 6-9.

Liu, L., S. Xu and B. Liu, 1988, "The Existences and the Expressions of Limit Impact Priority and Limit Absolute Priority", Reprints of the International symposium on The Analytic Hierarchy Process, pp. 237-246, Tianjin University, Tianjin, China, sept. 6-9.

Liu, B., 1991, "Group Judgments and The Analytic Hierarchy Process", Proceedings of the 2nd International symposium on The Analytic Hierarchy Process, Pittsburgh, PA, 149-156.

Liu, M.A., S.N. An and F. Duan, 1989, "An AHP Method of Assessing Synthetical Strength of Science and Technology", Decision \& The Analytic Hierarchy Process (China) 1, 89-94.

Liu, M., 1988, "The Applications of the AHP in Selecting Important Subjects of Syndrome of the Deficiency of Spleen $Q i$ in TCM", Reprints of the International Symposium on The Analytic Hierarchy Process, pp. 557-560, Tianjin University, Tianjin, China, sept. 6-9.

Liu, C.G. and S.X. Jiang, 1990, "Model of FUZZY Optimum Subordinate Degree Multiple Target optimization and its Application in Water Resources Priority Distribution in Economical Areas", Decision \& The Analytic Hierarchy Process (China) 2, 1-13.

Liu, S., 1987, "Research into the Application of AHP in Choosing Task of 'spark Scheme'", Industrial Economy 1.

Liu, J.Y., 1990, "An MBO-AHP Synthetical Model for the Basic Level of the Army", Decision \& The Analytic Hierarchy Process (China) 2, 44-49.

Liu, Q.J., 1990, "Error Analysis Method in AHP", Decision \& The Analytic Hierarchy Process (China) 2, 32-39. 
Liu, B., 1989, "Decision and AHP (Preface)", Decision and Analytic Hierarchy Process 1, 2-4.

Liu, B., S. Xu, H. Zhao and J. He, 1984, "The AHP - a Tool For Planning and Making Decisions", Theory Pract. Syst. Engng.

Liu, S., T. Zhou and P. Wu, 1991, "Application of the AHP to Scientific \& Technical Information Research", Proceedings of the 2nd International Symposium on The Analytic Hierarchy Process, Pittsburgh, PA, 451-460.

Liu, Z.C., 1990, "Analysis on Engineering of Irrigation with a Comprehensive Evaluation Model Involving Fuzzy Multistages", Decision \& The Analytic Hierarchy Process (China) 2, 50-57.

Liu, B., 1988, "AHP in China - Recent Development of Theory", Reprints of the International Symposium on The Analytic Hierarchy Process, pp. 18-24, Tianjin University, Tianjin, China, Sept. 69 .

Lobyntsev, V.A., 1981, "Application of the Influence Functions and Reciprocal Matrices in Solving Mathematical Physics Problems", Gosudarstvennyi Komitet po Ispol'zovaniyu Atomnoi Energii SSSR, Moscow Inst. Atomnoi Energii Report \# IAE-3396/1.

Lockett, A.G. and G. Islei, 1986, "An Approach to Preference Vector Derivation Using Least Squares Distance", VIIth International Conference on Multiple Criteria Decision Making, Kyoto, Japan.

Lockett, A.G., et. al., 1986, "Modelling a Research Portfolio Using AHP: A Group Decision Process", R\&D Management 16/2, 151160 .

Lootsma, F.A., 1991, "Scale Sensitivity and Rank Preservation in a Multiplicative Variant of the Analytic Hierarchy Process", Proceedings of the 2nd International Symposium on The Analytic Hierarchy Process, Pittsburgh, PA, 71-83.

Lootsma, F.A., 1990, "A Multiplicative Variant of the Analytic Hierarchy Process", Delft University of Technology, Reports of the Faculty of Technical Mathematics and Informatics no. 90-45.

Lootsma, F.A., 1987, "Modelisation du Jugement Humain Dans L'Analyse Multicritere au Moyen de Comparaisons par Paires", Operations Research 21/3, 241-257.

Lootsma, F.A., 1980, "Saaty's Priority Theory and the Nomination of a Senior Professor in Operations Research", European Journal of operational Research $4 / 6,380-388$.

Lu, L., 1985, "A Quantitative Method on the Selection and 
Assessment of Importation of Technology by the Enterporse: and AHP Approach", Master's Thesis, Dept. Management Engineering, Tianjin Univ., Tianjin.

Lund, J.R., and R.N. Palmer, 1986, "Subjective Evaluation: Linguistic scales in Pairwise Comparison Methods," Civil Engineering Systems 3, 182-186.

Luo, Y., N. Liu and Z. Zhao, 1988, "A Synthetical study of the Identification of Tea-Leaves Grades of Quality with Sense organs", Reprints of the International Symposium on The Analytic Hierarchy Process, pp. 561-568, Tianjin University, Tianjin, China, Sept. 6-9.

Lusk, E.J., 1979, "Analysis of Hospital Capital Decision Alternative: A Priority Assignment Model," Journal of Operational Research Society 30, 439-448.

Lutz, B., 1982, "Game-Theoretical Approach to Solving Problems Encountered in Energy Policy", Stuttgart Univ., Germany, Inst. Fuer Kernenergetik und Energiesysteme report \# IKE-4-105.

Ma, W.Y., 1990, "An Approximation Method of Improving Consistency of Pairwise Comparison Matrices", Decision \& The Analytic Hierarchy Process (China) 2, 26-31.

Ma, D. and B. Guo, 1988, "Two Techniques to Modify Judgments Matrices", Reprints of the International Symposium on The Analytic Hierarchy Process, pp. 18-24, Tianjin University, Tianjin, China, Sept. 6-9.

Ma, D. and X. Zheng, 1991, "9/9 - 9/1 Scale Method of AHP", Proceedings of the 2nd International symposium on The Analytic Hierarchy Process, Pittsburgh, PA, 197-202.

MacCormac, E.R., 1989, "Forecasting Loads and Designing Rates for Electric Utilities," in: B.L. Golden, E.A. Wasil and P.T. Harker (eds.), Applications of the Analytic Hierarchy Process, SpringerVerlag, New York, 138-154.

MacCormac, E.R., 1988, "The Analytic Hierarchy Process and Electric Utilities: Designing Rates", Reprints of the

International Symposium on The Analytic Hierarchy Process, pp. 322-329, Tianjin University, Tianjin, China, Sept. 6-9.

Madu, C.N., 1988, "An Economic Decision Model for Technology Transfer", Engineering Management International 5/1, 53-62.

Manabe, R., N. Masatake and K. Toshiyuki, 1991, "The Analytic Hierarchy Process Embedded in an Information Systems Development Methodology", Proceedings of the 2nd International Symposium on The Analytic Hierarchy Process, Pittsburgh, PA, 269-280. 
Manabe, R., 1986, "General Direction of AHP", Operations Research of Japan 31/8, 474-478.

Manabe, R., 1991, "An Analytical Hierarchy Process Embedded in an Information Systems Development", Second International Conference of the Information Resource Management Association, Memphis, TN.

Manabe, R., 1984, "For OR/MS Tomorrow - Comparing With Quality Control Today", Discussion Memo for 1984 International Conference on Economics and Management, Gakushuuin University, Tokyo.

Manabe, R., 1988, "An Overview of Researches and Applications of the AHP in Japan", Reprints of the International Symposium on The Analytic Hierarchy Process, pp. 25-31, Tianjin University, Tianjin, China, Sept. 6-9.

Manahan, M.P., 1989, "Technology Acquisition and Research Prioritization", International Journal of Technology Management $4 / 1,9-19$.

Markozashvili, N.I., 1983, "Using Saaty's Method in the Solution of Some Problems of the National Economy", In: Proc. Institute of Management of National Economy, state Committee for science and Technology of the Georgian SSR, Tbilisi (in Russian).

Masuda, T., 1990, "Hierarchical Sensitivity Analysis of Priority Used in Analytic Hierarchy Process", International Journal of Systems Science $21 / 2,415-427$.

Masuda, T., 1988, "Sensitivity Analysis Using Priority

Reachability Matrix for the Analytic Hierarchy Process", Reprints of the International Symposium on The Analytic Hierarchy Process, pp. 204-211, Tianjin University, Tianjin, China, Sept. 6-9.

Maszaros, J.R., 1989, "Stakeholder Versus Stockholder Management: Theory, Attitudes and Decision-Making Behaviors", DAI-A 50/02, 484 .

McCarthy, K.J., 1992, "Comment on the 'Analytic Delphi Method'", International Journal of Production Economics 27/2, 135-136.

McCarthy, K.J., 1992, "A Human Resource Planning Model for Hospital Clinical Laboratories Based on the Analytic Hierarchy Process", DAI-A, 53/01, 219.

McDermott, N.A., 1986, "The Internal Accounting Control System in a Microcomputer Environment: An Analytic Hierarchy Process Approach", The George Washington University, DAI-A 47/04, p. 1393.

Mei, J.C., 1989, "The Analytic Hierarchy Process for Many Policymakers", Natural Science Journal of Heilongjiang University 
$3,52-55$

Meng, Z.Z., 1990, "The AHP Applied to Comprehensive Evaluation of Drill Equipment", Decision \& The Analytic Hierarchy Process (China) $2,74-79$.

Meng, X., X. Zhou and Y. Zhou, 1988, "A Fuzzy AHP Model and Its Application to Evaluation of Tenders", Reprints of the International Symposium on The Analytic Hierarchy Process, pp. 301-308, Tianjin University, Tianjin, China, Sept. 6-9.

Meng, J., 1984, "A Case Study of Scale and structure of Raising Chickens in China Using the AHP", Presented at Conf. On Management Engineering of Poultry and Livestock Raising, China.

Merril, D.R., 1983, "Naval Aviation IMA Repair Capability: A Readiness to Resources Approach", Naval Postgraduate School, Monterey, CA.

Meyers, K.C., 1983, "Vulnerability of the U.S. to Non-Fuel Mineral Supply Problems (United States)", University of Pennsylvania, DAI 44/12, 3789.

Meziani, A.S., 1991, "A Multiple-Criteria Model for Assessing Political Risk Exposure in the Foreign Investment Decision", Proceedings of the 2nd International Symposium on The Analytic Hierarchy Process, Pittsburgh, PA, 337-347.

Meziani, A.S. and F. Rezvani, 1990, "Using the Analytic Hierarchy Process to select a Financing Instrument for a Foreign

Investment", Mathematical and Computer Modelling 13/7, 77-82.

Michaels, R.M., 1965, "Attitudes of drivers determine routes between alternate highways", Public Roads, 33, 225-236.

Might, R.J. and W.D. Daniel Jr., 1989, "Decision Support for War Games", in: B.I. Golden, E.A. Wasil and P.T. Harker (eds), Applications of the Analytic Hierarchy Process, Springer-Verlag, New York, 171-181.

Miller, G.A., 1956, "The Magical Number Seven Plus or Minus Two: Some Limits on Our Capacity for Processing Information", The Psychological Review 63, 81-97.

Miller, F.L., 1983, "Analytic Hierarchy Process in a Legal Setting", Proceedings of the International Conference on Systems, Man and Cybernetics, Bombay and New Delhi, India.

Millet, I., 1990, "An Expectancy-Oriented Management control System for Discretionary and Tactical Performance", DAI-A 50/07, 1834 . 
Millet, I. and P.T. Harker, 1990, "Globally Effective Questioning in the Analytic Hierarchy Process", European Journal of Operational Research $48 / 1,88-97$.

Min, H., 1992, "Selection of Software: ...", International Journal of Physical Distribution \& Logistics Management 22/1, $42 / 52$.

Mirkin, B.G., 1979, "Group Choice", Washington, DC: Winston.

Mitchell, K.H., 1983, "Applications of the Analytic Hierarchy Process as a Computer Assisted Multi-Person Multi-Criteria Decision-Making Support Tool", Woods Gordon, Management Consultants, Toronto, Canada.

Mitchell, K.H., 1982, "Assessing Intangible Benefits and Costs of Energy Policy Options", Proceedings of the 10th IMACS World Congress on System Simulation and Scientific Computation, Montreal, Canada, 314-316.

Mitchell, K.H. and G. Bingham, 1986, "Maximizing the Benefits of Canadian Forces Equipment overhaul Programs Using Multi-objective Optimization", INFOR 24/4, 251-264.

Mitchell, K.H. and M.P. Soye, 1983, "Measuring the Intangibles in Social Decisions: Assessing Benefits and Costs of Energy Policy Options", Mathematical and Computer Simulation (Netherlands) $25 / 2,135-145$.

Mitchell, K.H. and E.A. Wasil, 1989, "AHP in Practice: Applications and Observations from a Management Consulting Perspective", in: B.L. Golden, E.A. Wasil and P.T. Harker (eds), The Analytic Hierarchy Process, Springer-Verlag, New York, 192212 .

Mobolurin, A. and N. Bryson, 1993, "Aggregating Preference Rankings: An AHP-Based Approach", Journal of Multi-Critria Decision Analysis 2/1, 27-39.

Monte-White, K.J., 1991, "Benefit-Cost Analysis - Improving Informal Classified Communications - Panama", U.S. Department of State, Bureau of Diplomatic Security and Information Management, Planning and Development Directorate Office of Plans, Strategic Planning Division.

Moon, J.W., 1968, "Topics on Tournaments", New York, NY: Holt, Rinehart and Winston.

Moreno-Jimenez, J.M. and L.G. Vargas, 1993, "A Probabilistic study of Preference Structures in the Analytic Hierarchy Process with Interval Judgments", Mathematical and Computer Modelling $17 / 4-5,73-82$. 
Mortonson-Liedle, J., 1987, "Evaluating Cost-Effectiveness of Remedial Actions at an Uncontrolled Hazardous waste Site in New York", DAI-B 48/06, 1630.

Moutinho, L., 1993, "The Use of the Analytic Hierarchy Process (AHP) in Goal setting and Goal Assessment: ...", Journal of Professional Services Marketing 8/2, 97-114.

Muralidhar, K., R. Santhanam and R.L. Wilson, 1990, "Using the Analytic Hierarchy Process for Information System Project Selection", Information \& Management 18/2, 87-95.

Murphy, L.A., P.P. Sanchez and R. Tummala, 1988, "The AHP Technique in Determining Procurement of a Local Area Network Operating system", Reprints of the International symposium on The Analytic Hierarchy Process, pp. 261-268, Tianjin University, Tianjin, China, Sept. 6-9.

Murphy, C.K., 1993, "Limits on the Analytical Hierarchy Process from its Consistency Index", European Journal of Operational Research 65/1, 138-139.

Mustafa, M.A., 1991, "Multicriteria Expert Support System for Engineering Project Selection and Resource Allocation", DAI-B $51 / 10,4929$.

Mustafa, M.A. and E.L. Murphree, 1989, "A Multicriteria Decision Support Approach for Project Compression", Project Management Journal 20/2, 29-34.

Mustafa, M.A., 1987, "Multicriteria Decision Support System for Project Scheduling", TIMS National Meeting, st. Louis.

Mustafa, M.A. and J.F. Al-Bahar, 1991, "Project Risk Assessment Using the Analytic Hierarchy Process", IEEE Transactions on Engineering Management 38/1, 46-52.

Mustafa, M.A., 1989, "An Integrated Hierarchical Programming Approach for Industrial Planning", Computers \& Industrial Engineering 16/4, 525-534.

Myers, K.C., 1984, "Vulnerability of the US to Non-Fuel Mineral Supply Problems", DAI-A 44/12, 3789.

Namba, K., 1971, "An Axiom of Strong Infinity and Analytic Hierarchy of Ordinal Numbers", Axiomatic Set Theory, American Mathematics Society, RI, 279-319.

Nelson, C.W. and R. Balachandra, 1991, "Choosing the Right Expert System Building Approach", Decision Sciences 22/2, 354-368.

Neves, J.M., 1985, "Monitoring Consistency in Group Decision 
Making: An Empirical Study of the Analytic Hierarchy Process", University of Pennsylvania, DAI-A 45/07, p. 2277.

Nezhad, H.G., 1991, "To Drill or Not to Drill: A Synthesis of Experts' Judgments", International Journal of Systems Science $22 / 9,1613-1624$.

Nezhad, G.H., 1988, "Risk Assessment for International Investment", Reprints of the International symposium on The Analytic Hierarchy Process, pp. 371-380, Tianjin University, Tianjin, China, sept. 6-9.

Nezhad, H.G., 1983, "A New Model in the Energy Policy Planning", Journal of Mathematics and Computers in Simulation XXV, 125-134.

Nezhad, H.G., 1982, "Energy Policy Formulation: An Analytic Hierarchy Process", 10th IMACS World Congress on System Simulation and Scientific Computation, International Association for Mathematics and Computers in Simulation.

Nezhad, G.H., 1981, "Critical Choices for OPEC Members and the U.S.", J. of Conflict Resolution 25/1, 115-143.

Nezhad, H.G. and Y. Kathawala, 1987, "A New Approach to Facility Location Decisions", International Journal of Systems Science $18 / 2,389-402$.

Nezhad, H.G., 1986, "Marketing a New Product in International Environment", In: Marketing strategy for South Asia, Institute of Marketing Management, New Delhi, 101-110.

Nezhad, H.G., 1987, "Oil Price Scenarios: 1989 and 1995", Journal of Strategic Planning and Energy Management 7/1, 19-31.

Nezhad, G.H. and T.L. Saaty, 1982, "A Desired Energy Mix for the United States in the Year 2000: An Analytic Hierarchy Approach", International $\mathrm{J}$. of Policy Analysis and Information Systems 6/1, 47-64.

Nezhad, H.G., 1985, "The Analytic Hierarchy Process as a Tool for Modeling and Simulation", Modeling and Simulation on

Microcomputers, G.R. Lavry (ed.) 19-21.

Nezhad, H.G., 1990, "World Energy Scenarios for the Year 2010", Journal of Strategic Planning for Energy and the Environment 9/4, 26-44.

Nezhad, H.G. and S.R. Xia, 1984, "Formulating Energy Strategies and Policies for China: A Systematic Approach", Journal of Environment and Planning B: Planning and Design 11/2, 213-228.

Nezhad, H.G., 1984, "Energy Conservation: A Policy Model for the 
United States", In: Mathematical Modelling in Science and Technology, J.R. Xavier et. al. (eds.), Pergamon Press, NY, 969974 .

Nezhad, H.G. and T.L. Saaty, 1982, "High-Level Nuclear Waste Management: Analysis of Options", Journal of Environment and Planning B: Planning and Design 9, 181-196.

Nezhad, H.G., 1990, "Planning for India's Transition to Alternative Energy Sources", In: International Development and Alternative Futures: The Coming Challenges, M. Mtewa (ed.), Allied Publishers, India, 68-81.

Nezhac, H.G., 1985, "1995: The Turning Point in Oil Prices", In: The Global Economy: Today, Tomorrow, and the Transition, H.G. Didsbury (ed.), world Future society, Bethesda, MD, 296-314.

Nezhad, H.G., 1988, "Strategic Planning for the Commercialization of Synthetic Fuels from Coal", International Journal of Energy Systems $8 / 2,101-105$.

Noble, E.E., 1990, "Consistency in the Analytic Hierarchy Process", MAI 28/04, 633.

Normann, D., 1981, "Countable Functionals and the Projective Hierarchy", Journal of Symbolic Logic 46/2, 209-215.

Norris, D.M., 1992, "A Study of JIT Implementation Techniques Using the Analytic Hierarchy Process Model", Production \& Inventory Management Journal 33/3, 49-53.

Nydick, R.L. and R.P. Hill, 1992, "Using the Analytic Hierarchy Process to Structure the Supplier selection Procedure", International Journal of Purchasing \& Materials Management 28/2, 31-36.

Odynocki, B., 1979, "Planning the National Health Insurance Policy: An Application of the AHP in Health Policy Evaluation and Planning," Ph.D. Dissertation, University of Pennsylvania, Philadelphia.

Odynocki, B., 1982, "Planning National Health Policy: The Analytic Hierarchy Process in Public Policy Design", 10th IMACS World Congress on system simulation and Scientific computation, International Association for Mathematics and Computers simulation (IMACS).

Ohmae, Y., 1988, "Comparisons of the AHP and the Traditional Methods", Reprints of the International symposium on The Analytic Hierarchy Process, pp. 217-225, Tianjin University, Tianjin, China, Sept. 6-9. 
Olson, D.L., M. Venkataramanan and J.L. Mote, 1986, "A Technique Using Analytical Hierarchy Process in Multiobjective Planning Models", Socio-Economic Planning Sciences 20/6, 361-168.

Olson, D.L., 1988, "Opportunities and Limitations of AHP in Multiobjective Programming", Mathematical and Computer Modelling $11,206-209$.

Olson, D.L., 1991, "The Centroid Extension to AHP", Proceedings of the 2nd International Symposium on The Analytic Hierarchy Process, Pittsburgh, PA, 29-40.

Oswalt, I., 1990, "An Expected Utility Analysis of US Power Projection Conflicts: The Characterization of the status Quo", DAI-A 50/08, 2640 .

Overby, C.M., 1987, "Comparison of Analytical Hierarchy and QSort/Nominal-Interactive Processes in Group Activities" "The George Washington University, DAI-B 47/09, p. 3858 .

Pack, S.R., et. al., 1987, "Ranking Remedial Action Technologies", Hazardous Waste and Hazardous Materials 4/4, 363376.

Palmer, R.N and J.R. Lund, 1985, "Multi-Objective Analysis with Subjective Information", Journal of Water Resources Planning and Management $111 / 4,399-416$.

Pandya, A., 1987, "Strategic Market Planning for Development", Working paper 87-34, Northeastern University, Boston, MA.

Papantonopoulos, S.A., 1990, "A Decision Model for Cognitive Task Allocation", DAI-B 51/09, 4540 .

Par, K.H., 1991, "Development and Evaluation of a Prototype Expert System for Forecasting Models", DAI-A 51/11, 3822.

Partovi, F.Y., J. Burton and A. Banerjee, 1990, "Application of Analytical Hierarchy Process in Operations Management", International Journal of operations \& Production Management 10/3, 5-19.

Partovi, F.Y. and J. Burton, 1992, "An Analytical Hierarchy Approach to Facility Layout", Computers \& Industrial Engineering $22 / 4,447-457$.

Peniwati, K. and T. Hsiao, 1987, "Ranking countries according to economic, social and political indicators", Mathematical Modelling 9/3-5, 203-210.

Puelz, R., 1991, "A Process for Selecting a Life Insurance Contract", Journal of Risk \& Insurance 58/1, 138-146. 
Putrus, R.S., 1992, "Outsourcing Analysis and Justification Using AHP", Information Strategy: The Executive's Journal 9/1, 31-36. trne

putrus, R., 1990, "Accounting for Intangibles in Integrated Manufacturing (nonfinancial justification based on the AHP)", Information Strategy $6,25-30$.

Rabinowitz, G., 1976, "Some Aspects on Measuring World Influence", Journal of Peace Science 2, 49-55.

Rahman, S. and L.C. Frair, 1984, "A Hierarchical Approach to Electric Utility Planning", Int. J. Energy Res. 8/2, 185-196.

Rahman, S., 1983, "Market Penetration of Renewable Energy Technologies: Planning and Policy Issues", International Symposium-Workshop on Renewable Energy Sources, Lahore, Pak.

Rajasekera, J.R., 1990, "Outline of a Quality Plan for Industrial Research and Development Projects", IEEE Transaction on Engineering Management 37/3, 191-197.

Ramanujam, V. and T.I. Saaty, 1981, "Technological Choices in Less Developing Countries", Technological Forecasting and social Change $19 / 1,81-97$.

Ramsay, J.0., 1977, "Maximum Likelihood Estimation in Multidimensional Scaling", Psycholmetrika 42, 241-266.

Rao, C.R., 1973, "Linear Statistical Inference and its Applications", Second Edition. New York, NY: John Wiley and Sons.

Rapoport, A., D.S. Felsenthal and Z. Maoz, 1988, "Microcosms and Macrocosms: Seat Allocation in Proportional Representation Systems", Theory and Decision 24, 11-33.

Rappaport, J. and J. Neves, 1984, "Decision Making with Feedback: An Interactive Approach", Proceedings for The Thirteenth Annual Regional Conference for the American Institute for Decision Sciences, Boston, 121-123.

Reed, S.E., 1985, "Aggregating Individual Preferences in the Analytic Hierarchy Process Applied to the 1983 Battelle TAV study",

Rensema, P.H., 1984, "Decision Support Methodology for Space Technology Advocacy", Air Force Institute of Technology, Report \# AFIT/GSO/OS/84D-3.

Ridgley, M.A. and F.R. Rijsberman, 1992, "Multicriteria Evaluation in a Policy Analysis of a Rhine Estuary", Water Resources Bulletin 28/6. 
Ridgley, M.A., 1992, "Multicriteria Analysis of Estuary

Restoration in the Rhine Delta", 10th International Conference on Multiple Criteria Decision Making, Taipei, Taiwan.

Ridgley, M.A., 1991, "Determining Water Allocation During Drought: An Example From the Hawaiian Island of MAUI", Proceedings of the 2nd International Symposium on The Analytic Hierarchy Process, Pittsburgh, PA, 361-374.

Ridgley, M.A. and D.K. Chai, 1990, "Evaluating Potential Biotic Benefits from Conversation: Anchialine Ponds in Hawaii (USA)", Environmental Professional 12/3, 214-228.

Riel, P.F., 1990," An Evaluation Process for Material Handling Systems Within FMS", DAI-B 50/09, 4162.

Riley, A.C., 1987, "An Analytical Framework for the Evaluation of Inherent Audit Risk", DAI-A 47/12, 4436.

Rohrback, K.G. and L. Pingsun, 1991, "AHP in Allocating Hawaii's Agricultural Research and Development Resources", Proceedings of the 2nd International symposium on The Analytic Hierarchy Process, Pittsburgh, PA, 351-360.

Roman, C.S., 1991, "Selecting Tactics for Computer Performance Validation in Federal Acquisitions: An Investigation of the Applicability of a Rule-Based Expert System", DAI-A 52/04, 1433.

Roper-Lowe, G.C. and J.A. Sharp, 1990, "The Analytic Hierarchy Process and Its Application to an Information Technology Decision", Journal of the Operational Research Society 41/1, 4959.

Rosas, A.C., 1984, "Some Applications of Fuzzy Sets and the Analytical Hierarchy Process to Decision Making", Naval Postgraduate School, Monterey, CA.

Ross, M.E. and R.L. Nydick, 1992, "Selection of Licensing Candidates in the Pharmaceutical Industry: ...", Journal of Health Care Marketing 12/2, 60-65.

Roth, M., 1991, "Hockey", Section 10.7 in: T.L. Saaty and L.G. Vargas, Prediciton, Projection and Forecasting, Kluwer Academic Publishers.

Roth, M., 1991, "Basketball", Section 10.5 in: T.L. Saaty and L.G. Vargas, Prediciton, Projection and Forecasting, Kluwer Academic Publishers.

Rumsey, H.A., 1987, "Organizational Validity of Constrained Facet Analysis in U.S. Air Force Civil Engineering", University of Missouri - Rolla, DAI-B 47/10, p. 4266. 
Ruusunen, J. and R.P. Hamalainen, 1989, "Project selection by an Integrated Decision Aid", in: B.L. Golden, E.A. Wasil and P.T. Harker (eds), The Analytic Hierarchy Process, Springer-Verlag, New York, 101-121.

Saaty, T.L., 1977, "A Scaling Method for Priorities in Hierarchical Structures", Journal of Mathematical Psychology $15 / 3,234-281$.

Saaty, T.L. and J.P. Bennett, 1977, "XYZ Research Institute: Planning Resource Allocation Under Uncertainty", in: T.L. Saaty and L.G. Vargas (eds), The Logic of Priorities, Kluwer-Nijhoff Publishing, Boston, MA, 83-98.

Saaty, T.L., 1977, "Theory of Measurement of Impacts and Interactions in Systems", In: Proc. Int. conf. on Applied General Systems Research: Recent Developments and Trends, Binghamton, NY.

Saaty, T.L. and L.G. Vargas, 1980, "Hierarchical Analysis of Behavior in Competition: Prediction in Chess", Behavioral Science $25,180-191$.

Saaty, T.L. and M. Wong, 1983, "Projecting Average Family Size in Rural India by the Analytic Hierarchy Process", J. of Mathematical Sociology 9, 181-209.

Saaty, T.L., 1982, Decision Making for Leaders, Belmont, CA: Lifetime Learning Publications.

Saaty, T.L. and L.G. Vargas, 1992, "Deriving Bayes Theorem from the Analytic Hierarchy Process", forthcoming.

Saaty, T.L., 1990, The Analytic Hierarchy Process, paperback edition, RWS Publications, Pittsburgh, PA.

Saaty, T.L. and L.R. Rogers, 1976, "Higher Education in the United States (1985-2000): Scenario Construction Using a Hierarchical Framework with Eigenvector Weighing", Socio-Economic Planning Sciences 10, 251-263.

Saaty, T.L., and L.G. Vargas, 1987, "Uncertainty and Rank order in the Analytic Hierarchy Process," European Journal of Operational Research $32,107-117$.

Saaty, T.L., 1975, "Hierarchies and Priorities-Eigenvalue Analysis", Univ. of Pennsylvania, Philadelphia, PA.

Saaty, T.L., 1976, "Hierarchies, Reciprocal Matrices, and Ratio Scales", In: Modules in Applied Mathematics, Mathematical Association of America, Cornell Univ., Ithaca, NY.

Saaty, T.L., 1986, "A note on the AHP and expected value theory", 
Socio-Economic Planning Science 20/6, 397-398.

Saaty, T.L. and J. Alexander, 1989, "Conflict Resolution: The Analytic Hierarchy Process", Praeger, New York.

Saaty, T.L., 1980, "The Analytic Hierarchy Process", McGraw Hill, New York.

Saaty, T.L., 1987, "Rank according to Perron", Mathematics Magazine, forthcoming.

Saaty, T.L., L.R. Rogers, and R. Pell, 1980, "Portfolio Selection Through Hierarchies", J. of Portfolio Management 6/3, 16-21.

Saaty, T.L., L.G. Vargas and R.E. Wendell, 1983, "Assessing Attribute Weights by Ratios", Omega 11/1, 9-13.

Saaty, T.L., 1981, "Priorities in Systems with Feedbacks," International Journal of Systems, Measurement and Decisions 1 , 24-38.

Saaty, T.L., 1990, "Eigenvector and Logarithmic Least Squares", European Journal of Operational Research 48/1, 156-160.

Saaty, T.L., 1988, "Resolution of Retributive Conflicts: The Case of South Africa," ORION $4 / 1$.

Saaty, T.L., 1990, "Eigenvector and Logarithmic Least Squares", European Journal of Operational Research 48/1, 156-160.

Saaty, T.L. and M.H. Beltran, 1982, "The Analytic Hierarchy Process: A New Approach to Deal with Fuzziness in Architecture", Architectural Science Review 25, 64-69.

Saaty, T.L. and J.M. Alexander, 1981, "Thinking with Models", oxford, England: Praegar.

Saaty, T.L. and R.S. Mariano, 1979, "Rationing Energy to Industries: Priorities and Input-output Dependence", Energy systems and Policy 3 .

Saaty, T.L. and H. Gholamnezhad, 1981, "Oil Prices: 1985 and 1990", Energy Systems and Policy 5/4, 303-318.

Saaty, T.L., 1974, "Measuring the Fuzziness of Sets," Journal of Cybernetics $4,53-61$.

Saaty, T.L., 1990, "Multicriteria Decision Making: The Analytic Hierarchy Process", RWS Publications, Pittsburgh, PA.

Saaty, T.L., 1982, "How to Structure and Make Choices in Complex Problems", Human Systems Management 3/4, 255-260. 
Ruusunen, J. and R.P. Hamalainen, 1989, "Project Selection by an Integrated Decision Aid", in: B.L. Golden, E.A. Wasil and P.T. Harker (eds), The Analytic Hierarchy Process, Springer-Verlag, New York, 101-121.

Saaty, T.L., 1977, "A Scaling Method for Priorities in Hierarchical structures", Journal of Mathematical Psychology $15 / 3,234-281$.

Saaty, T.I. and J.P. Bennett, 1977, "XYZ Research Institute: Planning Resource Allocation Under Uncertainty", in: T.L. Saaty and L.G. Vargas (eds), The Logic of Priorities, Kluwer-Nijhoff Publishing, Boston, MA, 83-98.

Saaty, T.L., 1977, "Theory of Measurement of Impacts and Interactions in Systems", In: Proc. Int. conf. on Applied General Systems Research: Recent Developments and Trends, Binghamton, NY.

Saaty, T.L. and L.G. Vargas, 1980, "Hierarchical Analysis of Behavior in Competition: Prediction in Chess", Behavioral Science $25,180-191$.

Saaty, T.L. and M. Wong, 1983, "Projecting Average Family Size in Rural India by the Analytic Hierarchy Process", J. of Mathematical Sociology 9, 181-209.

Saaty, T.L., 1982, Decision Making for Leaders, Belmont, CA: Lifetime Learning Publications.

Saaty, T.L. and L.G. Vargas, 1992, "Deriving Bayes Theorem from the Analytic Hierarchy Process", forthcoming.

Saaty, T.I., 1990, The Analytic Hierarchy Process, paperback edition, RWS Publications, Pittsburgh, PA.

Saaty, T.L. and L.R. Rogers, 1976, "Higher Education in the United States (1985-2000): Scenario Construction Using a Hierarchical Framework with Eigenvector Weighing", Socio-Economic Planning Sciences 10, 251-263.

Saaty, T.L., and L.G. Vargas, 1987, in the Analytic Hierarchy Process," "Uncertainty and Rank order Operational Research 32, 107-117. European Journal of

Saaty, T.L., 1975, "Hierarchies and Priorities-Eigenvalue Analysis", Univ. of Pennsylvania, Philadelphia, PA.

Saaty, T.L., 1976, "Hierarchies, Reciprocal Matrices, and Ratio Scales", In: Modules in Applied Mathematics, Mathematical Association of America, Cornell Univ., Ithaca, NY.

Saaty, T.L., 1986, "A note on the AHP and expected value theory", 
Socio-Economic Planning Science 20/6, 397-398.

Saaty, T.L. and J. Alexander, 1989, "Conflict Resolution: The Analytic Hierarchy Process", Praeger, New York.

Saaty, T.L., 1980, "The Analytic Hierarchy Process", McGraw Hill, New York.

Saaty, T.L., 1987, "Rank according to Perron", Mathematics Magazine, forthcoming.

Saaty, T.L., L.R. Rogers, and R. Pell, 1980, "Portfolio Selection Through Hierarchies", J. of Portfolio Management 6/3, 16-21.

Saaty, T.L., L.G. Vargas and R.E. Wendell, 1983, "Assessing Attribute Weights by Ratios", Omega 11/1, 9-13.

Saaty, T.L., 1981, "Priorities in Systems with Feedbacks," International Journal of Systems, Measurement and Decisions 1 , 24-38.

Saaty, T.L., 1990, "Eigenvector and Logarithmic Least Squares", European Journal of Operational Research 48/1, 156-160.

Saaty, T.L., 1988, "Resolution of Retributive Conflicts: The Case of South Africa," ORION $4 / 1$.

Saaty, T.L., 1990, "Eigenvector and Logarithmic Least Squares", European Journal of Operational Research 48/1, 156-160.

Saaty, T.L. and M.H. Beltran, 1982, "The Analytic Hierarchy Process: A New Approach to Deal with Fuzziness in Architecture", Architectural Science Review 25, 64-69.

Saaty, T.L. and J.M. Alexander, 1981, "Thinking with Models", oxford, England: Praegar.

Saaty, T.L. and R.S. Mariano, 1979, "Rationing Energy to Industries: Priorities and Input-Output Dependence", Energy Systems and Policy 3.

Saaty, T.L. and H. Gholamnezhad, 1981, "Oil Prices: 1985 and 1990", Energy Systems and Policy 5/4, 303-318.

Saaty, T.L., 1974, "Measuring the Fuzziness of Sets," Journal of Cybernetics 4, 53-61.

Saaty, T.L., 1990, "Multicriteria Decision Making: The Analytic Hierarchy Process", RWS Publications, Pittsburgh, PA.

Saaty, T.L., 1982, "How to structure and Make Choices in Complex Problems", Human Systems Management 3/4, 255-260. 
Saaty, T.L. and K.P. Kearns, 1985, "Analytic Planning - The Organization of Systems", International Series in Modern Applied Mathematics and Computer Science 7, Oxford, England, Pergamon Press.

Saaty, T.L., 1986, "Absolute and Relative Measurement with the AHP: The Most Livable Cities in the United States," Socio-Economic Planning Sciences 20/6, 327-331.

Saaty, T.L. and L.G. Vargas, 1991, "Prediction, Projection and Forecasting", Kluwer Academic, Boston.

Saaty, T.L., 1987, "Concepts, Theory and Techniques: Rank Generation, Preservation and Reversal in the Analytic Hierarchy Process," Decision Sciences 18, 157-177.

Saaty, T.L. and J.P. Bennett, 1977, "A Theory of Analytical Hierarchies Applied to Political Candidacy", Behavioral Science $22,237-245$.

Saaty, T.L., 1973, "A Description of An Eigenvector Model for Rationing", Unpublished Paper, Research Project of the Center for Energy Management and Power, Univ, of Pennsylvania, Philadelphia, $\mathrm{PA}$.

Saaty, T.L. and L.G. Vargas, 1985, "Modeling of Behavior in Competition: The Analytic Hierarchy Process", Applied Mathematics and Computation, 16, 49-92.

Saaty, T.L. and L.G. Vargas, 1980, "A Note on Estimating Technological Coefficients by Hierarchical Measurements", SocioEconomic Planning Sciences 14.

Saaty, T.L., 1987, "A New Macroeconomic Forecasting and Policy Evaluation Method Using the Analytic Hierarchy Process", Mathematical Modelling 9/3-5, 219-232.

Saaty, T.L. 1980, The Analytic Hierarchy Process, McGraw Hill Company, New York.

Saaty, T.L. and V. Ramanujam, 1983, "An Objective Approach to Faculty Promotion and Tenure by the Analytic Hierarchy Process", Research in Higher Education 18, 311-331.

Saaty, T.L., 1985, "Axiomatization of the Analytic Hierarchy Process", Decision Making with Multiple Objectives, Springer, New York, 91-108.

Saaty, T.L. and L.G. Vargas, 1984, "Inconsistency and Rank Preservation", Journal of Mathematical Psychology 28, 205-214.

Saaty, T.L. and L.G. Vargas, 1979, "Estimating Technological 
Coefficients by the Analytic Hierarchy Process" Socio-Economic Planning sciences $13,333-336$.

Saaty, T.L., 1984, "Impact of Disarmament Nuclear Package Reduction," in: R. Avenhaus (ed.), Quantitative Assessment in Arms Control, Plenum Press, New York.

Saaty, T.L., 1987, "How to Handle Dependence with the Analytic Hierarchy Process", Mathematical Modelling, 9/3-5, 369-376.

Saaty, T.L., 1977, "Scenarios and Priorities in Transport Planning: Application to the Sudan", Transportation Research $11 / 5$.

Saaty, T.L., 1990, "How to Make a Decision: The Analytic Hierarchy Process", European Journal of Operational Research $48 / 1,10-26$

Saaty, T.L., 1993, "What is Relative Measurement? The Ratio Scale Phantom", Mathematical and Computer Modelling 17/4-5, 1-12.

Saaty, T.L., and L.G. Vargas, 1987, "Uncertainty and Rank order in the Analytic Hierarchy Process," European Journal of Operational Research 32/1, 107-117.

Saaty, T.L., 1972, "An Eigenvalue Allocation Model for Prioritization and Planning", Energy Management and Policy Center, Univ. of Pennsylvania, Philadelphia, PA.

Saaty, T.L., 1988, "Some Mathematical Topics in the Analytic Hierarchy Process", Mathematical Models for Decision support, Computer Systems Science 48, 89-107.

Saaty, T.L., J.W. France and K.R. Valentine, 1991, "Modeling the Graduate Business School Admissions Process", Socio-Economic Planning Sciences 25/2, 155-162.

Saaty, T.L., 1983, "Conflict Resolution and the Falkland Island Invasions", Interfaces $13 / 6,68-83$.

Saaty, T.L. and M.H. Beltran, 1980, "Architectural Design by the Analytic Hierarchy Process", J. Des. Meth. Theories 14, 124-134.

Saaty, T.L., 1992, Analytic Hierarchy, McGraw-Hill Encyclopedia of Science \& Technology, 559-563.

Saaty, T.L., F. Ma, and P. Blair, 1977, "Operational Gaming for Energy Policy Analysis", Energy Policy 5, 63-75.

Saaty, T.I., 1986, "Structure and Decision Making by Using AHP", Operations Research of Japan 31/8, 479-481. 
Saaty, T.L., 1978, "Exploring the Interface Between Hierarchies, Multiple objectives and Fuzzy sets," Fuzzy sets and systems, January.

Saaty, T.L., 1989, "Hierarchical Multiobjective Systems", control Theory and Advanced Technology 5/4, 485-498.

Saaty, T.L., 1983, "Procedures for synthesizing ratio judgments", J. Math. Psych. Vol. 27, pp.93-103.

Saaty, T.L., 1987, "Risk - Its Priority and Probability: The Analytic Hierarchy Process", Risk Analysis 7/2, 159-172.

Saaty, T.L., 1984, "Tutorial on Strategic Planning: New Concepts and Applications", Tim S. Yau (ed.), EPRI.

Saaty, T.L. and L.G. Vargas, 1981, "Financial versus Intangible Factors in Vehicle Fleet Buying/Leasing Decisions", Industrial Marketing Management 10. 1-10.

Saaty, T.L. and M. Takizawa, 1986, "Dependence/independence: from linear hierarchies to nonlinear networks", The European Journal of Operations Research 26, 229-237

Saaty, T.L., 1979, "Mathematical Modeling of Dynamic Decisions: Priorities and Hierarchies with Time Dependence", Mathematics and computers in simulation $21,352-258$.

Saaty, T.L. and L.G. Vargas, 1993, "A Model of Neural Impulse Firing and Synthesis", Journal of Mathematical Psychology 37 , 200-219.

Saaty, T.L., 1977, "The Sudan Transport Study", Interfaces 20/3, 147-157.

Saaty, T.L., 1991, "Rank and the Controversy About the Axioms of Utility Theory - A Comparison of AHP and MAUT", Proceedings of the 2nd International Symposium on The Analytic Hierarchy

Process, Pittsburgh, PA, 87-112.

Saaty, T.L., 1976, "Interval Scale From Pairwise Comparisons", In: Discrete and System Models, W.F. Lucas, F.S. Roberts and R.M. Thrall (eds.), Springer-Verlag, New York, 248-250.

Saaty, T.L., and Takizawa, M., 1986, "Dependence and Independence: from Linear Hierarchies to Nonlinear Networks," European Journal of Operational Research 26/2, 229-237.

Saaty, T.L., 1979, "The U.S.-OPEC Energy Conflict: The Payoff Matrix by the Analytic Hierarchy Process," International Journal of Game Theory 8/4, 225-234. 
Saaty, T.L., 1981, "The Analytic Hierarchy Process and Health Care Problems," Proceedings of International Conference on Systems Science in Health Care, Montreal, 1980.

Saaty, T.L., 1979, "The U.S.-OPEC Energy Conflict: The Payoff Matrix by the Analytic Hierarchy Process," International Journal of Game Theory 8/4, 225-234.

Saaty, T.L., 1988, "A Note on Multiplicative Operations in the AHP", Reprints of the International Symposium on The Analytic Hierarchy Process, pp. 82-86, Tianjin University, Tianjin, China, sept. 6-9.

Saaty, T.L., and Gholamnezhad, H., 1982, "High-Level Nuclear Waste Management: Analysis of Options," Environment and Planning (B) 9 , 181-196.

Saaty, T.L., V. Sethi, and A.K. Makhija, 1989, "The Conflict of Punjab: An Application of the Analytic Hierarchy Process in Conflict Resolution", Working Paper, University of Pittsburgh, Pittsburgh, PA.

Saaty, T.L., 1989, "Group Decision Making and the AHP", Chapter four in the book Applications of the Analytic Hierarchy Process by B.L. Golden, P.T. Harker and E.A. Wasil, Springer-Verlag.

Saaty, T.L. and J.P. Bennett, 1977, "Terrorism: Patterns for Negotiation: Three case Studies Through Hierarchies and Holarchies", Study for the Arms Control and Disarmament Agency, 208 .

Saaty, T.L., 1986, "Axiomatic Foundation of the Analytic Hierarchy Process", Management Science 32/7, 841-855.

Saaty, T.L. and L.G. Vargas, 1987, "Stimulus-Response with Reciprocal Kernels: the Rise and Fall of Sensation," Journal of Mathematical Psychology 31/1, 93-103.

Saaty, T.L., 1986, "The role of microcomputers in analysis and creativity", Impacts of Microcomputers on Operations Research, Gass, Greenberg, Hoffman and Langley, Editors, 1-25, Elsevier Science Publishing Co., Inc.

Saaty, T.L. and L.G. Vargas, 1993, "Experiments on Rank Preservation and Reversal in Relative Measurement", Mathematical and Computer Modelling 17/4-5, 13-18.

Saaty, T.L., 1981, "The Analytic Hierarchy Process: Scenarios Priorities and Cost-Benefits for the Sudan Transport Plan", in: J.P. Brans (ed), Operational Research '81, North Holland, Amsterdam, 161-175. 
Saaty, T.L., 1986, "Scaling the Membership Function," European Journal of Operational Research 25, 320-329.

Saaty, T.L., L.G. Vargas, and A. Barzilay, 1982, "High-level Decisions: A Lesson from the Iran Hostage Rescue Operation," Decision Sciences $13 / 2$, 185-206.

Saaty, T.L. and M.W. Khouja, 1976, "A Measure of the World Influence", J. of Peace Science, Spring.

Saaty, T.L. and L.G. Vargas, 1982, The Logic of Priorities, Applications in Business, Energy, Health, Transportation, KluwerNijhoff Publishing, Boston.

Saaty, T.L., 1990, "Physics as a Decision Theory", European Journal of Operational Research 48/1, 98-104.

Saaty, T.L., 1986, "Exploring Optimization Through Hierarchies and Ratio Scales," Socio-Economic Planning Sciences 20/6, 355-360.

Sadrian, A.A., 1987, "A Decision Support System for Portfolio Selection and Resource Allocation of R\&D Projects Using 0-1 Goal Programming", University of Pittsburgh, DAI-B 47/12, 5013.

Saito, S., 1989, "Ratio Scale Decomposition Analysis of Group Preference", Discussion Paper \#7, Faculty of Economics, Fukuoka University, JAPAN.

Salo, A.A., 1993, "Inconsistency Analysis by Approximately Specified Priorities", Mathematical and Computer Modelling 17/4$5, \quad 123-134$.

Salo, A. and R.P. Hamalainen, "Ambiguous Preference statements in the Analytic Hierarchy Process", Helsinki University of

Technology, Systems Analysis Laboratory, Research Reports A39.

Salo, A. and R.P. Hamalainen, 1991, "Interactive Decision Support Through Interval Judgments", Proceedings of the 2nd International Symposium on The Analytic Hierarchy Process, Pittsburgh, PA, 215226 .

Salo, A. and R.P. Hamalainen, 1990, "Processing Interval Judgments in the Analytic Hierarchy Process", Proceedings of the IX International Conference on Multiple Criteria Decision Making, Fairfax.

Schneeweiß, C., 1991, "Der Analytic Hierarchy Process als spezielle Nutzwertanalyse", in: G. Fandel and H. Gehring (eds.), operations Research, Beitrage zur quantitativen

Wirtschaftsforschung, Thomas Gal zum 65, Geburtstag, Heidelberg: Springer, 183-195. 
Schniederjans, M.J. and R.L. Wilson, 1991, "Using the Analytic Hierarchy Process and Goal Programming for Information system Project Selection", Information \& Management 20/5, 333-342.

Schoner, B. and W.C. Wedley, 1986, "Accuracy in Priority Scaling - An Experimental Test of the Analytic Hierarchy Process vs. Magnitude Estimation", Simon Fraser University, Burnaby, British Columbia, Canada.

Schoner, B., 1991, "Relative Priority Shifts and Rank Reversals in AHP", Proceedings of the 2nd International symposium on The Analytic Hierarchy Process, Pittsburgh, PA, 121-131.

Schoner, B. and W.C. Wedley, 1989, "Ambiguous Criteria Weights in AHP: Consequences and Solutions", Decision Sciences 20/3, 462475 .

Schoner, B, W.C. Wedley and E.U. Choo, 1993, "A Unified Approach to AHP with Linking Pins", European Journal of Operational Research $64 / 3,384-392$.

Schoner, B., W.C. Wedley and E.U. Choo, 1992, "A Rejoinder to Forman on AHP, with Emphasis on the Requirements of Composite Ratio Scales", Decision Sciences 23/2, 509-517.

Schwartz, R.G., et. al., 1986, "Measuring and Responding to Consumer Preferences for Medical Products and Services", The Business of Health Care Proceedings of the 1987 Annual Health Care Systems Conference, The American Hospital Association, 229239 .

Schwartz, R.G. and S. Oren, 1988, "Using Analytic Hierarchies for Consumer Research and Market Modelling", Mathematical and Computer Modelling 11, 266-271.

Searcy, W.P., Z.A. Karake and E.H. Forman, 1990, "Informational System for Integrating Strategic Management Methodologies", Information Age $12 / 3,130-140$.

Seidmann, A. and A. Arbel, 1983, "An Analytic Approach for Planning Computerized Office Systems", OMEGA 11/6, 607-617.

Seidmann, A. and A. Arbel, 1984, "Microcomputer Selection Process for organizational Information Management", Information and Management, 7/6, 317-329.

Seydel, J.F., 1991, "Development and Implementation of Multiple Criteria Approaches to optimization in Construction Bidding", DAI-A $52 / 06,2195$.

Shang, J.S., 1993, "Multicriteria Facility Layout Problem: An Integrated Approach", European Journal of Operational Research 
$66,291-304$

Shang, J., 1992, "A Unified Framework for the Selection of a Flexible Manufa ring System", Katz Graduate School of Business, University of $\mathrm{F}$ sburgh, Pittsburgh, PA.

Sharp, J.A., 1987, "Haulier Selection - An Application of the Analytic Hierarchy Process", OR: The Journal of the Operational Research Society $38 / 4,319-328$.

Shen, R., et. al., 1988, "Using AHP to synthetically Evaluate Labour Intensity of Jobs", Reprints of the International symposium on The Analytic Hierarchy Process, pp. 569-576, Tianjin University, Tianjin, China, sept. 6-9.

Shen, Y., A.E. Hoerl and W. McConnell, 1992, "An Incomplete Design in the Analytic Hierarchy Process", Mathematical and Computer Modelling 16/5, 121-129.

Shen, R., X. Meng and Y. Yan, 1990, "Analytic Hierarchy Process Applied to synthetically Evaluate the Labor Intensity of Jobs", Ergonomics $33 / 7,867-874$.

Shen, Y., 1988, "Optimal scale with Respect to consistency in the Analytic Hierarchy Process", Reprints of the International

Symposium on The Analytic Hierarchy Process, pp. 136-143, Tianjin University, Tianjin, China, Sept. 6-9.

Shen, R., X. Meng and Y. Yan, 1990, "Analytic Hierarchy Process Applied to Synthetically Evaluate the Labour Intensity of Jobs", Ergonomics 33/7, 867-874.

Shen, Y., 1988, "Analysis of Variance in the Analytic Hierarchy Process", Reprints of the International symposium on The Analytic Hierarchy Process, pp. 87-90, Tianjin University, Tianjin, China, sept. 6-9.

Shen, Y., 1990, "A Probability Distribution and Convergence of the Consistency Index $\mu$ in the Analytic Hierarchy Process", Mathematical and Computer Modelling $13 / 2,59-77$.

Shields, T.J., G.W. Silcock and H.A. Donegan, 1990, "Towards the Development of a Fire Safety systems Evaluation for Public Assembly Buildings", Construction Management \& Economics 8/2, 147-158.

Shim, J.P., 1989, "Bibliographical Research on the Analytic Hierarchy Process (AHP)", Socio-Economic Planning Sciences 23/3, 161-167.

Shim, J.P. and D.L. Olson, 1989, "A Note on the Analytic Hierarchy Process, Expert Choice vs. Spreadsheet", Mississippi 
State University.

Shoemaker, P.J.H., and Waid, C.C., 1982, "An Experimental Comparison of Different Approaches to Determining Weights in Additive Utility Models," Management Science 28, 182-196.

Shrestha, G. and S. Rahman, 1991, "Analytic Hierarchy Process in the Evaluation of Third Party Generation", Proceedings of the 2nd International symposium on The Analytic Hierarchy Process, Pittsburgh, PA, 481-494.

Shu, K. and Z. Liang, 1988, "The Exponential Scale Method in AHP", Reprints of the International symposium on The Analytic Hierarchy Process, pp. 144-148, Tianjin University, Tianjin, China, sept. 6-9.

Shuichi, K., 1991, "A Basic Study on Evaluation System for Public Riverworks - Analytic Hierarchy Process Application to Riverworks Planning", Proceedings of the 2nd International Symposium on The Analytic Hierarchy Process, Pittsburgh, PA, 375-387.

Simkin, M.G., N.A. Bagranoff, and P.J. Crawford, 1990, "Using A Decision Support System to Manage Exchange Rate Risk", Oklahoma Business Bulletin 58/3, 32-35.

Simpson, W.A., 1986, "Statistical Testing of the Analytic Hierarchy Process and Its Applicability to Modelling Industrial Buying Behavior," Technical Report, December, The Graduate School of Business, University of Cape Town, South Africa.

Singh, D.K. and R.P. Evans, 1993, "Effective Benchmarking: Taking the Effective Approach", Industrial Engineering 25/2, 22-24.

Singleton, L.G., 1986, "A Field Test of the Perceptions of the Qualitative characteristics of statement of Financial Accounting Concepts No. 2 by Practicing CPAs", The Louisiana state

University, DAI-A $47 / 03$, p. 972 .

Sinuany-Stern, Z., 1984, "A Network Optimization Model for Budget Allocation in a Multi-Campus University", J. of Operational Research Society 35, 749-757.

Sinuany-Stern, Z., 1988, "Ranking of sports Teams via the AHP", Journal of the Operational Research Society 39/7, 661-667.

Smith, K.L., 1993, "Selecting a Water Quality Model for Lake Okeechobee: An Application of the Analytic Hierarchy Process", Department of Environmental Studies, Graduate School of Duke University.

Sobanjo, J.O., 1992, "A Decision Support Methodology for the Rehabilitation and Replacement of Highway Bridges", Texas A\&M 
University, DAI-B 52/10, p. 5427 .

Society of Environmental Toxicology and Chemistry, 1993, "A Conceptual Framework for Life-Cycle Impact Assessment", Fava, J., F. Consoli, et. al. (eds.), section 6.3.2, Workshop report, SETAC Foundation for Environmental Education, Inc., Pensacola, FL.

Solomon, G.T. and B.G. Whiting, 1985, "Keys to the Future of American Business", Proceedings from the Creativity, Innovation \& Entrepreneurship Symposium, George Washington University,

Washington, D.C.

Song, Y., 1988, "The Method for Mixed-Attributes Group AHP and Its Software in Common Use", Reprints of the International

Symposium on The Analytic Hierarchy Process, pp. 278-287, Tianjin University, Tianjin, China, sept. 6-9.

Song, Y., 1986, "An Application of the AHP and Delphi Method to Decision Analysis in the Long-mid Term Planning of the Coal Mine Area", Coal Mine Des. 9.

Song, Y., 1989, "Superiority - Analyzing in the study of the Strategy of Development", Decision \& The Analytic Hierarchy Process (China) $1,30-34$.

Soyer, R. and R. Spring, 1991, "Evaluation of Soldier Integrated Protective Ensembles Using Analytic Hierarchy Process", Proceedings of the 2nd International Symposium on The Analytic Hierarchy Process, Pittsburgh, PA, 415-428.

Spinelli, F. and W.N. L'Abbe, 1984, "Identifying and Analyzing Components of Multi-Dimensional Attributes for Measuring Consumer Preferences", Proceedings of th 16th Annual Meeting of the American Institute for Decision Sciences, Toronto, 210-214.

Spires, E.E., 1991, "Using the Analytic Hierarchy Process to Analyze Multiattribute Decisions", Multivariate Behavioral Research $26 / 2,345-361$.

Spires, E.E., 1987, "An Investigation into Audits' Evaluations of Compliance Tests", DAI-A $48 / 02,433$.

Srinivasan, V. and Y.H. Kim, 1987, "Financial Theory, Financial Strategy and the Analytic Hierarchy Process", Working paper, Northeastern University.

Srinivasan, V., 1986, "Designing a Decision support system for Working Capital Management", DAI-A 47/01, 265.

Srinivasan, V. and P.J. Bolster, 1990, "An Industrial Bond Rating Model Based on the Analytic Hierarchy Process", European Journal of Operational Research $48 / 1,105-119$. 
Srinivasan, V. and R.A. Millen, 1986, "Evaluating Flexible Manufacturing systems as a strategic Investment", Proceedings of the Second ORSA/TIMS Conference on Flexible Manufacturing Systems: Operations Research Models and Applications, Amsterdam, The Netherlands.

Srinivasan, V. and Y.H. Kim, 1989, "Financial Applications of the Analytic Hierarchy Process", Proceedings of the International Conference on Multiple Criteria Decision Making: Applications in Industry and Service, Asian Institute of Technology, Bangkok, 795-832.

Srinivasan, V. and Y.H. Kim, 1988, "Financial Applications of the AHP", Reprints of the International symposium on The Analytic Hierarchy Process, pp. 577-586, Tianjin University, Tianjin, China, sept. 6-9.

Steenge, A.E., A. Bulten and F.G. Peters, 1990, "The Decentralization of a Sales Support Department in a Medium-Large Company: A Quantitative Assessment Based on Ideas of Thomas L. Saaty and Stafford Beer", European Journal of Operational Research $48 / 1,120-127$.

Steenge, A.E., 1986, "Saaty's Consistency Analysis: An Application to Problems in Static and Dynamic Input-output Models", Socio-Economic Planning Sciences 20, 173-180.

Steenge, A.E., 1987, "Consistency and Composite Numeraires in Joint Production Input-output Analysis: An Application of Ideas of T.L. Saaty", Mathematical Modelling, 9/3-5, 233-244.

Stewart, W.R. and E.R. Horowitz, 1991, "Environmental Factor Weighting at the Federal Energy Regulatory Commission", SocioEconomic Planning Sciences 25/2, 123-132.

Stout, D.E., M.J. Liberatore and T.F. Monahan, 1991, "Decision Support Software for Capital Budgeting", Management Accounting $73 / 1,50-53$.

Su, D. and L. Yu, 1988, Decision Making Analysis of Communication system in Liaoning Province", Reprints of the International

Symposium on The Analytic Hierarchy Process, pp. 512-517, Tianjin University, Tianjin, China, Sept. 6-9.

Su, T., E. Hu and C. Wang, 1988, "Some Notes on the Consistency Checks of the AHP with Discrete Scales", Reprints of the International Symposium on The Analytic Hierarchy Process, pp. 115-122, Tianjin University, Tianjin, China, Sept. 6-9.

Sullivan, W.G., 1986, "Models IEs Use to Include Strategic Non-Monetary Factors in Automation Decisions", Industrial Engineering $18 / 3,42-50$. 
Sun, H., P. Tian, Z. Wang and M. Gong, 1988, "Study on the System for Checking and Evaluating Military and Political officers", Reprints of the International symposium on The Analytic Hierarchy Process, pp. 381-392, Tianjin University, Tianjin, China, Sept. 6-9.

Sun, X.J., 1990, "Developments of Foreign Army $C^{3} I$ system", Decision \& The Analytic Hierarchy Process (China) 2, 65-68.

Swasono, Y., 1990, "Integrating Efficient Investment in Human Resources and Manpower Planning in Indonesia", DAI-A 51/04, 1341.

Tadisina, S.K. and V. Bhasin, 1989, "Doctoral Program Selection Using Pairwise Comparisons", Research in Higher Education 30/4, 403-418.

Tadisina, S.K., M.D. Troutt and V. Bhasin, 1991, "Selecting a Doctoral Programme Using the Analytic Hierarchy Process - The Importance of Perspective", Journal of the Operational Research Society $42 / 8,631-638$.

Takahashi, I., 1988, "Analysis of AHP by BIBD", Reprints of the International symposium on The Analytic Hierarchy Process, pp. 173-180, Tianjin University, Tianjin, China, Sept. 6-9.

Takeda, E and P.L. Yu, 1988, "Eliciting the Relative Weights from Incomplete Reciprocal Matrices", Reprints of the International

Symposium on The Analytic Hierarchy Process, pp. 192-200, Tianjin University, Tianjin, China, Sept. 6-9.

Takizawa, T., 1986, "Application of AHP to Product Design", Operations Research of Japan 31/8, 505-510.

Tarbell, D.S. and T.L. Saaty, 1980, "The Conflict in south Africa", J. of Peace Science 4, 151-168.

Tarimcilar, M.M. and S.Z. Khaksari, 1991, "Capital Budgeting in Hospital Management Using the Analytic Hierarchy Process", SocioEconomic Planning Sciences 25/1, 27-34.

Terano, T., 1986, "Diagnosis of A Dam Gate with the AHP", Operations Research of Japan 31/8, 500-504.

Terano, T., 1988, "Using the Analytic Hierarchy Process in FrameBased Expert Systems", Reprints of the International symposium on The Analytic Hierarchy Process, pp. 638-645, Tianjin University, Tianjin, China, sept. 6-9.

Theune, D.W., 1987, "An Alternative Method for the Valuation of Weapons for Mathematical Battle Simulations as Applied in the State of the Art Contingency Analysis Model (SOTACA)" Technical Support Division, Modern Aids to Planning Branch, The Pentagon, 
Washington, D.C.

Thurston, D.L. and Y.Q. Tian, 1993, "Integration of the Analytic Hierarchy Process and Integer Programming with Linear Constraints for Long Range Product Planning", Mathematical and Computer Modelling 17/4-5, 41-54.

Tian, P. and H. Sun, 1989, "Inquiring into the Interaction of AHP with Operational Research", Decision \& The Analytic Hierarchy Process (China) 1, 66-69.

Tone, K. and S. Yanagisawa, 1989, "Site Selection for a Large Scale Integrated Circuits Factory", in: B.L. Golden, E.A. Wasil and P.T. Harker (eds.), Applications of the Analytic Hierarchy Process, Springer-Verlag, New York, 242-250.

Tone, K. and R. Manabe, 1990, "Applications of the AHP", Nitskagiren Press.

Tone, K., 1986, "Application of AHP to Tax Structure", Operations Research of Japan 31/8, 494-499.

Tone, K., 1986, "Making a Decision, Feeling Like Playing A Game", Nitskagiren Press.

Tone, K., 1988, "A Comparative Study on AHP and DEA", Reprints of the International Symposium on The Analytic Hierarchy Process, pp. 37-43, Tianjin University, Tianjin, China, Sept. 6-9.

Tong, R.M., et. al., 1982, "Options Generation Techniques for Command and Control", AI\&DS project \# 3012 , Griffiss Air Force Base, NY.

Toshtzar, M., 1988, "Multi-Criteria Decision Making Approach to Computer Software Evaluation: Application of the Analytic

Hierarchy Process", Mathematical and Computer Modelling 11, 276281.

Triantaphyllou, E. and S.H. Mann, 1993, "A Computational Evaluation of the Original and Revised Analytic Hierarchy Process", working paper, Dept. of Industrial Engineering, Kansas state University.

Triantaphyllou, E. and S.H. Mann, 1990, "An Evaluation of the Eigenvalue Approach for Determining the Membership Values in Fuzzy Sets", Fuzzy Sets and Systems 35/3, 295-301.

Triantaphyllou, E., P.M. Pardalos and S.H. Mann, 1990, "The Problem of Determining Membership Values in Fuzzy sets in Real World Situations", in: Operations Research and Artificial Intelligence: The Integration of Problem Solving Strategies, D.E. Brown and C.C. White (eds.), Kluwer Academic Publishers, 197-214. 
Triantaphyllou, E., P.M. Pardalos and S.H. Mann, 1990, "A Minimization Approach to Membership Evaluation in Fuzzy sets and Error Analysis", Journal of optimization Theory and Applications $66 / 2,275-287$.

Triantaphyllou, E. and S.H. Mann, 1989, "An Examination of the Effectiveness of Multi-Dimensional Decision Making Methods: A Decision-Making Paradox", Decision Support Systems 5, 303-312.

Triantaphyllou, E. and S.H. Mann, 1992, "An Evaluation of the AHP and the Revised AHP When the Eigenvalue Method is Used Under a Continuity Assumption", working paper, Dept. of Industrial Engineering, Kansas state University.

Triantaphyllou, E., et. al., 1992, "On the Evaluation and Application of Different Scales for Quantifying Pairwise Comparisons in Fuzzy Sets", Dept. of Industrial Engineering, Kansas State University, working paper.

Triantaphyllou, E., 1993, "A Quadratic Programming Approach in Estimating Similarity Relations", IEEE Transactions on Fuzzy Systems.

Trobian, H.R., 1986, "From Family Trees to Decision Trees", In: Thinking Across the Disciplines, Proceedings of the Annual Conference of the International society for Individualized Instruction, Atlanta, GA.

Tscheulin, D.K., 1991, "Ein empirischer Vergleich der Eignung von Conjoint-Analyse und 'Analytic Hierarchy Process' (AHP) zur Neuproducktplanung", Zeitschrift fur Betriebswirtschaft 61/11, 1267-1280.

Tsuji, K., 1986, "Application of AHP to Evaluating Energy for Housing", Operations Research of Japan 31/8, 488-493.

Tummala, V.M.R., J.R. Smith and V.R.R. Uppuluri, 1982/83, "Evaluating Commercial Credit Decisions by Analytic Hierarchy Process", ASCI Journal of Management 12/1-2, 48-56.

Tummala, V.M.R. and P.P. Sanchez, 1982, "Evaluating Faculty Merit Awards by Analytic Hierarchy Process", Proceedings - 14th Annual Meeting of the American Institute for Decision Sciences, San Francisco, CA.

Tzeng, G.H., J.Y. Teng, T.A. Shiau and W.J. Hwang, 1990, "Computer-aided Multicriteria Decision Analysis for Power Generation Mix Problem", Energy Research Group and Institute of Traffic and Transportation, National Chiao University, Taiwan.

Tzeng, G.H., J.Y. Teng and C.P. Hu, 1991, "Urban Environmental Evaluation and Improvement: Application of Multiattribute Theory 
and Compromise Programming", Behaviormetrika 29, 83-98.

Uppuluri, U.R.R, 1983, "Expert Opinion and Ranking Methods", ORNL-CSD-TM-201, Oak Ridge National Laboratory, Oak Ridge, TN.

Uppuluri, U.R.R., 1978, "Logarithmic Least-squares Approach to Saaty's Decision Problem," in: W.E. Lever, D.E. Shepherd, R.C. Ward, and D.G. Wilson (eds.), Mathematics and Statistics Research Department Progress Report, Oak Ridge National Laboratory, Oak Ridge, TN37830, 19-21.

Usabiaga Campos, O., 1983, "A Planning Process for Regional Urban Development in Queretaro, Mexico: An Application of the Analytic Hierarchy Process", MA 23/01, 208.

Vachnadze, R.G., N.I. Markozashvili and M.o. Karchava, "Some Software Packages Realizing the Analytic Hierarchy Process", In Press.

Vachnadze, R.G. and N.I. Markozashvili, 1987, "Some Applications of the Analytic Hierarchy Process," Mathematical Modelling 9, 185-194.

van Laarhoven, P.J.M., and W. Pedrycz, 1979, "A Fuzzy Extension of Saaty's Priority Theory", Fuzzy Sets and Systems 11/3, 229241 .

Varga, R.S., 1962, "Matrix Iterative Analysis", Englewood Cliffs, NJ: Prentice-Hall.

Vargas, L.G., 1986, "Utility Theory and Reciprocal Pairwise Comparisons: the Eigenvector Method," Socio-Economic Planning Sciences 20/6, 387-391.

Vargas, L.G., 1987, "Priority Theory and Utility Theory", Mathematical Modelling 9/3-5, 381-385.

Vargas, L.G., Ed., 1987, Special Issue on the Analytic Hierarchy Process, Mathematical Modelling, 9/3-5.

Vargas, L.G., 1979, "Sensitivity Analysis of Reciprocal Matrices", Chap. 3. Ph.D. Dissertation, Wharton School, Univ. of Pennsylvania, Philadelphia, PA.

Vargas, L.G. and J.B. Roura-Agusti, 1989, "Business Strategy Formulation for a Financial Institution in a Developing Country," in: B.L. Golden, E.A. Wasil and P.T. Harker (eds.), Applications of the Analytic Hierarchy Process, Springer-Verlag, New York, 251-265.

Vargas, L.G., 1983, "Analysis of Sensitivity of Reciprocal Matrices", Applied Mathematics and Computation 12, 201-220. 
Vargas, L.G., 1983, "Prediction and the Analytic Hierarchy Process", Mathematical and Computer Simulation (Netherlands) $25 / 2,256-167$.

Vargas, L.G., 1980, "A Note on the Eigenvalue Consistency Index", Applied Mathematics and Computation 7, 195-203.

Vargas, I.G. and J.J. Dougherty, 1982, "The Analytical Hierarchy Process and Multicriterion Decision Making", American Journal of Mathematical and Management Sciences 2 .

Vargas, L.G., 1990, "An Overview of the Analytic Hierarchy Process and its Applications", European J. of Operational Research $48 / 1,2-8$.

Vargas, L.G., 1983, "Prospects for the Middle East: Is a Peaceful Settlement Attainable", European Journal of operational Research, 14/2, 169-192.

Vargas, L.G., 1982, "Reciprocal Matrices with Random Coefficients," Mathematical Modeling 3, 69-81.

Vargas, L.G., 1991, "Why the AHP is not Like MultiAttribute Utility Theory," in Multiple Criteria Decision Support, P. Korhonen, A. Lewandowski, and J. Wallenius (eds.), SpringerVerlag \#365.

Vargas, L.G. and T.L. Saaty, 1981, "Financial and Intangible Factors in Fleet Lease or Buy Decisions", Industrial Marketing Management $10 / 1,1-10$.

Varis, 0., 1989, "The Analysis of Preferences in Complex Environmental Judgments: A Focus on the Analytical Hierarchy Process", Journal of Environmental Management 28, 283-294.

Varney, M.S., W.G. Sullivan and J.K. Cochran, 1985, "Justification of Flexible Manufacturing Systems with the Analytical Hierarchy Process", In: C. Savage (Ed.), Focus on the Future: Proceedings of the 1985 Industrial Engineering Show, Atlanta: Industrial Engineering and Management Press.

Veerakool, V., 1989, "An Analytical Hierarchy Process Approach to Establish the Systems Analyst's Knowledge Base for Selecting an Information Requirements Determination Strategy", University of Missouri - Rolla, DAI-A 50/02, p. 284 .

Verkasalo, M. and R. Parkkinen, 1991, "AHP in High Tech Production Decisions", Proceedings of the 2nd International Symposium on The Analytic Hierarchy Process, Pittsburgh, PA, 319328 .

Vesely, W.E., A. Shataghi, I.J. Gary and D.M. Rasmusen, 1983, 
"Research Prioritization: Using the Analytic Hierarchy Process", NUREG / CR-3447.

Vlahakis, J.G. and W.R. Partridge, 1989, "Assessment of Security at Facilities that Produce Nuclear Weapons", in: B.L. Golden, E.A. Wasil and P.T. Harker (eds), Applications of the Analytic Hierarchy Process, Springer-Verlag, New York, 182-191.

Wabalickis, R.N., 1988, "Justification of FMS with the Analytic Hierarchy Process", Journal of Manufacturing Systems 17/3, 175182 .

Wan, Y., 1988, "Application of the AHP to the Evaluation of Bidders of Hydraulic Resources Capital Construction", Reprints of the International symposium on The Analytic Hierarchy Process, pp. 587-594, Tianjin University, Tianjin, China, Sept. 6-9.

Wan, Y.J., 1989, "The Method of Synthetical Appraisal for Economic Benefit of Industrial Enterprises", Decision \& The Analytic Hierarchy Process (China) 1, 75-82.

Wang, L., 1989, "New Elements Lead to the Condition of Rank Preservation in the AHP", Proceedings of Chinese Symposium on the Analytical Hierarchy Process, Peoples Republic of China.

Wang, L., 1988, "Establishing the Hierarchy Structure of AHP and Its Implementing on Computer", Reprints of the International Symposium on The Analytic Hierarchy Process, pp. 646-653, Tianjin University, Tianjin, China, Sept. 6-9.

Wang, H., S.C. Zhu and C.L. Song, 1990, "Evaluating and Analyzing the Combat Capabilities of Six Countries' Mechanized Divisions", Decision \& The Analytic Hierarchy Process (China) 2, 88.

Wang, L., 1989, "The Condition of Rank Preservation for Adding a New Element in the AHP", Proceedings of the International

Conference on Multiple Criteria Decision Making: Applications in Industry and Service, Asian Institute of Technology, Bangkok, $879-887$.

Wang, M. and G. Han, 1988, "Rank Preservation and Rank Structure of Judgment Matrix", Reprints of the International Symposium on The Analytic Hierarchy Process, pp. 104-109, Tianjin University, Tianjin, China, Sept. 6-9.

Wang, H., J. Guan and Y. Wu, 1988, "A New Method for Priorities of The Hierarchic System With Inner Dependence", Reprints of the International Symposium on The Analytic Hierarchy Process, pp. 255-268, Tianjin University, Tianjin, China, Sept. 6-9.

Wang, L. and T. Raz, 1991, "Analytic Hierarchy Process Based on Data Flow Diagram", Computers \& Industrial Engineering 20/3, 355- 
365 .

Wang, R., G. II and S. Xu, 1988, "An Approach to Synthesizing Judgments", Reprints of the International Symposium on The Analytic Hierarchy Process, pp. 288-300, Tianjin University, Tianjin, China, Sept. 6-9.

Wang, M.V., 1988, "Addition of a Cognitive Dimension to the Analytical Hierarchy Process - A Land Use Decision-Making Example", Indiana University, DAI-A 48/10, p. 2746.

Wang, I., G. Lu and Q. Lang, 1991, "The combination of AHP and $\mathrm{DEA}$, and its Application in Evaluating Economical and Social Systems", Proceedings of the 2nd International symposium on The Analytic Hierarchy Process, Pittsburgh, PA, 429-438.

Wasil, E.A., 1984, "Evaluating the Performance of Alternative Solution Methods for Combinatorial optimization and other Decision Problems", University of Maryland, DAI 46/02, 625.

Weber, K., 1993, "Mehrkriterielle Entscheidungen", R. Oldenbourg Verlag $\mathrm{GmbH}$, Munchen.

Weber, K., 1992, "Multiattribute Decision Analysis - The Analytic Hierarchy Process", in: P. Gritzmann, R. Hettich, R. Horst and E. Sachs (eds.), Operations Research 191, Heidelberg: Physica, 621624 .

Webster, D.D., 1988, "Hardware, Software, Firmware Allocation of Functions in Systems Development", MAI 26/04, 436.

Wedley, W.C., and T.L. Saaty, 1988, "Free Trade Discussions Between Canada and the United States," Canadian Journal of Administrative Sciences June, 67-76.

Wedley, W.C., 1989, "Consistency Tests for Incomplete AHP Matrices - A Comparison of Two Methods", Proceedings of the Administrative Sciences Association of Canada - Management Science Division.

Wedley, W.C., 1990, "Combining Qualitative and Quantitative Factors - An Analytic Hierarchy Approach", Socio-Economic Planning Sciences 24/1, 57-64.

Wedley, W.C., B. Schoner and T.S. Tang, 1993, "Starting Rules for Incomplete comparisons in the Analytic Hierarchy Process", Mathematical and Computer Modelling 17/4-5, 93-100.

Wedley, W.C., 1984, "Priority Scaling of Hierarchical Problems", ASAC Conference, University of Guelph.

Wedley, W.C., 1993, "Consistency Prediction for Incomplete AHP 
Matrices", Mathematical and Computer Modelling 17/4-5, 151-162.

Wedley, W.C., 1991, "Relative Measurement of the Consistency Ratio", Proceedings of the 2nd International symposium on The Analytic Hierarchy Process, Pittsburgh, PA, 185-196.

Wei, S. and H. Jing, 1988, "Completeness and Optimality of AHP Being Applied to MADM(FMADM)", Reprints of the International Symposium on The Analytic Hierarchy Process, pp. 131-135, Tianjin University, Tianjin, China, Sept. 6-9.

Wei, Y.X. and X.Y. Wang, 1989, "Application of AHP in the Evaluation and Selection of the Research Projects Applied to Science Foundations", Proceedings of the International Conference on Multiple Criteria Decision Making: Applications in Industry and Service, Asian Institute of Technology, Bangkok, 865-878.

Wei, Y.X., and X.M. Wan, 1991, "Feedback Structure Model and its Application", Proceedings of the 2nd International symposium on The Analytic Hierarchy Process, Pittsburgh, PA, 41-50.

Wei, S.X. and H. Jing, 1989, "Superiority and Perfection of AHP as MADM", Decision \& The Analytic Hierarchy Process (China) 1, 60-65.

Weil, R.D., 1991, "Artificial Intelligence Methods in Utilizing Low-Dimensional Models of Differential Games", Washington University, DAI-B 51/12, p. 6082 .

Weiss, E.N., 1990, "Fly Now or Fly Later? The Delayed Consumption Problem", European Journal of Operational Research 48/1, 128-135.

Weiss, E.N., 1987, "Using the Analytic Hierarchy Process in a Dynamic Environment," Mathematical Modelling 9/3-5, 211-218.

Weiss, E.N. and V.R. Rao, 1987, "AHP Design Issues for Largescale Systems", Decision Science 18, 43-61.

Whipple, T.W. and K.A. Simmons, 1987, "Using the Analytic Hierarchy Process to Assess Gender Differences in the Evaluation of Microcomputer Vendors", Journal of the Academy of Marketing Science $15 / 2,33-41$.

White, C.C. and A.P. Sage, 1983, "Multiple Objective Evaluation and Prioritization Under Risk With Partial Preference Information", International Journal of Systems Science 14/5, 467485 .

wiemen, Z., 1989, "Quartile Method for Synthesizing Group Judgment in AHP", Taiyuan Institute of Machinery, working paper. Wilkinson, J.H., 1965, "The Algebraic Eigenvalue Problem", 
London, England: Clarendon Press.

willett, K. and R. Sharda, 1991, "Using the Analytic Hierarchy Process in water Resources Planning: Selection of Flood Control Projects", Pergamon Press 25/2, 103-112.

Williams, C., and G. Crawford, 1980, "Analysis of Subjective Judgment Matrices", Report R-2572-AF. Santa Monica, CA: The Rank corp.

Wind, Y. and S. Douglas, 1981, "International Portfolio Analysis and Strategy: The Challenge of the $80^{\prime} \mathrm{s}^{\prime \prime}$, Journal of International Business studies $12 / 2,69-82$.

Wind, Y., 1987, "An Analytic Hierarchy Process Based Approach to the Design and Evaluation of a Marketing Driven Business and Corporate strategy", Mathematical Modeling 9/3-5, 285-291.

Wind, Y. and V. Mahajan, 1981, "Designing Product and Business Portfolio", Harvard Business Review 59/1, 155-165.

Wind, Y. and T.L. Saaty, 1980, "Marketing Applications of the Analytic Hierarchy Process", Management Science 26/7, 641-658.

Winkler, R.L., 1990, "Decision Modelling and Rational Choice: AHP and Utility Theory", Management Science 36/3, 247-248.

Wolfe, C., 1988, "How to Adjust Forecasts with the Analytic Hierarchy Process", Journal of Business Forecasting 7/1, 13-17.

Wolfe, C.J., 1985, "An Analysis of Judgmentally-Adjusted Earnings Forecasts", Kent State University, DAI-A 46/02, p. 490.

Wu, N.L., 1990, "Identifying, Measuring and Analyzing Multidimensional Attributes for Design and Redesign Consideration", International Journal of Operations \& Production Management $10 / 4,65-72$.

Wu, Y., Z. Zheng and Z. Chen, 1988, "The Comprehensive Evaluation Method at Professor's Level in Chinese University", Reprints of the International Symposium on The Analytic Hierarchy Process, pp. 393-399, Tianjin University, Tianjin, China, sept. 6-9.

Wu, Y.C., 1989, "A Model for Application of AHP to Arrange the Reform-Through-Labor-System Points in Order", Decision \& The Analytic Hierarchy Process (China) 1, 83-88.

Wu, Y., 1986, "The AHP - A New Model for Decision Analysis", Mod. Mgmt. Sci. 3 .

Wu, J., 1983, "A Systems Analysis of Energy Economy in Zhejiang Province using the AHP", Presented at the 1st Conf. on Energy 
Economics, Shanghai.

Wu, W., 1988, "Other Method for Examining Pairwise Comparison Matrix in the AHP", Reprints of the International symposium on The Analytic Hierarchy Process, pp. 201-203, Tianjin University, Tianjin, China, Sept. 6-9.

Wu, Y., 1988, "A Model for Application of AHP to Arrange the Reform-through-labour system Points in Order According to Reduction", Reprints of the International symposium on The Analytic Hierarchy Process, pp. 595-599, Tianjin University, Tianjin, China, sept. 6-9.

Wu, N.L., 1987, "A Note on an Application of the Analytic Hierarchy Process", Decision Science 18/4, 687-688.

Wu, J.A. and N.L. Wu, 1984, "Analyzing Multi-Dimensional Attributes for the Single Plant Location Problem via an Adaptation of the Analytic Hierarchy Process", International Journal of Operations and Production Management (UK) 4/3, 13-21.

Xu, S., 1988, "The Principle of AHP", Tianjin University Publishing Company.

Xu, S., 1988, "Characterizing Principal Left-right Eigenvector Reciprocity in a Positive Reciprocal Matrix", Reprints of the International symposium on The Analytic Hierarchy Process, pp. 165-172, Tianjin University, Tianjin, China, Sept. 6-9.

$\mathrm{Xu}, \mathrm{S}$. and J. He, 1984, "An Application of the AHP to Policy Analysis of Energy Supply of Tianjin Region", In: Energy Models and Systems Analysis, 117-124, Energy Press, Beijing.

Xu, S., 1991, "The Structure of Positive Reciprocal Matrices", Proceedings of the 2nd International Symposium on The Analytic Hierarchy Process, Pittsburgh, PA, 203-210.

$\mathrm{Xu}$, S. and B. Liu, 1986, "A New Dynamic Priorities Model and an Analysis of China's Energy strategy for the Future," The VII International Conference on MCDM, August 18-22, Kyoto, Japan.

Xu, S.B., 1989, "Today and Tomorrow of AHP Theoretical Research", Decision \& The Analytic Hierarchy Process (China) 1, 35-42.

$\mathrm{Xu}$, S. and M. Gong, "A Note of the Average Consistency Random Index (R.I.)".

Xu, S., 1990, "Fundamentals of AHP as Measure and Decision Thoery in Social Economic System", Decision \& The Analytic Hierarchy Process (China) 2, 18-25.

Xu, S., 1986, "A Survey of Theory and Applications of the AHP", 
Working Paper, Inst. Systems Engineering, Tianjin Univ., Tianjin, China.

Xu, S., 1989, "Current Status and Prospects of Theoretical Research on the AHP", Journal of Decision \& Analytic Hierarchy Process 1 (in Chinese), 35-41.

$\mathrm{Xu}, \mathrm{G}$. , 1988, "Application of AHP to the Determination of the Quality Class of City Ecological Environment", Reprints of the International Symposium on The Analytic Hierarcny Process, pp. 606-612, Tianjin University, Tianjin, China, Sept. 6-9.

Xu, S., et. al., 1982, "The AHP - A Useful Method for Decision Making. In: Proc. 1st Conf. on the Future Research Association of China, Hangzhou.

Xu, S., 1986, "References on the Analytic Hierarchy Process", Institute of systems Engineering, Tianjin University, Tianjin, China.

$\mathrm{Xu}, \mathrm{S}$. and J. He, 1985, "Lecture Notes on AHP", Teaching Material, Inst. of Systems Engineering, Tianjin University, Tianjin, China.

Xu, S., 1985, "Mathematical Principles of the AHP", Teaching Material, Inst. of Systems Engineering, Tianjin Univ., Tianjin.

Xu, G., 1988, "Application of AHP to the Determination of the Quality Class of City Ecological Environment", Reprints of the International Symposium on The Analytic Hierarchy Process, pp. 606-612, Tianjin University, Tianjin, China, Sept. 6-9.

Xu, L., 1988, "A Graphical Approach to Modeling of Complex Systems in AHP", Reprints of the International symposium on The Analytic Hierarchy Process, pp. 123-130, Tianjin University, Tianjin, China, Sept. 6-9.

Xuan, J., 1988, "Analysis of Competitive Power of Exporting Mechanical and Electronic Products - The AHP Model", Reprints of the International Symposium on The Analytic Hierarchy Process, pp. 485-489, Tianjin University, Tianjin, China, Sept. 6-9.

Yager, R.R., 1979, "An Eigenvalue Method of Obtaining Subjective Probabilities", Behav. Sci. 24, 383-387.

Yahagi, S., 1988, "Target Means Solution System and its Applications", Reprints of the International symposium on The Analytic Hierarchy Process, pp. 490-498, Tianjin University, Tianjin, China, sept. 6-9.

Yan, K.D. and S.X. Jiang, 1989, "AHP in Developing Ecoagricultural Experiment in Yan Kou Horticultural Farm at the 
First Time", Decision \& The Analytic Hierarchy Process (China) 1, 95-100.

Yang, J., et. al., 1988, "AHP for Rural Economic Developing Strategies", Reprints of the International symposium on The Analytic Hierarchy Process, pp. 506-511, Tianjin University, Tianjin, China, Sept. 6-9.

Yang, J.M., 1989, "An AHP-MLP Synthetical Model for Study of the Industrial Structure", Decision \& The Analytic Hierarchy Process (China) 1, 70-74.

Yang, J., 1988, "An AHP-MLP Synthetical Model for study of the Industrial structure", Reprints of the International symposium on The Analytic Hierarchy Process, pp. 499-505, Tianjin University, Tianjin, China, Sept. 6-9.

Yao, M., 1990, "A Practical Vague AHP", Soft Science 1.

Yao, S., Y. Zhao and D. Gu, "The Application of Fuzzy-AHP to Scientific Management of Ordnance", Reprints of the International Symposium on The Analytic Hierarchy Process, pp. 400-406, Tianjin University, Tianjin, China, Sept. 6-9.

Yi, Y. and Y. Zhang, 1988, "The Grey Strategy for a water Resource Allocation Using AHP", Reprints of the International Symposium on The Analytic Hierarchy Process, pp. 600-605, Tianjin University, Tianjin, China, Sept. 6-9.

Yoon, K., 1988, "The AHP with Bounded Interval Input", Reprints of the International Symposium on The Analytic Hierarchy Process, pp. 149-156, Tianjin University, Tianjin, China, Sept. 6-9.

Yu, F. and X. Shi, 1991, "Evaluation of Efficiency and Achievement for R\&D Institute with AHP", Proceedings of the 2nd International Symposium on The Analytic Hierarchy Process, Pittsburgh, PA, 405-414.

Yue, L., B. Liang and Z. Li, 1988, "A Kind of Coordinated Model for Social System", Reprints of the International Symposium on The Analytic Hierarchy Process, pp. 407-414, Tianjin University, Tianjin, China, Sept. 6-9.

Zahedi, F., 1986, "The Analytic Hierarchy Process--a Survey of the Method and its Applications", Interfaces 16/4, 96-108.

Zahedi, F., 1990, "A Method for Quantitative Evaluation of Expert Systems", European Journal of Operational Research 48/1, 136-147.

Zahedi, F., 1986, "A Simulation Study of Estimation Methods in the Analytic Hierarchy Process", Socio-Economic Planning Sciences $20 / 6,347-354$. 
Zahedi, F., 1985, "Database Management system Evaluation and Selection Decision," Decision Science 16/1, 91-116.

Zahedi, F., 1987, "A Utility Approach to the Analytic Hierarchy Process", Mathematical Modelling, 9/3-5, 387-395.

Zahir, M.S., 1991, "Incorporating the Uncertainty of Decision Judgments $i$ :. the Anaiytic Hierarchy Process", European Journal of operational Research 53/2, 206-216.

Zahir, S. and C.L. Chang, 1992, "Online-Expert: An Expert system for Online Database Selection", Journal of the American Society for Information Science $43 / 5,340-357$.

Zanakis, S.H., A. Kara, 1991, "An Analytic Evaluation of Microcomputer Educational OR/MS Software", Omega 19/6, 639-649.

Zbierski, P., 1981, "Nonstandard Interpretations of Higher Order Theories", Fundamental Mathematics 112/3, 175-186.

Zeeger, C.V. and R.L. Rizenbergs, 1979, "Priority Programming for Highway Reconstruction", Transportation Research Record n. 698, 15-23.

Zeng, M., 1983, "A Case Study of Business Management Using the AHP", Presented at the 2nd conf. On Energy systems Engineering, Hangshou.

Zhang, S., 1990, "The Two-Step Analytical Hierarchy Process and Environmental Qualitative Evaluation for a Chemical Factory", Chinese Journal of Environmental Science (Beijing) 11/1, 87-90.

Zhang, H.S., 1989, "Work Hard for the Development of Decision Science", Decision \& The Analytic Hierarchy Process (China) 1, 56 .

Zhang, L., Y. Xu and X. Feng, 1988, "The Application of AHP Method on the Developing strategy Planning of Physical Education", Reprints of the International Symposium on The Analytic Hierarchy Process, pp. 415-420, Tianjin University, Tianjin, China, sept. 6-9.

Zhang, W., 1991, "Principles of Rank Preservation Graded Eigenvector Method", Proceedings of the 2nd International symposium on The Analytic Hierarchy Process, Pittsburgh, PA, 113120 .

Zhang, Z.M. and Y.A. Du, 1990, "Effectiveness Function and Its Application Agricultural Decision", Decision \& The Analytic Hierarchy Process (China) 2, 14-17.

Zhao, H., S. Xu and J. He, 1986, "The Analytic Hierarchy Process 
- A New Method for Decision Making, Science Press, Beijing.

Zhao, X., T. Lu and Y. Sang, 1991, "AHP for Checking and

Ratifying Responsible Business contracts", Proceedings of the 2nd International Symposium on The Analytic Hierarchy Process, Pittsburgh, PA, 439-450.

Zhao, G. and N. Tan, 1988, "Reasonably selecting the will for Entering University", Reprints of the International Symposium on The Analytic Hierarchy Process, pp. 421-428, Tianjin University, Tianjin, China, Sept. 6-9.

Zheng, Z., et. al., 1988, "Application of AHP to Programming for Treatment of the Harm Caused by Dust and Toxicants in Tianjin", Reprints of the International Symposium on The Analytic Hierarchy Process, pp. 437-441, Tianjin University, Tianjin, China, Sept. 6-9.

Zheng, M. et. al., 1988, "Studies on Synthetic Evaluation of Scientific Research Outcomes", Reprints of the International Symposium on The Analytic Hierarchy Process, pp. 429-436, Tianjin University, Tianjin, China, Sept. 6-9.

Zhong P., 1986, "Analysis of Chinese Rural Development and its Impact on Groundwater Resource", 19th Congress of the

International Association of Hydrogeologists, Sept. 8-15, 1986, Karlovy Vary, Czechoslovakia.

Zhou, J.R., et. al., 1990, "The Application of the Analytic Hierarchy Process to Evaluation of Early People's Defense Engineering", Decision \& The Analytic Hierarchy Process (China) $2,80-87$.

Zhou, S., 1991, "A New Method of Structuring A Hierarchy", Proceedings of the 2nd International Symposium on The Analytic Hierarchy Process, Pittsburgh, PA, 51-58.

Zhu, Sc. and H. Wang, 1991, "The Analytic Hierarchy Process and Artificial Intelligence: A Comparative Study", Proceedings of the 2nd International Symposium on The Analytic Hierarchy Process, Pittsburgh, PA, 303-315.

Zhu, K.L. X.Q. Lai and Z.Y. Wu, 1990, "Determining the Power and Influence of Cluster Factor by Means of AHP", Decision \& The Analytic Hierarchy Process (China) 2, 69-73.

Zhu, G., 1985, "An Analysis of Energy Policy on the Economic Development of Rural Areas in Henan Province Using the AHP", Research Report, Inst. Energy Research, Academy of Henan Province.

Zhu, D. and C. Feng, 1988, "Application of AHP in Deciding Urban 
Land Use - Taking Chao Hu City as an Example", Reprints of the International Symposium on The Analytic Hierarchy Process, pp. 613-620, Tianjin University, Tianjin, China, Sept. 6-9.

Zuo, J., 1988, "Ordinal and Cardinal Pairwise Comparisons in AHP", Reprints of the International Symposium on The Analytic Hierarchy Process, pp. 157-164, Tianjin University, Tianjin, China, Sept. 6-9. 
$\sqrt{7}$

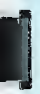

]

1

$-1$ 
1

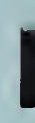

,

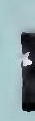

,

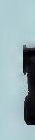

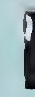

,

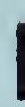

,

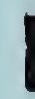

,

,

,

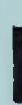

,

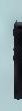

